Helgoländer wiss. Meeresunters. 29, 1-289 (1977)

\title{
Meeresalgen von Helgoland
}

\author{
Benthische Grün-, Braun- und Rotalgen
}

\author{
P. KoRNMANN \& P.-H. SAHLING \\ Biologische Anstalt Helgoland (Meeresstation); \\ Helgoland, Bundesrepublik Deutschland
}

\begin{abstract}
Marine algae of Helgoland. Benthic green, brown and red algae. This report represents a photographic documentation of the more conspicuous species of the marine algal vegetation of the island Helgoland (North Sea), based on collections and observations made since 1959. The catalogue is largely restricted to macroscopic forms, as adequate knowledge of most of the microscopic ones is not yet available. Remarks on some rare species are added in a special chapter; the list includes some 150 species. With a few exceptions, the figures have been obtained from living algae; they illustrate aspects of reproduction and development and, occasionally, demonstrate different seasonal habits. The simplified key may be useful for providing a guide both for naturalists and students of marine phycology. In addition, this algal flora enhances our knowledge of the distribution of benthic species along the European coasts, as the rocky island of Helgoland intervenes between southern Norway and the shores of the English Channel.
\end{abstract}

\section{VORWORT}

Aus der Geschichte der Botanik an der Biologischen Anstalt Helgoland wird es verständlich, warum bisher eine ausführliche Darstellung ïber die Helgoländer Algenvegetation fehlte. Geplant war sie schon von Paul Kuckuck; seit 1892 beschäftigte er sich eingehend mit der Algenflora der Insel und ergänzte in seinen "Bemerkungen zur marinen Algenvegetation von Helgoland“ (1894, 1897b) eine von Reinke (1891) veröffentlichte Liste der Braun- und Rotalgen durch eigene Beobachtungen. Einzelne Arten wurden in "Beiträge zur Kenntnis der Meeresalgen" $(1897$ a, 1912) ausführlicher bearbeitet. Der Plan einer "Algenflora der Nordsee" (1897b, p. 386) wird auch in einer kurzen Studie über das jahreszeitlich sich verändernde Erscheinungsbild der Helgoländer Algenflora erwähnt (Kuckuck, 1897c; p. 442). Auch für eine Darstellung der Algenvegetation von Rovigno liegen umfangreiche Tagebuch-Aufzeichnungen vor. Alle floristischen Arbeiten wurden jedoch zurückgestellt, nachdem Kuckuck sein besonderes Interesse einer Monographie der Phaeosporeen zugewandt hatte. Das Werk war leider un- 
vollendet, als Kuckuck 1918 in Berlin starb. Nur Teile dieser Arbeit blieben durch Nienburg und Kornmann der Wissenschaft erhalten (Kuckuck 1930, 1953-1964).

Kudkucks Nadfolger Nienburg (1921-1923) verdanken wir eine kurze Schilderung der Algenvegetation in ihrer Beziehung zu den ökologischen Gegebenheiten des Untersuchungsgebietes (1925). Inzwischen hatte O. C. Schmidt, Berlin, mit floristischen Studien in Helgoland begonnen; Schreiber (1925-1936) und Kornmann wählten die Entwicklungsgeschichte der Algen als Arbeitsgebiet. Ein fertiges Manuskript von O. C. Schmidt ging zusammen mit Kuckucks Exkursionstagebüchern während des Krieges im Botanischen Museum in Berlin-Dahlem verloren. Von Schmidts Vorarbeiten zu einer Algenflora Helgolands zeugen nur eine kurze Darstellung in "Vegetationsbilder" (1928) sowie zwei kleine Arbeiten über "Neue oder bemerkenswerte Meeresalgen aus Helgoland“ (1936, 1938).

Nach der Wiedereröffnung der Biologischen Anstalt auf Helgoland im Jahre 1959 konnten die 1939 dort abgebrochenen algologischen Arbeiten fortgesetzt werden. Der Schwerpunkt lag wiederum auf entwicklungsgeschidhtlich-taxonomischen Untersuchungen an mehreren Gattungen des Untersuchungsgebietes. Zugleich wurden umfangreiche Sammlungen von Herbarmaterial und mikroskopischen Präparaten angelegt, die Grundlage für die nun vorliegende Algenflora Helgolands. Genauere Kenntnis über die Vertikalverteilung der Algen im Sublitoral erbrachten die Tauchuntersuchungen von Lüning (1970b).

Die Besonderheit des vorliegenden Bandes ist eine umfangreiche photographische Dokumentation der häufigen Helgoländer Grün-, Braun- und Rotalgen. Sie wurden im allgemeinen in lebendfrischem Zustand aufgenommen, meist in einer flachen Wasserschicht untergetaucht. Nur wenigen Aufnahmen liegen Herbarblätter und Dauerpräparate zugrunde, was jeweils aus den Legenden zu ersehen ist. Ein besonderer Abschnitt enthält Angaben ẗber einige seltener gefundene Arten; unberücksichtigt blieben viele epi- oder endophytisch lebende Kleinalgen, über die uns ausreichende Beobachtungen fehlen. Rund 150 mit ziemlicher Sicherheit anzutreffende Arten kennzeichnen das gegenwärtige Bild dieses im Bereich der Deutschen Bucht einzigartigen Algenvorkommens. Helgoland fügt sich als einzige Felseninsel in den weiten Bogen zwischen den Küsten des Armelkanals und Norwegens ein. Die Darstellung ihrer Algenvegetation dürfte daher besonders für pflanzengeographische Vergleiche willkommen sein. Unmittelbar aber wird das Buch allen zugute kommen, die sich aus Liebhaberei oder als Teilnehmer an meeresbiologischen Lehrveranstaltungen mit Algen beschäftigen. Knapp gehaltene Bestimmungshilfen führen entweder zu Gattungen und Arten oder grenzen Algengruppen $a b$, in denen die Arten durch einen Vergleich mit den Abbildungen bestimmt werden können. Der Text vermittelt Anregungen für die Untersuchung der gesammelten Objekte und weist auf Besonderheiten ihrer Fortpflanzung und Entwicklung sowie die Variabilität der Formen im Jahresablauf hin. Die wenigen ausgewählten Literaturangaben vermitteln den Zugang zu einer gründlicheren Information; sie sind meist jüngeren Datums und geben Zeugnis von der regen Forschungsarbeit auf dem Gebiet des Formwechsels der Algen.

Die Nomenklatur schließt sich im allgemeinen an die Liste der britischen Meeresalgen von Parke \& Dixon (1976) an; das Manuskript stand uns durch die Liebenswürdigkeit von Dr. Mary Parke, Plymouth, schon während seiner Drucklegung zur Ver- 
fügung. Ihr sowie den Sachbearbeitern der einzelnen Algengruppen gilt dafür unser verbindlicher Dank. Synonyme wurden nur bei Namensänderungen neueren Datums angegeben. Die jetzt gültigen Namen werden sich in Verbindung mit den naturgetreuen Abbildungen leichter einbürgern. Größere Objekte wurden mit der Asahi Pentax Spotmatic aufgenommen; für die Mikrophotos wurde ein einfaches Zeiss-WinkelMikroskop mit einem Leitz-Photoaufsatz benutzt. Als Aufnahmematerial diente AgfaFilm.

\section{SYSTEMATISCHE ÜBERSICHT}

Die Liste enthält die im Text dargestellten Gattungen des Untersuchungsgebiets. Die eingeklammerten Namen bezeichnen einige in den letzten 20 Jahren nur selten beobachtete Algen; sie werden in einem besonderen Abschnitt (p. 272) weniger eingehend behandelt.

Die Anordnung der Braun- und Rotalgen folgt im allgemeinen der Liste von Parke \& Dixon (1976); der Gliederung der Grünalgen liegt ein modifiziertes System von Round (1971) zugrunde.

\section{Chlorophyta}

CODIOLOPHYCEAE

ULOTRICHALES

Codrolales

Monostromatales

Acrosiphoniales

Cladorhorales

Codiales
Ulotrichaceae

Codiolaceae

Monostromataceae

Acrosiphoniaceae
Ulotbrix

Hormiscia

Urospora

Monostroma

Acrosiphonia

Spongomorpha

\section{BRYOPSIDOPHYCEAE}

Cladophoraceae

Bryopsidaceae

Codiaceae
Cladophora

Chaetomorpha

Rhizoclonium

Bryopsis

Derbesia

Codium 


\section{CHLOROPHYCEAE}

$\begin{array}{lll}\text { Chlorococcales } & \text { Chlorococcaceae } & \text { Chlorochytrium } \\ \text { Ulvales } & \text { Capsosiphonaceae } & \text { Capsosiphon } \\ & \text { Percursariaceae } & \text { Percursaria } \\ & \text { Ulvaceae } & \text { Ulva } \\ & & \text { Enteromorpha } \\ & & \text { Blidingia } \\ & \text { (Kornmannia) } \\ \text { Prasiolales } & \text { Prasiolaceae } & \text { Prasiola } \\ \text { ChAETOPHORALES } & \text { Chaetophoraceae } & \text { Rosenvingiella } \\ & & \text { Phaeophila }\end{array}$

\section{Phaeophyta}

PHAEOPHYCEAE

EctocarpaLES

Ectocarpaceae

Acinetospora

Ectocarpus

Giffordia

Kützingiella

Laminariocolax

(Mikrosyphar)

Pilayella

Sorocarpus

Spongonema

Ralfsiaceae

Ralfsia

Myrionemataceae

Leptonematella

Elachistaceae

(Protectocarpus)

Chordariaceae

Elacbista

Chordaria

Striariaceae

Istbmoplea

(Stictyosiphon)

(Striaria)

Punctariaceae

Litosiphon

Punctariat

Dictyosiphonaceae

(Dictyosiphon)

Tilopteridaceae

Haplospora

Tilopteris

Scytosiphonaceae

Petalonia

Scytosiphon

Desmarfatiales

Desmarestiaceae

Desmarestia 


$\begin{array}{lll}\text { Laminariales } & \text { Chordaceae } & \text { Chorda } \\ & \text { Laminariaceae } & \text { Laminaria } \\ \text { SpHacelariales } & \text { Sphacelariaceae } & \text { Sphacelaria } \\ & \text { Cladostephaceae } & \text { Cladostephus } \\ \text { DiCtYotales } & \text { Dictyotaceae } & \text { Dictyota } \\ \text { FuCALES } & \text { Fucaceae } & \text { Ascophyllum } \\ & & \text { Fucus } \\ & \text { Cystoseiraceae } & \text { Halidrys } \\ & \text { Himanthaliaceae } & \text { Himanthalia }\end{array}$

\section{Rhodophyta}

\section{FLORIDEOPHYCEAE}

Nemalionales

Gigartinales

Cryptonemiales
Acrochaetiaceae

Helminthocladiaceae

Bonnemaisoniaceae

Gymnophlaeaceae

Furcellariaceae

Cruoriaceae

Polyideaceae

Rhodophyllidaceae

Phyllophoraceae

Gigartinaceae

Corallinaceae

Dumontiaceae

Gloiosiphoniaceae

Choreocolacaceae

Peyssonneliaceae

Hildenbrandiaceae
Acrochaetium Audouinella

Rbodochorton

(Nemalion)

Bonnemaisonia

(Platoma)

Furcellaria

Halarachnion

Cruoria

Petrocelis

Polyides

Cystoclonium

Ahnfeltia

Gymnogongrus

Pbyllophora

Chondrus

Corallina

Dermatolithon

Lithothamnium

Melobesia

Phymatolithon

Dumontia

(Dudresnaya)

(Gloiosiphonia)

Harveyella

Peyssonnelia

Rhodopbysema

Hildenbrandia 


\begin{tabular}{|c|c|c|}
\hline \multirow{9}{*}{$\begin{array}{l}\text { RHODYMENIALES } \\
\text { CERAMIALES }\end{array}$} & Champiaceae & Lomentaria \\
\hline & Ceramiaceae & Antithamnion \\
\hline & & Callithamnion \\
\hline & & Ceramium \\
\hline & & Plumaria \\
\hline & Delesseriaceae & Delesseria \\
\hline & & Membranoptera \\
\hline & Rhodomelaceae & Brongniartella \\
\hline & & $\begin{array}{l}\text { Polysipbonia } \\
\text { Rbodomela }\end{array}$ \\
\hline
\end{tabular}

\section{BANGIOPHYCEAE}

PORPHYRIDIALES

Bangiales
Goniotrichaceae

Erythropeltidaceae

Bangiaceae
Goniotrichum

Erytbrotricbia

Porphyropsis

Bangia

Porpbyra

\section{BESTIMMUNGSSCHLÜSSEL}

\section{Grünalgen}

\section{Einzelzellen}

A. Kugelige Epiphyten auf Enteromorpha und Blidingia oder Endophyten in Gallertschläuchen von Diatomeen

B. Eiförmige Endophyten in Polyides oder eiförmiglanggestielt in Petrocelis . . . . . . . . . . Sporophyt von

C. Köpfchen auf langen Stielen

a. Langgestreckt, auf Steinen und epiphytisch . . . Codiolum

b. Keulig, auf Steinen . . . . . . . . . . . Codiolum-Phase von Urospora wormskioldii 


\section{Unverzweigte Zellfäden}

A. Einreihig, schlaff

p.

a. Chromatophor gürtelförmig . . . . . . . . Ulotbrix 18

b. Chromatophor netzartig . . . . . . Hormiscia 20

c. Verworrene Fadenknäuel an Algen oder klumpige Stränge im unteren Litoral . . . . . . . . . Chaetomorpha tortuosa $\quad 38$

d. Grüne Oberzüge auf Hafenmolen (enthalten selten Doppelfäden oder 3- und 4reihige) . . . . . . Rosenvingiella polyrbiza $\quad 87$

e. Wollig-filziger Bewuchs an Hochwasserlinie . . . Rhizoclonium riparium $\quad 47$

f. Glatter Uberzug auf Fels und Algen im unteren Litoral . . . . . . . . . . . . . . Rhizoclonium kochianum

B. Einreihig, borstig steif, Zellen mit bloßem Auge sichtbar . . . . . . . . . . . . . Chaetomorpha 36

C. Zweireihig . . . . . . . . . . . . . . . Percursaria 62

D. Vielreihig mit Einschnürungen, nur an der Basis einreihig . . . . . . . . . . . . . .

Rosenvingiella constricta 84

\section{Büschel aus verzweigten Zellfäden}

A. Dünnwandig, Zellen an den Querwänden nicht eingeschnürt, auffallende Apikalzelle

a. Bis $10 \mathrm{~cm}$ hoch, nicht epiphytisch . . . . . . Acrosipbonia 28

b. Zartfädig, etwa $2 \mathrm{~cm}$ hoch, auch epiphytisch . . . Spongomorpha 34

B. Derbwandig, Zellen an den Querwänden eingeschnürt Cladophora 40

\section{Thallus nicht in Zellen gegliedert}

A. Achsen mit Fiederchen besetzt . . . . . . . . Bryopsis 48

B. Dünne Fäden gabelig bis unregelmäßig verzweigt . . Derbesia 53

C. Kugelige Blasen auf krustenförmigen Rotalgen . . . Halicystis 53 


\section{Thallus röhrig hohl}

A. Unverzweigte oder wenig bis stark verzweigte dünne Röhren sowie aus dünner Basis sich verbreiternder Thallus . . . . . . . . . . . . . . . .

B. Außerliche Merkmale wie A, jedoch durch ihr Vorkommen gut gekennzeichnet (Chromatophor sternförmig gelappt, Unterschied zu Enteromorpha)

a. Krauser, kurzer Bewuchs an der Hochwasserlinie

Blidingia

minima

b. Etwa $6 \mathrm{~cm}$ lange dünne Röhren in der Spritzzone oder an Mauern, die nur gelegentlich von Seewasser benetzt werden

Enteromorpha

\section{Blidingia}

marginata

80

C. Zellen rundlich und in auffallend schraubigen Reihen

Capsosiphon

\section{Thallus flächig}

\section{A. Einschichtig}

a. Ungestielt

Monostroma

b. Gestielt

* Mehrere Zentimeter hoch, gelbgrüne Fläche oft ausgebuchtet

Kornmannia

: $\%$ Bis $5 \mathrm{~mm}$ hohe Räschen an der Hochwasserlinie und daruiber

Prasiola

B. Zweischichtig

a. Oval, zungenförmig oder unregelmäßig lappig . .

Ulva

b. Aus dünner röhriger Basis sich verbreiternd, nur am Rand hohl .

Enteromorpha linza

7. Elastische, etwa $5 \mathrm{~mm}$ dicke, dichotom geteilte gewebeartige Schnüre

Codium

8. Mikroskopische, scheibenförmige oder fädig verzweigte

Thalli. Epi- und Endophyten oder auf Steinen . . . 


\section{Braunalgen}

\section{Große, lederartig derbe "Tange", mehrjährig}

A. In krallenartig verzweigtes Haftorgan, Stiel und einfaches oder fingerförmig geteiltes Laub gegliedert . .

Laminaria

p.

B. Mit Haftscheibe am Substrat verankert
a. Thallus flach mit Mittelrippe, dichotom verzweigt
b. Wenig verzweigt, leicht abgeflacht, Achse mit läng- lichen Luftblasen . . . . . . . . . . . .
c. Reich wechselständig in einer Ebene verzweigt, Zweige mit schotenförmigen, zugespitzten, gekam- merten Luftblasen . . . . . . . . . . . .
d. Kurz gestielter Napf mit langen, dichotom geteilten Bändern, meist werden nur diese angetrieben .

Fucus

162

Halidrys

170

Himantbalia

170

\section{Verzweigte feinfädige Algen}

A. Durchaus monosiphon . . . . . . . . . Ectocarpaceae

B. Mit Längswänden in den unteren Teilen der Achsen

Schlüssel

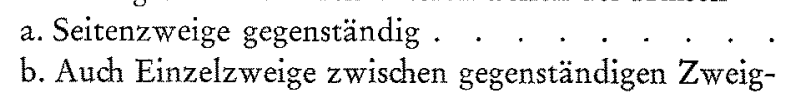
paaren . . . . . . . . . . . . . . .

Tilopteris

c. Hauptachse mit Zweigwirteln .

Haplospora

C. Polysiphon mit großer Scheitelzelle, wenig verzweigt

Sphacelaria

a. Mit zwei- oder dreistrahligen Brutknospen. . . Sph. furcigera

b. Ausgedehnte Polster in der Gezeitenzone . . . . Sph. radicans

c. Pinselige Büschel bis $1 \mathrm{~cm}$ Höhe, sublitoral . . Sph. caespitula

\section{Unverzweigte dünne Fäden}

A. Von einem basalen Knötchen ausstrahlend, Epiphyt auf Fucus . . . . . . . . . . . . . . . Elachista

B. Dichter Epiphytenbewuchs auf Laminaria. . . . . Litosipbon

Weiter auf p. 10. 
C. Auf einer basalen Scheibe

a. Bis $5 \mathrm{~mm}$ hohe pinselige Büschel, plurilokuläreSporangien je nach Fadendicke einseitig oder allseitig nur wenig papillenförmig vortretend. . . . .

b. Knapp $1 \mathrm{~mm}$ hoher Uberzug auf Steinen oder Algen, plurilokuläre Sporangien einseitig gereiht, of hahnenkammartig

Protectocarpus

\section{Unverzweigte größere Algen}

A. Hohl, Thallus oft eingeschnürt . . . . . . . Scytosiphon

B. Bis $3 \mathrm{~m}$ lange runde Schnüre

Chorda

\section{Verzweigter solider Thallus}

A. Allseitig verzweigt

a. Meist nur mit wenigen, die Achse überwachsenden Zweigen, schlïpfrig . . . . . . . . . . .

b. Seltener Epiphyt auf Chordaria, Thallus unten röhrig; nur unilokuläre Sporangien . . . . .

c. Auf festem Substrat und epiphytisch, selten; nur plurilokuläre Sporangien . . . . . . . . .

Chordaria

124

Dictyosipbon

Stictyosipbon

275

B. In einer Ebene verzweigt

a. Verzweigung gegenständig

* Didht fiederig verzweigt

Spbacelaria

plumosa

Achse rund und fleischig, einjährige Alge mit zarten Kurztriebbüscheln, wird an der Luft spangrün

Desmarestia viridis

b. Verzweigung unregelmäßig; Achse knorpelig, etwas abgeflacht. Im Frühjahr mit Kurztriebbüscheln, sonst mit kurzen Dornen besetzt .

Desmarestia aculeata

C. Achsen von kurzen, wirteligen, gekrümmten Astchen umhüllt .

6. Thallus hohl, verzweigt, sehr selten . . . . . . . Striaria 


\section{Thallus flächig oder bandförmig}

A. Ungeteilt p.

a. Bis $3 \mathrm{~mm}$ breite Bänder . . . . . . . . . . Petalonia

zosterifolia $\quad 137$

b. Aus dünnem Stiel breiter werdend

* Lanzettlich bis oval, oft leicht abgewinkelt;

Oberfläche glatt . . . . . . . . . . . Petalonia fascia

$\because$ Breit lanzettlich, durch Haarbüschel gepunktet; im Alter oft mit Längsrissen . . . . . . . Punctaria

plantaginea

x:\% Zarthäutig, lanzettlich, bis $4 \mathrm{~cm}$ lang. Selten im Herbst und Winter an Bojen . . . . . . . Punctaria biemalis

B. Dichotom geteilt . . . . . . . . . . . . . Dictyota

8. Thallus krustenförmig . . . . . . . . . . . . Ralfsia

9. Thallus mikroskopisch klein. Endophytisch in der Zellwand von Ceramium deslongchampsii, die dann leicht bräunlich wird . . . . . . . . . . . . . . Mikrosyphar polysiphoniae 


\section{Rotalgen}

\section{Kleinalgen}

A. Epiphytische Büschelchen

a. Echt verzweigt, meist unter $3 \mathrm{~mm}$ hoch $(A$. daviesit wächst im Sublitoral auch auf Steinen). . . . . Acrochaetium 174

b. Unecht verzweigt, Zellen in Gallerthülle . . . . Goniotrichum 256

B. Epiphytische Einzelfäden

a. Bis $2 \mathrm{~cm}$ lang, einreihig, sehr dünn . . . . . Erythrotrichia carnea

b. 1-5 mm lang, meist gekrümmt und in der Mitte mehrreihig . . . . . . . . . . . . Erythrotrichia reflexa

C. Endozoisch in Chitinmembranen von Hydrozoenstöckchen . . . . . . . . . . . . . . Audouinella

D. Parasitische Knötchen, weiß, 1-2 mm groß, auf Rhodomela. . . . . . . . . . . . . . . . Harveyella

\section{Monosiphone, verzweigte Feinalgen}

A. Pelzige Polster oder Rasen in der Gezeitenzone. . . Rbodochorton

B. Aufrechte zarte Algen

a. Verzweigung gegenständig, in einer Ebene. . . Antithamnion

b. Verzweigung alternierend

Callithamnion

C. Flödkchen aus unregelmäßig verzweigten Fäden, sublitoral . . . . . . . . . . . . Trailliella

\section{Unverzweigte Fäden}

a. Mono- und polysiphon, braunror . . . . . . Bangia

b. Monosiphon, sehr dün, rosa. . . . . . . Erythrotrichid 


\section{Thallus flächig}

A. Nicht von Rippen durchzogen

a. Lanzettlich, zungenförmig bis unregelmäßig lappig

b. Zarte rosenrote rundliche Thalli von $1-3 \mathrm{~cm}$ Durchmesser; sublitoral .

c. Gabelig in breite Lappen geteilt, mehrschichtig; sublitoral

Porpbyra

Porphyropsis

260

Halarachion 186

B. Mit Mittel- und Seitenrippen
a. Breitoval
b. Eichenlaubartig ausgebuchtet . . . . . . . .
c. Schmal geflügelte Mittelrippe, Seitenrippen nur im Sommer erkennbar . . . . . . . . . .

Delesseria

236

C. Festes, gabelig geteiltes oder ovales bis keilförmiges Laub auf langem Stiel . . . . . . . . . . . phyllophora

D. Kleine Algen aus dem Sublitoral

a. Kurz gestielt, derbhäutig, dunkelrot

Pbyllophora

traillii

b. Rosa, von kleinen Blättchen gesäumt

Lomentaria

orcadensis

\section{Thallus knorpelig}

A. Rund

a. 1-2 $\mathrm{mm}$ dick, steif und schlank, gabelig verzweigt

*Gegen das Licht betrachter rot . . . . . . .

** Gegen das Licht betrachtet bräunlich-violett .

b. Fadenförmig dünn, verworren, drahtige Büschel .

Polyides

192

Furcellaria

186

B. Abgeflacht, dichotom geteilt

Abnfeltia

197

a. Aus dünnem Stiel breiter werdend, Enden fächerartig bis kraus . . . . . . . . . . . .

b. Bandartig, etwa 2-3 mm breit. . . . . . . . Gymnogongrus

\section{Thallus in einer Ebene verzweigt}

A. Schwach knorpelig, das dichte Verzweigungsmuster ergibt keinen definierbaren Umriß . . . . . . .

B. Verzweigung ergibt federartigen Umriß . . . . .

C. Durch Kalkeinlagerung hart . . . . . . . . .
D. Gallertig, wiederholt fast gegenständig verzweigt. (Kann auch allseitig verzweigt sein.)

Plocamium

Corallina

Lomentaria clavellosa

E. Dichotom verzweigt, durch Rindengürtel geringelt. Jüngere Pflanzen von 


\section{Thallus rund}

A. Mit dichotom verzweigten Achsen, aber büschelig durch allseitige Adventiväste, Fäden durch Rindengürtel geringelt . . . . . . . . . . . . . . . . Ceramium

B. Achsen allseitig wiederholt verzweigt

a. Festfleischige, reich verzweigte Büschel . . . . .

Cystoclonium

194

b. Fäden in Segmente gleichhoher Zellen gegliedert, zumindest in den oberen Abschnitten unberindet . .

Polysiphonia 241

c. Zweige von kurzen Ästchen umhüllt . . . . .

d. Strauchartig sparrig, im Frühjahr mit dichten pinseligen Zweigenden . . . . . . . . . . . Rbodomela

e. Mit Hakenzweigen an anderen Algen befestigt . . Bonnemaisonia

\section{Thallus gallertig}

A. Häufig vorkommend

a. Thallus rund oder abgeplattet, Hauptachse of von den wenigen langen $Z$ weigen überwachsen . . . .

b. Hauptachse trägt reichlich nach oben kürzere Zweige, fast gegenständig oder allseitig . . . . . . Lomentaria

clavellosa

B. Sehr seltene, stark gallertige Algen

Dumontia 218

a. Spärlich gabelig verzweigte, $2-3 \mathrm{~mm}$ dicke, runde Schnüre . . . . . . . . . . . . . . .

b. Allseitig verzweigt. Zentralfaden trägt dicht zusammenschließende Zweigwirtel . . . . . . . .

c. Allseitig reich mit dünnen abstehenden Zweigen besetzt . . . . . . . . . . . . . . . .

d. Der mehrfach dichotom geteilte Thallus endet in schmalen spitzen Zipfeln . . . . . . . . . Platoma

Dudresnaya

Gloiosiphonia

\section{Thallus krustenförmig, nicht verkalkt}

A. Auf Steinen in der Gezeitenzone, aber auch im Sublitoral wachsend

a. Speckig, glänzend, weich, fast schwarz . . . . . Petrocelis

b. Hart, dünn, fest haftend

* Sporangien in Konzeptakelgruben (Flächenschnitt!). . . . . . . . . . . . . 
B. Sublitoral, meist auf Steinen p.

a. Zellfäden fest miteinander verbunden . . . . Peyssonnelia 220

b. Zellfäden durch Gallerte zusammengehalten . . . Cruoria 189

10. Thallus krustenförmig, verkalkt

A. Epiphytisch, häufig auf Laminaria byperborea

a. Vorwiegend auf den Haftkrallen; sehr zarte, rötliche Kruste . . . . . . . . . . . . . . . Melobesia 209

b. Auffallende grau-violette Kruste auf den Stielen . Dermatolithon 206

B. Auf Steinen

a. Im Felswatt verbreitet, auch sublitoral. . . . Phymatolithon 210

b. Sublitoral

*Ungeschlechtliche Konzeptakeln einporig . . . Lithophyllum

* Ungeschlechtliche Konzeptakeln vielporig. . . Lithotbamnium 215 


\section{Chlorophyta}

Ein von Round (1971) aufgestelltes System gliedert den Stamm der Chlorophyta, der grünen Algen im eigentlichen Sinne, in die Klassen der Zygnemaphyceae, Oedogoniophyceae, B ry opsid op h y cea e (p. 36) und Chlor oph y ce a e (p. 55). Die beiden erstgenannten Klassen enthalten nur Süßwasseralgen, die beiden letzteren sind im Süßwasser und im Meer vertreten. Einige ihrer Ordnungen hat Kornmann (1973) in einer neuen Klasse, Codi o l o p h y c e a e, vereinigt.

\section{Codiolophyceae}

Gemeinsames Merkmal der Klasse ist der einzellige Sporophyt im Lebenszyklus der Vertreter ihrer vier Ordnungen. Trotz morphologischer Verschiedenheit der Gametophyten sind die frühen Entwicklungsstadien der Sporophyten von erstaunlicher Gleichförmigkeit, eine Analogie, die als bedeutsam für die Annahme verwandtschaftlicher Beziehungen der in der Klasse vereinigten Ordnungen angesehen wird.

Die Vertreter der Codiolophyceen sind ausgeprägte Ephemerophyten. Die Gametophyten erscheinen gegen Ende des Winters, gelangen von März bis Mai zur vollen Entfaltung und verschwinden dann wieder aus dem Vegetationsbild. Soweit die Sporophyten (als Codiolum-oder Chlorochytrium-Arten) aus der Natur bekannt sind, werden sie in den Herbst- und Wintermonaten fertil; der Temperaturverlauf bedingt den jahreszeitlichen Rhythmus der Generationen in der Natur und bestimmt ihn durch die gewählten Bedingungen im Kulturversuch.

Die Codiolophyceae gliedern sich in vier Ordnungen:

Ulotrichales: Monosiphone, unverzweigte Fäden. Chromatophor ein bandförmiger, offener Ring. Ulotrichaceae, p. 18.

Codiolales: Monosiphone, unverzweigte Fäden. Chromatophor netzförmig. Zoosporen mit zugespitztem Hinterende. Codiolaceae, p. 19.

Monostromatales: Flächenförmiger, einschichtiger Thallus. Monostromataceae, p. 24. Acrosiphoniales: Monosiphone, verzweigte Fäden mit Spitzenwachstum. Acrosiphoniaceae, p. 28.

Abb. 1: Ulothrix. A Ein dunkles Band von Ulothrix über Blidingia minima am Anfang der Dünenmole Ost; auf der horizontalen Fläche wächst Enteromorpha (23. 5. 1972). B-F Ulothrix carmichaelii. Zottige Stränge auf Fucus, etwa $\times 0,5$; vegetative Fadenabschnitte aus der Basis, dem oberen Teil eines Stranges und fertile Fäden (11. 4. 1972). G Ulothrix geminaia, Zoosporangien $(5.8 .1972)$. H - J Ulothrix speciosa, vegetativ und mit Gametangien (6.3. 1973). Maßstrecken: $\mathrm{F}=500 \mu \mathrm{m} ; \mathrm{C}-\mathrm{E}, \mathrm{G}-\mathrm{J}=50 \mu \mathrm{m}$ 


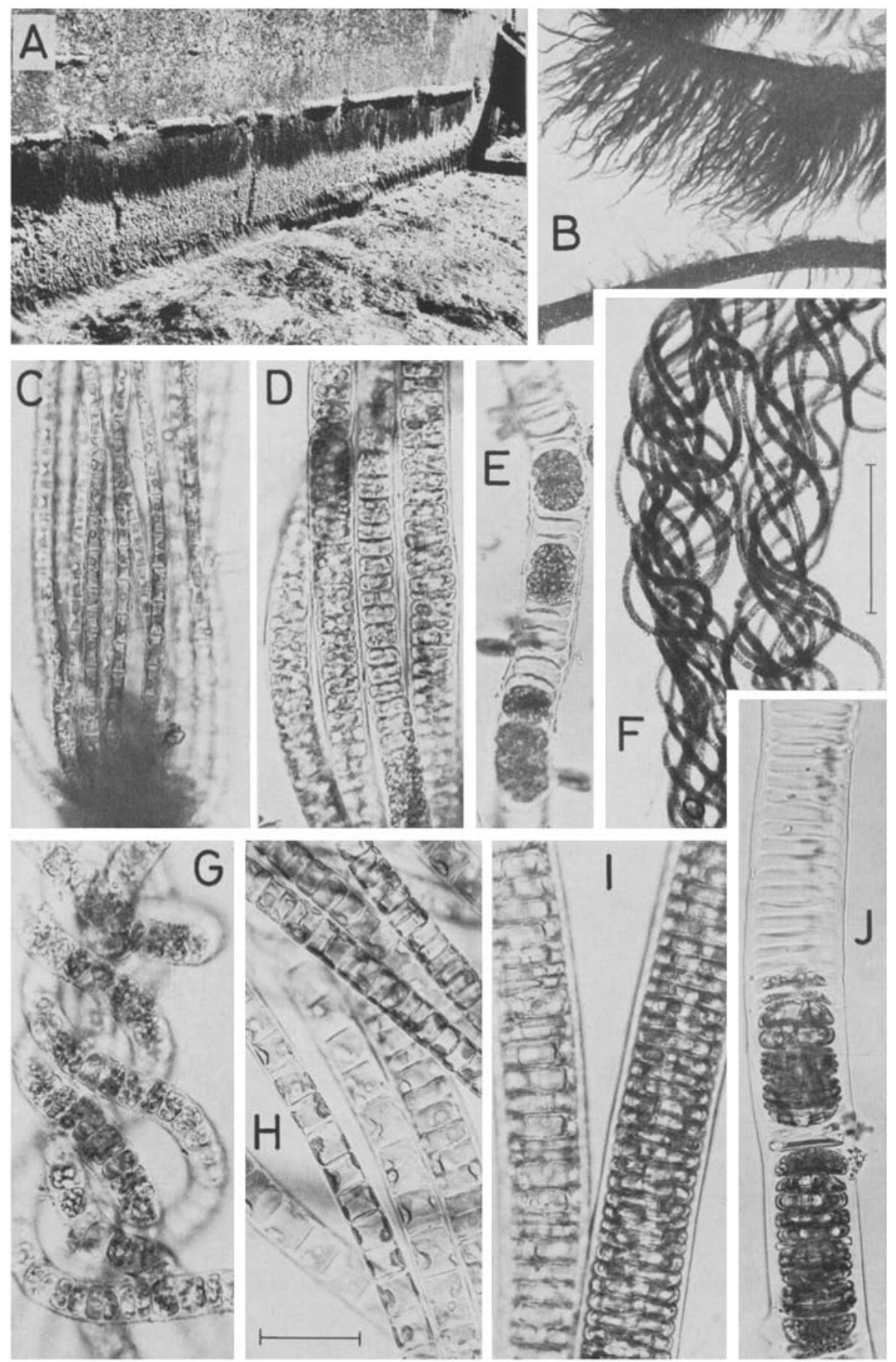




\title{
ULOTRICHALES
}

\author{
Ulotrichaceae
}

\section{Ulotbrix Kützing}

Die Gattung Ulothrix ist mit zahlreichen Arten bei Helgoland vertreten. Sie sollen hier nicht einzeln beschrieben werden, weil klare morphologische Bestimmungsmerkmale fehlen. Für ihre Unterscheidung sind Beobachtungen über die Natur der Schwärmer und ihre Entwicklung in Kultur unerläßlich. Einige Helgoländer Ulotbrix-Arten wurden von Kornmann (1964) näher gekennzeichnet; die taxonomische Bearbeitung der Gattung ist noch nidht abgeschlossen.

Am reichlichsten kommt Ulotbrix in den Frühjahrsmonaten vor und kann dann im Litoral Steine und Uferschutzbauten flächenweise besiedeln. Abbildung 1 zeigt bei A den Anfang der Dünenmole Ost, wo eine Ulothrix-Art als breites dunkelgrünes Band noch oberhalb von Blidingia minima wächst. Nur bei ungewöhnlich hohem Wasserstand wird sie hier überflutet, im allgemeinen nur von kräftig brandenden Wellen erreicht. Ulotbrix carmicbaelii (Harv.) lebt im unteren Litoral epiphytisch auf Fucus und auf Fels; die Fäden sind häufig zu zottigen Strängen zusammengedreht (B). In vielen Fällen ist eine Probe feinfädiger Grünalgen nicht artenrein; sie kann mehrere Ulothrix-Arten zusammen mit Hormiscia enthalten. Darüber gibt erst die mikroskopische Prüfung Aufschluß (vgl. Abb. 3).

Ein einzelner Ulotbrix-Faden ist keineswegs auf seiner ganzen Länge einheitlich. Die Fadenbreite nimmt von der Basis zur Spitze zu, zugleich verändert sich auch die Form der Zellen (C, D und H, I). In den gestreckten bis isodiametrischen Zellen der basalen Abschnitte ist der Chromatophor als offener, der Längswand anliegender Ring klar ausgeprägt. Mit zunehmender Fadenbreite werden die Zellen kürzer und sind bei einigen Arten scheibenartig flach (I). Die fertilen Fadenabschnitte sind oft in charakteristischer Weise lockenartig gewunden $(F, G)$.

Hinsichtlich der Fortpllanzung besteht eine große Mannigfaltigkeit. Die in den Figuren H-J dargestellte breite Ulothrix speciosa (Harv.) ist diözisch und bildet nur zweigeißelige Gameten. Bei der ebenfalls diözischen Ulotbrix carmichaelii (Harv.) kommen Zoosporangien und Gametangien in demselben Faden vor (B-F). Die morphologisch ganz ähnliche Ulotbrix geminata dagegen (G) vermehrt sich nur durch viergeißelige Zoosporen. (Der Name dieser Art ist noch nicht veröffentlicht; er bringt zum Ausdruck, daß der Zoosporenkeimling sich als wenigzelliger Faden zu einem Paar getrennter Keimlinge teilt.) Zoosporen entwickeln sich stets zu fädigen Pflanzen; aus Zygoten oder parthenogenetisch gekeimten Gameten entstehen mikroskopisch kleine, einzellige Sporophyten, die bei marinen Formen in der Natur noch nicht gefunden wurden. Den heteromorphen Generationswechsel der Süßwasser-Art U. zonata beschrieb Dodel schon 1876 vollständig. 

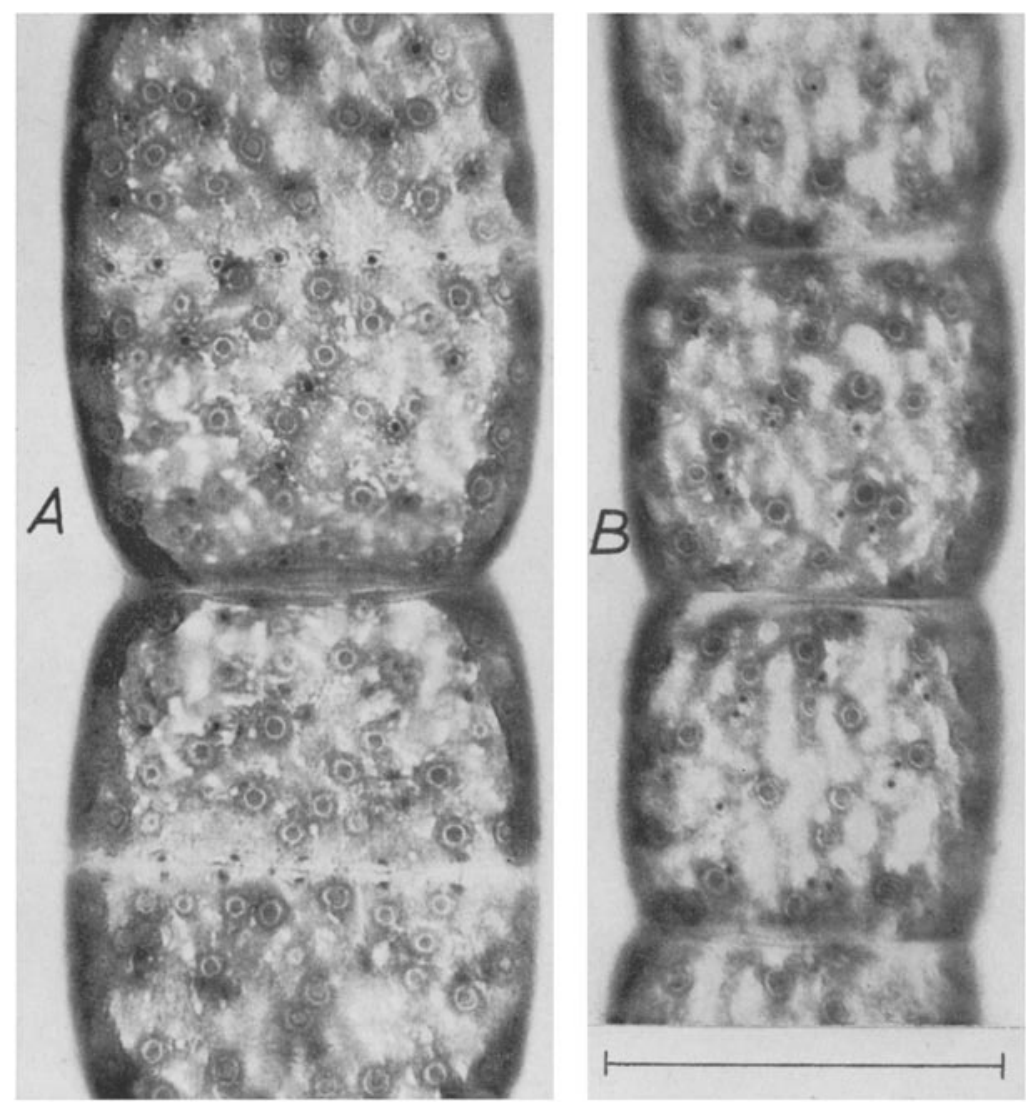

Abb. 2: Urospora wormskioldii, Zell- und Kernteilung, Färbung mit Eisenhämatoxylin nach Hansen. A Vor der Zellteilung ordnet sich ein Teil der Kerne in einem äquatorialen Ring an; alle Kerne teilen sich. B Freie Kernteilung in den heranwachsenden Schwesterzellen. Nach Kornmann 1966a. Maßstrecke $=100 \mu \mathrm{m}$

\section{CODIOLALES}

\section{Codiolaceae}

In früheren Systemen waren die Gattungen Hormiscia und Urospora den Cladophorales oder den Acrosiphoniales zugeordnet; die einzelligen, sehr heterogenen Vertreter der Gattung Codiolum fanden bei den Chlorococcales ihren Platz. Die zugespitzten Zoosporen der Fäden und der genetisch zu ihnen gehörenden CodiolumStadien werden jedoch als signifikantes Merkmal für die Aufstellung einer besonderen Ordnung angesehen. Die Zellen von Hormiscia und Urospora sind vielkernig. Der 
Zellteilung ist die Teilung der Kerne in einer besonderen Weise zugeordnet: Ein Teil der Kerne ordnet sich in einem äquatorialen Ring an, und zu Beginn der Wandbildung teilen sich nicht nur diese, sondern auch alle übrigen Kerne (Abb. 2 A). Damit bleibt ihre Anzahl dieselbe wie in der Mutterzelle; sie verdoppelt sich aber in den wachsenden Schwesterzellen durch eine freie Kernteilung (Abb. 2 B). (Eine einkernige monözische Art wird einer neuen Gattung zugeteilt werden.) Bei dieser und den Hormiscia-Arten entsteht das Codiolum-Stadium als echter Sporophyt aus einer Zygote. Bei den Urospora-Arten dagegen geht das Codiolum aus ungeschlechtlichen Schwärmern hervor. Ausführlicher unterrichten die Arbeiten von Kornmann (1961b, 1966a, b). Hormiscia penicilliformis Roth (Fries) und Hormiscia neglecta Kornm.
incl. Codiolum gregarium A. Braun

Die Darstellungen der Abbildung 3 können für die beiden obengenannten Hormiscia-Arten gelten. Sie sind häufig in derselben Probe vorhanden und morphologisch nicht zu unterscheiden, Hormiscia neglecta wächst jedoch vorzugsweise im oberen Litoral. Auf die unterschiedliche Ausbildung des Haftorgans der Fäden bei der Aufzucht aus Zoosporen soll hier nicht näher eingegangen werden. Auch sind die weiblichen Gameten beider Arten sehr unterschiedlich groß. Ganz wesentlich aber unterscheiden sich ihre Sporophyten-Generationen: Der bisher nur aus Kulturen bekannte Sporophyt von $H$. penicilliformis ist mikroskopisch klein, während der Sporophyt von $H$. neglecta schon vor über 100 Jahren bei Helgoland gefunden und als Codiolum gregarium beschrieben wurde (Abb. $4 \mathrm{~A}$ ). Diese Zusammenhänge konnten erst in den letzten Jahren durch Kulturversuche aufgeklärt werden.

Hormiscia kommt zusammen mit Ulothrix vor, von der sie sich bei mikroskopischer Kontrolle leicht durch den netzförmigen Chromatophor mit zahlreichen Pyrenoiden unterscheiden läßt. In den basalen Abschnitten mit reger interkalarer Teilungstätigkeit sind die Fäden geradlinig begrenzt, sie werden nach oben breiter, zugleich schnüren sich die Zellen an den Querwänden leicht ein. Die Sporangien sind ausgeprägt tonnenförmig. Sie erscheinen dunkelgrün durch die dichte Masse ihrer großen Schwärmer. In Präparaten trocken am Standort gesammelter Proben entleeren sich völlig reife Sporangien innerhalb weniger Minuten. Es ist sehr eindrucksvoll zu beobachten, wie der Inhalt eines Sporangiums zunächst in eine zartwandige Blase austritt und die Zoosporen nach dem Aufreißen dieser Hülle frei werden (E, F). Ganze Reihen reifer Sporangien können sich geradezu explosionsartig entleeren: $Z$ wischen den Bildern der Serie bei E liegen nur wenige Sekunden. Das Hinterende der Zoosporen läuft in eine feine Spitze aus, das Merkmal der Gruppe (G). Die Zoosporen schwimmen nur träge und ungerichtet umher.

Fäden mit Gametangien triff man aur selten an, im allgemeinen zusammen mit Zoosporangien, von denen sie leicht an der Körnung des Inhalts zu unterscheiden sind. Die männlichen Gametangien fallen durch ihre olivgrüne Färbung auf. Die Kopulanten sind ausgeprägt anisogam. Während die Zygoten von $H$. neglecta in Kultur langsam 

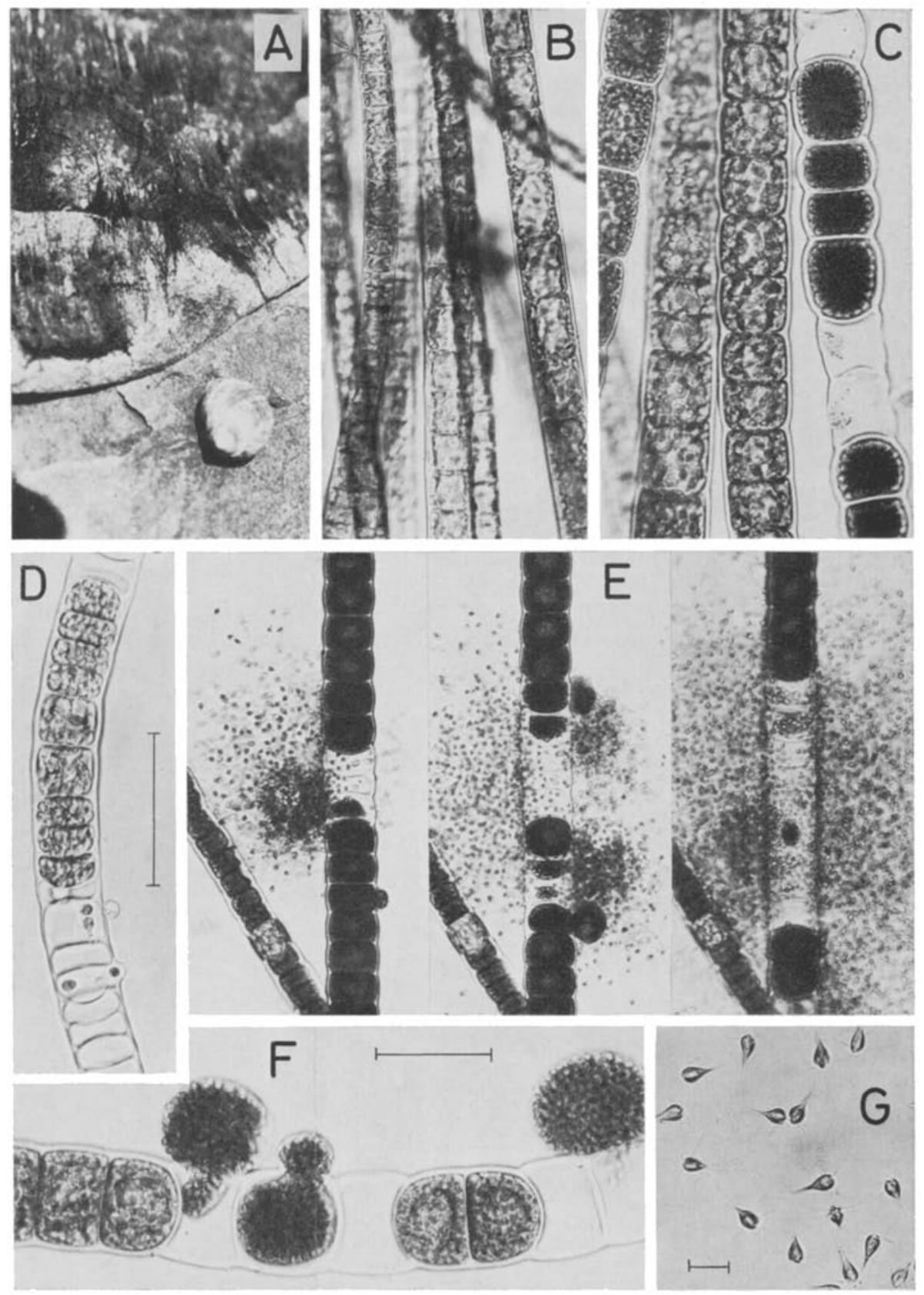

Abb. 3: Hormiscia penicilliformis. A Auf der fast senkrechten Fläche eines Steines wachsend, eine Littorina littorea als Maßstab (5, 6. 1972). B, C Basale und obere Fadenabschnitte aus demselben Strang, rechts Zoosporangien. D Fadenstück mit Gametangien (26. 2. 1973). E-G Sporangienentleerung und Zoosporen. Maßstrecken: $\mathrm{B}, \mathrm{C}, \mathrm{F}=100 \mu \mathrm{m} ; \mathrm{D}=50 \mu \mathrm{m} ; \mathrm{G}=20 \mu \mathrm{m}$ 
zur typischen Codiolum gregarium-Generation heranwachsen, bleiben die Sporophyten von $H$. penicilliformis mikroskopisch klein und werden schon nach etwa zwei Wochen fertil.

\section{Urospora wormskioldii (Mert. in Hornem.) Rosenv.}

Nur in den Jahren 1956 bis 1965 war diese, durch ihre langen, großzelligen Fäden auffallende Alge in der Frühjahrsvegetation Helgolands reichlich vertreten (D). Seitdem ist sie selten geworden, doch kommt ihr Codiolum-Stadium noch immer massenhaft auf den Molen vor, und die fädige Generation läßt sich im Laboratorium aus den Zoosporen kultivieren. Durch seine keuligen Köpfchen ist dieses Pflänzchen gut von Codiolum gregarium zu unterscheiden (B); es kommt auch erst im Januar und Februar zur Reife (C), während Codiolum gregarium meist schon im Dezember fertil wird. Beide Codiolum "Arten" können auf Steinen in der Spritzzone und auf Molen samtigrasige Überzüge bilden.

Der Entwicklungsgang von Urospora wormskioldii ist sehr variabel in Abhängigkeit von den Kulturbedingungen. Nur bei niedriger Temperatur (um $5^{\circ} \mathrm{C}$ ) erhält man in Kultur aus den Codiolum-Zoosporen die stattlichen, großzelligen Fäden (D). Bei höherer Temperatur - um $15^{\circ} \mathrm{C}$ - entwickeln sie sich zu einer Generation von Zwergpflanzen (E), die während des ganzen Jahres in dem grünen Anflug der rauhen Oberfläche des Betons der Molen vorkommen. Die Zwerggeneration bildet außer viergeißeligen Zoosporen auch ungeschlechtliche, zweigeißelige Schwärmer, aus denen das Codiolum-Stadium hervorgeht. Die Zoosporen der Fadengeneration entwickeln sich in Abhängigkeit von der Temperatur zu Fäden oder zu Zwergpflanzen.

Abb. 4: A Codiolum gregarium, der Sporophyt von Hormiscia neglecta (9. 1. 1973). B, C Urospora wormskioldii, Codiolum-Stadium (3.2. 1971). D, E Urospora wormskioldit, Fadenstadium $(17,4.1972)$ und Zwergpflanzen aus Kultur. Maßstrecken: $A, B=500 \mu \mathrm{m} ; \mathrm{C}=$ $100 \mu \mathrm{m} ; \mathrm{D}=1 \mathrm{~mm} ; \mathrm{E}=200 \mu \mathrm{m}$ 

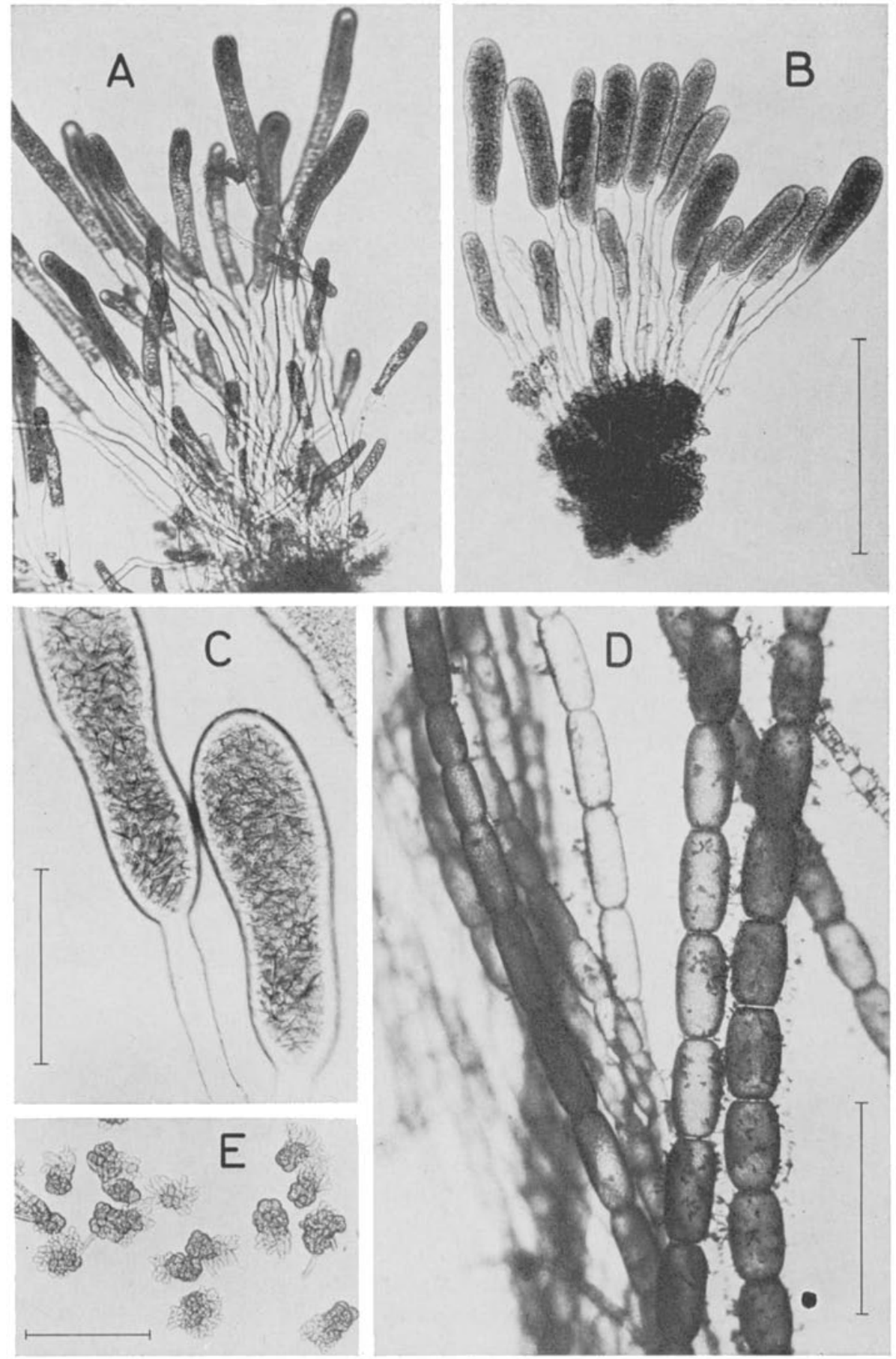


\section{MONOSTROMATALES}

\section{Monostromataceae}

Wegen ihres flächigen Thallus fand Monostroma bisher häufig ihren Platz neben Gattungen wie Ulva und Enteromorpha. Nicht nur ihr heteromorpher Lebenszyklus, sondern auch die ontogenetische Entwicklung der einschichtigen Fläche machen die Abtrennung von den Ulvales notwendig. Uber die bei Helgoland vorkommenden Arten haben Kornmann (1962a) und Kornmann \& Sahling (1962b) ausführlich berichtet.

Monostroma grevillei (Thur.) Wittr. und Monostroma arcticum Wittr.

Im März bis Mai findet man auf dem felsigen Untergrund nahe der Niedrigwasserlinie unregelmäßig zerschlitzte, bis etwa $8 \mathrm{~cm}$ lange hellgrüne flächige Thalli, deren Basis sich spitz, mitunter zu einer kegelförmigen Tüte verjüngt, in der sich beträchtliche Mengen von Detritus ansammeln können (B, C). Gezeitentïmpel und Becken in Betonblödken werden regelmäßig von zwei äußerlich gleichartig erscheinenden Monostroma-Arten besiedelt, deren dünnhäutige Membranen sich etwas schlüpfrig anfühlen.

Daß hier verschiedene Arten vorliegen können, wird erst durch das Verhalten ihrer Schwärmer und deren Entwicklung offenbar. Für diese Prüfung ist fertiles Material notwendig, das an der leicht orange oder olivgrün gefärbten Zone unterhalb der farblosen, bereits ausgeschwärmten Thallusenden zu erkennen ist (C). Solche Pflanzen stehen nicht immer zur Verfügung, weil die von der Spitze zur Basis fortschreitende Fertilisierung periodisch erfolgt. Etwa 20 Pflanzen werden einzeln in Petrischalen mit Seewasser gelegt. Je nach ihrer Reife erfolgt das Ausschwärmen sogleich oder erst am nächsten Tage. Die Schwärmer sind phototaktisch, aber ihr Verhalten kann ganz verschieden sein. In einem Teil der Schalen wird an der Lichtseite ein leicht orange beziehungsweise grüner Saum entstehen, während sich in anderen Schalen die Schwärmer am hinteren Rand ansammeln. Die positiv phototaktischen Säume enthalten die zweigeißeligen Gameten der diözischen Monostroma grevillei. Ihre anisogame Kopulation läßt sich im Tropfen unter dem Mikroskop leicht beobachten, ebenso die sofortige negative Phototaxis der Pärchen.

Die negativ phototaktischen Schwärmeransammlungen gehören zu Monostroma arcticum. Es sind zweigeißelige Zoosporen, die sich über ein Scheibenstadium unmittelbar wieder zum Monostroma-Thallus entwidkeln.

Aus den Zygoten von Monostroma grevillei entsteht in Kultur eine Generation einzelliger Sporophyten; schon nach vier bis füf Wochen werden sie fertil und entleeren viergeißelige Zoosporen durch einen Tubus $(G)$. Die weitere Entwicklung entspricht der von $M$. arcticum; es bildet sich zunächst eine einschichtige Scheibe, die sich bei niedriger Temperatur $\left(5^{\circ} \mathrm{C}\right)$ in der Mitte aufwölbt, so daß ein kugeliges Bläschen entsteht. Solche Entwicklungsstadien findet man im zeitigen Frühjahr auch in der Natur; Abbildung 5 A zeigt Fäden von Chaetomorpba aerea, die mit MonostromaSädkchen von verschiedener Größe besetzt sind. Durch Aufreißen an der Spitze entsteht der einschichtige Thallus. 

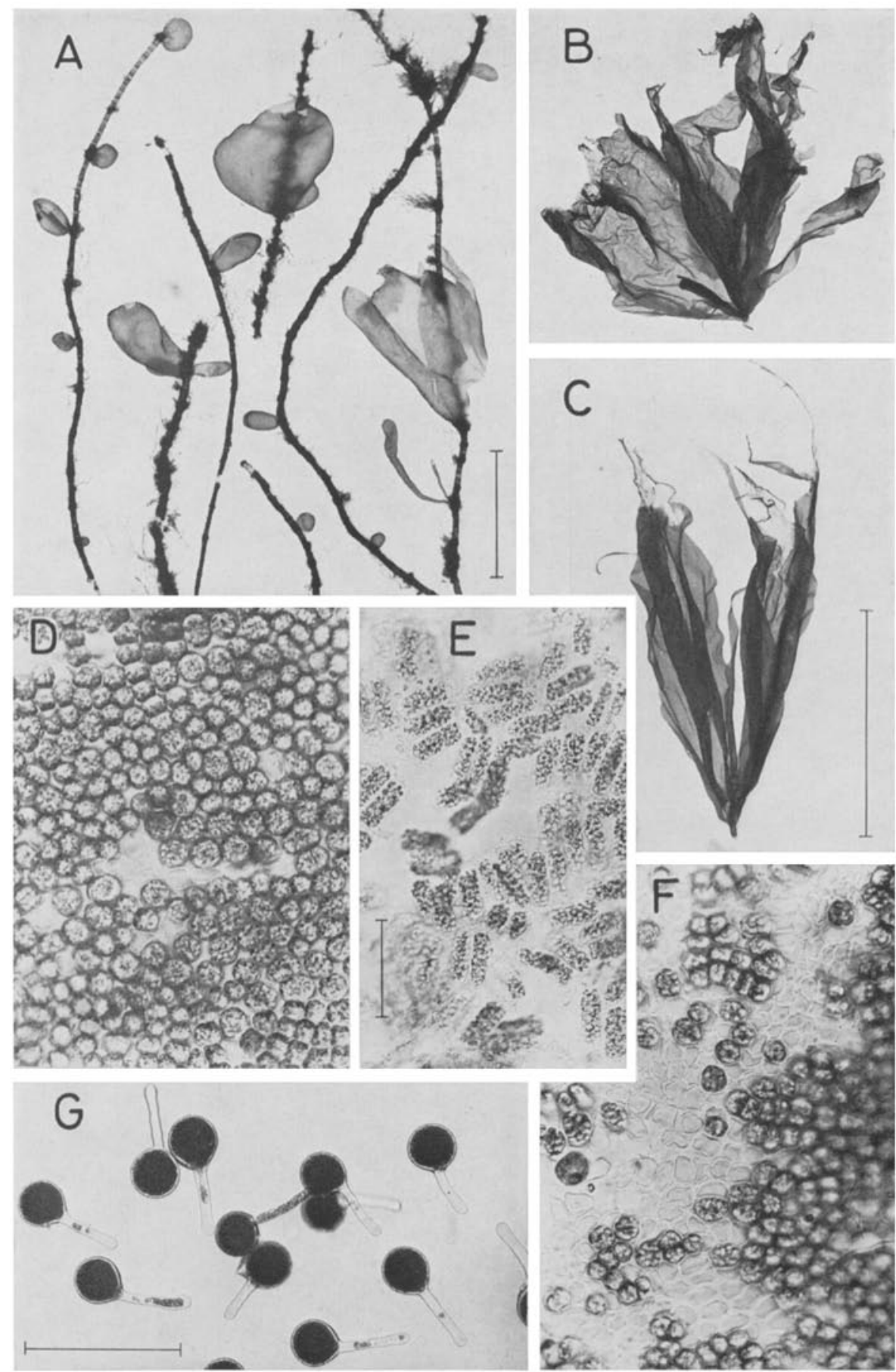

Abb. 5: Monostroma grevillei. A Junge Monostroma-Stadien epiphytisch auf Chaetomorpha aerea; die schmalen Pflänzchen links neben der Maßstrecke sind junge Blidingia minima (18. 4. 1974). B, C Habitus (11. und 17. 4. 1972). D Aufsicht auf den fertilen männlichen Thallus. E Durch leichten Druck auf das Deckglas ausgepreßte männliche Gametangien (18. 4. 1972). F Aufsicht auf den fertilen weiblichen Thallus (18.4.1972). G Nahezu reife Sporophyten aus einer Kultur. Maßstrecken: $A=5 \mathrm{~mm} ; \mathrm{B}, \mathrm{C}=5 \mathrm{~cm} ; \mathrm{D}-\mathrm{F}=50 \mu \mathrm{m} ; \mathrm{G}=200 \mu \mathrm{m}$ 

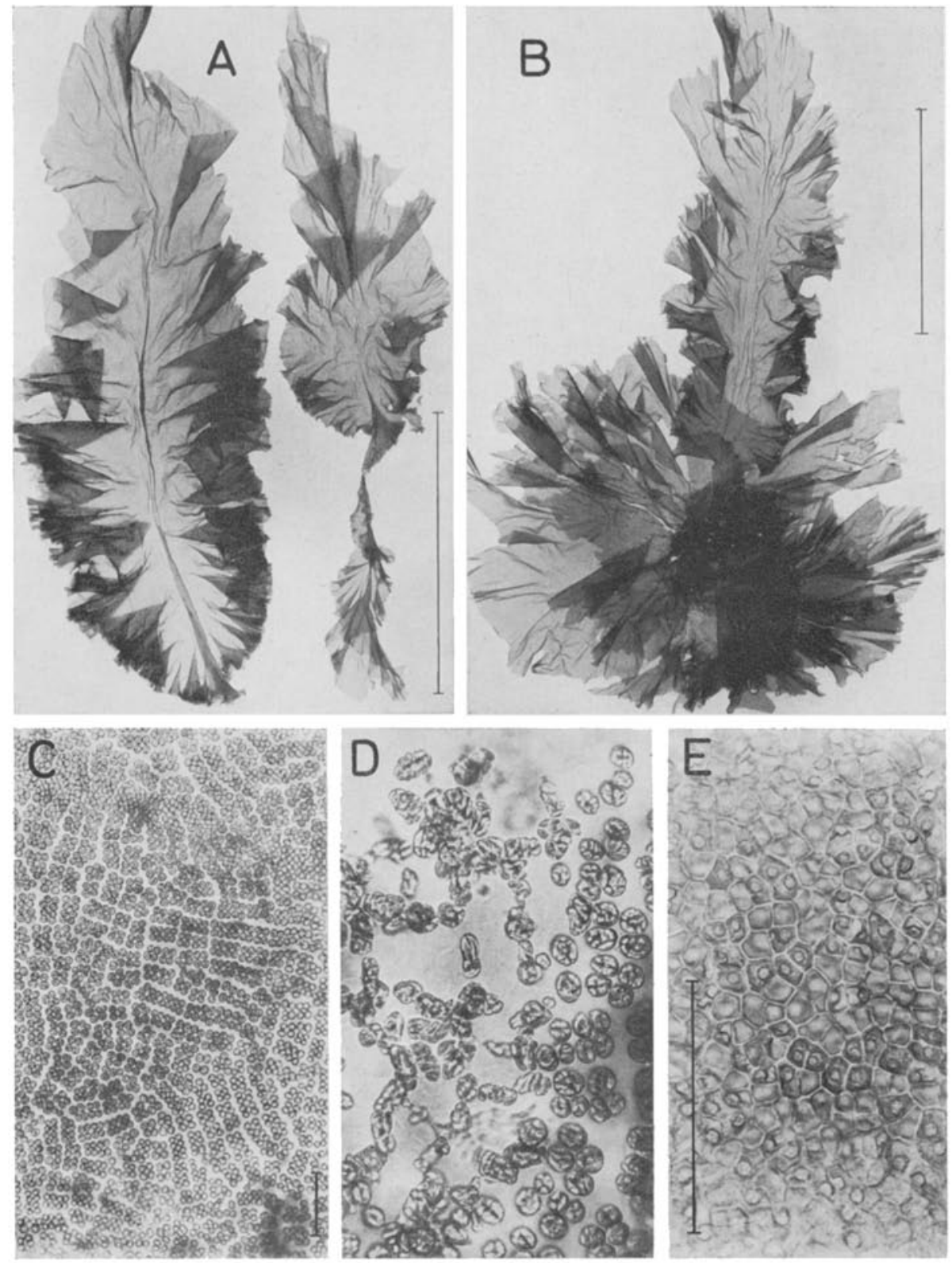

Abb. 6: Monostroma undulatum. A, B Habitus (24. 4. 1972 und 26. 5. 1970). C, D Aufsicht auf den fertilen Thallus und Ausfließen der meist noch von einer Hülle umgebenen Sporangien. E Vegetativer Thallus. Maßstrecken: A und B $=$ jeweils $10 \mathrm{~cm} ; \mathrm{C}=100 \mu \mathrm{m} ; \mathrm{D}, \mathrm{E}=100 \mu \mathrm{m}$ 
Die Aufsicht auf die Fläche einer fertilen weiblichen Pflanze zeigt die meisten Gametangien bis zu einer ziemlich scharfen Grenze entleert (F). Die schlauchförmigen Gebilde bei $\mathrm{E}$ sind männliche Gametangien, die durch leichten Drudk auf das Deckglas aus der verquellenden Membran herausgelöst wurden; dieses Bild gibt zugleich eine Vorstellung von der Höhe der Zellschicht.

Anmerkung: Ein Entleerungstubus weist darauf hin, daß sein Träger unter natürlichen Verhältnissen in einem Substrat eingesenkt lebt. Dies tritt bei der zu den Monostromataceae gehörenden Gomontia polyrbiza besonders klar in Erscheinung. Die eigenartige, ursprünglich als Codiolum polyrbizum beschriebene und als selbständig angesehene einzellige Alge lebt kalkbohrend zusammen mit einer Anzahl anderer Grïnalgen in Muschelschalen und ist am Strande des Wattenmeeres bei List/Sylt regelmäßig zu finden. Kulturversuche klärten den Zusammenhang auf: Die durch einen Tubus ins Freie gelangten Zoosporen entwickeln sich zu einer Generation monözischer, scheibenförmiger Gametophyten; sie sind in der Natur noch nicht beobachtet worden (Kornmann, 1959).

\section{Monostroma undulatum Wittr.}

Durch ihren Artnamen ist diese leuchtend-grüne, zarte flächige Alge mit ihrem wellig-faltigen, mitunter auch stark gekräuselten Rand treffend gekennzeichnet $(A, B)$. Die äußere Form variiert von schmal gestreckten bis zu rundlichen oder unregelmäßig gelappten Thalli. Auch die Größe ist unterschiedlich und kann zwischen 5 und $25 \mathrm{~cm}$ liegen.

Man findet Monostroma undulatum von März bis Mitte Juni im unteren Litoral. Sie wächst gerne auf Granit- und Betonblöcken, auf denen die Alge bei entsprechend dichter Besiedelung während des Trockenliegens eine fest anhaftende, dunkelgrün glänzende Schicht bildet. Epiphytisch kommt $M$. undulatum auf Chondrus crispus, Fucus serratus, Dumontia und Corallina vor. In manchen Jahren tritt sie so massenhaft auf, daß losgerissene Pflanzen einen dichten Spülsaum bilden und bei auflandigem Wind als breites Band an der Oberfläche treiben, wobei die vielen bei der Assimilation entstandenen Sauerstoffbläschen für den Auftrieb sorgen.

Die Aufsicht auf den vegetativen Thallus zeigt ein Netz unregelmäBig polygonaler Zellen; der Chromatophor mit dem Pyrenoid liegt nicht immer in der Bildebene (E). Der Fertilisierung gehen rasch aufeinanderfolgende Teilungen voraus, so daß aus jeder Zelle eine Gruppe von vier - im Querschnittsbild länglichen - Sporangien entsteht (C). Thre Entleerung bietet ein reizvolles Bild. Die 16 Schwärmer jedes Sporangiums bleiben meist von einer gemeinsamen Hülle umgeben und gleiten unter dem intakt gebliebenen Oberflächenhäutchen an den Rand des verquellenden Thallus (D). Auf diesem Wege können sie schon frei werden, oft aber bleiben sie nach dem Austreten in die Flüssigkeit zu sternförmigen Gruppen vereinigt. Die viergeißeligen Schwärmer - man hätte in Analogie zu anderen Monostroma-Arten zweigeißelige Gameten erwartet - zeigen nur geringe Eigenbewegung und kommen bald zur Ruhe. Sie entwickeln sich zu einzelligen Sporophyten mit viergeißeligen Zoosporen. Die Besonderheit des Entwicklungsganges von Monostroma undulatum ist die Aufeinanderfolge heteromorpher Generationen mit ungeschlechtlichen Schwärmern (Kornmann \& Sahling, 1962b; Tatewaki, 1972). 


\section{ACROSIPHONIALES}

Die Vertreter dieser Ordnung waren früher den Cladophorales zugeordnet, doch ähneln sie Cladopbora nur in der äußeren Erscheinung. Grundlegend verschieden sind aber der Lebenszyklus, die Art des Wachstums und die chemische Beschaffenheit der Zellwand. Die Zellen sind vielkernig bei Acrosiphonia, einkernig bei der sehr viel dünnfädigeren Spongomorpha. Kern- und Zellteilung erfolgen simultan. Drei Acrosiphonia-Arten sind im Gebiet um Helgoland in der unteren Gezeitenzone verbreitet und von März bis Mai am schönsten entwickelt. Es sind Büschel bis zu $10 \mathrm{~cm}$ Höhe, deren Aussehen sich im Laufe ihrer Vegetationszeit sehr verändert, wie aus den Habitusbildern von Acrosipbonia arcta ersichtlich ist (Abb. 7). Auf dem Felswatt an der Westseite kommen alle drei Arten zusammen mit $S$ pongomorpha aeruginosa vor.

Acrosiphoniaceae

Acrosiphonia arcta (Dillw.) J. Ag.

Sie ist ebenso wie die beiden folgenden Arten der Gattung bei mikroskopischer Betrachtung leicht von den ebenfalls einreihigen verzweigten Fäden der CladophoraArten zu unterscheiden. Die Zellen von Cladophora sind an den Querwänden mehr oder weniger stark eingeschnürt und haben geschichtete Membranen. Dagegen ist das Profil der Zellreihen von Acrosiphonia geradlinig. Wie schon der Gattungsname anzeigt, kommt der Spitzenzelle eine besondere Rolle für den streng gesetzmäßigen Aufbau von Acrosiphonia zu. Sie kann im Frühjahr bei niedriger Wassertemperatur vor der Teilung eine Länge von $3 \mathrm{~mm}$ erreichen. Besonders eindrucksvoll ist es, ihre inäquale Teilung zu beobachten (Abb. $8 \mathrm{G}$ ). Alle Endzellen teilen sich synchron in einem von den ökologischen Bedingungen bestimmten Rhythmus. Anfang März konnten Teilungsstadien an drei aufeinanderfolgenden Tagen jeweils um 9 Uhr an frisch gesammeltem Material beobachtet werden. Vor der Zellteilung sammeln sich die zahlreichen Kerne in einer gürtelförmigen Zone im oberen Teil der Zelle ( $\mathrm{H}$, gefärbt mit Karminessigsäure); nach ihrer simultanen Teilung entsteht hier die neue Membran (Pfeil links neben den gefärbten Kernen; die beiden anderen Hinweise werden in der Legende erläutert). In dieser Aufnahme einer lebenden Zelle rücken die Kerne schon wieder auseinander, dabei erhält die neue Apikalzelle den größeren Anteil der Kerne. Sie streckt sich im Laufe eines Tages bis zur nächsten Teilung auf die drei- bis vierfache Länge. Auch in Laboratoriumskulturen kann bei entsprechenden Bedingungen die Teilung der Apikalzellen synchron im Tagesrhythmus erfolgen (Kornmann, 1965).

Nur den jüngsten, bis etwa $2 \mathrm{~cm}$ hohen Büscheln fehlt ein kennzeichnendes Merkmal von Acrosiphonia arcta, die hakig gebogenen spitzen Kurztriebe, die die basalen Teile der Hauptfäden umklammern (E). Zwischen ihnen entwickeln sich aus Fadenzellen und abgebrochenen $Z$ weigen mit zunehmendem Alter immer mehr herabwachsende Rhizinen, so daß die älteren Pflanzen zu schwammig verfilzten, zottigen Klum- 

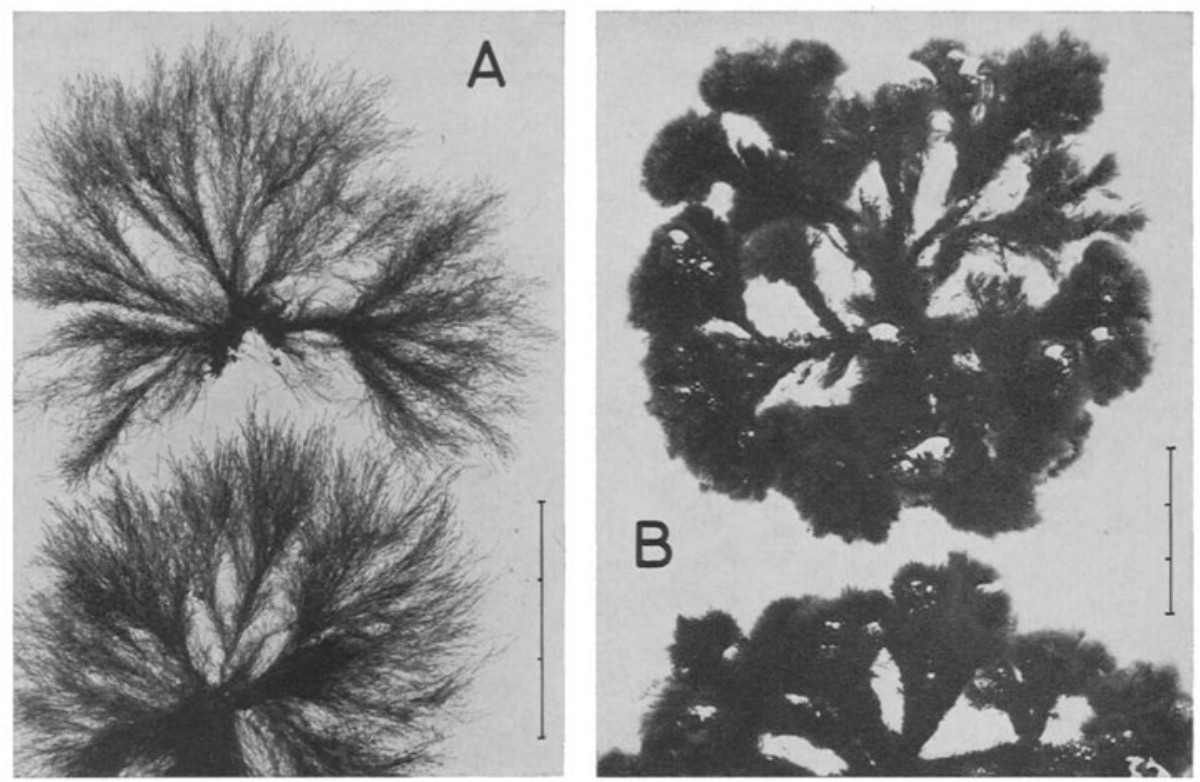

Abb. 7: Acrosiphonia arcta. A Voll entwickelte, aber noch verhältnismäßig lockere Büschel mit vielen freien Fadenenden, die basalen Abschnitte durch Haken und Rhizinen strangartig zum sammengehalten (9. 4. 1970). B Völlig verfilzte, schwammig-klumpige Büschel (23.6. 1970). Maßstrecke: $A$ und $B$ jeweils $=3 \mathrm{~cm}$

pen werden (Abb. 7 B). Die vegetativen Sprosse solcher im Juni oder später gesammelten Pflanzen haben nur kurze Apikalzellen, und es mag dem Betrachter schwerfallen, in den extremen Erscheinungsformen die gleiche Art zu erkennen.

Fertile Acrosipbonia arcta zeichnet sich durch ihre zugespitzten Kurztriebe aus (Abb. 8 C). Die Gametangien werden einzeln oder zu mehreren gleichzeitig reif. Thre Entleerung erfolgt durch eine kreisrunde, operculate Offnung, an der fast immer das Deckelchen haften bleibt (D). Dieser Entleerungsmechanismus ist ein kennzeichnendes Merkmal der Acrosiphoniales. Uber Nacht in einer feuchten Kammer aufbewahrt, kann fertiles Material so reichlich ausschwärmen, daß das Wasser von der Menge der zweigeißeligen Schwärmer grün gefärbt wird. Ein Teil von ihnen vereinigt sich zu negativ phototaktischen Zygoten. Die nicht verschmolzenen Schwärmer sammeln sich am Lichtrand an. 
Acrosiphonia arcta ist monözisch; in Kultur entwickeln sich sowohl Zygoten als auch unverschmolzene Schwärmer zu einer Generation vom Habitus der Ausgangspflanze. Dagegen entsteht ein einzelliger Sporophyt aus den Zygoten von Acrosiphonia spinescens, einer bei Helgoland nur seltenen Art, die morphologisch nicht von $A$. arcta zu unterscheiden ist (vgl. p. 34).

\section{Acrosiphonia centralis (Lyngb.) Kjellm.}

Bei Acrosiphonia centralis (Abb. 9) fehlen hakig gebogene oder zugespitzte fertile Kurztriebe, daher sind jüngere Pflanzen nicht sicher von $A$. arcta zu unterscheiden. Bis etwa Mitte Mai sind die Fäden noch nicht oder nur ganz wenig durch herablaufende Rhizinen verfilzt und vereinigen sich strahlig wie ein Pinsel (A). Auch wenn später bei älteren Büscheln mehrere Hauptfäden durch herablaufende Rhizinen miteinander verflochten werden (D), erscheinen die stattlichen Büschel von etwa $10 \mathrm{~cm}$ Länge doch noch strahlig.

Etwa ab Mitte April gibt sich Acrosiphonia centralis durch zerstreut in den Fäden liegende, fertil erscheinende Zellen zu erkennen (C). Jedoch wurden leere Sporangien weder im natürlichen Material noch an den unter den verschiedensten Bedingungen kultivierten Pflanzen beobachtet. Da die Acrosipbonia-Arten alljährlich immer wieder am gleichen Standort erscheinen, überbrücken sie sicherlich die 6 bis 7 Monate, während denen sie im Vegetationsbild fehlen, als kriechende Stadien. Tatsächlich ließen sich Stolonen mit jungen aufrechten Fäden aus sandigem oder schlickigem Substrat im August und Januar auswaschen (Abb. $8 \mathrm{~F}$ ). In Jahren mit stürmischer See verschwindet Acrosiphonia centralis ziemlich rasch, während die Büschel von A. arcta fester auf ihrem Substrat haften.

Abb. 8: Acrosiphonia arcta. A Fadenenden einer vegetativen Pfanze (24. 3. 1971). B Verzweigung; netzförmiger Chromatophor mit vielen Pyrenoiden. C Fertiles Zweigstück (18. 4. 1969). $\mathrm{D}$ Leere Gametangien mit Deckelöffnungen. E Aus einem Strang herausgelöster Hauptfaden mit Haken und Rhizinen (10.6. 1969). F Aus dem Substrat ausgewaschene kriechende vorjährige Adase mit jungen Sprossen (30.3. 1971). G Apikalzellen in synchroner Teilung. An der Stelle des oberen Pfeiles entsteht die neue Zellwand; der mittlere Pfeil zeigt ein etwas friheres Stadium an, das etwa der ringformigen Ansammlung der Kerne bei $H$ entspricht; der untere Pfeil weist auf den in die neue Apikalzelle vorrükenden Kernschwarm hin (9. 3, 1970). H Ringförmige Ansammlung der Kerne zu Beginn der Teilung einer Apikalzelle, gefärbt mit Karminessigsäure. Maßstrecken: $\mathrm{A}, \mathrm{C}, \mathrm{E}=1 \mathrm{~mm} ; \mathrm{B}, \mathrm{H}=100 \mu \mathrm{m}$ 

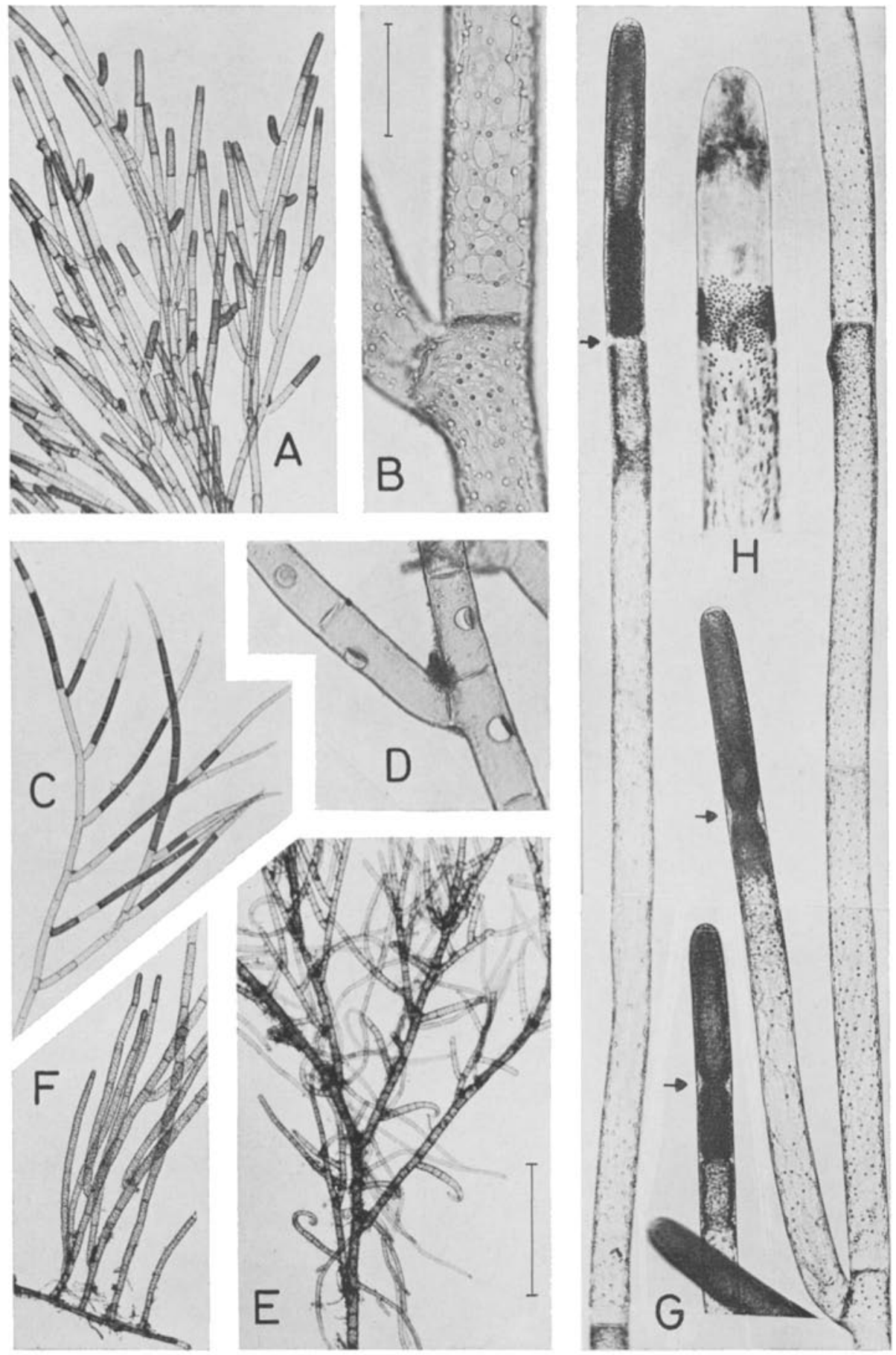

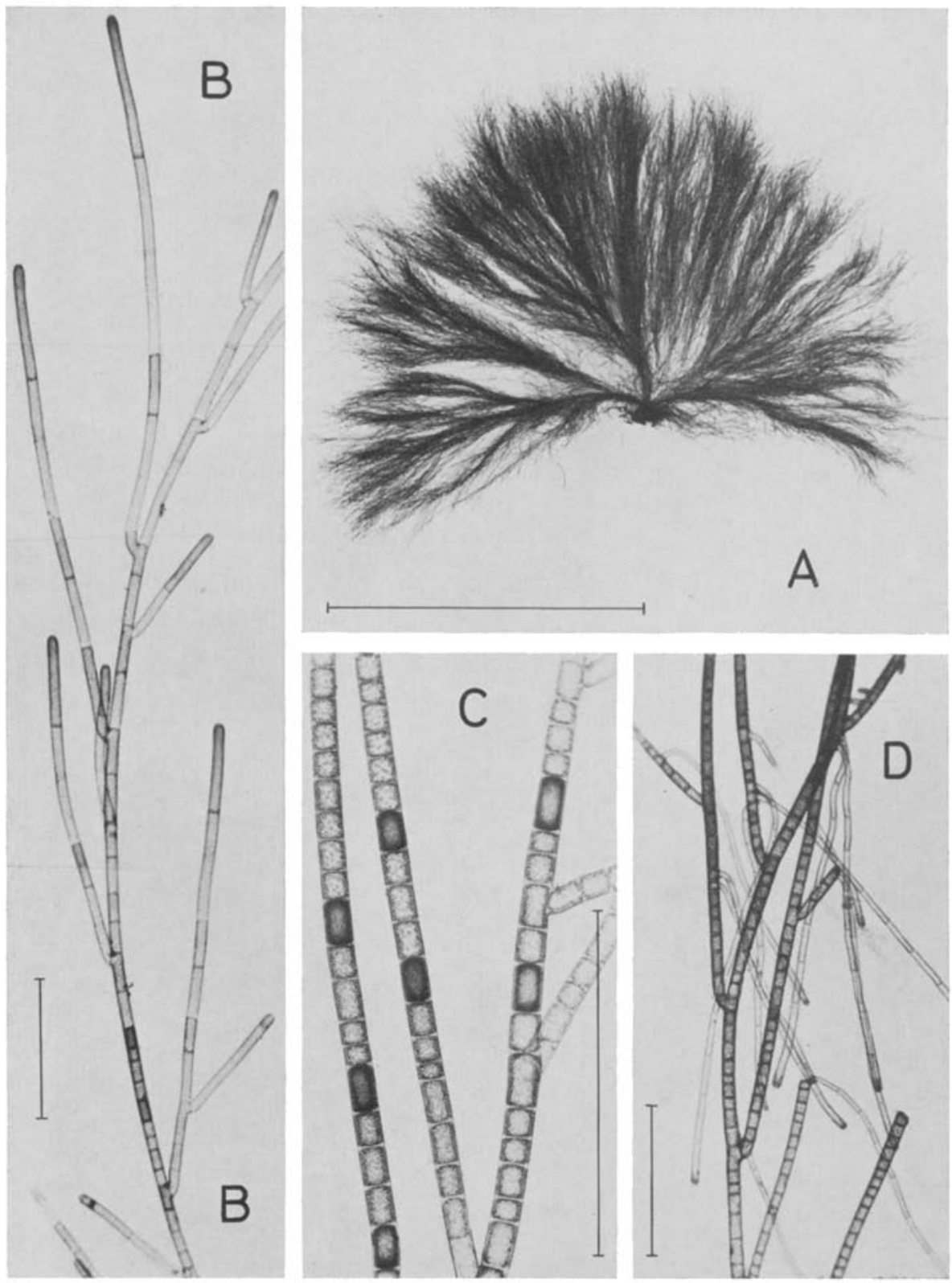

Abb. 9: Acrosiphonia centralis. A Büschel mit freien Fadenenden, die Pflanze verfilzt später zu zopfartigen Strängen (24. 4. 1972). B Ende eines Hauptfadens (4. 5. 1972). C Zerstreut in den Fäden liegende, fertil erscheinende Zellen (4. 6. 1969). D Beginnende Verfilzung der Pflanze durch Rhizinen (4.6.1969). Maßstrecken: $A=10 \mathrm{~cm} ; \mathrm{B}, \mathrm{C}$ und $\mathrm{D}$ jeweils $=1 \mathrm{~mm}$ 


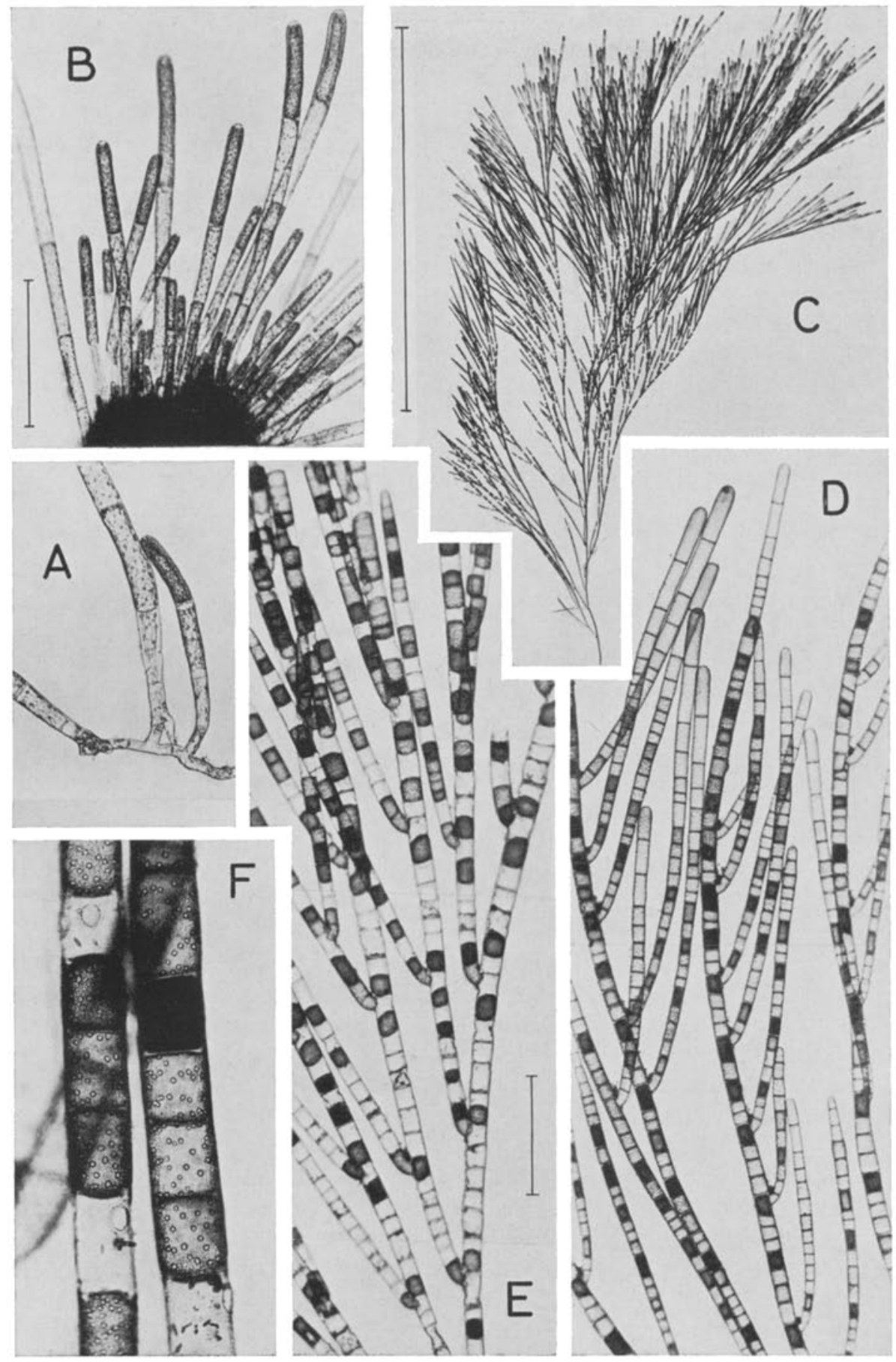

Abb. 10: Acrosiphonia sonderi. A, B Stolonen mit jungen, noch unverzweigten Fäden von einer Betonfläche abgelöst. Am Standort hat der pelzige Uberzug Ähnlichkeit mit einem CodiolumRasen (5. 4. 1969). C Habitus; vorwiegend einseitige Verzweigung. D, E Fertiler Thallus (4. 6. 1969 und 24, 4. 1972). F Fadenstüdke mit vegetativen Zellen $z$ wischen reifen und leeren Sporangien. Maßstrecken: $A, B=500 \mu \mathrm{m} ; C=5 \mathrm{~mm} ; \mathrm{E}=1 \mathrm{~mm}$ 


\section{Acrosiphonia sonderi (Kütz.) Kornm.}

Durch die vorwiegend einseitige Verzweigung ihrer kräftigen, etwas dunkler grün gefärbten Thalli und ihren irisierenden Glanz unterscheidet sich diese Art klar von den beiden anderen (Abb. 10). Eine lange Endzelle krönt nur ganz junge vegetative Fäden. Später werden die Fäden bis nahe an die wachsenden Apikalzellen fertilisiert (D). Die Sporangien werden einzeln angelegt; zwischen ihnen liegende vegetative Zellen werden erst später fertil. So kann man an älteren Pflanzen leere Sporangien mit Deckelöffnungen $z$ wischen heranreifenden und vegetativen Zellen finden (E, F). Die Vermehrung erfolgt durch ungeschlechtliche zweigeißelige Zoosporen.

Spongomorpha aeruginosa (L.) Hoek. incl. Codiolum petrocelidis und Chlorochytrium inclusum

Verglichen mit den Acrosiphonia-Arten hat Spongomorpha aeruginosa viel feinere Fäden und einkernige Zellen. Als zarte pinselige Räschen von 1 bis $2 \mathrm{~cm}$ Höhe findet man sie schon ab Februar an den gleichen Standorten wie die Arten der derberen Gattung. Die Fäden älterer Pflanzen können in ihrem unteren Abschnitt durch Haken und herablaufende Rhizinen strangartig zusammengedreht sein; solche im Juni und Juli bis zu $4 \mathrm{~cm}$ hohen Büschel erinnern dann in ihrem Aussehen etwas an die Sommerform von Acrosiphonia arcta. Spongomorpha aeruginosa wächst auf anstehendem Fels, Holz und eisernen Spundwänden, häufig auch epiphytisch auf verschiedenen Algen wie Fucus, Chondrus, Corallina und anderen (Abb. 11).

Schon im März wird Spongomorpha aeruginosa fertil. Sie ist monözisch; in den langen Reihen von Gametangien (D) entstehen zweigeißelige Gameten. Aus der Zygote entwickelt sich ein endophytisch in Rotalgen lebender einzelliger Sporophyt. Er ist $z$ wischen den Fäden der krustenförmigen Petrocelis bennedyi schon vor über 100 Jahren bei Helgoland gefunden worden; Kuckuck beschrieb ihn 1894 unter dem Namen Codiolum petrocelidis (E, F). Die schlauchförmigen Zellen dieses an seiner Basis häufig in eine lange farblose Spitze ausgezogenen Endophyten findet man während des ganzen Jahres in ihrer Wirtspllanze.

Die entwicklungsgeschichtlichen Zusammenhänge konnten erst durch Kulturversuche aufgeklärt werden (Kornmann, 1961a). Der Sporophyt ist von Dezember bis Februar fertil. Aus den viergeißeligen Zoosporen entsteht der fädig verzweigte Gametophyt, der vom Spätsommer bis zum Frïhjahr im Vegetationsbild fehlt. Der in der Rotalge Polyides rotundus lebende kugelig-eiförmige Endophyt Chlorochytrium inclusum (G) ist nur eine morphologische Variante des Sporophyten von Spongomorpha aeruginosa. Auch an anderen Küsten sind Endophyten gleichen Namens in mehreren Rotalgen weit verbreitet; einige haben sich als Sporophyten von Acrosipbonia-Arten erwiesen. So gehört z. B. das an den Küsten der Bretagne in Petrocelis cruenta lebende "Codiolum petrocelidis" in den Entwicklungszyklus von Acrosiphonia spinescens. 


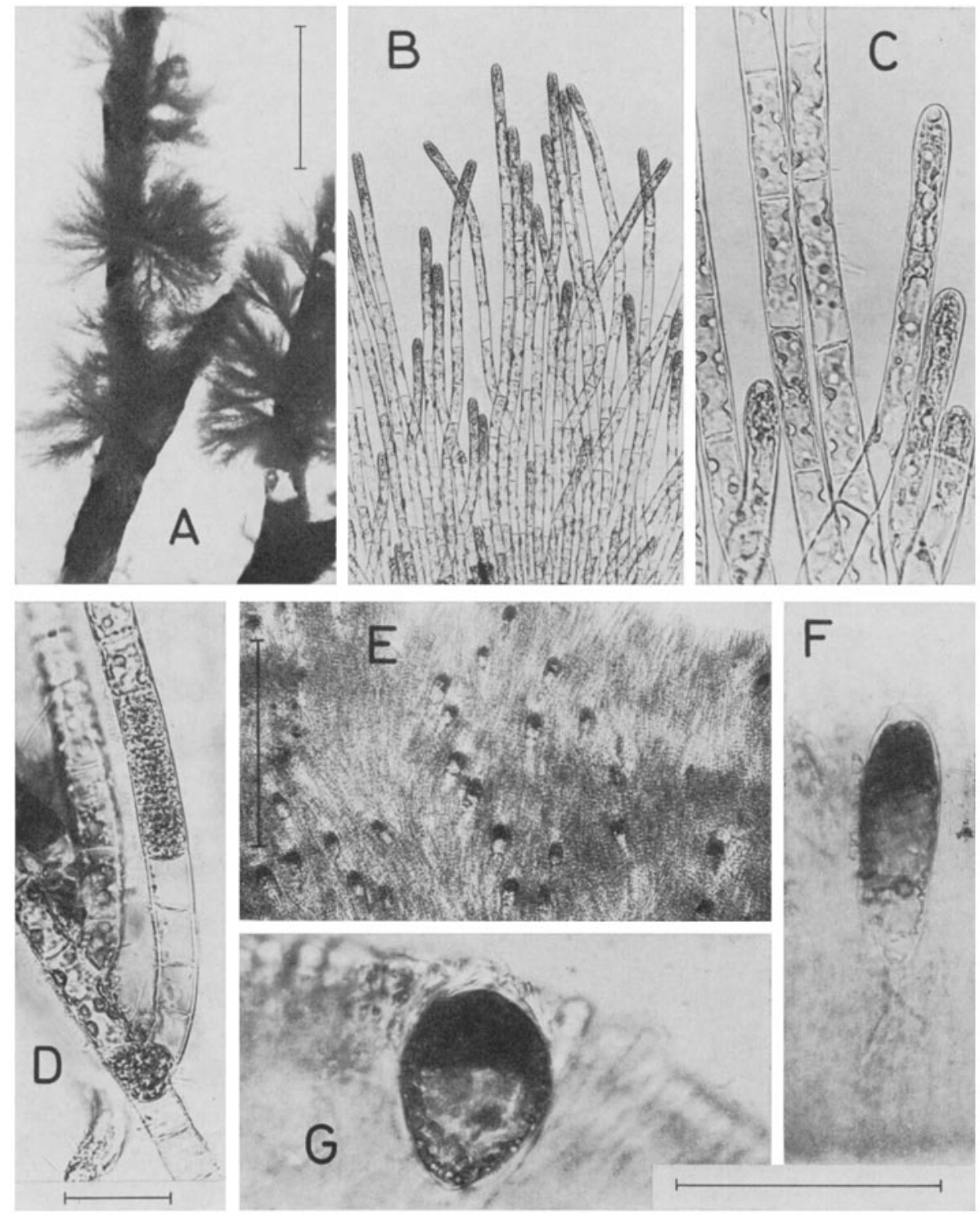

Abb. 11 : Spongomorpha aeruginosa. A Epiphytisch auf Fucus serratus (26.5.1970). B, C Fadenenden eines kurzen, noch wenig verzweigten Räschens (21. 2. 1972). D Verzweigter Faden mit gereihten, zum Teil leeren Gametangien (5.6.1972). E, F Codiolum petrocelidis in Petrocelis bennedyi (24. 6. 1960). G Chlorochytrium inclusum in Polyides rotundus (18. 1. 1960). Maßstrecken: $\mathrm{A}=1 \mathrm{~cm} ; \mathrm{C}, \mathrm{D}=50 \mu \mathrm{m} ; \mathrm{E}=500 \mu \mathrm{m} ; \mathrm{F}, \mathrm{G}=100 \mu \mathrm{m}$ 


\section{Bryopsidophyceae}

Die in dieser Klasse zusammengefaßten Algen sind im allgemeinen vielkernig, entweder ungegliederte Schläuche (Bryopsis) oder in Zellen gegliederte Fäden (Cladophora); die Teilung ihrer Kerne erfolgt unabhängig von der Teilung der Zellen. Den Hemisiphoniideae gehören die Ordnungen Cladophorales (p. 36) und Sphaeropleales an, die letzte ist auf das Süßwasser beschränkt. Die Dasycladales und Siphonocladales - Ordnungen der Cystosiphoniideae - sind Bewohner wärmerer Meere. Die Eusiphoniideae sind in unserem Untersuchungsgebiet nur mit der Ordnung Codiales (p. 48) vertreten; die Caulerpales leben in wärmeren Meeren.

\section{CLADOPHORALES}

\section{Cladophoracea e}

Diese einzige Familie der Cladophorales umfaßt die Gattungen Cladophora, Chaetomorpha und Rhizoclonium. Ihr einreihiger Thallus ist verzweigt bei Cladophora, unverzweigt bei den beiden anderen Gattungen. Rhizoclonium ist durch Rhizoidfortsätze aus einzelnen Fadenzellen gekennzeichnet.

\section{Chaetomorpha Kützing}

Bei Helgoland kommen drei Arten vor; die steifen Borsten von Chaetomorpha aerea und $\mathrm{Cb}$. melagonium sind leicht von den dünnfädigen, verworrenen Watten von Ch. tortuosa zu unterscheiden.

Chaetomorpha aerea (Gooden. ex Dillw.) Kütz.

Abbildung 12 zeigt Chaetomorpha aerea (A, B) und Ch. melagonium (C-E) bei gleicher Vergrößerung. Chaetomorpha aerea hat dünnere Fäden und etwa isodiametrische Zellen; sie wächst sehr viel rascher als Ch. melagonium; im allgemeinen teilen sich die Zellen, wenn ihre Höhe die Fadenbreite erreicht hat. Vor der Fertilisierung strecken sie sich zuweilen auf das Anderthalbfache ihrer Länge. Alle Zellen eines Fadens sind teilungsfähig, die Teilungsrate nimmt von der Basis zur Spitze zu. An den Fadenenden findet man häufig einen längeren Abschnitt fertiler oder bereits entleerter Zellen. Zweigeißelige Zoosporen sind die einzigen Fortpflanzungszellen. Darauf sei hier ausdrücklich hingewiesen, weil die Bezeichnung $C h$. aerea lange Zeit für Arten mit isomorphem Generationswechsel gebraucht wurde, z. B. für Chatomorpha linum (Müller) Kütz., deren Gametophỳten zweigeißelige Gameten, die Sporophyten viergeißelige Zoosporen bilden. Sie kommt bei List/Sylt und in der Ostsee festsitzend und dort auch in Form freitreibender Watten vor. Die Masse der im Wattenmeer von Sylt 

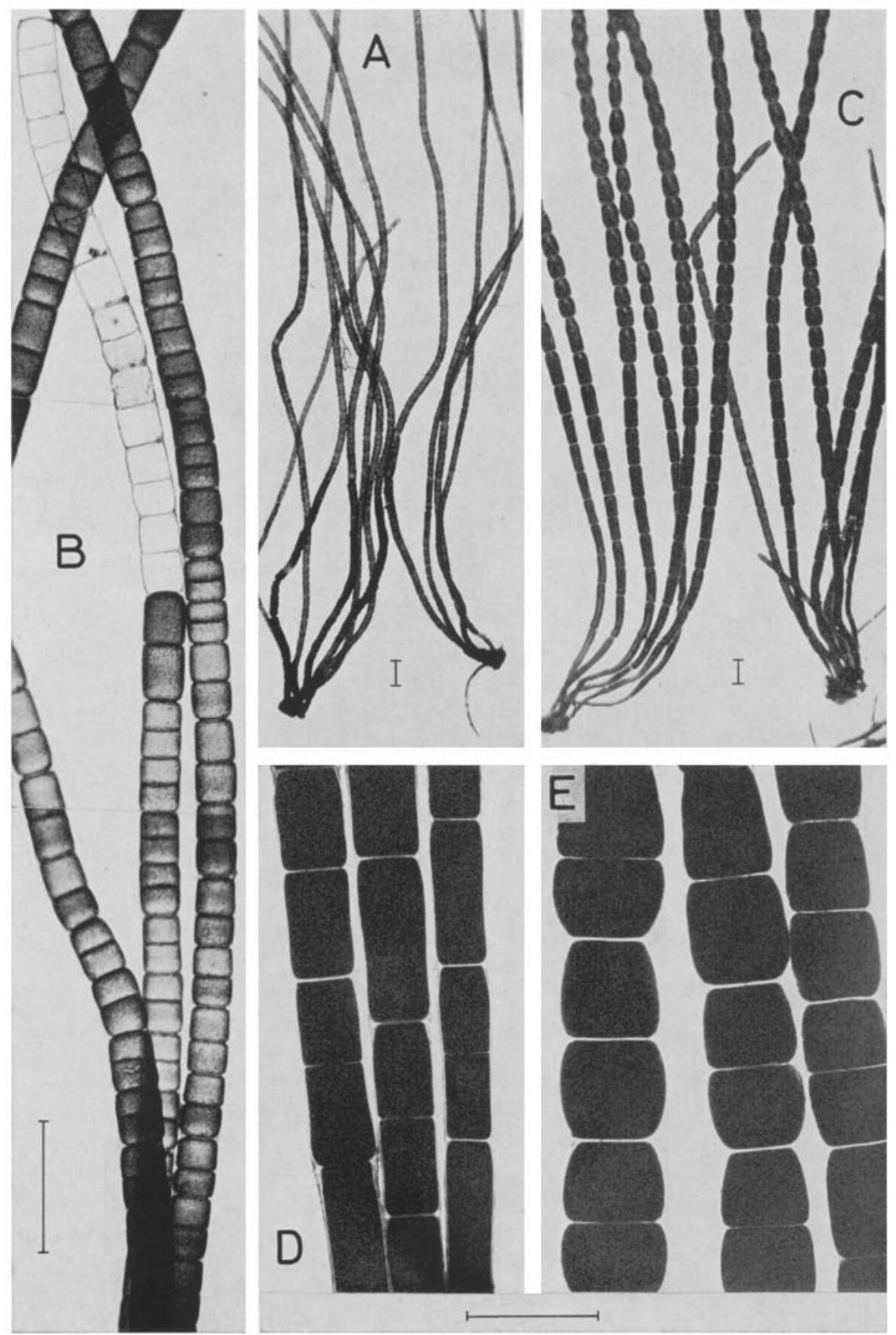

Abb. 12: A, B Chaetomorpha aerea, basale und obere Fadenabschnitte (13. 10. 1972). C-E Chaetomorpha melagonium, entsprechende Auswahl von Fadenstücken (13. 10. 1972). Maßstrecken jeweils $=1 \mathrm{~mm}$ 
treibenden Bestände gehört jedoch zu einer anderen Art, Chaetomorpha sutoria (Berkeley) Kornm.

Einzelne Fäden von Chaetomorpha aerea findet man in Prielen oder Gezeitentümpeln des Felswatts, ziemlich regelmäßig aber in den stets mit Wasser gefüllten Vertiefungen der Betonblöcke vor den Hafenmolen. Dort können die Fäden in reichlicher Menge vorkommen und bei starkem Licht und entsprechender Erwärmung des Wassers ziemlich blaßgrün werden.

\section{Chaetomorpha melagonium (Web. et Mohr) Kütz.}

Die Fäden von Chaetomorpha melagonium verbreitern sich aus dünner Basis zu einer Dicke von knapp $1 \mathrm{~mm}$. Durch ihre in den oberen Fadenabschnitten tonnenförmig eingeschnürten, dunkel blaugrünen Zellen ist diese Art eindeutig gekennzeichnet. In Prielen und Gezeitentümpeln kommt sie zusammen mit $\mathrm{Cb}$. aerea vor; auch im Kratzmaterial von Hafenmolen oder gedretschten Steinen sind immer einzelne Fäden zu finden. Nur an besonders günstigen Standorten, z. B. an der Schattenseite der als Wellenbrecher der West- oder Nordmole vorgelagerten Blöcke bildet Ch. melagonium ein schmales Band von bis zu $30 \mathrm{~cm}$ langen Fäden, die bei besonders tiefem Niedrigwasser auch kurze Zeit trocken liegen. Chaetomorpha melagonium fruktifiziert im Januar bis März; nur ein wenige Zentimeter langes Fadenstück oberhalb der Basis bleibt vegetativ und erneuert den stattlichen Faden. Die Zoosporen sind zweigeißelig, können aber einen geringen Anteil viergeißeliger Schwärmer enthalten. Geschlechtliche Vermehrung fehlt ebenso wie bei $C h$. aerea.

\section{Chaetomorpha tortuosa (Dillw.) Kütz.}

Erst vor wenigen Jahren hat sich diese Art bei Helgoland angesiedelt, zunächst nur auf dem Felswatt im Norden der Insel, wo sie im Sommer einen wesentlichen Bestandteil der Algenvegetation bildet. Inzwischen hat sie sich auf dem Felswatt im Südwesten ausgebreitet und ist auch im Bereich der Düne aufgetreten. Im Mai und Juni findet man ihre Anfänge: kraus gewundene, haardünne Fäden, die sich um Corallina oder Chondrus crispus schlingen (B). Im Juli und August bildet die Alge meterlange, wattige Stränge, die an Fucus oder lose liegenden Steinen Halt finden (A). Die Watten und Stränge werden bei bewegter See leicht losgerissen und am Strand ausgeworfen; mit den Herbststirmen verschwinden auch die letzten Reste der Alge.

Die Dicke der Fäden schwankt nur wenig um $60 \mu \mathrm{m}$; die Zellen strecken sich auf etwa doppelte Fadenbreite, bevor sie sich teilen. Bei dem lebhaften Wachstum der Fäden lassen sich fast in allen Proben Zellen finden, deren Kerne sich teilen (E).

Fertile Fäden sind am Standort noch niemals beobachtet worden, jedoch fruktifizierten alle in Kultur genommenen Proben mit viergeißeligen Zoosporen. Aus ihnen entstand eine gleichartige, haploide Fadengeneration (F). Nähere Angaben zur Kennzeichnung und Entwicklung aller erwähnten Chaetomorpba-Arten bei Kornmann (1972). 

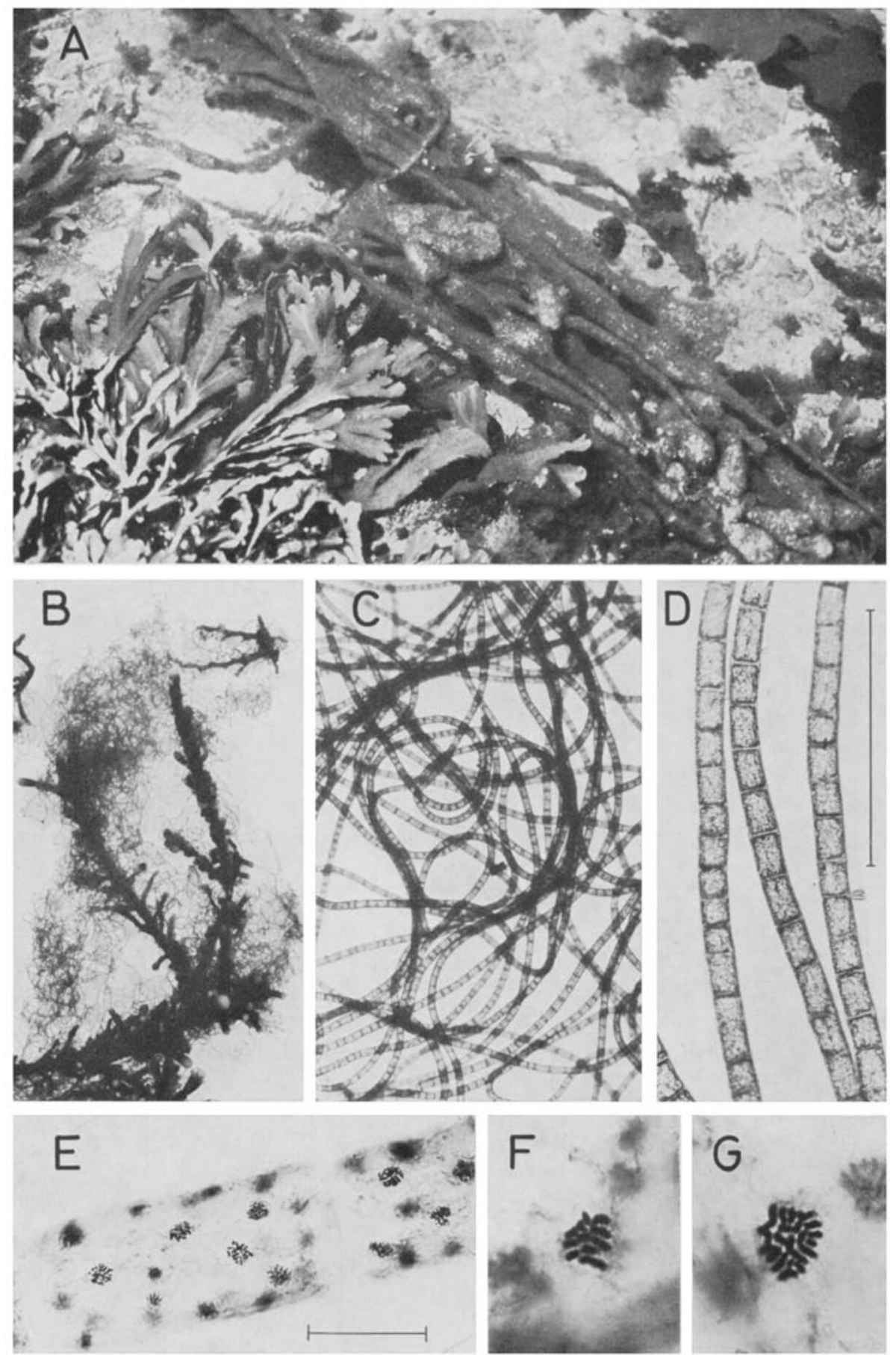

Abb. 13: Chaetomorpha tortuosa. A Wattige Stränge in einem flachen Tümpel des Felswatts im Nordosten (30.6.1971). B Fäden um Corallina geschlungen (29.5. 1971). C, D Fadengewirr und Einzelfäden. E Kerne in Teilung, gefärbt mit Karminessigsäure. F, G Metaphasen, haploid und diploid. Maßstrecken: $\mathrm{D}=500 \mu \mathrm{m} ; \mathrm{E}=50 \mu \mathrm{m}$ 


\section{Cladophora Kützing}

Cladophora gehört wie Enteromorpha zu den vielgestaltigen Formen, deren Bestimmung man am liebsten aus dem Wege geht, lassen sich doch kaum zwei Proben sammeln, deren Merkmale einander in allen Einzelheiten entsprechen. Die große Variabilität ist bedingt durch die Licht- und Strömungsverhältnisse an dem jeweiligen Standort wie auch den jahreszeitlich unterschiedlichen Lichtgenuß. So ist es nicht verwunderlich, daß Kützing in seiner Phycologia germanica (1845) rund 30 Arten für die Nord- und Ostsee angibt, bei Hauck (1885) sind es 17. Von den 23 Arten, die Newton (1931) für die britischen Küsten aufführt, gehören 6 als Synonyme zu Cladophora sericed (Parke and Dixon, 1976).

Die europäischen Cladophora-Arten haben durch die verdienstvollen Untersuchungen von van den Hoek (1963) und Söderström (1963) eine gründliche Revision erfahren. Es ist ein glücklicher Umstand, daß die Helgoländer Sammlung van den Hoek vorgelegen hat, sie wurde nachträglich auch von Söderström eingesehen. Die Autoren stimmen hinsichtlich der Nomenklatur der Arten nicht immer überein; wir schließen uns hier der Auffassung van den Hoeks an.

Von den 7 Helgoländer Arten ist Cladopbora rupestris eindeutig gekennzeichnet und kann mit keiner anderen verwedhselt werden. Am häufigsten wird man $\mathrm{Cl}$. sericea und $\mathrm{Cl}$. albida begegnen, gelegentlich auch $\mathrm{Cl}$. lehmanniana. Zweigstïcke dieser drei Arten sind zum besseren Vergleich bei derselben Vergrößerung dargestellt; die seltener vorkommenden $\mathrm{Cl}$. laetevirens, $\mathrm{Cl}$. vagabunda und $\mathrm{Cl}$. dalmatica seien hier nur erwähnt.

\section{Cladophora rupestris (L.) Kütz.}

Je mehr man sich der Niedrigwasserlinie nähert, um so häufiger findet man die durch ihren Habitus eindeutig gekennzeichneten Büschel von Cladophora rupestris. Die blaugrüne, bis über $12 \mathrm{~cm}$ lange Alge aus derben, geraden Fäden liebt schattige Standorte, sie wächst auf hartem Fels zusammen mit den Krusten von Pbymatolithon-Arten unter Fucus serratus (A), kommt aber auch an der Nordseite von Hafenmauern vor.

Das mikroskopische Bild zeigt die spitzwinkelige Anheftung der Verzweigungen (C), die häufig gegenständig, mitunter auch in Wirteln bis zu sechs ihrer Achsenzelle entspringen. Der Zellinhalt ist dicht, die Wände sind auffallend dick und deutlich geschichtet (D).

Fertile Pflanzen, sowohl Gametophyten als auch Sporophyten, findet man von Dezember bis April. Cladophora rupestris ist wie die anderen Arten diözisch, die Gameten der beiden Geschlechter sind gleichgroß. Aus der Zygote entwickelt sich der Sporophyt, der morphologisch den Gametophyten gleicht (isomorpher Generationswechsel).

Die unterste Bildreihe zeigt gefärbte Gameten eines Geschlechts (Abb. 14 E), 15 Minuten alte Kopulanten (F) sowie 24 Stunden alte Keimlinge $(\mathrm{G}-\mathrm{H})$. Bei den 8 Tage alten Keimlingen $(I, J)$ wurde nach der Kernfärbung mit Karminessigsäure zufällig derselbe Bildausschnitt wiedergefunden. 

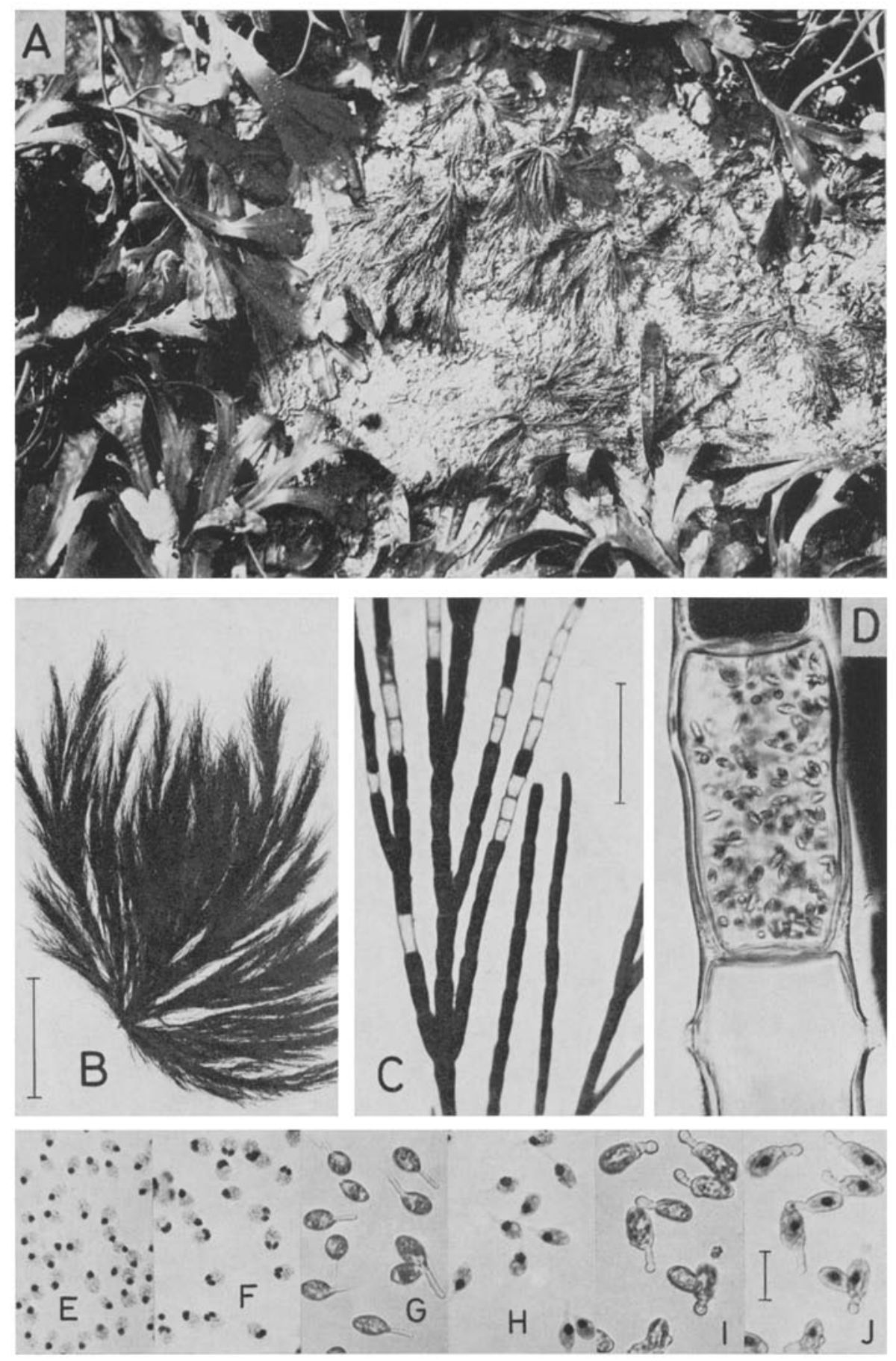

Abb. 14: Cladophora rupestris. A Aufnahme am Standort, unter Fucus serratus wachsend (24. 4. 1973). B Habitus eines Büschels. C Ausschnitt aus einem fertilen Thallus. D Unvollständig entleertes Gametangium, die leere Nachbarzelle mit zwei Offnungen (30. 1, 1971). $\mathrm{E}-\mathrm{J}$ Erläuterung im letzten Absatz. Maßstrecken: $\mathrm{B}=5 \mathrm{~cm} ; \mathrm{C}=1 \mathrm{~mm} ; \mathrm{E}-\mathrm{J}=30 \mu \mathrm{m}$ 

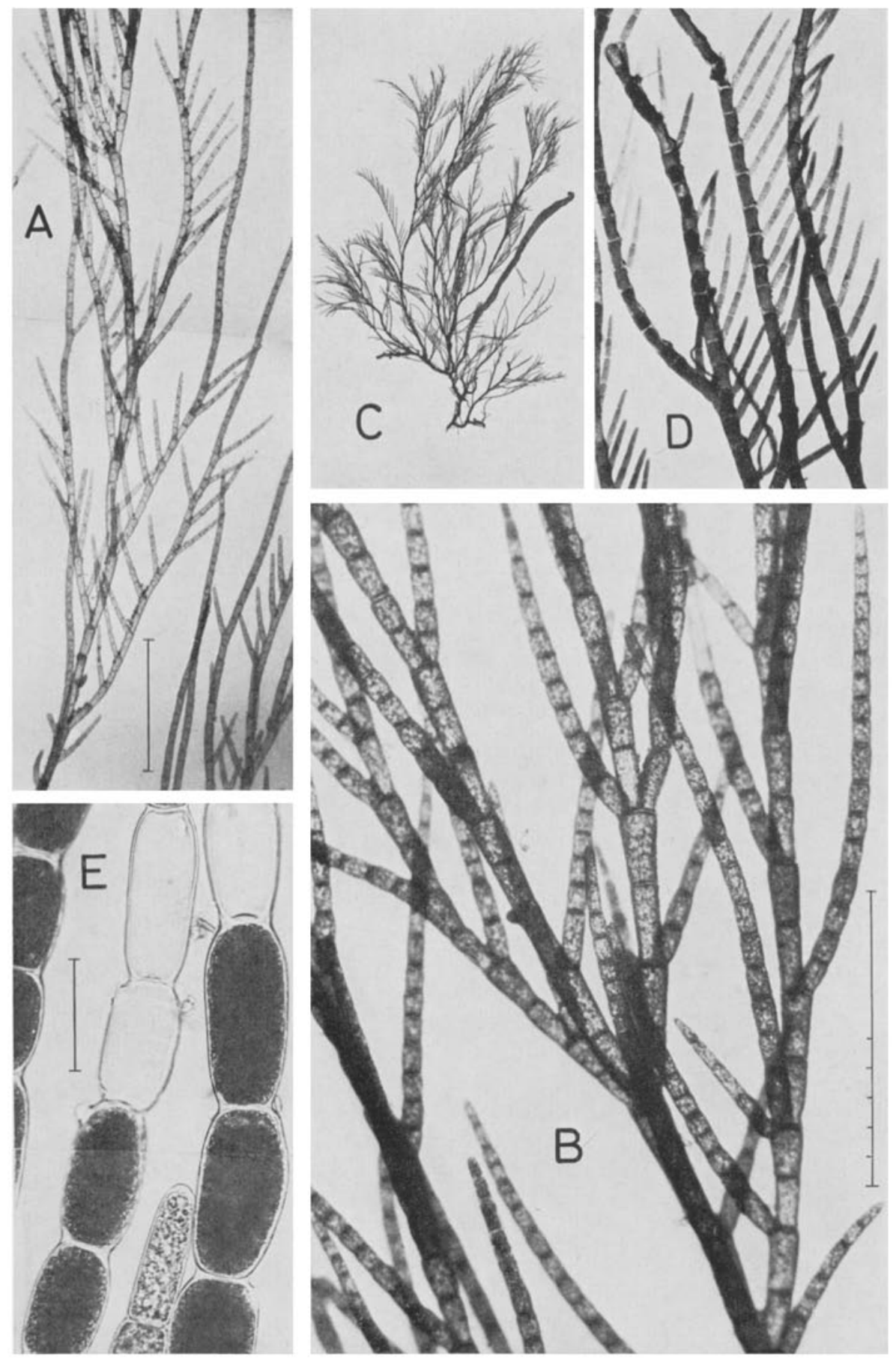

Abb. 15: Cladophora sericea. A, B Z Weigstïcke aus vollentwickelten Pflanzen (Juli). C Aus vorjährigen Achsen regenerierende, 2,3 cm hohe Pflanze (12.5. 1973). D Entsprechend C, stärker vergrößert (12. 1. 1973). E Fertile Zellen. Maßstrecken: A, D = $1 \mathrm{~mm} ; \mathrm{B}=1 \mathrm{~mm}$; $\mathrm{E}=100 \mu \mathrm{m}$ 


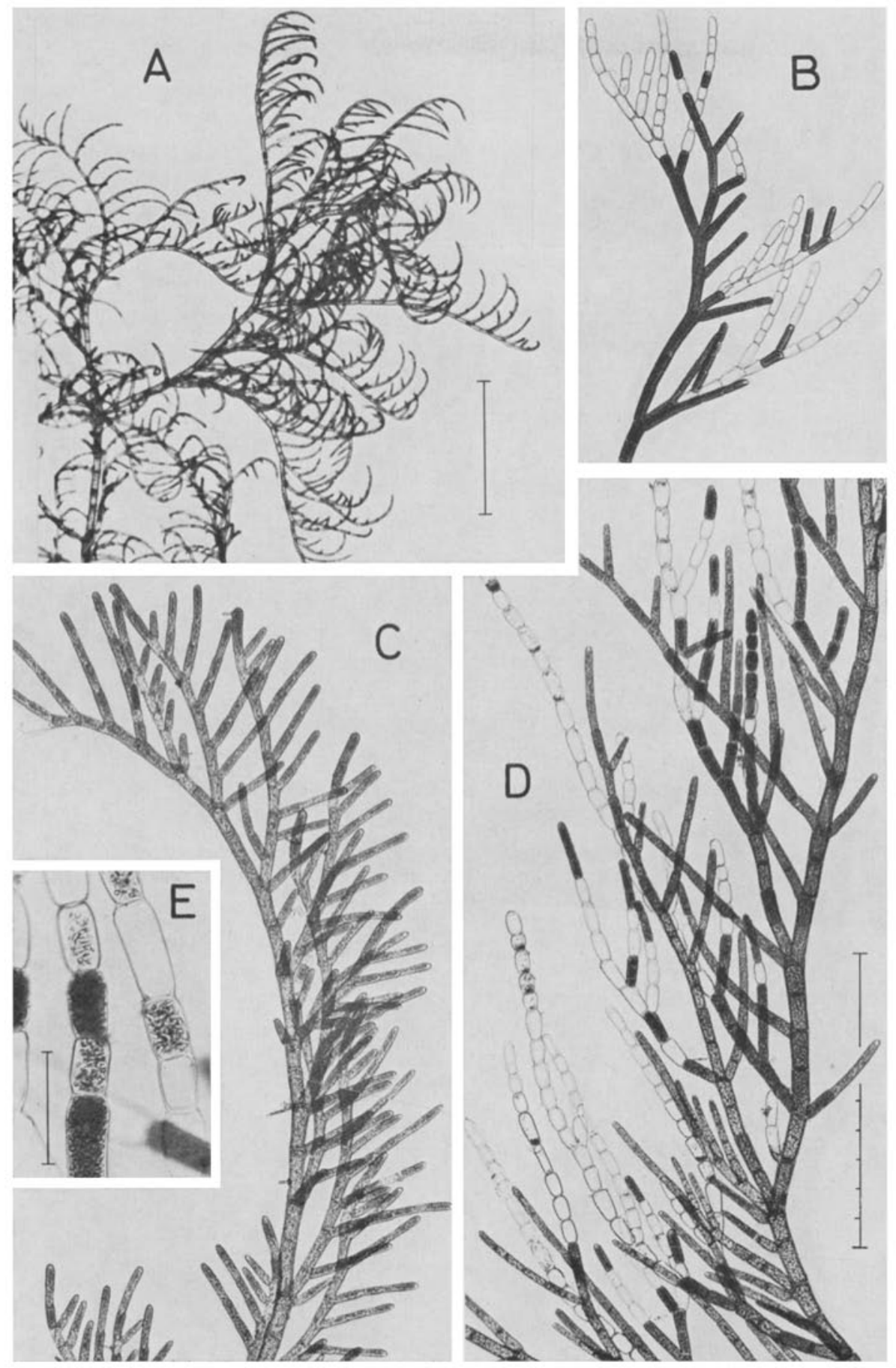

Abb. 16: Cladophora albida. A Zweigende mit einseitswendig zurückgekrümmten Ästchen (4. 7. 1973). B-D Fertile und vegetative Zweigstücke (18. 9. 1974). E Fertile Zellen. Maßstrecken; $\mathrm{A}=1 \mathrm{~mm} ; \mathrm{B}-\mathrm{D}=1 \mathrm{~mm} ; \mathrm{E}=100 \mu \mathrm{m}$ 


\section{Cladophora sericea (Huds.) Kütz.}

Im Juni und Juli sind die Cladophora-Arten am schönsten entwickelt. Wer Proben von verschiedenen Standorten gesammelt und mikroskopische Präparate verglichen hat, wird die beiden häufigen Arten, Cladophora sericea und Cl. albida, leicht unterscheiden können. Beide werden bis $35 \mathrm{~cm}$ lang, doch sind die Büschel von Cladophora sericea derber als $\mathrm{Cl}$. albida. Im mikroskopischen Bild sind die sich verjüngenden Seitenzweige charakteristisch, während die Breite entsprechender $\mathrm{Zweige}$ von $\mathrm{Cl}$. albida nahezu gleichbleibt (15 B im Vergleich zu 16 D). Auch die fertilen Zellen sind bei Cl. sericea erheblich größer, wie die bei gleicher Vergrößerung dargestellten Abbildungen $15 \mathrm{E}$ und $16 \mathrm{E}$ zeigen.

In einer völlig anderen Tracht erscheint Cladopbora sericea in den Winter- und Frühjahrsmonaten. Als $1-3 \mathrm{~cm}$ hohe, steife dunkelgrüne Pflänzchen kann man sie auf dem Felswatt im Südwesten der Insel finden, wo später die typischen Pflanzen reichlich vorkommen (C, D). Die meist einseitige, kammartige Verzweigung gibt den Pflänzchen ein ganz anderes Aussehen, und es ist nicht verwunderlich, daß Kützing sie als eigene Art unter dem Namen Cladopbora birta beschrieb. Aus den dicken Hauptachsen vorjähriger Pflanzen sprossen die für die Art typischen, sich verjüngenden $Z$ weige aus.

Im Entwicklungszyklus von Cladophora sericea und $\mathrm{Cl}$. albida folgen einander Sporophyten mit viergeißeligen Zoosporen und getrenntgeschlechtliche Gametophyten mit Isogameten. Bei beiden Arten sind aber auch Formen bekannt geworden, die sich nur durch ungeschlechtliche zweigeißelige Schwärmer vermehren (van den Hoek, 1963).

\section{Cladophora albida (Huds.) Kütz.}

Auch diese Art ist in ihrer äußeren Erscheinung recht mannigfaltig. Im allgemeinen findet man sie an gesdützten Standorten als zartfädige, locker flutende Büschel von uber $35 \mathrm{~cm}$ Länge. Soldhe Pflanzen sind weniger stark verzweigt als die bei C und D abgebildeten Ausschnitte und haben gerade oder nur schwach gekrümmte Seitenzweige. An mehr exponierten Standorten hingegen wie auch im August werden die Pflanzen nur 10-12 cm hoch; sie bilden etwas schwammige Büschel mit dichterer Verzweigung und zurückgebogenen Ästchen (A). Kennzeichnend für die Art sind die nahezu zylindrischen, sich an den Enden nur unwesentlich verjüngenden Seitenzweige; die Apikalzellen sind meist nur 20-25 $\mu \mathrm{m}$ dick. Auch die fertilen Zellen sind wesentlich kleiner als bei $C l$. sericea (Abb. $15 \mathrm{E}$ und $16 \mathrm{E}$ ). 

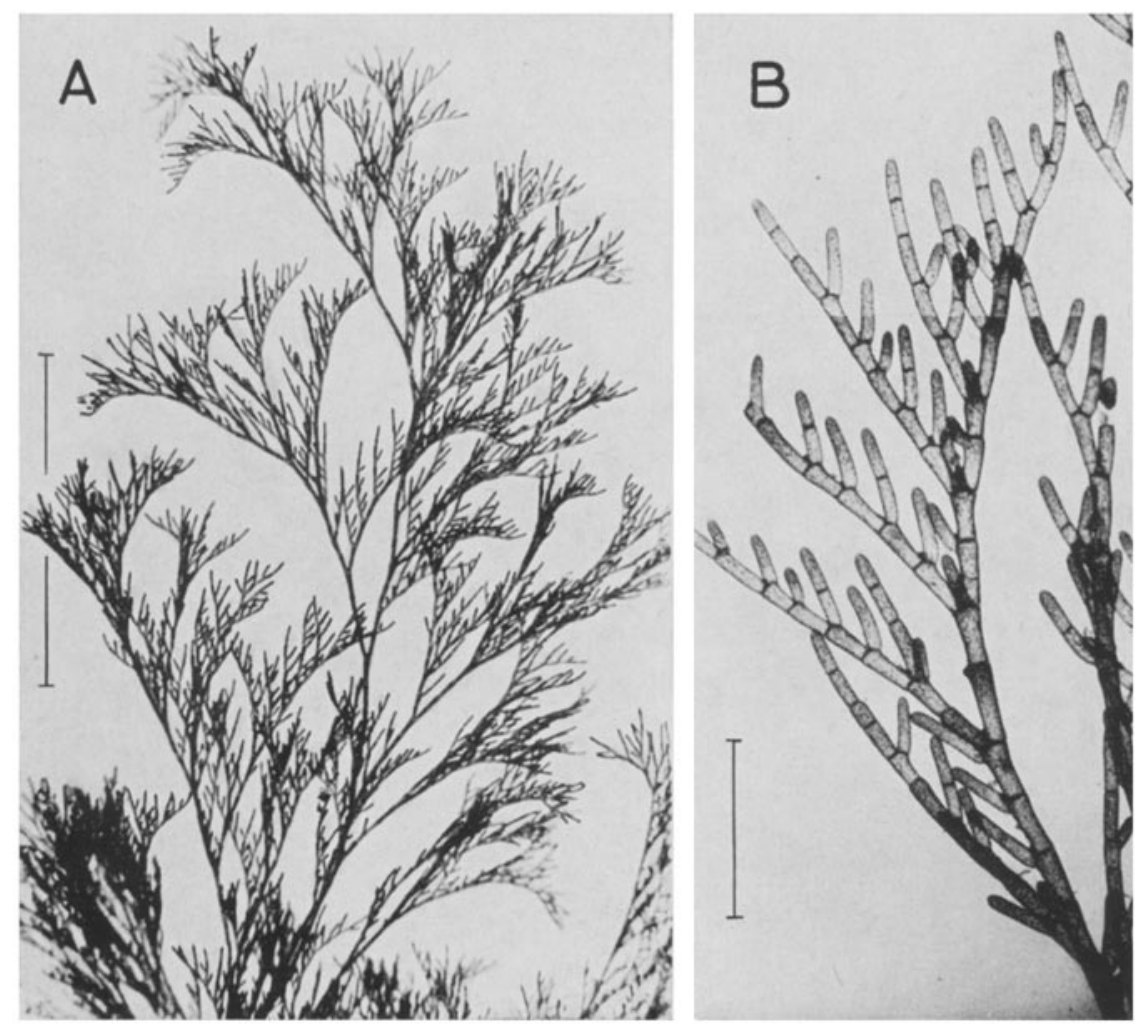

Abb. 17: Cladophora lehmanniana. A Ausschnitt aus dem oberen Teil einer etwa 3 fach vergrößjerten Pflanze (12. 8. 1972). B Ende eines Zweiges. Maßstrecken: $A=1 \mathrm{~cm} ; B=1 \mathrm{~mm}$

\section{Cladophora lebmanniana (Lindenb.) Kütz.}

Diese Art ist seltener als die beiden vorher erwähnten, man kann sie aber ziemlich regelmäßig im Juli und August auf Steinen am Oststrand vor der Kurpromenade finden. Es sind stattliche, bis $25 \mathrm{~cm}$ hohe Pflanzen, in deren Hauptachsen sich die Zellen basalwärts fortschreitend in immer stärkerem Maße interkalar teilen, so daß die Seitenzweige dort auf Abstände von 1-2 cm auseinanderrücken. An den Zweigenden letzter Ordnung erfolgt vorwiegend Apikalwachstum. So entsteht ein sehr charakteristisches Erscheinungsbild, das durch die dichte einseitige Verzweigung und die leicht zurückgebogenen Aistchen sein besonderes Gepräge erhält. Durch die etwa $80 \mu \mathrm{m}$ dicken Endzellen und ihren Habitus unterscheidet sich Cladophora lebmanniana gut von den beiden häufigen Arten. Für den Größenvergleich sei darauf hingewiesen, daß Abbildung $17 \mathrm{~B}$ denselben Maßstab hat wie $15 \mathrm{~A}$ und $16 \mathrm{~A}$. 

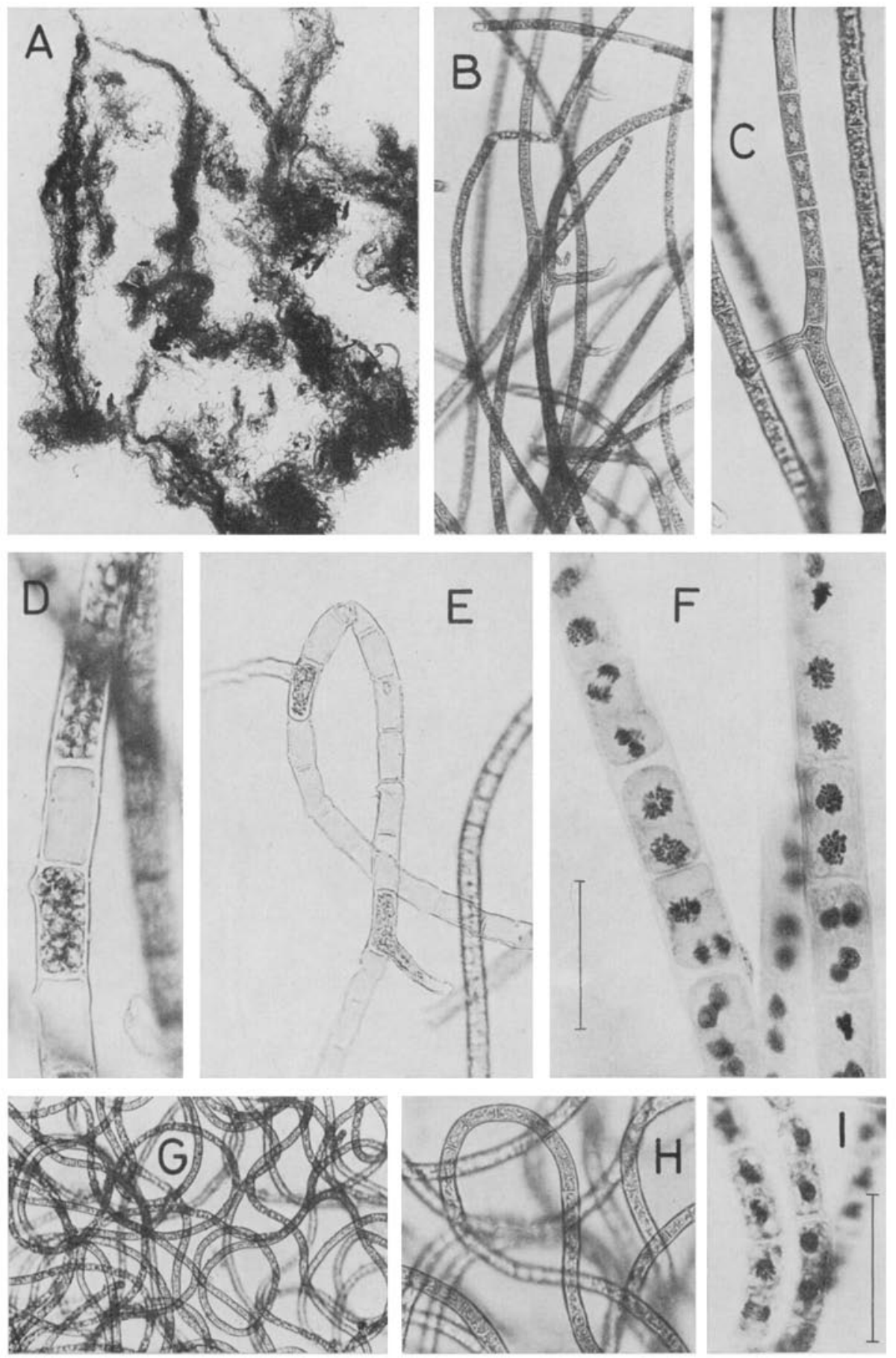


\section{Rbizoclonium riparium (Roth) Harv.}

Die Alge bildet während des ganzen Jahres im oberen Litoral meist wollige, hellgrüne Oberzïge auf totem Substrat, Holzpfählen, Betonmauern oder Treppenstufen, sie kommt aber auch epiphytisch auf Fucus spiralis vor und wächst gern in Gesellschaft von Blidingia minima. Die mikroskopische Untersuchung der verworrenen Watten zeigt 20-25 $\mu \mathrm{m}$ dicke unverzweigte Fäden. Kennzeichnend für die Art sind die aus einzelnen Fadenzellen auswachsenden kurzen Rhizoiden (B), die man in den Proben mit unterschiedlicher Häufigkeit antrifft. In den lebenden Zellen lassen sich die beiden großen Kerne oft leicht erkennen (C); nach Färbung mit Karminessigsäure ergeben sich besonders klare Kernteilungsfiguren (F).

Bei der Fertilisierung entstehen in den rhizoidfreien Fadenzellen viergeißelige Zoosporen (D, E). Die aus ihnen kultivierte Generation fruktifizierte in gleicher Weise; nach den Untersuchungen Blidings (1957) an Material aus der Ostsee und von North Wales hätte man eine geschlechtliche Generation erwarten können.

\section{Rhizoclonium kochianum Kütz.}

Die hier mit Vorbehalt zu Rhizoclonium kochianum gestellte Art hat dünnere Fäden, wie die bei gleicher Vergrößerung dargestellten Figuren B und $G$ erkennen lassen; auch fehlen ihr die Rhizoiden. Zu den morphologischen Unterschieden kommen ökologische: Rh. kochianum wächst in der unteren Gezeitenzone, wo sie gern die weichen Polster des Röhrenwurmes Fabricia überzieht, aber auch glatte Lager auf dem anstehenden Fels bildet und sich um Algen schlingt.

Abb. 18: A-F Rbizoclonium riparium. A Wollige Lager von der Treppe des NO-Hafens, etwa natüliche Größe (10. 12. 1970). B Fäden mit Rhizoiden. C Kerne in lebenden Zellen sichtbar. D, E Fertiler und entleerter Faden (29.6. 1972). F Kerne in Teilung, gefärbt mit Karminessigsäure. $G-I$ Rhizoclonium kochianum. $G$ Fảden bei gleicher Vergrößerung wie $B$. H Ausschnitt, die Vergrößerung entspricht der von $C$ und E. I Kernteilungen, Färbung mit Karminessigsäure. Maßstrecken: $\mathrm{C}, \mathrm{E}, \mathrm{H}=190 \times ; \mathrm{F}, \mathrm{I}=50 \mu \mathrm{m}$ 


\section{CODIALES}

Die Ordnung Codiales gliedert sich in zwei Familien. Zu den Bryopsidaceae gehören die Gattungen Bryopsis mit fiedriger Verzweigung und Derbesia mit unregelmäßig dichotom verzweigtem schlauchförmigem Thallus. Ihr Lebenszyklus umfaßt heteromorphe Generationen mit stephanokonten Zoosporen. Bei den Codiaceae verflechten sich dünne Fäden unter Abgliederung dicht palisadenartig aneinanderschlieBender Blasenzellen zu einem schwammigen, derben Thallus. Einzige Gattung Codium.

\section{Bryopsidaceae}

\section{Bryopsis bypnoides Lamour.}

Die reich verzweigten Büschel werden bis zu $12 \mathrm{~cm}$ lang. Im allgemeinen ist die Hauptachse ringsum mit Seitenzweigen besetzt, die sich wiederum mehrfach allseitig verzweigen $(A, C)$. Diese Verzweigungsart ist aber nicht unbedingt kennzeichnend; man findet besonders im Frühjahr und Spätsommer auch Exemplare, deren Fiederchen zweizeilig angeordnet sind (B). In Kultur wachsen die Spitzen solcher PAlanzen schon nach wenigen Tagen unter allseitiger Verzweigung weiter.

Der schlauchartige Thallus hat keine Querwände; ein abgeschnittener Zweig wird mit allen seinen Fiederchen schlaff, nur die sich $z u$ Gametangien umwandelnden oder schon verzweigten Fiederäste sind durch einen Membranpfropf von der Hauptachse abgeschlossen und bleiben turgeszent. Die Regeneration erfolgt rasch; schon nach etwa einem halben Tag hat sich der abgelöste Plasmaschlauch wieder an die Zellwand angelegt. Er enthält viele Kerne und spindelförmige Chromatophoren mit einem deutlichen Pyrenoid $(G)$.

Häufig sind die am Standort gesammelten Pflanzen bereits fertil, sonst werden sie es im allgemeinen schon nach ein- bis zweitägigem Stehenlassen in Seewasser. Der vorher gleichmäßig grüne Wandbelag zieht sich zu netzartigen Strängen zusammen, aus denen sich schließlich die Gameten differenzieren (C-E). Häufig sind die Gametangien hermaphroditisch, wobei im oberen Teil die kleinen männlichen, im unteren Teil die größeren weiblichen Gameten gebildet werden. Es kann aber auch umgekehrt sein, ebenso können gemischt- und eingeschlechtliche Fiederchen am gleichen Thallus vorkommen. Getrenntgeschlechtliche Pflanzen werden seltener angetroffen.

Bis vor wenigen Jahren galt Bryopsis als Typus eines Diplonten mit Reduktionsteilung bei der Gametenbildung. Entwicklungsgeschichtliche Untersuchungen an verschiedenen Bryopsis-Arten ergaben aber einen Generationswechsel mit einem Protonema-Stadium, in dem Zoosporen mit einem Geißelkranz gebildet werden (Rietema, 1971). Sie entsprechen den in den Sporangien von Derbesia gebildeten stephanokonten Zoosporen. Jedoch verhalten sich die Pflanzen von verschiedenen Punkten der europäischen Küsten nicht gleichartig; bei Bryopsis bypnoides von Helgoland erhebt sich aus dem kriechenden Stadium unmittelbar die gefiederte Pflanze (Neumann, 1969). 

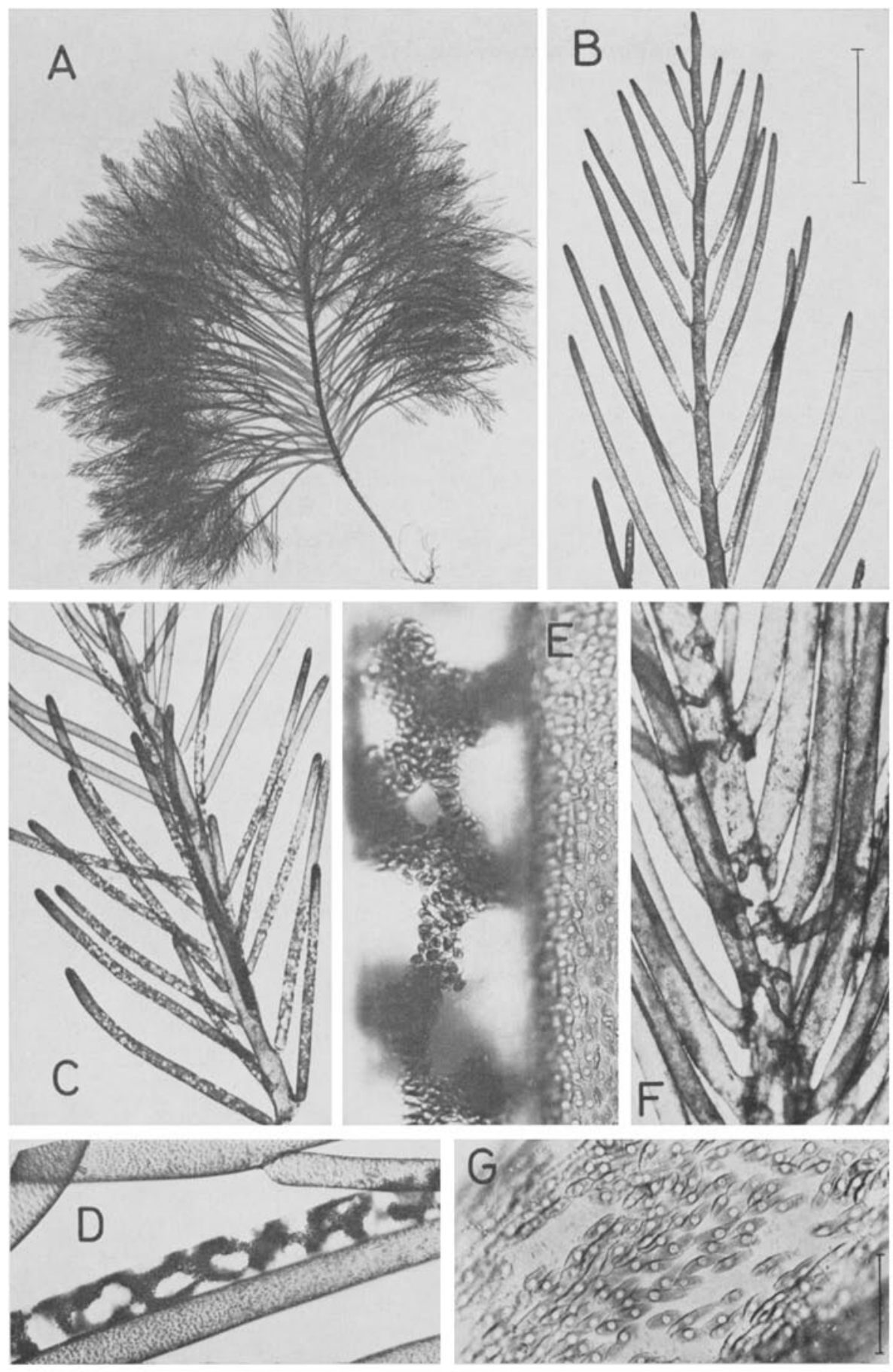

Abb. 19: Bryopsis bypnoides. A Habitus der wiederholt allseitig verzweigten Pflanze, schwach verkleinert (18.6.1970). B Spitze eines zweizeiligen Thallus (19.7. 1974). C-E Fertiler Zweig und Ausschnitte bei stärkerer Vergrößerung. F Rhizoiden an der Basis älterer primärer Zweige. G Chromatophoren mit Pyrenoid. Maßstrecken: B, C, F $=1 \mathrm{~mm} ; \mathrm{E}, \mathrm{G}=50 \mu \mathrm{m}$ 
Bryopsis bypnoides ist nicht selten in ruhigen Gezeitenbecken oder an der Innenseite der Hafenwände an und unter der Niedrigwasserlinie zu finden. Bei älteren Exemplaren treiben an der Basis der primären Zweige rhizoidale Auswüchse aus $(F)$.

\section{Bryopsis lyngbyei Hornem.}

Diese von Helgoland seit langem bekannte, aber stets als Bryopsis plumosa angesehene Art ist streng zweizeilig gefiedert. Durch ihre dichtstehenden, nach oben nur ganz allmählich kürzer werdenden Fiederchen ähnelt sie einer Vogelfeder, besonders vor der ersten Fertilisierung, wenn etwa zwei Drittel der Achse Fiederchen trägt (A). Nach der spitzenwärts fortschreitenden Fertilisierung sprossen zwischen den entleerten und später abgeworfenen Gametangien neue Fiederchen aus (A, F). Durch ihre kräftigen, nur wenig verzweigten Hauptachsen ist diese Art steifer als die vorige. Bryopsis lyngbyei bevorzugt tiefere Standorte; im gedretschten oder durch Taucher beschafften Material ist sie nicht selten, gelegentlich treiben auch losgerissene Stückchen im Plankton. Bei ungewöhnlich tiefem Niedrigwasser kann man sie auch an den Wänden tieferer Priele an der Südwestseite der Insel finden.

Bryopsis lyngbyei ist diözisch, die männlichen und weiblichen Gameten sind von sehr unterschiedlicher Größe $(\mathrm{H}, \mathrm{J})$. Aus der Zygote entwickelt sich ein kriechendes Sporophytenstadium mit stephanokonten Zoosporen. Bryopsis lyngbyei bastardiert nicht mit B. plumosa, während die Kreuzung plumosa $\times$ bypnoides ohne weiteres gelingt (Kornmann \& Sahling, 1976). Damit ist nicht nur die Selbständigkeit der ursprünglich von den Färöer beschriebenen $B$. lyngbyei erwiesen, sondern auch die nahe Verwandtschaft der beiden anderen Arten.

Abb. 20: Bryopsis lyngbyei. A Pflanzen aus etwa $6 \mathrm{~m}$ Tiefe; die linke war noch nicht fertil, die übrigen tragen junge adventive Fiederchen zwischen den schon entleerten (Ausschnitt bei $F$, 14. 6. 1973). B Auf einem Stein zusammen mit Lomentaria clavellosa. Primärfiedern nur noch an den Spitzen (26.6.1971). C Protoplast mit Chromatophoren. D, E Männliche und weibliche Gametangien. F Adventive Fiederchen $z$ wischen leeren. G, H und I, J Männliche und weibliche Gameten, lebend und gefärbt. Maßstrecken: $A, B=1 \mathrm{~cm} ; \mathrm{C}, \mathrm{G}, \mathrm{I}=50 \mu \mathrm{m} ; \mathrm{D}, \mathrm{E}=100 \mu \mathrm{m}$; $\mathrm{H}, \mathrm{J}=50 \mu \mathrm{m}$ 

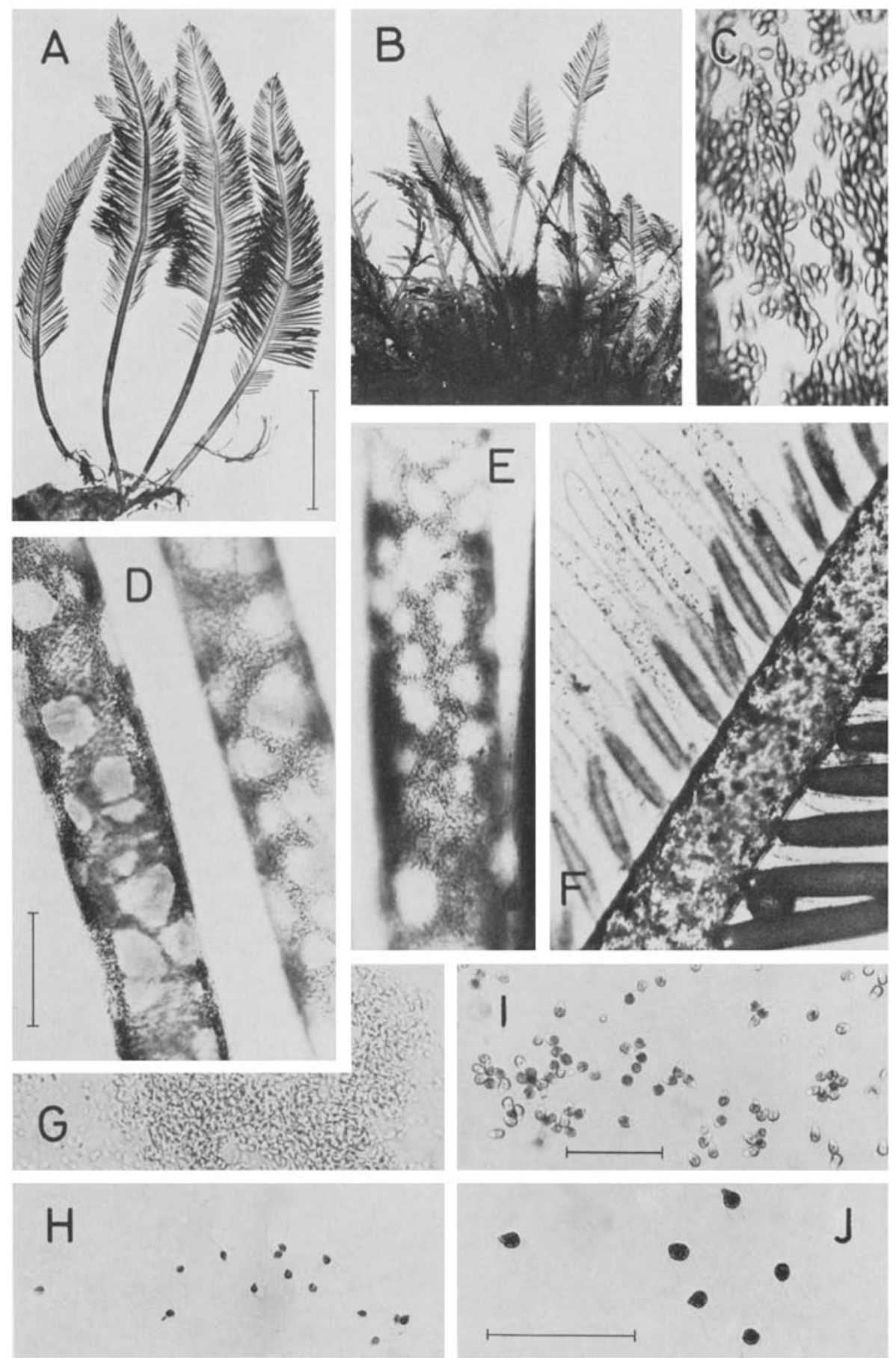

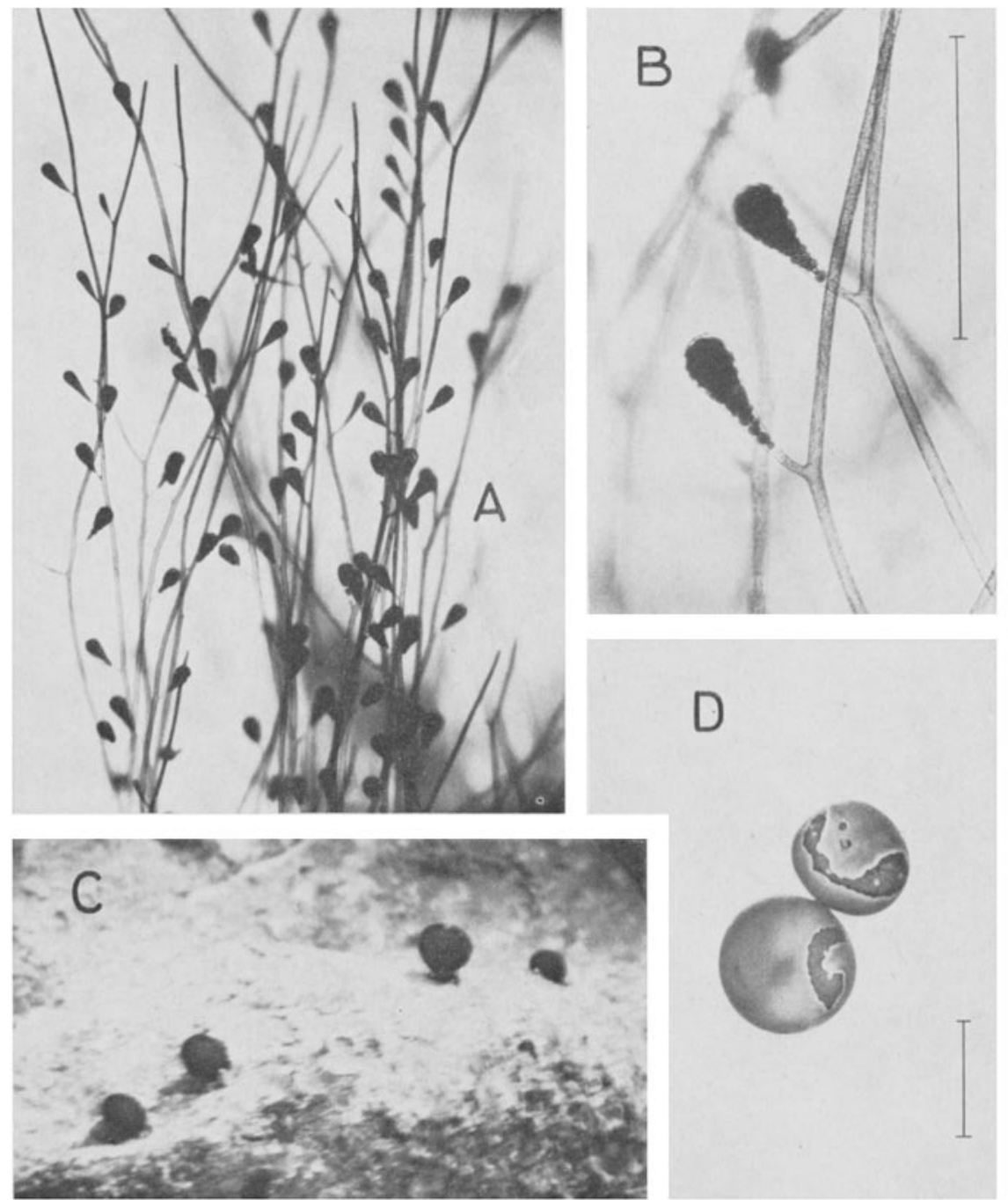

D
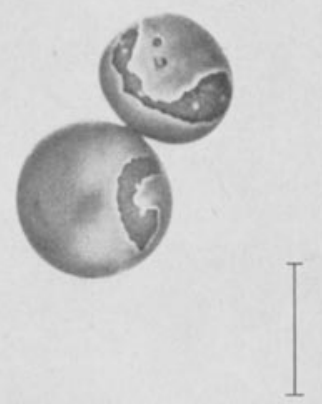

Abb. 21: A, B Derbesia marina mit Zoosporangien, aus Kultur. C Halicystis ovalis auf einer Phymatolithon-Kruste im Schauaquarium, etwa $\times 1,5$. Aufnahme A. Holtmann. D Fertile Halicystis-Blasen aus Kultur. Maßstrecken: $\mathrm{B}=100 \mu \mathrm{m} ; \mathrm{D}=5 \mathrm{~mm}$ 
Derbesia marina (Lyngb.) Solier incl. Halicystis ovalis (Lyngb.) Aresch.

Es ist nicht verwunderlich, daß diese beiden morphologisch so verschiedenen Algen früher als selbständige Arten angesehen wurden. Erst durch Kulturversuche im Laboratorium wurden sie als Glieder eines heteromorphen Lebenszyklus erkannt (Kornmann, 1938). Der Sporophyt, Derbesia (A, B), besteht aus Watten von dünnen, unregelmäßig dichotom verzweigten Fäden. Er trägt keulige, mit bloßem Auge gerade noch erkennbare Zoosporangien. Aus den mit einem Geißelkranz versehenen Zoosporen entwickelt sich eine Generation getrenntgeschlechtlicher kugeliger Gametophyten, die lange vor der Klärung der Zusammenhänge als Halicystis ovalis bekannt waren (C, D).

An ihrem eigentlichen Standort im Sublitoral sind beide Partner nur äußerst selten zu finden. Derbesia marina stellt sich aber regelmäßig in Aquarienbecken ein und läßt sich auch leicht im Laboratorium kultivieren. 1974 trat auch Halicystis ovalis zum ersten Male in einem Becken des Schauaquariums auf (C). Wie in der Natur saßen die Kugeln auf roten Krustenalgen, in denen die rhizoidale Basis von Halicystis endophytisch lebt. 1975 und 1976 erschienen sie in weit größerer Anzahl an denselben Stellen wieder, fruktifizierten mehrfach und verschwanden im Herbst.

\author{
Codiaceae
}

\title{
Codium fragile (Sur.) Hariot
}

Codium ist die morphologisch am stärksten differenzierte Grünalge der Helgoländer Algenflora. Der Thallus besteht aus mehr oder weniger regelmäßig dichotom verzweigten, schwammig-filzigen, runden, etwa 5-8 $\mathrm{mm}$ dicken Schnüren, die mehrere Dezimeter lang werden können (A, B). Die Oberfläche zeigt blasige, von einer Spitze gekrönte Zellen, die palisadenartig dicht zu einer Rinde zusammenschließen (C, D), während dünne verzweigte Längsfäden den zentralen Raum ausfüllen. Ringförmige Membranauflagerungen verengen das Lumen der schlauchförmigen Fäden an der Basis ihrer Verzweigungen, doch sind keine eigentlichen Querwände vorhanden.

Gelegentlich findet man die Alge, besonders in einer Zone unterhalb der Thallusenden, von einem Flaum feiner, wenig gefärbter Haare umhüllt; sie entspringen den Blasen, werden periodisch abgeworfen und hinterlassen Narben. Die Gametangien entstehen im Spätsommer und Herbst als besondere Organe seitlich an den Blasen, einzeln oder auch zu mehreren (D, E). Ein Schleimpfropf an der Spitze des reifen Gametangiums läßt eine kleine linsenförmige Stelle der Wandung frei. Hier platzt das Gametangium auf, und mit dem aufquellenden Schleim werden die Gameten entleert.

Im allgemeinen ist Codium fragile monözisch, zum Beispiel die Population im Limfjord, doch überwiegr bei verschiedenen Exemplaren ein Geschlecht. Bei Helgoland und an der nordfranzösischen Küste wurden aber nur weibliche Pflanzen gefunden. Wahrscheinlich unterbleibt hier die vor der Bildung der Gameten erfolgende Reduktionsteilung. Die Gameten entwickeln sich in Kultur parthenogenetisch zu einem aus 

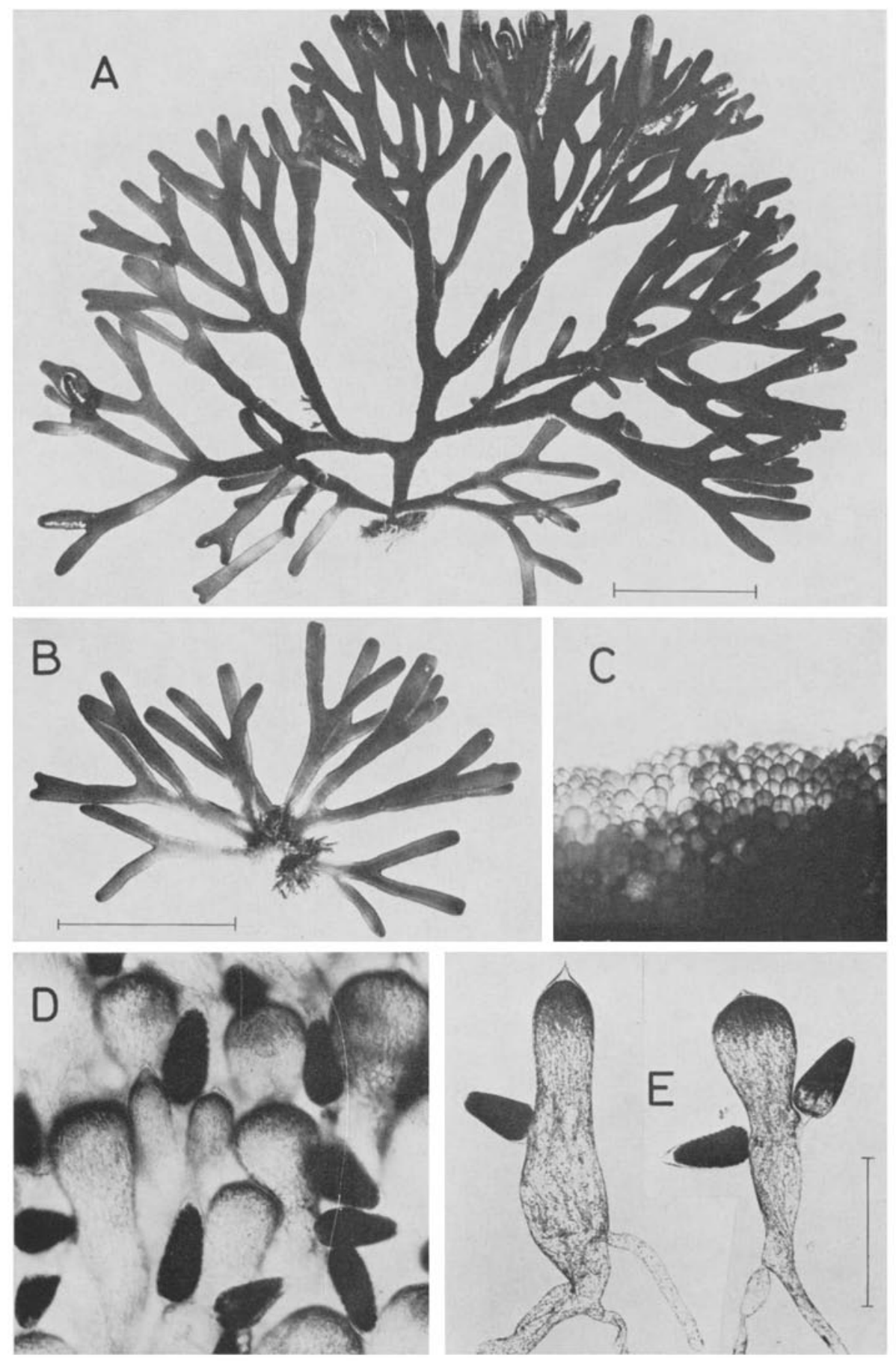

Abb. 22: Codium fragile. A, B Habitus einer älteren und einer jungen Pflanze (15. 7. 1972). $C, D$ Aufsicht auf den yegetativen und den fertilen Thallus. E Blasen mit Gametangien (5.8. 1969). Maßstrecken: A, B jeweils $=3 \mathrm{~cm} ; \mathrm{E}=500 \mu \mathrm{m}$ 
monopodial verzweigten Fäden bestehenden primären Thallus, der den Boden der Kulturschale überzieht. An einzelnen Stellen schwellen die $Z$ weigenden an und werden spitz: es sind die Entstehungszentren aufrechter Sprosse. Sie haben keinen eigentlichen Vegetationspunkt, sondern das Schlauchsystem baut sich sympodial auf, indem die an der Basis der Blasen entspringenden $Z_{\text {weige }}$ an ihren Enden wiederum zu Blasen anschwellen. Die in Kultur erzielten Codium-Thalli wurden etwa $2 \mathrm{~cm}$ lang, aber nicht fertil.

Codium fragile wächst in geringer Menge auf dem Felswatt im Südwesten der Insel gern an Stellen, die wegen einer Schlickauflage nicht von Fucus serratus besiedelt werden. Am häufigsten kommt die Alge sublitoral an den Hafenmauern vor, wo die Lichtmenge zur Ausbildung typischer Pflanzen ausreicht. An schattigen Stellen entstehen auf dem fädigen Primärthallus zopfartige Büschel, die unterwärts strangartig zusammengedreht sind und sich an den Enden locker auflösen. In dieser Wuchsform können am Standort flutende Büschel Bryopsis bypnoides ähneln.

\section{Chlorophyceae}

Die verbleibenden Ordnungen der Grünalgen in einer Klasse zu vereinigen, ist vielleicht eine etwas zu bequeme Lösung. Freilich gibt es gemeinsame Merkmale, z. B. die stets einkernigen Zellen und die übereinstimmende Ausbildung ihrer beweglichen Stadien. Andererseits weichen die Ordnungen in morphologischer Hinsicht so weitgehend voneinander $a b$, daß ihre Zusammenfassung nicht im Sinne einer natïlichen Verwandtschaft angesehen werden kann.

In der folgenden Übersicht sind nur die Ordnungen aufgeführt, die auch im Meer vertreten sind.

Volvocales: $\quad$ Freibewegliche Einzelzellen oder Kolonien (Gattungen Dunaliella, Chlamydomonas); sie werden hier nicht berücksichtigt.

Chlorococcales: Epi-und endophytisch lebende Einzelzellen. Chlorococcaceae. p. 56. Ulvales: Thallus röhrenförmig oder zweischichtig flächig; ein zweireihiger Faden bei Percursaria. Drei Familien. p. 60.

Prasiolales: Die Ordnung ist durch den sternförmigen Chromatophor gekennzeichnet und steht völlig isoliert. Prasiolaceae. p. 82 .

Chaetophorales: Faden- oder scheibenförmige Kleinalgen, auf Steinen wachsend oder Epi- und Endophyten. Chaetophoraceae. 


\section{CHLOROCOCCALES}

\section{Chlorococcaceae \\ Chlorochytrium Cohn}

Nur mit großem Vorbehalt geben wir den hier beschriebenen Arten ihren Platz in der Gattung Chlorochytrium. Es ist zweifelhaft, ob die marinen Vertreter mehr als eine äußere Ahnlichkeit mit den in den Blättern von Lemna lebenden Endophyten verbindet. Schon Wright (1877, S. 368) weist darauf hin, daß sein Chlorochytrium cohnii nicht ganz den Merkmalen der Gattung entspricht. Wahrscheinlich können auch die verschiedenen hier gefundenen Formen nicht als Arten einer Gattung angesehen werden. Eine Klärung ist vielleicht durch entwicklungsgeschichtliche Untersuchungen zu erwarten, doch sollen die noch bestehenden taxonomischen Unklarheiten die Bekanntgabe unserer Beobachtungen an den bei Helgoland gefundenen Formen nicht verzögern. Daß der unter dem Namen Chlorochytrium inclusum beschriebene Endophyt in Polyides rotundus als Sporophyt zu Spongomorpha aernginosa gehört, wurde schon frïher erwähnt (p. 34).
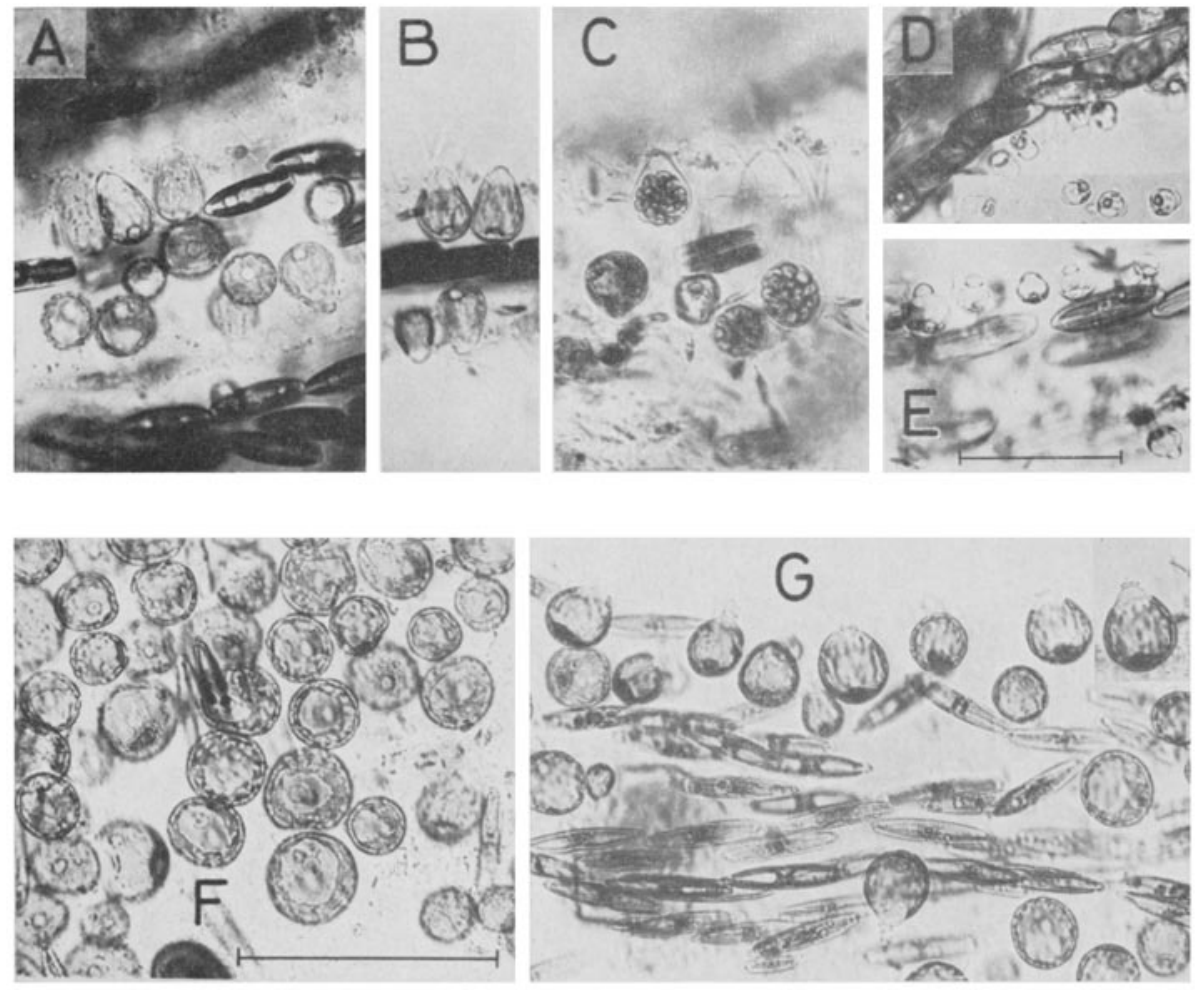

Abb. 23: Chlorochytrizm cobniz. A - C Zellen von ausgeprägt eiförmigem Umriß, vegetativ und fertil (10.9. 1971). D, E Stadien kurz nach der Infektion der Wirtspllanze. F, G Mehr kugelig geformte Endophyten in der Aufsicht und von der Seite (aus einem Präparat vom 21. 9. 1959). Maßstrecken: $A-C, F, G=100 \mu \mathrm{m} ; \mathrm{D}, \mathrm{E}=50 \mu \mathrm{m}$ 


\section{Cblorochytrium cobnii Wright}

Unter diesem Namen beschrieb Wright (1877) kugelige Endophyten in den Gallertschläuchen von Diatomeen. Solche Endophyten trifft man bei Helgoland nicht selten in zwei verschiedenen Erscheinungsformen an. Die in Abbildung 23 dargestellten Zellen sind kugelig bis eiförmig, bei vielen liegt der breiteste Durchmesser im unteren Drittel (A, B). Der von kleinen Löchern durchbrochene becherförmige Chromatophor kleidet den größten Teil der Zellwand aus (A, B, G). In der Aufsicht umgrenzt sein scharfer oberer Rand eine nahezu runde Offnung, durch die man den großen basalen Pyrenoid erkennt (F). Wahrscheinlich entspricht diese Form der von Wright beschriebenen Art.
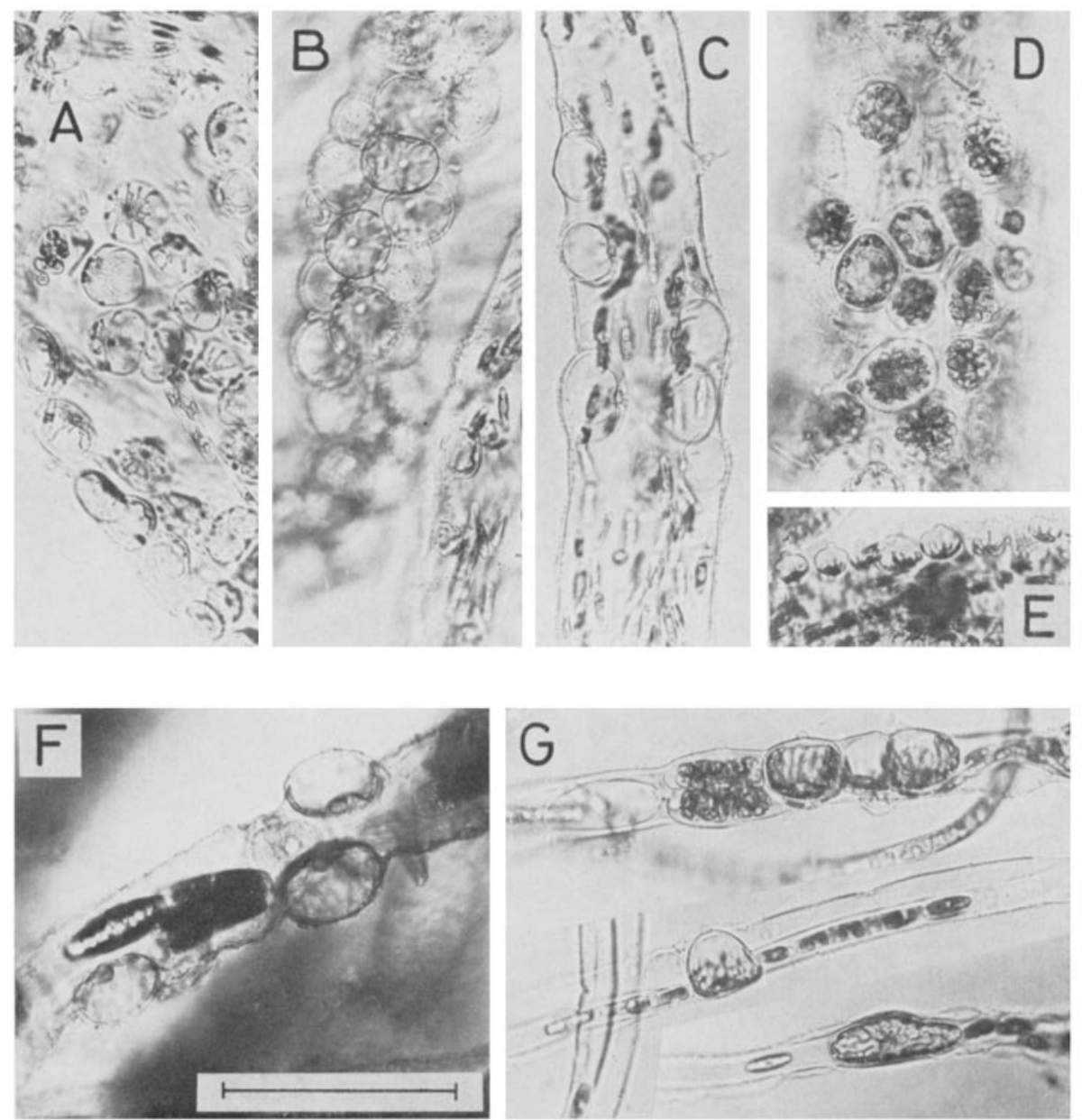

Abb. 24: Chlorochytrium cobnii?. A - C, F Abgeplattete Zellen mit fingerförmigem Chromatophor (A aus Präparat vom 29. 8. 1960, B, C und F lebend rom 6. 7. 1971 und 19. 4. 1974). D Fertile Zellen (26.8.1971). E Junge Endophyten (aus einem Präparat vom 29. 8. 1960). $G$ An den verfügbaren Raum angepaßte Zellformen (5.11.1974). Maßstrecke: $A-G=100 \mu \mathrm{m}$ 
Ganz anders sehen die in Abbildung 24 dargestellten Endophyten aus. Räumlich nicht bedrängt wachsende Zellen sind abgeplattet-kugelig (C, F); unter Anpassung an den verfügbaren Raum kann ihre Form jedoch recht variabel sein $(G)$. Der Chromatophor mit deutlichem Pyrenoid strahlt in mehrere, dünne Lappen aus, die nur etwa die Mitte der Zellwand erreichen (A, F). Die Zellen erscheinen daher sehr hyalin. Wright beschreibt dagegen seine Zellen als smaragdgrün; ein fingerförmig-strahliger Chromatophor wäre seiner Beobachtung sicherlich nicht entgangen.

Eine morphologische Besonderheit der vegetativen Zellen beider Formen ist das kreisrunde, gewölbte Deckelchen, das über die Oberfläche der Gallertschläuche ragt (Abb. $23 \mathrm{G}, 24 \mathrm{G}$ ). Es entsteht im Zusammenhang mit der Infektion. Die auf der Oberfläche ihrer Wirtspflanze zur Ruhe gekommenen Schwärmer umhäuten sich. Nach dem Durchdringen der Diatomeengallerte ergießt sich der Protoplast in das Schlauchinnere. Die Zoosporenmembran bleibt als Deckel erhalten, der Protoplast wandert an den ihm gegenüberliegenden Pol (Abb. $23 \mathrm{D}, \mathrm{E}$ ). Auch in freier Kultur erfolgt die Entwicklung in gleicher Weise. Das Deckelchen ist die für den Schwärmeraustritt vorgegebene Stelle.

\section{Chlorocbytrium (?) willei Printz}

Diese Alge ist durch die Beschreibung ihres Autors gut gekennzeichnet. Die Zellen leben halb eingesenkt in der Zellschicht von Blidingia minima, in der sie nach dem Ausschwärmen Löcher zurïcklassen (Abb. 25 B). Bei starkem Befall bleibt dann von dem Blidingia-Thallus ein lockeres, stellenweise nur noch einreihiges Netz von Zellen übrig,

Die auf der Oberfläche zur Ruhe gekommenen Schwärmer dringen in die Zellschicht der Wirtsalge ein und wachsen mit der sich vergrößernden Thallusfläche mit. Im ausgewachsenen Zustand ragen die bis $50 \mu \mathrm{m}$ dicken, fast kugeligen Zellen uber die Oberfläche der Blidingia hinaus. Der Chromatophor mit seinem großen Pyrenoid liegt stets an der äußeren Zellwand (A); dies ist ein wesentlicher Unterschied von allen übrigen hier beobachteten Formen von "Cblorochytrium". Er bedeckt die Zellwand als weitmaschiges Netz (D).

\section{Cblorocbytrium (?) sp.}

Epiphytisch auf Enteromorpha wachsende Chlorochytrium-Formen werden in der Literatur mehrfach erwähnt. Der hier dargestellte Epiphyt wuchs auf einer reichverzweigten Enteromorpha. Einzelnstehende, nicht durch einen zu dichten Bewuchs deformierte Zellen sind abgeflacht kugelig. Die Hauptmasse des Chromatophors mit einem großen Pyrenoid liegt an der basalen Fläche der Zelle und setzt sich strahlig in äußerst zarte Lappen fort (Abb. $25 \mathrm{E}, \mathrm{F}$ ). 
Wie bei Chlorochytrium (?) willei werden die Schwärmer durch Aufreißen der Membran frei. Die auf der Wirtspflanze zur Ruhe gekommene Schwärmspore umhäutet sich und wächst unmittelbar zum Epiphyten heran, ein wesentlicher Unterschied gegen Cblorocbytrium cobnii.
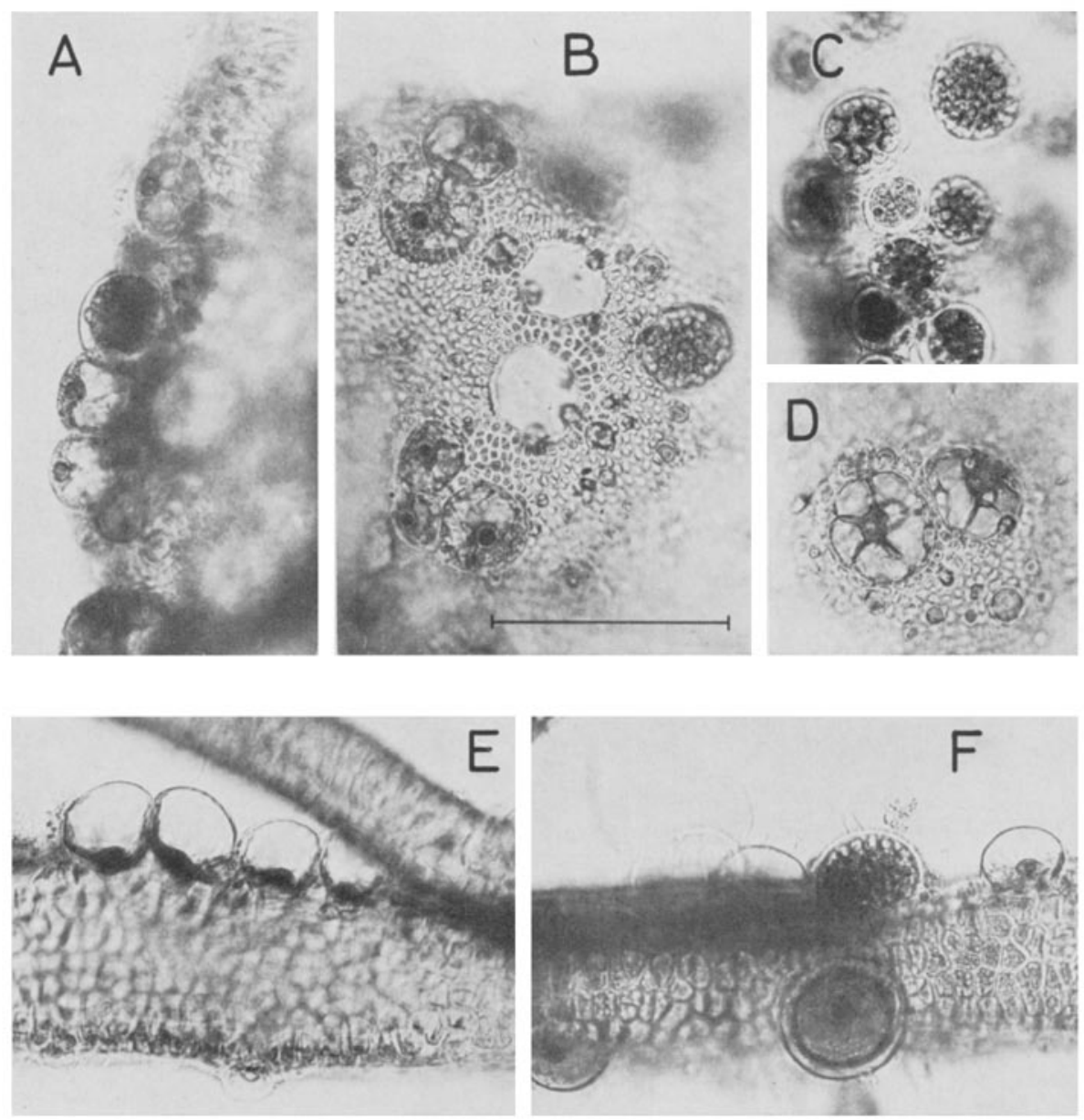

Abb. 25: A - D Chlorocbytrium (?) willei. A, B Auf Blidingia minima seitlich und in Aufsicht (aus einem Präparat yom 7. 7. 1969). C Fertile Zellen. D Zwei Zellen vor Beginn der Fertilisierung. E, F Chlorocbytrium (?) spec. auf einer feinfädigen Enteromorpha (aus einem Präparat vom 6.8. 1964). Maßstrecke: $\mathrm{A}-\mathrm{F}=100 \mathrm{um}$ 


\section{ULVALES}

Die Ordnung Ulvales wurde von Bliding $(1963,1968)$ taxonomisch und entwicklungsgeschichtlich eingehend bearbeitet. Ohne die von ihm noch einbezogenen Monostromataceae (p. 24) erscheint sie als recht einheitliche Gruppe, deren geschlechtlich sich vermehrende Formen einen isomorphen Generationswechsel haben.

Der Aufgliederung in Familien und Gattungen liegen Unterschiede der frühen Entwicklungsstadien zugrunde.

\section{Capsosiphonaceae.}

Wie bei Enteromorpha und Ulva entsteht zunächst ein monosiphoner Keimling; er bildet aber keine Rhizoiden, sondern haftet mit einer durch Längsteilungen der Basalzelle entstandenen Scheibe auf dem Substrat. Einzige Gattung: Capsosiphon, p. 62.

\section{Percursariaceae.}

In der Entwicklung des zweireihigen Fadens gibt es kein röhriges Stadium. Einzige Gattung: Percursaria, p. 62.

\section{Ulvaceae.}

a. Enteromorpha, p. 69.

Der zunächst monosiphone Keimling verankert sich mit Rhizoiden; er wird durch Längsteilung seiner Zellen röhrig. Damit ist das morphologische Stadium von Enteromorpha erreicht, der hohle einschichtige Thallus, der sich mehr oder weniger stark verzweigt.

b. Ulva, p. 64 .

Entwicklung zunächst wie bei Enteromorpha, dann flacht sich der wenige Millimeter hohe röhrige Keimling ab, und die sich berührenden Zellschichten verwachsen zum zweischichtigen Thallus.

c. Blidingia, p. 78 .

Nur mit Vorbehalt findet diese Gattung hier ihren Platz. Sie wurde wegen der andersartigen Entwicklung ihrer Keimlinge von Enteromorpha abgetrennt, aber schon in dem ursprünglichen Gattungsmerkmal stimmen die beiden Arten nicht überein (vgl. Abb. $38 \mathrm{H}$ und 39 F). Blidingia könnte wie Capsosiphon und Percursaria auf den Rang einer Familie erhoben werden. Bliding (1968, S. 621) ordnet sie als abweichende Gattung den Monostromataceae zu.

d. Kornmannia, Beschreibung auf p. 272. 

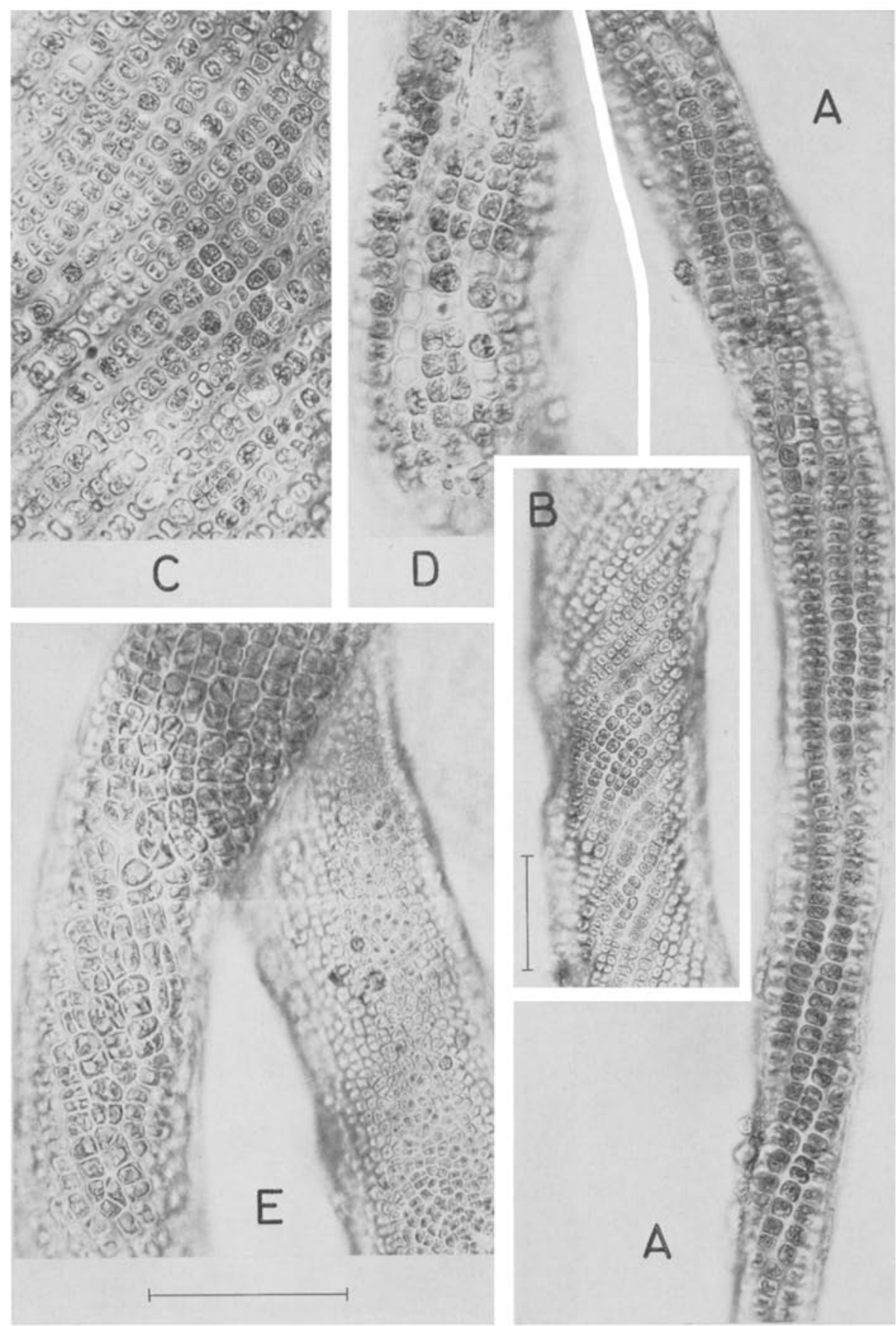

Abb. 26: Capsosiphon fulvescens. A Thallus dicht oberhalb der Basis (13, 2. 1974). B Aus einem oberen Thallusabschnitt mit stark gedrehten Zellreihen. C W/ie B, der Thallus verbreitet sich durch Verdoppelung der Zellreihen (2. 7. 1969). D Fertiler Thallusabschnitt (13. 2. 1974). E Links Capsosiphon, rechts Blidingia minimat (2. 3. 1974). Maßstrecken: $A, C-E=100 \mu \mathrm{m}$; $\mathrm{B}=100 \mu \mathrm{m}$ 
Capsosiphonaceae

Capsosipbon fulvescens (C. Ag.) Setch. et Gardn.

Dieser Alge begegnet man am ehesten, wenn man Proben von Blidingia oder Urospora aus dem obersten Litoral in einer Schale aufschwemmt. Dann wird man gelegentlich schmale, 1-8 cm lange unverzweigte Thalli von leicht olivgrüner bis goldgelber Farbe zwischen der derberen, etwas krausen Blidingia minima finden. Das mikroskopische Bild läßt das kennzeichnende Merkmal klar erkennen: In der Wandung des im allgemeinen unter $0,5 \mathrm{~mm}$ breiten röhrigen Thallus liegen die Zellen in deutlichen, mehr oder weniger stark gewundenen Längsreihen geordnet (Abb. 26). Schließlich sind die Zellen viel größer als bei Blidingia, ihr rundliches Lumen ist in dicke Zellwände eingebettet (zum Vergleich mit Blidingia bei E). Nach der Teilung verbleiben of 2 bis 4 Zellen in der Membran ihrer Mutterzelle.

Die Vermehrung erfolgt durch viergeißelige Zoosporen. Aus ihnen entsteht eine gleichartige Generation. Fertile Pflanzen triff man während des ganzen Jahres an.

\section{Percursariaceae}

\section{Percursaria percursa (C. Ag.) Rosenv.}

Bei Helgoland kann man diese Alge regelmäßig in den mit Wasser gefüllten Vertiefungen der Betonblöcke finden, die den Hafenmolen und Uferschutzbauten als Wellenbrecher vorgelagert sind. Viele dieser "Aquarien" liegen hoch ïber der durchschnittlichen Hochwasserlinie und werden nur durch Spritzwasser erreicht; ihr Salzgehalt ist sehr veränderlich infolge Verdunstung oder Aussüßung durch Regenwasser, ebenso schwankt die Temperatur stark im Tagesgang.

percursaria percursa ist in diesen kleinen Becken während des ganzen Jahres zu finden, im Sommer meist als verworrene Watten aus langen, sehr dünnen Fäden von blaßgrüner Farbe. Sie geben sich unter dem Mikroskop als doppelreihiges Band zu erkennen, das von der Kante gesehen einreihig erscheint (A). Die Zellen strecken sich etwa bis zur Thallusbreite, bevor sie sich teilen. In den blaßgrünen Fäden ist der Chromatophor auf einen schmalen Gürtel in der Mitte der Zelle reduziert, im allgemeinen sind 2 bis 3 Pyrenoide vorhanden.

Während der Herbst- and Wintermonate sind die Fäden dunkler grün, vor allem, wenn noch andere Mitbewohner wie Enteromorpha oder Cladophora einen Teil des Lichtes abschirmen. Dann bleiben die Zellen kürzer; der in der Mitte von Abbildung 27 B liegende Faden zeigt sehr anschaulich die durch den Wachstumsvorgang - Zellteilung und -streckung - bedingte Schwankung der Zellenmaßse.

Am natürlichen Standort wurde Percursaria niemals fertil angetroffen. Die entwicklungsgeschichtliche Untersuchung ergab einen Wechsel gleichgestalteter Sporophyten und Gametophyten, abgesehen von der Möglichkeit der Entwidklung unverschmolzener Gameten (Kornmann, 1956a). 


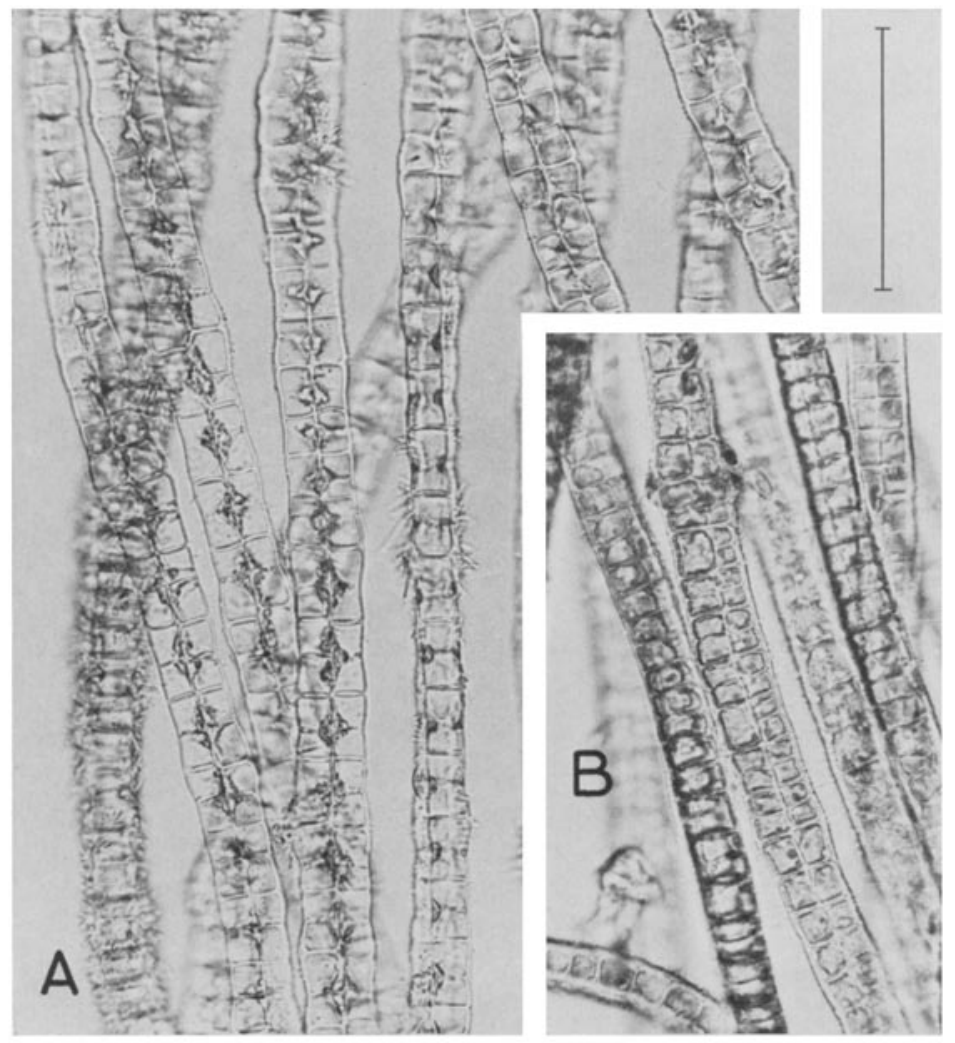

Abb. 27: Percursaria percursa. A In großer Helligkeit gewachsene Fäden (1. 7. 1971). B Dunkelgrüne Fäden vom 23. 10. 1973. Maßstrecke: $100 \mu \mathrm{m}$ 


\section{Ulvaceae}

\section{Ulva Linnaeus}

Die Gattung Ulva ist bei Helgoland mit zwei Arten vertreten, der weitverbreiteten Ulva lactuca und der auf wenige Fundorte beschränkten Ulva curvata.

\section{Ulva lactuca $\mathrm{L}$.}

Von April bis zum Ende des Jahres triff man sie in der unteren Gezeitenzone an, besonders reichlich in den Sommermonaten. In Form und Größe variieren die flächigen Thalli sehr; die meisten sind im Umriß oval oder langgestreckt, oft aber auch in unregelmäßige Lappen geteilt. Die Fläche ist stets mehr oder weniger stark wellig (A), Herbarpflanzen haben daher einen faltigen Rand. Uber einem kurzen, aber deutlich abgesetzten Haftorgan verbreitert sich der Thallus unmittelbar, was die Unterscheidung von ähnlich gestalteten Formen von Enteromorpba linza erleichtert (vgl. Abb. 35). Ulva lactuca wächst sowohl auf harter Felsunterlage als auch epiphytisch auf größeren Algen wie Fucus. Im allgemeinen wird der Thallus etwa $20 \mathrm{~cm}$ groß, kann aber im Sommer in ruhigem, nährstoffreichem Wasser auf $100 \times 50 \mathrm{~cm}$ heranwachsen, einzelne Pflanzen können sogar $3 \mathrm{~m}$ Länge erreichen.

Die Thallusfläche ist glatt und fest, sie besteht aus zwei Schichten von vertikal etwas gestreckten Zellen. In der Aufsicht sieht man ein geschlossenes Netz von undeutlich in gekrümmten Reihen angeordneten Zellen $(B, C)$. Der plattenförmige Chromatophor trägt ein Pyrenoid. Bei einseitig starker Beleuchtung der Pflanzen richten sich die Chromatophoren phototaktisch aus.

Fertile Pflanzen heben sich in auffallender Weise durch die andersartige und matte Färbung ihrer Randpartien gegen die kräftig grün gefärbte vegetative Thallusfläche ab. Ein gelblicher Saum deutet auf männliche, ein olivgrüner auf weibliche Pflanzen hin, während Sporophyten einen dunkelgrünen Rand haben. Die Schwärmerbildung erfolgt periodisch.

Fertile Ulva ist ein beliebres Objekt zur Demonstration der verschiedenen Fortpflanzungszellen. Am besten sammelt man schon am Standort etwa 20 fertile Pflanzen einzeln in Röhrengläser oder Plastikbeutel und verwahrt sie darin mehrere Stunden oder über Nacht. In Schalen mit Seewasser übertragen, entleeren sich die Gametangien bzw. Zoosporangien; die ausgeschwärmten Partien bleiben als farbloser Saum gegen den vegetativen Thallus abgegrenzt (A). Schwärmersäume am Lichtrand enthalten Gameten; nach ihrer gelblichen oder olivgrünen Färbung lassen sie sich leicht den Geschlechtern zuordnen. In einem Tropfen zusammengebracht, vereinigen sich die zweigeißeligen Gameten unter Gruppenbildung zu anisogamen Pärchen (G); die Zygoten sind negativ phototaktisch und schwimmen zum hinteren Tropfenrand. In den Schalen mit Sporophyten sammeln sich die viergeißeligen Zoosporen am hinteren Rand an. 

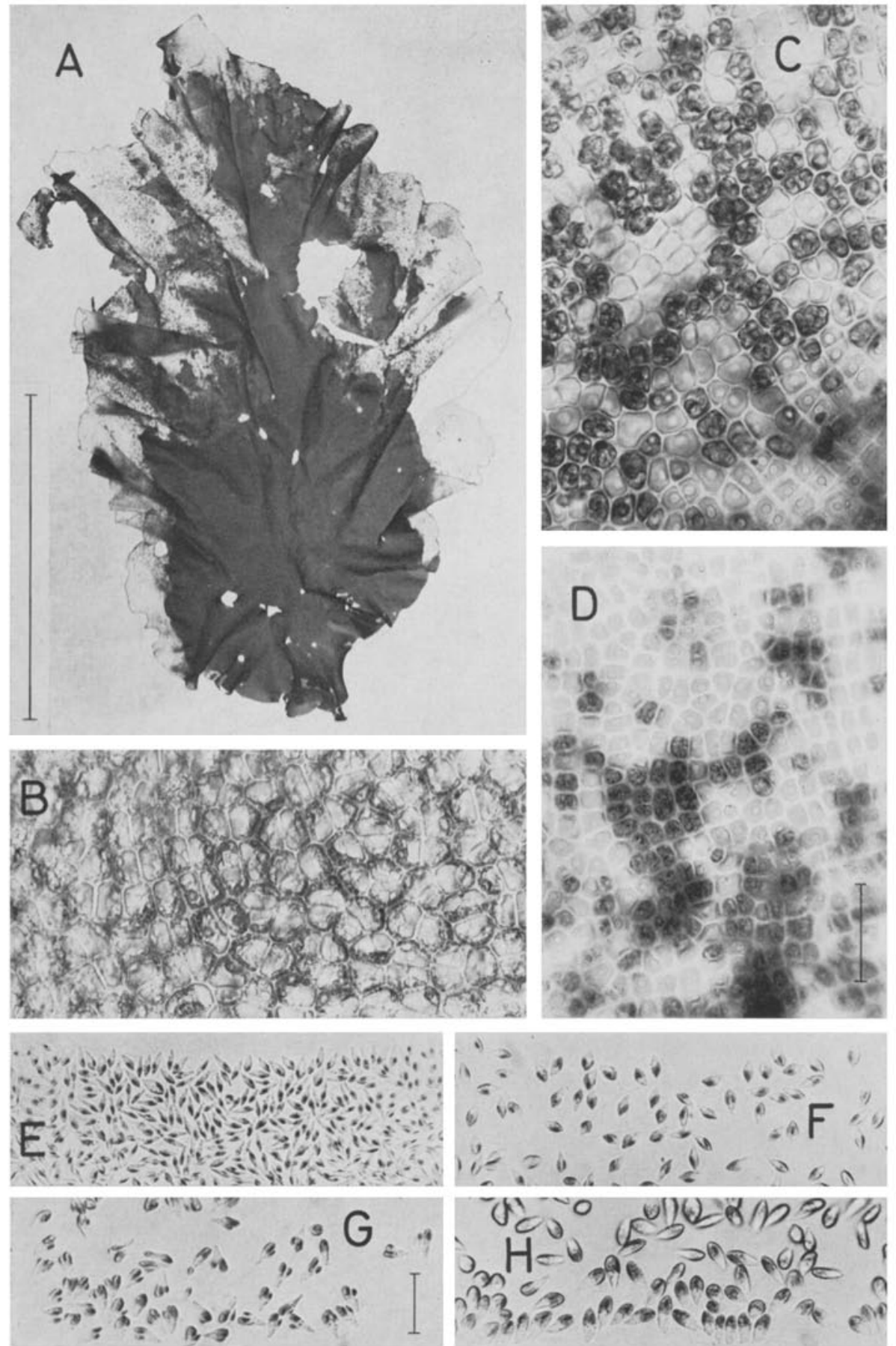

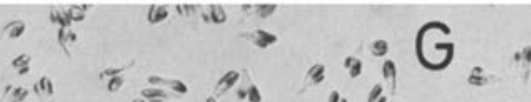

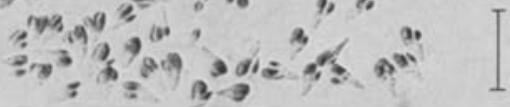

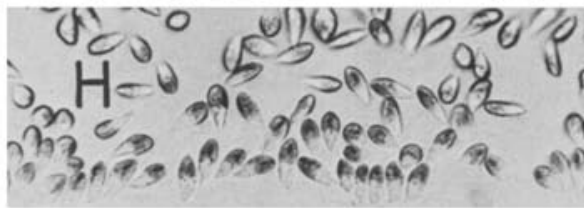

Abb. 28: Ulva lactwca. A Untergetauchter Thallus kurz nach dem Ausschwärmen (30.8. 1974), $B-D$ Aufsicht auf den vegetativen Thallus, die fertile Zone eines Sporophyten und einer männlichen Pflanze. E-H Männliche und weibliche Gameten, Kopulanten und Zoosporen. Maßstredken: $\mathrm{A}=10 \mathrm{~cm} ; \mathrm{B}-\mathrm{D}=50 \mu \mathrm{m} ; \mathrm{E}-\mathrm{H}=20 \mu \mathrm{m}$ 
Für die mikroskopische Untersuchung des fertilen Thallus wählt man Randstücke aus, in denen noch Schwärmer in einzelnen Zellen verblieben sind. Die Zoosporangien (C) enthalten wenige große Schwärmer, verglichen mit den kleinen männlichen Gameten (D). Ganz deutlich sind die runden Austrittsöffnungen in der Außenwand der leeren Zellen zu erkennen. Nur in den größten Sporangien liegen sie annähernd in der Mitte der Zellwand; in vielen Fällen sind sie einander paarweise genähert. Solche Zellen sind nach gerade erfolgter Teilung gleichsam von der Fertilisierung "überrascht" worden.

Die Abbildungen $\mathrm{E}$ bis $\mathrm{H}$ zeigen männliche und weibliche Gameten, die anisogamen Kopulanten sowie Zoosporen, alle lebend am Rand flacher Tropfen aufgenommen. Zygoten und Zoosporen wachsen unmittelbar zu einem zunächst einreihigen Keimling aus. Er wird durch Längsteilung der Zellen röhrig; durch Abflachung des Keimlings und Verwachsung seiner inneren Zellwände entsteht der zweischichtige Gewebethallus.

Die Fähigkeit zur parthenogenetischen Keimung der männlichen und weiblichen Gameten ist zur feststehenden Lehrmeinung in der Literatur über die Entwicklung von Ulva geworden. Sie trifft aber in dieser Verallgemeinerung nicht zu. Zwar erhält man in Kulturen mit entsprechenden Mengen von Gameten reichlich Keimlinge. In einem Tropfen von "normaler" Dichte gehen aber fast alle männlichen Gameten zugrunde; von 1000 gelangt vielleicht einer zur Keimung. Sehr wahrscheinlich sind dies einzelne der dickeren Schwärmer, die man stets zwischen den Gameten antriff (E). Auch von den weiblichen Gameten keimen nur wenige, jedoch mehr als in vergleichbaren Kulturen männlicher Gameten. Für das mehrfach beobachtete Oberwiegen männlicher Geschlechtspflanzen gegenüber weiblichen und Sporophyten in natürlichen Populationen gibt es keine Erklärung. Von 20 am 17. September 1975 gesammelten Pflanzen erwiesen sich 15 als männliche, 2 als weibliche Gametophyten und 2 als Sporophyten, eine schwärmte nicht.

\section{Ulva curvata (Kütz.) De Toni}

Ulva curvata ist nicht so häufig wie die vorige Art und kann daher auch nicht planmäßig gesammelt werden. Jedoch wird dem aufmerksamen Beobachter die Eigenart von Ulva curvata in einer Algenprobe auffallen, etwa vom Bewuchs einer Boje, von einer der Landungstreppen, von Steinen vor der Kurpromenade oder auch vom Felswatt der Südwestseite.

Die Pflanzen sind meist nur 5-8 cm groß, dunkelgrün und ziemlich eben, also nur wenig gewellt. Im allgemeinen wird man in einer Population auch bogig gekrümmte, schmale Exemplare finden, die das im Namen herausgestellte Merkmal zeigen; oft sind sie aber rundlich oder zweiteilig und haben einen herzförmigen Grund. Ein wesentliches Kennzeichen dieser Art ist die auffallend scharfe Abgrenzung der vegetativen gegen die ausgeschwärmte Thallusfläche. Ulva curvata hat isomorphen Generationswechsel wie $U$, lactuca.

Unter der Bezeichnung Ulva latissima f. nana Subr wurde die Art schon von Kuckudk (1894) angegeben und ganz treffend abgebildet. Auch die von Schiller (1928) veröffentlichten Figuren lassen keinen $Z$ weifel an der Identität dieses vermeintlich für 

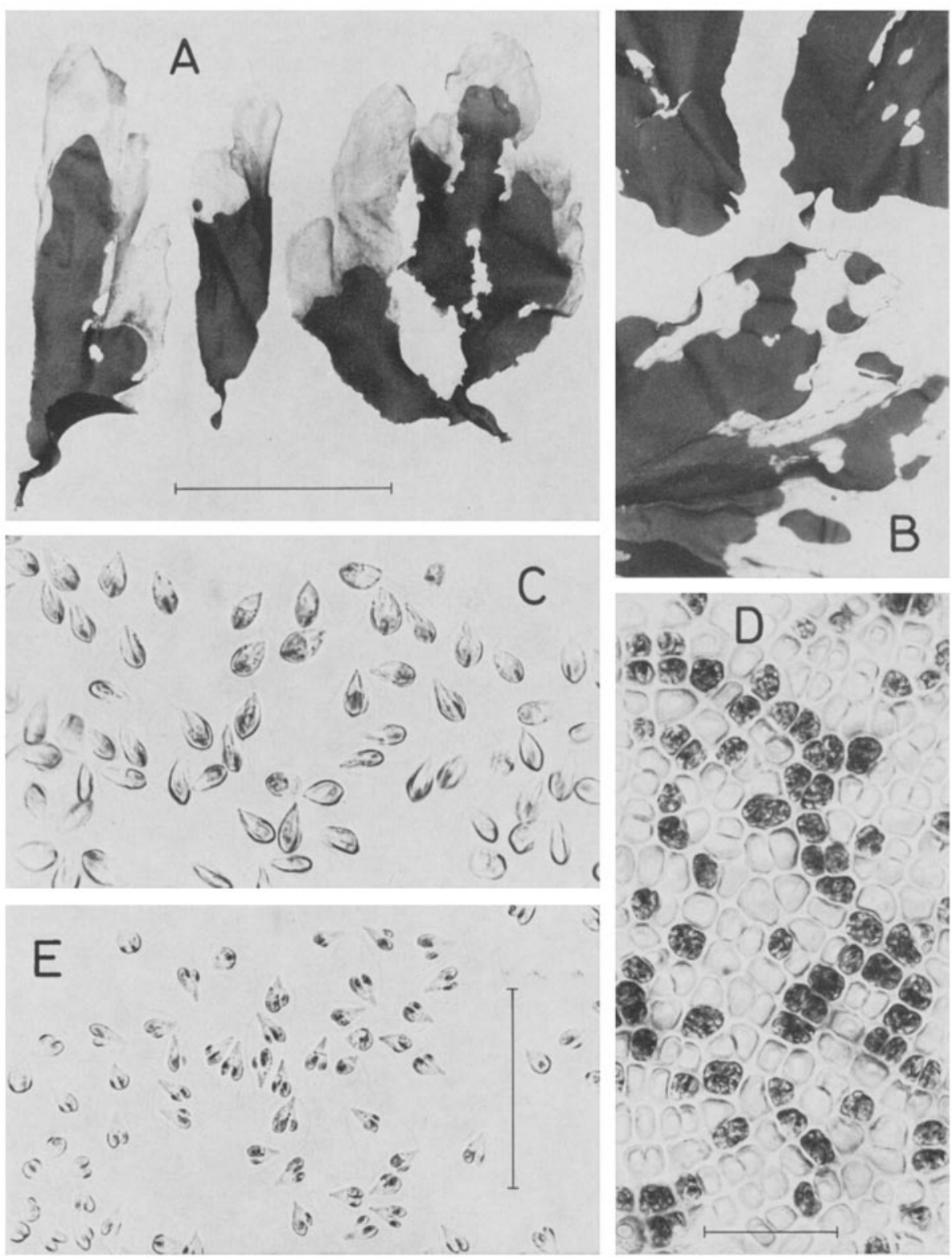

Abb. 29: Ulva curvata. A Fertile, frisch schwärmende Pfanzen. B Pflanzen mit herzförmigem Grund; vegetative Abschnitte - auch Inseln - scharf gegen ausgesdwärmte Flächen abgegrenzt. C Zoosporen. D Aufsicht auf einen weiblichen Thallus. E Kopulanten. Maßstrecken: A, B = $5 \mathrm{~cm} ; \mathrm{D}, \mathrm{C}$ und $\mathrm{E}$ jeweils $=50 \mu \mathrm{m}$ 
Helgoland neuen Fundes von Ulva curvata. Schließlich wurde sie von O. C. Schmidt (1936) unter dem Namen Ulva kuckuckiana als neue Art beschrieben, doch hat er in seiner späteren Arbeit (1938) die Identität mit Ulva curvata nicht bemerkt.

Bei dieser lange Zeit unklaren Lage schien es zweckmäßig, die etwas einseitige Auswahl von Habitusbildern der Abbildung 29 durch ein umfangreicheres Material zu ergänzen. Die Aufsammlung in Abb. $30 \mathrm{~A}$ ist vegetativ, nur an einer Pflanze ist ein entleerter Thallusabschnitt gut zu erkennen. Zweifellos haben die meisten Exemplare schon einmal oder wiederholt geschwärmt. Mit dem Verlust der ausgeschwärmten Zone kann eine Pflanze ihre Form und Größe von einem Tag zum anderen stark verändern, wie Abb. 30 B sehr anschaulich zeigt. Mehr als die Hälfte der Fläche kann mit scharfer Begrenzung abgelöst werden; die verbleibenden Reste haben danach im allgemeinen die Größe der Aufsammlung bei A. Wahrscheinlich erreichen die Pflanzen vor der nächsten Fertilisierung wieder ihre vorherige Größe.
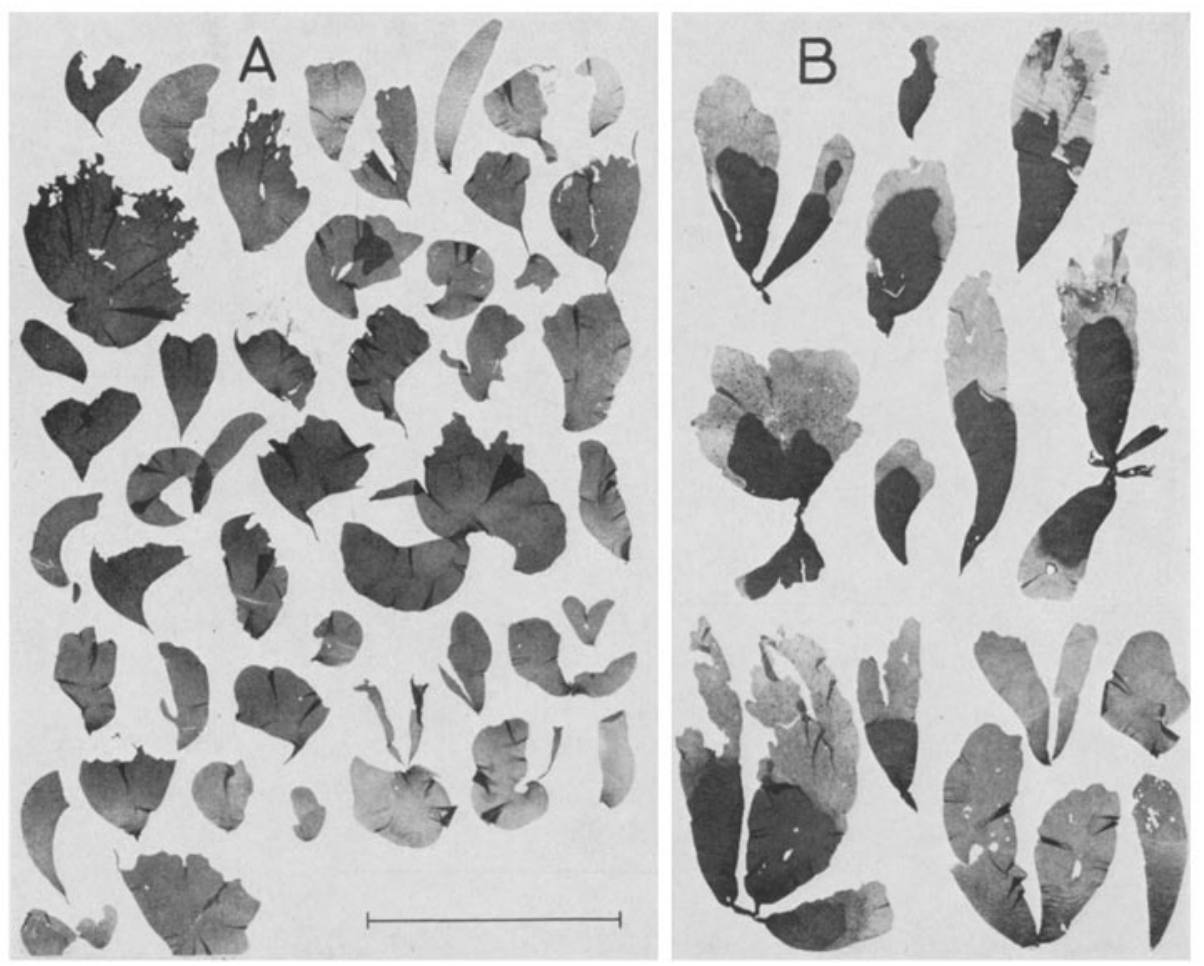

Abb. 30: Ulva curvata. A Herbarblatt vom 18. 9. 1974. B Herbarblatt vom 16. 11. 1958. Die ungewöhnlich kräftige Färbung der ausgeschwärmten Thallusabschnitte ist durch einen Niederschlag aus dem stark durch tonige Teilchen getrübten Wasser bedingt. Maßsstrecke $=10 \mathrm{~cm}$ 


\section{Enteromorpha Link}

Gattungsmerkmal ist, wie der Name zum Ausdruck bringt, der röhrige Thallus; seine Wandung ist einschichtig. Eine vermittelnde Stellung zu Ulva nimmt Enteromorpha linza ein, deren Thallus mit Ausnahme eines hohlen basalen Abschnittes und des Randsaumes zweischichtig ist. Die Arten dieser Gattung sind außerordentlich vielgestaltig, wobei sich die ökologischen Faktoren des jeweiligen Standorts, Nährstoffangebot und Wasserbewegung sowie die jahreszeitlich schwankenden Licht- und Temperaturverhältnisse auswirken. Es ist daher nicht verwunderlich, daß eine große Zahl von Enteromorpha-Arten beschrieben worden ist, von denen sich viele als synonym erwiesen haben. Bliding (1963) hat die Gattung umfassend und kritisch bearbeitet und in sieben Gruppen eingeteilt. Bei einigen Arten werden Unterarten und Varietäten oder Typen unterschieden, die völlig verschieden aussehen können. Die Bestimmung nach äußeren Merkmalen wird daher in vielen Fällen nicht $\mathrm{zu}$ einem gesicherten Ergebnis führen; die Kenntnis der Fortpflanzungsverhältnisse ist oft für die Identifizierung der Arten und die genetische Zusammengehörigkeit verschieden aussehender Typen der gleichen Art unerläßlich. Im Lebenszyklus stehen getrenntgeschlechtliche Gametophyten mit gleichgestalteten Sporophyten in einem Generationswechsel; bei einigen Arten folgen nur ungeschlechtlich sich vermehrende Generationen aufeinander.

Die im Folgenden dargestellten Enteromorpha-Arten erschöpfen sicherlich nicht den Formenreichtum des Gebietes um Helgoland. Es sind Arten ausgewählt, die man hier antreffen und auch mit einiger Sicherheit bestimmen kann. Für eine eingehendere Beschäftigung mit dieser Gattung sei auf die Arbeit von Bliding (1963) verwiesen.
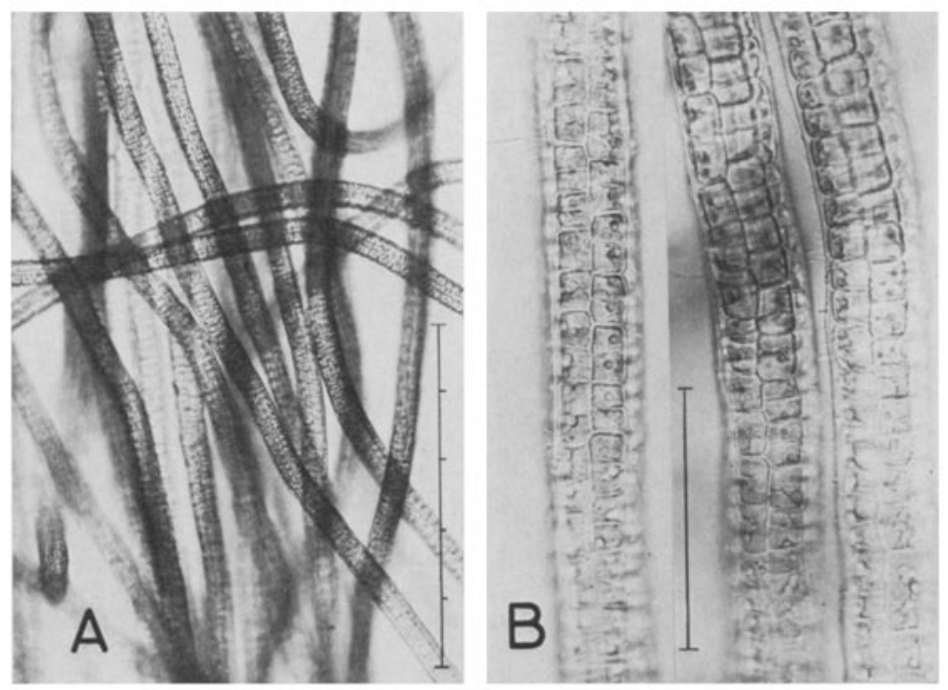

Abb. 31: Enteromorpha torta (2. 7. 1969). Maßstredken: $\mathrm{A}=500 \mu \mathrm{m} ; \mathrm{B}=100 \mu \mathrm{m}$ 


\section{Enteromorpba torta (Mert. in Jürg.) Reinb.}

Nur in dem ruhigen Wasser der Hafenbecken wurde diese Art von Mai bis September gesammelt. Die dünnen, unverzweigten Fäden bilden teppichartige Lager auf Trümmersteinen nahe der Niedrigwasserlinie oder wachsen als wattige Stränge an Bojen und umschlingen deren Haltetaue. 3 bis 8, mitunter auch bis 12 Reihen von Zellen umschließen das sehr enge Lumen der dünnen Fäden. Die Chromatophoren tragen im allgemeinen nur einen Pyrenoid (Abb. 31).

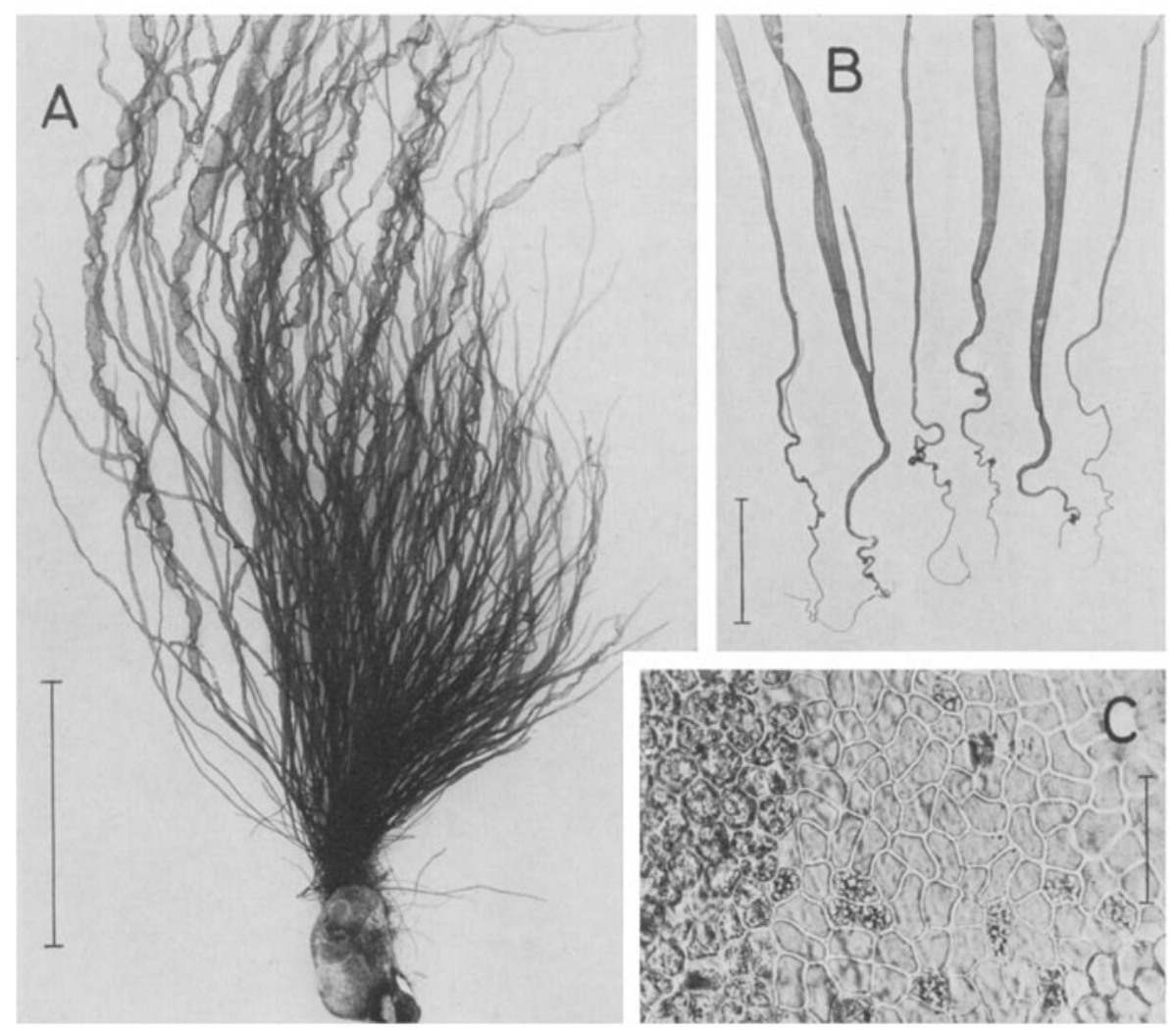

Abb. 32: Enteromorpha prolifera. A Pflanzen auf einem eingesandeten Stein (25. 6. 1970). B Unregelmäßig spiralig gewundene Basalteile. C Übergangszone eines fertilen Gametophyten. Maßsstrecken: $\mathrm{A}=5 \mathrm{~cm} ; \mathrm{B}=1 \mathrm{~cm} ; \mathrm{C}=50 \mu \mathrm{m}$ 
Enteromorpha prolifera (O. F. Müll.) J. Ag.

An dem unregelmäßig spiralig gewundenen Basalabschnitt, der sich zumindest bei einem Teil der Pflanzen finden läßt, ist Enteromorpha prolifera leicht und sicher zu erkennen. Abbildung 32 B zeigt die Basen einiger von einem Stein abgelösten Exemplare. Auch der in Einzahl vorhandene Pyrenoid gehört zu den Merkmalen der Art.

Enteromorpha prolifera bildet von April bis September im mittleren bis unteren Litoral stellenweise ausgedehnte reine Bestände, z. B. auf dem Felswatt im Nordosten der Insel. Man findet sie aber auch auf dem Sandstrand der Düne, auf Steinen sitzend, die in den Sand eingespült sind (A).

Die im allgemeinen nur schwach verzweigten Pflanzen sind durchschnittlich 15 bis $35 \mathrm{~cm}$ lang und meist unter $1 \mathrm{~cm}$ breit. Unter günstigen Bedingungen können die Thalli auch bis $1 \mathrm{~m}$ lang werden.

Fertile Einzelpflanzen sind wie Ulva geeignet, um die verschieden großen männlichen und weiblichen Gameten sowie die wesentlich größeren Zoosporen zu zeigen.

\section{Enteromorpha flexuosa (Wulf. ex Roth) J. Ag.}

In der flexuosa-Gruppe mit mehreren Arten unterscheidet Bliding (1963) allein bei Enteromorpha flexuosa 5 Unterarten, die im Habitus wie auch hinsichtlich ihrer Fortpflanzung voneinander abweichen. Dieses Beispiel zeigt eindringlich, wie schwierig die Bestimmung dieses Komplexes ist. Gruppenmerkmal ist die durchschnittliche Zweizahl der Pyrenoide (Abb. 33 D), während die Chromatophoren der clatbrata-Gruppe oft drei und mehr Pyrenoide tragen (Abb. 34 C).

Ein Büschel von fünf an ihrer Basis zusammenhaftenden Pflanzen mit den morphologischen Merkmalen von Enteromorpba flexuosa subsp. flexwosa ist bei A dargestellt. Die zarten Algen können 30-40 cm lang werden; die an den Enden 1-2 mm breiten Hauptachsen sind locker mit fadenartig dünnen, meist einfachen Verzweigungen besetzt. Die Zellen sind, zumindest in den schmaleren Abschnitten, ziemlich groß und rechteckig; ihr zylinderförmiger Chromatophor kleidet die Wand nur teilweise aus. In vielen Zellen sind 2 Pyrenoide deutlich zu erkennen $(C, D)$.

Eine Probe fertiler Pflanzen enthält in der Regel Gametophyten und Sporophyten. Die Kopulanten sind schwach anisogam (F), die Zoosporen (E) ganz erheblich größer als die Gameten.

Enteromorpha flexuosa findet man in den Sommermonaten als dichten, glatten Bewuchs auf Steinen im unteren Litoral, im Gebiet des Südhafens und auch auf der Düne. 

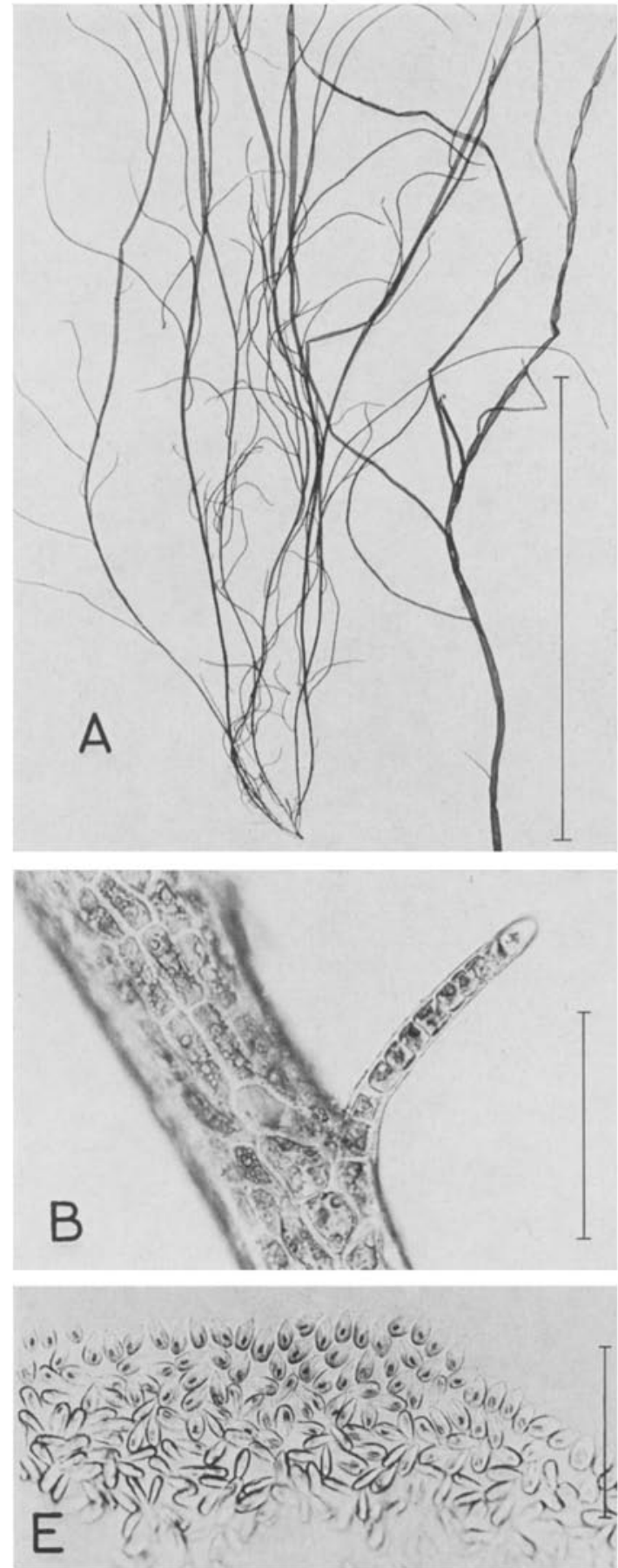
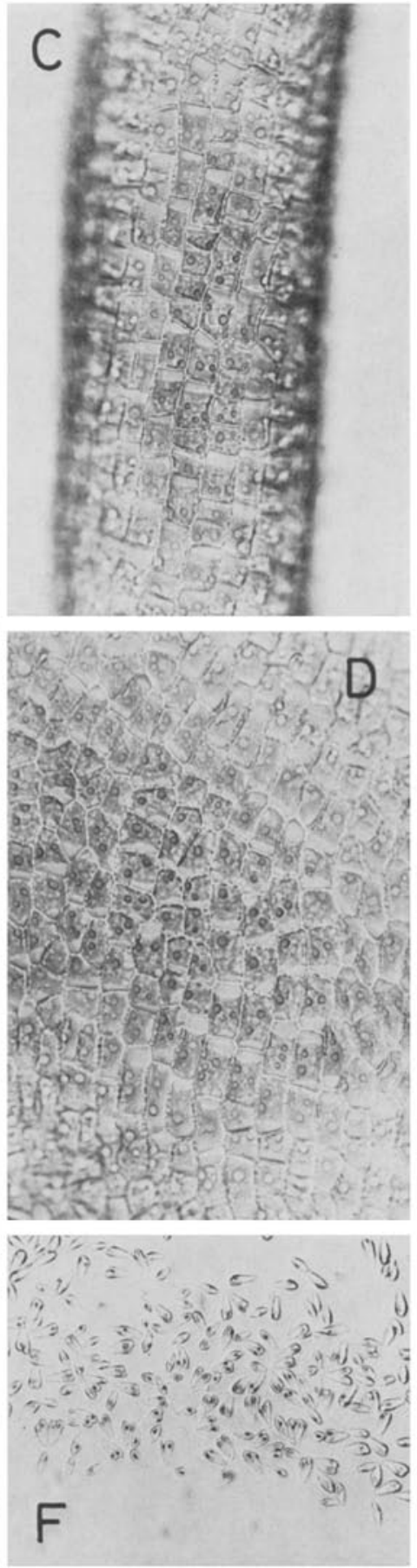

Abb. 33: Enteromorpha flexuosa. A Büschel von 5 Pflanzen (17. 7. 1972). B Thallusabschnitt mit Verzweigung. C, D Zellenanordnung in einem schmalen und einem breiteren Thallusstück. $\mathrm{E}, \mathrm{F}$ Zoosporen und anisogame Kopulanten. Maßstrecken: $\mathrm{A}=5 \mathrm{~cm} ; \mathrm{B}-\mathrm{D}=100 \mu \mathrm{m}$; $\mathrm{E}, \mathrm{F}=50 \mu \mathrm{m}$ 

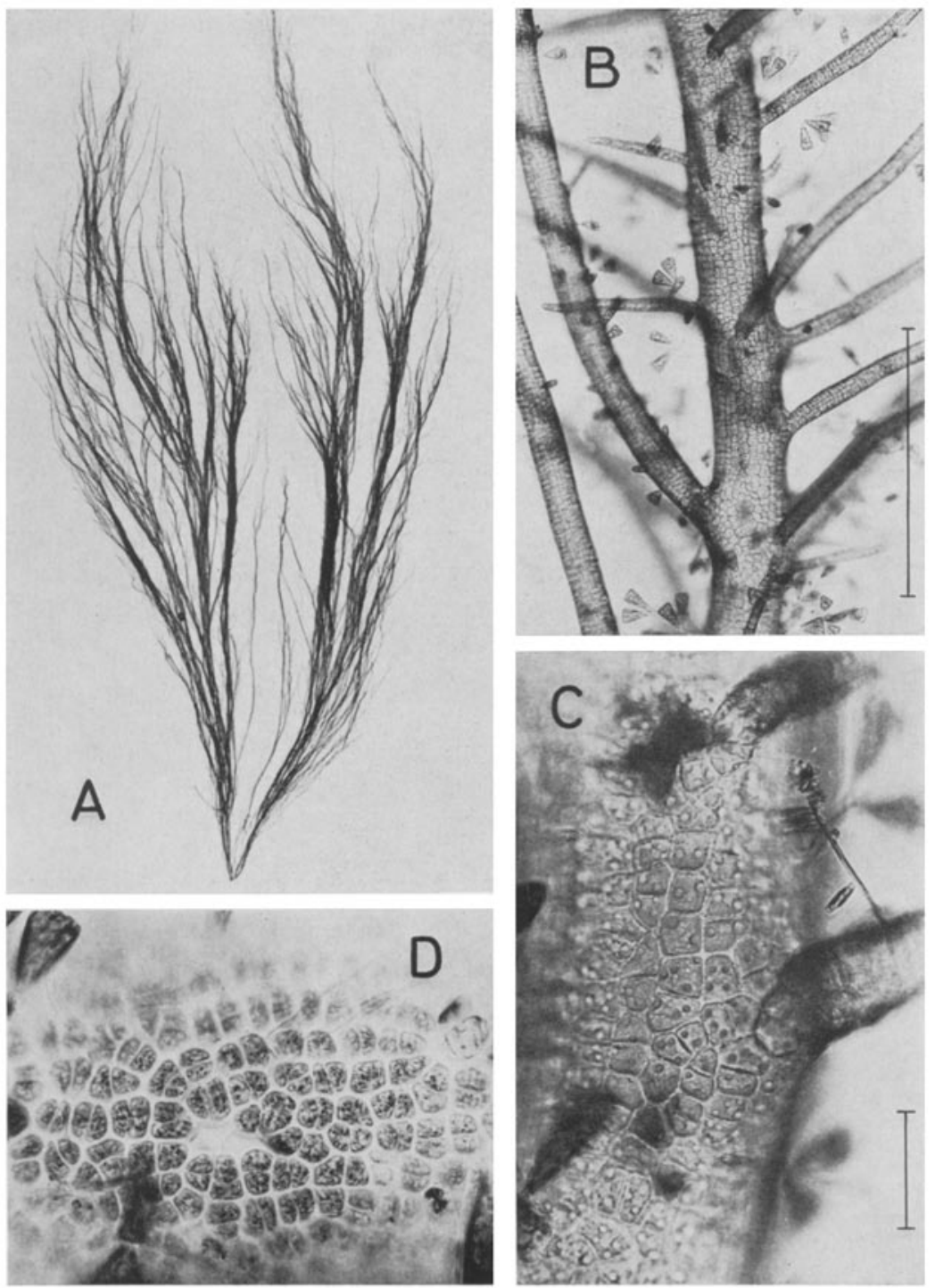

Abb, 34: Enteromorpba clatbrata. A Büschel von 4 Pflanzen, etwa natürliche Größe (Herbarblatt yom 2. 7. 1964). B Ausschnitt aus der verzweigten Hauptachse (17. 9. 1969). C Zellen mit mehreren Pyrenoiden. D Fertiler Gametophyt. Maßstrecken: B $=0,5 \mathrm{~mm} ; \mathrm{C}, \mathrm{D}=50 \mu \mathrm{m}$

\section{Enteromorpha clatbrata (Roth) Grev.}

Die sehr feinfädige Art wird 10-15 cm hoch. Ihre durchgehende Hauptachse ist dicht mit wiederholt verzweigten dünneren Astchen besetzt (A, B). Die besonders im Hauptstamm recht großen Zellen enthalten einen gelappten oder leicht zerschlitzten Chromatophor, an dem in vielen Fällen 3-5 Pyrenoide zu finden sind.

Enteromorpba clatbrata wächst gern an ruhigen Plätzen und erscheint in dichter Lagerung dunkelgrün. 
Enteromorpha linza (L.) J. Ag.

Diese von April bis September häufige und leicht identifizierbare Art ist in Form und Größe recht variabel. Riesenexemplare können in stark nährstoffreichem Wasser bis zu $1 \mathrm{~m}$ lang und $10 \mathrm{~cm}$ breit werden; solche Pflanzen kann man im Juli nach länger anhaltendem ruhigen Wetter auf dem Felswatt im Nordosten finden, bei denselben Bedingungen, unter denen auch Ulva zu ungewöhnlicher Größe heranwächst. Im allgemeinen aber sind die zartgrünen, am Rande wellig faltigen Thalli etwa $25-30 \mathrm{~cm}$ lang und $3 \mathrm{~cm}$ breit (A). Jüngere Exemplare sind ebener, ihr Thallus ist mehr oder weniger gedreht $(B, C)$. Ältere Exemplare schließlich, auf die basalen Abschnitte reduziert, nehmen den Habitus wie bei D an. Enteromorpha linza ist unverzweigt, ihre Basis verjüngt sich in einen schmalen, hohlen Stiel und sitzt dem Substrat mit einer punktförmigen Haftscheibe auf. Die fest miteinander verwachsenen Schichten der Thallusfläche trennen sich nur in einem schmalen hohlen Saum am Rand (E).

Enteromorpha linza vermehrt sich nur durch viergeißelige, schlanke Zoosporen von sehr unterschiedlicher Größe (G), Gelegentlich findet man zwischen ihnen auch einzelne zweigeißelige Schwärmer.

\section{Die intestinalis-Gruppe}

Zwischen der unverzweigten Enteromorpha intestinalis und spärlich bis wiederholt verzweigten Formen von $E$. compressa besteht äußerlich ein fließender Übergang. Bei beiden Arten liegen die Zellen im Thallus ungeordnet; der Chromatophor trägt einen Pyrenoid, der im allgemeinen nahe der äußeren Zellwand liegt und daher meist deutlich erkennbar ist.

Der taxonomische Status des E. intestinalis/compressa-Komplexes war kürzlich Gegenstand einer experimentellen Untersuchung (De Silva \& Burrows, 1973) mit dem Ergebnis, daß die beiden Taxa trotz bestehender Intersterilitätsschranken nicht getrennt werden können. Da der Artname intestinalis Priorität hat, wurden die unverzweigten und verzweigten Pflanzen als Unterarten intestinalis und compressa unterschieden.

Dieser Auffassung schließen wir uns nicht an, sondern betrachten die unverzweigten Formen mit vorwiegend fleckenweiser Fertilisierung und die verzweigten mit zonenweise basal fortschreitender Fertilisierung als getrennte Arten.

Abb. 35: Enteromorpha linza, A-D Variabilität der Erscheinungsform: A Pflanzen mit stark gewelltem Rand (30.6.1971). B Junge, noch ziemlich glatte Thalli (20. 5. 1972). C Schraubig gewundene, fertile Pflanzen (1. 4. 1971). D Auf die Basalabschnitte reduzierte Exemplare (7. 7. 1970). E Querschnitt durd den Thallusrand. F Aufsicht auf den Thallus, fertile Zone scharf abgegrenzt. $\mathrm{G}$ Zoosporen. Maßstrecken: $\mathrm{A}-\mathrm{D}$ jeweils $=3 \mathrm{~cm} ; \mathrm{E}=100 \mu \mathrm{m} ; \mathrm{F}, \mathrm{G}=$ $50 \mu \mathrm{m}$ 


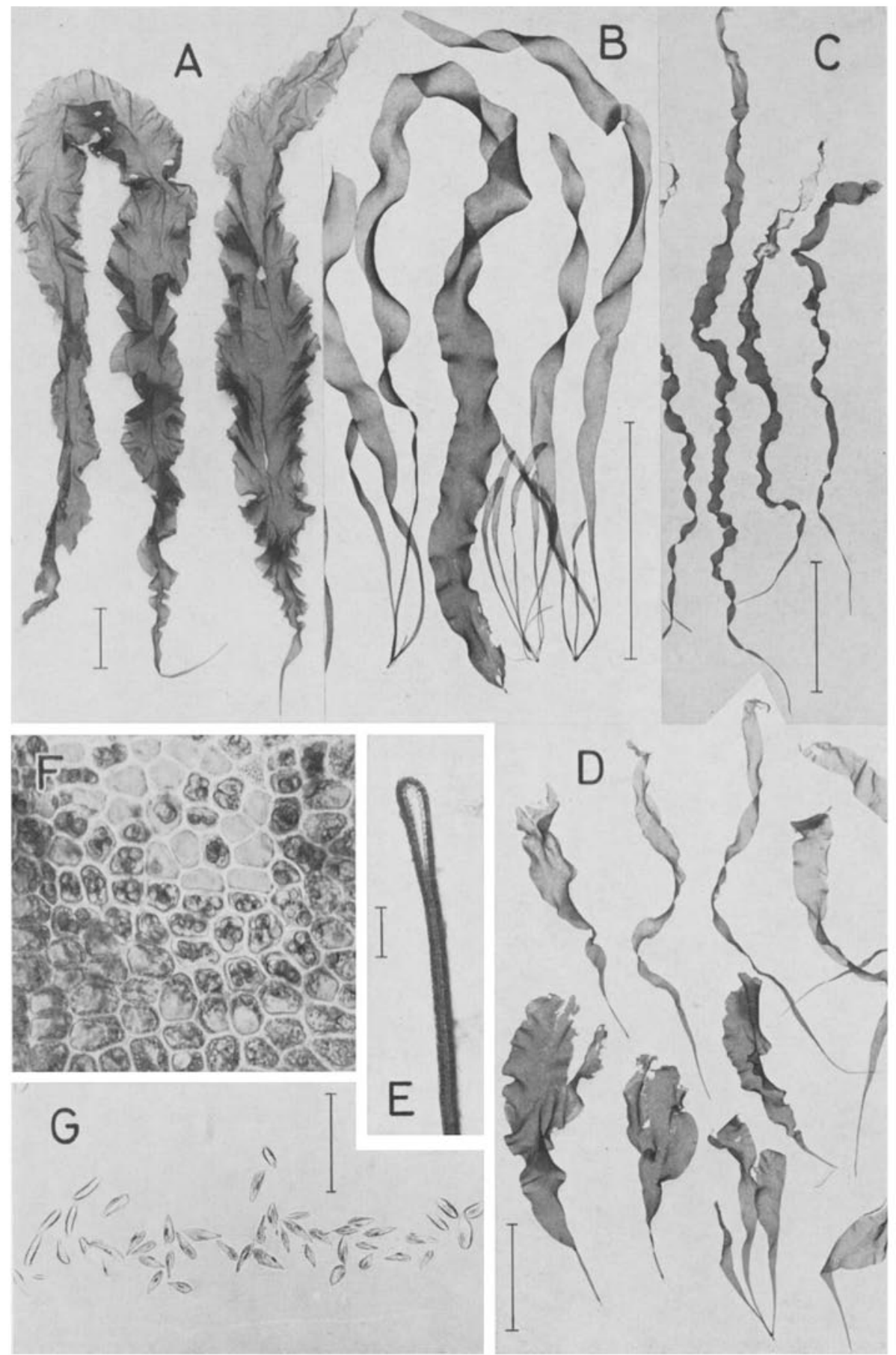



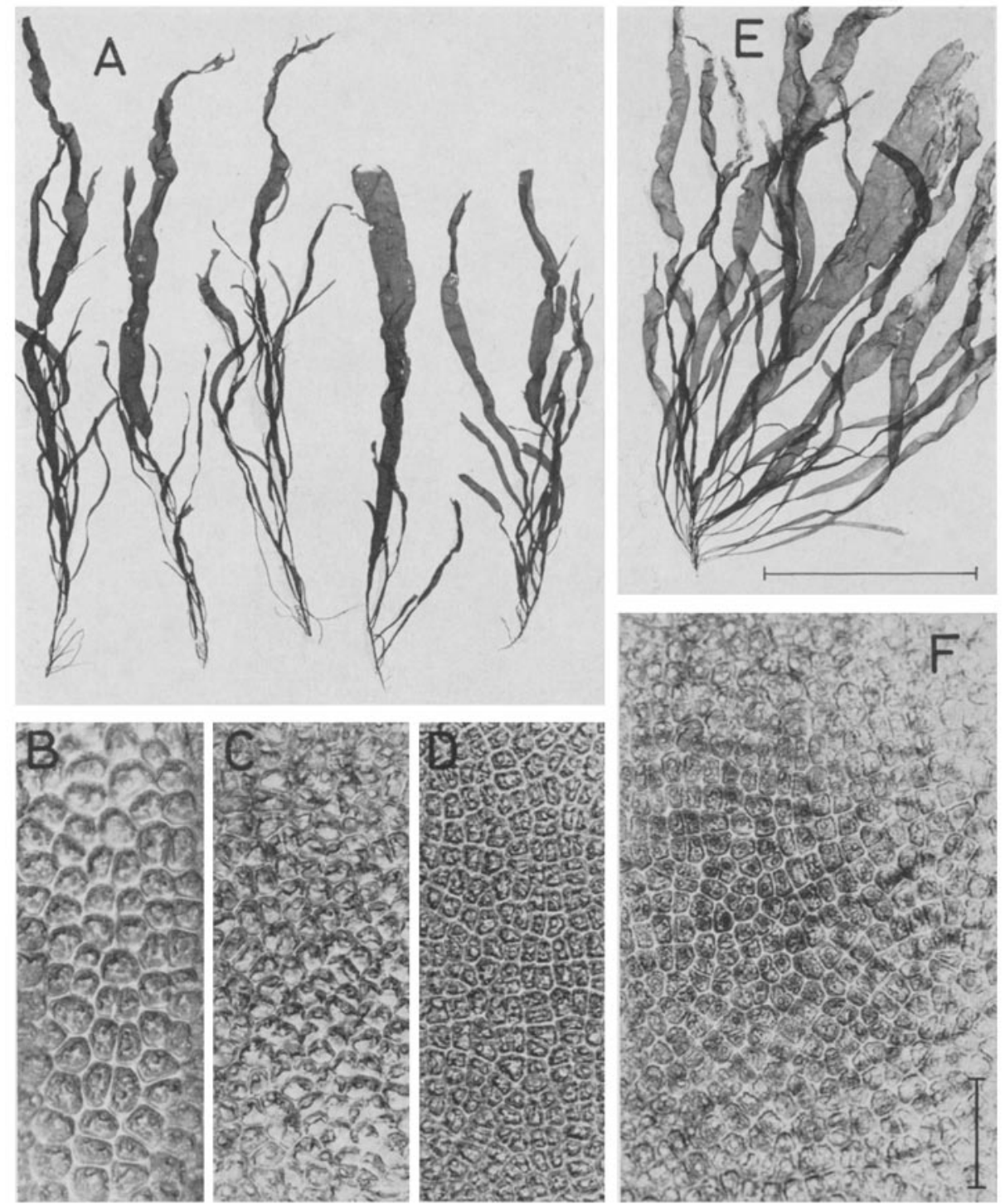

Abb. 36: Enteromorpha compressa. A Pflanzen einer Aufsammlung (1.9. 1976). B-D Zellen aus einer dieser Pflanzen: B Etwa $4 \mathrm{~mm}$ oberhalb der Basis eines Zweiges, $\mathrm{C}$ aus einer schmalen und D aus einer breiten Thallusfläche. E, F Breiteres, fertiles Exemplar (8. 8.1970) und Zeflen aus der breiten Zellfläche. Maßsstrecken: $A, E=5 \mathrm{~cm} ; \mathrm{B}-\mathrm{D}, \mathrm{F}=50 \mu \mathrm{m}$ 

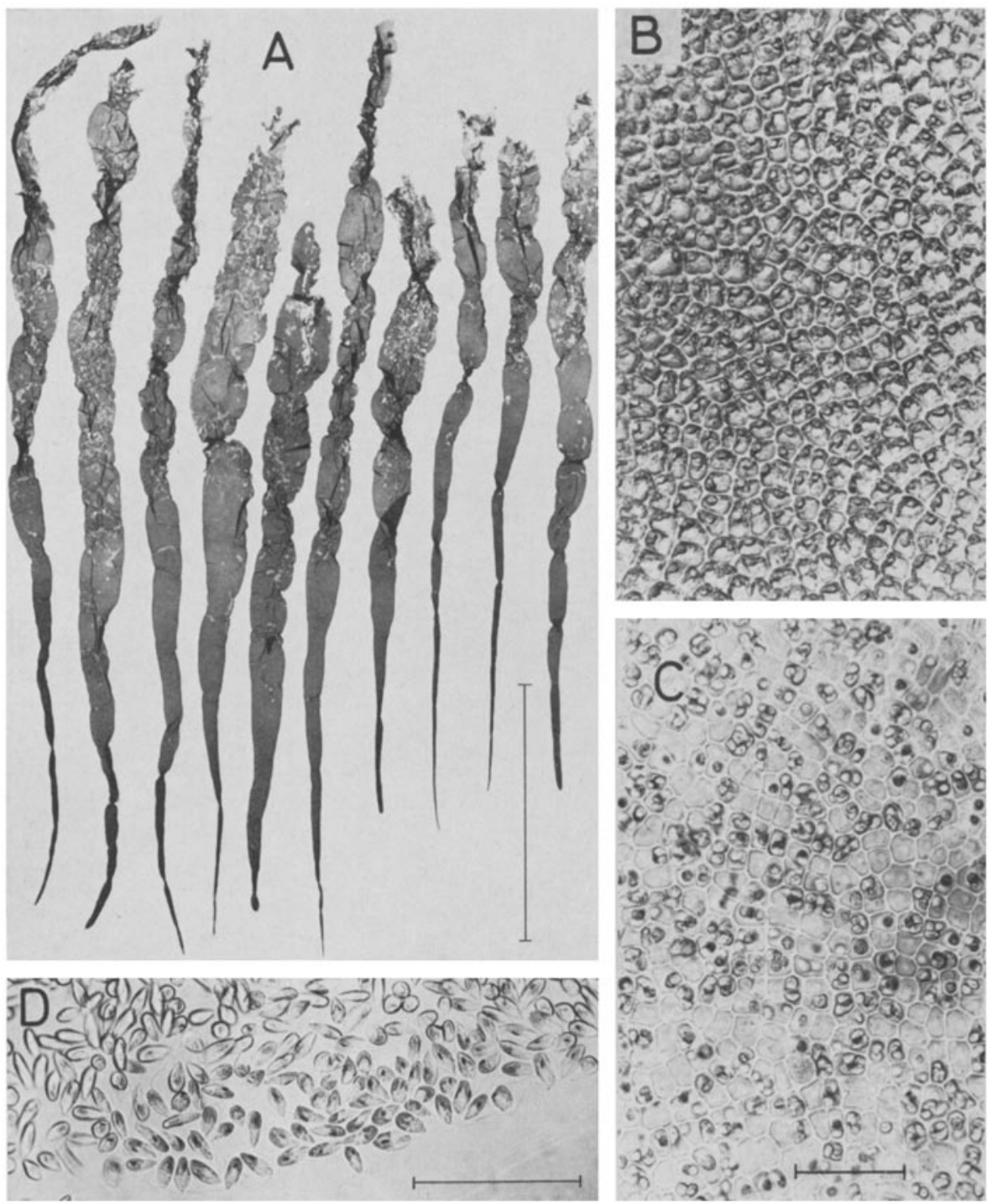

Abb. 37: Enteromorpha intestinalis var. asexualis. A Habitus, Pflanzen vom Oststrand vor der Kurpromenade (12. 8. 1972). B, C Aufsicht auf den vegetativen und fertilen Thallus. D Zoosporen. Maßstrecken: $A=10 \mathrm{~cm} ; \mathrm{B}, \mathrm{C}$ und $\mathrm{D}=$ jeweils $50 \mu \mathrm{m}$ 


\section{Enteromorpha compressa (L.) Grev.}

Die Pflanzen der Abbildung $36 \mathrm{~A}$ entstammen derselben Aufsammlung und zeigen wie das Exemplar bei $\mathrm{E}$ ein charakteristisches Merkmal der Art, die aus dünner Basis sich verbreiternden Haupt- und Seitenachsen. Der abgeflachte dunkelgrüne Thallus ist stellenweise leicht aufgetrieben. Das Zellennetz zeigt in den breiten Teilen eine undeutliche Längs- und Querreihung (F). Die oft sehr schön phototaktisch einer Zellwand genäherten Chromatophoren tragen einen Pyrenoid. In dieser Beziehung stimmen sie gut mit $E$. intestinalis überein. Die Größe der Zellen schwankt in verschiedenen Abschnitten desselben Thallus erheblich (B-D, vgl. Legende), wie das auch bei anderen Arten der Fall ist und hier an einem Beispiel veranschaulicht wird.

Im unteren Litoral, aber auch in Wassertümpeln in höherem Niveau kommt Enteromorpha compressa in Beständen gleichartiger Pflanzen vor. Das Fehlen unverzweigter intestinalis-Formen spricht für die Spezifität der beiden Arten.

\section{Enteromorpha intestinales (L.) Link}

Diese Art wurde bei Helgoland nur in ihrer var. asexualis gefunden, die sich durch ungeschlechtliche viergeißelige Zoosporen vermehrt (Abb. 37). Die unverzweigten Pflanzen ähneln in ihrer äußeren Form Enteromorpha linza, sind aber kräftiger grün und derbwandiger. Der Thallus ist mitunter an mehreren Stellen eingeschnürt. Die Fertilisierung schreitet im allgemeinen nicht von oben nach unten fort, sondern es grenzen kleinere Partien von verschieden weit fortgeschrittener Fertilisierung mosaikartig aneinander.

Die bis $40 \mathrm{~cm}$ große Alge wurde in den Sommermonaten zwischen Ulva auf Steinen wachsend vor der Kurpromenade, auf der Düne und auf dem Felswatt an der Südwestseite gefunden.

\section{Blidingia minima (Näg. ex Kütz.) Kylin}

Sie ist an der Hochwasserlinie weit verbreitet und kommt ziemlich regelmäßig zusammen mit Porpbyra umbilicalis vor. Als weiße Flächen erscheinen die ausgeschwärmten Pflanzen in der Standortaufnahme (A) an der senkrechten Wand einer

Abb. 38: Blidingia minima. A Standortaufnahme an der Dünenmole; die Kante des Sodkels liegt etwa in der Hodwasserlinie; nähere Erläuterung im Text. B Breite, krause Pflanzen von einer Boje (21.9.1971). C Gewöhnliche Erscheinungsform, Hafenmole (12.10.1972). D Pflanze mit Verzweigungen und Proliferationen aus der Probe von $\mathrm{C}$. E Thallus mit eingeschlossenen Luttblasen. F, G Vegetativer und fertiler Thallus. H, I Keimlinge mit leerer Embryospore und 9 Tage alte Basalscheiben. Maßstredsen: $B, C=1 \mathrm{~cm} ; \mathrm{D}, \mathrm{E}$ jeweils $=1 \mathrm{~mm} ; \mathrm{F}, \mathrm{G}=50 \mathrm{~km}$; $\mathrm{H}, \mathrm{I}=30 \mu \mathrm{m}$ 

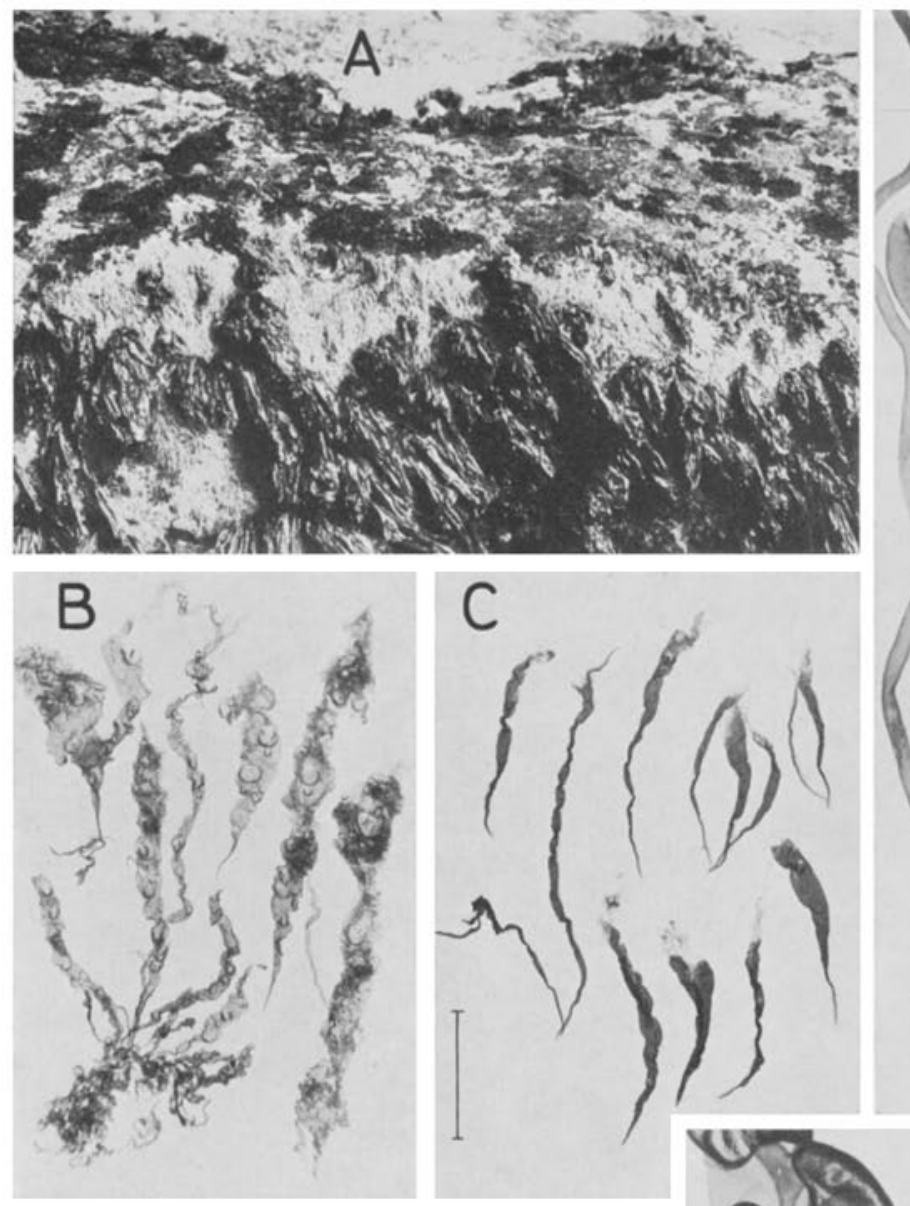

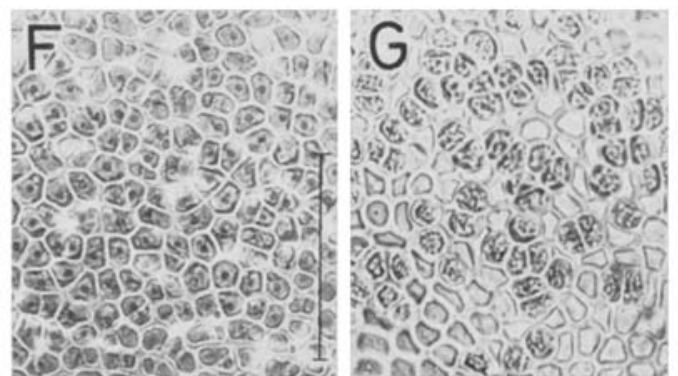
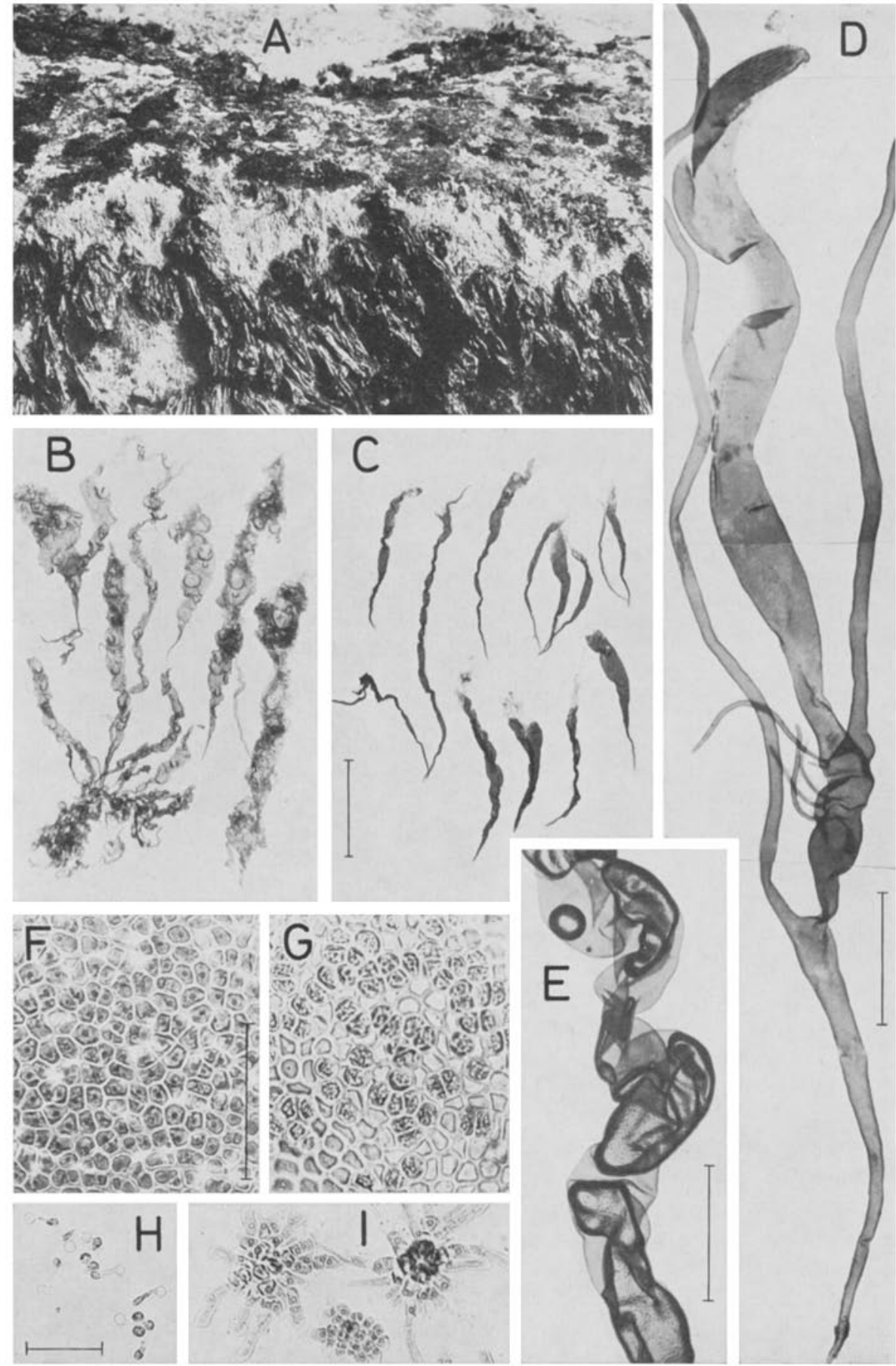
Mole oberhalb und zwischen den abstehenden Büscheln von Porphyra umbilicalis; auf der horizontalen Sockelkrone wächst Blidingia zwischen den dunklen Inseln von Prasiola stipitata. Felsblödke im entsprechenden Niveau oder die Eintauchzone von Bojen sind of dicht von einem kurzen, pelzartigen Rasen von Blidingia minima überzogen. Die im allgemeinen weniger als $3 \mathrm{~cm}$ hohen Thalli sind meist unverzweigt, doch triff man verzweigte Pflanzen in den Proben mit unterschiedlicher Häufigkeit an (D). Ziemlich breite und durch eingeschlossene Luftblasen krause Pflanzen mit einem kurzen, of deutlich abgesetzten Stiel wurden an einer Boje gesammelt (B). Dagegen verbreitern sich die an Hafenmolen wachsenden Pflanzen meist nur ganz allmählich aus ihrem hohlen Stiel und flachen sich ab (C). Das Zellnetz ist in Abhängigkeit von dem jeweiligen Standort polygonal oder rundlich-dickwandig (F, G). Der Chromatophor liegt der äußeren Zellwand an und erscheint durch die nach innen ragenden Lappen sternförmig, er trägt einen zentralen Pyrenoid.

Es sind nur ungeschlechtliche viergeißelige Schwärmer bekannt, die sich nach dem Festsetzen umbäuten. Der schlauchförmige Keimling gliedert sich von der leeren Embryospore $a b$ und entwickelt sich zu einer in der Mitte zweischichtigen Basalscheibe $(\mathrm{H}, \mathrm{I})$. Aus einem Kranz von Initialzellen erhebt sich unmittelbar der hohle aufrechte Thallus.

\section{Blidingia marginata (J.Ag.) P. Dang.}

Die flächenweise an Hafenmolen wachsenden, glattgekämmten Überzüge - Abbildung 39 A zeigt eine Probe des von der Unterlage abgelösten Belages in etwa natürlicher Größe - könnte man leicht für fadenförmige Grünalgen halten. Im mikroskopischen Bild erweisen sich die Stränge als schmale Röhren und Bänder, die nur selten wenig verzweigt sind (B). Derselbe Strang enthielt auch die bis $250 \mu \mathrm{m}$ breiten, stark gewellten oder schraubig gedrehten Thallusabschnitte bei $C$. Und schließlich endeten diese Pflanzen wieder mit einem geraden, röhrigen Abschnitt. Die Zellen sind klein, ihr sternförmiger Chromatophor trägt einen zentralen Pyrenoid (D).

Ohne eine Embryospore abzugliedern, entwickelt sich die zur Ruhe gekommene Zoospore zu einer Basalscheibe. Auf ihr entsteht der hohle aufrechte Thallus in gleicher Weise wie bei Blidingia minima (F, G).

Blidingia marginata ist eine an den Hafenmauern während des ganzen Jahres häufige Alge. Als glatt gekämmten Überzug findet man sie weit über der Hochwasserlinie an Stellen, die häufig von Wellenspritzern benetzt oder auch von auflaufenden Wellen ïberspült werden. Auf den horizontalen Flächen der Landungstreppen kommt sie im Bereich der Hochwasserlinie mitunter in ziemlich reinen Beständen vor. An schattigen Stellen der inneren Brüstungsmauern von Hafenmolen und der Uferschutzmauer besiedelt Blidingia marginata oft größere Flächen; sie wird dort zeitweilig von spritzendem Seewasser überrieselt, bleibt aber auch für längere Zeit trocken oder erhält nur Regenwasser. In solchen gelblichen bis blaßgrünen Beständen wächst sie häufig zusammen mit Rosenvingiella polyrbiza. 

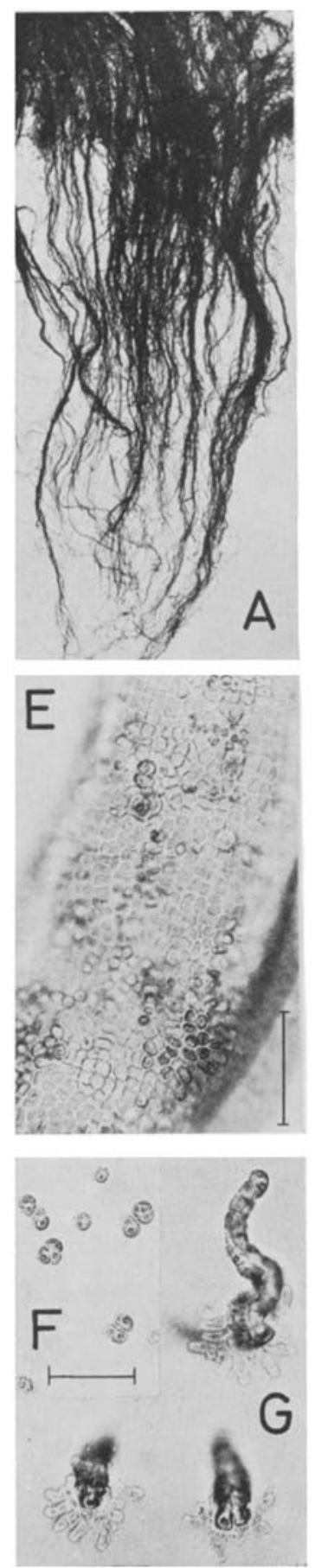
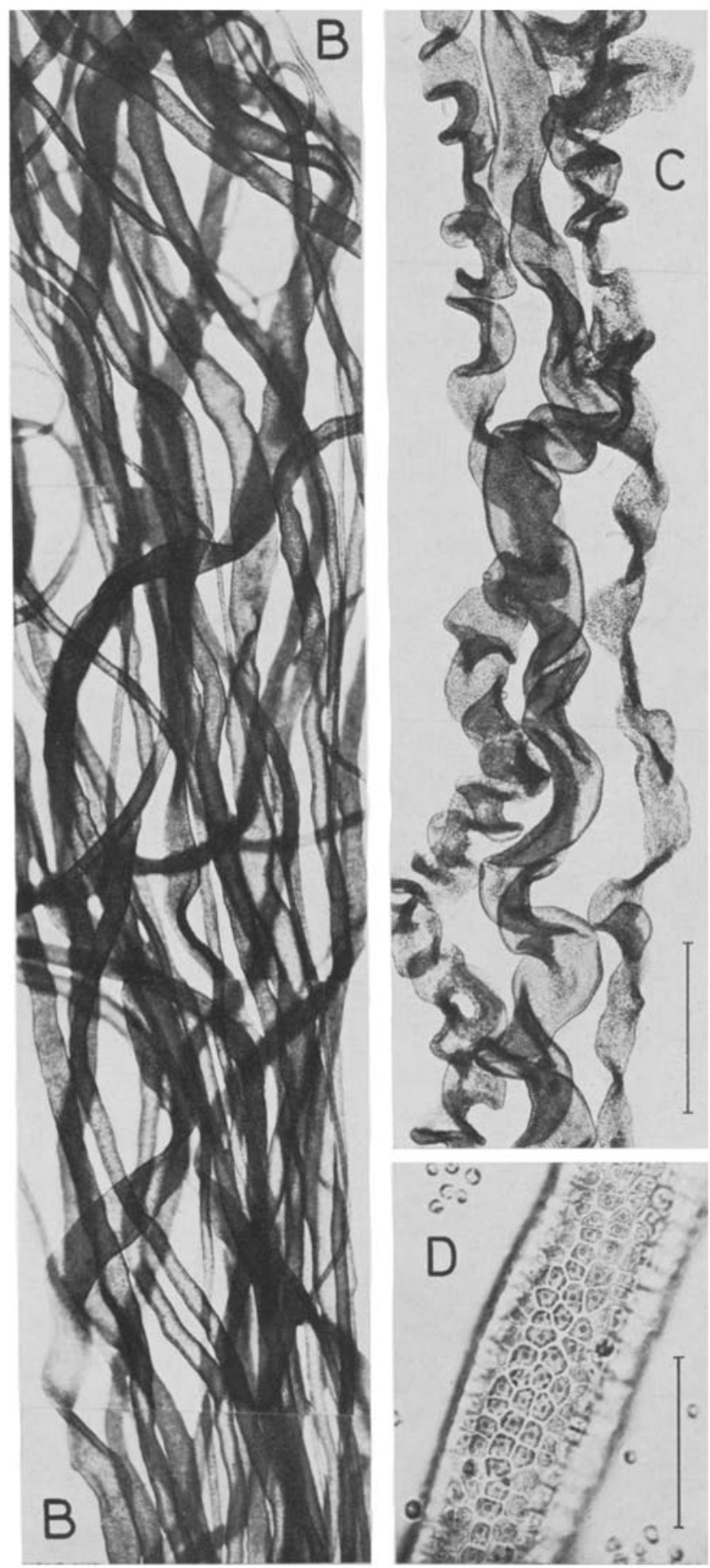

Abb. 39: Blidingia marginata. A Vom Substrat abgelöste Stränge in etwa natürlicher Größe. B, C Basale und mittlere Thallusabschnitte eines Stranges (14.9. 1972). D, E Vegetativer und fertiler Thallus. F, G 4 bzw. 9 Tage alte Keimlinge. Maßstrecken: B, C $=500 \mu \mathrm{m}$; D, E jeweils $=50 \mu \mathrm{m} ; \mathrm{F}, \mathrm{G}=30 \mu \mathrm{m}$ 


\section{PRASIOLALES}

Die Ordnung Prasiolales hat in dem sternförmigen Chromatophor mit zentralem Pyrenoid ein Merkmal, das sie klar von allen anderen Ordnungen der Chlorophyceen trennt. Bei einigen Vertretern ist geschlechtliche Fortpflanzung durch Oogamie bekannt.

Drei Gattungen mit insgesamt 7 Arten wurden bei Helgoland gefunden. Aber nur Prasiola stipitata und Rosenvingiella constricta wachsen an Standorten, wo sie ziemlich regelmäßig überflutet oder durch Seewasser benetzt werden. Die übrigen gedeihen nicht nur in Küstennähe, sondern kommen auch weit im Binnenland vor. Rosenvingiella polyrbiza, die zeitweilig die Molen mit einem grünen Bewuchs überzieht, soll aber hier nicht übergangen werden. Über die Morphologie und Entwicklung der auf Helgoland gesammelten Arten haben Kornmann \& Sahling (1974) ausführlich berichtet.

\section{Prasiolaceac}

\section{Prasiola stipitata Suhr in Jessen}

Es ist nicht sicher, ob die an verschiedenen Standorten vorkommenden und äußerlich einander recht ähnlichen Pflänzchen nicht doch verschiedenen Arten angehören. Auf der Brüstungsmauer der Westmole des Südhafens bilden die etwa $3 \mathrm{~mm}$ hohen, krausen Räschen unregelmäßige Netzmuster auf der rauhen Betonoberläche (Abb. 40). Hier werden die fächerartigen gestielten Pflänzchen (D, E) nur gelegentlich ron Spritzwasser benetzt; Regen und wochenlange Austrocknung werden ohne Schaden ertragen. Auf anderen Molenflächen wächst die Alge in dichten Beständen völlig im Möwenkot verkrustet, auch hier noch weit über der Hochwasserlinie. Und schließlich findet man sie auch an Plätzen, die ziemlich regelmäßig bei Hochwasser von Spritzern oder auflaufenden Wellen benetzt werden, z. B. an den Betontreppen im Hafenbereich oder auf Molenstufen im entsprechenden Niveau. Obwohl Prasiola stipitata und die übrigen Vertreter der drei Gattungen an ihrem natürlichen Standort nur zeitweise iiberflutet werden, gedeihen sie im Kulturmedium dauernd untergetaucht ausgezeichnet.

Die Aufsicht auf den einschichtigen Thallus $(\mathrm{H})$ zeigt die deutlich areolierte Anordnung der Zellen, wobei jede Gruppe auf die Teilung einer Ursprungszelle zurückgeht. Die Vermehrung erfolgt durch ungeschlechtliche Sporen; an ihnen ist der sternförmige Chromatophor mit zentralem Pyrenoid besonders deutlich erkennbar. Sie entstehen entweder am apikalen Thallusrand (,$K$ ) oder in umgrenzten Flecken der Fläche. Dieser Unterschied könnte vielleicht ein differenzierendes taxonomisches Merkmal sein.

Geschlechtspflanzen wurden bei. Helgoland nicht gefunden, sie sind aber an den englischen Küsten verbreitet. Thre diploide Basis trägt oberhalb einer Zone, in der die Reduktionsteilung erfolgt, den apikalen, haploiden Thallus. In ihm liegen Areale männlicher und weiblicher Gametangien mosaikartig nebeneinander. 

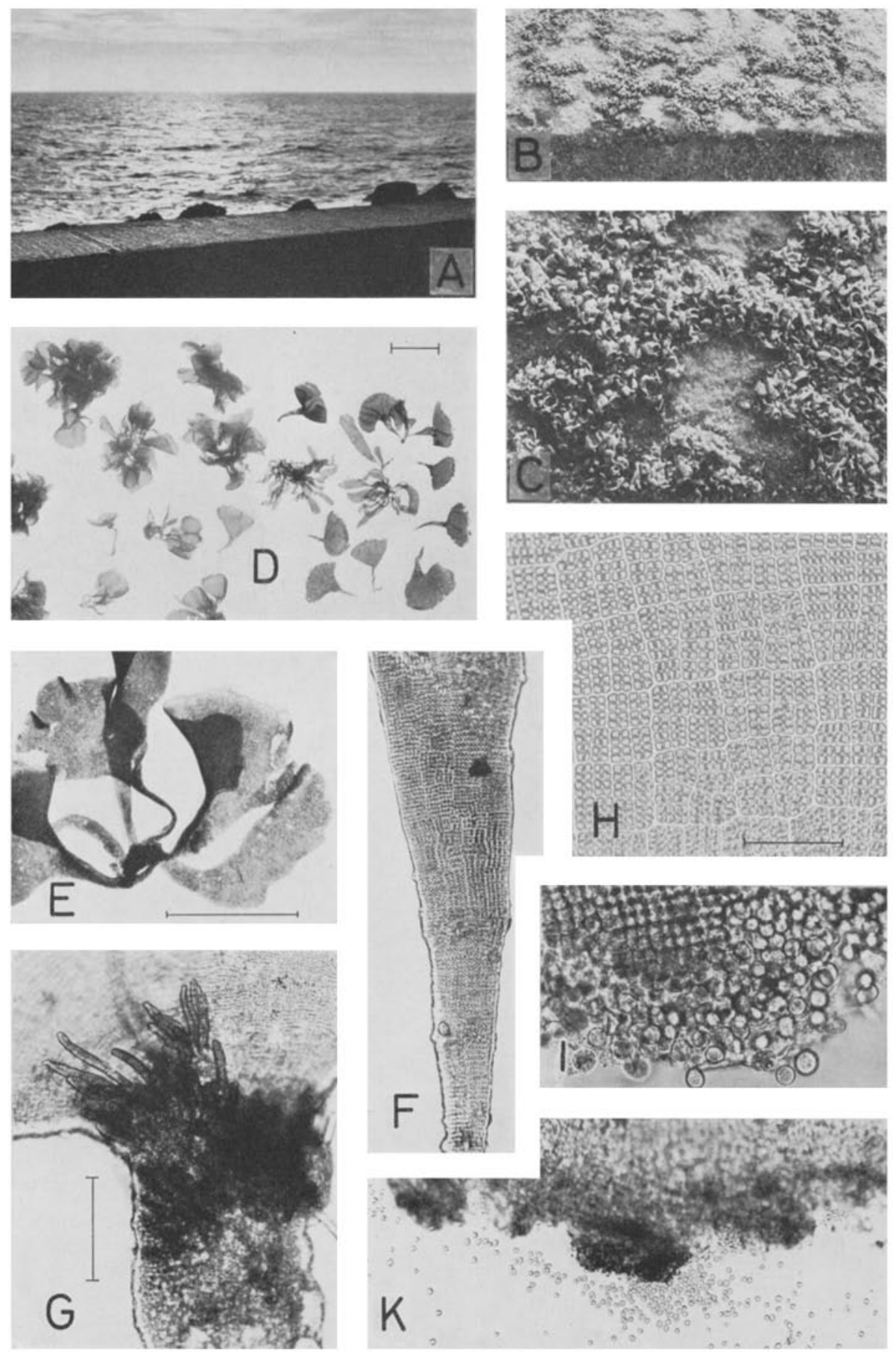

Abb. 40: Prasiola stipitata. A-C Ein Standort auf der Brüstungsmauer der Westmole des Sïdhafens. D, E Abgelöste Büschel und Einzelpflanzen. F Ausschnitt aus dem Stiel. G In einem geschädigten Thallusabschnitt sind einzelne Zellen intakt geblieben und zu Keimlingen ausgewachsen. $H$ Aufsicht auf die areolierte Thallusfläche. I, $\mathrm{K}$ Verquellende Randpartie mit Sporen. Maßstrecken: $\mathrm{D}=3 \mathrm{~mm} ; \mathrm{E}=1 \mathrm{~mm} ; \mathrm{F}, \mathrm{G}, \mathrm{K}=200 \mu \mathrm{m} ; \mathrm{H}, \mathrm{I}=50 \mu \mathrm{m}$ 


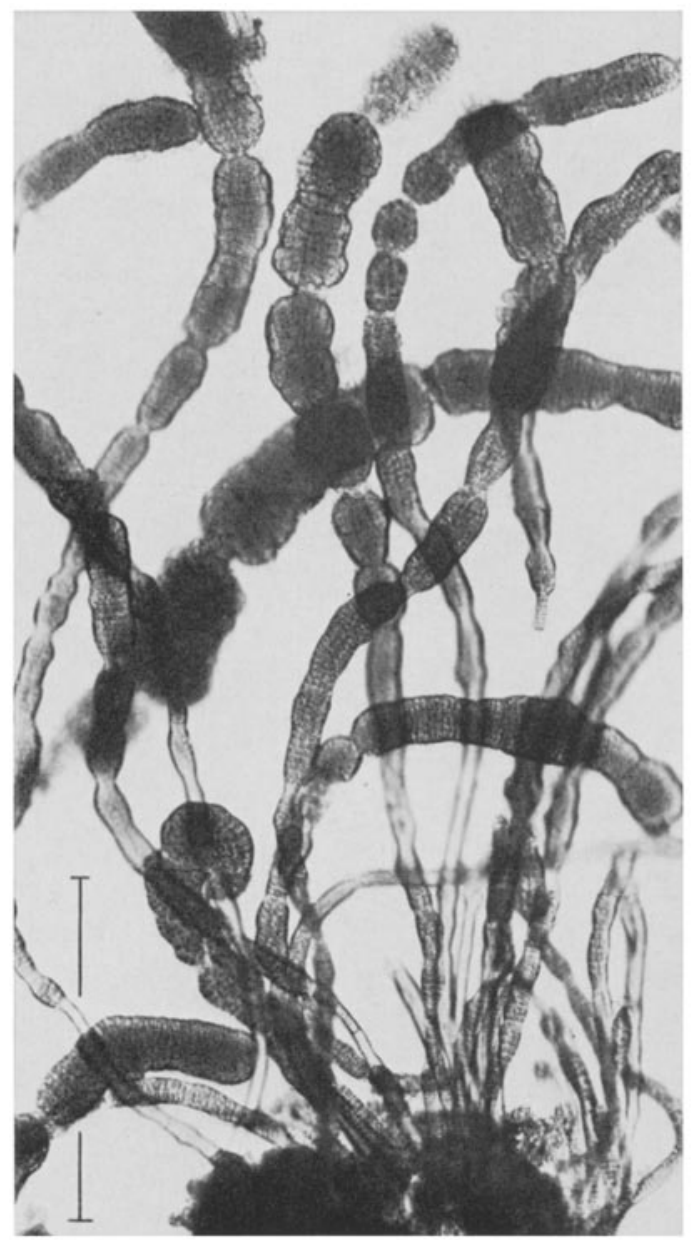

Abb. 41: Rosenvingiella constricta. Vom Substrat abgelöste Gruppe (7. 9. 1973). Maßstrecke: $0,5 \mathrm{~mm}$

Rosenvingiella constricta (Setchell \& Gardner) Silva

Diese an der pazifischen Küste Nordamerikas beheimatete Alge war bisher in Europa nur von zwei älteren Aufsammlungen aus der Ostsee bekannt. Im Herbst 1973 wurde sie zum ersten Male bei Helgoland auf einer nur mit dem Boot erreichbaren Mole im Nordwesten der Insel gefunden, wo sie - zusammen mit Prasiola stipitata ziemlich regelmäßig von Spritzwasser erreicht oder von Brandungswellen überflutet wird. 
Die damals nur an zwei Stellen der Mole beobachtete Rosenvingiella constricta war 1975 viel reichlicher vorhanden. Die etwa $5 \mathrm{~mm}$ hohen Pflänzchen stehen dicht rasenartig aufrecht nebeneinander. Eine monosiphone Basis verbreitert sich in den pseudoparenchymatischen keuligen und unregelmäßig eingeschnürten Thallus (Abb. 41). Diese "Glieder" werden von der Spitze zur Basis fortschreitend fertil und zerfallen nach ihrer Entleerung. Auf getrennten Pflanzen werden Eier beziehungsweise zweigeißelige männliche Gameten erzeugt. Reife Gametangien lassen ihr Geschlecht schon bei geringer Vergrößerung an der unterschiedlichen Färbung und der Größe der Gametangien erkennen.

Der vollständige Entwicklungsgang konnte im Kulturversuch verfolgt werden; aus jeder kreuzweise geteilten Zygote entstehen je zwei männliche und weibliche Gametophyten, ein experimenteller Nachweis für die in der keimenden Zygote erfolgende Reduktionsteilung. Ungeschlechtliche Fortpflanzungszellen wurden im Entwicklungszyklus nicht beobachtet, jedoch keimen einzelne unbefruchtete Eier. 

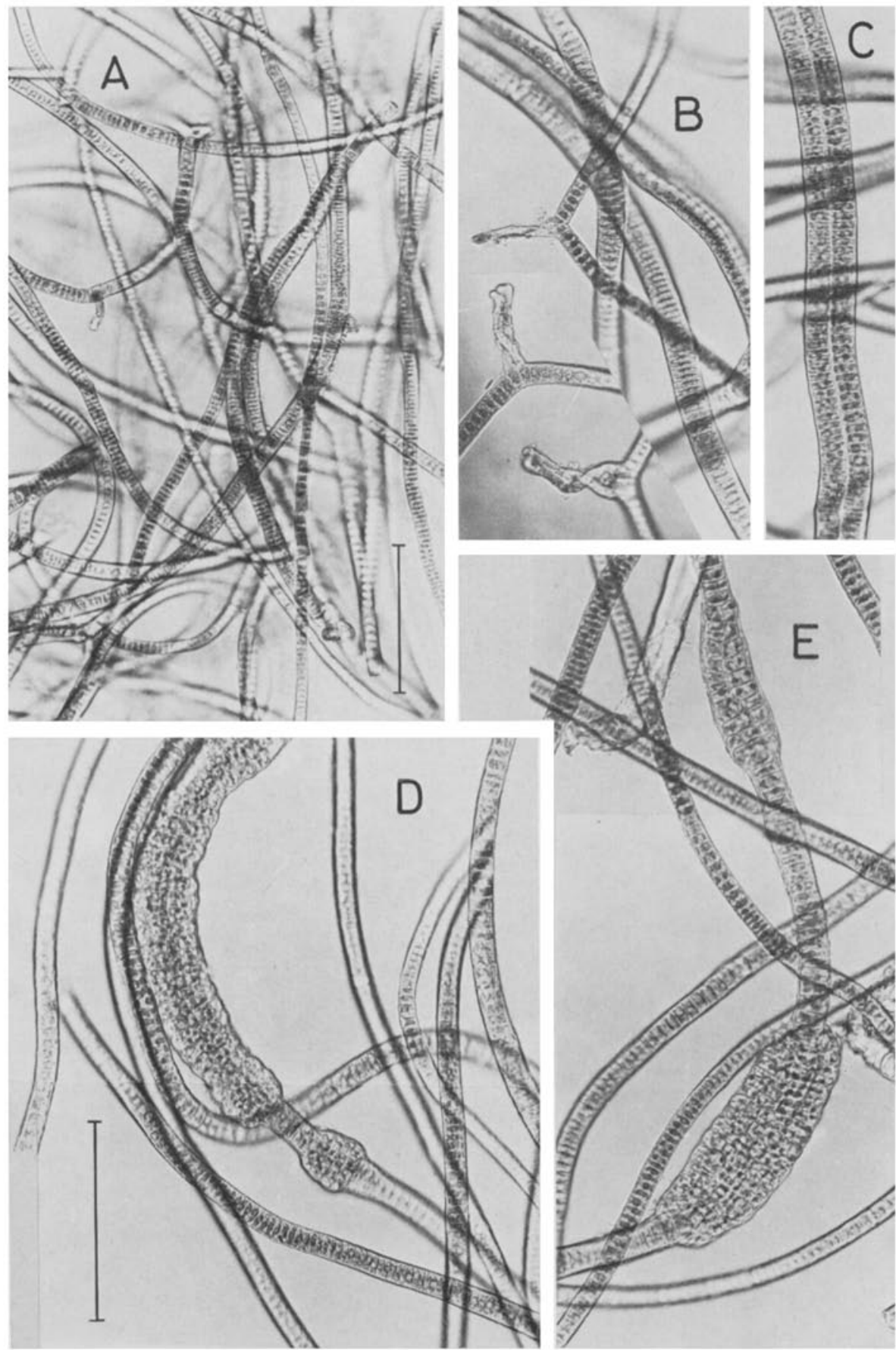

Abb. 42: Rosenvingiella polyrhiza. A Aus dem fädigen Belag auf einer Hafenmole (22. 2. 1973). B Fadenstücke verschiedener Breite mit Rhizoiden. C Zweireihiger Faden. D, E Polysiphone Fadenabschnitte $(20.3 .1974)$. Maßstrecken: $\mathrm{A}=100 \mu \mathrm{m} ; \mathrm{B}-\mathrm{E}=100 \mu \mathrm{m}$ 


\section{Rosenvingiella polyrbiza (Rosenv.) Silva}

Im Winter und zeitigen Frühjahr sind Molen und Uferbefestigungen stellenweise grüngefärbt von Rosenvingiella polyrbiza. Bei trockener Witterung ist der fest auf dem Boden haftende, etwas seidig schimmernde Belag hellgrün. Nach Benetzung wird er sofort dunkelgrün, und die einzelnen feinfädigen Stränge oder verfilzten Uberzüge lassen sich dann leicht von dem Substrat abnehmen. In Pfützen oder in den Rillen von Schienen auf den Molen wächst die Alge zusammen mit einer feinfädigen Ulotbrix. Aber auch auf der ganzen Insel ist Rosenvingiella polyrhiza weit verbreitet, man kann sie auf den Treppen zum Oberland und an vielen Stellen - Mauern, Kellertreppen innerhalb der Ortschaft finden. $\mathrm{Zu}$ ihren regelmäßigen Begleitern gehört Prasiola calophylla.

Das mikroskopische Bild zeigt ein Gewirr monosiphoner, unverzweigter Fäden von unterschiedlicher Breite (A). Mit zunehmender Fadenbreite werden die Zellen flacher, während sie in dünnen Fäden vor der Teilung fast isodiametrisch sind. In ihnen ist der sternförmige Chromatophor mit zentralem Pyrenoid am deutlichsten zu erkennen. Rhizoiden kommen in den einzelnen Proben mit unterschiedlicher Häufigkeit vor, meist entspringen sie benachbarten Zellen (B). Bei einigem Suchen kann man stets mehrreihige Fäden finden, meist zweireihige (C), gelegentlich auch bis zu fünfreihige Bänder. Sie verbreitern sich aber niemals zu einer flächigen Prasiola, etwa der zungenförmigen Prasiola calopbylla, deren Selbständigkeit im Kulturversuch nachgewiesen wurde. Die bei $\mathrm{D}$ und $\mathrm{E}$ abgebildeten räumlich-polysiphonen Fadenabschnitte triff man seltener an. Sie sind in unterschiedlicher Länge in die monosiphonen Fäden eingeschaltet. Ganz offensichtlich handelt es sich wie bei Rosenvingiella constricta um Gametangien; ihre Entleerung konnte jedoch nur wenige Male beobachtet werden. Aus gelblichgrünen, kleingefächerten Fadenabschnitten wurden zweigeißelige Gameten, aus dunkelgrünen, großgefächerten Behältern Eier entleert. Da der Austritt niemals gleichzeitig erfolgte, wurden keine Zygoten erhalten, die Lebensgeschichte von Rosenvingiella polyrbiza bleibt daher ungeklärt. Einzelne unbefruchtete Eier entwickelten sich zu fädigen Pflanzen.

\section{CHAETOPHORALES}

Vertreter der Chaetophorales sind mit zahlreichen epi- und endophytisch sowie auf totem Substrat lebenden Kleinalgen in unserem Untersuchungsgebiet verbreitet. Wir verfügen nicht über die notwendigen Beobachtungen an Naturmaterial in Verbindung mit Kulturen im Laboratorium, um diese schwierige Gruppe mit Originalabbildungen vorzustellen. Wer diese Algenflora als Arbeitsbuch während eines kurzfristigen Aufenthalts benutzt, wird ohnehin eine Beschreibung der vielen meist mikroskopischen Grün- und Braunalgen nicht vermissen. 


\section{Chaetophoraceae}

\section{Phaeophila wittrockii (Wille) Nielsen}

Am ehesten wird man noch Phaeophila wittrockii zufällig oder nach planmäßigem Suchen als Epiphyt auf den Assimilationsfäden von Elacbista fucicola begegnen. Flache grüne Zellreihen schmiegen sich den Assimilationsfäden dicht an; sie können sich verzweigen und die Wirtspflanze umwachsen. Die wachsenden Fadenenden flachen sich keilförmig $\mathrm{ab}$. Vegetative Zellen sind meist 2-3 mal so lang wie hoch und tragen gelegentlich Borsten. Vor der Fertilisierung wölben sich die Zellen in der Fadenmitte papillenartig vor. Die im allgemeinen dreigeißeligen Zoosporen haben zwei Augenflecke.

Neben Phaeophila wittrockii trifft man auf Elachista häufig auch einen kleinzelligen grünen Epiphyten an, der die Fäden mantelförmig dicht umhüllt. Seine Sporangien enthalten $z$ wei Zoosporen.

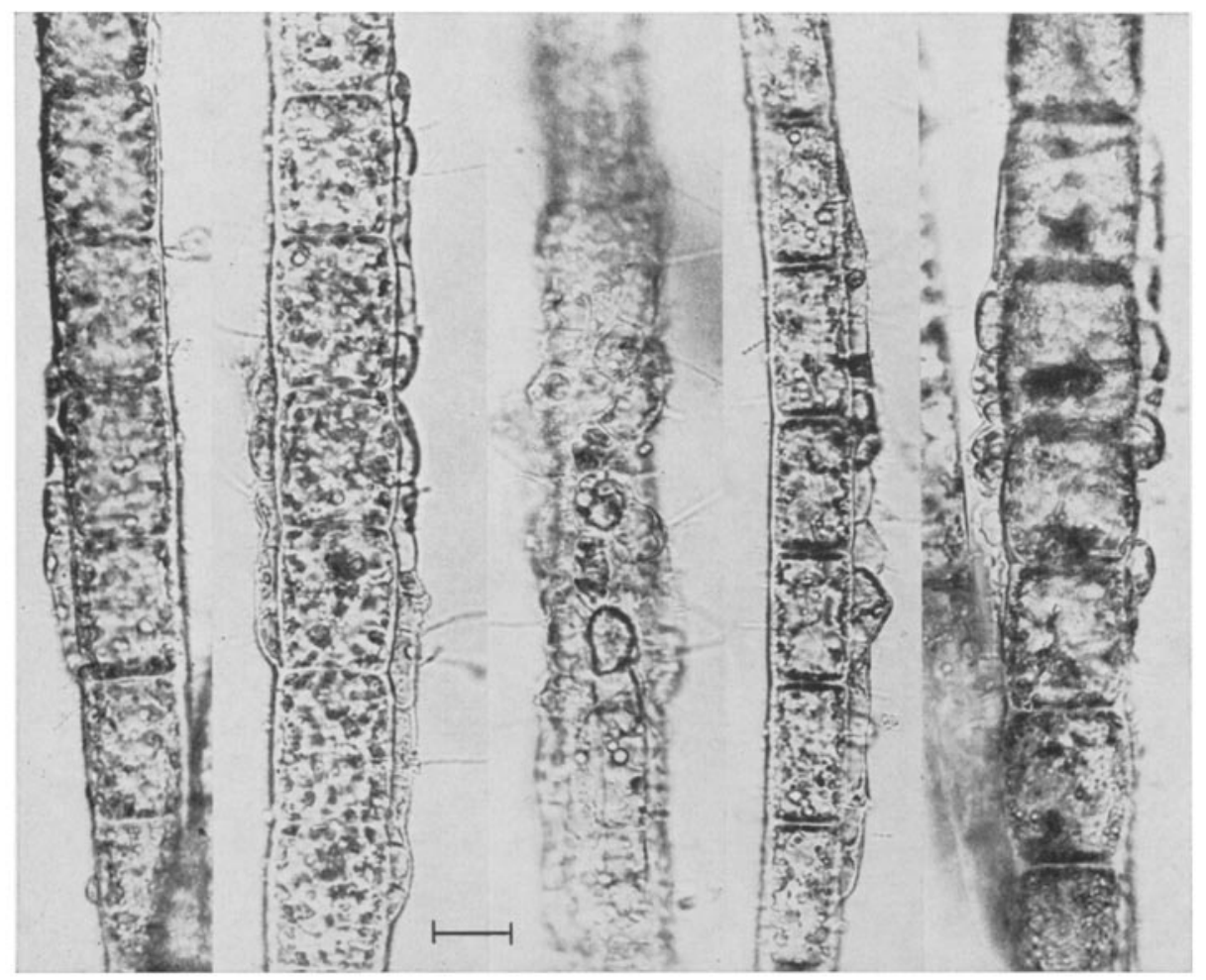

Abb. 43: Phaeopbila wittrockii auf Assimilationsfäden von Elachista fucicola (10. 6. 1976). Maßstredke $=20 \mu \mathrm{m}$ 


\section{Phaeophyta}

Die Klassifizierung der Braunalgen war immer problematisch. Einige Ordnungen grenzen sich morphologisch und entwidklungsgeschichtlich klar ab. Die vielen hier in der Ordnung Ectocarpales zusammengefaßten Familien sind jedoch nicht nur in ihrem Aufbau sehr verschieden, sondern folgen auch in ihrer Entwicklung teils isomorphen, teils heteromorphen Zyklen. Aus einer von Russell \& Fletcher (1975) an den 197 Braunalgenarten der englischen Küsten durchgeführten Faktorenanalyse mit 132 Merkmalen aus Morphologie, Fortpflanzung und Okologie ergab sich ihre Gliederung in 7 Ordnungen.

Das so erzielte System - es weicht nicht wesentlich von älteren $a b$ - liegt der neuen Algenliste von Parke \& Dixon (1976) zugrunde und wurde auch in der vorliegenden Darstellung übernommen (Übersicht p. 4). Kylin (1933) gliederte die Phaeophyta auf entwicklungsgeschichtlicher Grundlage in die Klassen der Isogeneratae, Heterogeneratae und Cyclosporeae. Im Grunde genommen verschieben sich in den beiden Systemen nur Rang und Stellung bei einigen der höheren taxonomischen Einheiten.

In einer gerade erschienenen Arbeit kombinierten Wynne \& Loiseaux (1976) die Ergebnisse neuerer entwicklungsgeschichtlicher Untersuchungen der Braunalgen mit ihrer morphologischen Organisation zu einem Schema möglicher phylogenetischer Beziehungen. Der Unterstamm der Phaeophycidae, mit den Cyclosporidae einer unbekannten Wurzel entspringend, teilt sich in den Ectocarpales in drei Entwicklungsreihen auf, in denen die Ordnungen mit gleichem Bauplan (haplo-, poly- und haplopolystich) von isogamer zu oogamer Fortpflanzung aufsteigen. Das Schema bringt damit die wesentlichen Merkmale der Braunalgen-Ordnungen übersichtlich zum Ausdruck. 


\section{Phaeophyceae}

\section{ECTOCARPALES}

\section{Ectocarpace a}

Auf niederliegenden Basalfäden erhebt sich der einreihige, oft reichlich verzweigte Thallus. Der Habitus schwankt zwischen kurzen gedrungenen, unter $1 \mathrm{~cm}$ hohen Rasen oder Büscheln und lang flutenden, bis über $20 \mathrm{~cm}$ großen lockeren Watten, deren Hauptfäden sich oft strangartig umeinanderwinden. Bei der epiphytisch lebenden Spongonema sind die Hauptfäden zu zopfartigen Schnüren zusammengedreht und durch besondere Hakenzweige miteinander verfestigt. Die meisten Arten wachsen sowohl auf festem Substrat als auch auf Algen; Acinetospora schlingt sich um andere Algen oder bildet verworrene filzige Stränge, die keine Polarität erkennen lassen. Laminariocolax ist ein obligater Endophyt in der Rinde von Laminaria, die aufrechten Fäden umschlingen sich zu kurzen Zöpfchen.

Unterscheidende Merkmale für die Aufgliederung der Familie sind die Chromatophoren sowie Form und Anheftung der Sporangien.

1. Mehrere schmal-bandförmige, mitunter leicht verzweigte

2. Ein oder zwei leicht gewundene platten- oder kurz-bandförmige Chromatophoren

a. Längsfäden von hakig gebogenen Zweigen umklammert, meist größere Epiphytenstränge auf Fucus . . . .

b. Nur auf Laminaria, kurze dünnfädige Zöpfchen, plurilokuläre Sporangien einreihi

Spongonema $\quad 101$

Laminariocolax 103

3. Zellen mit vielen scheibenförmigen Chromatophoren

a. Sporangien sitzend. . . . . . . . . . . Giffordia 108

b. Sporangien in interkalaren oder endständigen Ketten . Pilayella 105

c. Sporangien meist in traubenförmigen Gruppen . . . Sorocarpus 115

d. Fäden ohne erkennbare polare Differenzierung um andere Algen gewunden oder verworrene Watten bildend. Auffallend großgefächerte plurilokuläre Sporangien .

e. Kurze pelzige Rasen auf exponierten Schichtköpfen, selten . 


\section{Ectocarpus Lyngbye}

Die Identifizierung der Ectocarpus-Arten wird stets unbefriedigend bleiben, weil es keine absoluten Merkmale für ihre Bestimmung gibt. Besonders die Sporangienform schwankt in weiten Grenzen, und die Zahl der synonym beschriebenen Arten ist groß. Natürlich gibt es Erscheinungsformen, die man immer wieder antriff und die man einem bestimmten Typus zuordnen kann. In vielen Fällen aber wird eine sichere Entscheidung nicht möglich sein.

Als Ausweg aus diesen Schwierigkeiten schien es zweckmäßig, sich an Stelle der vielen nicht klar gegeneinander abzugrenzenden Arten auf zwei Formenkreise zu beschränken, die sich in ihrem morphologischen Aufbau eindeutig unterscheiden. So enthält das Verzeichnis der britischen Meeresalgen von Parke \& Dixon (1976) nur noch zwei Ectocarpus-Arten. Ectocarpus siliculosus mit unregelmäßiger, alternierender oder pseudodichotomer Verzweigung ermangelt einer besonders hervortretenden Hauptachse. Der siliculosus-Komplex schließt mehrere Arten mit unterschiedlicher Sporangienform ein. Der Formenkreis um Ectocarpus fasciculatus ist dagegen durch eine deutliche Hauptachse gekennzeichnet, die büschelige Verzweigungen trägt.

Diese Beschränkung läßt die Möglichkeiten außer acht, die das Kulturexperiment für die Kennzeichnung der Ectocarpus-Arten bietet; seine planmäßige Anwendung kann vielleicht noch wesentlich zur Klärung beitragen. Das Sporophytenstadium von Ectocarpus trägt zweierlei Sporangien, plurilokuläre, deren Schwärmer der direkten Vermehrung dienen und unilokuläre, in denen die Reduktionsteilung erfolgt. Leider treten unilokuläre Sporangien nicht allzu häufig auf. Die Diagnose einer EctocarpusArt sollte sich eigentlich auf die Kenntnis des vollständigen Entwicklungszykjus gründen, nach Möglichkeit ergänzt durch zytologische Daten. Wie an drei Beispielen gezeigt wird, kann die aus den Schwärmern unilokulärer Sporangien kultivierte Generation Merkmale zeigen, die sie als eine längst unter einem anderen Namen beschriebene Art erscheinen läßt.

Ectocarpus spec. incl. Ectocarpus dasycarpus Kuck.

Das Ausgangsmaterial (Abb. 44 B, C), zuerst mehrfach in Planktonproben, später auch auf Haftkrallen alter Laminaria hyperborea und auf Steinen aus entsprechender Tiefe gefunden, gehört dem Formenkreis der siliculosi an; eine nähere Zuordnung des Sporophyten zu einer der beschriebenen Arten ist kaum möglich. Die plurilokulären Sporangien sind kurz und schmal; an Regeneraten des Ursprungsmaterials waren sie bei etwas breiterer Basis länger gestreckt und zugespitzt (D). Die unilokulären Sporangien waren auffallend langoval (C). Uberraschend andersartig sah die in Kultur aus ihren Schwärmern entstandene Generation aus: Mit ihren langgestreckten zylindrischen Gametangien gleicht sie durchaus der als Ectocarpus dasycarpus bekannten Art (Abb. 45 A). Zum Vergleich ist die in Kultur erhaltene Pflanze einer Probe aus der Natur bei gleicher Vergrößerung gegenübergestellt (Abb. 44 A). 

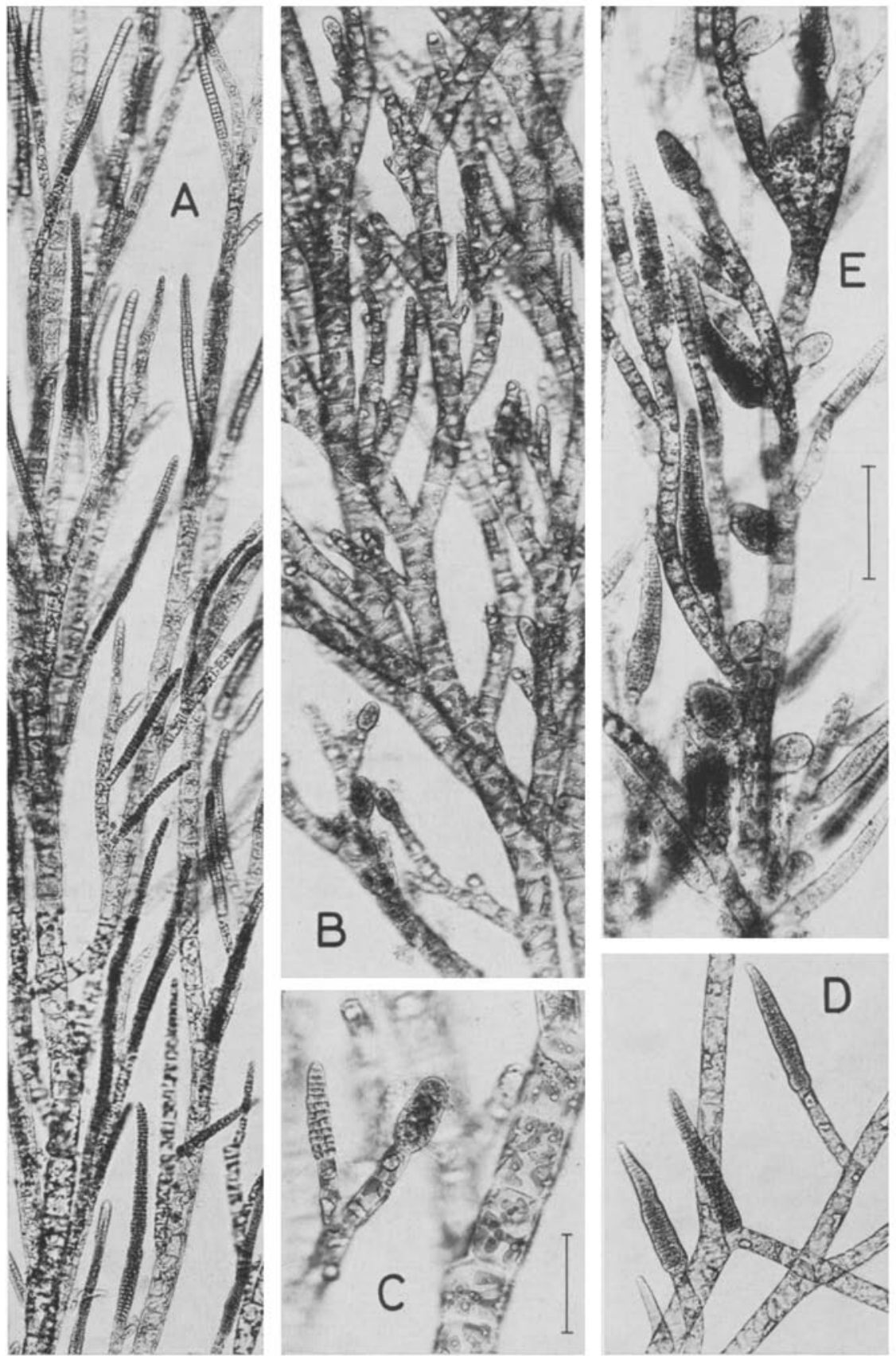

Abb. 44: A Ectocarpus dasycarpus, epiphytisch auf Desmarestia aculeata (aus einem Präparat vom 29. 7. 1964). B-C Ectocarpus spec. (29. 4. 1975), Ausgangsmaterial der in Abb. 45 A dargestellten Generation. D Regenerat yon B in Kultur. E Ectocarpus siliculosus, Sporangien ohne Haarspitze (13.6. 1973). Maßstrecken: A, B, D, E $=100 \mu \mathrm{m} ; \mathrm{C}=50 \mu \mathrm{m}$ 

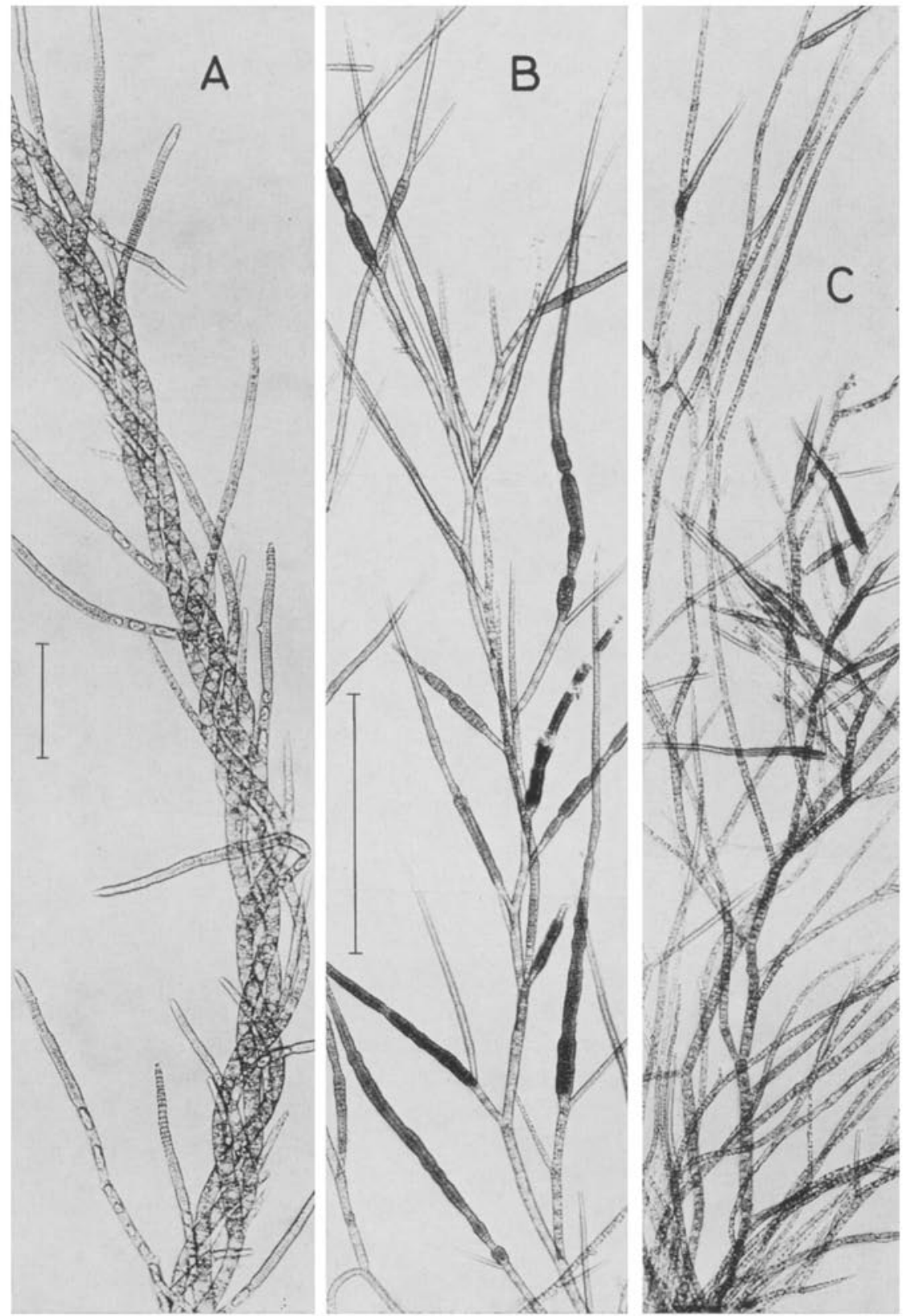

Abb. 45: Aus Schwärmern unilokulärer Sporangien kultivierte Generationen. A Entspricht Ectocarpus dasycarpus, Ursprungspflanze ist Abb. $44 \mathrm{~B}$, C. B Entspricht Ectocarpus siliculosus var. varians, Ursprungspflanze ist Abb. $46 \mathrm{C}-\mathrm{E}$. C Entspricht Ectocarpus draparnaldioides (?), Ursprungspflanze ist Abb. $48 \mathrm{D}$, E. Maßstrecken: $\mathrm{A}=100 \mu \mathrm{m} ; \mathrm{B}, \mathrm{C}=500 \mu \mathrm{m}$ 
Ectocarpus siliculosus (Dillw.) Lyngb. incl. var. varians Kudk.

Die gelbbraunen, etwas schlüpfrig sich anfühlenden Büschel von Ectocarpus siliculosus wachsen von Mitte März bis Ende Juni in Tümpeln nahe der Niedrigwassergrenze auf Steinen und epiphytisch auf Fucus serratus, Chondrus crispus, Cladophora rupestris und anderen Algen. Die meisten am Strand angetriebenen Pflanzen stammen aber wohl aus dem Sublitoral. Das Habitusbild ( $\mathrm{Abb}$. 46 A) gibt einen Eindruck von der Zartheit der lockeren Büschel. Aus einem seilartigen Strang lösen sich einzelne Aste, verzweigen sich zunächst unregelmäßig und tragen dann an ihren büscheligen Enden bei dichter werdender einseitiger Verzweigung die Sporangien $(C, D)$.

Die plurilokulären Sporangien sind gestielt und lang schotenförmig; bei der hier dargestellten Probe verlängern sie sich in eine wenigzellige Haarspitze. Die Schwärmer treten in diesem Falle durch eine seitliche Offnung im oberen Drittel des Sporangiums aus (F). Nach Auflösung der inneren Kammerwände fließen sie in einem stetigen Strom in einer Reihe hintereinander zum Ausgang, ein reizvolles Bild, das man gelegentlich in Präparaten von feucht am Standort eingesammeltem Material beobachten kann.

Die stets ungestielten eiförmigen unilokulären Sporangien kommen im allgemeinen gemeinsam mit plurilokulären auf derselben Pflanze vor, sind aber viel seltener. Aus ihren großen Zoosporen entstand in Kultur eine Generation, die schon nach drei Wochen fertil war und ungewöhnlich lange und dünne Sporangien trug (Abb. $45 \mathrm{~B}$ ). Stimmen sie in Form und Maßen nicht völlig mit denen der von Kuckuck (1892) beschriebenen var. varians überein?

Bei der in Abbildung $44 \mathrm{E}$ dargestellten Probe von Ectocarpus siliculosus laufen die plurilokulären Sporangien nicht in Haare aus; sie entleeren sich an der Spitze.

\section{Ectocarpus confervoides (Roth) Le Jolis}

In ihrem Habitus ist diese Art Ectocarpus siliculosus ähnlich. Die Seitenzweige und Sporangien sind aber im allgemeinen nicht so eng an ihre Achse angeschmiegt, sondern bilden einen etwas weiteren Winkel. Die plurilokulären Sporangien sind kürzer und gedrungener, keil-oder spindelförmig und stets ohne Haarspitze, meist kurz gestielt und nur selten sitzend. Die unilokulären Sporangien, gelegentlich auf derselben Pflanze vorkommend, sind kurzoval (Abb. 47).

Ectocarpus confervoides kommt erst ab Mitte Mai vor, während man Ectocarpus siliculosus schon im zeitigen Frühjahr findet. In welchen Grenzen eine Art unter den sich ändernden ökologischen Bedingungen variieren kann, sollte experimentell geprïtt werden. 

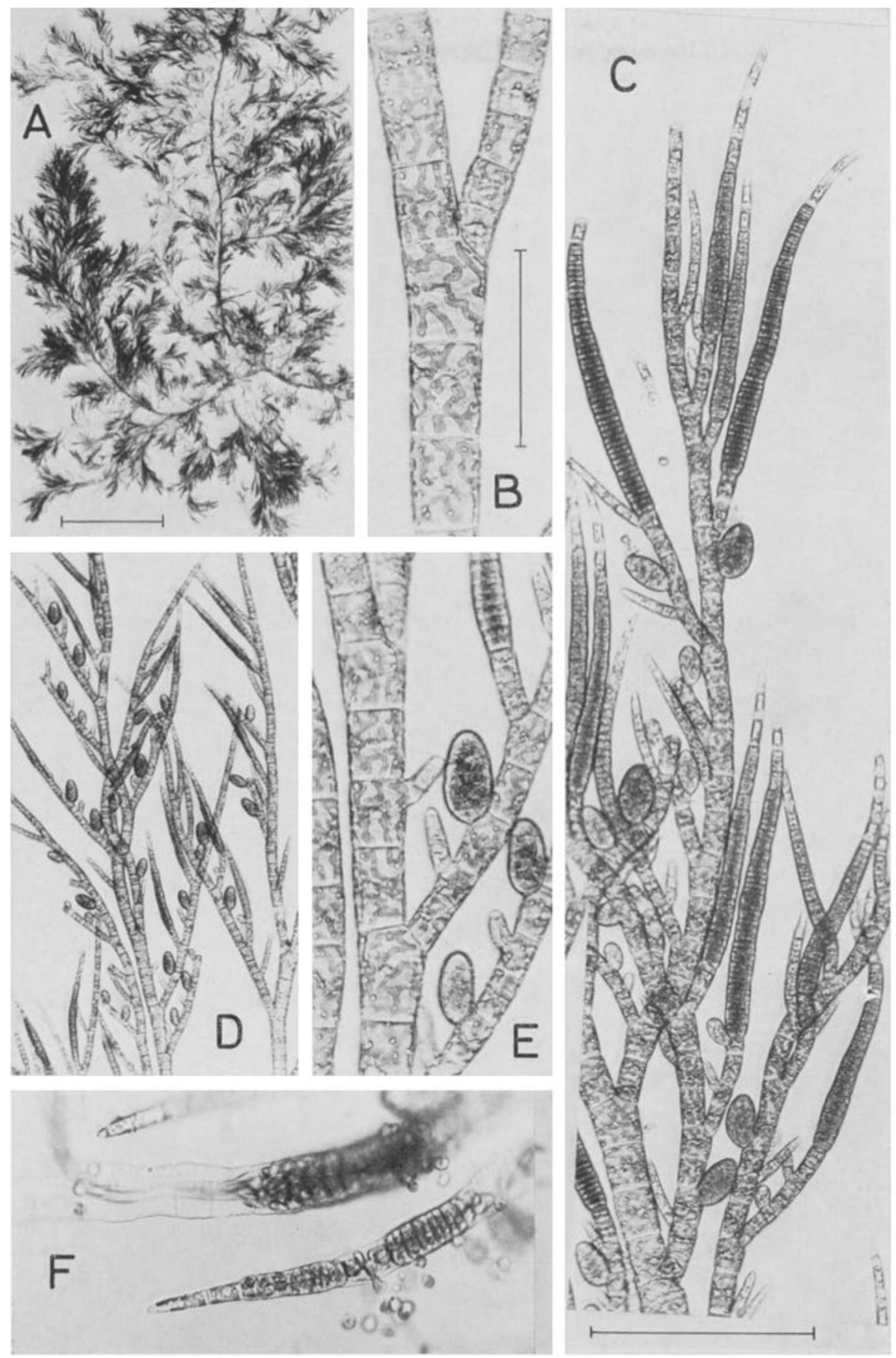

Abb. 46: Ectocarpus siliculosus. A Habitus $(13,5.1974)$. B Zellen mit verzweigten bandförmigen Chromatophoren. C-E Pluri- und unilokuläre Sporangien, Ausgangsmaterial der in Abb. $45 \mathrm{~B}$ dargestellten Generation (26. 4. 1975). F Plurilokuläre Sporangien mit Haarspitzen, ihre Entleerung erfolgt seitlich. Maßstrecken: $A=1 \mathrm{~cm} ; \mathrm{B}, \mathrm{E}, \mathrm{F}=100 \mu \mathrm{m}$; 

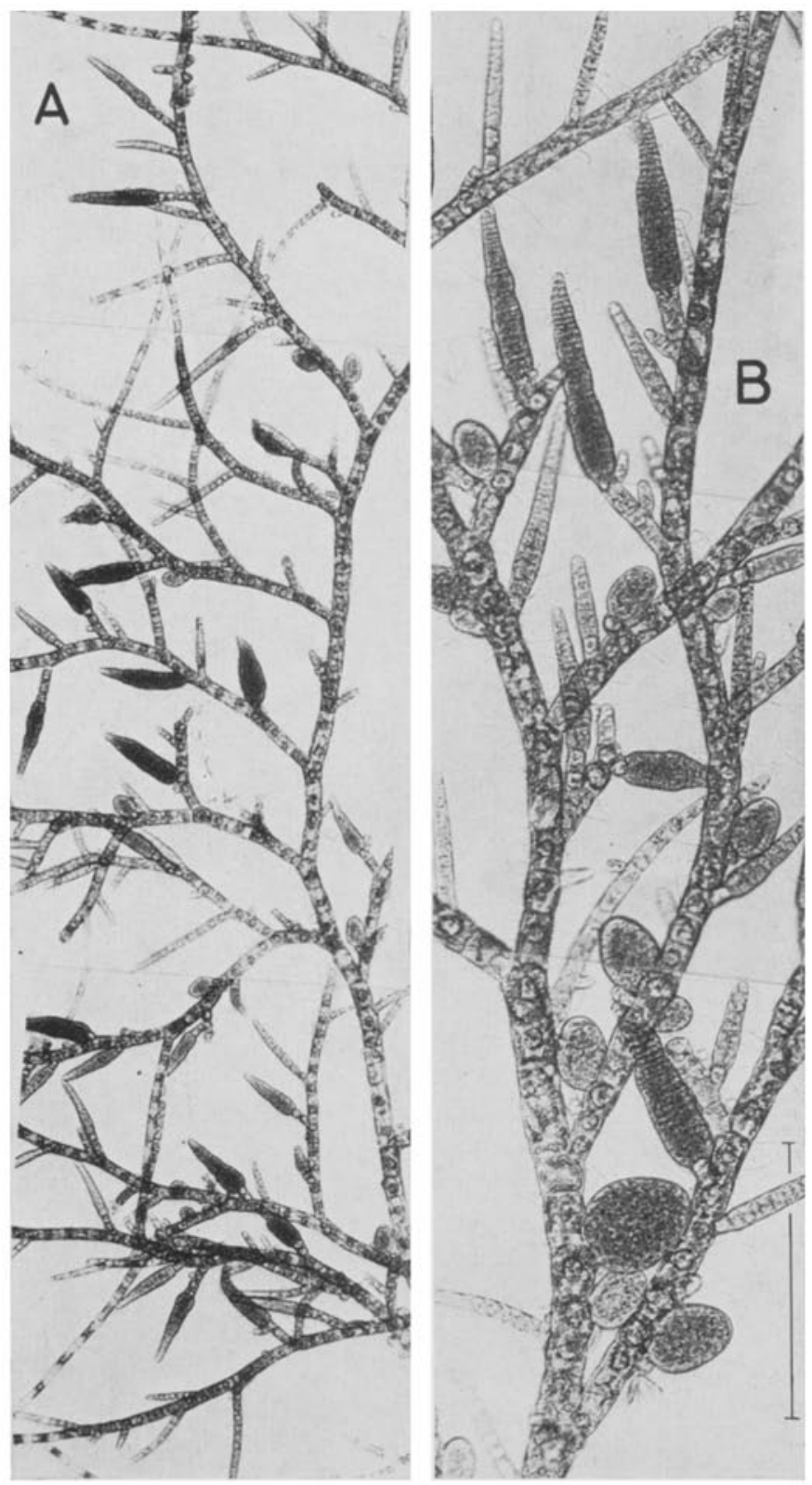

Abb. 47: Ectocarpus confervoides mit pluri- und unilokulären Sporangien (11. 6. 1975). Maßstrecke: $\mathrm{B}=200 \mu \mathrm{m}$ 
Ectocarpus fasciculatus Harv. incl. E. draparnaldioides(?)

Ectocarpus fasciculatus bildet bereits im März 1-2 $\mathrm{cm}$ hohe pelzige Überzüge auf den Phylloiden von Laminaria digitata (Abb. $48 \mathrm{~A}$ ). Folgegenerationen kann man ab Mai und Juni auf Laminaria finden, sie sehen aber etwas anders aus (Abb. 49 C).

Die Frühjahrspflanze ist an ihrer leicht abgewinkelten Hauptachse ziemlich dicht mit kurzen $Z$ weigbüscheln besetzt, die die länglichen plurilokulären Sporangien tragen (Abb. 48 B, C). Im Sommer tritt der gegliederte Aufbau stärker in Erscheinung, weil die Abstände zwischen den Zweigbüscheln im allgemeinen größer sind (Abb. $49 \mathrm{~A}$ ). Die plurilokulären Sporangien sind dann auch deutlich kürzer. Im Kulturexperiment erwiesen sich die aus den beiden so verschieden aussehenden Pflanzen erzielten Nachkommenschaften als gleichartig.

Nur im Frühjahr trugen einzelne Pflanzen des pelzartigen Uberzugs fast ausschließlich unilokuläre Sporangien (Abb. 48 D, E). Aus den Meiozoosporen entwickelte sich in Kultur ein lockerer büscheliger Gametophyt, der nur bei jungen Pflanzen den charakteristischen fasciculatus-Aufbau erkennen läßt. Die in lange Haarspitzen auslaufenden Zweige tragen langgestreckte Gametangien (Abb. $45 \mathrm{C}$ ). Der in so wesentlichen Merkmalen von dem Sporophyten abweichende Gametophyt wird von Müller (1972) als die unter dem Namen Ectocarpus draparnaldioides beschriebene Art angesehen. Allerdings werden von den Autoren wohl verschiedenartige Formen mit diesem Namen bezeichnet.

Ein weiteres Beispiel für den unterschiedlichen Habitus der Sporophyten- und Gametophytengeneration erbrachte Kornmann (1956b) für eine Art, die sicherlich eher in den Formenkreis der fasciculati gehören dürfte als zu Ectocarpus confervoides, wie dort angegeben. Schließlich sei in diesem Zusammenhang auf das Ergebnis früherer Kulturversuche mit Acinetospora crinita (Abb. 60) hingewiesen. Aus den Schwärmern der unilokulären Sporangien wurde eine Generation mit Antheridien und großgefächerten Sporangien erhalten, die durchaus die Merkmale der Ectocarpaceen-Gattung Feldmannia trug (Kornmann, 1953). 

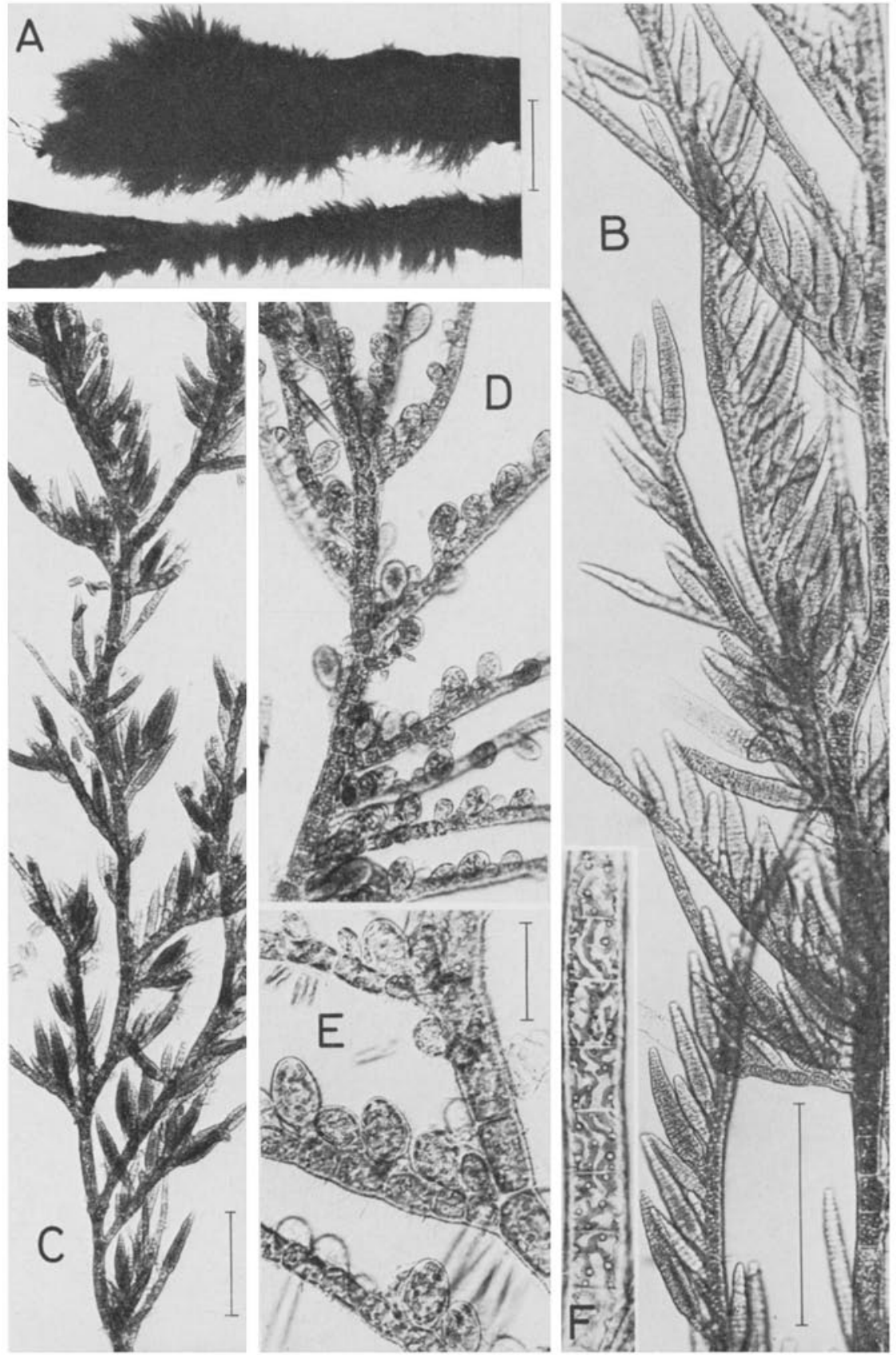

Abb. 48: Ectocarpus fasciculatus. A Pelziger Oberzug auf Laminaria digitata (28. 3. 1974). B, C Fadenstücke mit plurilokulären Sporangien, D, E Unilokuläre Sporangien. F Verzweigte, bandförmige Chromatophoren. Maßstrecken: $\mathrm{A}=2 \mathrm{~cm} ; \mathrm{B}, \mathrm{D}=200 \mu \mathrm{m} ; \mathrm{E}, \mathrm{F}=50 \mu \mathrm{m}$ 

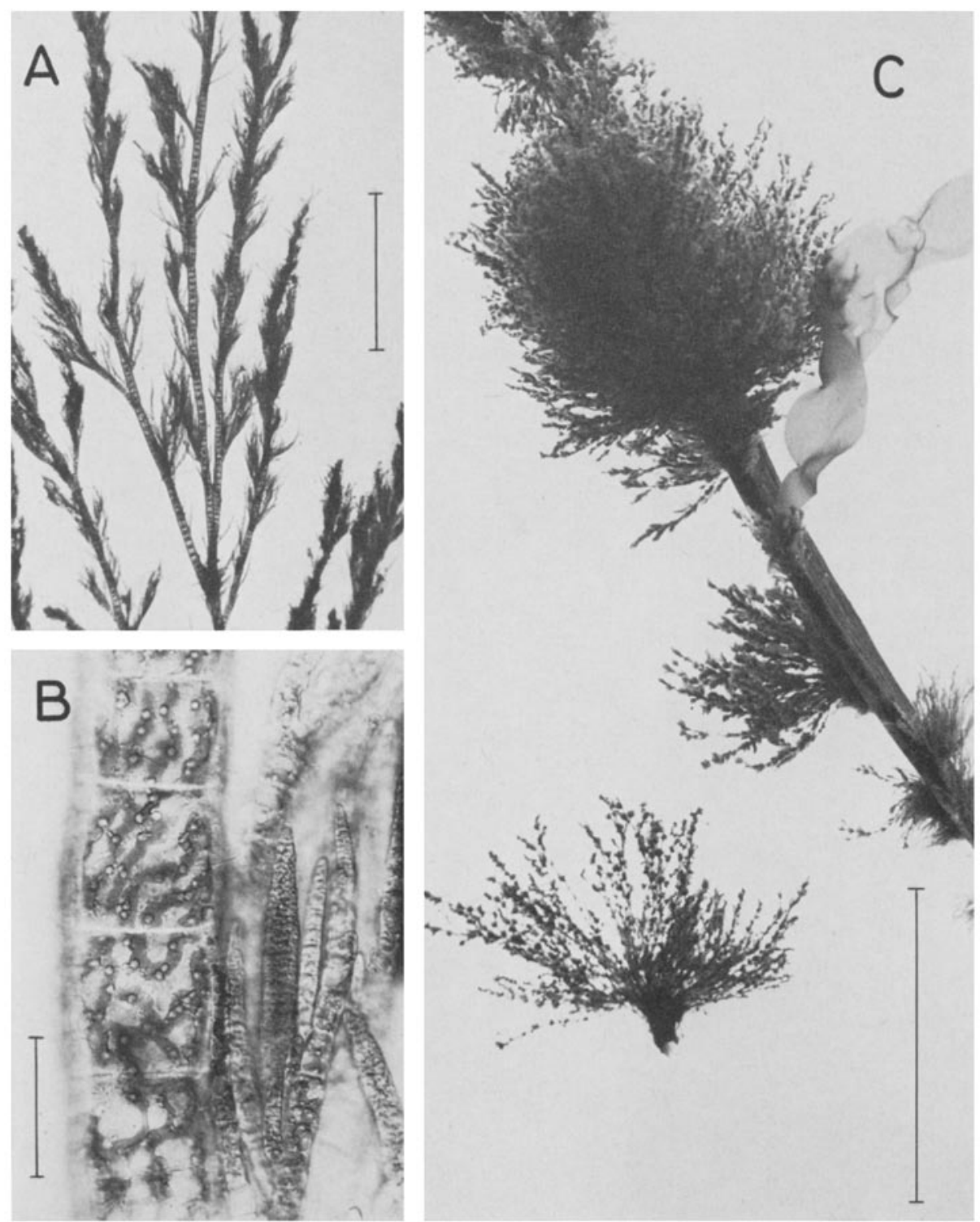

Abb. 49: Ectocarpus fasciculatus. A, B Auf einem Stein gewachsen (26.7. 1971). C Zusammen mit Ulva auf Laminaria digitata (12. 7. 1975). Maßstredken: $\mathrm{A}=1 \mathrm{~mm} ; \mathrm{B}=100 \mu \mathrm{m}$; $\mathrm{C}=1 \mathrm{~cm}$ 

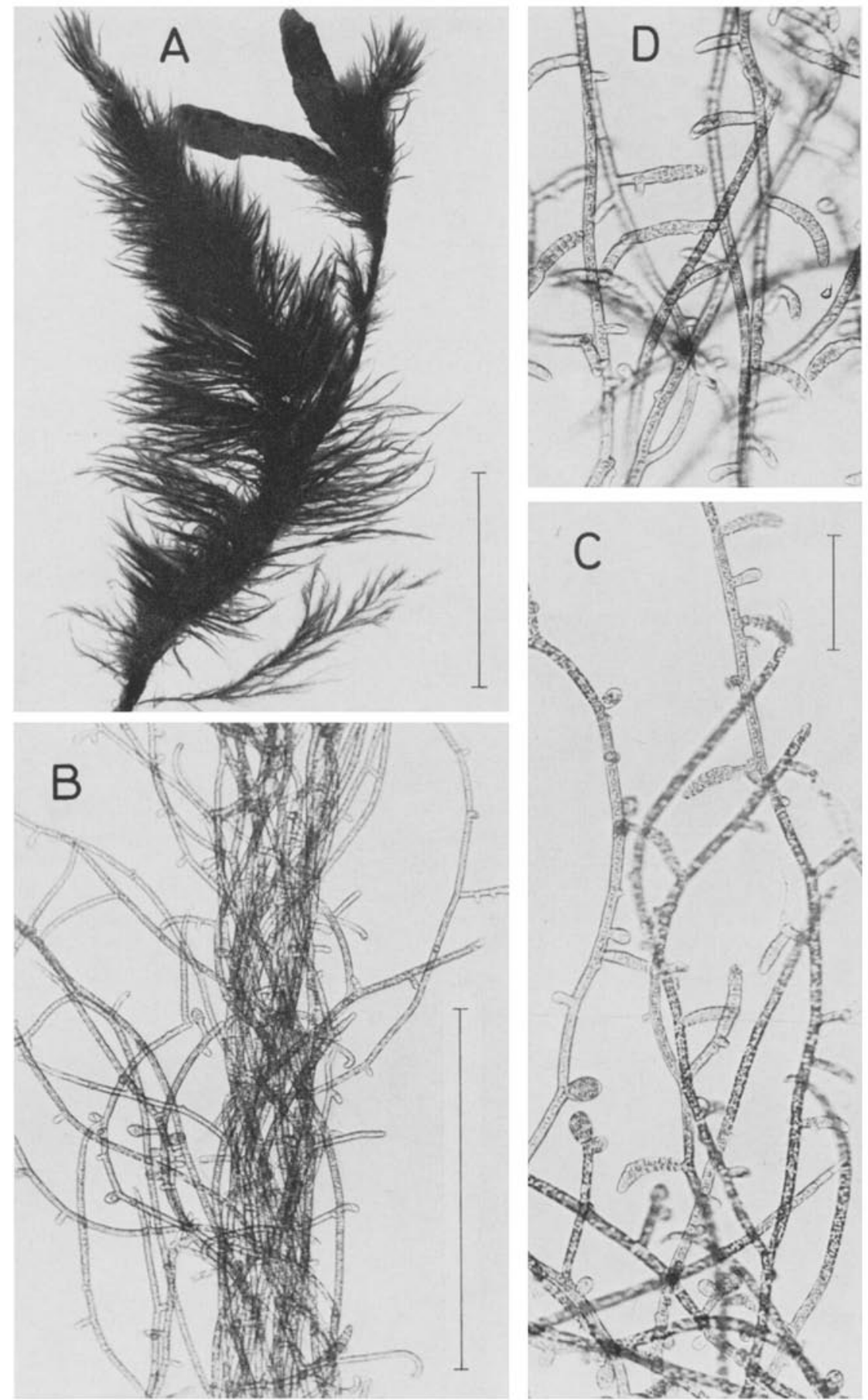

Abb. 50: Spongonema tomentosum. A Zopfige Stränge auf Fucus spiralis, ganz unten rechts eine Pflanze yon Pilayella littoralis (24. 5. 1972). B-D Abschnitte aus einem jungen Strang, unten nur mit unilokulären, weiter oben nur mit plurilokulären Sporangien (17. 3. 1975). Maßstrecken: $A=5 \mathrm{~cm} ; B=500 \mathrm{~mm}, \mathrm{C}, \mathrm{D}=100 \mathrm{~mm}$ 


\section{Spongonema tomentosum (Huds.) Kütz.}

Im Mai und Juni findet man auf Fucus-Arten, besonders auf Fucus serratus, die dunkelbraunen, zopfartigen Stränge von Spongonema tomentosum (Abb. 50 A). Die nur wenig zerteilten filzigen Zöpfe sind meist $4-6 \mathrm{~cm}$, mitunter auch über $10 \mathrm{~cm}$ lang. Ihr Mittelstrang besteht aus chromatophorenarmen, seilartig zusammengedrehten Fäden. Sie sind nur wenig und unregelmäßig verzweigt, hakig gebogene Kurztriebe umklammern die nach außen wachsenden Fäden und ziehen sie an den Mittelstrang heran.

Diesen Aufbau veranschaulicht Abbildung $50 \mathrm{~B}$ an einem Ausschnitt aus einem jungen, am 17. März 1975 knapp $1 \mathrm{~cm}$ hohen Thallus. Die Pflanze trägt in ihrem unteren Teil noch reichlich unilokuläre Sporangien, in dem Ausschnitt bei $\mathrm{C}$ auch schon plurilokuläre. In den oberen Teilen sind diese ausschließlich vorhanden (D); unilokuläre Sporangien werden mit vorrückender Jahreszeit nicht mehr angelegt.

Bevor sich im Frühjahr zottige, seilartig zusammengedrehte Büschelchen zeigen, findet man auf der Wirtspflanze einen kurzrasigen, pelzartigen Oberzug (Abb. $51 \mathrm{~A}$, B). Solche Prostadien kann man während des ganzen Winters finden; ihre Fäden tragen überwiegend unilokuläre Sporangien. Sie enthalten nur wenige auffallend große Zoosporen mit deutlich erkennbarem Augenfleck (C).

Die ausgewachsene Pflanze fruktifiziert an den freien Fäden reichlich mit plurilokulären Sporangien, die mitunter verzweigt sind. Uber dem sporangientragenden Fadenabschnitt folgt eine Zone von kurzen, chromatophorenreichen Zellen in reger Teilung; der Faden endet haarartig mit langgestreckten Zellen.

Spongonema tomentosum wird im Juli überständig und verschwindet im August. Im September kann man wieder kurze, pelzige Uberzüge mit plurilokulären Sporangien finden, sie wachsen aber nicht mehr zu einer zopfigen Generation heran. Von November bis Januar tragen die Prostadien nur unilokuläre Sporangien. 

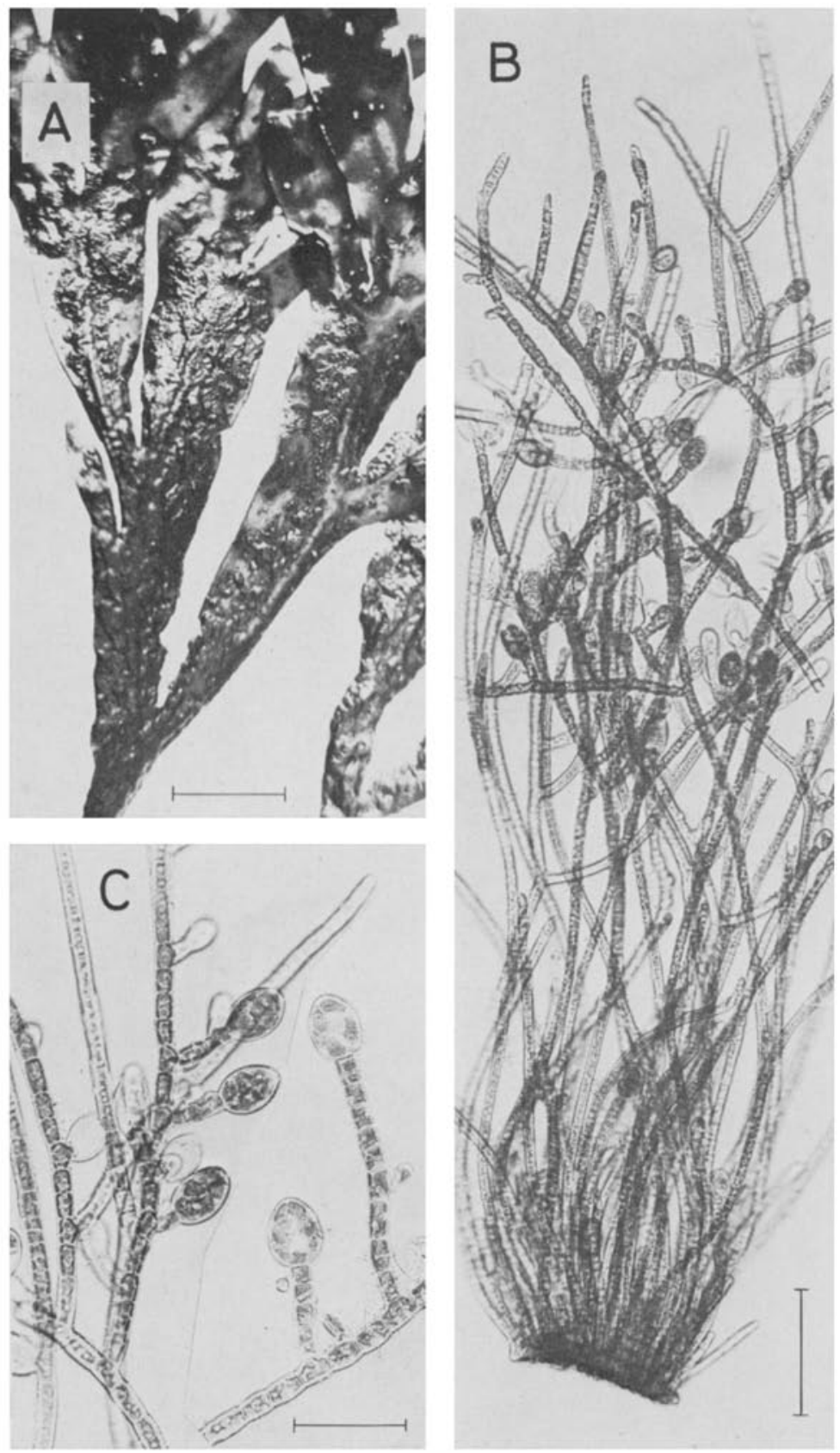

Abb. 51: Spongonema tomentosum, Prostadien auf Fucus vesiculosus. A Kurzer, pelziger Überzug. B, C Büschel mit überwiegend unilokulären Sporangien, ein einzelnes plurilokuläres an einem Fadenende (1.2.1975). Maßstrecken: $A=1 \mathrm{~cm} ; \mathrm{B}=100 \mu \mathrm{m} ; \mathrm{C}=50 \mu \mathrm{m}$ 


\section{Laminariocolax tomentosoides (Farl.) Kylin}

Der Gattungsname bringt das obligate Zusammenleben dieser Alge mit ihrer Wirtspflanze zum Ausdruck. Ihre Basis lebt endophytisch im Gewebe von Laminaria und bildet im Frühjahr zunächst auf der Oberfläche ein basales Lager mit plurilokulären Sporangien, auf dem sich dann die dünnen aufrechten Fäden erheben. Diese Besonderheiten machten die Abtrennung aus der Gattung Ectocarpus notwendig. Der Artname tomentosoides weist auf eine Ahnlichkeit der seilartigen Büschel mit Spongonema tomentosum hin (Abb. $52 \mathrm{~A}, \mathrm{~B})$.

Man findet die Alge im März und April in dem dichten, etwa $1 \mathrm{~cm}$ hohen braunen Pelz, der die Thallusenden der Laminaria-Arten häufig bedeckt. Der abgeschabte Bewuchs enthält im allgemeinen verschiedene Epiphyten, die unverzweigten Fäden von Litosiphon filiformis (Abb. 67) oder die Büschel von Ectocarpus fasciculatus (Abb. 48) und Giffordia hincksiae (Abb. 58). Die Zöpfchen von Laminariocolax tomentosoides sind etwas heller gefärbt und bestehen aus sehr dünnen, seilartig umeinandergewundenen Fäden. Sie verzweigen sich nur selten zu Langtrieben; die langen einreihigen plurilokulären Sporangien, nicht dicker als der Faden selbst, sitzen den Zellen meist ungestielt auf und stehen etwa rechtwinklig $a b(C)$. Mitunter sitzen sie auch an wenigzelligen Kurztrieben (D). Die Zellen enthalten im allgemeinen zwei plattenförmige Chromatophoren. 


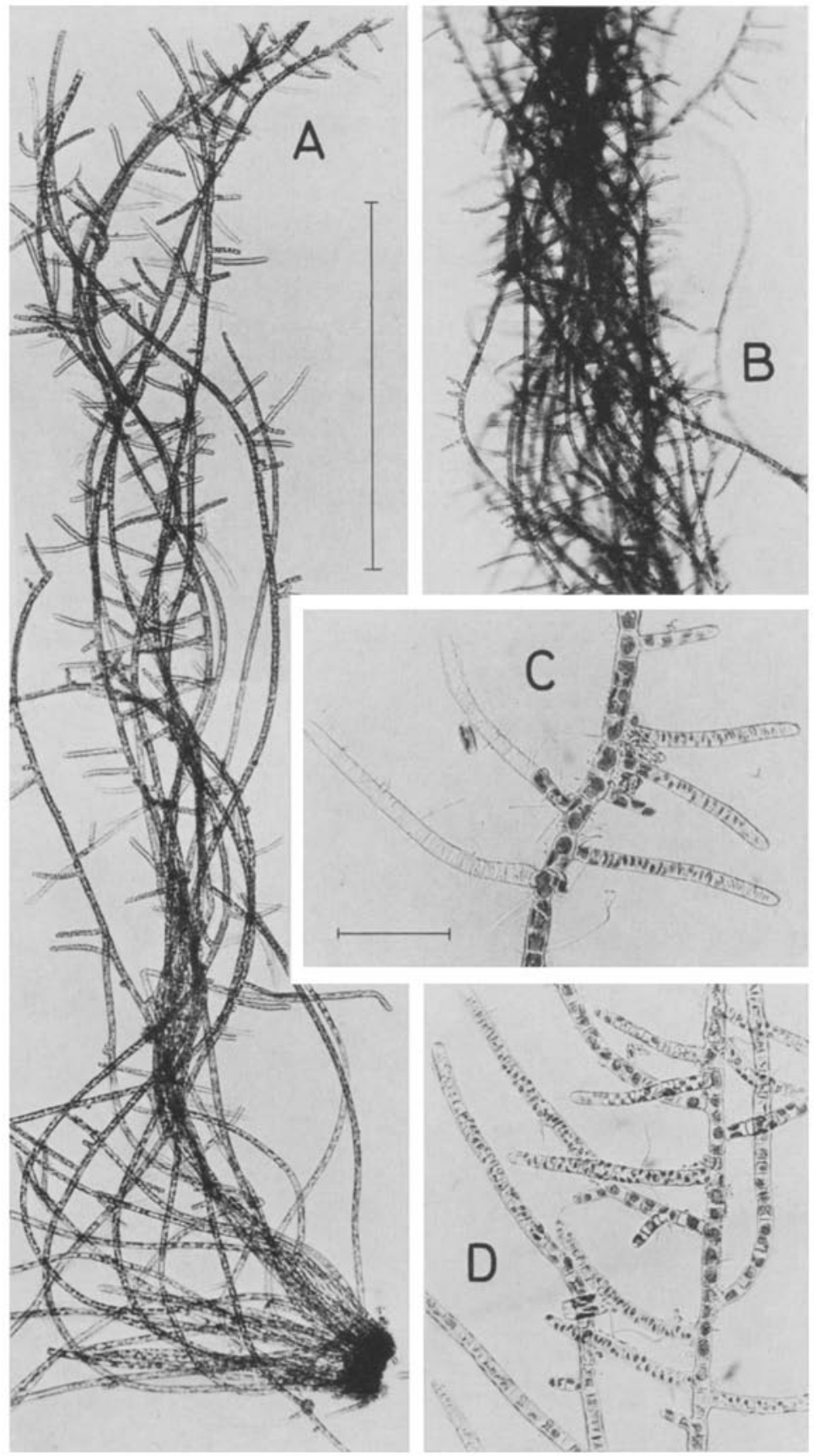

Abb. 52: Laminariocolax tomentosoides. A, B Habitus einer kleinen Pflanze und Ausschnitt aus einem dichten Strang (1. 4. 1975). C, D Fadenstücke mit Sporangien. Maßstrecken: A, B = $0,5 \mathrm{~mm} ; \mathrm{C}, \mathrm{D}=50 \mathrm{~mm}$ 


\section{Pilayella Bory}

Neben Pilayella littoralis kommt bei Helgoland eine Form mit so eindeutig andersartigen Merkmalen vor, daß sie nicht als Varietät dieser Art angesehen werden kann. Um die einschlägige Literatur nicht noch mehr $\mathrm{zu}$ belasten, bleibt sie zunächst unbenannt; ihre eingehende Beschreibung und Abbildung soll den Vergleich mit Formen benachbarter Florengebiete ermöglichen und die Frage ihres taxonomischen Status zur Diskussion stellen. Sie kann nicht mit $P$. rupincola identifiziert werden, die sich nach Russell (1961) morphologisch nicht wesentlich von $P$. littoralis unterscheidet.

\section{Pilayella littoralis (L.) Kjellm.}

Pilayella littoralis ist in der Gezeitenzone Helgolands weit verbreitet. Die dunkelbraunen, verzweigten Büschel aus seilartig zusammengedrehten Strängen treten stets in größerer Menge auf; sie wachsen epiphytisch auf Fucus oder bedecken größere Flächen auf Steinen mit einem geschlossenen Uberzug.

Die in Ketten aneinandergereihten Sporangien - oft bis zu 20 - sind das unverkennbare Merkmal der Gattung. Die unilokulären Sporangien sind tonnenförmig, meist isodiametrisch oder auch etwas kürzer als breit. Im allgemeinen sind sie endständig an kurzen Seitenzweigen und tragen eine haarartige Spitze von inhaltsarmen Zellen $(B, D)$. Sie können aber auch interkalar in Fäden eingeschaltet sein, die sich oberhalb noch verzweigen.

Gegenständige Verzweigungen findet man mühelos, besonders an jungen Pflanzen; sie sind für Pilayella littoralis charakteristisch. Es entspringen aber auch einzelne Zweige zwischen den Paaren, und unregelmäßige Verzweigungen können an den Endabschnitten älterer Pflanzen vorherrschen.

Bei den meisten Pflanzen triff man nur unilokuläre Sporangien an, seltener kommen auch plurilokuläre Sporangien auf derselben Pflanze vor (B). Auch sie sind kettenartig aneinandergereiht, doch ist ihre gegenseitige Abgrenzung schwerer zu erkennen als bei den unilokulären. Längsteilungen einzelner Zellen vor der Fertilisierung sind bei beiderlei Sporangien nicht selten $(\mathrm{C})$.

Im Juni und Juli findet man zwischen den derben, strangartigen Pflanzen auch locker verzweigte, sehr viel zartere Exemplare, die ausschließlich plurilokuläre Sporangien tragen, die Gametophyten.

Pilayella littoralis kommt während des ganzen Jahres in mehreren aufeinanderfolgenden Generationen vor. 

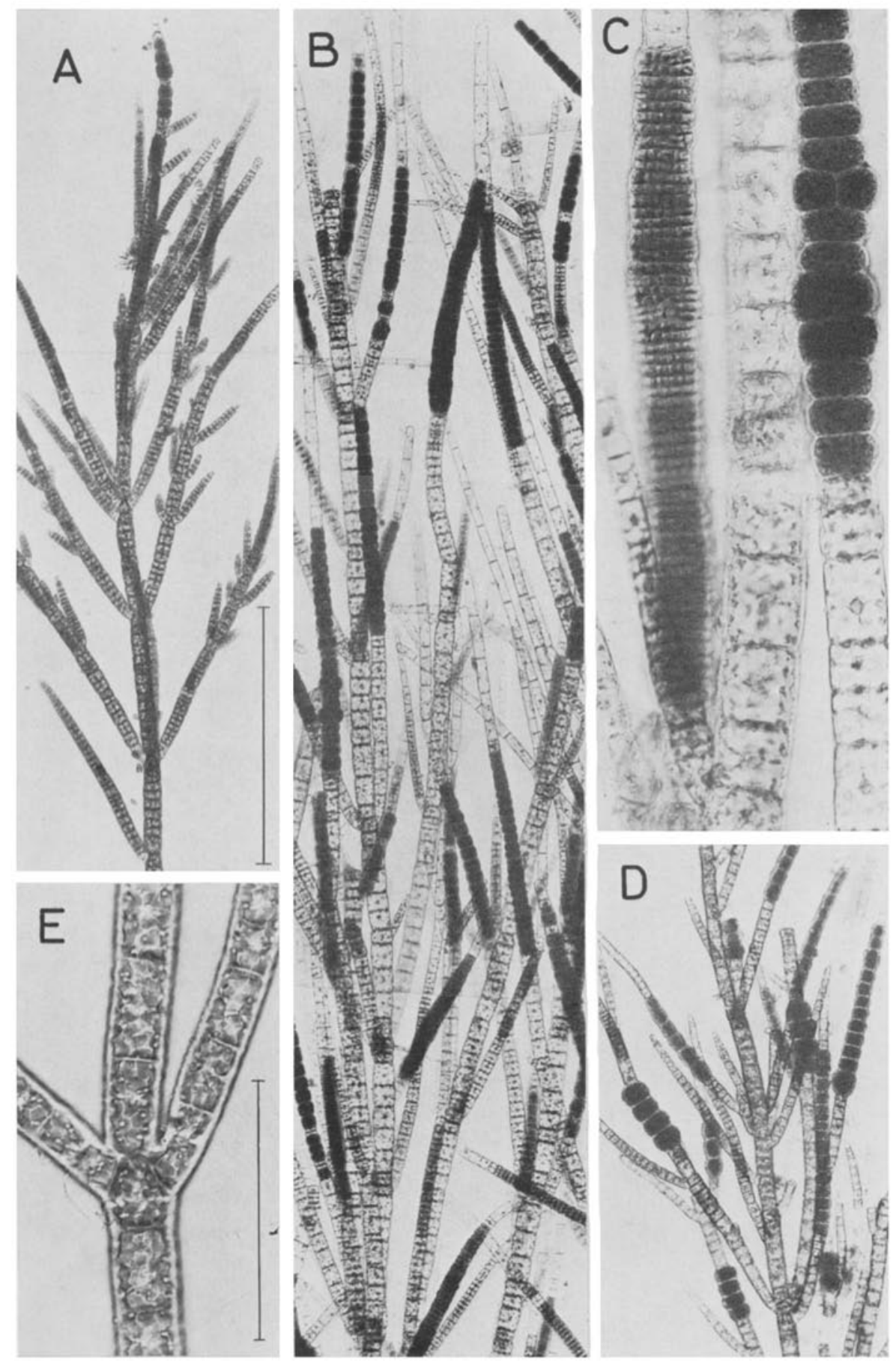

Abb. 53: Pilayella littoralis. A Junge, überwiegend gegenständig verzweigte Pflanze (aus Präparat vom 6. 3. 1959). B Vollentwickelte Pflanze mit uni- und plurilokulären Sporangien (aus Präparat vom 9. 5. 1960). C Detail aus B. D Pflanze mit unilokulären Sporangien (26. 7. 1971). E Zellen mit Chromatophoren. Maßstrecken: $A, B, D=500 \mu \mathrm{m} ; \mathrm{E}=100 \mu \mathrm{m}$ 

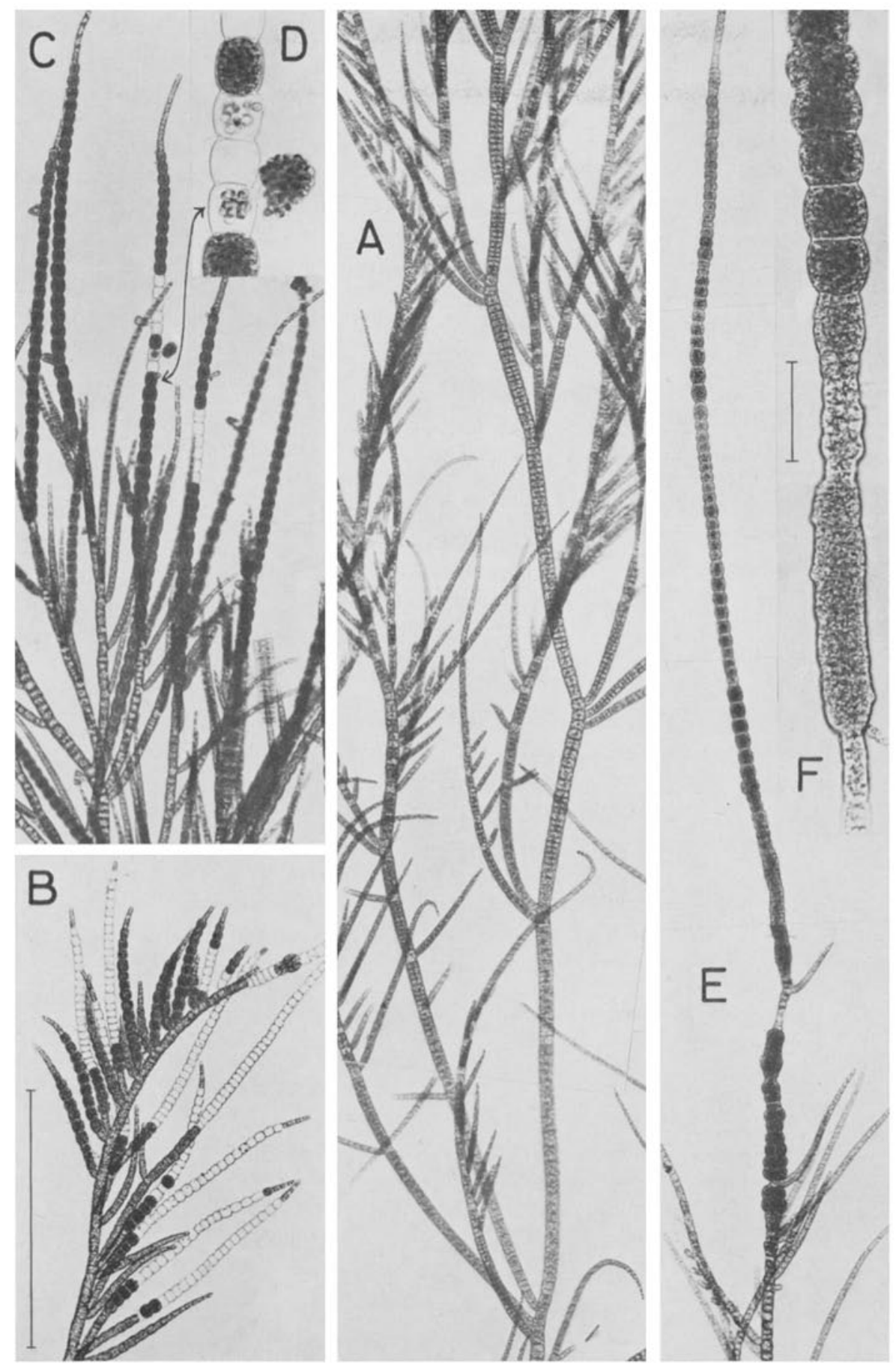

Abb. 54: Pilayella spec. A Habitus einer jungen Pflanze (aus einem Präparat vom 16. 3. 1964). B, C Fertile Thallusenden (24.4. 1969 und 17. 4. 1972). D Detail aus C: Entleerung von unilokulären Sporangien, die Pfeilspitzen zeigen auf dieselbe Zelle der Sporangienreihe. E, F Mehrfach wechselnde Abschnitte von uni- und plurilokulären Sporangien (1.6. 1972). Maßstrecken: $A-C, E=500 \mu \mathrm{m} ; \mathrm{D}, \mathrm{F}=50 \mu \mathrm{m}$ 
Pilayella spec.

Diese Form unterscheidet sich in mehrfacher Hinsicht ganz wesentlich von Pilayella littoralis. Sie kommt nicht in der Gezeitenzone vor, und nur bei besonders stark ablaufendem Wasser kann man sie an ihrem Standort sammeln. Die locker verzweigten Büschel werden in den Frühjahrsmonaten oft reichlich am Strand ausgeworfen; nach ihrem Habitus könnte man sie für Ectocarpus siliculosus halten, und erst bei mikroskopischer Prüfung wird die Alge durch ihre kettenförmigen Sporangien als Pilayella erkannt. Die zarte und etwas schlïpfrig sich anfühlende Pflanze ist übrigens gegen Trockenliegen recht empfindlich; sie stirbt schnell ab und wird dabei grünlich. Wie bei Ectocarpus siliculosus sind die Hauptfäden seilartig umeinandergewunden, aus denen sich dann die locker flutenden Zweigbüschel lösen.

Der Verzweigungsmodus ist ein absolutes Unterscheidungsmerkmal gegenüber Pilayella littoralis. Gegenständige $\mathrm{Zweige} \mathrm{kommen} \mathrm{nicht} \mathrm{vor,} \mathrm{dagegen} \mathrm{entspringen} \mathrm{of}$ 2 bis 5 Seitenzweige einseitig übereinander aus benachbarten Zellen (A). Auch die Zweige höherer Ordnung sind vielfach einseitig gereiht. In solchen Zweigenden bleiben die dicht gedrängten Sporangienketten meist nur kurz (B).

Die Fäden dieser Pilayella-Art sind etwas duinner als die der Schwesterart; die Zweigenden jüngerer Pflanzen sind oft hakig gekrümmt (A). Die unilokulären Sporangien sind im allgemeinen schlanker als bei Pilayella littoralis (C). Besonders die an den Thallusenden gebildeten Sporangien können in lange Haare mit spitzer Endzelle auslaufen, während die Haare über den reifen Sporangien von Pilayella littoralis sich nur unwesentlich verjüngen.

Die meisten Pflanzen tragen unilokuläre Sporangien, nur selten kommen beiderlei Sporangien auf derselben Pflanze vor, mitunter in einer langen Kette abwechselnd (E, F). Gelegentlich teilen sich die Sporangienanlagen durch eine Längswand.

Pilayella spec. kommt bei Helgoland nur von März bis Mitte Mai vor, während Pilayella littoralis - in mehreren Generationen - fast das ganze Jahr über zu finden ist.

\section{Giffordia Batters}

Die Arten dieser Gattung sind durch ihren Habitus sowie die Form und Anordnung ihrer plurilokulären Sporangien recht gut gekennzeichnet. Aus der Mannigfaltigkeit der Erscheinungsformen konnten bei Giffordia granulosa und Giffordia fuscata hier nur die am häufigsten gefundenen wiedergegeben werden. Ausfuhrlich sind diese von Kuckuck $\uparrow$ (1961) beschrieben und abgebildet worden. 


\section{Giffordia granulosa (Sm.) Hamel}

Einer kräftigen Hauptachse entspringen im allgemeinen gegenständige Verzweigungen (A, B). Ihr Winkel zur Hauptachse schwankt bei verschiedenen Pflanzen zwischen etwa $45^{\circ}$ und knapp $90^{\circ}$, was sich dann auch auf die Erscheinungsform auswirkt. Die oft nur geringe Höhe der Achsenzellen weist auf ihre rege interkalare Teilung hin. Die Hauptachsen sind an ihrer Basis von einem Rhizinenmantel umbüllt, der die Alge am Substrat befestigt.

Mit beginnender Fertilisierung ändert sich der Verzweigungsmodus: Sporangien und vegetative Zweige, deren Endzellen sich haarartig verlängern, stehen gereiht an der Innenseite ihrer Träger (A, B). Die großen, stets mit breiter Basis aufsitzenden plurilokulären Sporangien sind schief-eiförmig mit konvexer Außenseite; sie können gedrungen oder stark verlängert sein (D), ihre Form kann aber selbst auf derselben Pflanze erheblich schwanken. Unilokuläre Sporangien wurden bei Helgoland nicht gefunden.

Giffordia granulosa wächst auf Steinen oder schwimmenden Gegenständen, häufig auch epiphytisch auf untergetauchten Algen wie Laminaria, Chorda, Desmarestia aculeata, um nur einige zu nennen. Die Alge kann wenige Zentimeter hoch sein und dann etwas robust wirken oder bis $20 \mathrm{~cm}$ lange, locker flutende Büschel bilden. Giffordia granulosa ist von April bis September nicht selten in Kratzmaterial von den Molen oder am Strand und im Plankton treibend zu finden.

\section{Giffordia sandriana (Zanard.) Hamel}

Die locker verzweigten Büschel sind auffallend zart. Die Verzweigung der Hauptfäden ist zerstreut (A); den Zellen der basalen Fadenabschnitte entspringen Rhizinen, die an den Stämmchen herablaufen und sie am Substrat befestigen (E). Die Fadenzellen sind meist ebenso bis doppelt so lang wie breit.

Die plurilokulären Sporangien stehen an der Innenseite ihrer Tragäste gereiht, im allgemeinen ohne zwischengeschaltete vegetative Astchen. Sie sind etwas unsymmetrisch, mitunter dem Tragfaden angeschmiegt, verlängert eiförmig und zugespitzt. Sie sitzen ihrer Ursprungszelle nur mit einer schmalen Basis auf (C, D).

Giffordia sandriana ist keine häufige Alge; die bis zu $20 \mathrm{~cm}$ langen Büschel wachsen stets untergetaucht auf Steinen oder Schiffsböden sowie epiphytisch in tieferen Gezeitenbecken von Mai bis September. In völlig normaler Ausbildung wurde sie auch im Oktober und November in einem flachen Hälterungsbecken mit durchfließendem Seewasser gefunden. 


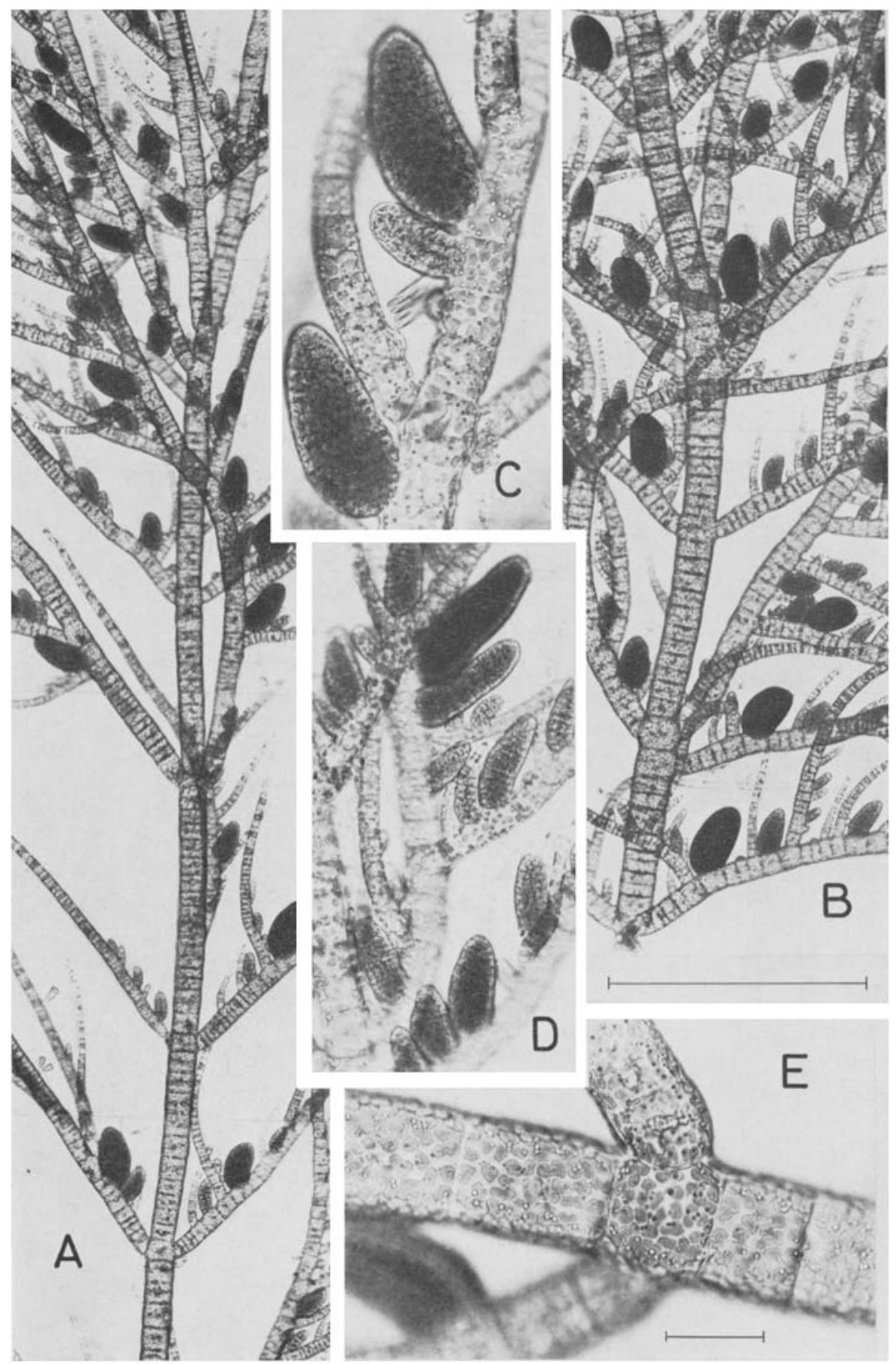

Abb. 55: Giffordia granulosa. A, B Lodker und dichter verzweigte Wuchsformen (27. 4. 1974 und 7. 6. 1973). C, D Variation der Sporangienform. E Zellen mit Chromatophoren. Maßstrecken: $A, B=500 \mu \mathrm{m} ; \mathrm{C}, \mathrm{E}=50 \mu \mathrm{m}$ 


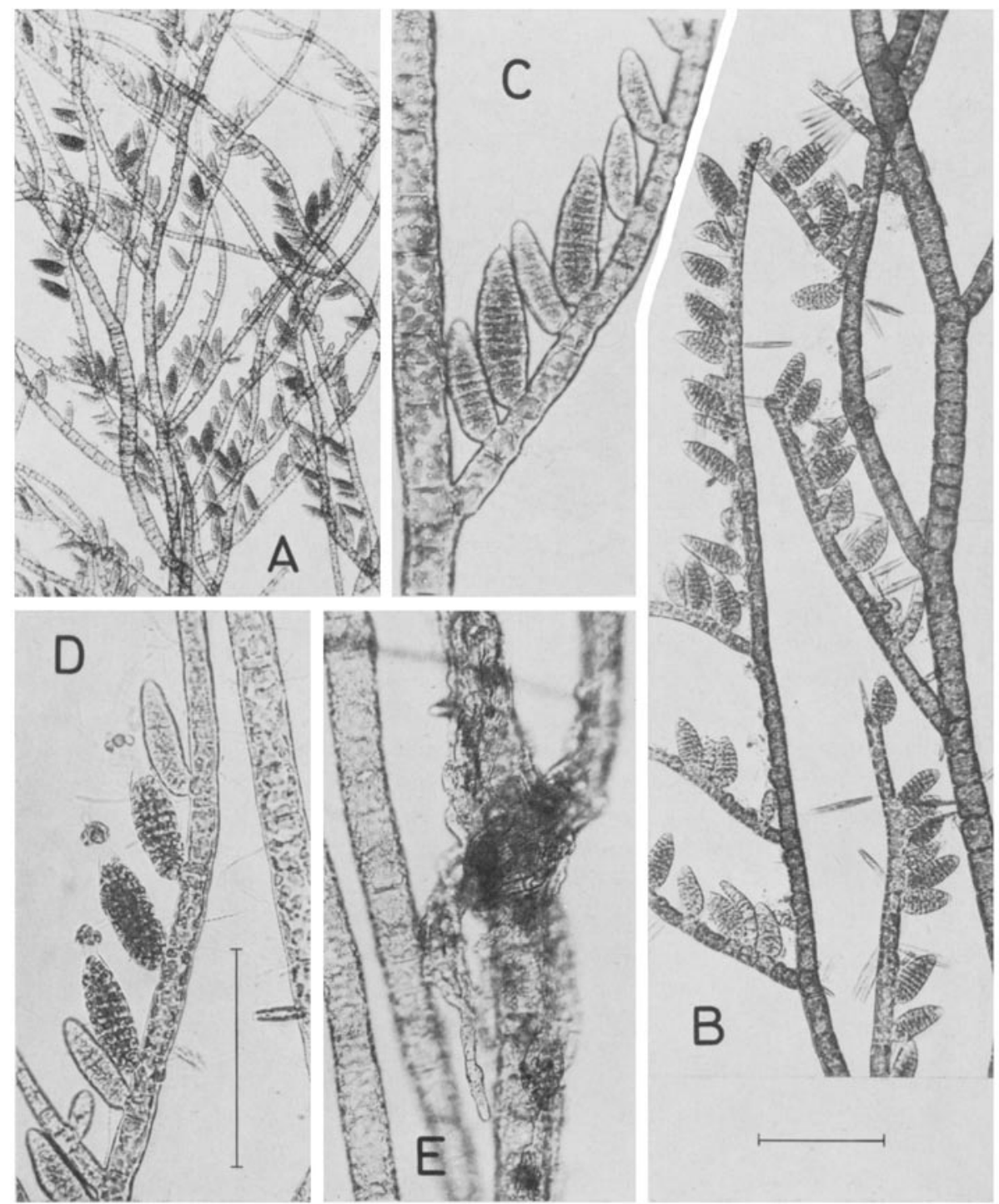

Abb. 56: Giffordia sandriana. A Teil eines Büschels (11. 9. 1971). B, C Fadenstücke mit plurilokulären Sporangien. D Drei Sporangien beginnen auszuschwärmen. E Rhizinen an der Basis eines Fadens. Maßstrecken: $\mathrm{B}, \mathrm{E}=100 \mu \mathrm{m} ; \mathrm{C}, \mathrm{D}=100 \mu \mathrm{m}$ 
Giffordia fuscata (Zanard.) Kuck. syn. Giffordia ovata (Kjellm.) Kylin

Der hier angewandte Artname wird von Kuckuck $†$ (1961) begründet; in dieser Studie werden auch mehrere Varietäten der Alge beschrieben.

Die Besonderheit dieser Art ist ihr wirteliger Aufbau. Durch die stockwerkartig aus mehreren benachbarten Zellen entspringenden gegenständigen Verzweigungen erscheinen die Hauptachsen in Knoten und Internodien gegliedert (A). Dabei können auch Sporangien die Stelle von Seitenzweigen einnehmen $(B, C)$. An ihnen kann sich der Verzweigungsmodus wiederholen, oft aber tragen die Zweige nur opponierte Sporangien. Plurilokuläre und unilokuläre Sporangien (D) können gemeinsam wie auch auf getrennten Pflanzen vorkommen.

Die Büschel von Giffordia fuscata werden bei Helgoland nur etwa $2 \mathrm{~cm}$ hoch. Sie wachsen von März bis Juli in 2-5 m Tiefe an Hafenmauern, Steinen und Krallen von Laminaria byperborea. Wie die anderen Arten der Gattung trifft man sie auch nach stürmischem Wetter im Plankton treibend an. Nur bei besonders niedrigem Wasserstand kann man sie gelegentlich auch an ihrem Standort sammeln.

\section{Giffordia bincksiae (Harv.) Hamel}

Die mehrfach wiederholte Einseitigkeit der oftmals fast senkrecht auf ihren Achsen inserierten $Z$ weige gibt dieser Alge ihr unverkennbares Gepräge. Die kegelförmigen plurilokulären Sporangien, die mit breiter Basis lückenlos nebeneinandersitzen, sind ein kennzeichnendes Merkmal. Ohne die Unterbrechung durch vegetative Ästchen wäre das Bild eines Sägeblattes vollkommen. Die nahezu kugeligen, ebenfalls ihrer Ursprungszelle breit aufsitzenden unilokulären Sporangien findet man nur selten auf Pflanzen, die zugleich auch plurilokuläre Sporangien tragen $(D, E)$. Häufig sind die Zweigenden hakig zurüdkgekrümmt.

Giffordia bincksiae ist ein verbreireter Epiphyt auf Algen des Sublitorals wie Laminaria digitata oder Desmarestia aculeata. Man findet die 1 bis $5 \mathrm{~cm}$ hohen Büschel von März bis September. 

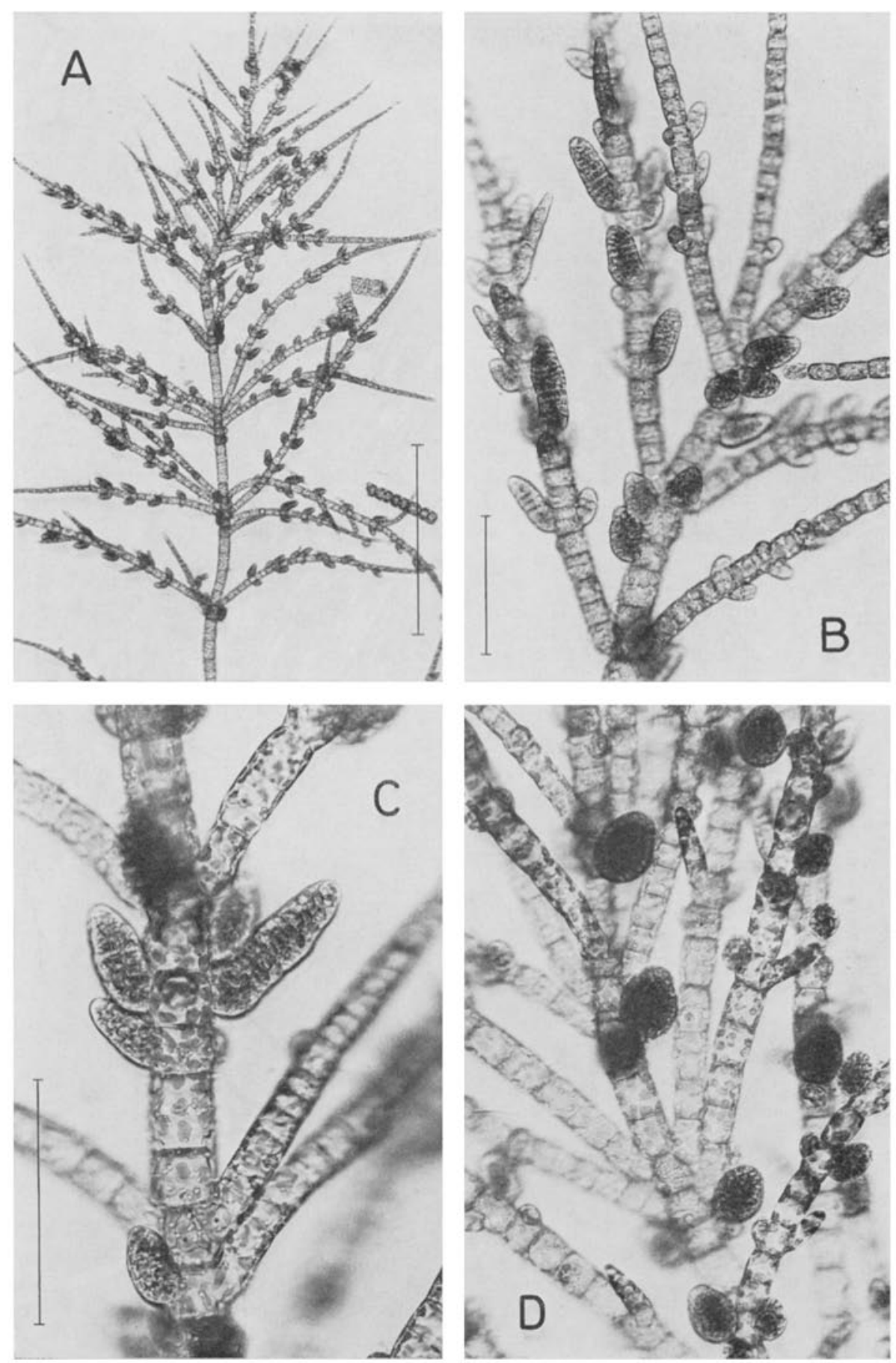

Abb. 57: Giffordia fuscata. A Oberer Teil einer Pflanze (11. 4. 1972). B, C Zweigstücke mit plurilokulären, $\mathrm{D}$ mit unilokulären Sporangien. Maßstrecken: $\mathrm{A}=500 \mu \mathrm{m} ; \mathrm{B}, \mathrm{D}=100 \mu \mathrm{m}$; $\mathrm{C}=100 \mu \mathrm{m}$ 

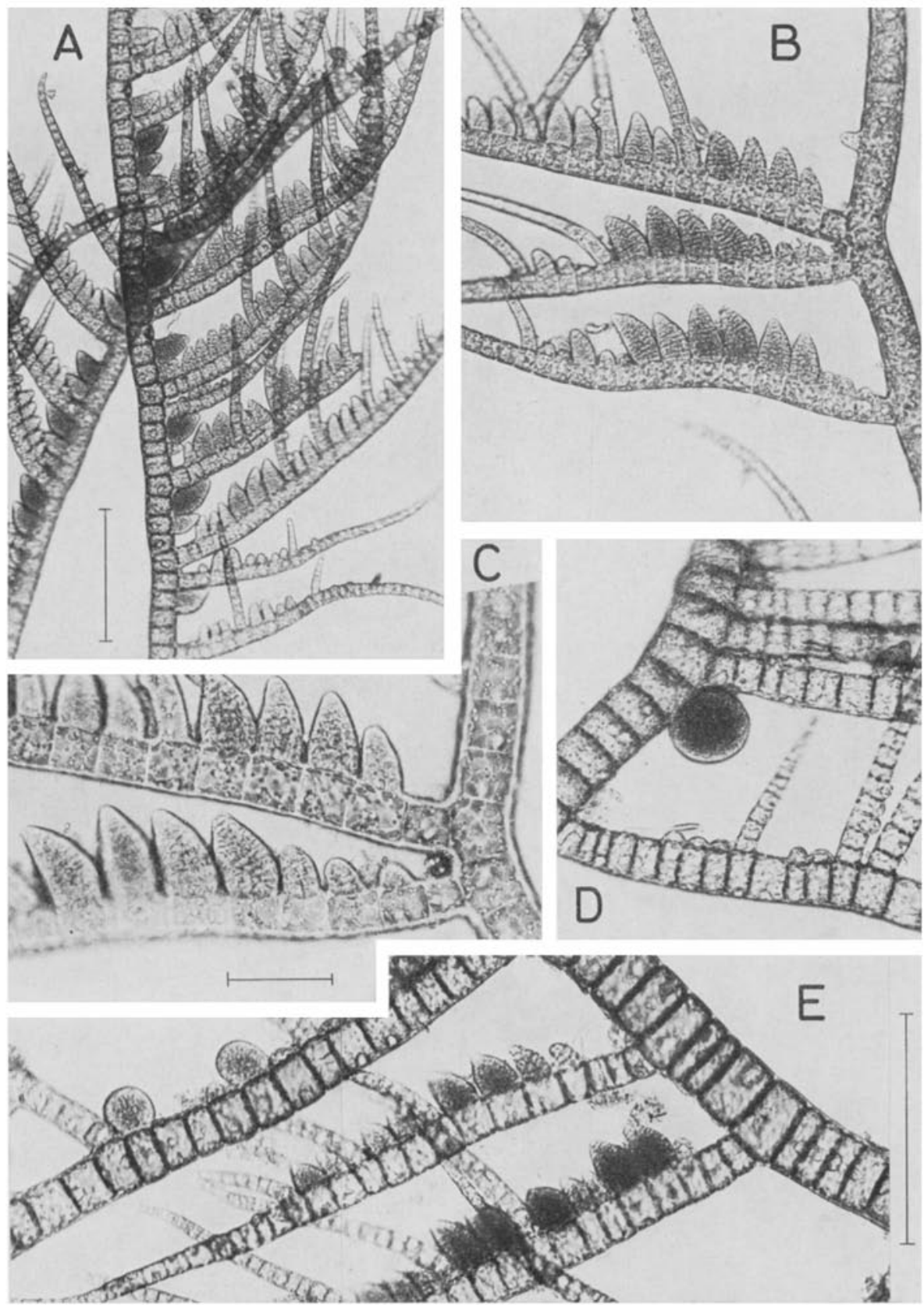

Abb. 58: Giffordia bincksiae. A - C Zweigstücke mit plurilokulären Sporangien. D, E Unilokuläres Sporangium und Zweigstïck mit beiderlei Sporangien. Maßstrecken: $A=200 \mu \mathrm{m}$; $\mathrm{B}, \mathrm{D}, \mathrm{E}=200 \mu \mathrm{m} ; \mathrm{C}=50 \mu \mathrm{m}$ 


\section{Sorocarpus micromorus (Bory) Silva}

Sorocarpus ist im Gebiet von Helgoland sicherlich nicht selten, jedoch triff man die Alge nur gelegentlich von März bis Juni nahe der Niedrigwassergrenze an. Losgerissene Exemplare treiben mitunter im Plankton.

Die etwas wattigen Büschel werden bis $8 \mathrm{~cm}$ hoch, die Hauptfäden winden sich seilartig umeinander. Sie erscheinen etwas sparrig durch die unregelmäßig inserierten, leicht abstehenden Zweige (A). Verzweigungen höherer Ordnung entspringen der Innenseite ihrer Achse. Sie endigen in echten farblosen Haaren mit teilungsfähigen Basalzellen. Die plurilokulären Sporangien sitzen den Ästchen einzeln oder zu kleinen Klumpen vereinigt auf $(C, D)$.

Aus den nicht kopulierenden Schwärmern erhielt Pedersen (1974) wieder eine Generation mit plurilokulären Sporangien. Die in der Basalzelle von Haaren und im Sporangium festgestellte Zahl von 9 Chromosomen spricht dafür, daß Sorocarpus micromorus - wenigstens im atlantischen Bereich seines Vorkommens - als haploid anzusehen ist.

\section{Acinetospora crinita (Carm. ex Harvey) Kornm.}

Mit ziemlicher Regelmäßigkeit ist diese Alge von Mai bis September in Kratzmaterial-Proben von den inneren Molen des Südhafens zu finden. Im allgemeinen schlingen sich die wenig verzweigten Fäden um Cladophora- oder Ceramium-Zweige (A). Die langen Fäden weisen mehrere Wachstumszonen auf. Kurze Hapteren entspringen meist aus benachbarten Zellen $(F)$. Eine Polarität ist nicht ausgebildet; zwischen ihren Verankerungen wachsen die Fäden schleifenartig aus. Die zylindrischen Zellen enthalten viele scheibenförmige Chromatophoren.

Nur gelegentlich triff man im Sommer Acinetospora als wattige Stränge von mehreren Dezimetern Länge an, die sich nahe der Niedrigwassergrenze an Algen festhalten. Ihre parallel verlaufenden oder auch mehr oder weniger seilartig umeinandergewundenen Fäden können dreierlei Fortpflanzungsorgane tragen, meist sind es plurilokuläre Sporangien (C, D), seltener unilokuläre (E) oder Monosporangien (G). Die plurilokulären Sporangien haben auffallend große Fächer (D); sie entlassen nahezu runde, zweigeißelige Zoosporen, die aber nur schwach beweglich sind. In einer ruhigstehenden Schale sinken die meisten der aus einem Sporangium entleerten Zoosporen zu Boden und sind schon am nächsten Tag als dichte Gruppe von Keimlingen aufzufinden $(\mathrm{H})$. Die verhältnismäßig großen Schwärmer aus den unilokulären Sporangien schwimmen längere Zeit in ruhiger Bewegung ohne phototaktische Orientierung umher. Die Monosporangien enthalten jeweils eine große kugelige, bereits im Sporangium von einer Membran umhïllte unbewegliche Monospore.

Öber entwicklungsgeschichtliche Zusammenhänge vgl. p. 97. 

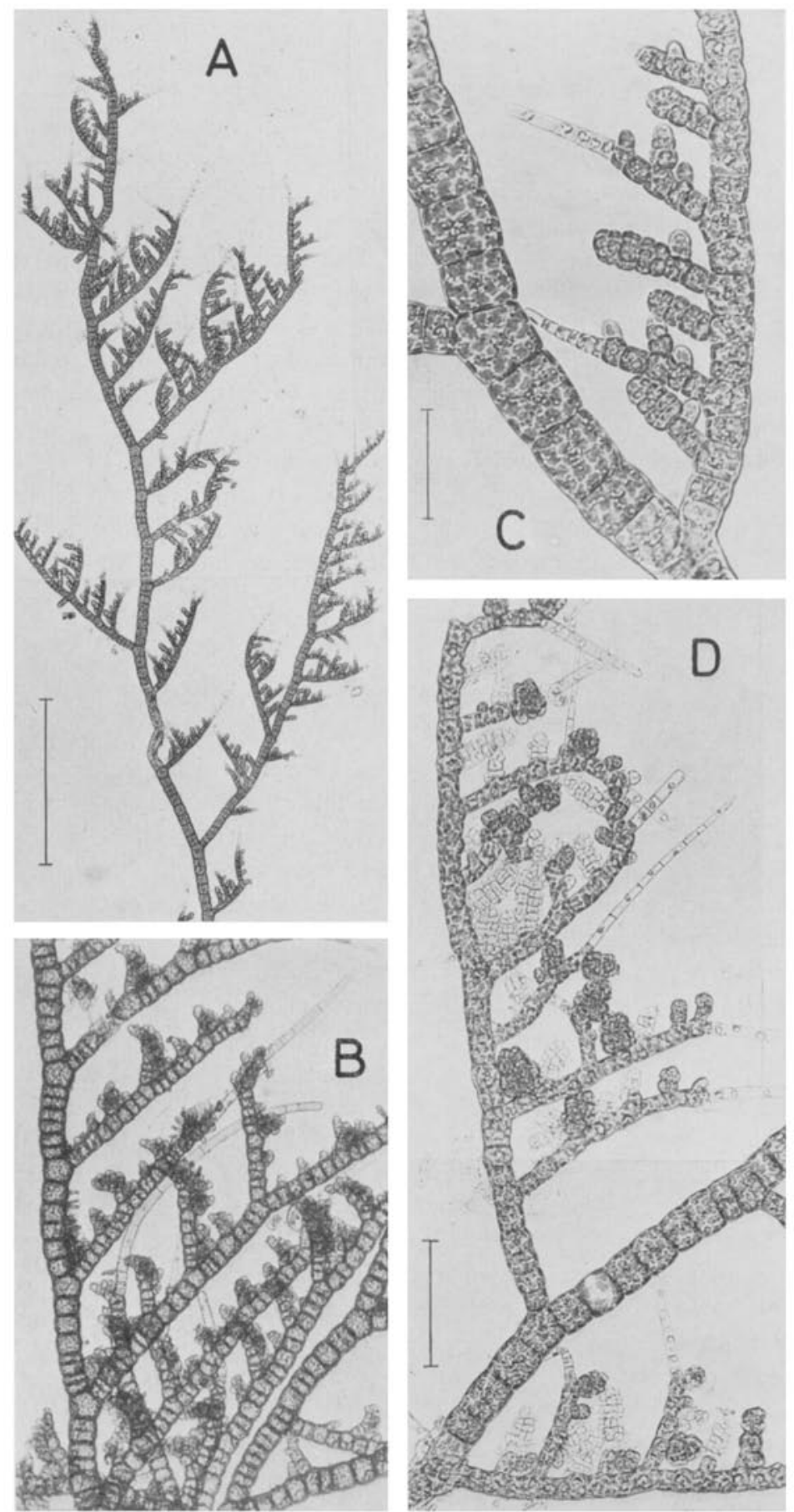

Abb. 59: Sorocarpus micromorus. A Ende eines Hauptfadens (29. 4. 1974). B, D Zweigstiicke mit Sporangien. C Scheibenförmige Chromatophoren und Zweig mit jungen Sporangien. Maßstrecken: $A=500 \mu \mathrm{m} ; \mathrm{C}=50 \mu \mathrm{m} ; \mathrm{D}=100 \mu \mathrm{m}$ 

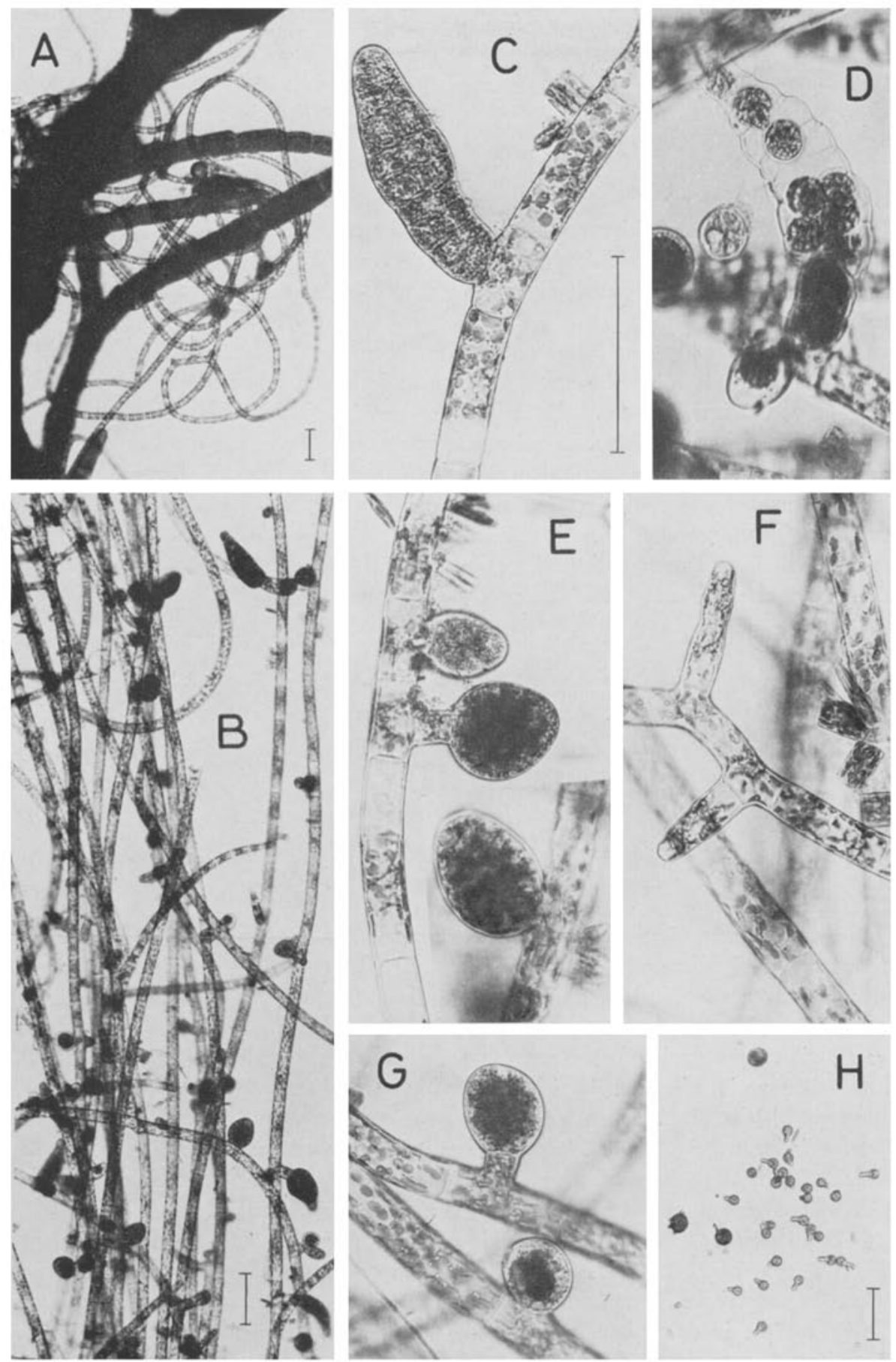

Abb. 60: Acinetospora crinita. A Um Cladophora geschlungene Fäden (9. 7. 1974). B Strang mit pluri- und unilokulären Sporangien (2. 7. 1975). C-D Fadenstücke mit plurilokulären, E mit unilokulären Sporangien. F Aus benachbarten Zellen entspringende Hapteren. G Monosporangien. H Gruppe von Keimlingen aus einem plurilokulären Sporangium und drei Monosporen. Maßstrecken: $\mathrm{A}=100 \mu \mathrm{m} ; \mathrm{B}=100 \mu \mathrm{m} ; \mathrm{C}-\mathrm{G}=100 \mu \mathrm{m} ; \mathrm{H}=100 \mu \mathrm{m}$ 


\author{
Kützingiella bolmesii (Batt.) Russell \\ in Parke et Dixon
}

Man kann diese Alge nicht als selten bezeichnen, kehrt sie doch regelmäßig in den Herbstmonaten an einigen exponierten Klippenzügen im Felswatt der Südwestseite in der Nähe des Lummenfelsens wieder. Allerdings tritt der niedrige pelzige Überzug, der die Kante solcher Schichtköpfe oft als meterlanges Band säumt, nicht besonders in Erscheinung, es sei denn durch die gelbe Farbe, die der Belag nach dem Antrocknen annimmt.

Der dicht geschlossene Rasen aufrechter Fäden von 2-3 mm. Höhe erhebt sich auf einem Geflecht von niederliegenden Stolonen. Die Fäden sind in ihrer unteren Hälfte spärlich verzweigt; eine deutliche Wachstumszone ist nicht vorhanden, die Endzellen sind nicht verlängert. Zahlreiche uni- und plurilokuläre Sporangien nehmen meist eine Zone in mittlerer Höhe der Fäden ein (A). Beiderlei Sporangien kommen auf derselben Pflanze vor (B); die gedrungen spindelförmigen plurilokulären Sporangien sind meist wenigzellig gestielt $(\mathrm{C})$, die eiförmig bis kugeligen unilokulären Sporangien mitunter auch sitzend oder endständig auf kurzen Fäden aus dem Basallager (D). Die Zellen enthal ten viele scheibenförmige Chromatophoren.

\title{
Ralfsiaceae
}

Ralfsia verrucosa (Aresch.) J. Ag.

Ihrer äußeren Erscheinung nach könnte man die in der oberen Hälfte der Gezeitenzone verbreitete schwärzliche Kruste eher für eine Flechte halten als für eine Braunalge. An der Hochwasserlinie wächst sie zusammen mit der Seepocke Balanus balanoides und mit Porpbyra umbilicalis; sie dominiert auf größeren Flächen des Felswatts, die wegen starker Brandung nur spärlich bewachsen sind, und sie erreicht ihre untere Grenze im obersten Bereich der geschlossenen Fucus serratus-Vegetation. Dort gesellen sich ihr die Krusten von Pbymatolithon lenormandii $\mathrm{zu}$ (Abb. 118), auch Petrocelis hennedyi (Abb. 105) und die in diesem Niveau noch seltene Rbodopbysema elegans (Abb. 126). Seepocken und viele der unzähligen Strandschnecken, ebenso die stellenweise vorkommenden Miesmuscheln tragen Ralfsia-Krusten.

In angetrocknetem Zustand erscheinen die Krusten schwarz, angefeuchtet werden sie olivbraun. Junge, bis etwa $1 \mathrm{~cm}$ große Krusten wachsen flach auf dem Substrat und zeigen konzentrische Zuwachsringe; bei den größeren und fertilen Krusten wölbt sich die Oberfläche in der Mitte zu unregelmäßig warzig-höckerigen Sori auf (A). Nach längerem Austrocknen heben sich die Ränder der nur lose mit einem Rhizoidenfilz haftenden Krusten vom Substrat ab und rollen sich ein, größere Krusten zerreißen auch in der Mitte (B). 

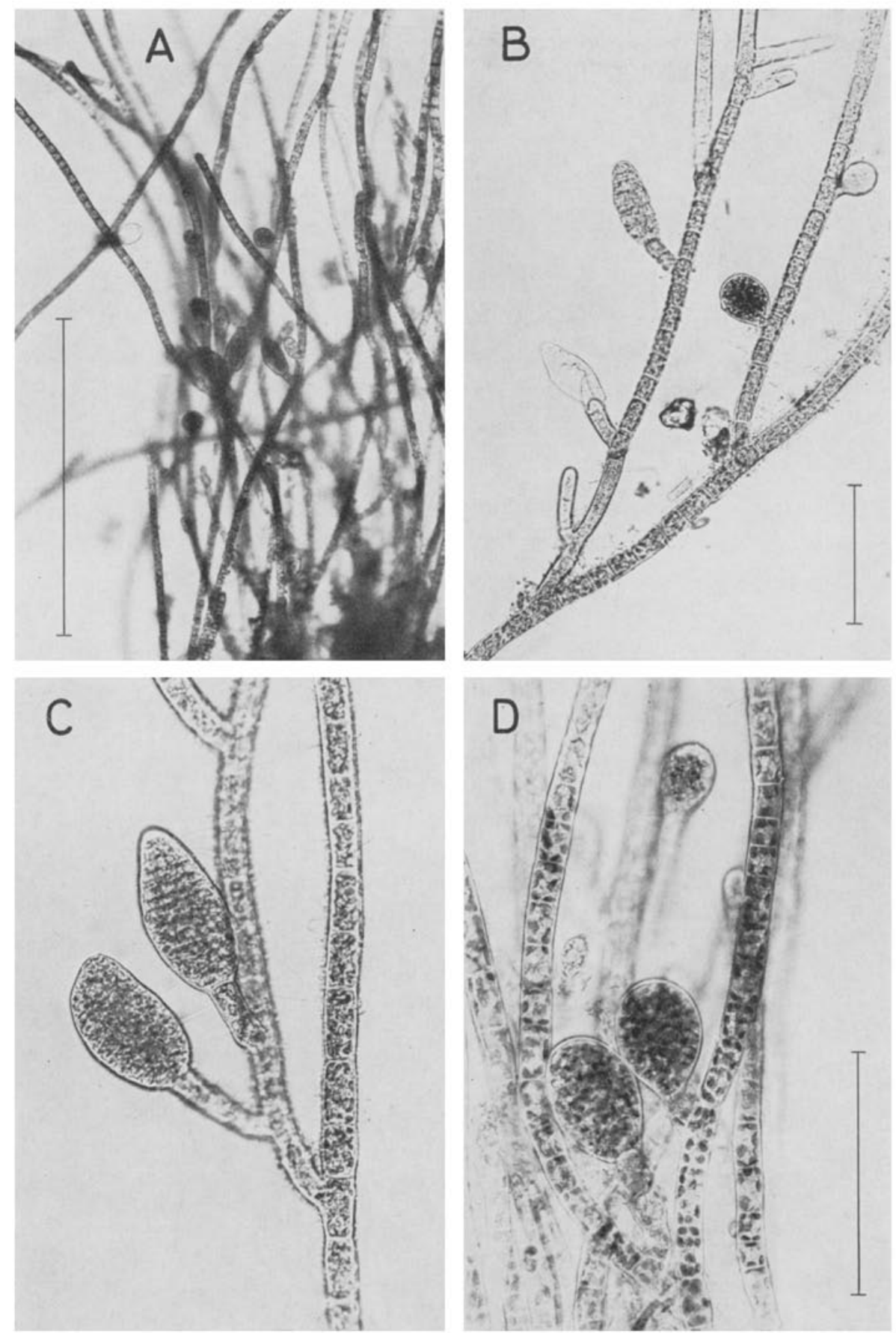

Abb. 61: Kützingiella bolmesii. A aus dem mittleren Teil eines Büschels (25. 11. 1970). B Verzweigter Faden mit uni- und plurilokulären Sporangien. C Plurilokuläre, D unilokuläre Sporangien. Maßstrecken: $\mathrm{A}=0,5 \mathrm{~mm} ; \mathrm{B}=100 \mu \mathrm{m} ; \mathrm{C}, \mathrm{D}=100 \mu \mathrm{m}$ 
Der lederartig harte Thallus besteht aus einer einschichtigen, am Rande wachsenden Basalscheibe, von der sich bogig aufsteigend fest untereinander zu einem pseudoparenchymatischen Gewebe verbundene Fäden erheben. Haarbüschel endogenen Ursprungs sind über den Thallus verstreut.

Die Fortpflanzungsorgane werden in Sori auf der Oberfläche des Thallus gebildet. Bei Helgoland wurden nur unilokuläre Sporangien, besonders in den Sommermonaten, beobachtet. Sie entstehen an der Basis keuliger, mehrzelliger Paraphysen (C).

Anmerkung: Aus entwicklungsgeschichtlichen Untersuchungen ergab sich, daß die nach äußerer Ahnlichkeit zur Gattung Ralfsia gestellten Formen nicht einheirlich sind. Ralfsia clavata (Abb. 72) ist eine krustenförmige Phase im Lebenszyklus von Petalonia fascia; die flächige oder krustenartige Erscheinungsform wird im wesentlichen durch unterschiedliche Tageslänge und Wassertemperatur bestimmt. Ralfsia verrucosa dagegen kommt nur als Kruste vor (Fletcher, 1974).
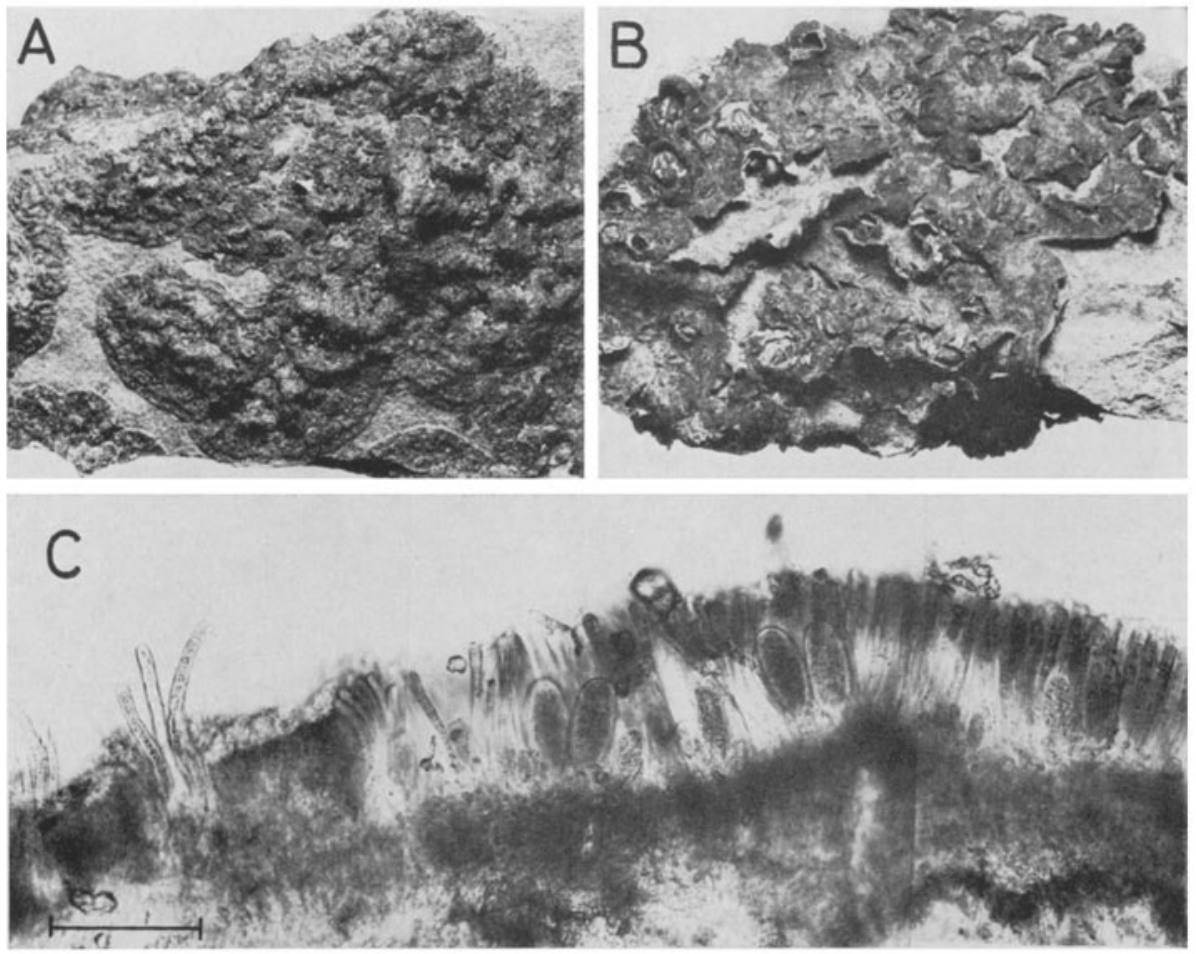

Abb. 62: Ralfsia verrucosa. A Fertile Krusten (13.8. 1976). B Nach scharfem Antrocknen vom Substrat abgelöste Krusten (18. 5. 1976). C Querschnitt durch eine fertile Kruste mit unilokulären Sporangien (14.8.1976). A, B eța natürliche Größe, Maßsțrecke C $=100 \mu \mathrm{m}$ 
Myrionemataceae

\section{Leptonematella fasciculata (Reinke) Silva}

In der Natur findet man die zartfädigen Büschel nur gelegentlich auf gedretschten Steinen, am ehesten noch epiphytisch auf Algen in Wasserlöchern, zum Beispiel auf Chatomorpha aerea (A). Sie tritt aber nicht selten im Laboratorium in Becken mit durchfließendem Seewasser oder in Rohkulturen von Algen verschiedener Herkunft auf.

Die unverzweigten, bis $5 \mathrm{~mm}$ langen Fäden erheben sich von einem auf dem Substrat kriechenden Basallager. Die Zellen enthalten zahlreiche Chromatophoren. Die Fertilisierung beginnt im allgemeinen am Fadenende, während die basalen Abschnitte sich noch durch interkalare Teilungen weiter strecken. Je nach Fadendicke sehen die fertilen Fäden ganz verschieden aus. Bei dünnen Fäden entsteht aus jeder Zelle ein Sporangium, ihre papillenartigen Vorwölbungen liegen einseitig gereiht (B), solche Fäden sind oft hakig gekrümmt. Aus den Zellen dickerer Fäden werden nach entsprechender Längsteilung mehrere allseitig vorspringende plurilokuläre Sporangien gebildet (D).

Diese Alge lebt - wie der Artname angibt - epiphytisch auf Fucus (A, B). Sie kommt auf allen drei Fucus-Arten vor, ausnahmsweise auch auf anderen Algen, zum Beispiel auf Chondrus crispus oder Enteromorpha. Als Besonderheit sei hier erwähnt, daß sie an der nicht mehr existierenden Anlegebrücke auf dem Ellenbogen bei List/ Sylt regelmäßig auf den Holzpfählen im oberen Litoral zu finden war; es ist uns in der Literatur keine Angabe ihres Vorkommens auf totem Substrat bekannt.

Die bis $1,5 \mathrm{~cm}$ hohen Büschel einreihiger unverzweigter Fäden erheben sich über einem festen, kugeligen pseudoparenchymatischen Knötchen. Ein vom Substrat abgelöstes Polster, etwas zerteilt und unter dem Deckglas gequetscht, zeigt den Aufbau des Thallus; dem basalen Mark entspringen Assimilationsfäden mit vielen scheibenförmigen Chromatophoren, nahezu farblose, keulige Paraphysen und zahlreiche langgestreckte unilokuläre Sporangièn (C).

Aus den Zoosporen entwickeln sich bei $15^{\circ} \mathrm{C}$ stets gleichartige Generationen mit unilokulären Sporangien, bei $5^{\circ} \mathrm{C}$ dagegen kriechende Stadien mit plurilokulären Sporangien (Kornmann, 1962b). Sie sind offenbar die aus der Natur nicht bekannte Wintergeneration. Man findet die Büschel in voll entwickeltem Zustand von April bis August, danach als überständige Knötchen mit Resten von Assimilationsfäden bis Oktober, 

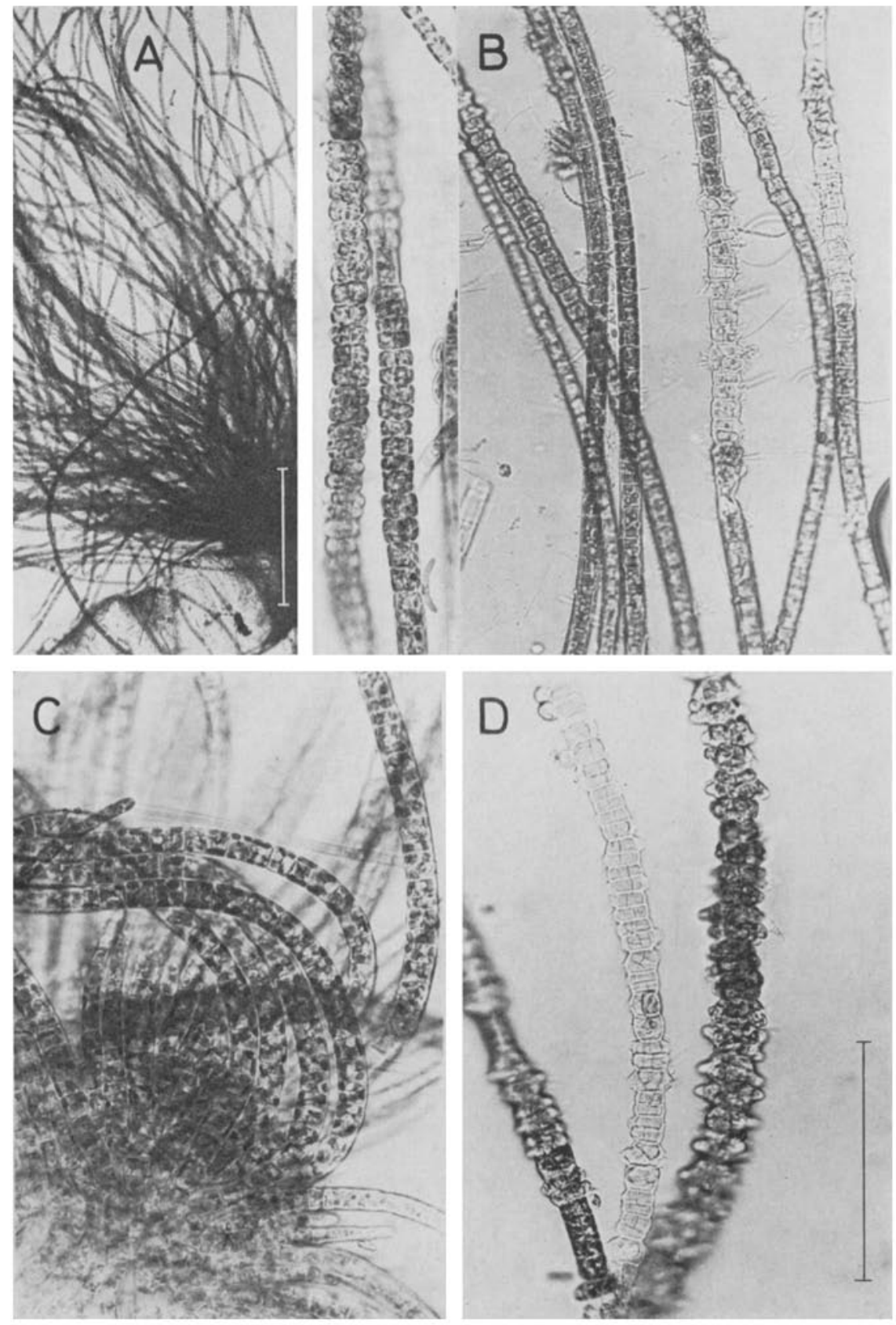

Abb. 63: Leptonematella fasciculata. A Epiphytisch auf Chaetomorpha aerea (29.4. 1975). C Basis eines Büschels. B, D Fercile dünne und dickere Fäden. Maßstrecken: $A=500 \mu \mathrm{m}$; $\mathrm{B}-\mathrm{D}=100 \mu \mathrm{m}$ 

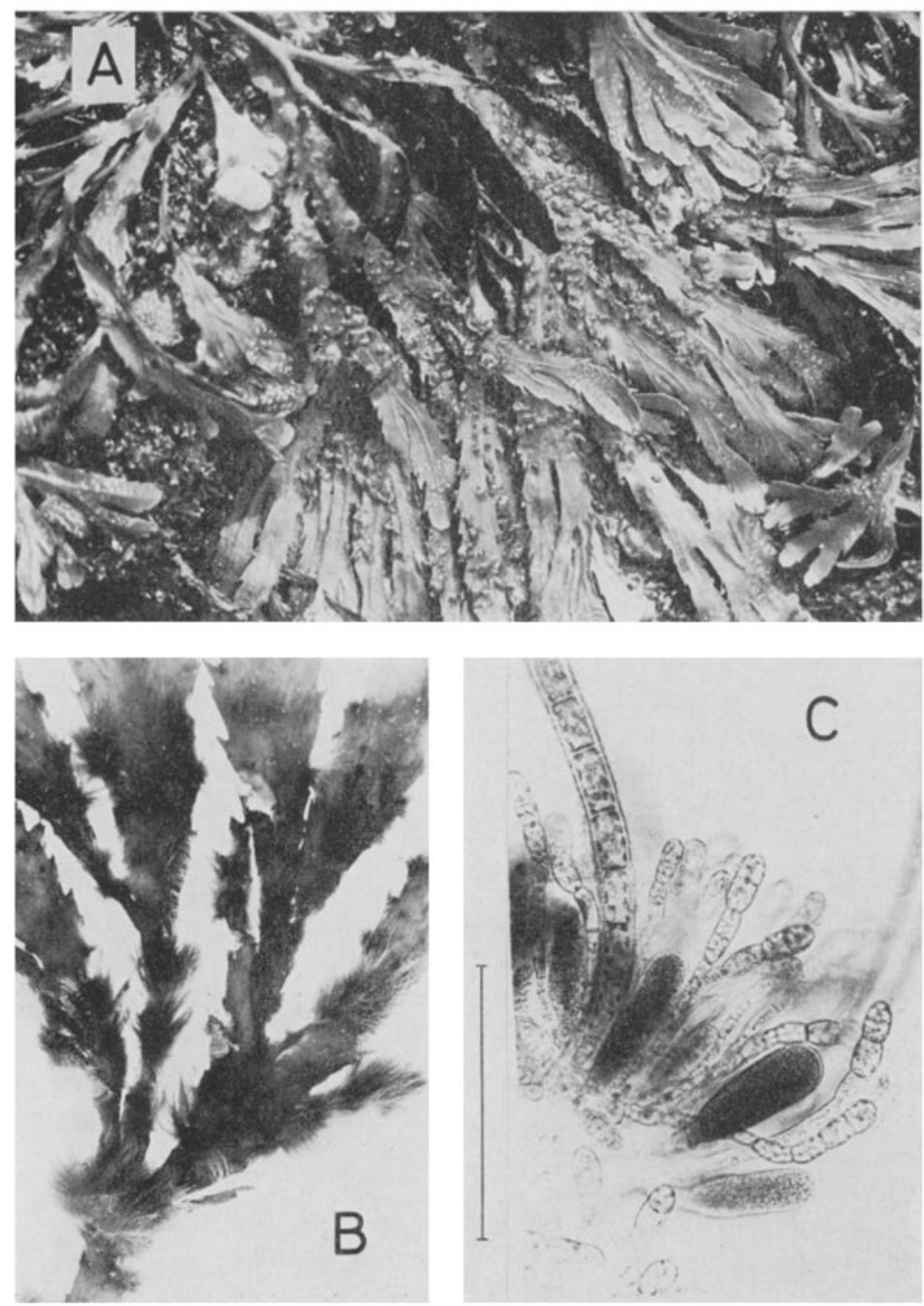

Abb. 64: Elacbista fucicola. A, B Auf Fucus serratus wachsend. C Quetschpräparat mit einem Assimilationsfaden, gegliederten keuligen Paraphysen und langovalen unilokulären Sporangien (2.6.1971). Maßstrecke: $\mathrm{C}=200 \mu \mathrm{m}$ 
Diese als Geißeltang bezeichnete Alge trägt an ihrer Hauptachse die meist in weitem Winkel abstehenden, knapp $1 \mathrm{~mm}$ dicken Verzweigungen. Habitus und Farbe variieren seht in Abhängigkeit von dem Alter der Pflanze. Junge Exemplare sind hellbraun und haben kurze, wenig verästelte Seitenzweige (A). Mit ihrer Verlängerung verändert sich das Aussehen der Alge (B), besonders wenn im ausgewachsenen Zustand die Hauptachse von den Zweigen ibergipfelt wird (C). Auch die Dichte der Verzweigung ist sehr unterschiedlich. Die Abbildung zeigt bei $\mathrm{C}$ eine mäßig stark verzweigte Pflanze mit einer reich verzweigten, epiphytischen jüngeren. Die ausgewachsene Pflanze ist dunkel- bis schwarzbraun und wird bis zu $50 \mathrm{~cm}$ lang.

Auf Chordaria flagelliformis siedelt sich gern Dictyosiphon foeniculaceus an (Dictyosiphonaceae), ein Epiphyt von einer ähnlichen äußeren Erscheinungsform. Die in den letzten Jahren ziemlich selten gewordene Alge fühlt sich nicht schlüpfrig an wie Chordaria, ist etwas heller gefärbt und meist dichter verzweigt. Eine mikroskopische Untersuchung enthebt aller Zweifel; die festen Schnüre von Chordaria sind von einem Mantel gegliederter Assimilatoren mit kugeligen, chromatophorenreichen Endzellen umhüllt. Dictyosipbon dagegen hat eine Rinde von kleinen polygonalen Zellen, die Hauptachse und älteren $Z_{\text {weige sind hohl. }}$

Chordaria flagelliformis kommt von April bis November in zwei (oder mehreren?) Generationen vor, sie wächst auf felsigem. Untergrund oder epiphytisch auf Fucus serratus. Ab Ende Mai fruchtet sie mit unilokulären Sporangien.

\section{Striariacea e \\ Isthmoplea sphaerophora (Carm. ex Harv. in Hook.) Kjellm.}

Die bis zu $2 \mathrm{~cm}$ hohen Epiphyten auf Polysiphonia urceolata könnte man nach ihrem Habitus für kleine Ectocarpus-Büschel halten, und sie wurden ursprünglich auch dieser Gattung zugeordnet. Die Hauptachsen sind in ihren unteren Teilen polysiphon und erscheinen durch die meist aus benachbarten Zellen entspringenden Zweige in Knoten und Internodien gegliedert (A-D). Ot gesellen sich den Zweigwirteln auch unilokuläre Sporangien zu (C, D).

In den zunächst monosiphonen Zweigen teilen sich die Zellen durch zwei Längswände, bevor aus den beiden peripheren Zellen Sporangien oder Verzweigungen entstehen. Häufig sitzen zwei Sporangien einander gegenüber, seltener stehen sie einzeln oder sind einem $Z_{w}$ eig opponiert. Die kugeligen unilokulären Sporangien sind ungestielt.

Rueness (1974) untersuchte die Entwicklung einer Population aus dem Oslofjord im Kulturversuch. Bei der Schwärmerbildung findet keine Reduktionsteilung statt; es folgen gleichartige Generationen mit unilokulären Sporangien aufeinander, die Chro- 

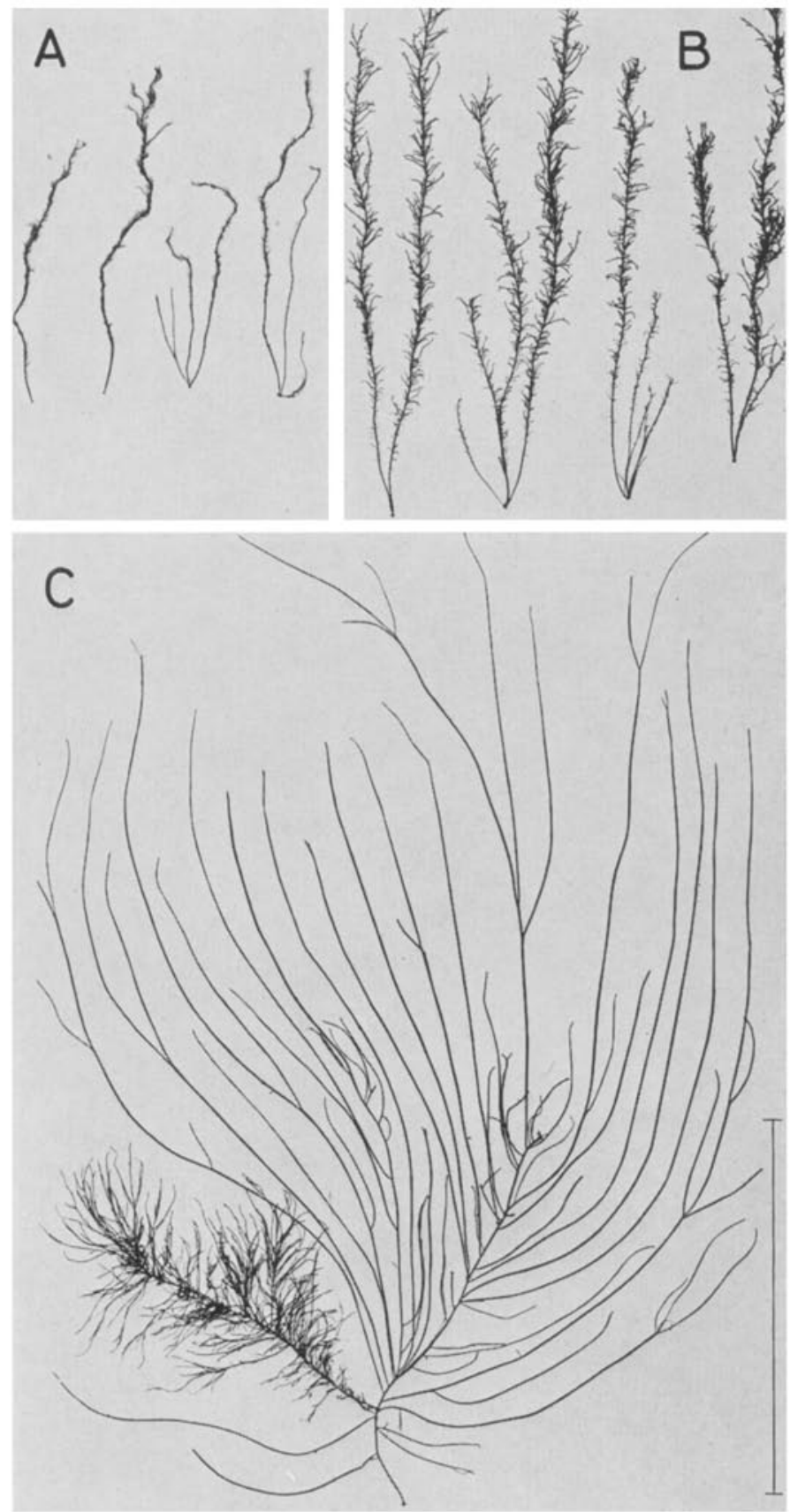

Abb. 65: Chordaria flagelliformis, altersbedingte Variation des Habitus, Herbarmaterial. A, B Jüngere Pflanzen (24.4.1952 und 8.5.1954). C Ausgewachsenes Exemplar mit einer epiphytischen jüngeren Pflanze (5.8.1951). Maßstrecke: $\mathrm{A}-\mathrm{C}=10 \mathrm{~cm}$ 

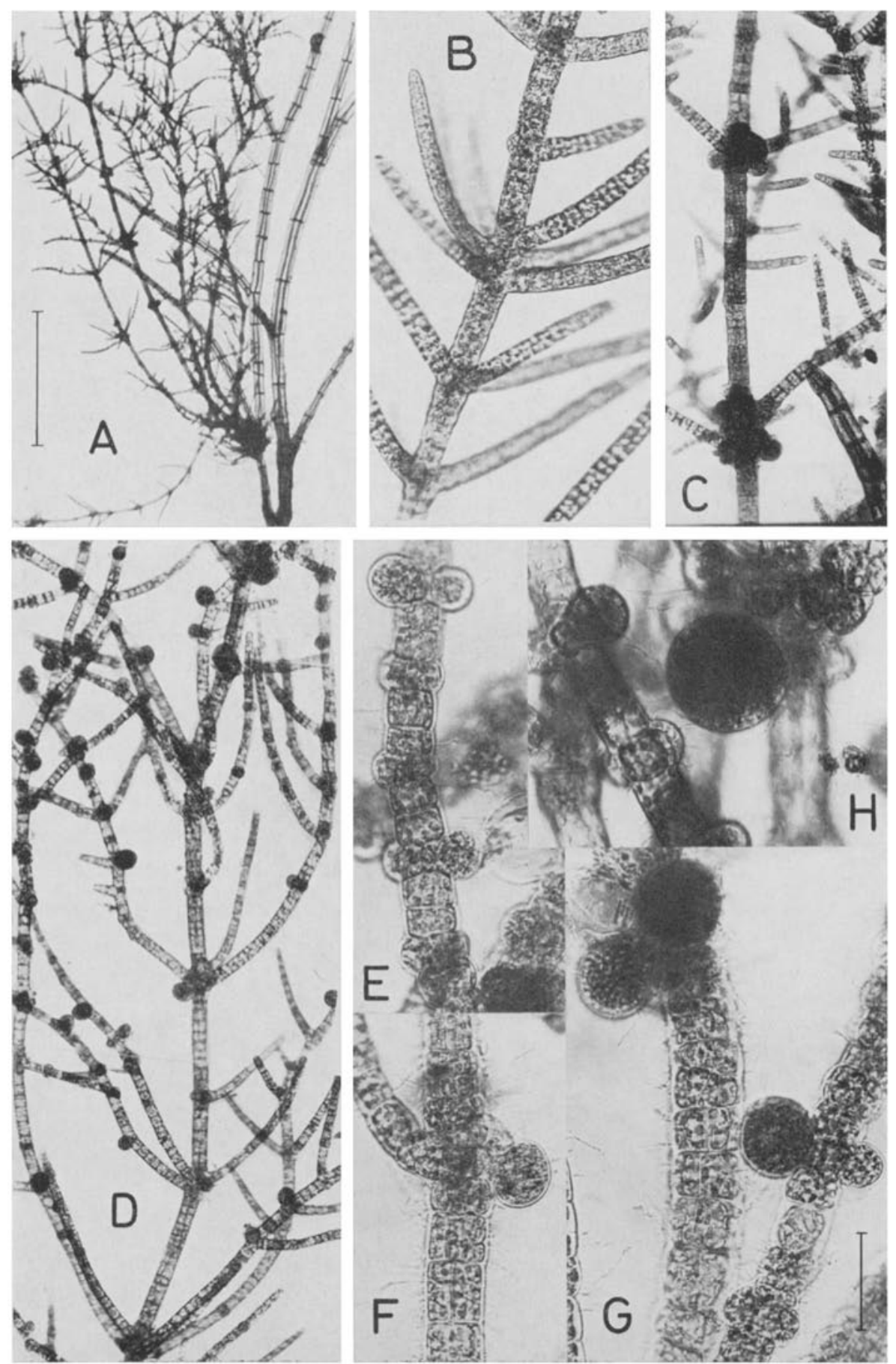

Abb. 66: Istbmoplea sphaerophora. A Epiphytisch auf Polysiphonia urceolata (24. 4. 1972). B Achse mit vegetativen $Z$ weigen (28. 3. 1974). C, D Hauptachsen mit quirligen $Z$ weigen und unilokulären Sporangien. E, F Sporangien einander oder einem Zweig opponiert. G, H Reife unilokuläre Sporangien. Maßstrecken: $A=1 \mathrm{~mm} ; \mathrm{E}-\mathrm{H}=50 \mu \mathrm{m}$ 
mosomenzahl war 24. Pedersen (1975) fand 8 Chromosomen in Material aus Grönland, sowohl in vegetativen Zellen als auch im unilokulären Sporangium. Die Ergebnisse werden so gedeutet, daß auch die haploide Pflanze unilokuläre Sporangien tragen kann und die Population im Oslofjord triploid ist.
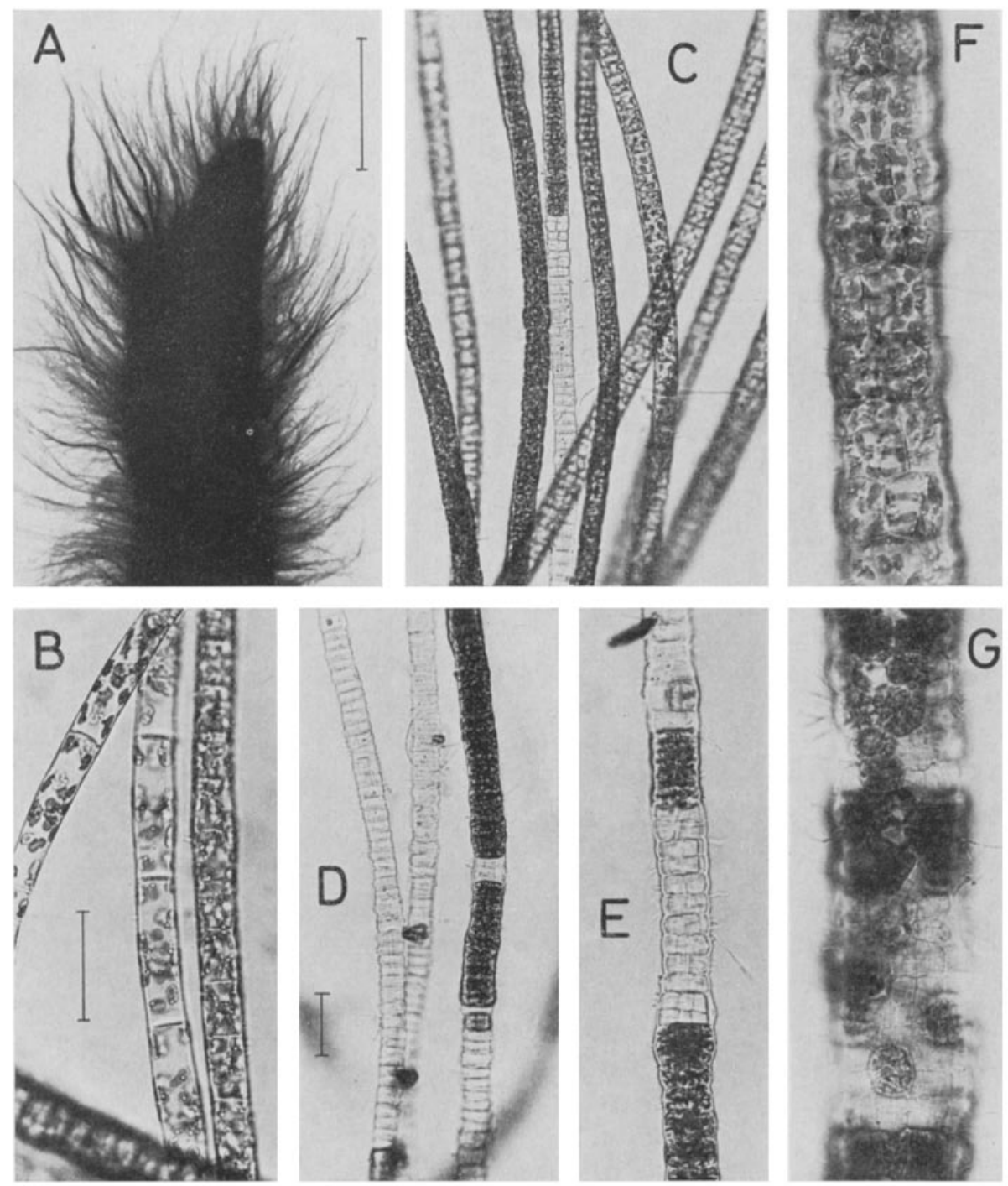

Abb. 67: Litosiphon filiformis. A Epiphytisch auf einem Laminaria-Thallusstreifen (22. 4. 1970). B - E Fadenstücke aus der Basis und den oberen Abschnitten dieser Probe. F, G Vegetatives und fertiles Fadenstück aus einer Probe mit dickeren Fäden (24.4.1974). Maßstrecken: $A=1 \mathrm{~cm}$; $\mathrm{B}, \mathrm{E}-\mathrm{G}=50 \mu \mathrm{m} ; \mathrm{C}, \mathrm{D}=50 \mu \mathrm{m}$ 


\section{Litosipbon filiformis (Reinke) Batt.}

Im März bis Ende Mai sind die nach dem Laubwechsel oft massenweise ausgeworfenen vorjährigen Blattreste von Laminaria byperborea oder L. saccharina häufig dicht mit einem Pelz von braunen Epiphyten, meist Litosiphon filiformis, bedeckt (A). Die 1 bis $3 \mathrm{~cm}$ langen Fäden sind unverzweigt und tragen keine Haare. Basis und Spitzenabschnitte sind monosiphon, in seinem mittleren Teil ist der Faden durch Längswände aufgeteilı und kann $60 \mu \mathrm{m}$ breit werden.

Alle Zellen des Thallus werden bei ihrer Fertilisierung in plurilokuläre Sporangien umgewandelt. Thre Entleerung schreitet nicht, wie es im allgemeinen der Fall ist, von der Spitze zur Basis fort; häufig wechseln fertile und bereits entleerte Fadenabschnitte miteinander $a b$.

\section{Punctaria plantaginea (Roth) Grev.}

Punctaria plantaginea ist eine flächige Braunalge von lanzettlichem Umriß. Die jüngeren, im März und April gesammelten Pflanzen sind hellbraun; durch die zahlreichen farblosen, aber meist dicht von Diatomeen besetzten Haarbüschel erscheint die Fläche getüpfelt $(A, B)$. Die bis zu $35 \mathrm{~cm}$ langen und 1 bis $5 \mathrm{~cm}$ breiten Algen wachsen gesellig als Büschel auf Steinen im unteren Litoral. An Bojen trifft man sie häufig zusammen mit Petalonia fascia an. Im Mai bis Juli wird die Alge immer mehr dunkelbraun; auf der rauhen Oberfläche siedeln sich außer Diatomeen gern zahlreiche Epiphyten an: Ectocarpus-Arten, Ceramium, Enteromorpha und andere (C).

Jüngere Pflanzen unterscheiden sich von Petalonia fascia gut durch ihre Punktierung. Der ältere Thallus von Punctaria ist dunkler und derber und weist oft Längsspalten auf. Im Zweifelsfalle wird ein Querschnittsbild Aufschluß geben: Die Zellen des 4- bis 6schichtigen Thallus von Punctaria sind ziemlich einheitlich groß, während Petalonia eine kleinzellige Rinde hat. Unilokuläre Sporangien sind zerstreut in der Oberfläche eingesenkt, man findet sic von April bis Juni.

Die selten gefundene Punctaria hiemalis wird auf p. 278 beschrieben.

Abb. 68: Punctaria plantaginea. A Jüngere, noch hellbraune Pflanzen (9.4.1970). B Altere Pflanzen, deren Thallus rissig und durchlochert wird (6.5.1971). C uberständige, stark mit Ectocarpus bewadisene Probe (16.6.1971). Maßstrecke: $\mathrm{A}-\mathrm{C}=6 \mathrm{~cm}$ 

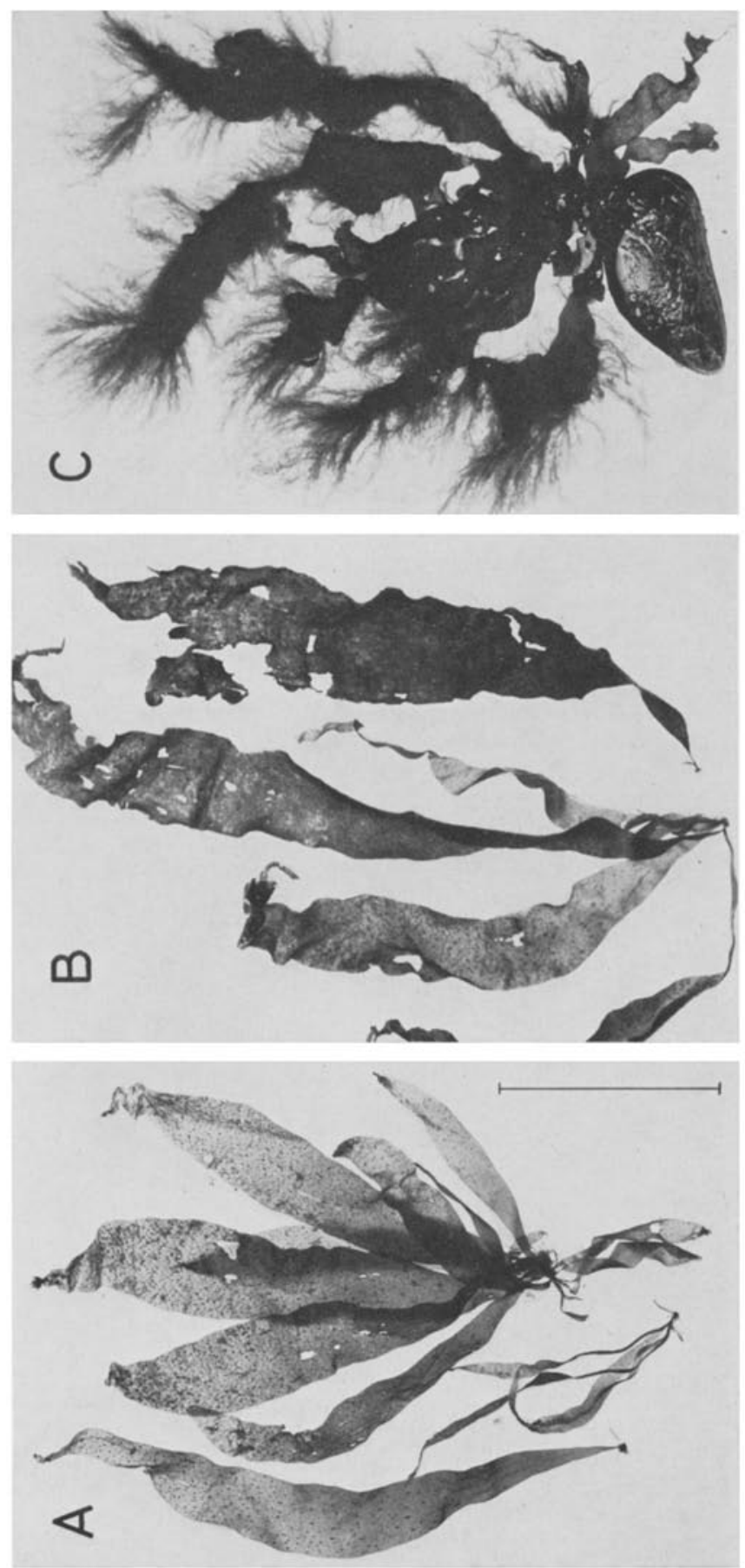


\section{Tilopterid a cea e}

\section{Tilopteris mertensii (Turn. in Sm.) Kütz.}

Das in der Abbildung bei $\mathrm{A}$ dargestellte Büschel besteht aus zahlreichen einzelnen Pflanzen, jede von einer deutlichen Hauptachse durchzogen und fiederig verzweigt. Man kann die zierliche, bis etwa $7 \mathrm{~cm}$ hohe Braunalge nur gelegentlich bei besonders niedrigem Wasserstand unmittelbar an Steinen oder epiphytisch sammeln. Sie ist aber in Tiefen bis zu $6 \mathrm{~m}$ offenbar nicht selten, denn man erhält sie im April bis Juni verhältnismäßig häufig in Planktonproben.

Die Stämmchen sind dicht besetzt mit gegenständigen Kurztrieben von verschiedenem Alter (B). Die Sprosse haben zunächst eine trichothallische Wachstumszone, oberhalb derer sich die Zellen haarförmig verlängern. Später teilen sich die Zellen der einreihigen Fäden interkalar (C). In einzelnen Abschnitten - und durchaus nicht nur in den unteren Teilen der Achse - werden die Zellen durch Längswände aufgeteilt (D). Jede Zelle enthält zentral eine stark lichtbrechende Plasmamasse mit dem Kern und viele kleine scheibenförmige Chromatophoren.

Die sekundären, wie auch die später aus den Stämmchen entsprossenden Fiederchen tragen interkalar die Fortpflanzungsorgane: kleingefächerte hohle, in reifem Zustand orangefarbene plurilokuläre Sporangien und einzelne oder paarige, seltener bis zu 5 aneinandergereihte Parthenosporangien (C, E).

Die entwicklungsgeschichtlichen Zusammenhänge sind noch nicht völlig geklärt. Sehr wahrscheinlich entwickelt sich aus den einkernigen Parthenosporen wieder eine gleichartige Generation. Uber die Rolle der plurilokulären Organe ist nichts bekannt, wahrscheinlich fehlen Generationswechsel und geschlechtliche Vermehrung (South, 1975).

Abb. 69: Tilopteris mertensi, alle Bilder aus Material vom 14.6.1973. A Viele Pflanzen zusammen mit Wohnrohren von Polydora ciliata auf einem Stein aus etwa $5 \mathrm{~m}$ Tiefe. B Ubersichtsbild, gegenständige Verzweigung. C Seitenzweig mit plurilokulären Sporangien und Parthenosporangien. D Hauptachse mit längsgeteilten Zellen. E Plurilokuläres Sporangium und Parthenosporangium. Maßstrecken: $\mathrm{A}=0,5 \mathrm{~cm} ; \mathrm{D}=300 \mu \mathrm{m} ; \mathrm{E}=100 \mu \mathrm{m}$ 

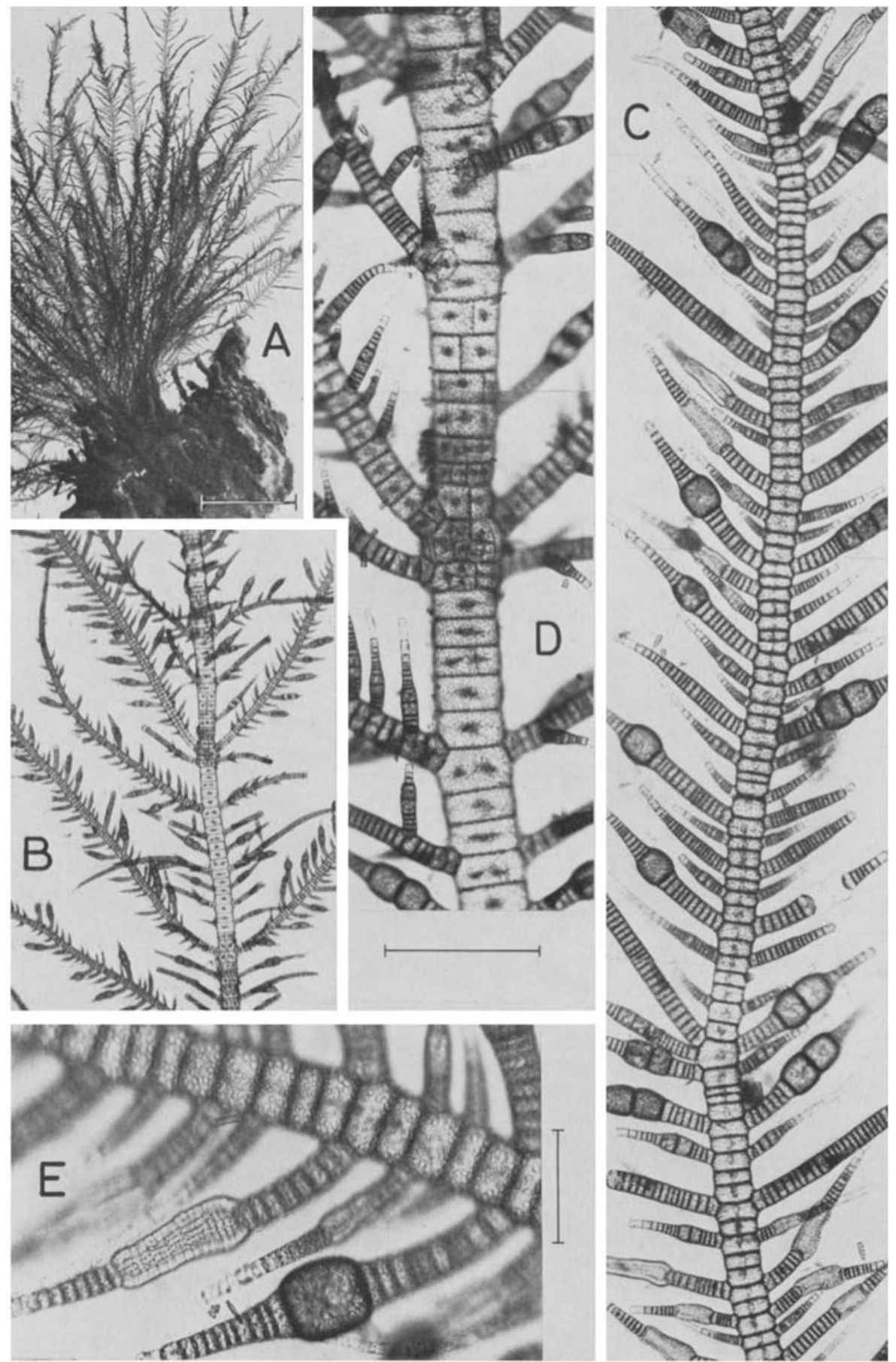


\section{Haplospora globosa Kjellm.}

Haplospora globosa kommt zur gleichen Zeit und an den gleichen Fundorten wie Tilopteris vor. Die Büschel können über $15 \mathrm{~cm}$ hoch werden, sie sehen ganz ähnlich aus wie Ectocarpus. Die Hauptachsen der locker verzweigten Alge sind oft seilartig zusammengedreht. Den Endabschnitt eines Zweiges gibt das Übersichtsbild bei A wieder. Bei älteren Pflanzen sind die Astchen nicht mehr so stark sichelförmig zurückgekrümmt.

Einem Hauptfaden entspringen zerstreute, häufig aber auch gegenständige Zweige, die auf ihrer Innenseite gereiht Seitenäste und gestielte Monosporangien tragen $(B, C)$. Oberhalb einer meristematischen Teilungszone verlängern sich die Zellen der Fadenenden haarartig. In den nicht mehr teilungsfähigen Achsen erreichen die Zellen die Höhe der Fadenbreite und werden durch Längswände geteilt (E). In den Zellen fällt eine zentrale, stark lichtbrechende Plasmamasse auf, die den Kern umschließt (C); die zahlreichen kleinen Chromatophoren sind scheiben-, in der Teilung biskuitförmig $(F)$.

Bei Helgoland wurden keine anderen Fortpflanzungsorgane als Monosporangien gefunden. Die Monosporen werden vor ihrer Reife durch einen doppelten Teilungsschritt vierkernig; in den Abbildungen C und D sind mehrfach 2 oder 3 dieser Kerne erkennbar. Sie sammeln sich dann nach beträchtlicher Größenzunahme im Zentrum der Monospore.

Pflanzen von gleichem Habitus mit Antheridien und Oogonien sind von der Ostsee, der schwedischen und norwegischen Westküste sowie der Ostküste von Kanada als Scaphospora speciosa bekannt. Im Kulturexperiment wurde die entwicklungsgeschichtliche Zusammengehörigkeit mit Haplospora als Sporophytengeneration nachgewiesen (Sundene, 1966).

Abb. 70: Haplospora globosa. A Habitus eines Zweigstïcks (24.4.1972). B Ausschnitt aus A mit jungen Monosporangien. C, D Fadenstïcke mit reifenden, vierkernigen Monosporen; eine Monospore tritt aus der Hülle aus (6.5.1974). E Altere Fadenabschnitte mit Längsteilungen. $\mathrm{F}$ Zellen mit Chromatophoren. Maßstrecken: $\mathrm{A}=1 \mathrm{~cm} ; \mathrm{C}, \mathrm{E}=500 \mu \mathrm{m} ; \mathrm{F}=50 \mu \mathrm{m}$ 

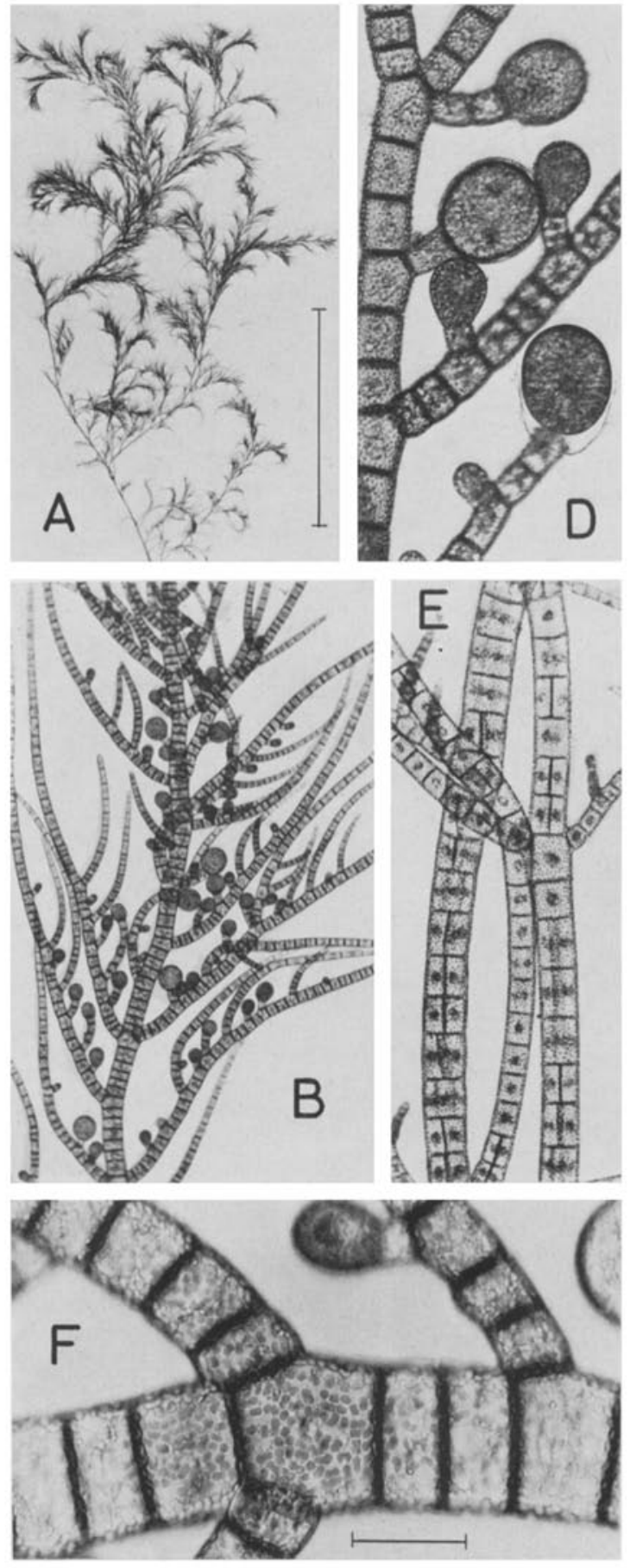
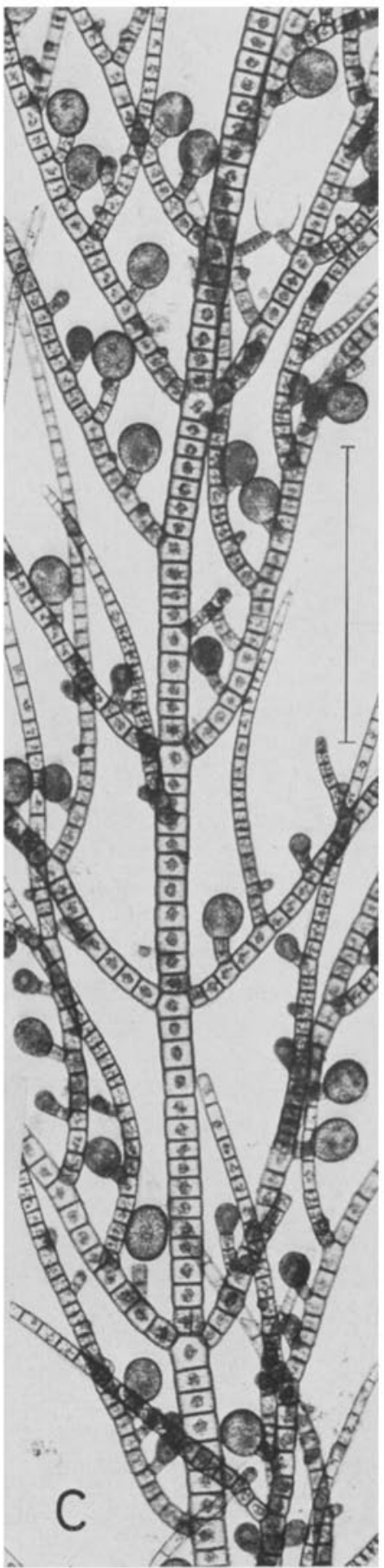


\section{Petalonia fascia (O. F. Müll.) O. Kuntze}

Die außerordentliche Variabilität von Petalonia fascia wird aus der Abbildung ersichtlich. So ist es verständlich, daß von manchen Autoren mehrere Varietäten unterschieden werden. Häufig findet man 10 bis $20 \mathrm{~cm}$ lange, lanzettliche, in der Mitte bis $1 \mathrm{~cm}$ breite Exemplare, deren Thallus in einer ganz charakteristischen. Weise abgewinkelt ist (A). Andere sind zungen- oder eiförmig und werden bei 10 bis $20 \mathrm{~cm}$ Länge bis zu $5 \mathrm{~cm}$ breit (B, C). Die größten Pflanzen waren $40 \mathrm{~cm}$ lang und bis $6 \mathrm{~cm}$ breit. Stets aber verjüngen sie sich an ihrer Basis in einen kurzen Stiel. Im allgemeinen entspringt eine ganze Anzahl von Pflanzen aus einem gemeinsamen Haftorgan; die Oberfläche ist stets glatt, anders als bei Punctaria.

Der mehrschichtige Thallus besteht aus einer kleinzelligen Rinde und größeren, fast farblosen Zellen in der Mitte. Die gesamte Thallusfläche ist bei der Reife auf beiden Seiten lückenlos von plurilokulären Sporangien bedeckt; sie gehen aus den äußeren Rindenzellen hervor, sind einreihig und etwa 6 Fächer hoch. Das Ausschwärmen eines Thallus schreitet von der Spitze zur Basis fort; der ausgeschwärmte Teil grenzt sich deutlich gegen den dunkleren, noch von der Sporangienschicht überzogenen Abschnitt ab (C, D). Das Ausschwärmen kann man leicht an Pflanzen beobachten, die man trocken am Standort gesammelt hat und in eine Schale mit Meerwasser legt. Da die ganze Oberfläche von einem zarten Cuticularhäutchen überzogen ist, entströmen ganze Wolken von Schwärmern an seinen Rißstellen (vgl. Abb. $73 \mathrm{C}$ ). Im mikroskopischen Präparat ist das Fließen der Schwärmer unter dem Oberflächenhäutchen gut zu beobachten. Die Zoosporen entwickeln sich in Kultur zu verzweigten kriechenden Fäden, auf denen sich die flächigen Thalli erheben (Abb. $72 \mathrm{~F}$ ).

Im Lebenszyklus von Petalonia fascia und Scytosiphon lomentaria ist seit einigen Jahren ein nicht obligater Zusammenhang mit krustenförmigen, Ralfsia-ähnlichen Algen bekannt geworden (Nakamura, 1965; Fletcher, 1974). Entsprechende Beobachtungen konnten auch in Kulturversuchen mit Ralfsia clavata von Helgoland gemacht werden. Die im Sublitoral wachsende Kruste fruktifiziert mit unilokulären Sporangien (Abb. $72 \mathrm{~A}$ ). Aus ihren Schwärmern war nach 4 Wochen die bei B abgebildete Generation hervorgegangen: auf kriechenden, reich verzweigten Basalfäden entstanden bandförmige, etwas gedrehte Thalli mit abgerundetem Ende. Ganz ähnlich sehen auch junge Stadien von Petalonia fascia im Naturmaterial aus. Die 8 Wochen alte Kultur enthielt fertile und bereits weitgehend ausgeschwärmte Thalli (C). Thre Fläche ist mehr-

Abb. 71: Petalonia fascia von verschiedenem Habitus, alle Proben im April gesammelt. A-C aus Herbarmaterial, $D$ lebend und weitgehend ausgeschwärmt. Maßstrecken: $A-C=10 \mathrm{~cm}$; $\mathrm{D}=5 \mathrm{~cm}$ 

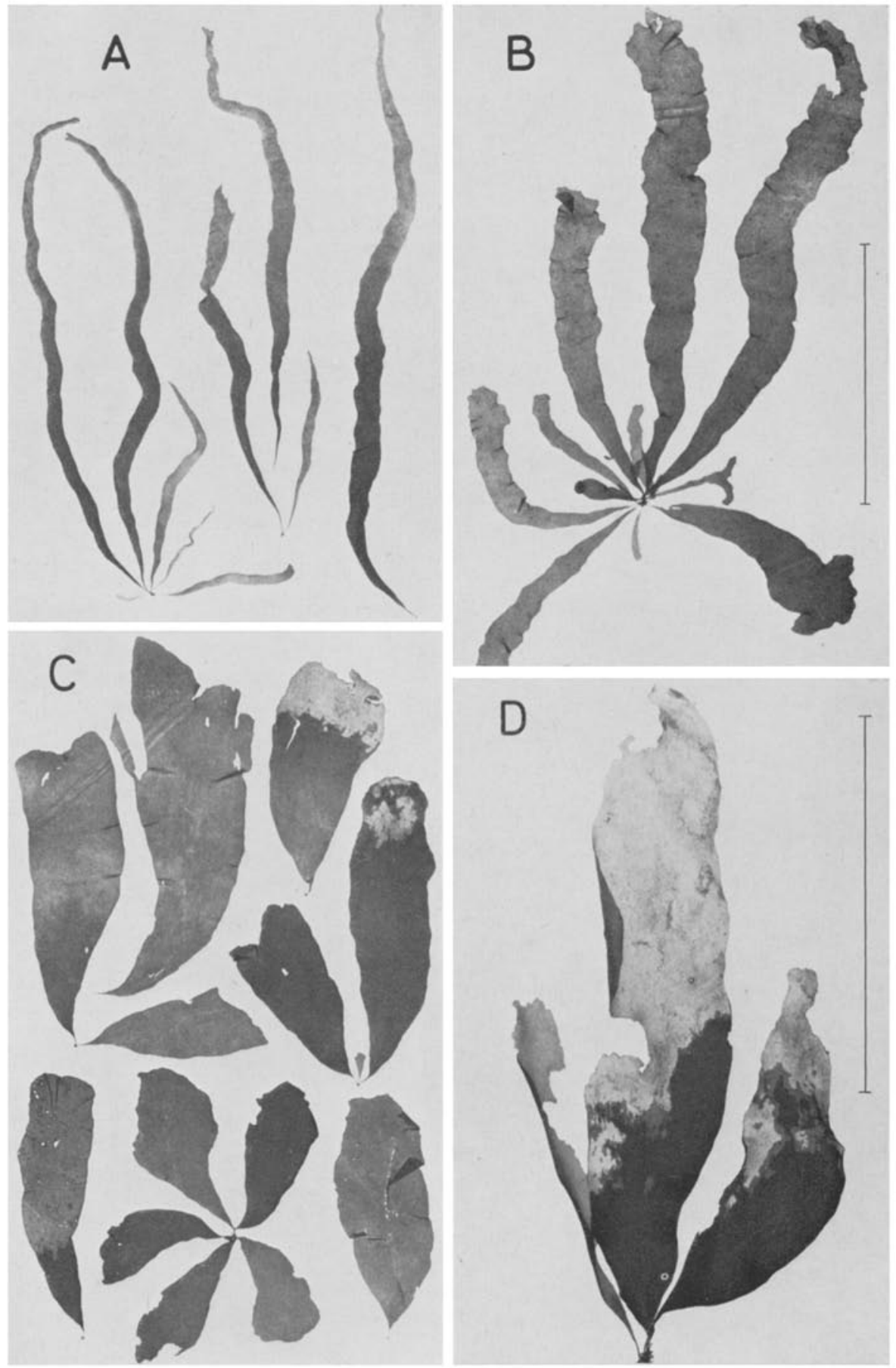

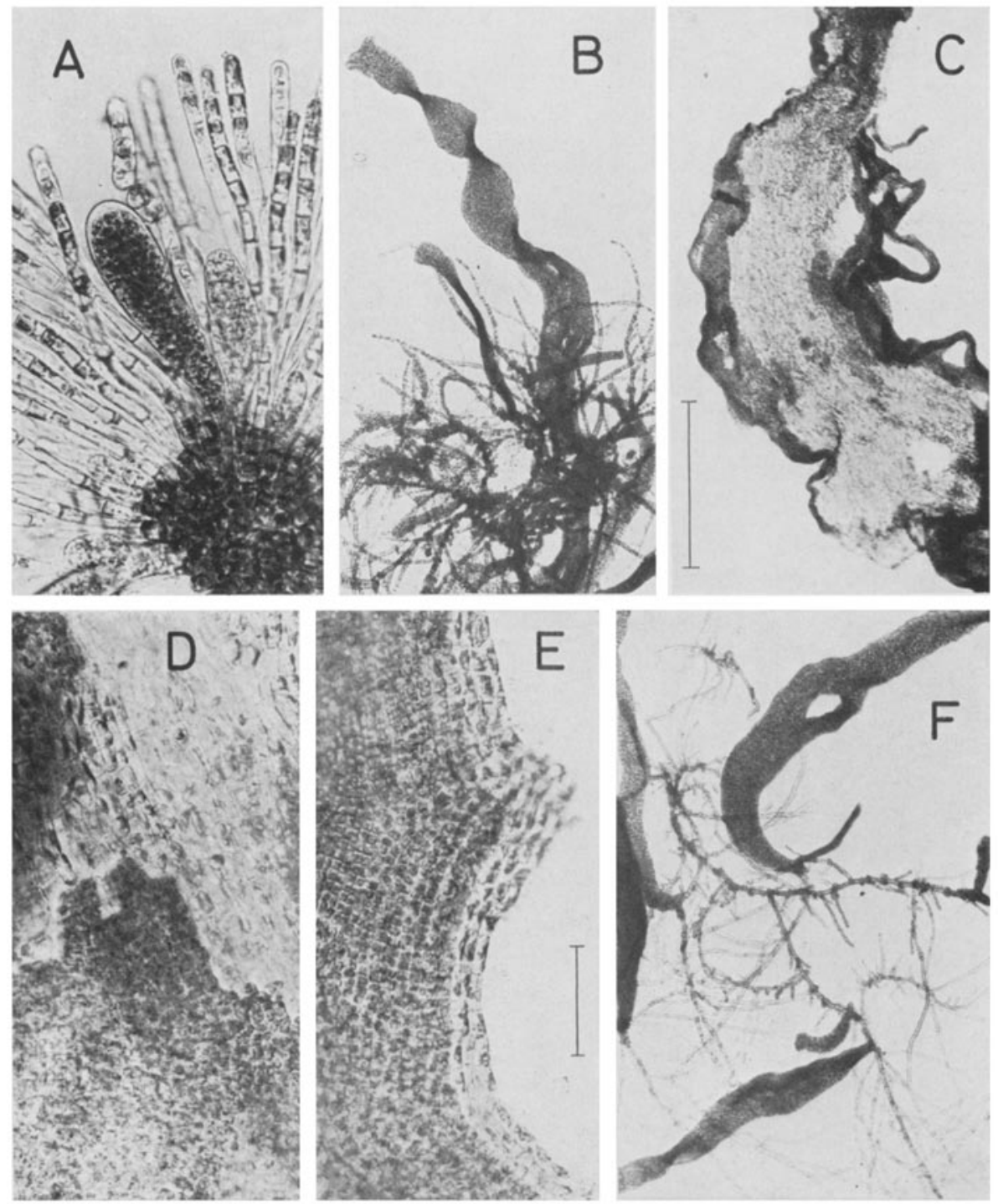

Abb. 72: Entwicklung von Petalonia fascia. A Das Ausgangsmaterial, Ralfsia clavata, mit unilokulären Sporangien (20.8.1971). B Aus Zoosporen entstandene bandförmige Thalli in einer 25 Tage alten Kultur. C Ausgeschwärmter Thallus mit sterilem Rand. D, E Fertiler Thallus, teilweise ausgeschwärmt und mit vegetativen Randzellen. F Aus Zoosporen der plurilokulären Sporangien entstandene, 15 Tage alte Generation. Maßstrecken: $\mathrm{A}, \mathrm{D}, \mathrm{E}=50 \mu \mathrm{m}$; $\mathrm{B}, \mathrm{C}, \mathrm{F}=500 \mu \mathrm{m}$ 
schichtig; die mittleren großen Zellen sind von einer geschlossenen Schicht kleiner, fertiler Zellen bedeckt, und nur ein schmaler Rand vegetativer Zellen säumt den Thallus (D, E). Die Schwärmer erbrachten wieder eine Generation flächiger Pflanzen (F); krustenförmige Stadien traten nicht wieder auf.

Mit Ausnahme von August und September kommt Petalonia fascia während des ganzen Jahres vor, am reichlichsten von März bis Anfang Juni. Sie wächst gesellig auf Steinen oder in kleinen Tümpeln nahe der Niedrigwasserlinie, geht aber auch ins Sublitoral. Fertile Pflanzen findet man von März bis Ende Mai.

\section{Petalonia zosterifolia (Reinke) Kuntze}

Der schmale linearische Thallus kennzeichnet diese Braunalge ganz eindeutig. Im allgemeinen sind die Bänder etwa $1 \mathrm{~mm}$ breit und $20 \mathrm{~cm}$ lang, sie können aber auch doppelt so lang und bis zu $5 \mathrm{~mm}$ breit werden. Die Thallusenden junger Pflanzen verschmälern sich; nach vermindertem Längenwachstum wachsen auch sie auf die Breite der unteren Thalluspartien heran. Häufig verbreitert oder gabelt sich die Spitze unregelmäßig, gelegentlich findet man auch eine kurze Verzweigung in der apikalen Zone (E). Natürlich lassen sich diese Merkmale nur an vollständigen Pflanzen beobachten, oft werden die Spitzen älterer Pflanzen - besonders nach der Fertilisierung nicht mehr vorhanden sein.

In ihrem Aufbau und der Fertilisierung gleicht diese Art der vorigen. Das ausgeschwärmte Thallusstück bei $\mathrm{C}$ zeigt die Cuticularmembran. Bei $\mathrm{D}$ ist ein stehengebliebener Streifen von Sporangien zu sehen, die Sporangienreihen sind unter dem Deckglas etwas zur Seite gedrückt. Im Lebenszyklus von Petalonia zosterifolia ist kein krustenförmiges Stadium bekannt.

Petalonia zosterifolia wächst von Februar bis Anfang Mai in höherem Niveau als $P$. fascia. Etwas erhöhte Klippenzüge des Felswatts sind häufig dicht von ihr bedeckt.

\section{Scytosipbon lomentaria (Lyngb.) Link}

Der einfache, röhrenförmige, unregelmäßig eingeschnürte Thallus gibt dieser Braunalge ihr unverkennbares Gepräge. Und doch bedarf diese Kennzeichnung einer Einschränkung: nur die älteren Pflanzen zeigen diesen gliederartigen Aufbau. Da aber im allgemeinen verschieden alte Pflanzen zusammen in einem Büschel wachsen, werden alle Übergänge von ganz dünnen Röhren bis zu den typisch eingeschnürten Exemplaren vertreten sein (A). Natürlich kann man noch im April Büschel finden, deren $30 \mathrm{~cm}$ lange und $1,5 \mathrm{~mm}$ breite Schläuche nicht eingeschnürt sind, während sie im Mai den Habitus wie bei $\mathrm{B}$ zeigen. Mit $70 \mathrm{~cm}$ Länge und bis $8 \mathrm{~mm}$ Durchmesser sind die Maße für den Spielraum der äußerlich recht unterschiedlichen Braunalge angegeben. 

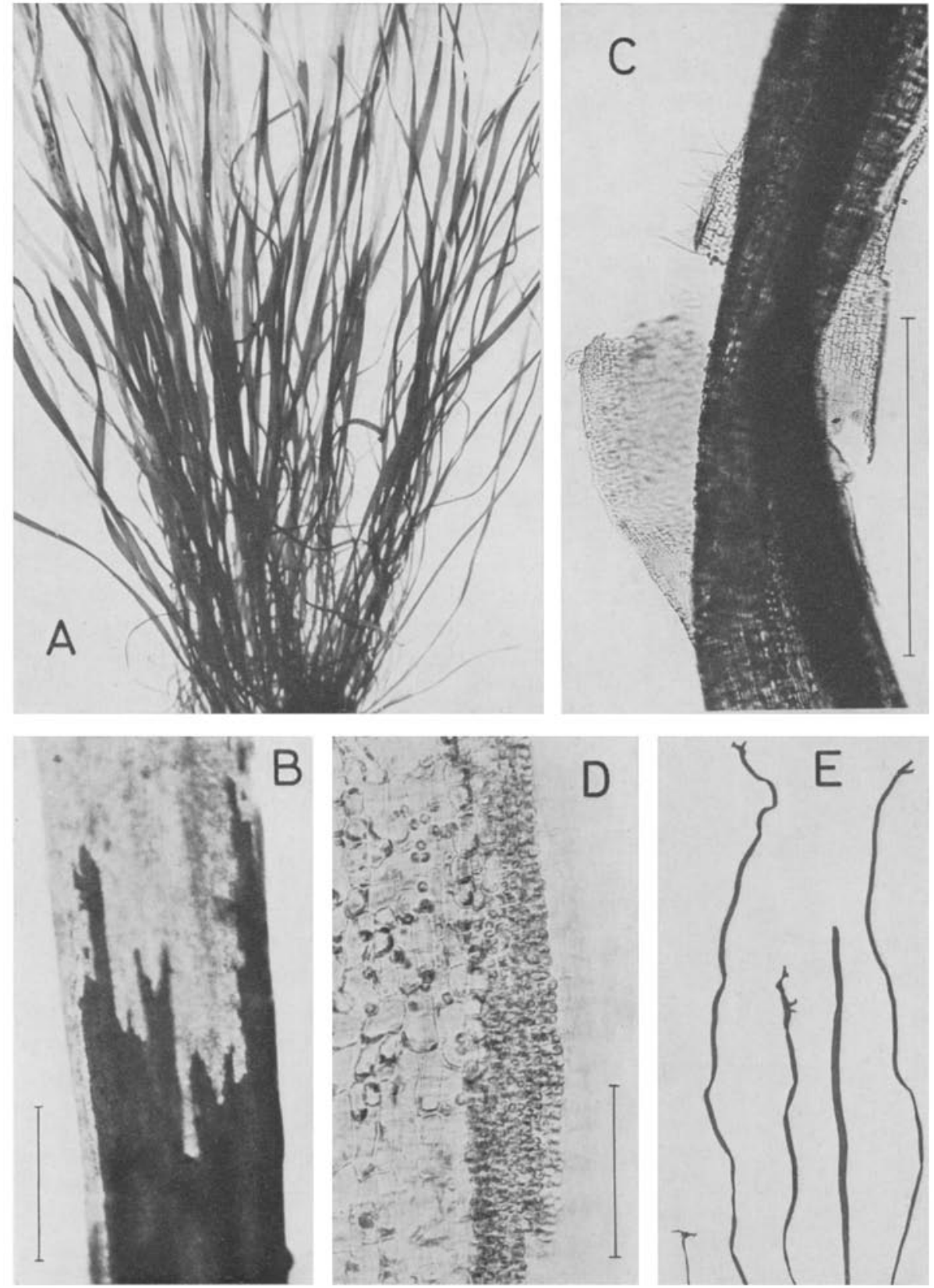

Abb. 73: Petalonia zosterifolia. A Büschel in etwa natürlicher Größe (8. 5. 1952). B Fertiler, zum Teil ausgeschwärmter Thallus. C Ausgeschwärmtes Thallusstüd mit abgelöster Cuticularmembran. D Sorus mit gereihten plurilohulären Sporangien. E Thallusenden mit unregelmäßiger Gabelung oder Verzweigung (Herbar, 24. 4. 1952). Maßstrecken: $\mathrm{B}=500 \mu \mathrm{m}$; $\mathrm{C}=500 \mathrm{~mm} ; \mathrm{D}=100 \mu \mathrm{m}$ 
Scytosiphon lomentaria kommt reichlich von März bis Juni, vereinzelt aber das ganze Jahr über vor. Man findet die Alge im unteren Litoral auf Steinen, bei Niedrigwasser trocken liegend oder gern auch in kleinen Tümpeln wachsend. Gereihte plurilokuläre Sporangien mit eingestreuten Paraphysen überziehen den fertilen Thallus in geschlossener Schicht. Ausgeschwärmte Abschnitte sind deutlich heller als die noch von Sporangien bedeckten.
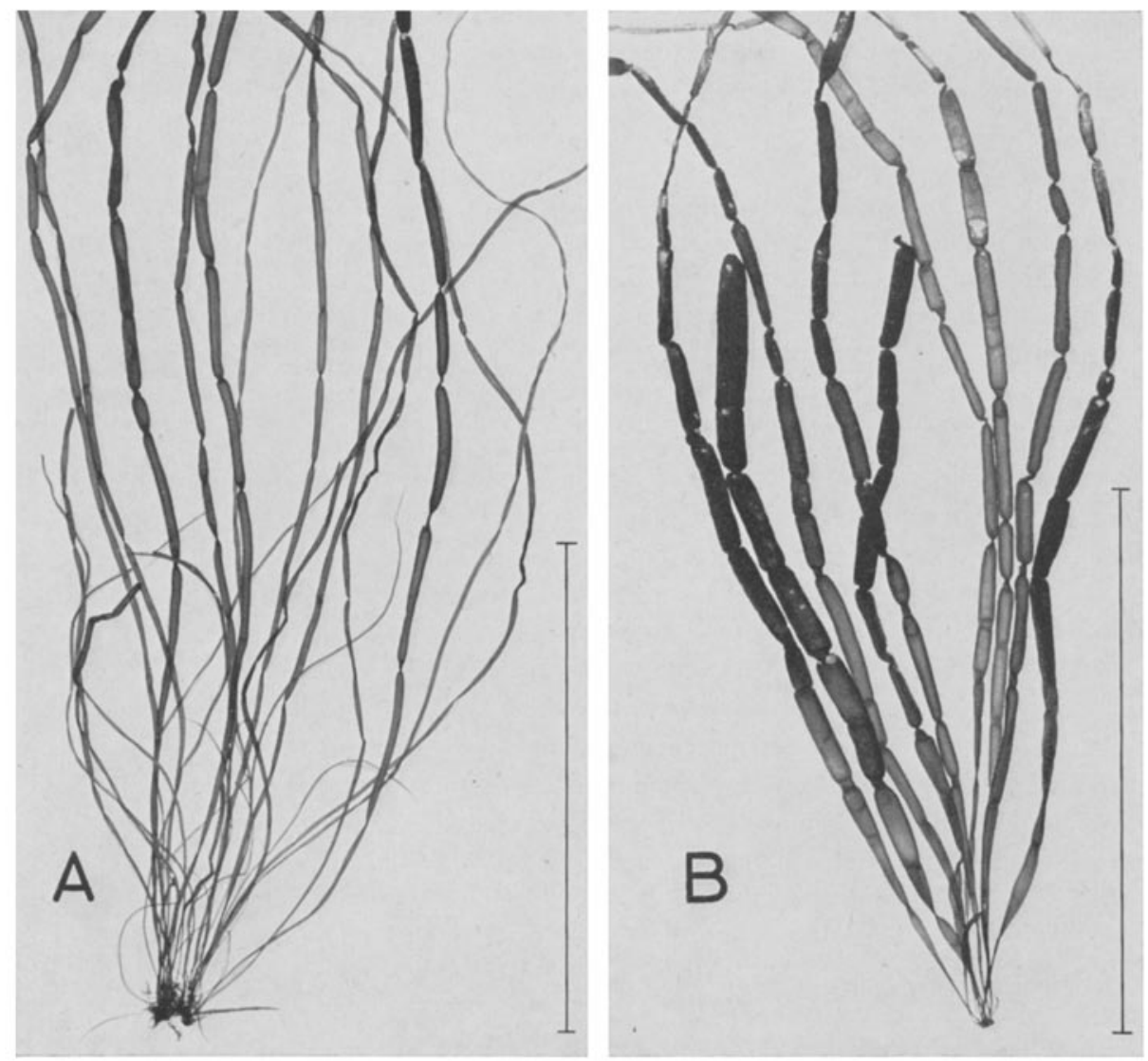

Abb. 74: Scytasiphon lomentaria. A Junge röhrige und ältere eingeschnürte Thalli (17. 4. 1972). $B$ Breite, stark eingeschnürte Exemplare $(24,5.1972)$. Maßstrecke jeweils $=10 \mathrm{~cm}$ 


\section{DESMARESTIALES}

In ihrem heteromorphen Generationswechsel mit Oogamie gleicht die Ordnung den Laminariales. Der gewebeartige Thallus des Sporophyten besteht jedoch nicht aus echtem Parenchym, sondern aus einer berindeten zentralen Achse. In der Algenflora Helgolands ist die Ordnung nur mit der Familie Desmarestiaceae vertreten.

\section{Desmarestiaceae}

\section{Desmarestia Lamouroux}

Die beiden Arten der Gattung wachsen im Sublitoral in Tiefen bis etwa $6 \mathrm{~m}$. Nur bei sehr tiefem Niedrigwasser trifft man sie zwischen Laminarien wachsend an. Beide Arten werden mitunter reichlich an den Strand gespült; sie sind aber in ihrem Habitus und in ihrer Lebensweise so verschieden, daß ihre nahe Verwandtschaft nicht ohne weiteres ersichtlich ist.

\section{Desmarestia aculeata (L.) Lamour.}

Nur im Sommer und Herbst kennzeichnet der Name Stacheltang die sparrige und mit kurzen, dornartigen $Z$ weigen besetzte Art (A). Während des Winters geht häufig ein Teil der stacheltragenden Aste verloren und es bleiben nur die krättigen, etwas abgeflachten Hauptachsen ïbrig. Ab Mitte Februar beginnt die Lauberneuerung dieser mehrjährigen Alge, indem aus den Achseln der Verzweigungen kräftige Langtriebe aussprossen, die sich verzweigen und bis Ende Juni etwa $40 \mathrm{~cm}$ lang werden $(B, C)$. Sie tragen dicht gereiht gegenständige gelbbraune Haarbüschel (D). Die jungen Sprosse sind noch frei von Stacheln, diese erscheinen erst als zerstreute Kurztriebe Anfang Mai. Schon im Juni werden die Haarbüschel abgeworfen und die zunächst noch grünlich-braunen Triebe färben sich im Laufe des Jahres immer dunkler.

Die Entwicklung von Desmarestia umschließt einen Wechsel heteromorpher Generationen. Unilokuläre Sporangien werden im Dezember in Sori zwischen den Rindenzellen gebildet. Aus den Zoosporen entsteht eine Generation mikroskopisch kleiner, getrenntgeschlechtlicher Gametophyten von ähnlichem Aussehen wie die von Laminaria (vgl. Abb. 78). Die aus der Zygote sich entwickelnden Sporophyten erreichen schon Anfang Mai eine Länge von $30 \mathrm{~cm}$.

Abb. 75: Desmarestia aculeata. A Habitus im Sommer und Herbst (22. 8. 1970). B Langtriebe aus den Zweigachsen älterer Hauptsprosse (17. 2. 1971). C Habitus im Frihjahr (9. 4. 1970). D Tell einer mit kräfigen Assimilationsbüscheln besetzten Pflanze in etwa natürlicher Größe (17. 5. 1971). Maßstrecke: $C=4 \mathrm{~cm}$ 

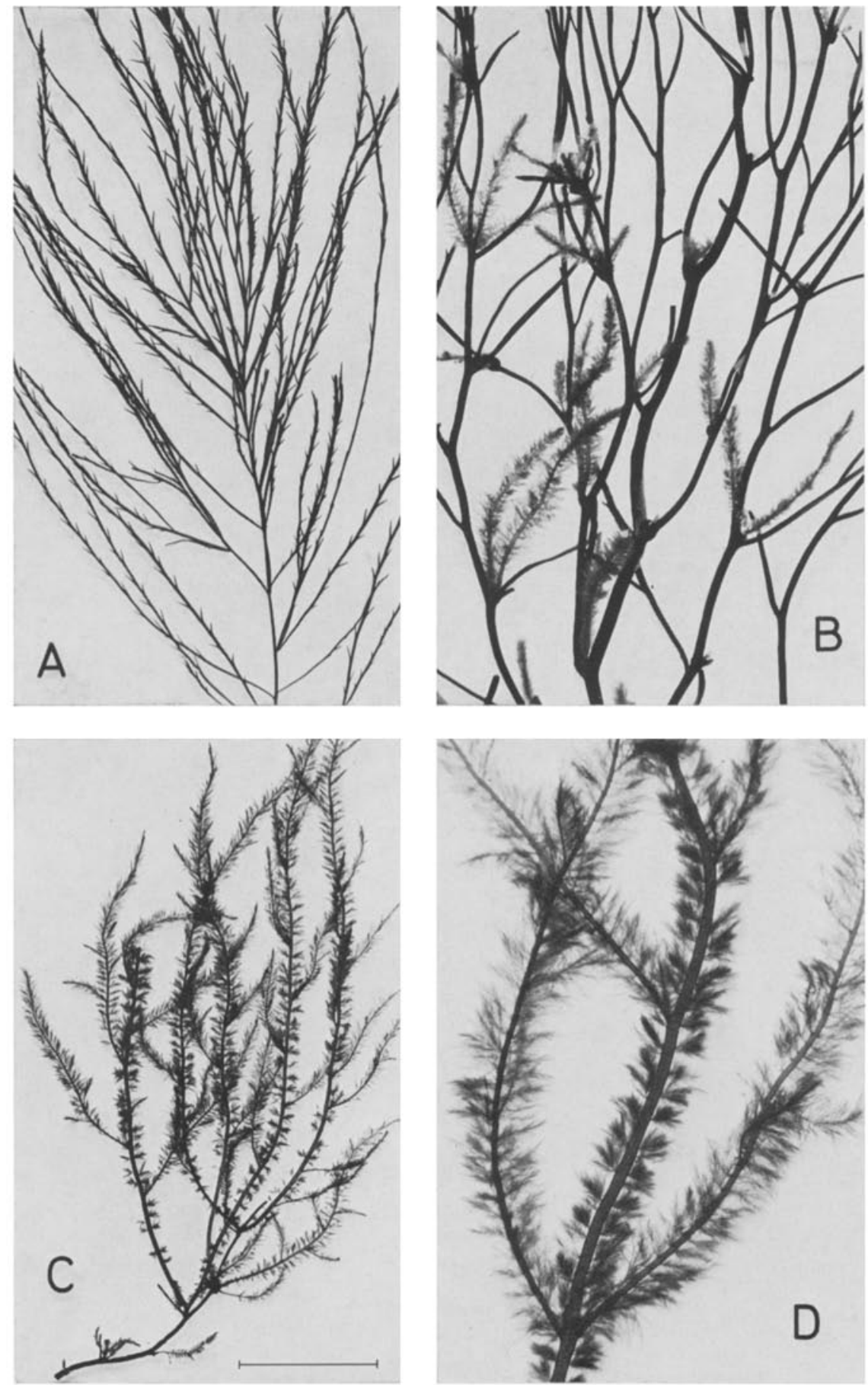


\section{Desmarestia viridis (O. F. Müll.) Lamour.}

Der Artname viridis ist für eine Braunalge ungewöhnlich; er geht darauf zurück, daß die schön gelbbraun gefärbten Büschel an der Luft rasch spangrün werden. Der Zellsaft enthält Schwefelsäure, und schon bei der geringsten Schädigung geht die Pflanze zugrunde, wobei sich der Farbstoff zersetzt. Eine auf einem Laminaria-Thallus absterbende Desmarestia viridis hinterläßt auf diesem ihr Abbild, da die Rindenzellen der Laminaria zerstört werden.

Desmarestia viridis ist im Gegensatz zu $D$. aculeata einjährig und gegenständig verzweigt. Dicht mit Haarbüscheln besetzt findet man sie im April und Mai (A, B),

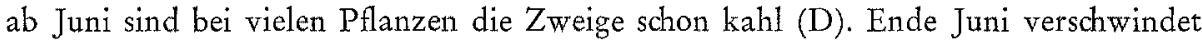
die zuweilen in großen Mengen an den Strand gespülte Alge.

Wie bei Desmarestia aculeata stehen auch bei dieser Art unilokuläre Sporangien in Gruppen zwischen den Rindenzellen, sind aber von diesen nur schwer zu unterscheiden (E). Die Gametophyten sind monözisch und werden im Winter bei entsprechend niedriger Wassertemperatur fertil. Mitte Februar kann man winzige Sporophyten epiphytisch an Algen aus etwa $3 \mathrm{~m}$ Tiefe finden. Solche etwa $1 \mathrm{~mm}$ hohe Keimlinge haben eine monosiphone Hauptachse; sie sehen ähnlich aus wie die bei $\mathrm{C}$ abgebildete Zweigspitze. Unterhalb eines interkalaren Meristems werden die Achsenzellen berindet, oberhalb desselben strecken sie sich stark in die Länge. Erstaunlich schnell wachsen die Pflanzen zu einer Größe von 25-30 cm heran.

Abb. 76: Desmarestia viridis. A Epiphytisch zusammen mit Phycodrys rubens und Plumaria elegans (22. 4. 1970). B Mit feinen Haarbüscheln besetzte Pflanze (24. 4. 1972). C Ausschnitt aus der Hauptachse einer jungen Pflanze. D Kahle Pflanze nach Verlust der Assimilationsbüschel (5.6.1972). E Aufsicht auf die Rinde mit reifen und entleerten unilokulären Sporangien. Maßstrecken: $A=1 \mathrm{~cm} ; B=5 \mathrm{~cm} ; \mathrm{C}=300 \mu \mathrm{m} ; \mathrm{E}=50 \mu \mathrm{m}$ 

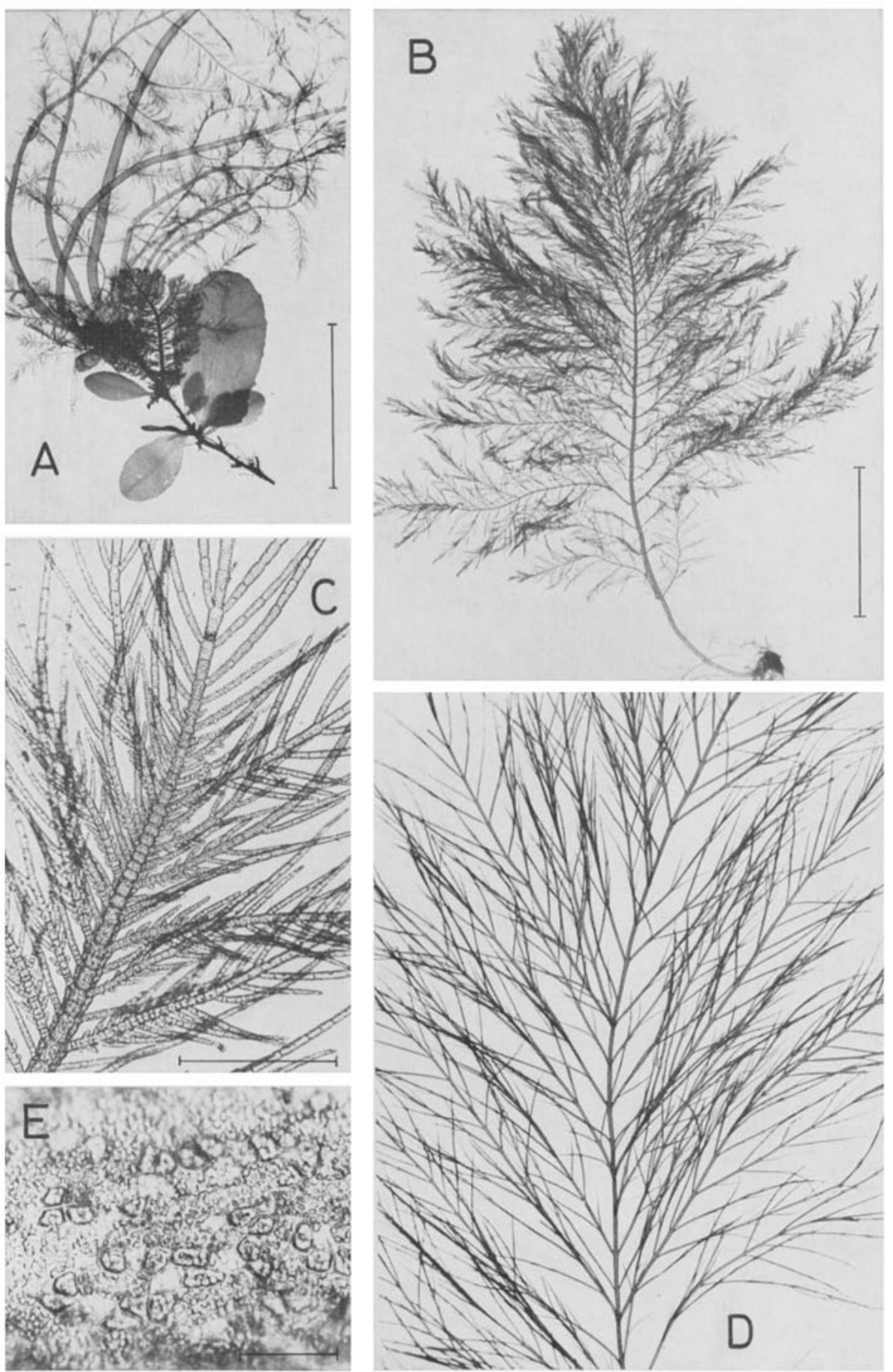


\section{LAMINARIALES}

In seiner äußeren und inneren Morphologie ist der aus echtem Parenchym aufgebaute Sporophytenthallus weitgehend differenziert. Die diözischen Gametophyten sind einreihig und wenigzellig, die Befruchtung ist oogam.

Die Ordnung ist bei Helgoland mit $z$ wei Familien vertreten. Die Chordaceae enthalten die beiden Arten der Gattung Chorda, einjährige, lange schnurartige, unverzweigte Algen (p. 150). Die Laminariaceae sind ausdauernd, ihr Thallus ist in einen Stiel und eine blattartige Fläche gegliedert. Die Beschreibung der drei Arten, ihrer Okologie und Biologie erfolgt in einer zusammenfassenden Darstellung.

\section{Laminariacea e}

Laminaria saccharina (L.) Lamour.

Laminaria digitata (Huds.) Lamour.

Laminaria byperborea (Gunn.) Fosl.

\section{Morphologische Kennzeichnung}

Die drei Laminaria-Arten sind die stattlichsten Vertreter der Helgoländer Algenflora. Sie leben im Sublitoral, und wer bei glatter See mit dem Boot über die Tangwälder gleitet, gewinnt einen Eindruck von der Eigenart dieser Vegetation. Ausgeworfene Exemplare kann man immer am Strand finden. Ein kräftiges, krallenartiges Haftorgan verankert den Laminaria-Thallus so fest auf der Unterlage, daß die losgerissenen Algen häufig Stücke des Substrats verfrachten (Abb. $78 \mathrm{~A}$ ). Laminaria saccharina hat einen bandförmigen, bis $4 \mathrm{~m}$ langen, am Rand mehr oder weniger stark gewellten Thallus (Abb. 77 A); die Laubfläche der beiden anderen Arten ist fingerförmig geteilt. Laminaria digitata hat einen glatten, abgeflachten, elastischen Stiel, der sich unmittelbar in die Blattfläche verbreitert (Abb. $77 \mathrm{D})$. Dagegen hat Laminaria byperborea einen herzförmigen Blattansatz ( $\mathrm{Abb} .78 \mathrm{C}$ ); ihr rauher, runder Stiel ist steif und häufig von Rotalgen besetzt (I). Die Länge des Stiels von L. byperborea hängt von der Wassertiefe $a b$, in der die Pflanzen wachsen; sie nimmt von 10 bis $20 \mathrm{~cm}$ bei $0,5 \mathrm{~m}$, auf $150 \mathrm{~cm}$ bei $4 \mathrm{~m}$ Tiefe zu. Der Stiel ist in eine Rindenschicht und einen Zentralkörper differenziert, im Mark verlaufen echte Leitungsbahnen; Ringbildungen zeigen ein sekundäres Dickenwachstum an. Nur die Stiele sind im eigentlichen Sinne mehrjährig, während das Laub in jedem Jahr erneuert wird.

Abb. 77: Laminaria saccharina. A Ausgeworfene, etwa $2 \mathrm{~m}$ lange Pflanzen (1.6. 1971). B Fertilex Thallus mit Sorusstreifen (8. 12. 1971). C Junge ausgeworfene Exemplare, die obere helle Randzone ist noch einschichtig (17.4.1972). Maßstrecke: $\mathrm{C}=5 \mathrm{~cm}$

D Laminaria digitata. Reiner Bestand vor der Ostkaje bei tiefern Niedrigwasser (29, 3, 1974) 

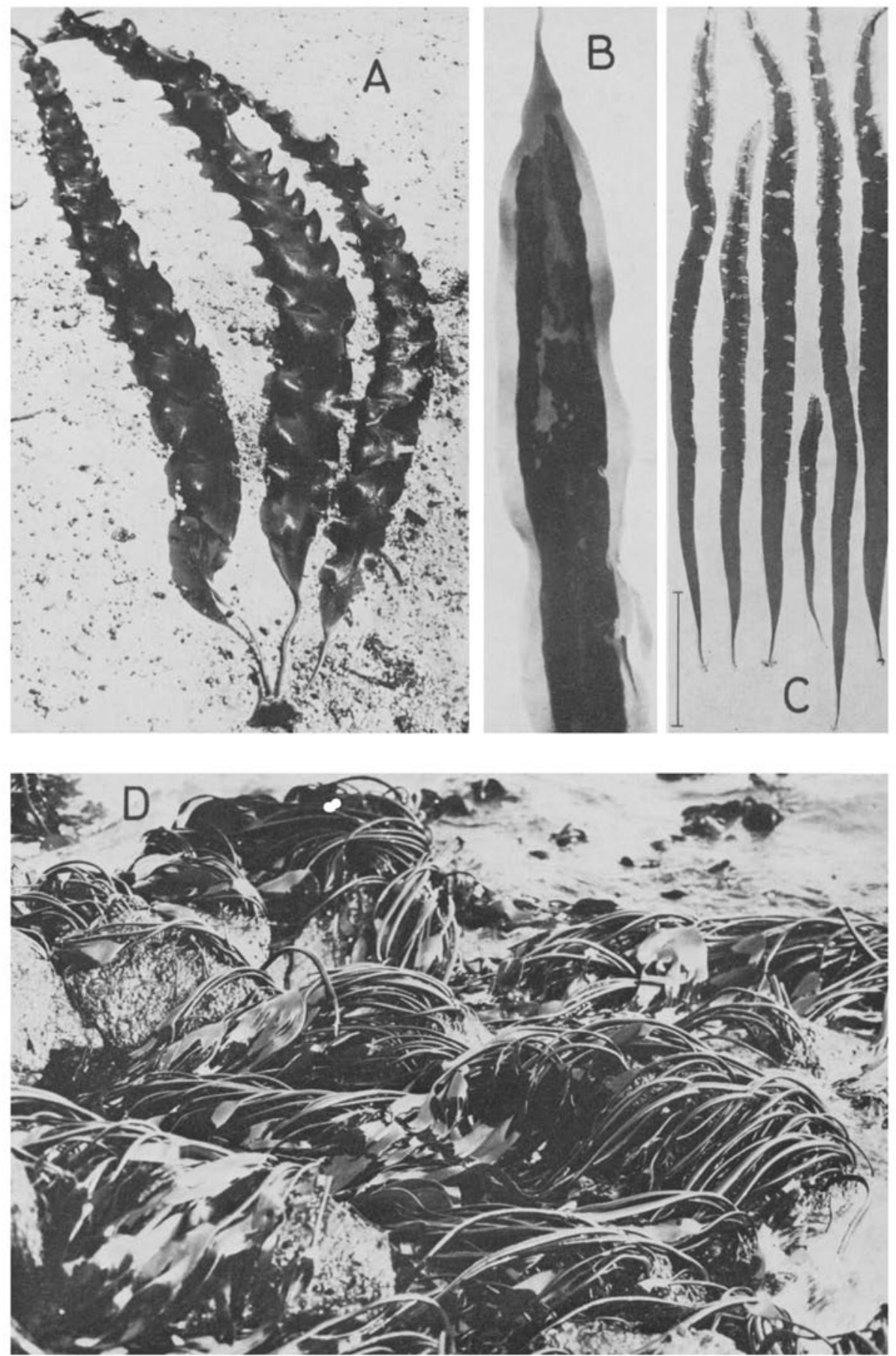


\section{Lauberneuerung}

Den "Laubwechsel" zeigt Abb. $78 \mathrm{D}$ bei Laminaria byperborea. Er beginnt schon in der dunkelsten Jahreszeit, im Dezember bis Januar, dabei werden zunächst die im alten Laub gespeicherten Reservestoffe für den Aufbau des neuen Blattes mobilisiert, bevor auch die Assimilationsleistung bei zunehmendem Licht dazu beiträgt (Lüning, 1970a). Die Meristemzone liegt an dem Ubergang des Stiels in den flächigen Thallus; das alte Laub sitzt dem neuen Phylloid noch bis etwa Anfang Mai auf. Um diese Zeit werden größere Mengen des überständigen Laubes nach stürmischem Wetter abgerissen und an den Strand gespült. Nicht so augenfällig wie bei Laminaria byperborea und $L$. saccharina vollzieht sich der Laubwechsel bei Laminaria digitata. Das vorjährige Laub wird nicht abgestoßen, sondern vor dem wachsenden Blattstreifen weitergeschoben und degeneriert an den Enden.

\section{Entwicklung}

Im späten Winter und Frühjahr findet man in der unteren Gezeitenzone zuweilen große Mengen winziger Laminaria-Pflänzchen unmittelbar auf felsigem Substrat oder epiphytisch, z. B. auf Cladophora rupestris (Abb. 79 C). Auch Rotalgen aus dem Sublitoral, wie Polysiphonia urceolata oder Plocamium cartilagineum sind oft dicht damit besetzt (Abb. 79 A). Thre Herkunft und Entwicklung war bis 1915 unbekannt und wurde durch das Kulturexperiment geklärt.

Auf dem Laub ausgewachsener Laminarien findet man im Herbst und Winter nur bei Laminaria digitata schon von Juni bis Oktober - die Sori der Sporangienlager als unregelmäßig begrenzie, etwas erhabene Flecke von dunklerer Farbe (Abb. $77 \mathrm{~B}$, Abb. 78 E). Aus den 32 Zoosporen ihrer schlauchförmigen Sporangien gehen je zur Hälfte diözische Geschlechtspflanzen hervor, mikroskopisch kleine, einreihige, verzweigte Pflänzchen (Abb. $78 \mathrm{~F}-\mathrm{H}$ ). In den Kulturen bleiben die Eier im allgemeinen an der Mündung der schlauchförmigen Oogonien haften und entwickeln sich nach der Befruchtung durch die Spermatozoiden zu Sporophytenkeimlingen $(\mathrm{H})$, die ganz den jüngsten Stadien aus der Natur gleichen. Mitte April kann man schon 20 bis $30 \mathrm{~cm}$ lange, zarte Thalli von Laminaria saccharina mit einem hellen, noch einschichtigen Rand finden; sie werden of in großen Mengen an den Strand gespült ( $\mathrm{Abb}, 77 \mathrm{C}$ ).

Abb. 78: Laminaria byperborea. A Langstielige Exemplare, zum Teil mit Brocken des Substrats ausgeworfen (30. 5. 1971). B Hoher Wall von ausgeworfenen Laminarien, meist L. byperborea (28. 7. 1971). C Kurzstielige Pflanzen mit herzförmigem Blattansatz (16.8. 1972). D Beginnende und fortgeschrittene Lauberneuerung (2. 2. 1971). E Blattstreifen mit Sporangiensori (3. 2. 1971). F Zwei Tage alte Zoosporenkeimlinge. G Männlicher Gametophyt mit reifen und leeren Antheridien. H Weiblicher Gametophyt mit Eiern und einreihigen Sporophytenkeimlingen an der Mündung der schlauchförmigen Oogonien sowie einem bereits flächigen Sporophyt. I Häufig auf dem Stiel anzutreffende Epiphyten: Membranoptera alata, Polysiphonia urceolata und die Krustenalge Dermatolithon pustulatum (3.5.1971). Maßstrecken: F und G je $10 \mu \mathrm{m}$; $\mathrm{H}=100 \mu \mathrm{m}$ 


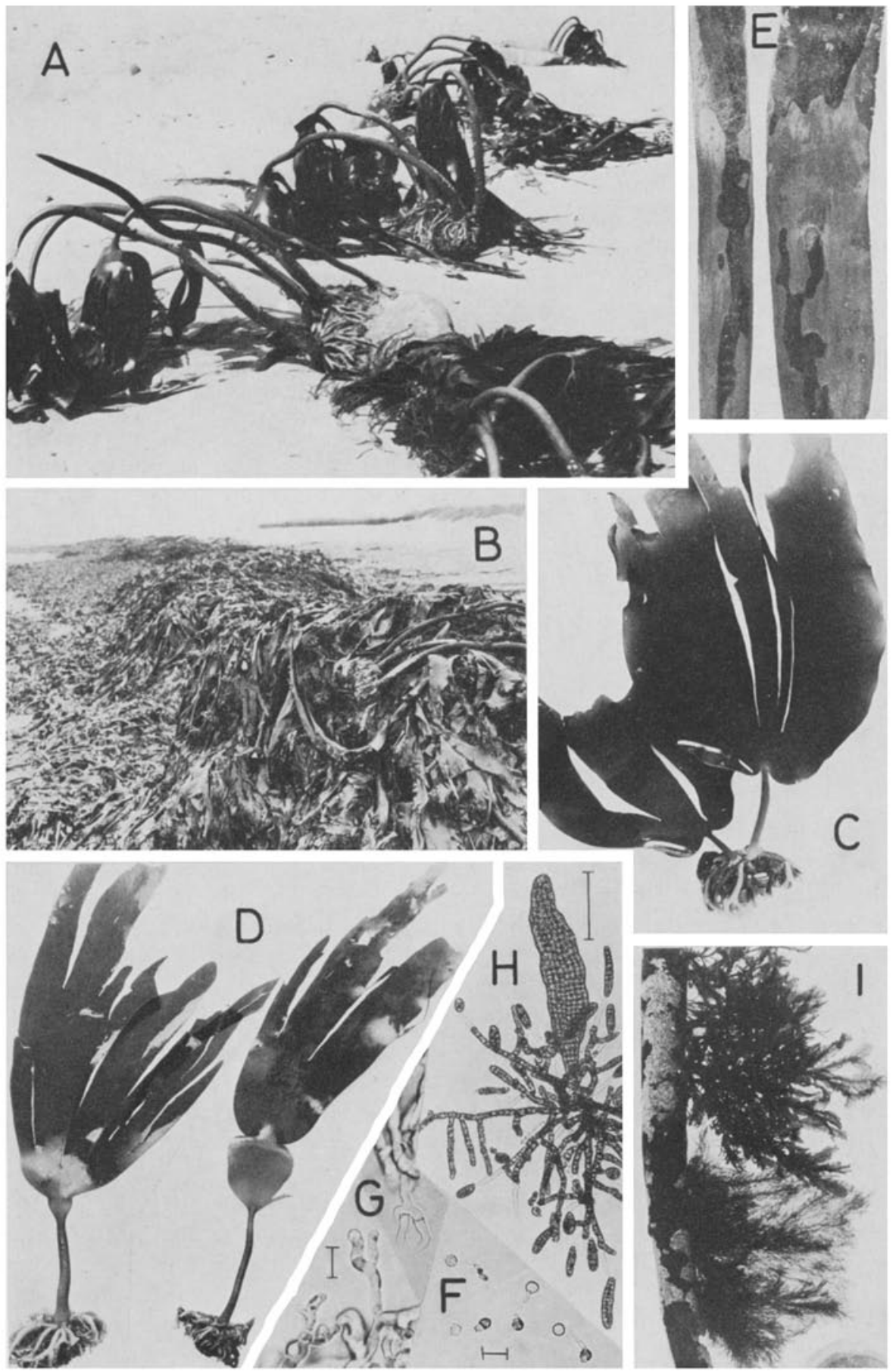


Wenn auch Laminaria-Keimlinge und junge Pflanzen im unteren Litoral und im Sublitoral weit verbreitet sind, so können die drei Arten doch nur bei entsprechender Gedeihtiefe zu großen Pflanzen heranwachsen. Sie werden im zweiten oder dritten Jahr erstmalig fertil.

\section{Vertikalzonierung}

Die Laminaria-Arten besiedeln den felsigen Untergrund des Sublitorals in einer ihren unterschiedlichen Lichtansprüchen entsprechenden vertikalen Zonierung. An der Niedrigwassergrenze flutet Laminaria digitata; bei sehr tiefem Wasserstand liegen die Pflanzen auch für kurze Zeit frei (Abb. $77 \mathrm{D})$; sie gedeiht bis zu einer Tiefe von 1,5 m. $\mathrm{Zu}$ ihr gesellt sich im unteren Bereich Laminaria saccharina, die ihre untere Grenze bei $3 \mathrm{~m}$ Wassertiefe hat. Laminaria byperborea wächst in geschlossener Vegetation zwischen 1 und $4 \mathrm{~m}$ Tiefe, die zwischen Laminaria digitata wachsenden Pflanzen sind kurzstielig. Unterhalb von $4 \mathrm{~m}$ geht Laminaria byperborea in eine offene Vegetation über und findet bei $8 \mathrm{~m}$ Wassertiefe ihre untere Grenze, die dort wachsenden Exemplare sind klein und stark von Moostierchen, Membranipora membranacea, überwachsen (Lüning, 1970b). Wohlgemerkt gelten diese Angaben für die hydrographischen Verhältnisse bei Helgoland; die Vertikalzonierung und Gedeihtiefen können an anderen Küsten sehr davon abweichen.

\section{Wirtschaftliche Nutzung}

Seit altersher wurden in küstennahen Gebieten die ausgeworfenen oder bei Niedrigwasser am Standort geernteten Algen als Dünger genutzt. Im Mittelalter wurden große Mengen von Algen verascht, um den wachsenden Bedarf an Alkalien für die Seifen- und Glasherstellung zu gewinnen. Nach Einführung technischer Verfahren zur Sodaherstellung ging die Tangveraschung sehr zurück, kam aber nochmals zur Blüte, nachdem das Jod in der Asche entdeckt worden war. Seine billigere Herstellung aus Chilesalpeter brachte die Tangveraschung wiederum zum Erliegen.

Neuerdings haben die Algen wegen ihrer Phykokolloide wirtschaftliche Bedeutung erlangt; aus Rotalgen werden Agar und Carraghenan gewonnen, die Braunalgen enthalten Alginsäure. Die mannigfache Verwertung ihrer Salze, der Alginate, kann hier nur angedeutet werden. Sie sind ungiftig und bilden hochviskose Lösungen oder Gele. Alginate dienen als Druckverdickungsmittel in der Textilindustrie, als Emulgatoren oder Geliermittel in der Nahrungsmittelindustrie (Speiseeis, künstliche Sahne, Fleischsiilzen), in der Kautschukindustrie zur Herstellung von Schaumgummi, in der Papierindustrie werden sie zur Oberflächenveredelung verwandt. Zusammenfassende Darstellungen mehrerer Autoren in deutscher Sprache enthält Botanica Marina Vol. III

Suppl.: Meeresalgen - Industrielle Bedeutung und Verwendung (1962), im Literaturverzeichnis unter Hoppe, Hoppe \& Schmid, Maass, Schmid, Schmid \& Hoppe, Schulzen. 

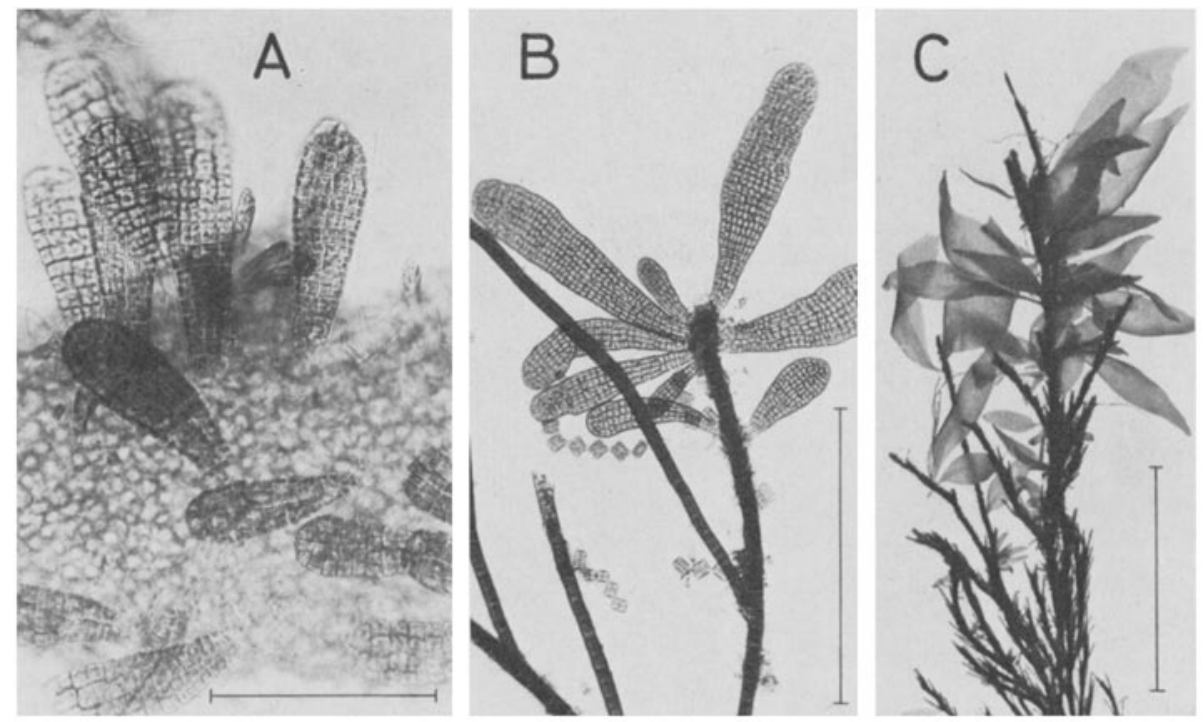

Abb. 79: Junge Laminaria-Sporophyten aus der Natur. A Auf Plocamium cartilagineum (4. 3. 1970). B Auf Sphacelaria caespitula (13. 3. 1972). C auf Cladophora rupestris (12. 4. 1972). Maßstrecken: $\mathrm{A}=100 \mu \mathrm{m} ; \mathrm{B}=500 \mu \mathrm{m} ; \mathrm{C}=1 \mathrm{~cm}$ 


\section{Chorda filum (L.) Stadkh.}

Die Gemeine Meersaite wird bis zu $5 \mathrm{~mm}$ dick und $3 \mathrm{~m}$ lang. Jüngere Pflanzen sind von einem Flaum farbloser Haare besetzt. Sie ist mengenmäßig in den letzten Jahren stark zurückgegangen, tritt aber in jedem Jahr immer wieder an denselben Standorten auf. Bei Niedrigwasser sieht man die Schnüre unter der Wasseroberfläche fluten, im allgemeinen zu Büscheln vereinigt und umeinandergewunden (A). Der hohle Thallus erhält durch eingeschlossene Luft Auftrieb.

Junge Pflanzen findet man ab April, sie sind noch frei von Epiphyten. Mit großer Regelmäßigkeit siedeln sich später Polysipbonia violacea und Ceramium rubrum auf den dunkelbraunen Schnüren an (B), Ende August können sie einen dichten Bewuchs der genannten Epiphyten sowie von Ulva lactuca, Enteromorpha linza und Giffordia granulosat tragen (C). Um diese Zeit werden die Pflanzen auch schon überständig und verschwinden Mitte September. Fertile Pflanzen wurden Anfang Juli gesammelt, Sporangien und Paraphysen umkleiden den gesamten Thallus mit Ausnahme der Basis in einer geschlossenen Schicht.

\section{Chorda tomentosa Lyngb.}

Mit Ausnahme ihrer kahlen Basis trägt die Zottige Meersaite einen dichten Pelz goldbrauner Haare. Die Pflanzen sind stets frei von Epiphyten. Junge Pflanzen findet man schon Anfang April, aber Mitte Juni sind die ausgewachsenen Pflanzen bis 1,5 m lang und fertil. Im Laufe des Juli verschwindet diese Art.

Nur bei besonders tiefem Wasserstand kann man Chorda tomentosa an einzelnen wenigen Stellen erreichen, sie wächst etwas tiefer als Chorda filtum. Man findet sie aber häufig am Strand der Düne angetrieben. Sie siedelt sich gerne an Molen an, an denen sauberes Wasser entlangströmt.

Abb. 80: Chorda flum. A Uber einer Wiese von Ulva lactuca in einer dünnen Wasserschicht flutend (21. 5. 1973). B Mit Ceramium rubrum und Polysipbonia violacea als Epiphyten (2. 8. 1972). C Besonders dichter Aufwuchs von Polysipbonia violacea, junger Ulva lactuca und Enteromorpha linza (21.8. 1974). Maßstredsen: B, C jeweils $=5 \mathrm{~cm}$ 

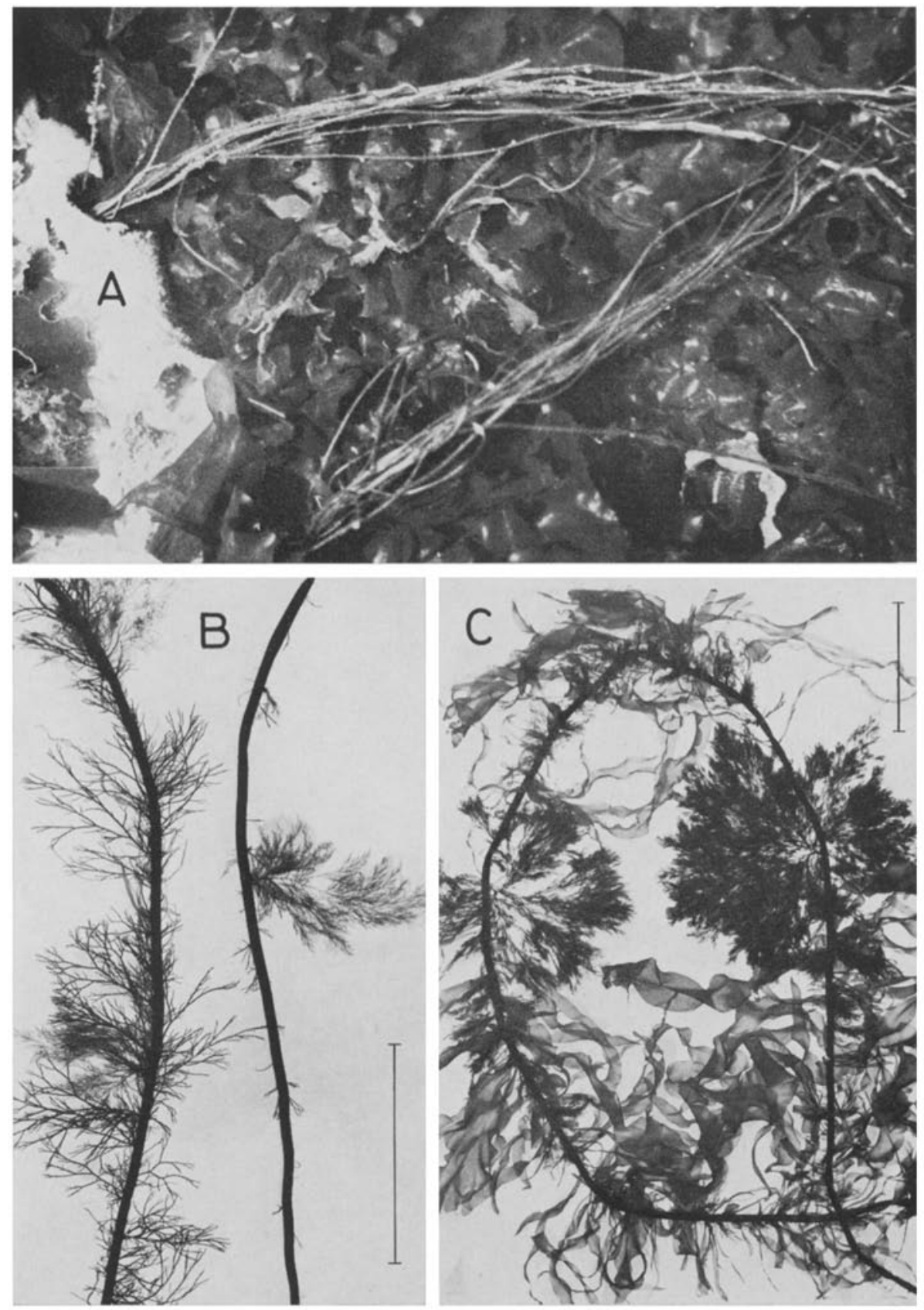


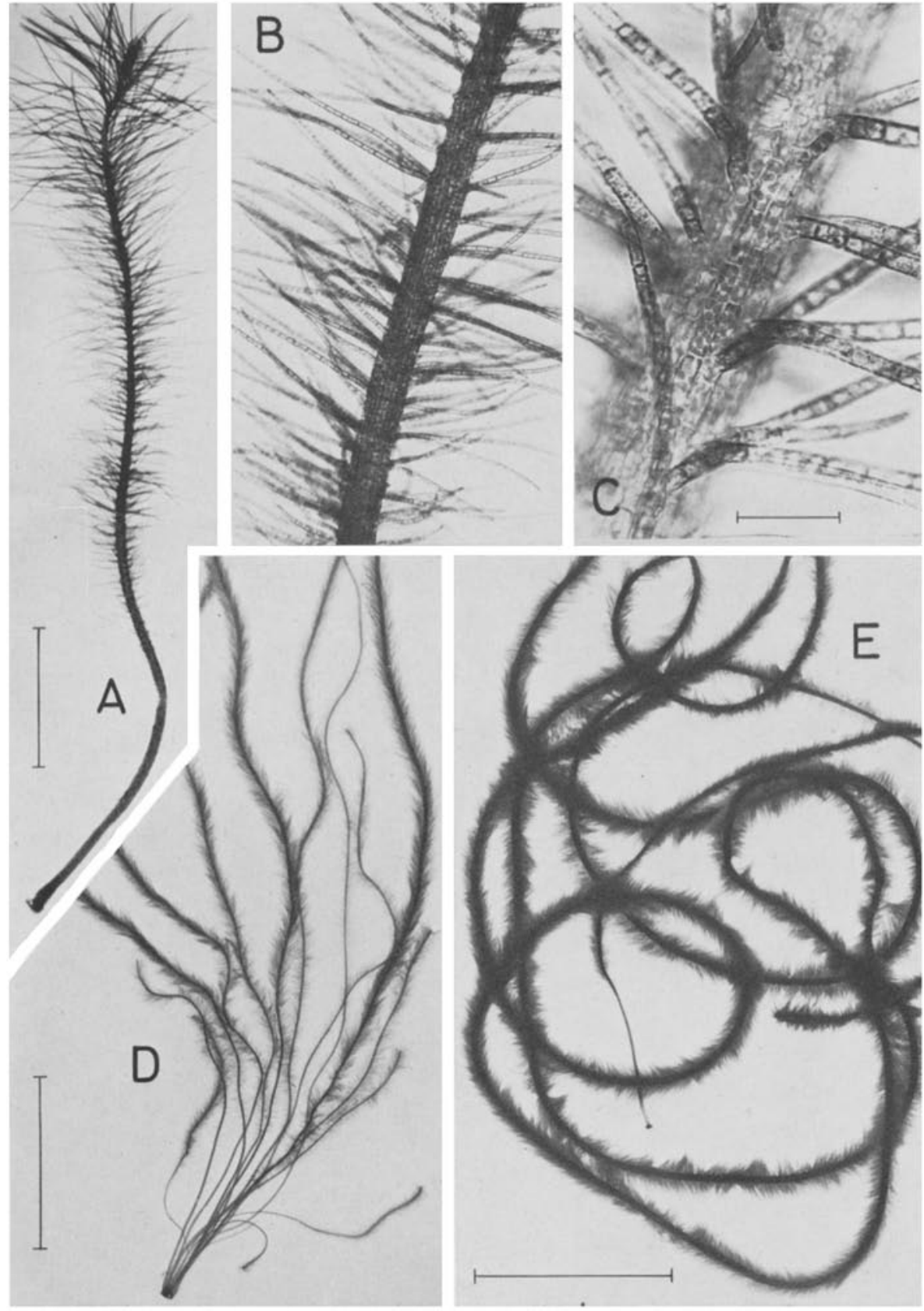

Abb. 81: Chorda tomentosd. A-C Junge Pflanze und Ausschnitte stärker vergrößert (3.5.1973). D, E Altere und ausgew achsene Pflanzen (17.4.1972 und 3.6.1971). Maßstrecken: $A=1 \mathrm{~mm}$; $\mathrm{C}=50 \mu \mathrm{m} ; \mathrm{D}, \mathrm{E}$ jeweils $=5 \mathrm{~cm}$ 


\section{SPHACELARIALES}

Kennzeichnendes Merkmal der Ordnung ist die apikale Scheitelzelle der büscheligen und verzweigten Algen; die Segmente werden durch Längs- und Querteilungen gewebeartig aufgeteilt. Im Entwicklungszyklus folgen einander nahezu gleichgestaltete Sporophyten und Gametophyten (vgl. p. 159).

Die fädig verzweigten Arten der Gattung Sphacelaria finden ihren Platz in der Familie Sphacelariaceae; die Gattung Cladostepbus mit quirligen Kurztrieben an verzweigten, berindeten Achsen bildet eine eigene Familie, Cladostephaceae, p. 156.

\section{Sphacelariaceae}

\section{Sphacelaria furcigera Kütz.}

Sie ist die einzige der von uns bei Helgoland gefundenen Sphacelaria-Arten mit Brutknospen; fast alle von Mai bis November gesammelten Proben tragen diese vegetativen Vermehrungsorgane. Gabelige oder dreistrahlige Brutknospen kommen auf derselben Pflanze vor, doch überwiegen auf verschiedenen Exemplaren die einen oder die anderen. Haare wurden nur spärlich beobachtet; sie werden endständig angelegt, dann aber setzt die darunterliegende Fadenzelle als neue Apikalzelle die Achse fort.

Sphacelaria furcigera wächst nahe der Niedrigwassergrenze auf Fels und epiphytisch auf Fucus serratus, Ceramium rubrum, Cladostephus spongiosus und anderen Algen. Die Büschel bleiben hier meist unter 1,5 cm hoch. Ein bevorzugter Standort sind die den Hafenmolen als Wellenbrecher vorgelagerten Betonblöcke. An ihren Außenflächen, besonders aber in den stets wassergefüllten Becken werden die Büschel bis zu $3 \mathrm{~cm}$ lang; sie besiedeln die Wände oder die in diesen "Aquarien" wachsenden Algen. 

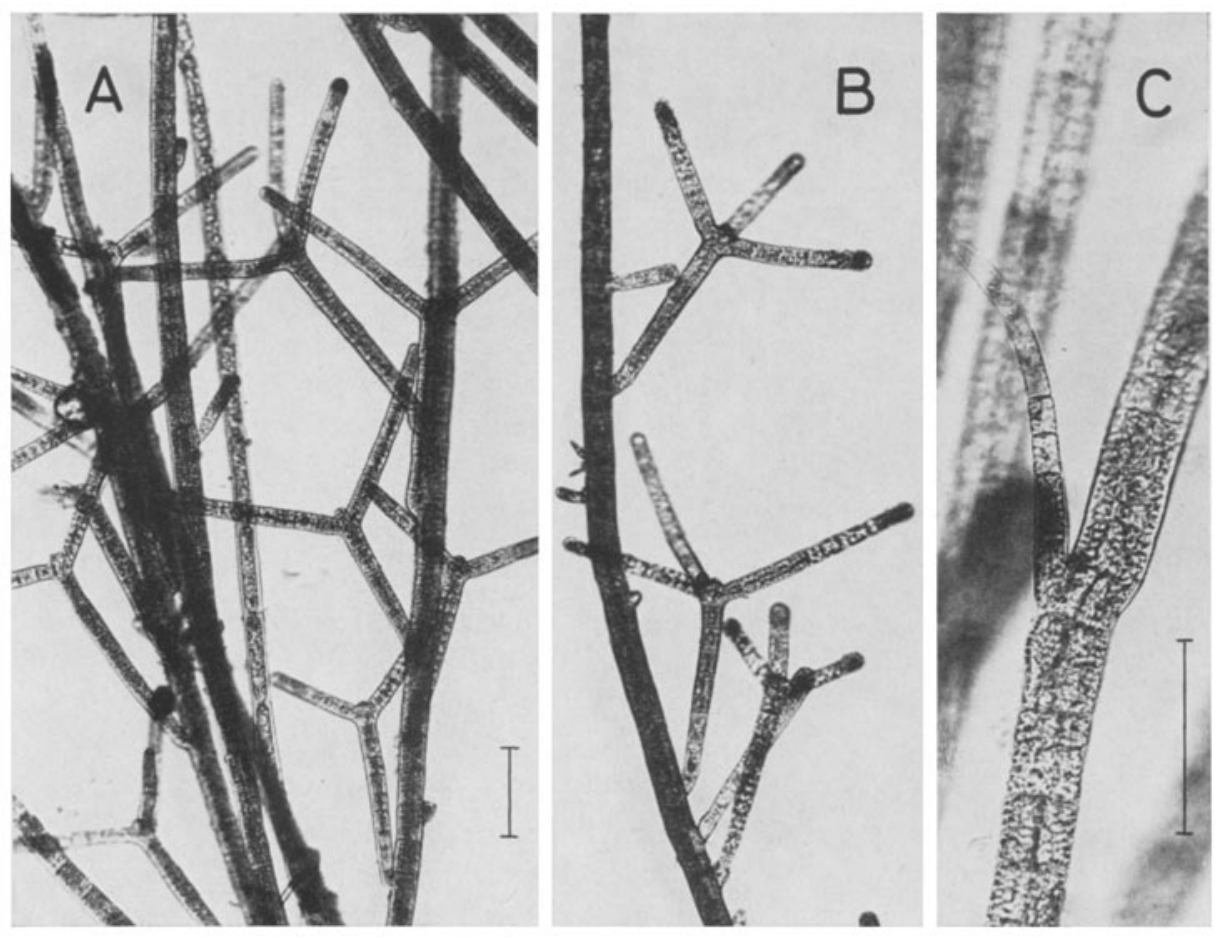

Abb. 82: Sphacelaria furcigera. A Pflanze mit iberwiegend zweistrahligen Brutknospen (aus einem Präparat vom 7. 7. 1959). B Dreistrahlige Brutknospen (13.10. 1970). C Ursprünglich endständiges Haar zur Seite gedrängt. Maßstrecken: A, B $=100 \mu \mathrm{m} ; \mathrm{C}=100 \mu \mathrm{m}$

\section{Sphacelaria radicans (Dillw.) C.Ag.}

Sphacelaria radicans bildet im unteren Litoral auf festem Untergrund unter $F u$ cus serratus dunkelbraune, pelzartige Rasen von 1 bis $1,5 \mathrm{~cm}$ Höhe. Sie kommt aber auch auf den sogenannten weichen Klippen zusammen mit Rhodochorton floridulum zwischen den Wohnröhren von Fabricia sabella vor. Aus einem Stück des auf festem Substrat gewachsenen didhten Rasens sind einige Büschel herausgelöst (A). Die aufrechten Stämmchen erheben sich auf einem niederliegenden Basallager; sie tragen in ihrem oberen Teil wenige zerstreute Äste. Rhizinen entspringen aus dem mittleren und unteren Teil der Stämmchen und verfestigen die Polster, zwischen deren Fäden sich reichlich Detritus ansammeln kann. Die Stämmchen werden gern von kleineren Epiphyten besiedelt.

Sphacelaria radicans fruktifiziert von November bis Februar. Es sind nur unilokuläre Sporangien bekannt; sie sitzen den Stämmchen oft paarig oder gehäuft und ungestielt auf $(C, D)$; auf den Rhizinen können sie auch kurzgestielt sein (B). 

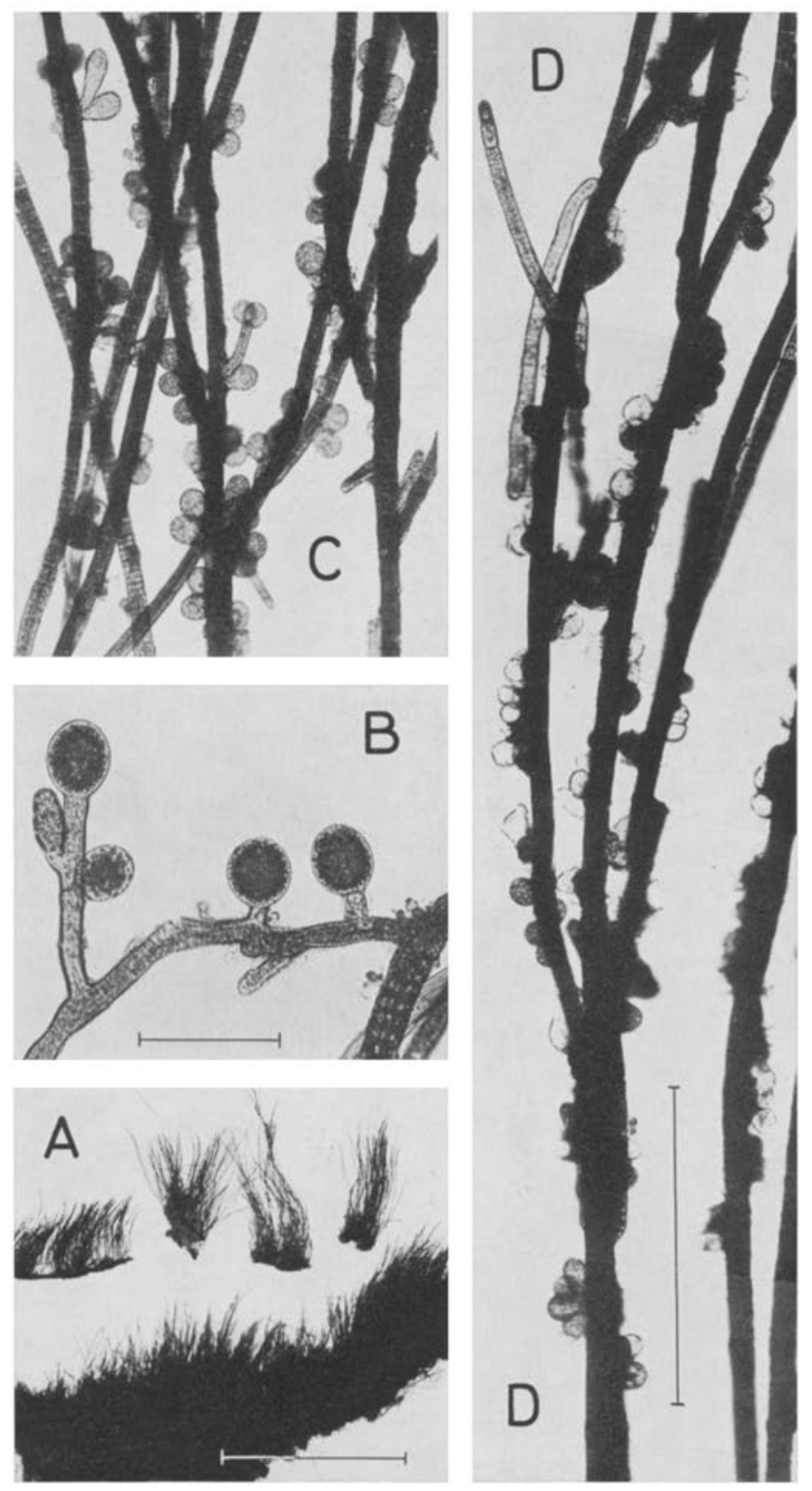

Abb. 83: Sphacelaria radicans. A Pelzartige Rasen und herausgelöste Büschel (18. 2. 1971). B Gestielte unilokuläre Sporangien auf einer Rhizine. C, D Stämmchen mit meist paarigen unilokulären Sporangien und Rhizinen (7.12. 1971 und 18.2.1971). Maßstrecken: $A=1 \mathrm{~cm}$; $B=100 \mu \mathrm{m} ; \mathrm{D}=500 \mu \mathrm{m}$ 
Sphacelaria caespitula Lyngb.

An Dretschmaterial oder von Tauchern beschafften Steinen aus dem Nordhafen ist diese Alge ziemlich regelmäßig vertreten. Es sind kleine, pinselartige Büschelchen von 5 bis $10 \mathrm{~mm}$ Höhe (A). Die Fäden sind nur wenig und unregelmäßig verzweigt $(F)$.

Sphacelaria caespitula ist im Winter fertil. Im allgemeinen trägt sie ovale, gestielte plurilokuläre Sporangien, vorwiegend auf den unteren Abschnitten der Fäden (B-E). Nur in einer Probe vom 2. März 1961 wurden auf einem Büschel ausschließlich unilokuläre Sporangien gefunden; durch ihre kugelige Form und die viel dickere Membran sind sie leicht von den plurilokulären Sporangien zu unterscheiden (G).

\section{Sphacelaria plumosa Lyngb.}

syn. Chaetopteris plumosa (Lyngb.) Kütz.

Diese schön fiedrige Braunalge des Sublitorals ist in Kratzmaterial von den Hafenmauern oder an gedretschten Steinen recht häufig zu finden. Sie ist mehrjährig und regeneriert ihre Federn in jedem Frühjahr aus den vorjährigen dicken, dunkelbraunen Stämmchen (A, B). Altere Keimlinge und Jugendstadien, unmittelbar dem Substrat aufsitzend, sind bei $C$ und $D$ abgebildet.

Die Achse des Thallus trägt zweizeilig angeordnete, meist gegenständige Fiedern, die im allgemeinen nur wenige Fiederchen zweiter Ordnung tragen. Zu einer Gabelung der Achse oder einem büscheligen Auswachsen kommt es häufig nach dem Verlust der Sproßspitze (F). Die Stämmchen werden bis zum Herbst etwa $2 \mathrm{~cm}$ lang und verdicken sich in ihrem unteren Teil durch eine aus Rhizinen gebildete pseudoparenchymatische Rinde. Im Winter gehen die Fiederchen weitgehend verloren, und aus der Rinde sprossen kurze, dünne Zweige, an denen später die gestielten Sporangien entstehen. Am 22. Februar 1972 gesammeltes Material trug reichlich plurilokuläre Sporangien $(\mathrm{G}, \mathrm{H})$; ein frisch austreibender vegetativer Sproß ist bei $G$ unscharf zu erkennen. Unilokuläre Sporangien werden in entsprechender Weise gebildet.

\section{Cladostephacea e}

\section{Cladostephus spongiosus (Huds.) C.Ag.}

Der grünlich- bis dunkelbraune Thallus ist unregelmäßig gabelig verzweigt, sehr wahrscheinlich in ähnlicher Weise infolge des Verlustes der Scheitelzelle wie bei $S p h a-$ celaria plumosa (vgl. Abb. 85 F). Die Achsen sind dicht mit Wirteln von bogig gekrümmten Kurztrieben besetzt, die sich überdecken und die Alge als wollig-filzige Dochte erscheinen lassen (A). Sie beherbergen oft zahlreiche epiphytische Kleinalgen, auch Fucus-Keimlinge, Ceramium oder Ulva siedeln sich darauf an. Die Stämmchen vorjähriger Pflanzen sind in ihrem unteren Teil kahl. Cladostepbus spongiosus wächst auf exponierten Schichtköpfen in der mittleren und unteren Gezeitenzone. 

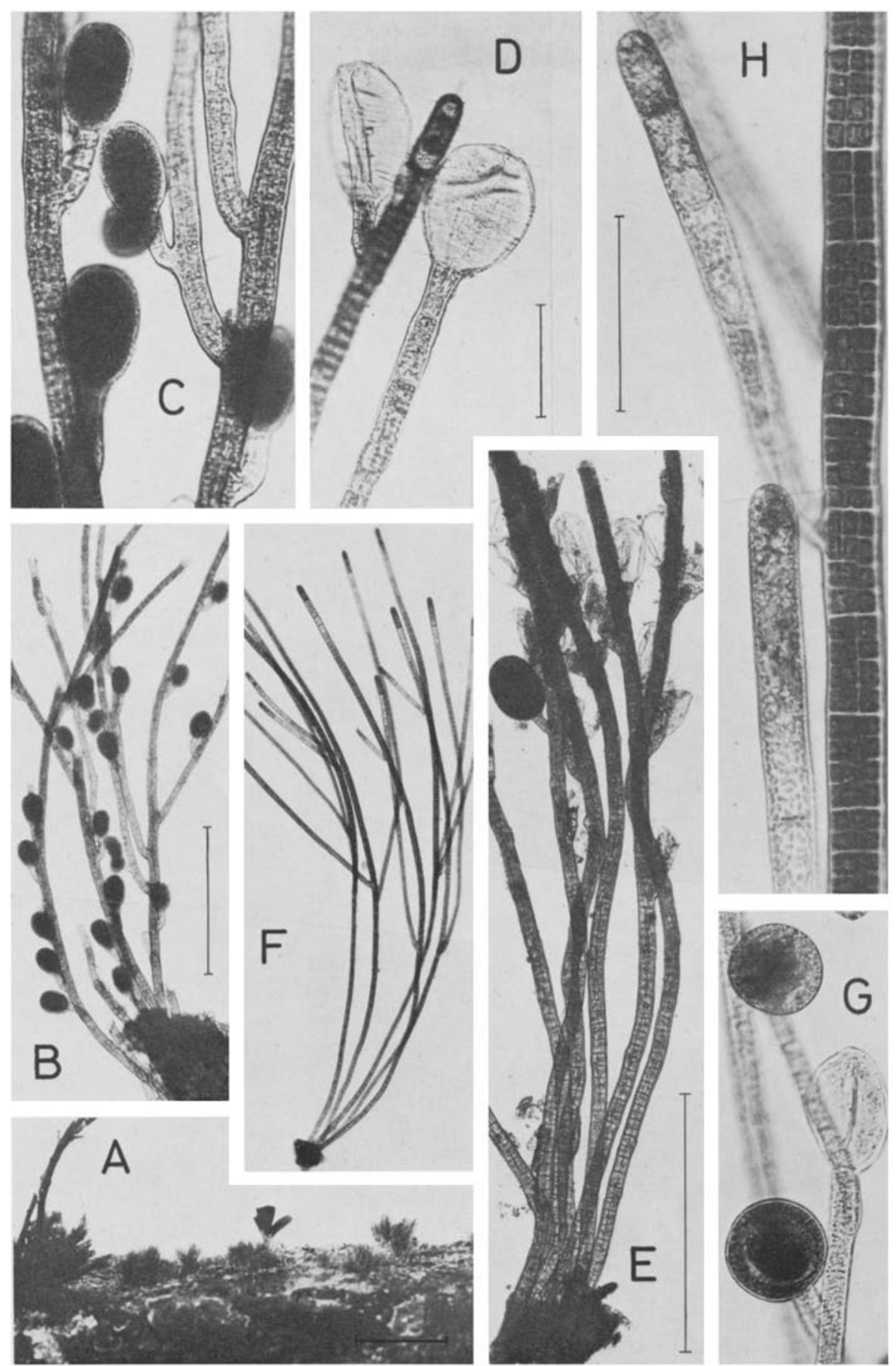

Abb. 84: Sphacelaria caespitula. A Kleine Büschel auf einem Stein aus $5 \mathrm{~m}$ Tiefe (11. 3. 1972). B-E Stämmchen mit plurilokulären Sporangien (22. 2. 1972). F Verzweigte Fäden aus einem etwa $2 \mathrm{~mm}$ hohen Büschel (11.3. 1972). G Unilokuläre Sporangien (aus Präparat vom 2. 3. 1961). H Scheitelzellen und gegliederter Faden. Maßstrecken: $A=1 \mathrm{~cm} ; B, F=500 \mu \mathrm{m}$; $C, D, G=100 \mu \mathrm{m} ; \mathrm{E}=500 \mu \mathrm{m} ; \mathrm{H}=100 \mu \mathrm{m}$ 

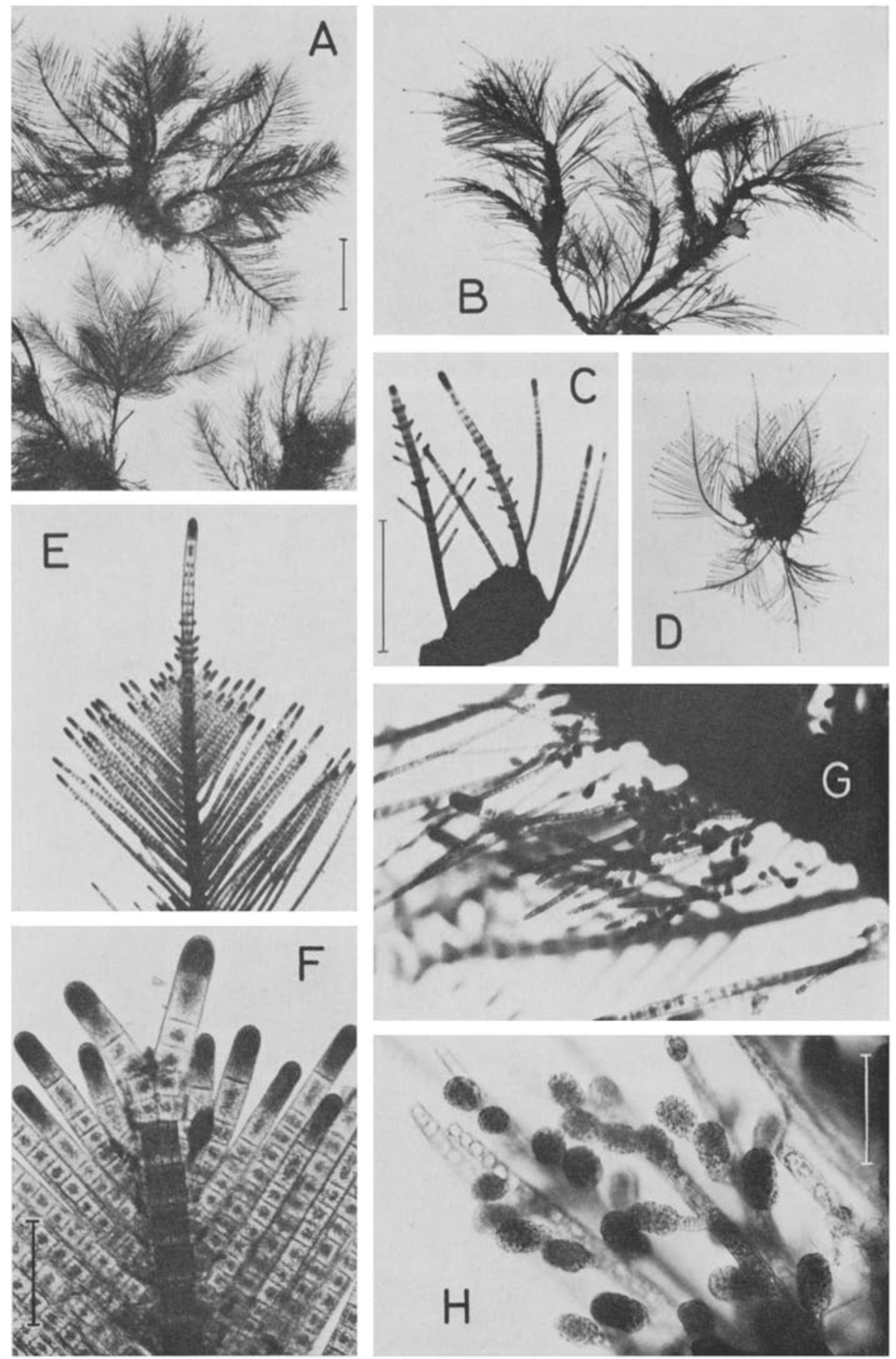

Abb. 85: Sphacelaria plumosa. A, B Altere, büschelige PAanzen (26. 5. 1970 und 10. 3. 1972). C, D Keimlinge und junge Pflanzen auf ihrem Substrat (22. 2. 1972 und 10. 3. 1972). E Sproß mit intakter Spitze (26. 5. 1970). F Gabelung der Achse nach Verlust der Sproßspitze (26, 5. 1970). G, H Plurilokuläre Sporangien (22. 2. 1972). Maßstrecken: $A=1 \mathrm{~cm} ; C, E=1 \mathrm{~mm}$; $\mathrm{F}=200 \mu \mathrm{m} ; \mathrm{H}=100 \mu \mathrm{m}$ 
Von November bis Februar findet man getrenntgeschlechtliche Gametophyten neben der gleichgestalteten Sporophytengeneration. Jedoch sind die Gametophyten etwas zarter und heller gefärbt als die Sporophyten, so daß man sie bei einiger Vertrautheit mit dem Material aus einem Gemisch aussuchen kann. Die plurilokulären Sporangien (D) stehen ebenso wie die unilokulären (B, C) kurz gestielt an besonderen Ästchen, die den Rindenzellen der basalen Thallusabschnitte entspringen.
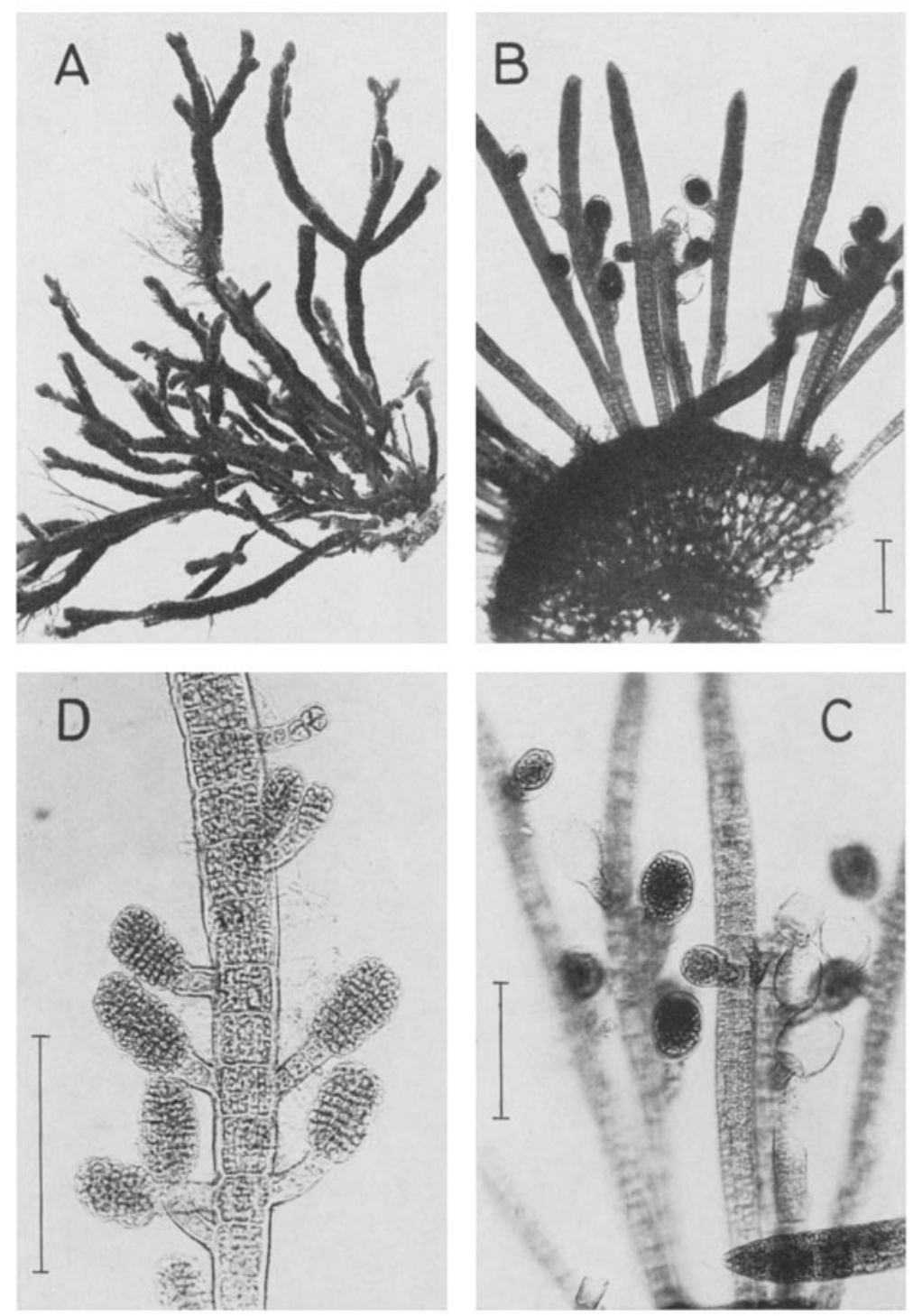

Abb. 86: Cladostephus spongiosus. A Büschel mit Epiphyten, ganz schwach vergrößert (26. 11 . 1970). B Querschnitt durch ein fertiles Stämmchen mit unilokulären Sporangien. C, D Ästchen mit uni- und plurilokulären Sporangien (aus fixiertem Material vom 6. 11. 1959). Maßstrecken: $\mathrm{B}, \mathrm{C}, \mathrm{D}$ jeweils $=100 \mu$ 

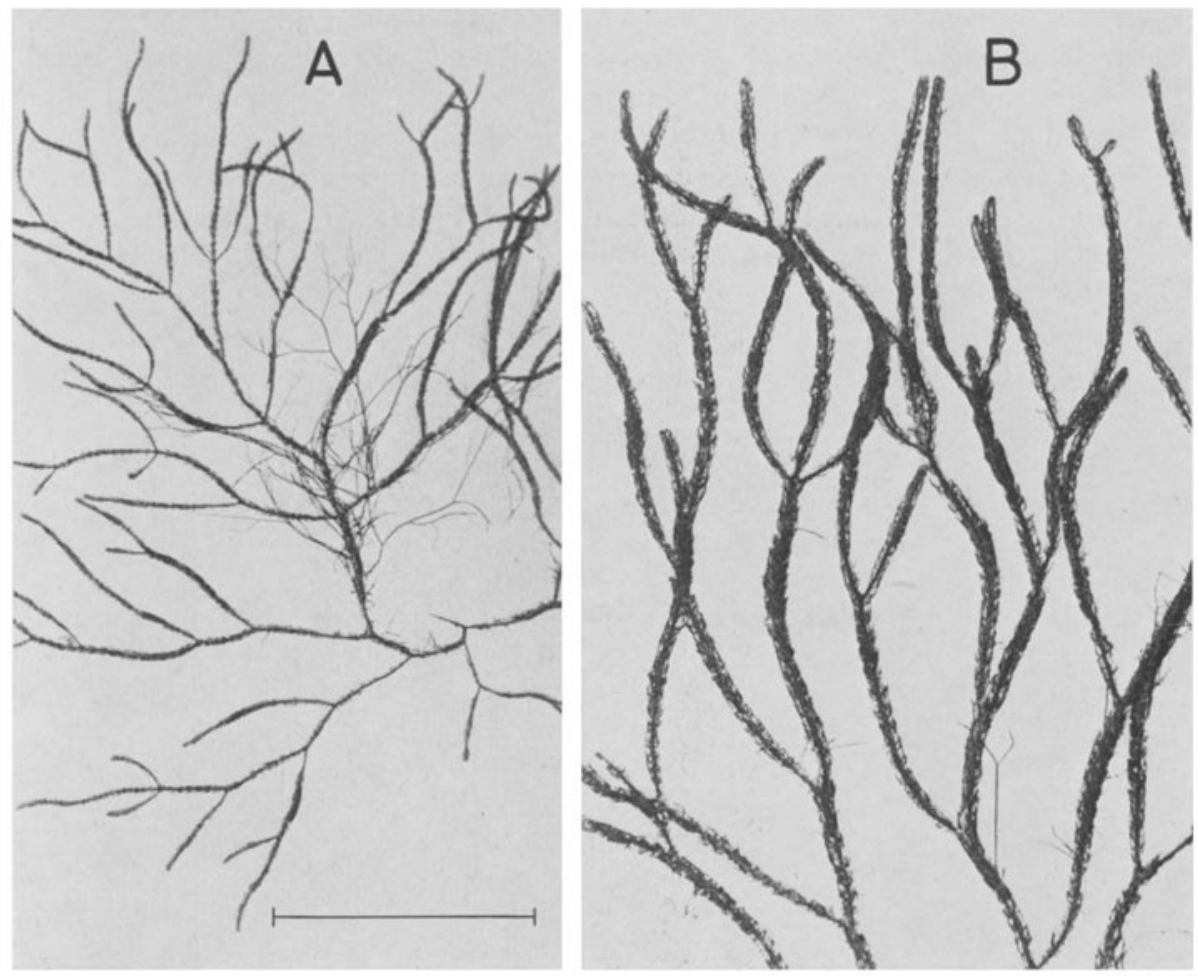

Abb. 87: Cladostephus verticillatus. A, B Herbarexemplare vom 11. 10. 1966. Maßstrecke = $5 \mathrm{~cm}$

\section{Cladostephus verticillatus (Lightf.) C.Ag.}

Bei Cladostephus verticillatus sind die Wirtel der Kurztriebe so weit voneinander getrennt, daß sie deutlich als Stockwerke zu erkennen sind. Im Vergleich zu der gedrungenen Erscheinungsform von Cladostephus spongiosus ist Cladostephus verticillatus viel lockerer aufgebaut. Im allgemeinen triff man die unteren Achsenabschnitte ohne Zweigwirtel an; häufig werden die Büschel über $15 \mathrm{~cm}$ hoch, $\mathrm{Cl}$. spongiosus dagegen bei Helgoland höchstens $7 \mathrm{~cm}$.

Cladostepbus verticillatus wächst im allgemeinen in etwas tieferem Niveau und ist nur bei besonders stark abgelaufenem Wasser zu erreichen. Die größten und schönsten Exemplare findet man am Strand ausgeworfen. Er wird neuerdings nicht mehr als eigene Art, sondern als sublitorale Form von Cladostephus spongiosus angesehen (Prud'homme van Reine, 1972). Nach unseren Beobachtungen kann man beide Formen gelegentlich im selben Niveau antreffen; auch das Herbarium Kuckuck enthält ein typisches Exemplar von Cladostephus verticillatus mit dem Vermerk "Westseite, emergierend u. neben $\mathrm{Cl}$. spongiosts wachsend. 18. September $1894^{\circ}$. 


\section{DICTYOTALES}

\section{Dictyotaceae}

\section{Dictyota dichotoma (Huds.) Lamour.}

Dictyota dichotoma kann hier eigentlich nur als Beispiel für laufende Veränderungen in der Algenvegetation Helgolands angeführt werden. Noch in den dreißiger Jahren kam sie reichlich im unteren Litoral des Felswatts im Südwesten der Insel vor, In den letzten 15 Jahren wurden nur gelegentlich noch einzelne Exemplare gefunden. Die Ursachen ihres Verschwindens sind ebenso unbekannt wie die für die gleichzeitige Einbürgerung und Ausbreitung anderer Arten, zum Beispiel Codium fragile.

Der bandartig flache gelbbraune Thallus zeichnet sich durch seine sehr regelmäßige Dichotomie aus, die auf eine Längsteilung der linsenförmigen Scheitelzelle in der Achsenrichtung zurückgeht. Zwei horizontale Wände in den jungen Segmenten führen $\mathrm{zu}$ einem parenchymatischen Thallus mit einer großzelligen Mittelschicht zwischen kleinen Rindenzellen.

Dictyota dichotoma hat isomorphen Generationswechsel mit der Einschränkung, daß die Sporophyten merklich schmaler sind als die Gametophyten. Eier und Spermatozoiden entstehen auf getrennten Pflanzen. Der Sporophyt bildet unbewegliche Sporen in Tetrasporangien aus.

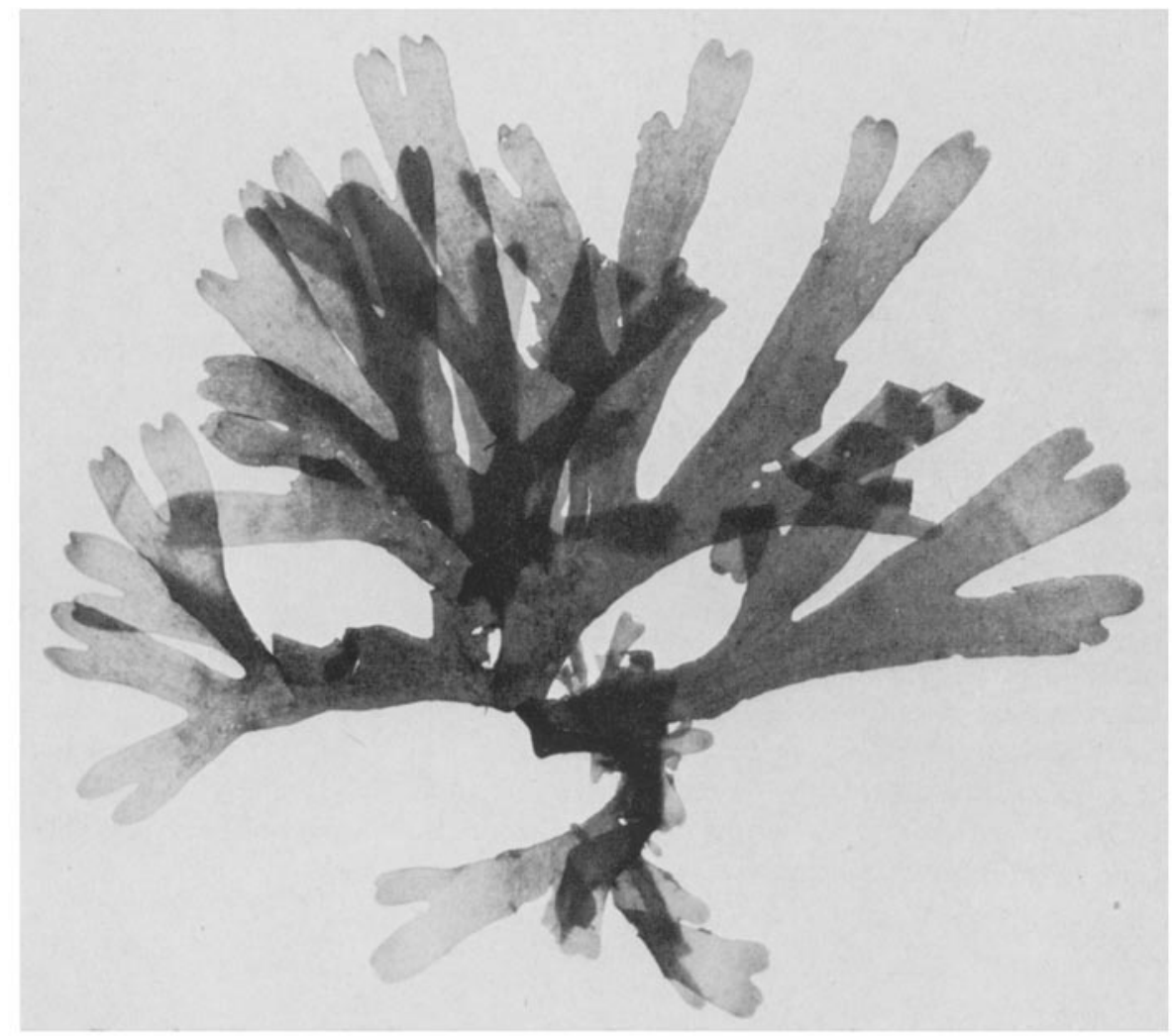

Abb. 88: Dictyota dichotoma. Am 8, 8. 1970 treibend gefundener männlicher Gametophyt. 


\section{FUCALES}

Die Ordnung enthält derbe, lederartige, gabelig geteilte oder unregelmäßig verzweigte Algen mit echter Gewebebildung. Es sind Diplonten mit oogamer Fortpflanzung.

Die bei Helgoland yorkommenden Gattungen gehören drei Familien an.

Fucaceae: der flache, gabelig verzweigte Thallus ist von einer Mittelrippe durchzogen. Rezeptakeln in den Thallusenden. Fucus Die Hauptachse mit dicken ovalen Luftblasen trägt in einer Ebene zerstreut Seitenzweige und gestielte Rezeptakeln. Ascopbyllum

Cystoseiraceae: Der in einer Ebene unregelmäßig verzweigte Thallus trägt schotenförmige, gekammerte Luftblasen. Halidrys

Himanthaliaceae: Einem kleinen napfförmigen Thallus entspringen lange gabelig verzweigte Rezeptakelbänder. Mitunter in Massen angetrieben, jedoch meist ohne die vegetative Basis.

Himanthalia

\section{Fuc a cea e}

\section{Fucus Linnaeus}

Drei Fucus-Arten geben der Algenvegetation in der Gezeitenzone Helgolands das Gepräge. Sie siedeln sich überall auf festem Untergrund an, wo nicht eine allzu starke Brandung das Aufkommen von Keimlingen unmöglich macht. Die stattlichen, mehrjährigen Pflanzen sind mit einem zur Scheibe verbreiterten Haftorgan fest mit dem Substrat verbunden; der buischelige und stets in einer Ebene gabelig verzweigte, laubartig abgeflachte Thallus wird von einer kräftigen Mittelrippe durchzogen. In den basalen Teilen älterer Pflanzen bleibt sie nach Verlust der Randsäume als fester Stiel übrig.

Jede Art nimmt in der Gezeitenzone ihren ganz bestimmten Lebensraum ein, in Abhängigkeit von der jeweiligen Überflutungsdauer. Aber nur an den senkrechten oder durch Stufen gegliederten Hafenmauern prägt sich ihre gürtelförmige Zonierung in idealer Weise aus, wo von oben nach unten $F$ ucus spiralis, $F$. vesiculosus und $F$. serratus einander folgen. Auf dem nur schwach geneigten und mit Trümmerblöcken bedeckten Felswatt kommt der mengenmäßig stark zurücktretende Fucus vesiculosus zuweilen auch in dem obersten Bereich yon Fucus serratus vor (Abb. $90 \mathrm{~A}$ ).

Die drei. Arten sind morphologisch gut gekennzeichnet und an Hand der Abbildungen 89-91 leicht zu bestimmen. 

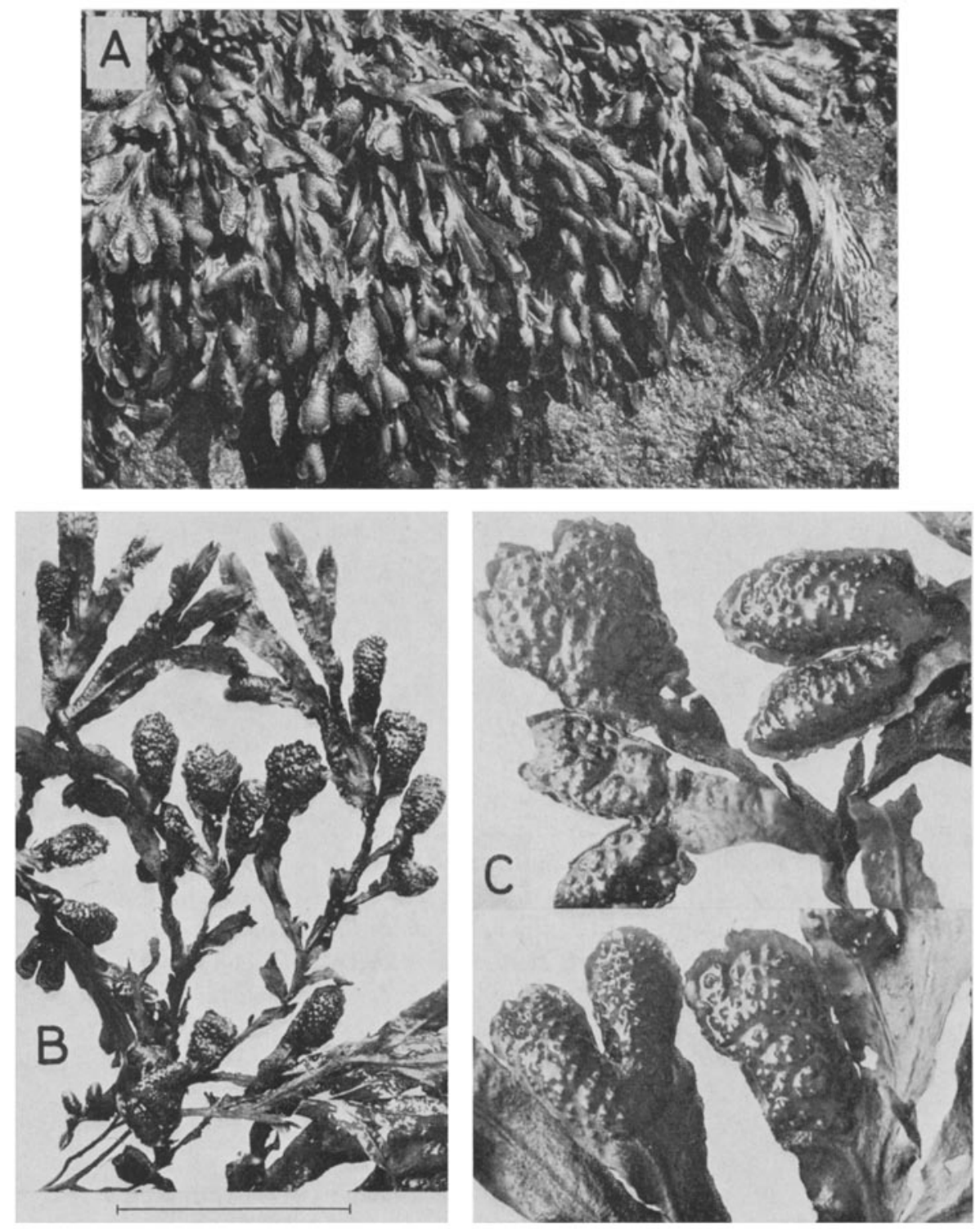

Abb. 89: Fucus spiralis. A Auf einem Betonblock in NO-Felswatt; rechts Porpbyra umbilicalis (30. 6. 1971). B, C Fertile Pflanzen und Thallusenden mit Randsaum (25. 7. 1970). Maßstrecke bei $B=10 \mathrm{~cm}$ 


\section{Fucus spiralis L.}

Die Größe und das Aussehen von Fucus spiralis hängt sehr von den ökologischen Gegebenheiten des jeweiligen Standorts ab. An einer stark besonnten Mauer werden die am höchsten wachsenden Exemplare nur wenige Zentimeter groß, dagegen erreichen schattig wachsende Pflanzen an ihrer unteren Grenze eine Länge von 40 bis $50 \mathrm{~cm}$. Die Helgoländer Population gehört ausschließlich der Varietät platycarpus (Thur.) Batters an; die Varietät typicus Börgesen zeigt eine spiralige Drehung des Thallus, auf die sich der Artname bezieht. Die vegetativen Thallusenden sind flach, nach starker Besonnung mitunter auch stark aufgebläht und hohl. Dadurch unterscheiden sie sich von den dicken fertilen Thallusenden, die im Inneren von einer schleimigen Masse erfüllt und von. einem etwa $1 \mathrm{~mm}$ breiten Rand gesäumt sind (C). Die krugförmigen Konzeptakeln sind in das feste äußere Gewebe eingesenkt.

Fucus spiralis ist zwittrig, in jedem Konzeptakel stehen zwischen farblosen Haaren einzellig gestielte Oogonien und verzweigte Antheridienstände. Geschlechtsreife Pflanzen findet man von April bis Oktober, dann zerfallen die Fruchtkörper. Im Januar sind im allgemeinen keine fertilen Thallusenden vorhanden. Durch Wellenschlag oder Fraß beschädigte Pflanzen können an den Wundflächen leicht neue, oft dicht büschelige Sprosse regenerieren. Solche Adventivsprosse dienen nicht der vegetativen Vermehrung; die stets zahlreich und in verschiedener Größe anzutreffende Generation junger Pflanzen entwickelt sich aus befruchteten Eiern.

\section{Fucus vesiculosus L. \\ Fucus serratus L.}

Fucus vesiculosus, der Blasentang, hat Luftblasen; sie sind paarig in dem Thallussaum angeordnet und stehen einzeln in den Gabelungen (Abb. $90 \mathrm{~B}$ ). Fucus serratus, der Sägetang, ist an seinem scharf gesägten Laub zu erkennen (Abb. 91). Beide Arten sind getrenntgeschlechtlich und eignen sich gut zur Beobachtung der Eibefruchtung. Allerdings sind reife Oogonien und Antheridien nur periodisch in Intervallen von etwa 14 Tagen verfügbar. Am Standort kann man gelegentlich die ausgetretenen Geschlechtsprodukte auf den fertilen Thallusenden beobachten, wenn reife Pflanzen durch Regen oder Nieseln benetzt worden sind. Mit dem aufquellenden Schleim treten dann die Antheridien und Oogonien aus der Mündung ihrer Konzeptakeln aus (Abb. $90 \mathrm{C}$, D; $91 \mathrm{D})$. Die männlichen Pflanzen fallen durch ihre orangefarbenen schleimigen Tröpfchen ohne weiteres auf (Abb. $90 \mathrm{C}$ ), dagegen sind die ausgetretenen Oogonien

Abb. 90: Fucus vesiculosus. A Auf einer Stufe der Ostmole zusammen mit Fucus serratus (23, 9. 1971). B Teil einer Pflanze mit Luftblasen und fertilen Thallusenden (29. 8. 1974). C In schleimigen Tröpfchen entleerter Inhalt männlicher Konzeptakeln (22. 5. 1973). D Oogonienhaufen vor der Mündung weiblicher Konzeptakeln (22. 5. 1973). E Entleerung der Antheridienschläuche. F Freiwerden der Eier aus den Oogonien, Aufnahmen in Abständen von 5 Minuten. Maßstrecken: $\mathrm{E}$ und $\mathrm{F}$ jeweils $=100 \mu \mathrm{m}$ 


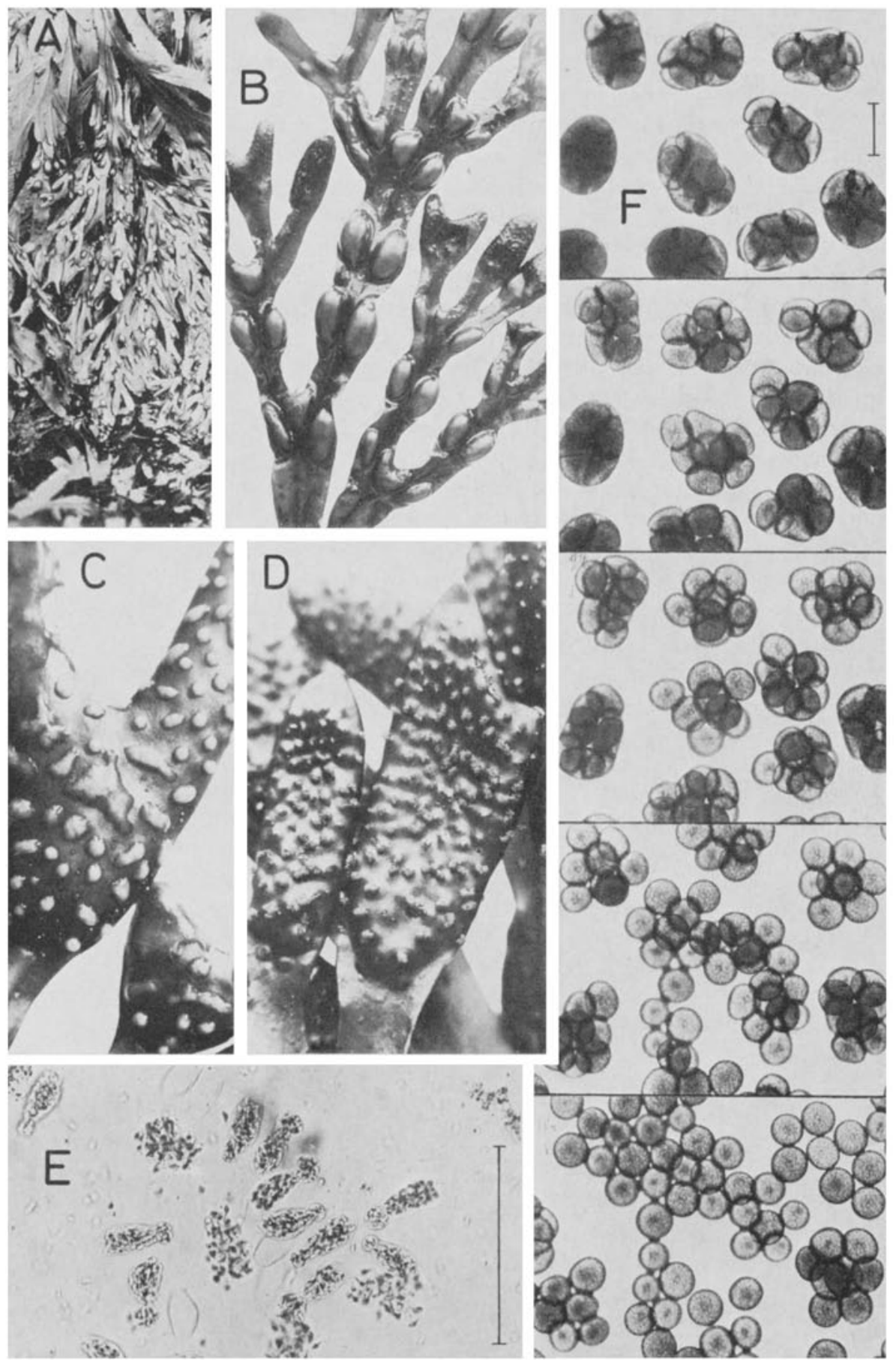


erst bei näherem Hinsehen als körnige Häufchen über den Konzeptakeln zu erkennen (Abb. $90 \mathrm{D}$ ). Wenige solcher fertilen Thallusenden - vorsichtig in Röhrengläsern ins Laboratorium gebracht - genügen, um einen ganzen Kurs mit Untersuchungsmaterial $\mathrm{zu}$ versorgen. Die Oogonien lösen sich nach Eintauchen in ein Röhrenglas mit Seewasser $\mathrm{ab}$ und sinken zu Boden. Man läßt sie zur Reinigung nochmals durch eine Säule von Seewasser sinken und bringt sie sofort auf einen hohlen Objektträger. Dort erfolgt dann die in Abbildung $90 \mathrm{~F}$ in Intervallen von jeweils fünf Minuten dargestellte Entleerung der 8 Eier eines jeden Oogoniums (die zarten Oogonhüllen sind nur bei stärkerer Vergrößerung zu sehen). Die Entleerung der 64 Spermatozoiden eines Schlauches erfolgt in einem Tropfen Seewasser sehr rasch. Neben leeren Hüllen sieht man verschieden weit fortgeschrittene Entleerungsstadien (Abb. $90 \mathrm{E}$ ). Der hier nicht näher zu schildernde Befruchtungsversuch gelingt leicht, wenn man einetn Tropfen mit freien Eiern eine genügend konzentrierte Aufschwemmung von Antheridien zufügt.

Mit reifem Material läßt sich die Entleerung der Konzeptakeln auch im Laboratorium einleiten, indem man die Thallusenden mit Süßwasser besprengt und in einer feuchten Kammer verwahrt. Am natürlichen Standort werden die Gameten aus den bei Niedrigwasser mehr oder weniger ausgetrockneten reifen Pflanzen nach der Uberflutung entleert.

Die Hauptreifezeit von Fucus vesiculosus und F. serratus fällt in die Zeit von September bis Mai. Im Juni und Juli findet eine Erneuerung der Fruchtkörper statt. Während die alten, überständig gewordenen Fruchtkörper degenerieren, werden in den Thallusenden junge Konzeptakeln angelegt (Abb. $91 \mathrm{C}$ ganz links), und ab August werden wieder die ersten Gameten reif. Schwankungen in der Fruktifikationszeit ergeben sich aus dem Witterungsablauf des Jahres und den unterschiedlichen ökologischen Bedingungen des jeweiligen Standorts. 

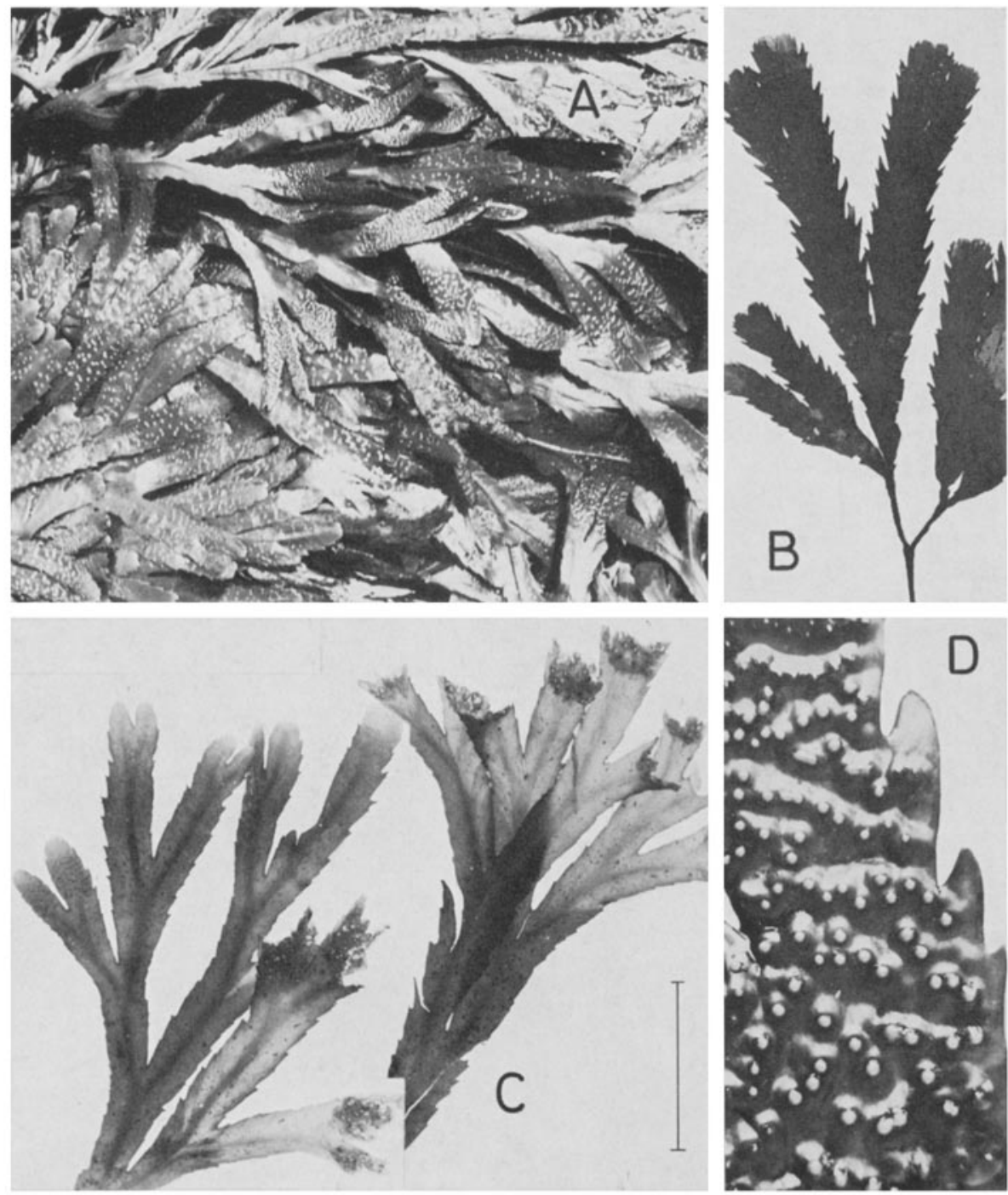

Abb. 91: Fucus serratus. A Dichter Bestand fertiler Pflanzen; die weißen Pünktchen auf den glatten, nicht fertilen Enden sind farblose Haare, die aus besonderen Haargruben entspringen (21. 5. 1973). B Vegetativer Thallus mit stark gesägtem Rand (27. 6. 1973). C Zerfall und Erneuerung der fertilen Enden (15.6. 1971). D Thallusende mit ausgetretenen Antheridientröpfchen (25. 4. 1973). Maßstrecke bei $\mathrm{C}=5 \mathrm{~cm}$ 
Ascopbyllum nodosum (L.) Le Jol.

Der Knotentang, Ascopbyllum nodosum, kommt in der Gezeitenzone Helgolands nur an wenigen Stellen in geringer Menge vor. In der vertikalen Zonierung liegt sein Bereich zwischen Fucus spiralis und $F$. vesiculosus. Die kräftigen, bis $70 \mathrm{~cm}$ großen Pflanzen bestehen aus locker verzweigten Langtrieben, die sich in ziemlich gleichmäßigen Abständen zu Schwimmblasen erweitern. Im August entspringen aus Randspalten des abgeflachten Thallus meist büschelige Kurztriebe (A), deren Enden im Laufe der Vegetationsperiode zu keuligen Fruchtkörpern anschwellen. Ascopbyllum zeigt daher im Jahresablauf ein ganz verschiedenartiges Erscheinungsbild. Üppig fertil sind die Pflanzen im April bis Juni, zu dieser Zeit entsteht am Ende jedes Langtriebes eine neue Schwimmblase (D). Ende Juni werden die kleiner und überständig gewordenen Fruchtkörper samt ihren Stielen abgeworfen (C), und die Pflanzen sehen vor dem Heranwachsen neuer Kurztriebe recht sparrig aus. Im September entstehen in den leicht anschwellenden Enden der Kurztriebe die ersten Konzeptakelanlagen (B), Anfang Dezember sind sie dann schon zu kleinen Keulen angeschwollen. Ascopbyllum nodosum ist diözisch; das Oogonium enthält 4 Eier.

Nach den Beobachtungen von Printz (1925) im Trondhjemsfjord wird vom dritten Jahre an am Ende jeder Achse eine Schwimmblase gebildet, so daß man das Alter der Pflanzen leicht ablesen kann.

Abb. 92: Ascophyllum nodosum. A Aus Randspalten der Langtriebe treiben büschelige Kurztriebe aus (14.8. 1971). B Die Enden der Kurztriebe beginnen zu Fruchtkörpern anzuschwellen (29. 9. 1971). D Reife männliche Pflanze mit jungen Langtrieben (22. 5. 1973). C Pflanze mit überständigen Fruchtkörpern, die bald abgeworfen werden $(15.6 .1971)$. Maßstrecke bei $\mathrm{B}=$ $5 \mathrm{~cm}$ 

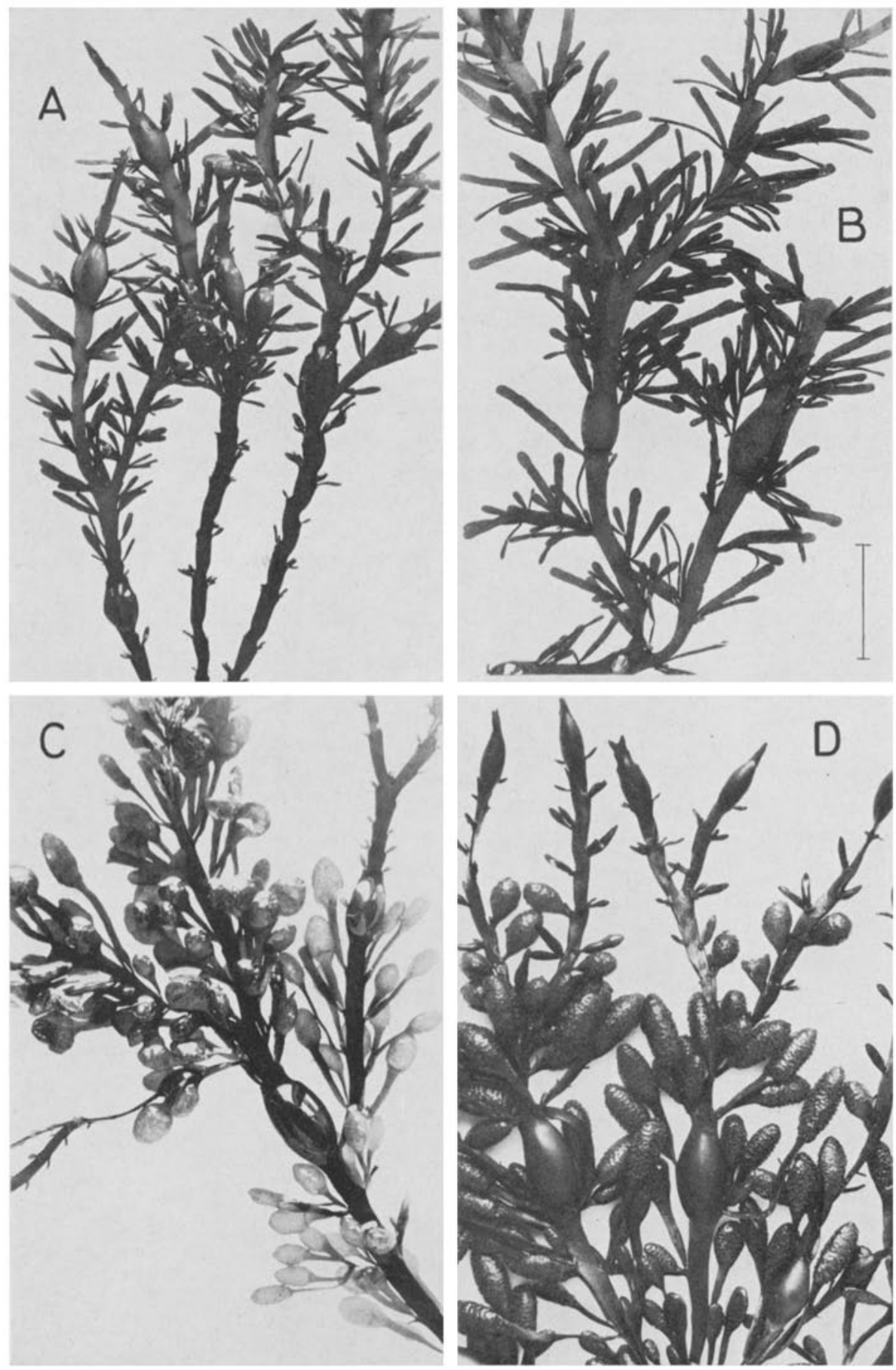
Halidrys siliquosa (L.) Lyngb.

Die Meereiche, Halidrys siliquosa, hat ihren Lebensraum im Sublitoral und wird wie andere Algen aus diesem Bereich bei stürmischem Wetter losgerissen und an den Strand gespült. Nur bei besonders tiefem Niedrigwasser kann man ihr in einigen stets wasserführenden Prielen an der Westseite oder breiteren Mulden im Nordosten der Insel begegnen, in denen die bis zu $80 \mathrm{~cm}$ hohen Pflanzen an der Wasseroberfläche fluten (A). Der büschelige und nur schwach abgeflachte Thallus ist in einer Ebene regelmäßig wechselseitig verzweigt. An jeder Verzweigung wird die Achse leicht abgewinkelt, wodurch sie ihr charakteristisches Aussehen erhält (B).

Die andere deutsche Bezeichnung Schotentang bezieht sich auf die an den Seitenzweigen stehenden langgestreckten und gekammerten Schwimmblasen (B). Sie sind gestielt und laufen in eine dünne Spitze aus. Die lanzettlichen Fruchtsprosse stehen an den Zweigenden (C). Halidrys siliquosa ist monözisch.

Himanthaliaceae

Himanthalia elongata (L.) S. F. Gray

Der bei Helgoland nicht heimische Riementang wird in jedem Spätsommer nach Weststürmen mitunter in großen Mengen an den Strand gespült. Daher soll diese auffällige Alge hier nicht übergangen werden, zumal sie auch in den Jahren 1959 bis 1961 Gast der Helgoländer Algenvegetation war. Der Thallus besteht aus der gestielten napfartigen vegetativen Basis yon 2-4 cm Durchmesser, der die bis zu $2 \mathrm{~m}$ langen und wiederholt gabelig verzweigten Bänder entsprossen (B). In ihnen werden auf getrennten Pflanzen Konzeptakeln mit Antheridien und Oogonien gebildet.

Meist findet man nur die abgerissenen flachen Bänder, gelegentlich auch vollständige Pflanzen, deren napfartige Basis häufig mit Epiphyten besetzt ist (B). Abb. $94 \mathrm{C}$ zeigt ein weibliches Rezeptakel, das - ruhig in einer Schale mit flachem Wasser untergetaucht - seine Oogonien entleert hat. Durch die Menge der Eier - jedes Oogonium enthält nur eine Eizelle - zeichnet sich auf dem Boden der Schale die Form des fertilen Bandes ab. 

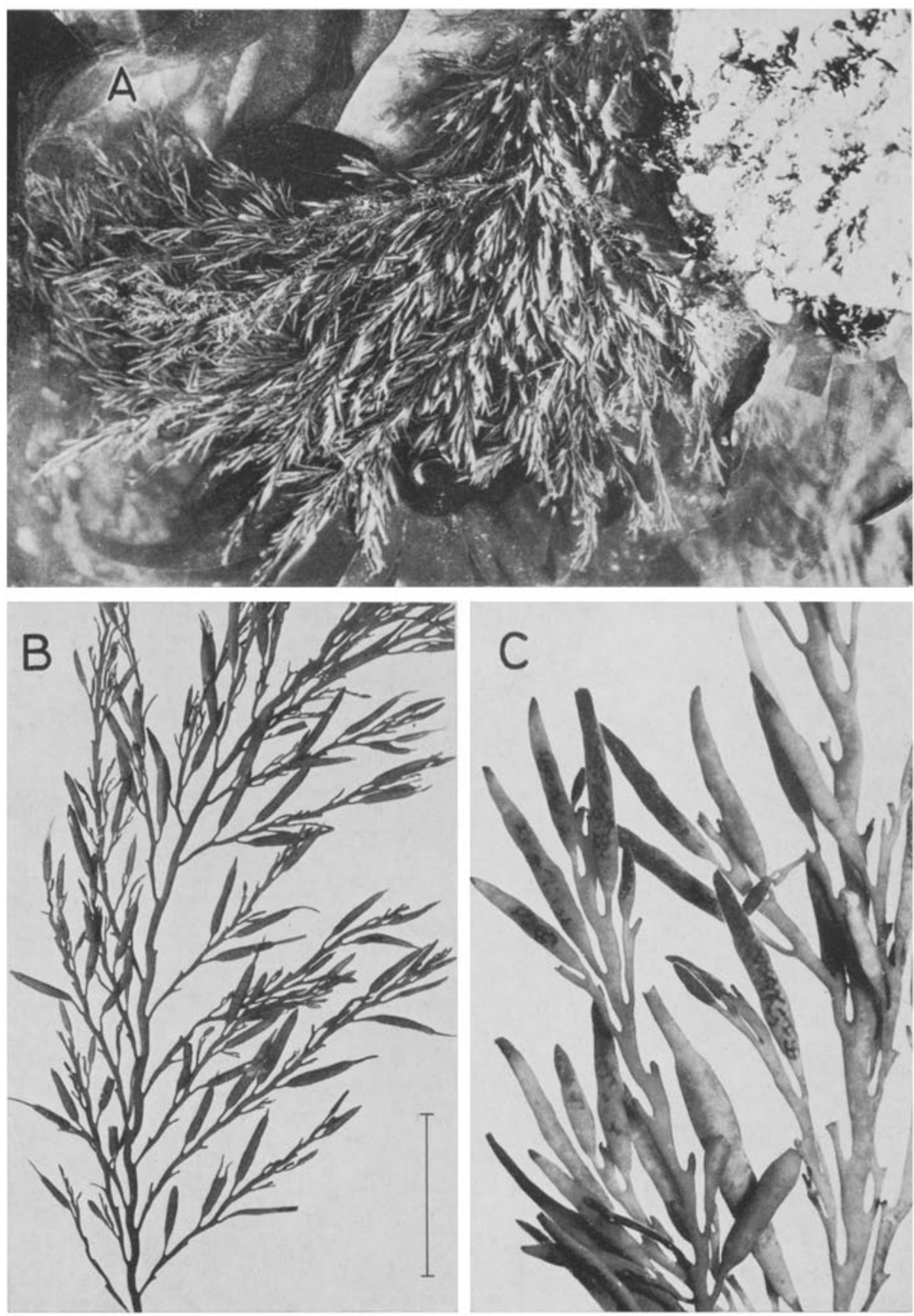

Abb. 93: Halidrys siliquosa. A In einem stets wasserführenden Priel bei Niedrigwasser flutend. B Habitus einer fertilen Pflanze (25. 8. 1975). C Zweigenden dieser Pflanze mit Rezeprakeln. Maßstrecke bei $B=5 \mathrm{~cm}$ 

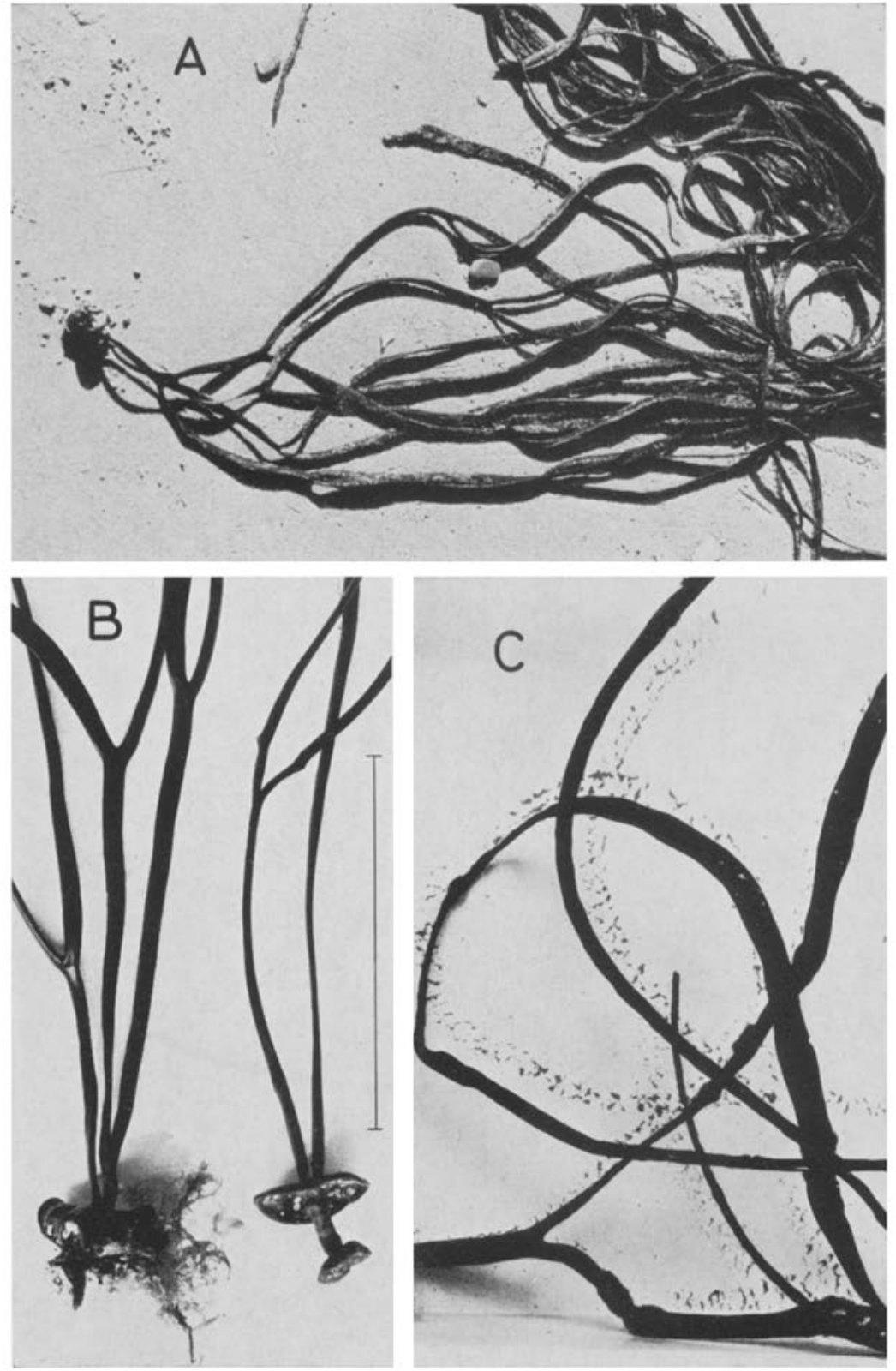

Abb. 94: Himanthalia elongata. A Am Strand der Düne angetriebene Pflanzen (12. 8. 1972). B Der napfartigen Basis entspringen die bandförmigen Rezeptakeln, links mit Epiphyten besetzt. C Erläuterung im Text. Maßstrecke bei $B=10 \mathrm{~cm}$ 


\section{Rhodophyta}

Im Rahmen dieser floristischen Darstellung kann die einleitende Betrachtung über die Rotalgen bei der Mannigfaltigkeit der Erscheinungen nur einige wesentliche Punkte berühren. Für eine eingehendere Unterrichtung sei das Buch von Dixon "Biology of the Rhodophyta" (1973) empfohlen.

Der Stamm der Rhodophyta gliedert sich in die Klassen Florideophyceae (p. 174) und Bangiophyceae, die hinsichtlich ihrer Morphologie und Fortpflanzung einfacher organisierte Gruppe (p. 256). Bei aller äußeren Verschiedenheit läßt sich der Thallus der Florideophyceae auf ein System verzweigter Zellfäden mit Spitzenwachstum zurückführen. Diese können frei sein oder sich durch eine Interzellularsubstanz zu einem pseudoparenchymatischen Gewebe zusammenschließen. Im allgemeinen erhebt sich der aufrechte Thallus von einer auf dem Substrat kriechenden Basis; er baut sich um eine zentrale Hauptachse (uniaxial, Zentralfadentypus) oder viele gleichgeordnete Achsen auf (multiaxial, Springbrunnentypus).

Außerlich betrachtet erscheinen die meisten Florideophyceen als gleichgestaltete geschlechtliche und ungeschlechtliche Pflanzen. Das als Karpogon bezeichnete weibliche Organ ist das Endglied eines kurzen Astes und verlängert sich in die haarartige Trichogyne. Durch sie gelangt der Kern der unbeweglichen männlichen Keimzelle, des Spermatiums, zum Karpogonkern. Aus der Zygote entwickelt sich auf dem Gametophyten eine diploide Phase, der Karposporophyt oder Gonimoblast. In mehr oder weniger differenzierten Fruchtgebilden entstehen Karposporen, durch die sich die diploide Phase in der Tetrasporophytengeneration fortsetzt. Die Reduktionsteilung erfolgt bei der Bildung der Tetrasporen. Sie geben den diözischen Gametophyten den Ursprung. Nicht alle Florideophyceen folgen diesem Polysiphonia-Schema der Entwicklung (p. 244), das durch eine verschiedenartige Morphologie der Generationen nicht wesentlich abgeändert wird. Mit der Verschiebung der Reduktionsteilung an eine andere Stelle des Entwicklungsablaufes ändert sich die Lebensgeschichte jedoch grundsätzlich. Auf solche Abweichungen wird jeweils bei der Beschreibung der betreffenden Arten verwiesen.

Die systematische Gliederung der Florideophyceae gründet sich auf Besonderheiten bei der Gonimoblastenbildung. Sie sind der direkten Beobachtung nicht zugänglich und für die Bestimmung der Arten ohne Bedeutung. Damit erübrigt sich auch eine nähere Kennzeichnung der Ordnungen und Familien. 


\section{Florideophyceae}

\section{NEMALIONALES}

\section{Acrochaetiaceae}

Die Familie umfaßt eine große Zahl von zartfädigen, einreihigen verzweigten Rotalgen. Die bei Helgoland vorkommenden Vertreter sind morphologisch und durch die Gestalt ihrer Chromatophoren klar unterschieden.

Viel schwieriger ist es, sie adäquat zu benennen, da die systematische Aufgliederung der Familie und die Nomenklatur ihrer Gattungen in den letzten Jahrzehnten mannigfachen Anderungsvorschlägen unterlag. Einige Autoren hielten die Aufteilung in eine größere Anzahl von Gattungen für berechtigt, während Woelkerling (1971, 1973) nur zwei Gattungen beibehält. Er stellt die Formen mit geschlechtlicher Vermehrung zu Audoninella, während die Gattung Colaconema alle Arten aufnimmt, bei denen nur ungeschlechtliche Vermehrung, meist durch Monosporen, bekannt ist. Die Liste von Parke \& Dixon (1976) schließlich faßt alle Arten in der Gattung Audouinella zusammen (unter Bezugnahme auf Dixon, in Vorbereitung). Dieser Auffassung haben wir uns nicht angeschlossen und behalten für die bei Helgoland beobachteten Formen die Gattungen Acrochaetium, Audouinella und Rhodochorton bei.

\section{Acrochaetium Nägeli}

$\mathrm{Zu}$ dieser Gattung gehören viele der häufigen Epiphyten, die vor allem in der Gezeitenzone ihre Wirtspflanzen in einen dichten Pelz aus zierlichen, 1 bis $2 \mathrm{~mm}$ hohen Büscheln einhüllen können und dann als hellroter Anflug nicht zu übersehen sind. Zahlreiche Arten sind beschrieben worden; bei Helgoland triff man vorwiegend in den Sommermonaten drei morphologisch gut gekennzeichnete und an Hand der Abbildungen leicht zu identifizierende Arten an.

\section{Acrochaetium virgatulum (Harv.) J. Ag.}

Diese Art bildet ebenso wie die folgende kurze epiphytische Räschen auf verschiedenen Algen des Litorals. Die Büschel werden selten höher als $1 \mathrm{~mm}$ und tragen reichlich farblose Haare. Auf einer Basalscheibe erheben sich die geraden Fäden; zahlreiche Seitenzweige schmiegen sich meist der Achse an, was der Artname zum Ausdruck bringen will. Fast jede Achsenzelle wächst zu einem längeren oder kürzeren Zweig aus. Die nicht mit einem Monosporangium endenden $Z$ weige setzen sich in langen Haaren fort. Die Zellen sind meist dreimal so lang wie breit; der axiale Chromatophor mit kräftigem Pyrenoid liegt der apikalen Querwand an und entsendet schmale Fortsätze nach unten. Im allgemeinen sind die Pflanzen reichlich mit Monosporangien besetzt (C-E), sie stehen endständig an kurzen Verzweigungen oder ungestielt auf ihrer Tragzelle. Nur ganz selten beobachtet man auch Tetrasporangien (F). 


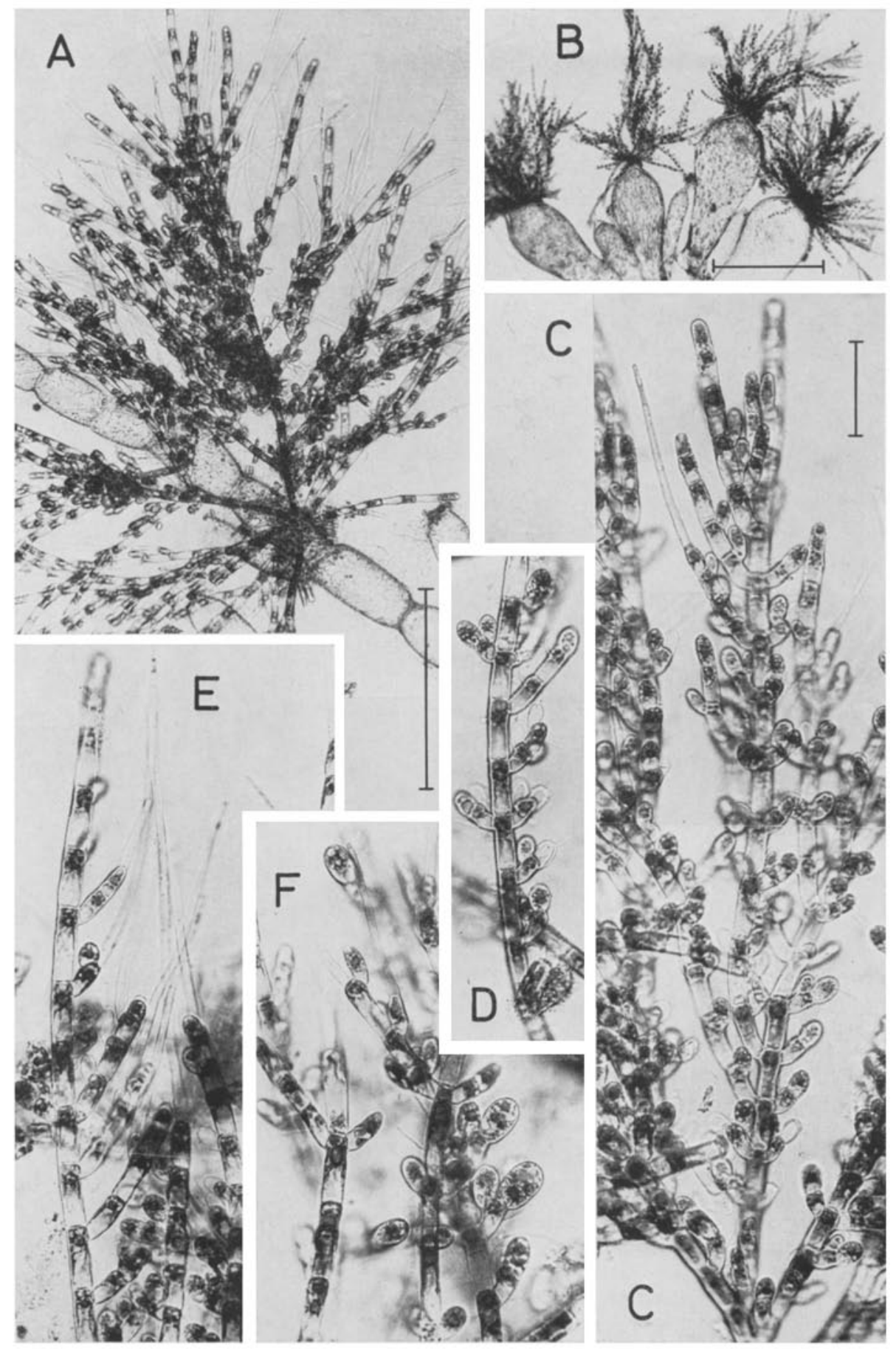

Abb. 95: Acrochaetium virgatulum. A Büschel auf ausgeschwärmter Cladophora (11. 6. 1974). B Auf Codium fragile als rosafarbener Uberzug (18.7. 1972). C Dicht gegenständig verzweigte Wuchsform (auf Polysipbonia elongata, 8. 6. 1973). D Fadenstück mit reifen und leeren Monosporangien. E Fadenende mit meist einseitiger Verzweigung und reichlicher Haarentwicklung. F Fadenstück mit Tetrasporangien (24. 6. 1969). Maßstrecken: $\mathrm{A}=300 \mu \mathrm{m} ; \mathrm{B}=500 \mu \mathrm{m}$; $\mathrm{C}-\mathrm{F}=50 \mu \mathrm{m}$ 


\section{Acrochaetium secundatum (Lyngb.) Näg.}

Diese Art wird im allgemeinen nur $0,5 \mathrm{~mm}$ hoch und trägt selten Haare. Ihr Habitus ist gedrungener als $A$. virgatulum, bedingt durch die etwas kürzeren Zellen und die häufig einseitige Verzweigung, die eine bogige Krümmung der Hauptachsen bewirkt. Chromatophor und Monosporangien entsprechen denen der vorigen Art.

Nach Woelkerling (1973) sind Acrochaetium virgatulum und A. secundatum konspezifisch; wir halten sie jedoch getrennt, da sie in ihrer charakteristischen Tracht oft nebeneinander auf demselben Substrat vorkommen.

\section{Acrochaetium daviesii (Dillw.) Näg.}

Acrochaetium daviesii ist eine Alge des Sublitorals; sie wurde in den Sommermonaten nur auf Steinen und auf Stielen von Laminaria byperborea in etwa $6 \mathrm{~m}$ Tiefe sowie einmal auf einem Schiffsboden gefunden. Es sind bis etwa $3 \mathrm{~mm}$ hohe halbkugelige Büschel von verzweigten Fäden, die einer gemeinsamen Basalscheibe entspringen. Die einzelnen Fäden sind erst in ihrer oberen Hältte reichlich allseitig verzweigt (A). Durch ihre gerade abstehenden Zweige erscheinen sie steif im Vergleich zu den beiden vorigen Arten, von denen sie sich durch ihre an kurzen Ästchen stehenden dichten Monosporangienbüschel klar unterscheidet (B). Die Zellen enthalten einen wandständigen, gelappten Chromatophor mit großem Pyrenoid (C).

Die Helgoländer Pflanzen trugen nur Monosporangien; Geschlechtspflanzen und Tetrasporophyten sind von der nordostamerikanischen Atlantikküste bekannt (Woelkerling, 1973).

Abb. 96: Acrochaetium secundatum. A Epiphytisch auf Chaetomorpha melagonium und $C h$. aerea (ausgeschwärmter Faden, 7. 6. 1973). B Auf Sphacelaria radicans; austretende Monosporen (2. 4.1975). C Infolge einseitiger Verzweigung zurückgebogene Wuchsform (30.1.1970). $\mathrm{D}$ Von Codium fragile gelöste Pflanze mit scheibenförmiger Basis; reife und leere Monosporangien (27.9.1972). E Keimlinge auf Cladophora (18.9.1974). Maßstrecken: $A=5 \mathrm{~mm} ; \mathrm{B}=$ $300 \mu \mathrm{m} ; \mathrm{C}-\mathrm{E}=50 \mu \mathrm{m}$ 


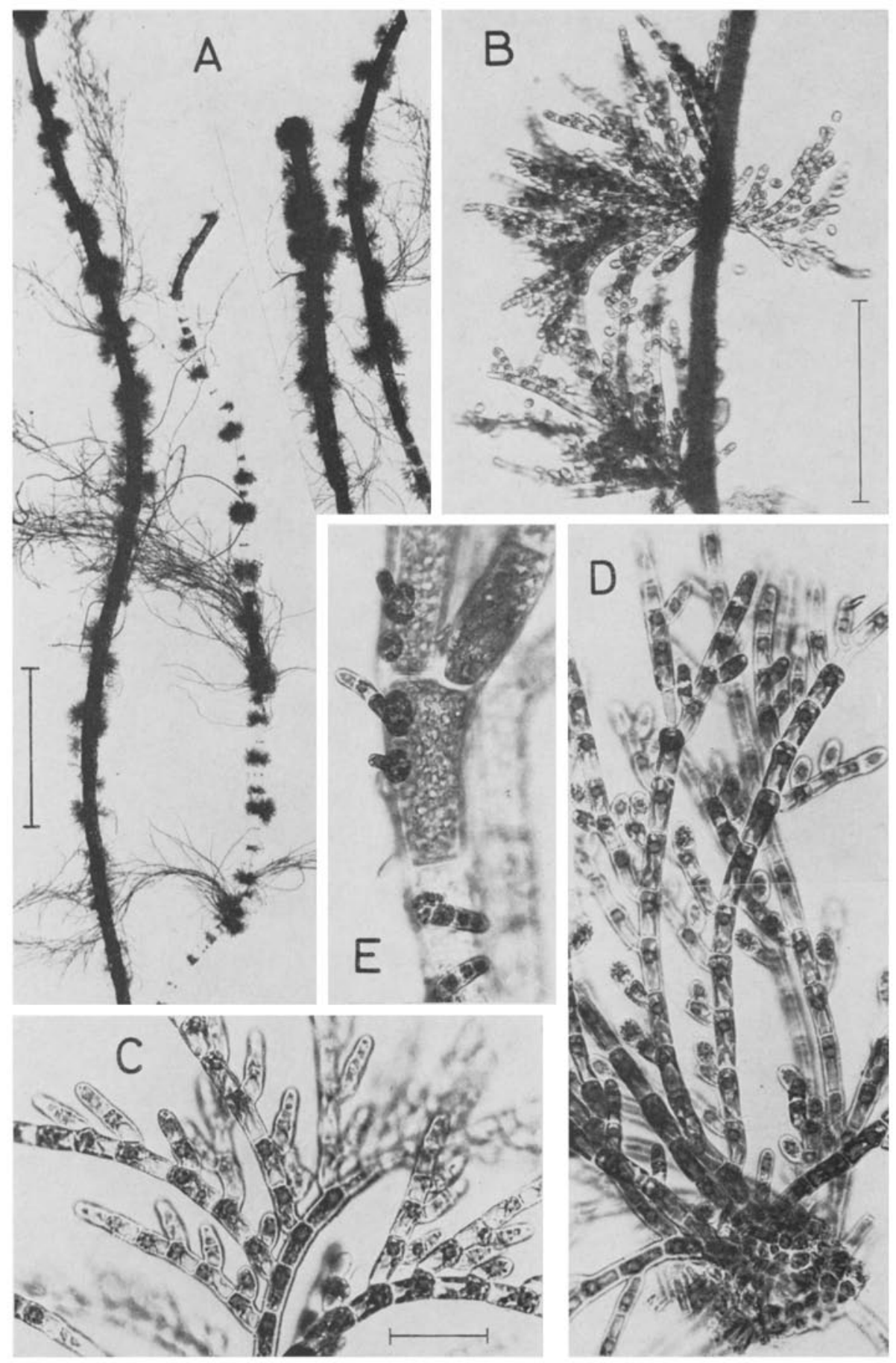




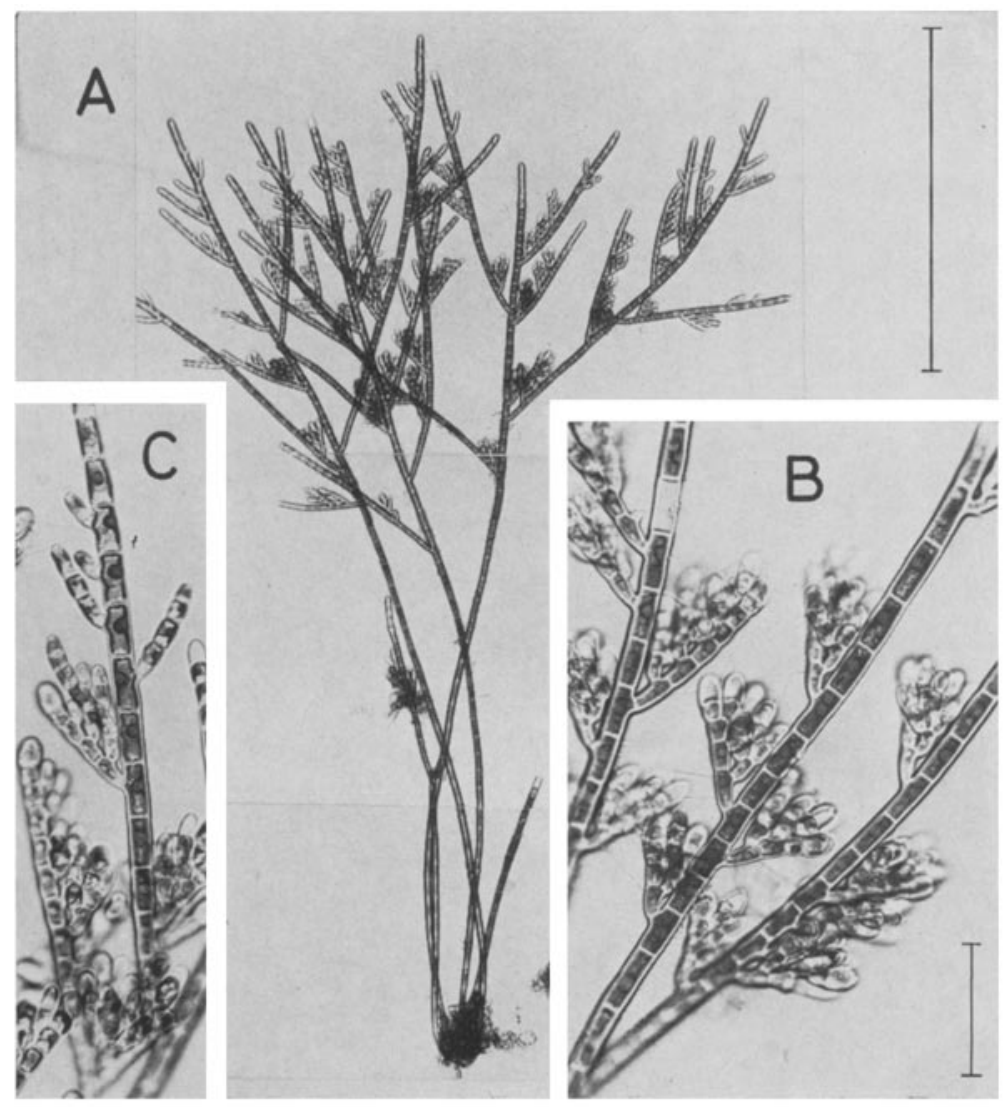

Abb. 97: Acrochaetium daviesii. A Einige Fäden aus einem dichten Büschel (16. 6, 1972). B Büschelige Monosporangien. $\mathrm{C}$ Zellen mit wandständigem Chromatophor. Maßstrecken: $\mathrm{A}=$ $0,5 \mathrm{~mm} ; \mathrm{B}, \mathrm{C}=50 \mu \mathrm{m}$

\section{Andoninella membranacea (Magnus) Papenfuss}

Chitingehäuse von Sertularien beherbergen häufig diese mikroskopische Rotalge und fallen dann durch ihre mehr oder weniger starke rosa Färbung auf. Der endozoisch in der Membran kriechende Thallus bildet ein Netz aus unregelmäßig verzweigten Fäden; die Zellen können langgestreckt sein, aber auch breiter und isodiametrisch werden und sich flächenartig zusammenschließen (A-C). Sie enthalten mehrere unregelmäßig scheibenförmige bis schwach verzweigte bandartige Chromatophoren ohne Pyrenoid. 

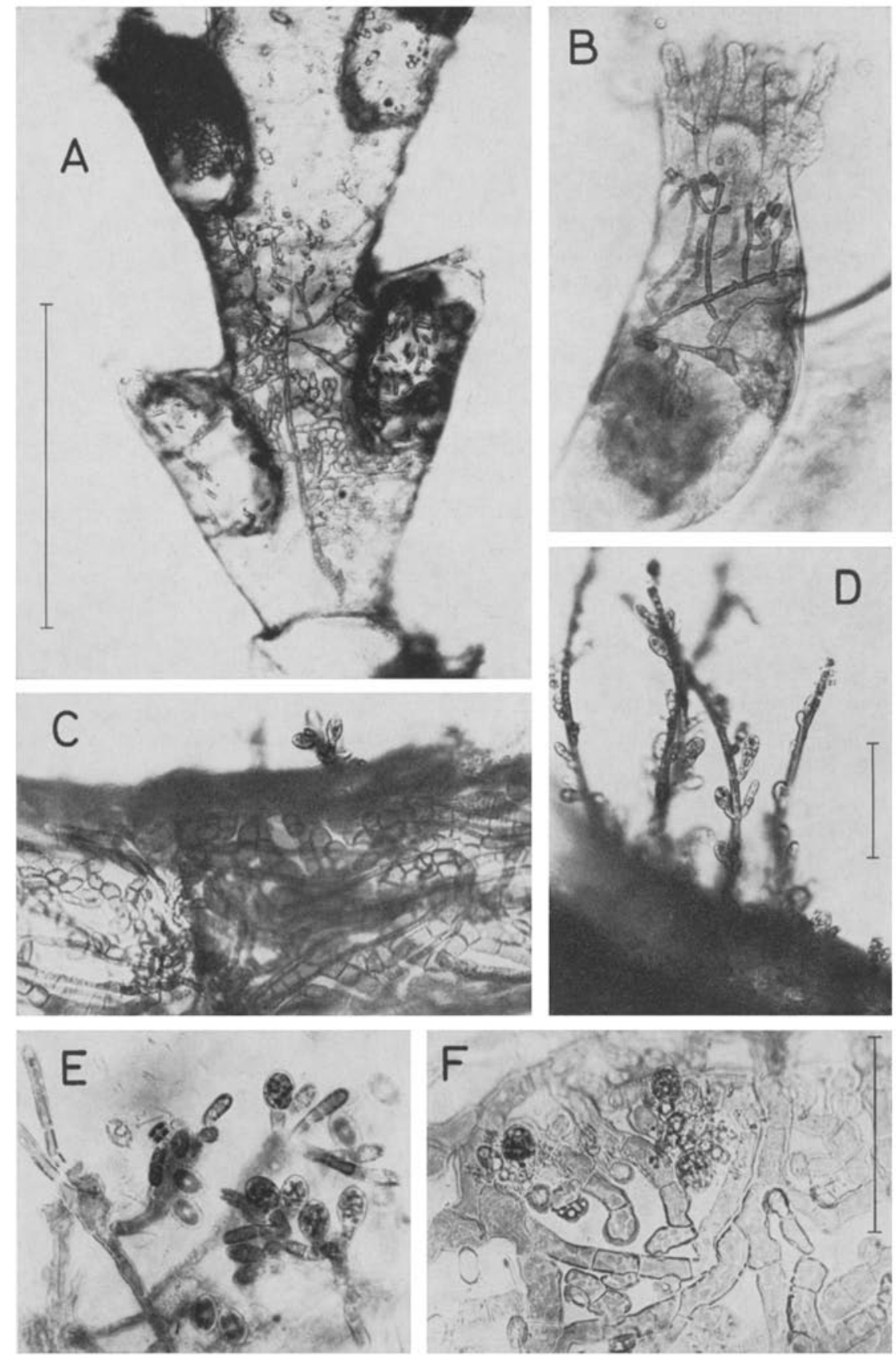

Abb. 98: Audoninella membranacea. A, B In leeren Theken bzw. einem lebenden Polypenköpfchen wachsend. C, E Tetrasporangien an kurzen Verzweigungen dicht über dem Substrat. D Tetrasporangien an längeren aufrechten Fäden. F Zellen des Basallagers mit Chromatophoren. Maßstrecken: $\mathrm{A}=500 \mu \mathrm{m} ; \mathrm{B}-\mathrm{D}=100 \mu \mathrm{m} ; \mathrm{E}, \mathrm{F}=100 \mu \mathrm{m}$ 
Es sind nur Tetrasporangien bekannt; sie werden an Fäden gebildet, die über einem dichten Basallager aus dem Substrat herauswachsen. Meistens bleiben sie kurz und verzweigen sich wenig (C, E, F), gelegentlich werden sie auch etwa $300 \mu \mathrm{m}$ lang (D).

Audoninella membranacea findet man während des ganzen Jahres, am sichersten in losgerissenen, im Plankton treibenden Fragmenten von Sertularien, aber auch in Hydroidstöcken aus dem Litoral und Sublitoral bis $13 \mathrm{~m}$ Tiefe. Tetrasporangien wurden das ganze Jahr über beobachtet.

\section{Rhodochorton floridulum (Dillw.) Näg.}

Eine Besonderheit dieser Art ist ihr Standort: Man findet sie stets auf etwas höheren und schwach geneigten Schichtflächen des Felswatts, auf denen der Borstenwurm Fabricia sabella dichte Uberzüge bildet (A). In dem Pelz aus Algenfäden und Wohnröhren des Wurms sammelt sich reichlich Schlick an. Nach sorgfältigem Auswaschen einer Probe erhält man die bei B schwach vergrößert abgebildeten, reichverzweigten schmutzig violetten Büschel, deren Fäden sich von horizontal im Substrat kriechenden Stolonen erheben. Das Vorkommen mit Fabricia ist nicht obligat, die Alge wächst auch auf festem Substrat unter Fucus serratus oder an Hafenmolen. Die zylindrischen Zellen mit recht dicker Membran enthalten mehrere wandständige, sternförmig gelappte Chromatophoren mit großem zentralen Pyrenoid (C).

Rhodochorton floridulum ist während des ganzen Jahres zu finden; die ziemlich kugeligen, kreuzförmig geteilten Tetrasporangien (D, E) werden aber nur in der kalten Jahreszeit, November bis Februar, gebildet. In Kulturversuchen mit Material von der englischen Küste entwickelten sich die Tetrasporen zu einer Generation mikroskopischer, getrenntgeschlechtlicher Gametophyten (Knaggs \& Conway, 1964).

Abb. 99: Rbodochorton floridulum. A Fabricia-Polster mit Rbodocborton und Fucus-Keimlingen (15. 3. 1973). B Aus dem Substrat ausgewaschene Büschel (26. 11. 1970). C Sternförmig gelappte Chromatophoren mit zentralem Pyrenoid. D, E Fadenenden mit Tetrasporangien (26. 11. 1970). Maßstrecken: $\mathrm{B}=1 \mathrm{~cm} ; \mathrm{D}=300 \mu \mathrm{m} ; \mathrm{E}=100 \mu \mathrm{m}$ 

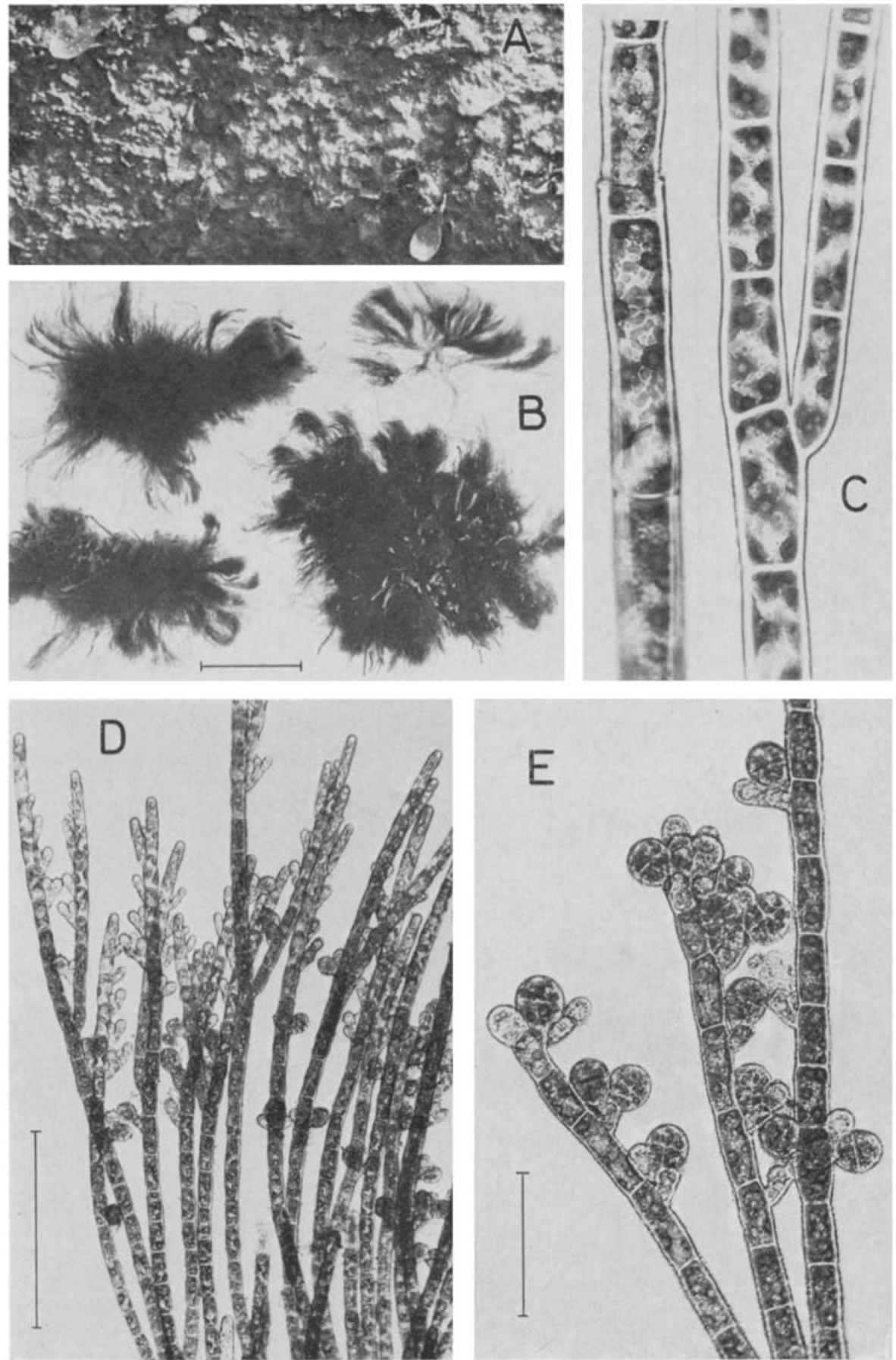


\section{Rbodochorton purpureum (Lightf.) Rosenv.}

Rhodochorton purpureum wächst stets auf hartem Substrat, gern auf dem Granitsockel der Uferschutzmauer, doch findet man die ausgedehnten pelzigen, dunkelpurpurroten Uberzüge auch auf harten Buntsandsteinflächen im unteren Litoral. Die Büschelchen werden bis $4 \mathrm{~mm}$ lang (A). Ein einzelner verzweigter Faden ist bei B dargestellt. Die Zellen enthalten eine große Anzahl kleiner, scheibenförmiger Chromatophoren ohne Pyrenoid (C). Die etwas länglichen, kreuzförmig geteilten Tetrasporangien stehen dicht gedrängt an den Fadenenden (D, E); man trifft sie nur von November bis März an.

Der Lebenszyklus wurde an Material von der englischen und der nordpazifischen Küste Amerikas untersucht (Knaggs, 1968; West, 1969). Aus den Tetrasporen gingen in den Kulturen diözische Geschlechtspflanzen hervor, die in der Natur noch nicht bekannt und kleiner waren als die Tetrasporophyten. Aus dem befruchteten Karpogonium entstanden fädige Gonimoblasten, die unmittelbar - also ohne Karposporenbildung - zu Tetrasporophyten auswuchsen.

Bonnemaisoniaceae

Bonnemaisonia hamifera Hariot incl. Trailliella intricata Batters

In der Form ihres Gametophyten, Bonnemaisonia bamifera, war diese Alge in den sechziger Jahren vorübergehend Gast der Helgoländer Algenflora. Ihr Sporophyt, Trailliella intricata, ist dagegen seit seiner Einwanderung aus Ostasien am Ende des vorigen Jahrhunderts an vielen europäischen Küsten heimisch. Uber den Fund fertiler Geschlechtspflanzen bei Helgoland und die Entwicklung der Karposporen zu Trailliella berichteten Kornmann \& Sahling (1962a). In den folgenden Jahren trat Bonnematsonia

Abb. 100: Rbodochorton purpureum. A Vom Substrat abgeschabte Büschel, etwa natürliche Größe (30. 11. 1971). B Einzelner verzweigter Faden. C Zellen mit Chromatophoren. D, E Fäden mit Tetrasporangien (30.1. 1970 und 9.1.1973). Maßstrecken: $\mathrm{B}=1 \mathrm{~mm} ; \mathrm{C}=50 \mu \mathrm{m}$; $\mathrm{D}=300 \mu \mathrm{m} ; \mathrm{E}=50 \mu \mathrm{m}$ 

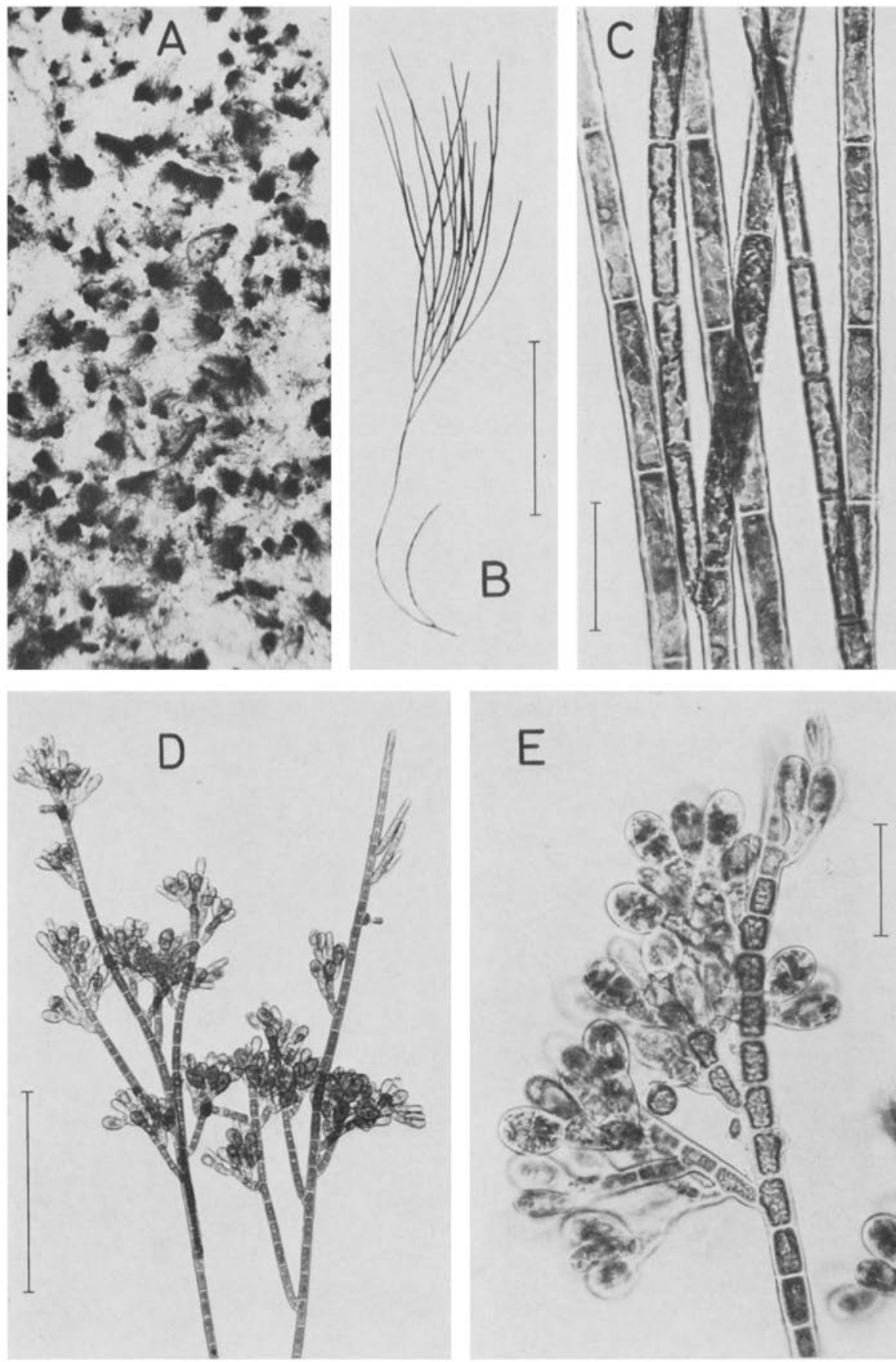

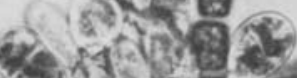

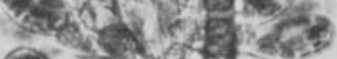

(19)
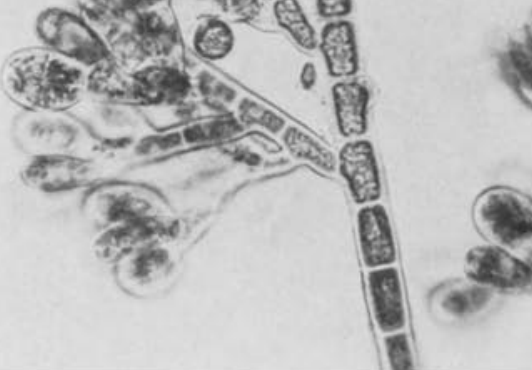
nur vereinzelt auf, 1968 und 1969 aber massenhaft. Jedoch wurden immer nur sterile und männliche Pflanzen beobachtet; in einer am 19. September 1968 wahllos aufgesammelten Probe von 100 Pflanzen waren sie etwa zu gleichen Teilen enthalten (48:52). Seit 1972 ist die Alge nicht mehr gefunden worden.

Bonnemaisonia bamifera besiedelte hauptsächlich die flachen Mulden des Felswatts im Nordosten, doch waren die Pflanzen niemals mit einer Haftscheibe auf einem Substrat angewachsen (A). Die im März und April gefundenen Exemplare trugen häufig kleine epiphytische Laminaria-Thalli, was darauf schließen $1 a ̈ ß t$, daß vorjährige Pflanzen in etwas tieferem Wasser uberwinterten und auf das Felswatt verdriftet wurden. Sie könnten aber auch - wie der am 1. 12. 1964 auf Trailliella gefundene junge Gametophyt (E) - aus Tetrasporen entstanden sein. Immer waren es Fragmente, die mit ihren eigenartigen Hakenzweigen an anderen Algen, Corallina, Chondrus, Abnfeltia, Ceramium oder den Strängen von Chaetomorpha tortuosa festgehakt waren. Auch treibende Thallusstücke von Desmarestia aculeata oder Plocamium dienten zur Verankerung. Die Hakenzweige ermöglichen eine ausgiebige, rein mechanische vegetative Vermehrung, indem kleine festhaftende Zweigstücke beim Zerreißen der Mutterpflanze oder ihrer Substratalge selbständig werden. Ein unmittelbares Aussprossen einer Pflanze aus dem Haken selbst, wie es Chemin (1929) beschrieb, konnten wir nicht beobachten. Die ausgiebige Fähigkeit zur vegetativen Vermehrung und das üppige Wachstum in dem nährstoffreichen Wasser an ihrem Fundort machen die ungewöhnliche Ausbreitung von Bonnemaisonia im Spätsommer 1968 verständlich. Damals bedeckte die Alge größere Flächen mit einem dichten Teppich. Nach stïrmischem Wetter im Oktober waren sämtliche Pflanzen vertrieben.

Bonnemaisonia hamifera ist reich verzweigt, die Zweige entspringen den Achsen allseitig. Die kräftigen Greifhaken wie auch die Antheridienstände und Karpogonanlagen sind umgewandelte Verzweigungen (B, C, D).

Trailliella intricata, der Sporophyt, galt vor der Klärung des entwidklungsgeschichtlichen Zusammenhangs (Kodh, 1950) als selbständige Form. Durch ihren für Rotalgen ungewöhnlichen Aufbau war die systematische Eingliederung problematisch. Der Thallus besteht aus einreihigen, unregelmäßig verzweigten Fäden, die ineinander verwoben als Flöckchen oder niedrige Überzüge im Sublitoral auf festem Substrat oder anderen Algen wachsen $(\mathbf{F})$. Aus Zellen der basalen Fäden entspringen kurze Hapteren $(G)$. Auffallend sind die stark lichtbrechenden kleinen Blasenzellen, die rom oberen Rand junger Fadenzellen abgegliedert werden. Sie speichern Jod, das bei saurer Reaktion frei wird. Die Tetrasporangien entstehen gereiht an kurzen $Z_{\text {weigen }}(\mathrm{H})$; sie treten nur gelegentlich von Oktober bis Dezember auf. Keimlinge und kleine Bonnemaisonia-Pflänzchen wurden mehrfach auf ihrem Sporophyten wachsend in Naturmaterial gefunden $(\mathrm{E})$. 


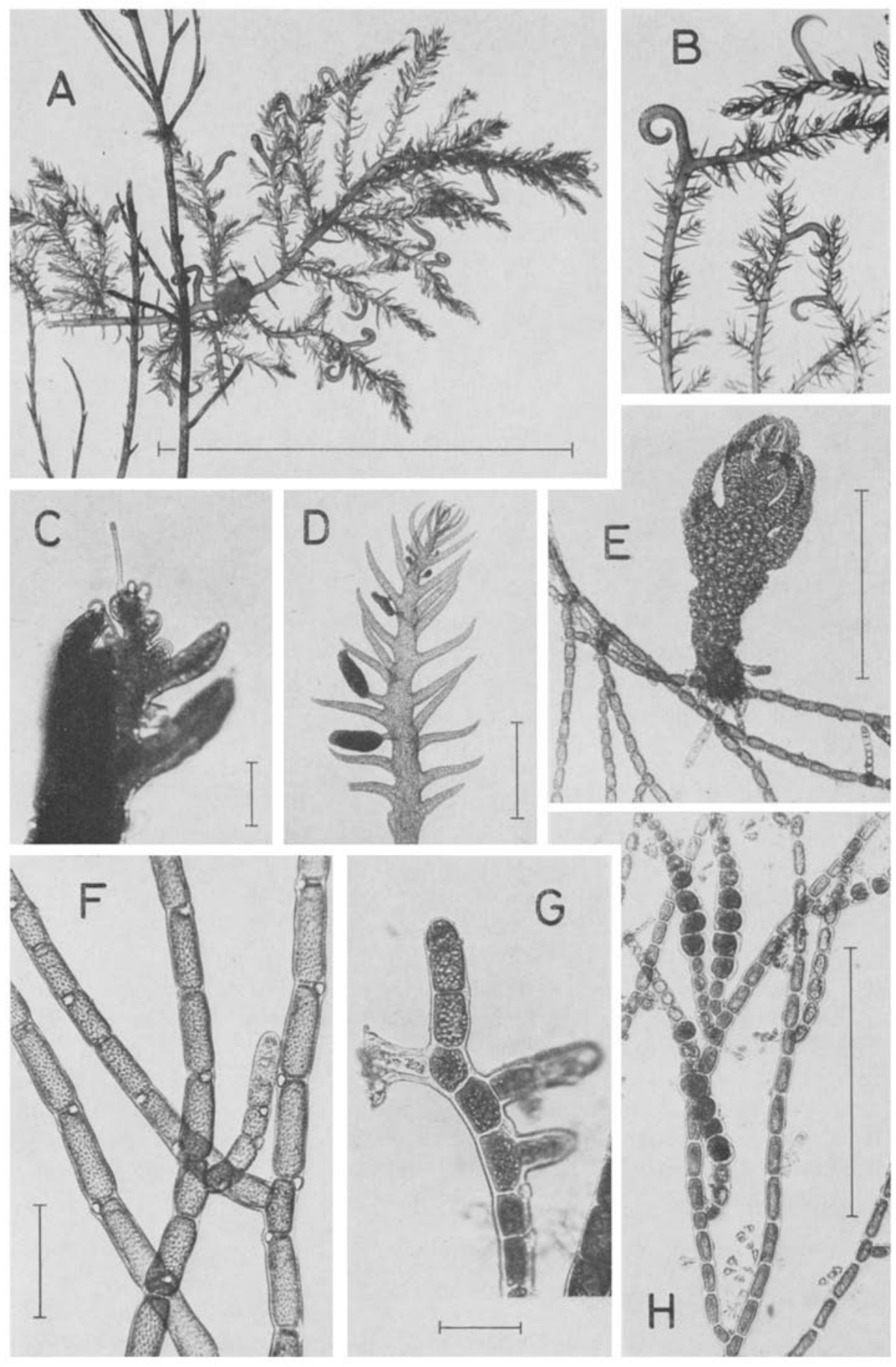

Abb. 101: Bonnemaisonia bamifera. A Pflanze auf treibender Desmarestia aculeata angehakt (29. 5. 1971). B Thallusstiicke mit Hakenzweigen. C, D Fertiler weiblicher und männlicher Gametophyt, aus Tetrasporen kultiviert. E Trailliella intricata mit aufsitzendem jungem Gametophyt (Naturmaterial, 1. 12. 1964). F Trailliella intricata (3. 9. 1970). G Faden mit Haptere. H Sporophyt mit Tetrasporangien (19.10.1964). Maßstrecken: $A=5 \mathrm{~cm} ; \mathrm{C}=100 \mu \mathrm{m}$; $\mathrm{D}=1 \mathrm{~mm} ; \mathrm{E}=500 \mu \mathrm{m} ; \mathrm{F}=100 \mu \mathrm{m} ; \mathrm{G}=100 \mu \mathrm{m} ; \mathrm{H}=500 \mu \mathrm{m}$ 
Furcellariaceae

\section{Furcellaria lumbricalis (Huds.) Lamour. syn. Furcellaria fastigiata}

Die dichten Büschel der bis etwa $20 \mathrm{~cm}$ hohen Alge entspringen einer rhizoidartig verzweigten Basis. Der feste, knorpelige Thallus ist stielrund, nur im oberen Teil wenig abgeflacht und wiederholt gabelig verzweigt. In ihrer Erscheinungsform sind Furcellaria und Polyides einander ähnlich; eines der unterscheidenden Merkmale ist die scheibenförmige Basis von Polyides.

Fertile Pflanzen findet man von Dezember bis März. Die männlichen Pflanzen sind schon äußerlich an ihren hellgefärbten spindelförmigen Thallusenden zu erkennen (D). Weibliche Gametophyten und Tetrasporophyten sind äußerlich nicht zu unterscheiden; die Ballen der Gonimoblasten (E) und die quergeteilten Tetrasporangien (C) liegen im Rindengewebe der leicht verdickten oberen Gabeläste.

Furcellaria lumbricalis ist eine Alge des Sublitorals. Nur bei außergewöhnlich tiefem Niedrigwasser kann man sie an ihrem Standort sammeln, gelegentlich findet man sie am Strand ausgeworfen. Die reichen Bestände von Furcellaria im Kattegat werden wirtschaftlich zur Herstellung eines Agar-ähnlichen Phykokolloids genutzt. Die jährlich angelandete Menge beträgt dort durchschnittlich 25000 Tonnen Frischgewicht (Lund \& Christensen, 1969).

\section{Halarachnion ligulatum (Woodw.) Kütz.}

An Steinen in 6 bis $7 \mathrm{~m}$ Tiefe wachsen die flächenartigen, rosa bis fleischrot gefärbten Thalli von Halarachnion ligulatum, die man gelegentlich auch am Strand angetrieben findet. Der bis $9 \mathrm{~cm}$ hohe, aus schmaler Basis sich verbreiternde Thallus teilt sich unregelmäßig gabelig und wächst am Rand zungenförmig aus (A).

Im Entwicklungszyklus folgen heteromorphe Generationen aufeinander (Boillot, 1972). Die im Juli und August reifen weiblichen Pflanzen sind durch unregelmäßig über das ganze Laub verteilte Karposporenhaufen dunkel gepunktet (A). Aus den Karposporen entsteht in Kultur ein krustenförmiger Thallus, der Tetrasporen erzeugt (B-D). Er entspricht nach Boillot der unter dem Namen Cruoria rosea Crouan beschriebenen Krustenalge. Die Tetrasporen entwickeln sich zu Basalscheiben, denen schon bald die flächenförmigen Gametophyten entsprossen $(E)$. 

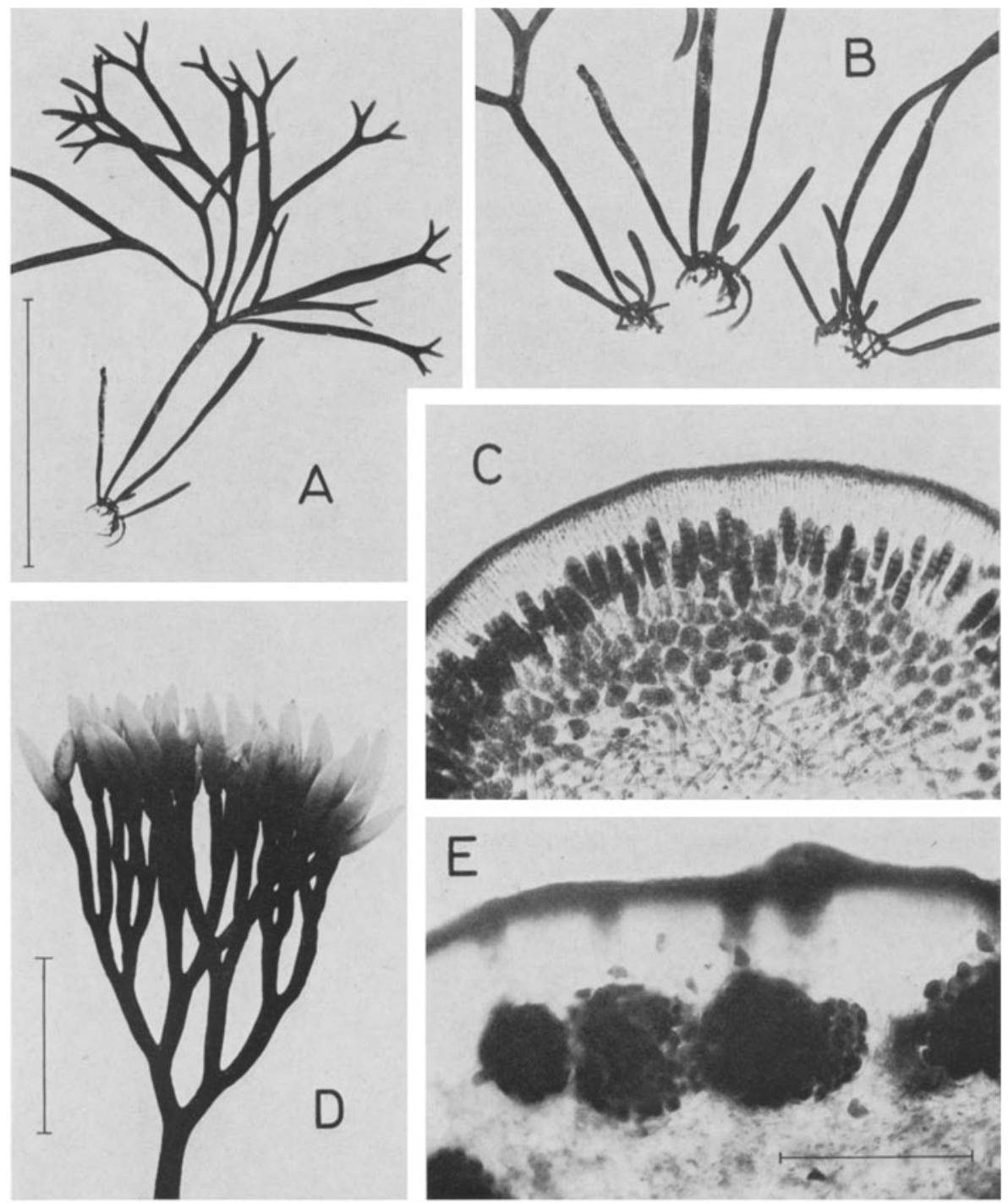

Abb. 102: Furcellaria lumbricalis. A, B Teil eines Büschels und Basalteile mit verzweigten Haftorganen (2.8. 1972). C Querschnitt mit Tetrasporangien (aus konserviertem Material vom 7. 12. 1959). D Thallusende einer männlichen Pflanze (1. 2. 1960). E Querschnitt durch eine weibliche Pflanze mit reifen Karposporen (aus konservicrtem Material vom 1. 2. 1960). Maßstrecken: $\mathrm{A}=5 \mathrm{~cm} ; \mathrm{C}, \mathrm{E}=500 \mu \mathrm{m} ; \mathrm{D}=1 \mathrm{~cm}$ 

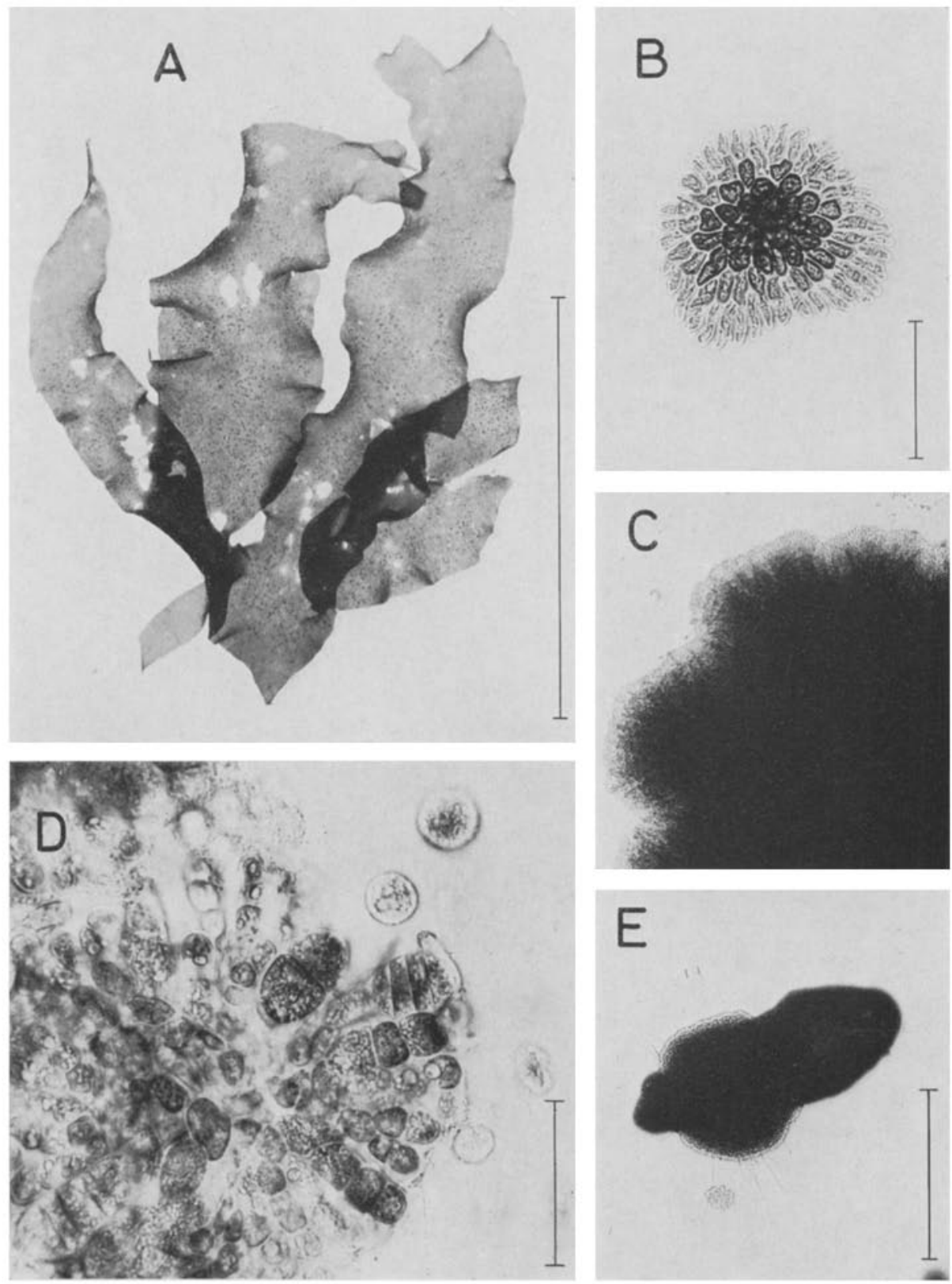

Abb. 103: Halaracbnion ligulatum. A Fertiler weiblicher Gametophyt (18. 8. 1971). B Krustenförmiger Sporophyt, 12 Tage alt. C Teil eines 5 Monate alten, fertilen Sporophyten. D Quetschpräparat mit drei quergeteilten Tetrasporangien und freien Tetrasporen. E 35 Tage alter Gametophyt. Maßstrecken: $\mathrm{A}=5 \mathrm{~cm} ; \mathrm{B}=50 \mu \mathrm{m} ; \mathrm{D}=50 \mu \mathrm{m} ; \mathrm{E}=0,5 \mathrm{~mm}$ 


\section{Cruoriaceae}

\section{Cruoria pellita (Lyngb.) Fries}

Die schlüpfrig glatten, etwas glänzenden dunkelweinroten Krusten von rundlichem bis unregelmäßigem Umriß kommen reichlich auf Geröllsteinen in einigen Meter Tiefe vor (A). Von der fest auf dem Substrat haftenden Basalschicht erheben sich die dïnnen aufrechten Fäden; sie sind einfach oder spärlich verzweigt, nur locker untereinander durch Gallerte verbunden, so daß sie sich im mikroskopischen Präparat leicht voneinander trennen. Die Fortpflanzungsorgane werden nicht in besonderen Nemathezien, sondern zwischen den Fäden angelegt. Große, zonenförmig geteilte Tetrasporangien sitzen seitlich an den Fäden (B).

In vegetativem Zustand sind Cruoria pellita und die ebenfalls im Sublitoral häufigen Krusten von Peyssonnelia dubyi durch ihren Aufbau leicht zu unterscheiden (vgl.p. 220).
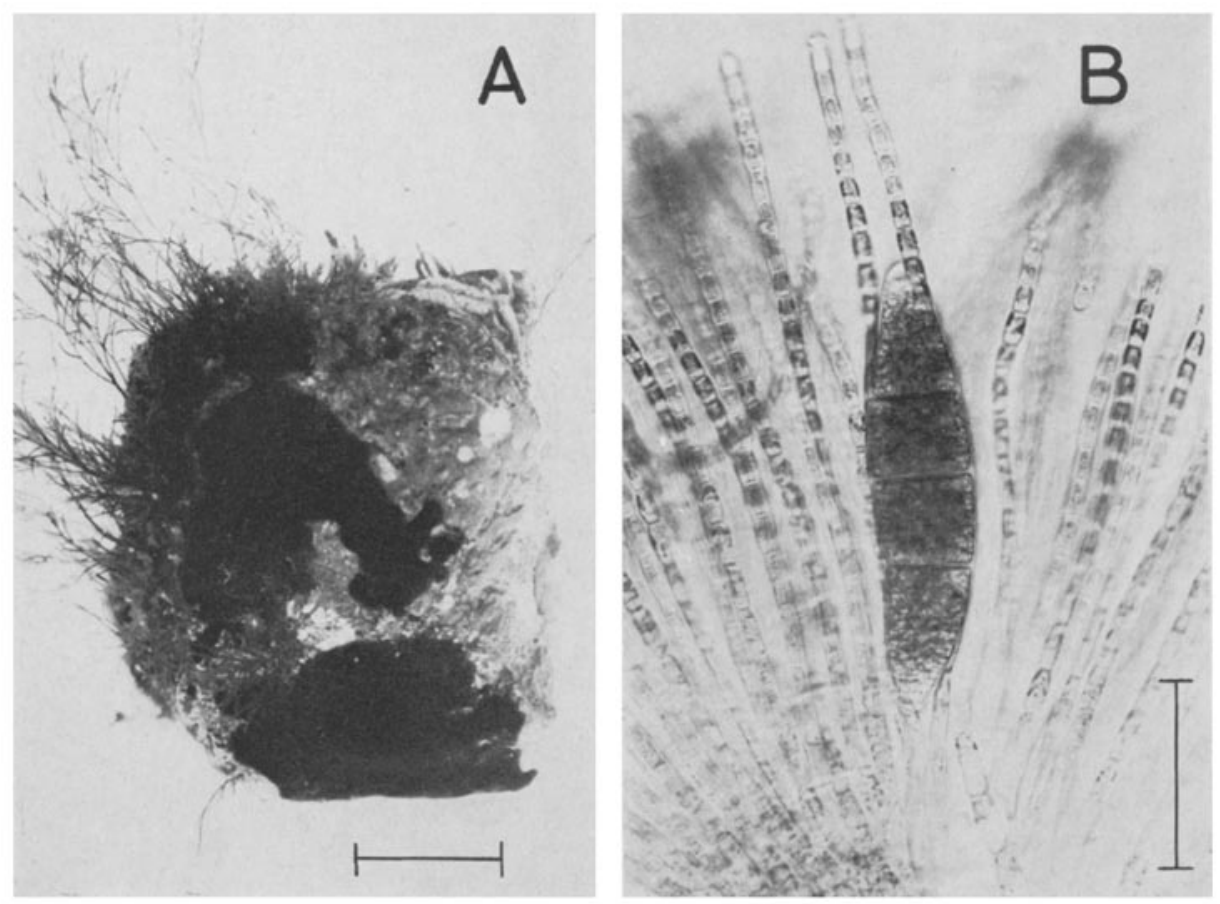

Abb. 104: Cruoria pellita. A Zwei Krusten auf einem Stein aus $5 \mathrm{~m}$ Tiefe zusammen mit Polysiphonia urceolata (8. 6. 1976). B Schnitt durch die Kruste mit Tetrasporangium (18. 2. 1975). Maßstrecken: $\mathrm{A}=1 \mathrm{~cm} ; \mathrm{B}=100 \mu \mathrm{m}$ 


\section{Petrocelis hennedyi (Harv.) Batt.}

Petrocelis bernedyi ist in der Gezeitenzone unter Fucus serratus stellenweise recht verbreitet. Es sind speckige, dunkelviolette, fast schwärzliche Krusten von rundlichem oder unregelmäßigem Umriß, im Durchmesser oft mehr als $5 \mathrm{~cm}$. Die Oberfläche der deutlich über das Substrat erhabenen Krusten ist glatt; in den weichen Thallus läßt sich ein Fingernagel leicht eindrücken. Diese einfache Probe gelingt nicht bei der im gleichen Niveau häufigen Hildenbrandia rubra, deren Krusten hart und sehr fest sind.

Ein Schnitt durch die Kruste zeigt den Aufbau aus meist unverzweigten dünnen parallelen Fäden, die durch eine gallertige Substanz locker miteinander verbunden sind. In den Wintermonaten findet man Tetrasporangien interkalar in den Fäden gereiht; sie sind unregelmäßig kreuzförmig geteilt. Die Gonimoblasten liegen als unregelmäßig gelappte Körper zerstreut zwischen den aufrechten Fäden, sie enthalten zahlreiche recht kleine Karposporen (Präparat vom 23. 1. 1960). Die Krusten von Petrocelis bennedyi beherbergen häufig und während des ganzen Jahres Codiolum petrocelidis, den einzelligen Sporophyten von Spongomorpha aeruginosa (Abb. $11 \mathrm{E}, \mathrm{F})$.

Von Parke \& Dixon (1976) wird die Gattung Petrocelis bei den Gigartinaceae eingegliedert, nachdem $P$. franciscana von der kalifornischen Küste als Tetrasporophyt von Gigartina agardbii erkannt wurde (West, 1972). Wahrscheinlid gehören die Petrocelis-Arten mit einzeln beziehungsweise gereiht in den Fäden liegenden Tetrasporangien zu verschiedenen Formenkreisen. Petrocelis bennedyi hat gleichgestaltete Sporophyten und Gametophyten. Zudem kommen Gigartina-Arten als mögliche Partner ihrer Lebensgeschichte bei Helgoland nicht vor. Wir ziehen daher die Einordnung von Petrocelis bennedyi neben Cruoria pellita vor.

Abb. 105: Petrocelis bennedyi. A Mehrere Krusten (dunkel) auf Felsstüd mit Pbymatolithon polymorphum (fertil, Konzeptakeln mit Dedeln), Conallina officinalis und Keimlingen yon Fucus serratus (oben links). B, C Querschnitt bzw. Quetschpräparat mit Tetrasporangien. Maßstrecken: $A=2 \mathrm{~cm} ; B=100 \mu \mathrm{m} ; C=50 \mu \mathrm{m}$ 

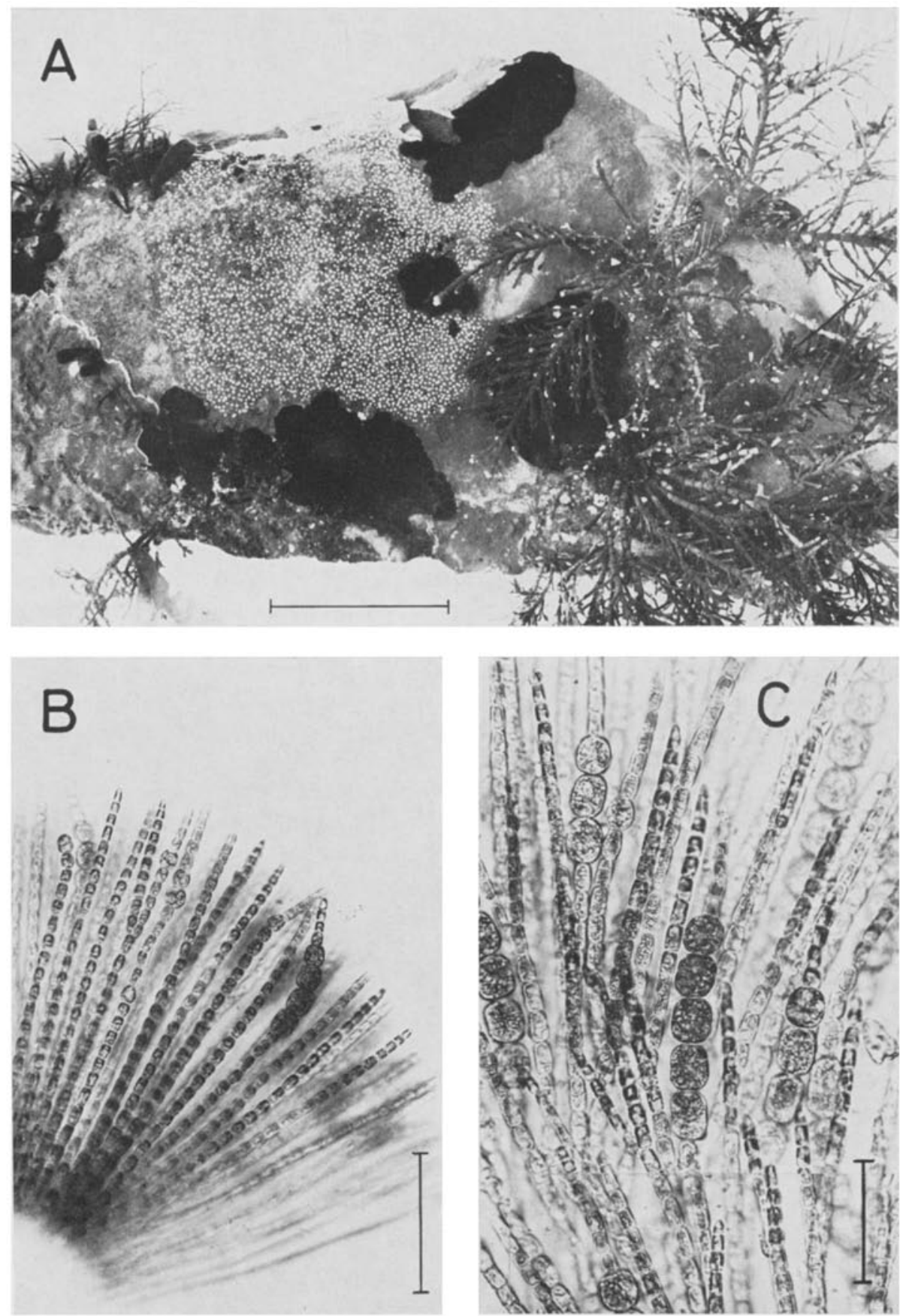
Polyides rotundus (Huds.) Grev.

Morphologisch und anatomisch sind Polyides rotundus und Furcellaria lumbricalis einander sehr ähnlich, Polyides wird aber nur 10 bis $15 \mathrm{~cm}$ hoch (A). Fragmente lassen sich durch ihre Färbung den beiden Arten zuordnen; im durchfallenden Licht erscheint Polyides rot, Furcellaria braun-violett. Die Basis vollständiger Pflanzen bietet ein absolutes Unterscheidungsmerkmal; die Sprosse von Polyides entspringen einer gemeinsamen Haftscheibe (B), während Furcellaria mit verzweigten Haftorganen am Substrat befestigt ist (Abb. $102 \mathrm{~A}, \mathrm{~B}$ ). Polyides veranschaulicht damit klar das Muster eines heterotrichen Thallusaufbaus: Auf einer krustenförmig wachsenden Basis erheben sich die aufrecht wachsenden Sprosse. Ihr pseudoparenchymatisches Gewebe besteht aus einem zentralen Mark von vielen unbegrenzt wachsenden Längsfäden; ihre $Z$ weige beenden in der nach außen immer kleinzelliger werdenden Rinde ihr Wachstum ("Springbrunnentypus").

Die Geschlechtsorgane werden im Spätsommer angelegt. Im August kann man männliche Pflanzen finden, die Nemathezien sind nur wenig erhabene Polster auf den oberen Thallusabschnitten (C, D). Ein Querschnitt durch ein solches Lager zeigt parallele Fäden, aus deren Zellen die Spermatien entstehen (E). Die Nemathezien der weiblichen Pflanzen heben sich zur Zeit der Karposporenreife, Dezember und Januar, als kräftige, hellrote Warzen auf den oberen Thallusabschnitten ab (F). Die Gonimoblasten liegen als dichte Haufen dunkler Zellen $z$ wischen den der Rinde entspringenden Fäden (G). Die kreuzgeteilten Tetrasporangien findet man im Januar und Februar in der Rinde wenig verdickter Thallusenden eingestreut $(\mathrm{H})$.

Polyides ist wie Furcellaria eine Alge des Sublitorals und wurde aud bei ungewöhnlich tiefem Niedrigwasser an den gleichen Standorten gesammelt. Vereinzelte Exemplare von Polyides triff man aber auch schon im unteren Litoral an.

Abb. 106: Polyides rotundus. A, B Teil eines Büschels und Basalscheibe von unten mit zahlreichen aufrechten Sprossen (6.8. 1969). C-E Männlicher Gametophyt und Querschnitte durch das Nemathezium (21.8.1974). F, G Weiblicher Gametophyt (15. 1. 1973) mit jüngeren Gonimoblasten (25. 10,1975). H Tetrasporangien (aus konserviertem Material vom 1. 2. 1960). Maßstredken: $A=5 \mathrm{~cm} ; D=1 \mathrm{~mm} ; \mathrm{E}, \mathrm{G}, \mathrm{H}$ jeweils $=100 \mu \mathrm{m}$ 


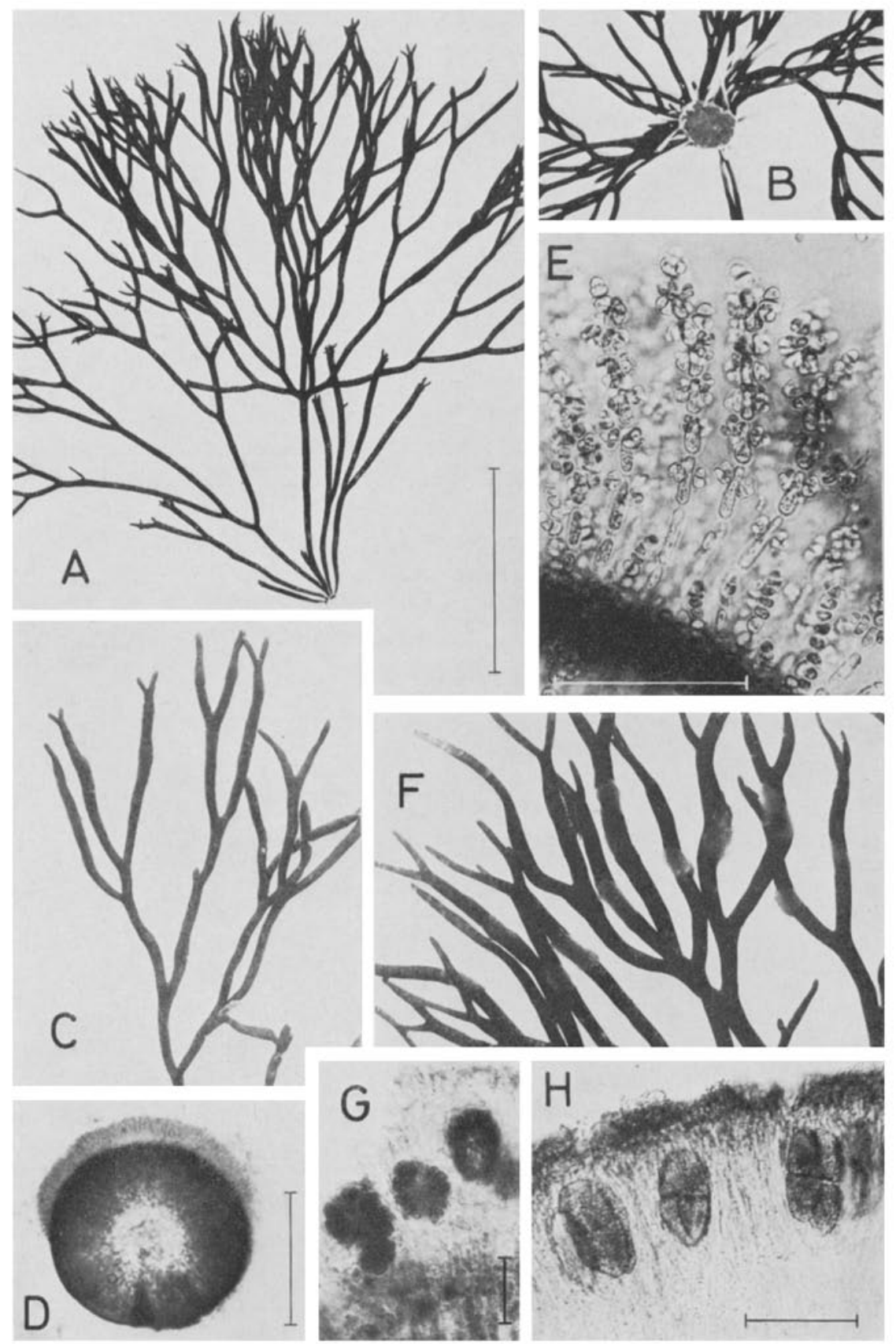


Rhodophyllidacea e

\author{
Cystoclonium purpureum (Huds.) Batt. \\ syn. Cystoclonium purpurascens
}

Diese stattliche, meist braunrote fleischig-feste Alge wird bis $40 \mathrm{~cm}$ hoch. Die Hauptachse trägt allseitig zahlreiche Aste, die sich wiederum reichlich verzweigen. Die Zweigenden laufen haarartig dünn aus und können rankenartig eingerollt sein (B). Diese Besonderheit zeigen jedoch längst nicht alle Pflanzen und auch nur ein Teil ihrer Zweigenden. Der bis $3 \mathrm{~mm}$ dicke Hauptstamm entspringt einer Haftscheibe; nahe der Basis sorgen wurzelartige Verzweigungen für eine zusätzliche Befestigung am Substrat (A).

Reife weibliche Pflanzen findet man im Juni und Juli; die dunklen Zystokarpien, jedoch ohne besondere Mündung, sind als knotige ovale Anschwellungen in den Zweigen zu erkennen (C). Die Tetrasporophyten haben keine besonderen äußeren Merkmale, sie sind ebenfalls im Juli reif.

Cystocloniwm purpureum wächst von Januar bis August hauptsächlich auf Steinen im Sublitoral. Auf dem Felswatt kommt sie an der Grenze zum Sublitoral vor, man findet sie in flachen Tümpeln oder an Prielrändern. Sie siedelt sich auch gern auf schwimmenden Gegenständen an, zum Beispiel auf Bojen. In den Sommermonaten wächst Cystoclonium auch in mehreren Meter Tiefe.

\title{
Plocamiaceae
}

\section{Plocamium cartilagineum (L.) Dixon syn.Plocamium coccineum}

Die Bezeichnung Kammtang bringt ein auffallendes Merkmal dieser Alge zum Ausdruck, die kammartige Anordnung der jüngsten Verzweigungen. Die schön rot gefärbte Alge ist im Sublitoral sehr verbreitet; ausgeworfene Exemplare sind während des ganzen Jahres, besonders aber im Sommer am Strand zu finden. Nur bei extrem tiefem Niedrigwasser während anhaltenden Oststurmes triff man sie weit draußen in größeren Beständen auf den von Phymatolithon-Krusten besiedelten Flächen an.

Der in einer Ebene sympodial verzweigte Thallus ist durchgehend flach, die Büschel können $20 \mathrm{~cm}$ Durchmesser erreichen. Die Achsen sind nur scheinbar einheitlich; sie setzen sich aus Sproßabschnitten zusammen, deren jeweils oberster, am kräftigsten entwickelte Zweig das System fortsetzt. Die Mutterachse wird zur Seite gedrängt und endet als kurzer unverzweigter Dorn abwechselnd links und rechts der scheinbaren Hauptachse (B). Uber ihm folgen dann einseitig 3 oder 4 zunehmend stärker ausgebildete Seitenzweige, deren oberster die scheinbare Hauptachse fortsetzt. Dieser sympodiale Aufbau ist auch in der Abbildung $C$ eines Tetrasporophyten klar zu erkennen. 
Reife weibliche Pflanzen tragen kugelige, zerstreut am Thallusrand sitzende Zystokarpien (B). Man findet sie wie die Tetrasporophyten zu jeder Jahreszeit. Die Tetrasporangien werden in den Enden kleiner Zweigbüschel gebildet, die kurz und gedrungen oder länger gestreckt sein können $(C, D)$.
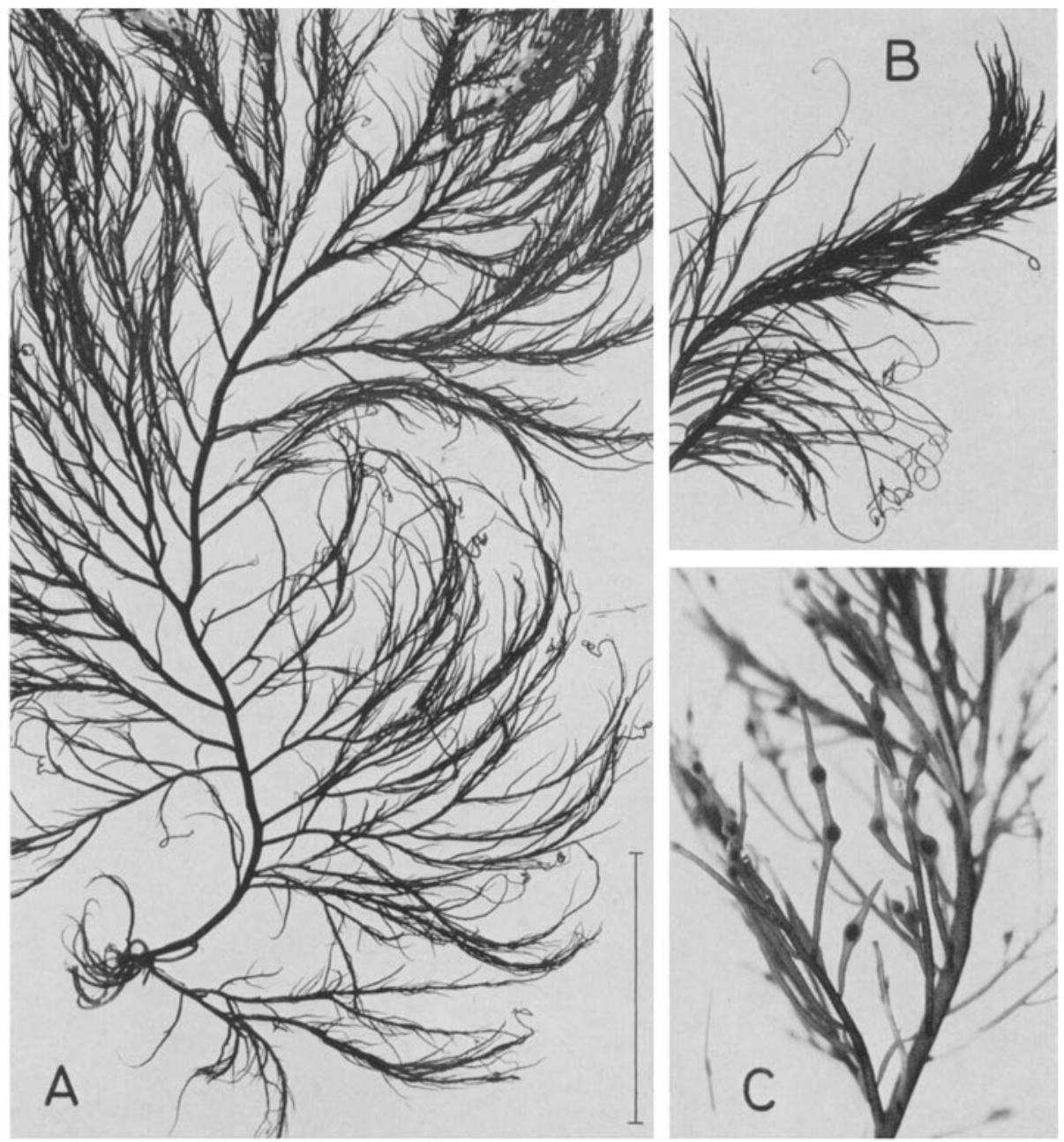

Abb. 107: Cystoclonium purpureum. A Teil einer etwa $30 \mathrm{~cm}$ langen Pflanze (24. 4. 1975). B Spiralig eingerollte Zweigenden. C Teil einer weiblichen Pflanze mit reifen Zystokarpien (24. 7. 1970). Maßstrecke: $A=5 \mathrm{~cm}$ 

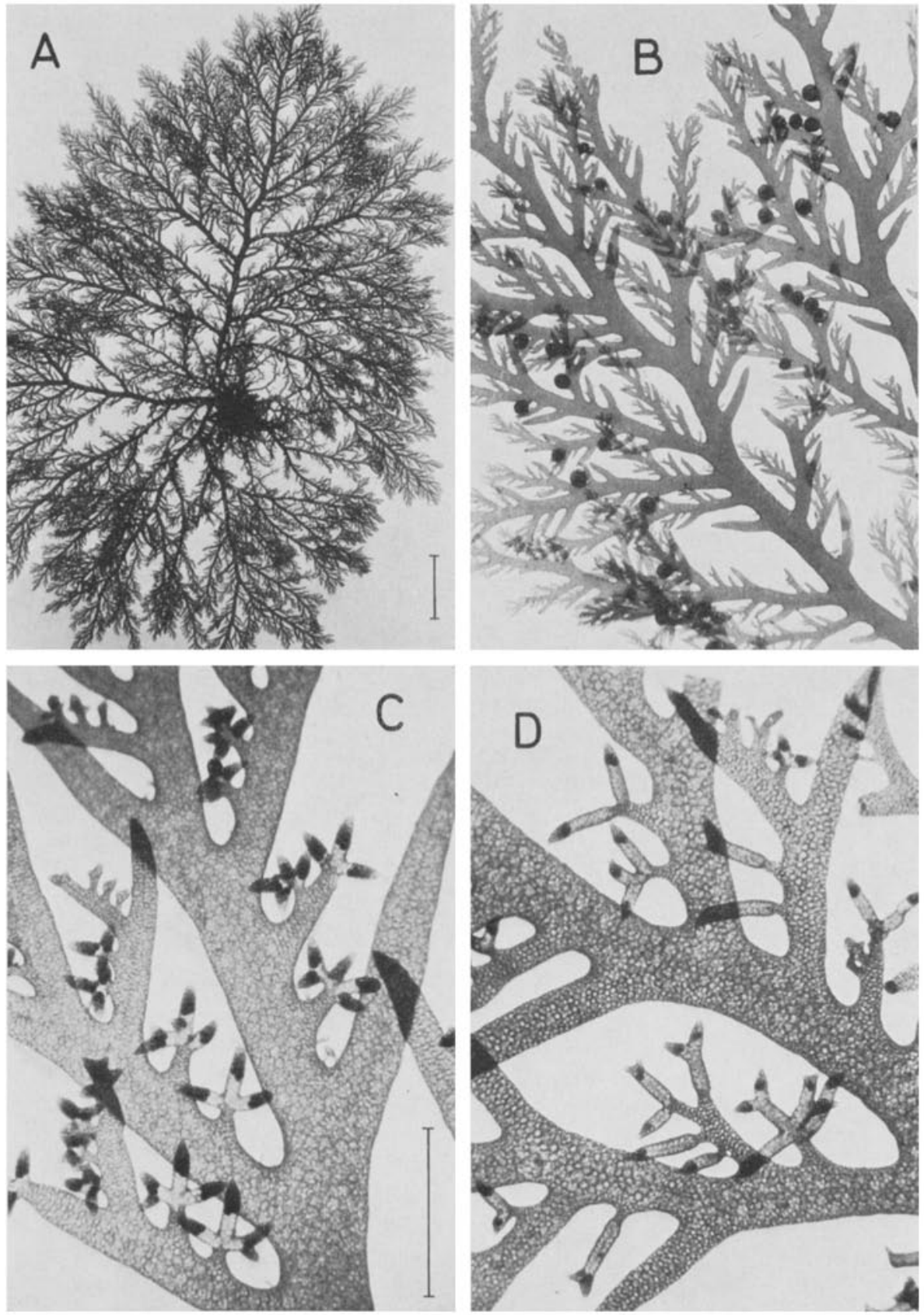

Abb. 108: Plocamium cartilagineum. A Habitus (19.11. 1970). B Weibliche Pflanze mit Zystokarpien (9. 3. 1971). C, D Tetrasporophyten mit verschiedener Ausbildung der fertilen Ästchen (August 1971). Maßstrecken: $A=1 \mathrm{~cm} ; C, D=1 \mathrm{~mm}$ 


\section{Abnfeltia plicata (Hudson) Fries}

Mit keiner anderen Alge können die drahtartig festen, verworrenen Büschel von Abnfeltia plicata verwechselt werden. Auf einer Basalscheibe erheben sich mehrere runde, 0,5 bis knapp $1 \mathrm{~mm}$ dicke, dichotom verzweigte und unregelmäßig proliferierende Fäden. Die Farbe ist braun-violett bis schwarz, nur die leicht angeschwollenen wachsenden Endabschnitte sind weißlich. Die Büschel der ausdauernden Alge werden bis $20 \mathrm{~cm}$ hoch; man findet sie bei gutem Niedrigwasser im unteren Litoral auf Fels und besonders auf Feuersteinen; im Sublitoral kommt Abnfeltia plicata bis zu etwa $3 \mathrm{~m}$ Tiefe vor.

Im Februar bis April tragen die Fäden kleine, nur wenig erhabene und den Thallus halb oder ganz umfassende Höckerchen. Es sind Nemathezien, in denen Monosporen erzeugt werden, bis vor kurzem die einzigen bekannten Fortpflanzungszellen. Früher wurden diese Wärzchen als eine parasitische Rotalge, Sterrocolax decipiens, angesehen.

Farnham \& Fletcher (1976) fanden in der krustenartigen Basalscheibe von Abnfeltia plicata quergeteilte Tetrasporangien; sie stimmt in diesem Merkmal und in ihrem Aufbau mit der als Porphyrodiscus simulans Batters beschriebenen Krustenalge überein. Die Tetrasporen entwickelten sich in Kultur zu Scheiben, die denen aus Monosporen von Abnfeltia ähnlich sind. Die damit aufgedeckten entwicklungsgeschichtlichen Zusammenhänge haben bei den Rotalgen bisher keine Parallele.

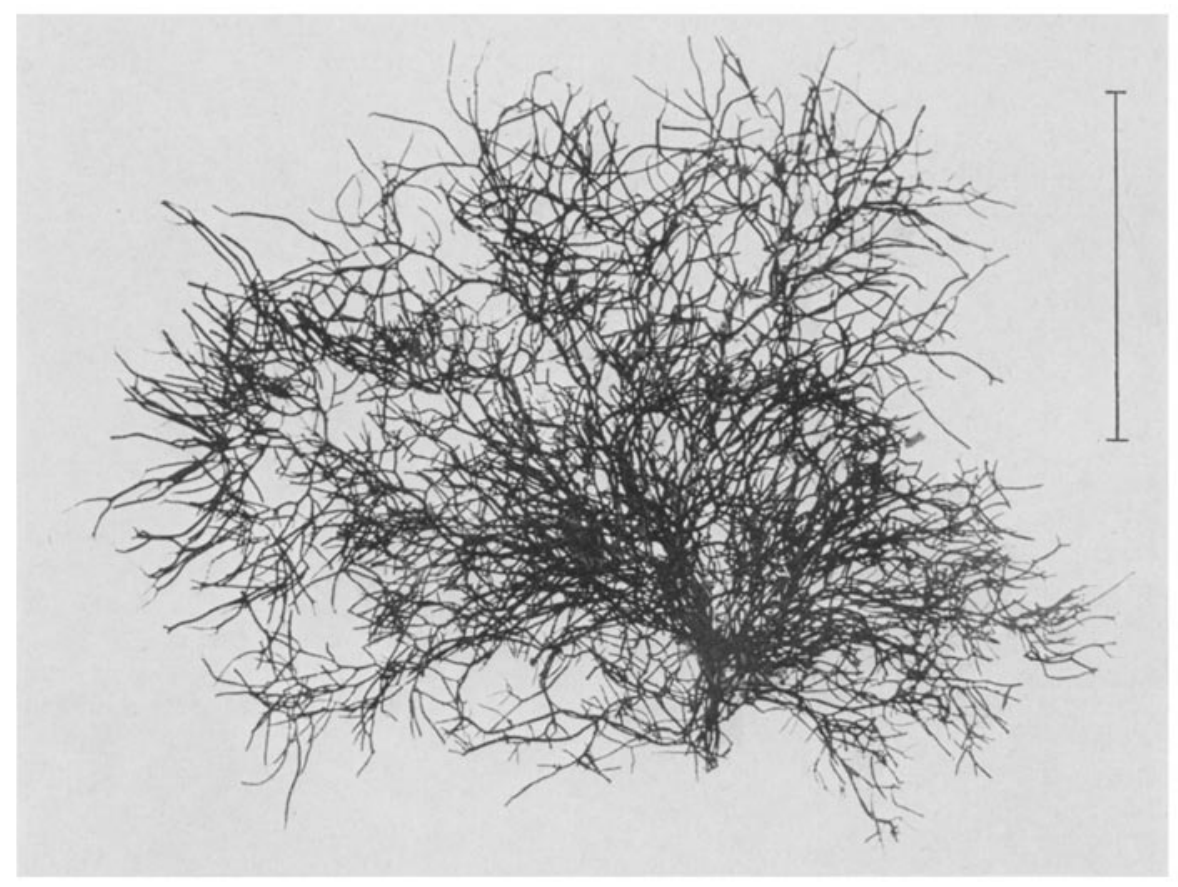

Abb. 109: Abnfeltia plicata. Habitus eines Büschels (9. 9. 1971). Maßstrecke $=5 \mathrm{~cm}$ 


\section{Gymnogongrus crenulatus (Turn.) J. Ag.} syn. Gymnogongrus norvegicus

Bis etwa $2 \mathrm{~mm}$ breit ist der dicke, bandartige, wiederholt dichotom geteilte, fleischrote Thallus von Gymnogongrus crenulatus und dadurch leicht von dem breiteren Chondrus crispus zu unterscheiden. Unsere Abbildung zeigt ein besonders stattliches Exemplar. Die nicht gerade häufige Alge wädst gern gesellig auf hartem Substrat, zum Beispiel auf Feuerstein. Man kann sie von Juli bis November im Felswatt zu beiden Seiten der Nordmole finden, immer untergetaucht in Mulden oder Prielen wachsend. Im Sublitoral kommt sie noch in knapp $7 \mathrm{~m}$. Tiefe vor.

In ähnlicher Weise wie bei Pbyllopbora truncata ist auch der Lebenszyklus von Gymnogongrus crenulatus abgekürzt, eine selbständige Tetrasporophytengeneration fehlt. Die etwa $1 \mathrm{~mm}$ großen, halbkugeligen Erhebungen auf dem Thallus hielt man fruiher für eine parasitische Rotalge, Actinococcus peltaeformis. Sie stellen jedoch Nemathezien eines Tetrasporoblasten dar, der sich unmittelbar aus dem wahrscheinlich befruchteten Karpogonium entwickelt. Die recht komplizierten und keineswegs einheitlichen Fortpflanzungsverhältnisse in der Gattung Gymnogongrus untersuchte Schotter (1968).

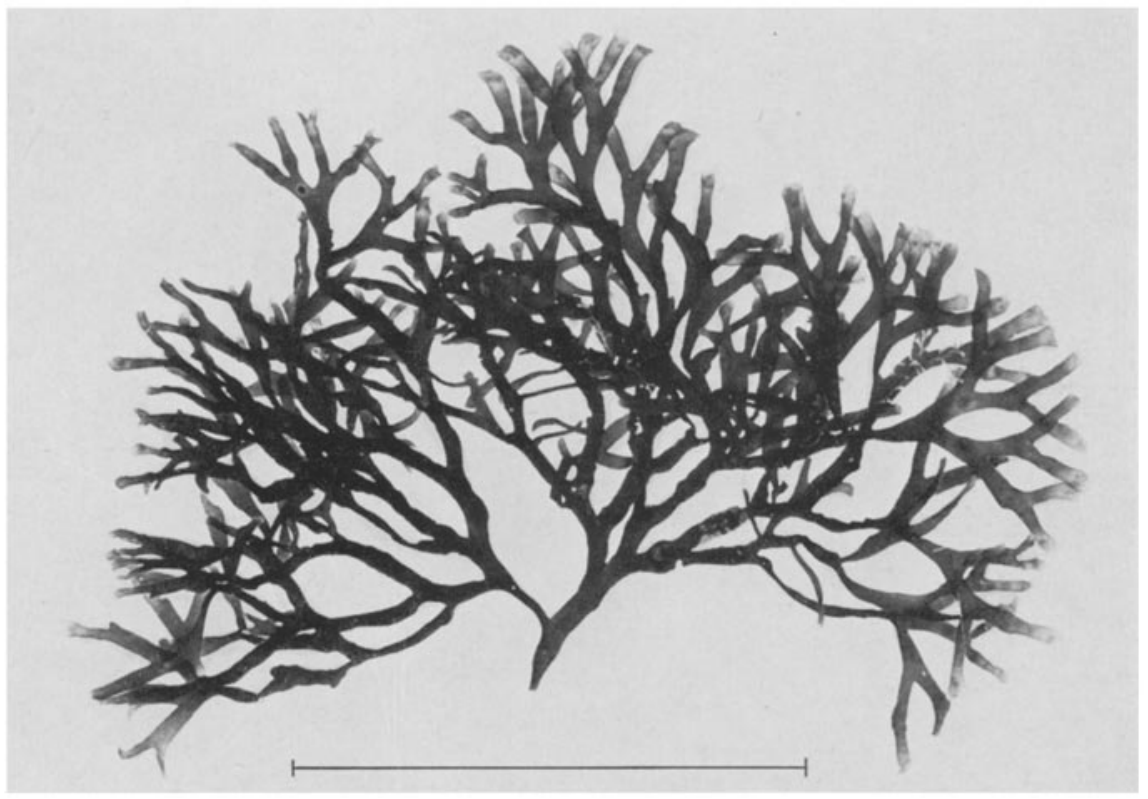

Abb. 110: Gymnogongrus crenulatus. Fertile Pflanze (9.9. 1971). Maßstrecke $=5 \mathrm{~cm}$ 
Phyllophora pseudoceranoides (S. G. Gmel.) Newr. et A. R. A. Taylor syn. Phyllophora membranifolia

Die beiden auf Abbildung 111 dargestellten Pbyllophora-Arten sind einander recht ähnlich; die Unterscheidung wird erleichtert, wenn man sie miteinander vergleichen kann. Der Gattungsname deutet den Aufbau des Thallus an: Blattartige Thalli werden auf festen, runden, mehrere Zentimeter langen Stielen getragen. Der Stiel kann sich unmittelbar in die Fläche verbreitern oder sich an seinem Ende fächerartig in das mehrfach gegabelte Laub aufteilen. Das ist besonders bei der ab Februar aus den Stielen proliferierenden Laubgeneration der Fall. Die frisch ausgewachsenen Lappen haben einen glatten Rand. Er wächst später in schmalere und weniger regelmäßige Gabeläste oder Proliferationen aus. Pbyllophora pseudoceranoides ist pergamentartig dün, im Farbton etwas rötlich violett (Abb. $111 \mathrm{D}, \mathrm{E})$.

Am Rande und auf der Fläche des vorjährigen Laubes kann man im Winter reife Zystokarpien finden; es sind kurzgestielte, kugelige bis längliche Auswüchse. Durch ihre Form und den dunklen Inhalt unterscheiden sie sich von jungen vegetativen Sprossen (E). Phyllophora pseudoceranoides ist diözisch; entsprechende Blättchen mit Spermatangien wurden im Juni und Oktober beobachtet. Die Tetrasporangien werden auf einer selbständigen, gleichgestalteten Generation gebildet; der Lebenszyklus von Pbyllophora pseudoceranoides entspricht also dem allgemeinen Schema der Rotalgenentwicklung.

Die Phyllophora-Arten sind mehrjährige Rotalgen des Sublitorals; ältere Thalli sind oft stark von Bryozoen und Hydroiden besiedelt. Nur vereinzelt triff man sie auch schon unter Fucus serratus oder in Wasserlöchern an. Pbyllophora psendoceranoides findet man nach stürmischem Wetter reichlicher am Strand ausgeworfen als die folgende Art.

\section{Pbyllophora truncata (Pall.) Zinova syn. Phyllophora brodiaei}

Phyllophora truncata teilt den Standort mit der vorigen Art. Sie ist im Vergleich mit $P b$. pseudoceranoides meist derber, ihre Stengel bleiben in der Regel kürzer, sie verbreitern sich auch gern zu einem schmalen flächigen Abschnitt (B). Ab Februar treiben aus dem vorjährigen, braunrot gefärbten Thallus kurzgestielte ovale und sich dann keilförmig verbreiternde hellrot gefärbte Blättchen aus (A). Das junge Laub wird nicht wie bei Phyllophora pseudoceranoides wiederholt gabelig aufgeteilt.

Der Lebenszyklus weicht von dem allgemeinen Rotalgen-Schema $a b$, er ist verkürzt. Ohne Zwischenschaltung einer Karposporophytenphase entwickelt sich ein Tetrasporoblast unmittelbar - wahrscheinlich nach Befruchtung des Karpogons - auf dem monözischen Gametophyten zu einem etwa $2 \mathrm{~mm}$ dicken Knötchen (C). Die Reduktionsteilung bei der Tetrasporenbildung ist nachgewiesen. Newroth (1971) stellte fest, daß die Tetrasporoblasten mindestens 18 Monate bis zur Reife brauchen, daher findet man die dicken Knötchen nur an 'den vorjährigen Thallusteilen. Früher hielt man die Knötchen für eine parasitische Rotalge, Actinococcus subcutanełs, 


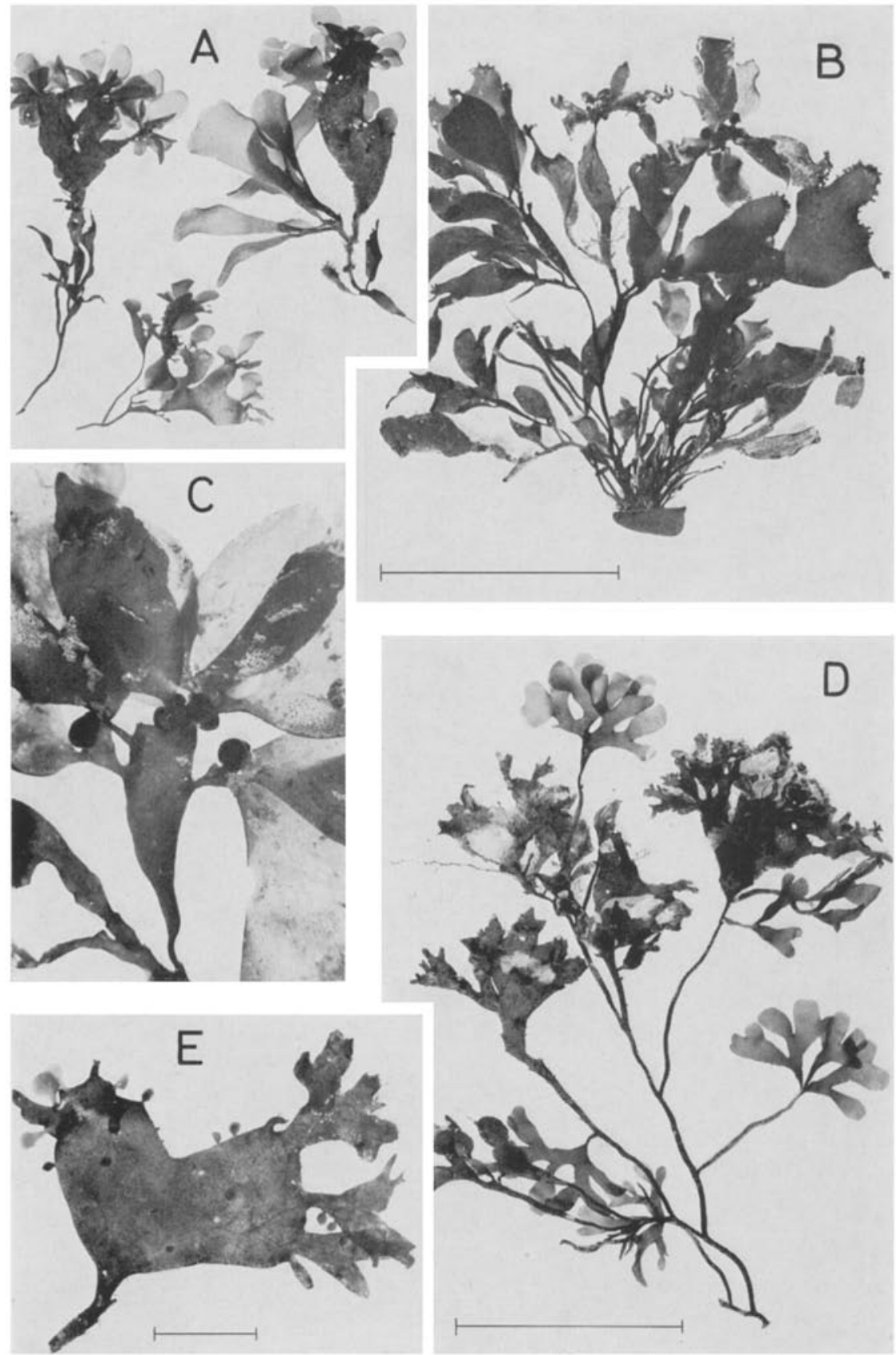

Abb. 111 A-C: Pbyllopbora truncata. A Pflanzen mit jungem Laub (5. 4. 1969). B Büschelig auf festem Substrat (26. 8. 1971). C Thallusstück mit Tetrasporoblasten (26. 8. 1971). D, E: Pbyllopbora pseudoceranoides. D Habitus einer Pflanze mit alten und frischen Thallusteilen (9. 2. 1971). E Vegetative Blättchen und Zystokarpien am Thallusrand und vereinzelt auf der Fläche (9. 2. 1971). Maßsstrecken: $B, D$ jeweils $=5 \mathrm{~cm} ; E=1 \mathrm{~cm}$ 


\section{Phyllophora traillii Holm. ex Batt.}

Dieser kleinen Rotalge begegnet man nur auf gedretschten oder von Tauchern besorgten Steinen und auf Krallen von Laminaria byperbored. Bei höchstens $2 \mathrm{~cm}$ Höhe wird sie nicht wie die beiden anderen Pbyllophora-Arten vom Standort losgerissen und am Strand ausgeworfen. Phyllophora traillii kommt in allen Tiefenstufen des Helgoländer Sublitorals vor (Lüning, 1970b, als Phyllophora crispa). Als einzige thallöse Rotalge dringt sie in mehr als $12 \mathrm{~m}$ Tiefe vor, ein Bereich, der nur noch von krustenförmigen Rotalgen besiedelt wird.

Auf einer deutlichen Haftscheibe erhebt sich der kurzgestielte flächige Thallus, der bei den im September gesammelten Pflanzen nur wenig geteilt war (A). Der Bryozoenbewuchs läßt darauf schließen, daß die Pflanzen nicht mehr ganz jung waren, wie auch die kleinen randständigen Auswüchse an einigen Pflänzchen auf eine beginnende Fertilisierung hinweisen. Der Rand einer reifen männlichen Pflanze ist von gestielten, rundlich ovalen farblosen Blättchen gesäumt, einzelne erheben sich auch auf der Fläche (D). Die in Gruppen angeordneten Spermatangien bilden in der Aufsicht ein zierliches Muster (E, F). Stärkere Proliferationen aus den Stielen zeigen die Pflänzchen einer Aufsammlung vom Februar (B), von denen einige nahezu reife, kurzgestielte Zystokarpien trugen (C).

\section{Gigartinaceae}

\section{Chondrus crispus Stadkh.}

Aus der Fülle der Erscheinungsformen dieser Alge seien hier nur zwei recht gegensätzliche ausgewählt (A, B). Dargestellt ist jeweils ein aufrechter Thallus, von denen oft viele verschiedenen Alters einer Basalscheibe entspringen, die mehrere Jahre alt wird. Solche Büschel können bei entsprechender Aufteilung der Endabschnitte wie ein krauser Schwamm aussehen, bei geringer und regelmäßig dichotomer Verzweigung aus flachem Laub bestehen. Der knorpelige Thallus verjüngt sich in einen über der Basis runden Stiel.

Die Vielgestaltigkeit von Chondrus ist - vielleicht nicht ausschließlich - durch die sehr verschiedenartigen ökologischen Bedingungen seines jeweiligen Standorts bedingt. Büschel, die im Litoral auf nacktem Fels wachsen, wo sie bei jeder Tide emergieren und auch starkem Wellenschlag ausgesetzt sind, bleiben gedrungen und schmal; sie sind mehr braun als rot. Unter einer dichten Vegetation von Fucus serratus dagegen findet man breite, sehr regelmäßig gegabelte Formen von braunvioletter Farbe, die im Sonnenlicht stahlblau irisieren. Es darf auch nicht übersehen werden, daß ein Thallus sein Aussehen schon im Laufe einiger Monate bei fortschreitender Verzweigung in schmalere Abschnitte sehr verändern kann. 

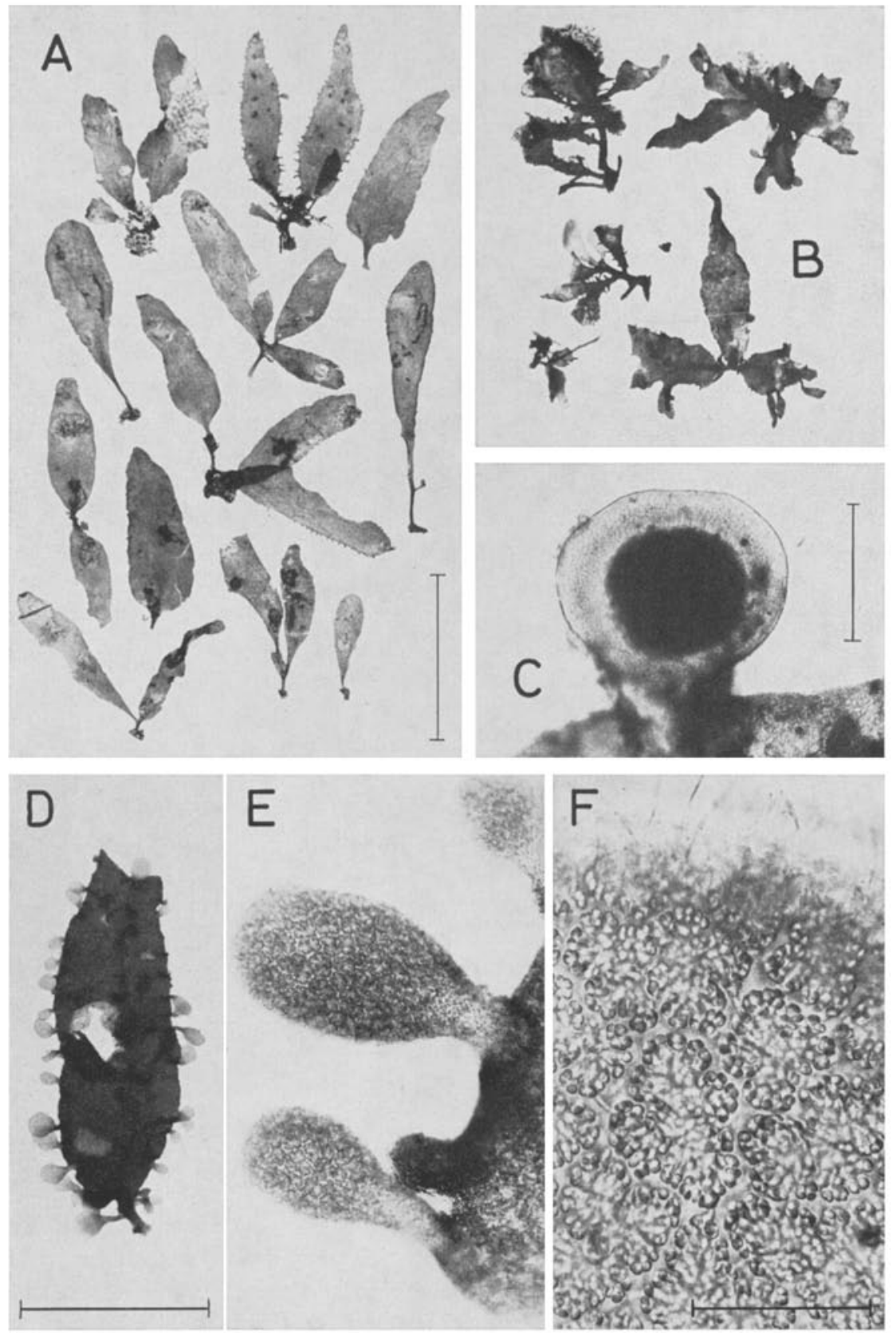

Abb. 112: Pbyllophora traillii. A Wenig verzweigte, flächige Exemplare, einige mit jungen fertilen Blättchen $(6.9 .1972)$. B Stärker verzweigte und proliferierende Pflanzen, die beiden rechts mit Zystokarpien (17. 2. 1975). C Ziemlich reifes Zystokarp (aus Präparat vorn 13. 2. 1967). D-F Männliche Pflanze und Aufsicht auf fertile Blättchen (8.9. 1976). Maßstrecken: A, B = $1 \mathrm{~cm} ; \mathrm{C}=500 t \mathrm{~m} ; \mathrm{D}=0,5 \mathrm{~cm} ; \mathrm{F}=50 \mu \mathrm{m}$ 
Fertile Pflanzen findet man zu jeder Jahreszeit, am häufigsten sind Tetrasporophyten. Die Tetrasporangiensori erscheinen als beiderseitige flach warzenförmige Flecken von länglichem oder unregelmäßigem Umriß und dunkelroter Farbe (C). Weibliche Gametophyten sind selten; die ovalen Zystokarpien liegen zerstreut in den jüngeren Thallusabschnitten eingesenkt und erscheinen als flache einseitige Vorwölbungen (D). Die Fortpflanzungszellen werden durch Degeneration der Rindenzellen frei.

Seit alters wurde Chondrus crispus als Nahrungsmittel und Tierfutter genutzt und diente getrocknet als Carragheen oder Irländisches Moos als schleimlösendes Mittel. Heute ist Chondrus Grundlage für eine bedeutende Algenindustrie. Ihr Inhaltsstoff, das Carraghenan, findet als Emulgator und Stabilisator vielfache Verwendung, besonders in der Nahrungsmittel- und pharmazeutischen Industrie sowie für die Herstellung von Seifen und Kosmetika, in der Textilindustrie als Appreturmittel. Hinweise auf einschlägige Literatur auf p. 148.
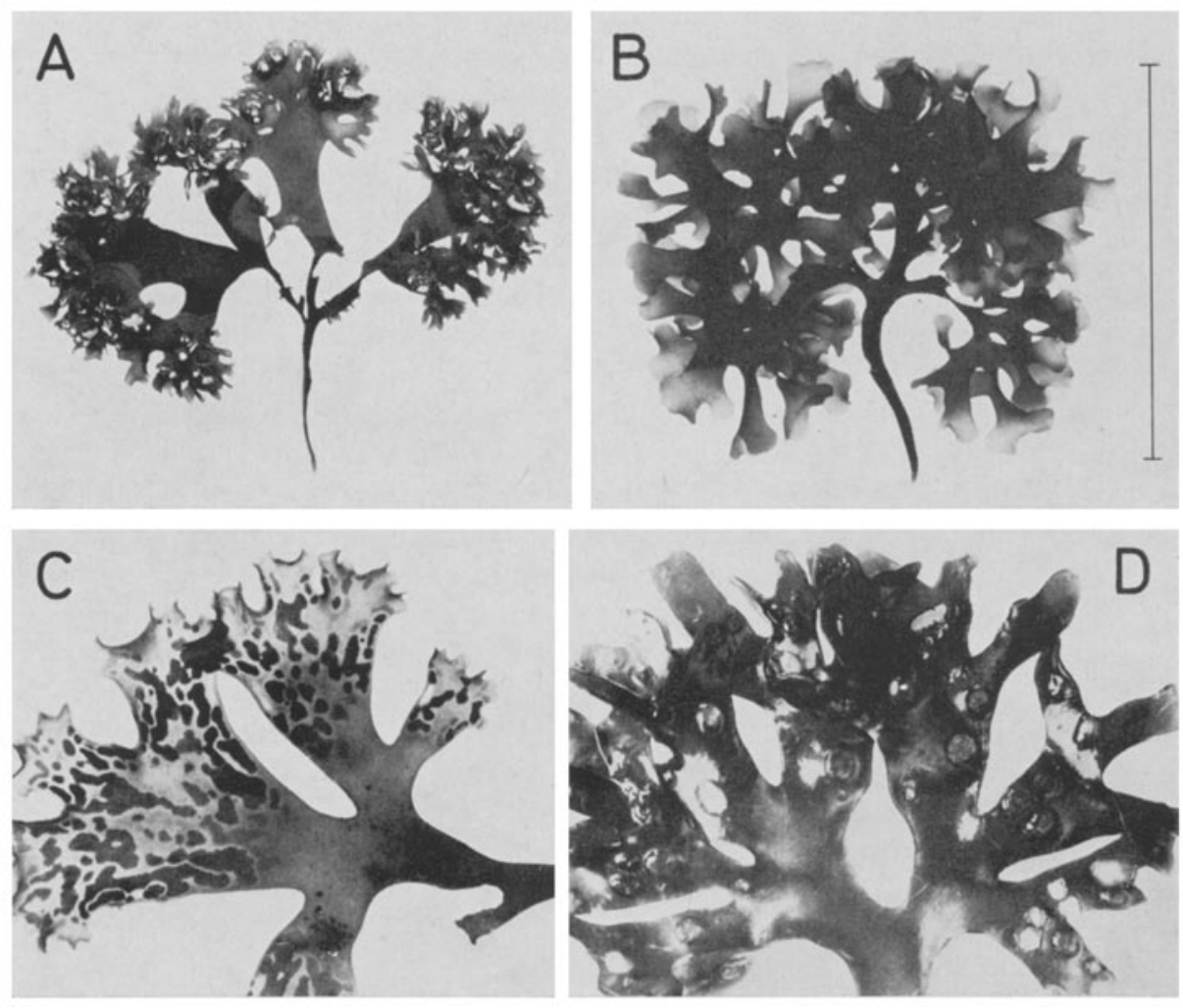

Abb. 113: Chondrus crispus. A, B Variabilität der Erscheinungsform. C Thallusende mit Tetrasporangiensori (3. 6. 1971). D Weibliche Pflanze mit Zystokarpien, einige bereits entleert (27. 8. 1975). Maßstrecke: $A, B=10 \mathrm{~cm}$ 


\section{CRYPTONEMIALES}

Corallinaceae

Durch Einlagerung von Kalk in die Zellwände ist der Thallus hart und brüchig; er besteht bei den meisten hier vertretenen Gattungen aus einer auf dem Substrat festgewachsenen dorsiventralen Kruste. Bei Corallina (p. 206) erhebt sich ein aufrechter, gegliederter Sproß auf einer krustig ausgebreiteten Basalscheibe.

Die Bestimmung der Krustenalgen erfordert eine anatomische Untersuchung entkalkten Materials mit den klassischen Methoden der mikroskopischen Technik, die über den Bau des Thallus und der Vermehrungsorgane Aufschluß gibt; dabei sind die Merkmale der ungeschlechtlichen Konzeptakeln besonders wichtig. Die wenigen im Gebiet um Helgoland vorkommenden Arten lassen sich aber - besonders in den Wintermonaten, in denen die ungeschlechtlichen Konzeptakeln reifen - auch nach äußerlich sichtbaren Merkmalen mit Hilfe eines Präpariermikroskops und Vergleichen mit den beigegebenen Abbildungen identifizieren. Im Litoral kommen auf Steinen drei $P b y$ matolithon-Arten vor. Ph. lenormandii (p. 210) trifft man schon in einer Zone an, in der sonst wenig mehr als Ralfsia verrucosa wächst; auf den von Fucus serratus bedeckten Schichtflächen und in flachen Mulden gesellen sich Ph. laevigatum (p. 213) und Ph. polymorphum (p. 213) hinzu. Alle drei Arten gehen im Sublitoral auf 5-6 m herunter. Ebenfalls auf Steinen, aber nur im Sublitoral wurde in $2 \mathrm{~m}$ Tiefe Lithophyllum orbiculatum angetroffen (p. 215), daneben Lithothamnium sonderi (p. 215), das auch noch in mehr als $11 \mathrm{~m}$ Tiefe vorkommt. Von den epiphytischen Corallinaceae besiedelt Dermatolithon pustulatum (p. 206) die Stiele und Haftkrallen älterer Laminaria byperborea; Melobesia membranacea (p. 209) findet man ziemlich regelmäßig auf den Haftkrallen von Laminaria byperborea und L. saccharina.

Die klimatischen Bedingungen Helgolands schränken eine allzı üppige Entfaltung der Kalkalgen in der Gezeitenzone ein. Bei winterlichen Ostwetterlagen mit weit ablaufendem Wasser sind die trockenliegenden Krusten mitunter viele Stunden lang niedrigen Temperaturen ausgesetzt und gehen zugrunde; besonders Corallina und Phymatolithon polymorphum werden dann völlig weiß. Ungeschädigt überdauern nur die in flachen Mulden in Wasser untergetauchten oder von Fucus serratus bedeckten Bestände. Es ist aber erstaunlich, wie weitgehend sich die Populationen während der Sommermonate, der Zeit ihres intensiven vegetativen Wachstums, erholen können.

Die auf Steinen wachsenden krustenförmigen Corallinaceen der englischen Küsten fanden durch Adey \& Adey (1973) eine ausführliche Darstellung mit Bestimmungsschlüsseln. Die roten Krustenalgen mit Ausschluß der Corallinaceen wurden von Denizot (1968) eingehend bearbeitet. 


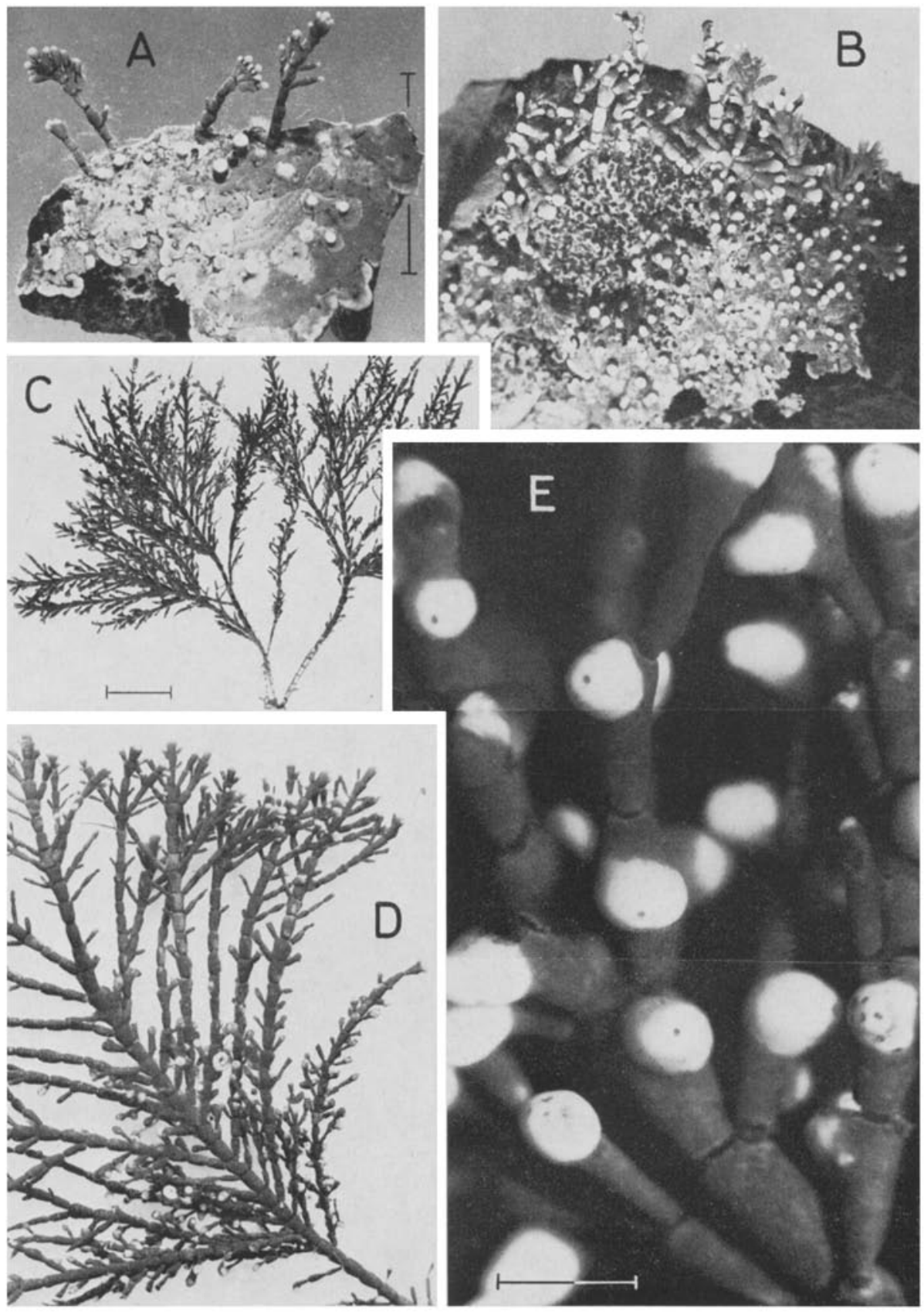

Abb. 114: Corallina officinalis. A, B Basalkrusten mit jungen knopfartigen und gegliederten Sprossen (21. 4. 1976). C, D Fertile Thalli, bei D mit zwei Wohnröhren des PosthörnchenRöhrenwurms Spirorbis (11. 6. 1976 und 8. 10. 1969). E Ausschnitt aus C, Konzeptakeln endständig oder seitlich. Maßstrecken: $A, B=1 \mathrm{~cm} ; C=1 \mathrm{~cm} ; E=1 \mathrm{~mm}$ 


\section{Corallina officinalis L.}

Auf einer ausgebreiteten verkalkten Kruste erheben sich zahlreiche gegliederte aufrechte Thalli; in ganz jungem Zustand erscheinen sie als kugelige oder ovale Knöpfchen auf dem Basallager (A, B). Die Stämmchen sind ziemlich regelmäßig opponiert verzweigt; die Zweige entspringen aus kleinen Höckerchen am oberen Ende der verkalkten, etwas abgeflachten Glieder. Diese sind durch unverkalkte Gelenke miteinander verbunden.

Die Konzeptakeln entstehen entweder terminal an den Enden kürzerer oder längerer Zweige oder als adventive seitliche Auswïchse an den Gliedern (D, E). Sie werden als muldenförmige Vertiefung angelegt und von den Randpartien überwachsen. Meist findet man ungeschlechtliche Individuen; die diözischen Geschlechtspflanzen sind selten.

Corallina officinalis ist in Gezeitentümpeln oder flachen wasserführenden Mulden verbreitet. Im Sublitoral kommt sie bis zu einer Tiefe von etwa $5 \mathrm{~m}$ vor.

\section{Dermatolithon pustulatum (Lamour.) Fosl.}

Haftrallen und Stiele alter Laminaria byperborea tragen of auffallende, lilafarbene dünne Krusten mit weißlichem Anflug, mitunter werden die Stiele davon fast eingehïllt (B). In einem solchen einheitlich erscheinenden Überzug sind die ursprünglich rundlichen bis nierenförmigen Individuen miteinander verschmolzen; die Krusten überwachsen einander, wie ein Querschnittsbild mit eingelagerten Konzeptakelresten zeigt (H). Wo die Ränder junger Krusten sich berühren, entsteht eine leichte Felderung (A). Selbst Krusten von kaum mehr als $1 \mathrm{~mm}^{2}$ sind schon als Dermatolithon zu erkennen, solche von 4-5 mm Durchmesser können 4 oder mehr Konzeptakeln tragen. Die Konzeptakeln sind flach warzenförmig mit einer Mündung (C, F). In den Sporangien aller untersuchten Pflanzen wurden nur Bisporen beobachtet.

Auf den Krallen von Laminaria byperborea kommt Dermatolithon häufig zusammen mit Melobesia membranacea vor, deren dünne Krusten (D, unten) von dem kräftigeren Dermatolitbon überwachsen werden. Junge epiphytische Krusten (E) sind durch ihren weißlichen Anflug und die Größe ihrer Zellen leicht von Melobesia zu unterscheiden ( $\mathrm{E}$ ). Ebenso ist der nierenförmige Keimling auf Melobesia membranacea in Abb. 116 D, E ohne weiteres als Dermatolithon anzusprechen.

Abb. 115: Dermatolithon pustulatum. A Jüngere Krusten auf einem Stiel von Laminaria hyperborea mit Bryozoen und Epiphyten, schwach vergrößert (3. 8. 1976). B Altere Krusten, den Laminaria-Stiel fast umhïllend, schwach verkleinert (3.8.1976). C Aufsicht auf die Kruste mit Konzeptakeln. D Dermatolitbon zusammen mit Melobesia membranacea (unten) auf einer Kralle von Laminaria sacharina (29.4.1976). E Junge Dermatolithon-Kruste auf Melobesia membranacea (25.2.1976). F Wie C, stärker vergrößert. G, H Querschnitte durch eine jingere und eime ältere Kruste mit ubberwachsenen Konzeptakeln; Handschnitte nach Entkalkung. Maßstrecken: $\mathrm{C}, \mathrm{D}=1 \mathrm{~mm} ; \mathrm{E}, \mathrm{F}=500 \mu \mathrm{m} ; \mathrm{G}=100 \mu \mathrm{m} ; \mathrm{H}=300 \mu \mathrm{m}$ 

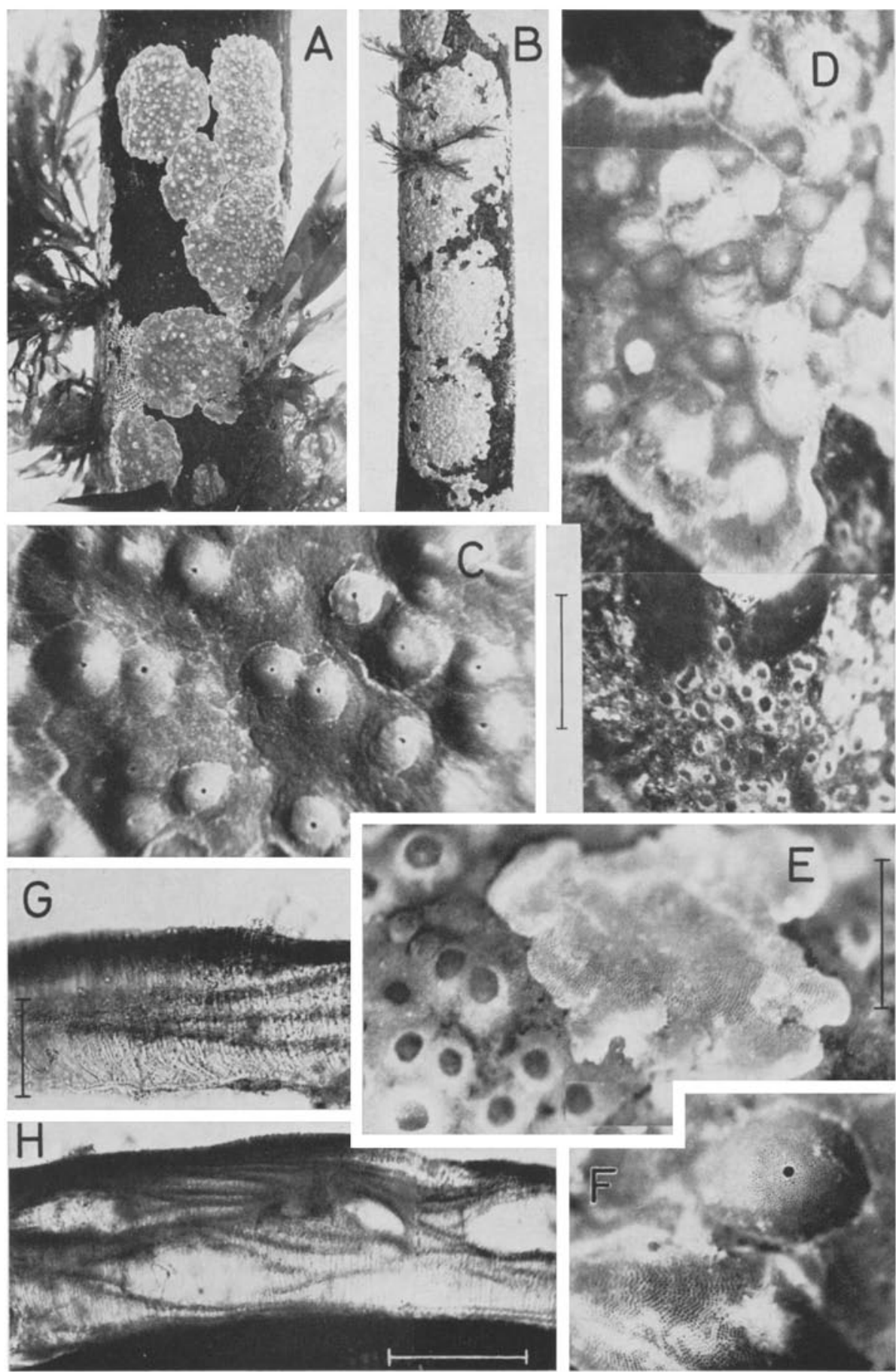


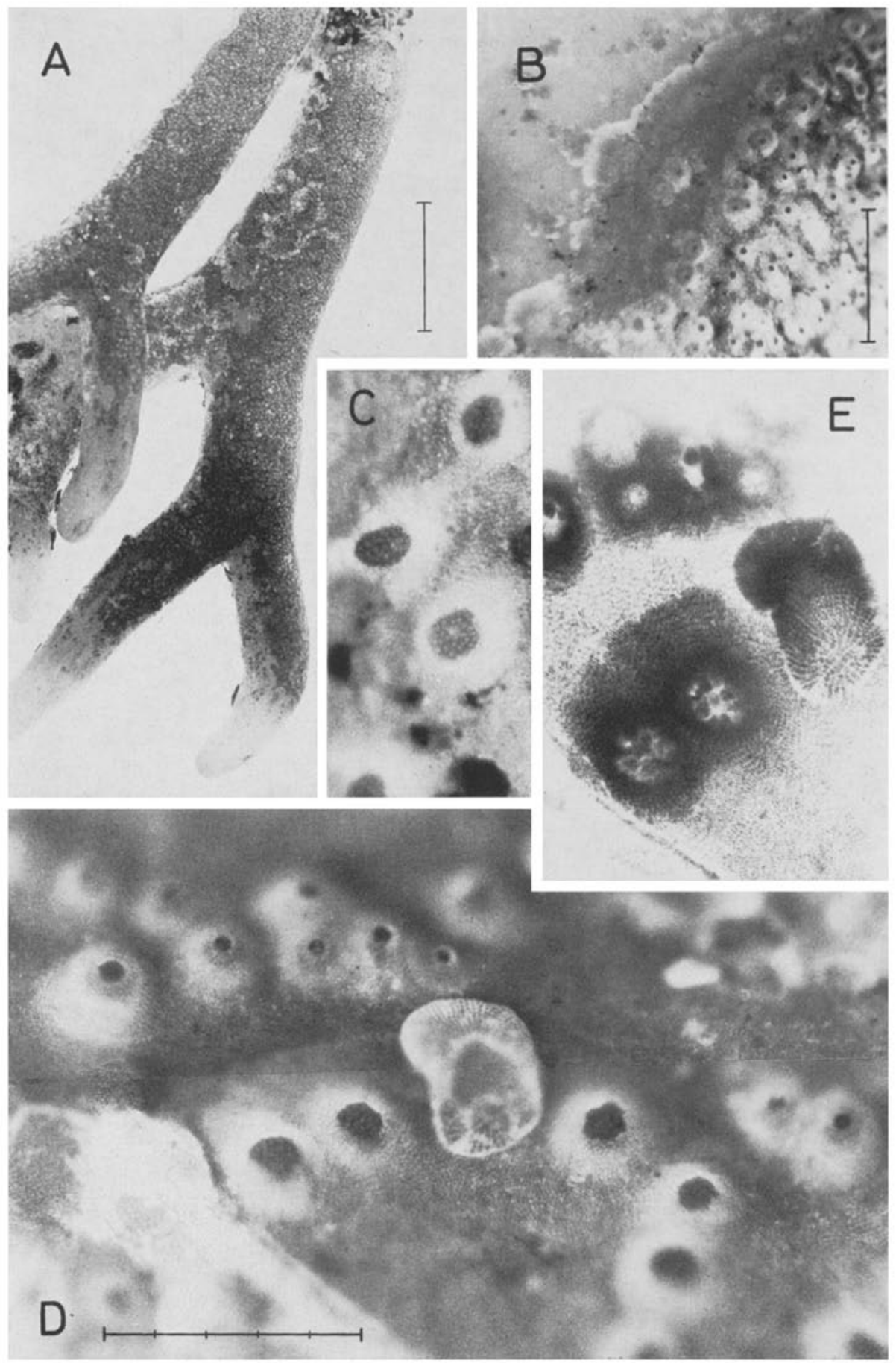

Abb. 116: Melobesia membranacea. A Krusten auf jungen Krallen von Laminaria byperborea (7. 8. 1976). B Rand einer Kruste mit (meist) gesdlechtlidhen Konzeptakeln (29. 4. 1976). C Ungeschlechtliche Konzeptakeln. D Ein Sporophyt mit Dermatolitbon-Keimling überwächst eine Gametophytenkruste (9.8. 1976). E Flächenschnitt aus D, lebend. Maßsstrecken: $A=1 \mathrm{~cm}$; $B=1 \mathrm{~mm} ; \mathrm{C}-\mathrm{E}=500 \mu \mathrm{m}$ 


\section{Melobesia membranacea (Esper) Lamour.}

Auf den Haftkrallen von Laminaria byperborea ist Melobesia membranacea neben Dermatolithon pustulatum ziemlich regelmäßig zu finden, doch bedarf es genauer Beobachtung, um die sehr zarten, etwas rötlichen Krusten zu crkennen (116 A). Schon bei 20 facher Vergrößerung zeigt sich die Oberfläche bis in die Nähe des wachsenden Randes übersät von rötlichen warzenförmigen Konzeptakeln (B). Das Dach der ungeschlechtlichen Konzeptakeln ist von 10 bis 25 Poren durchbrochen ( $C$ und $D$ unten); die Konzeptakeln der Geschlechtsgeneration haben nur eine Mündung ( $B$ und D oben). Nach der Sporenentleerung degenerieren die Konzeptakeln zu kraterartigen Höhlungen.

Tangentiale Schnitte von lebendem oder besser noch entkalktem Material lassen Einzelheiten an den Konzeptakeln erkennen. Abb. $116 \mathrm{D}$ und E zeigen Ausschnitte einer Kruste in der Aufsicht und als Lebendpräparat; durch den epiphytischen Dermatolithon-Keimling sind die einander entsprechenden Areale markiert. In der Höhlung unter den Porendächern liegen zonal geteilte Tetrasporangien, stärker vergrößert
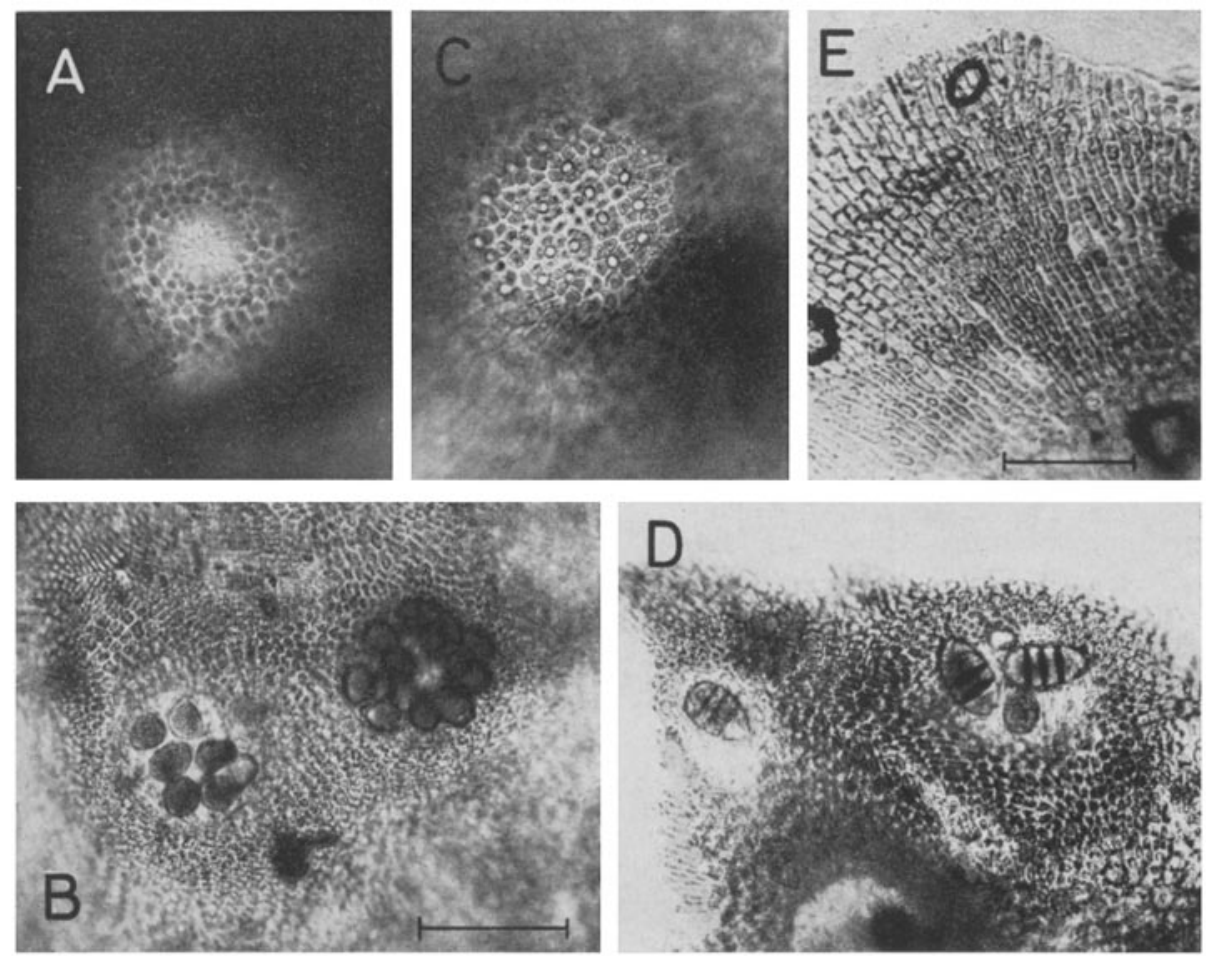

Abb. 117: Melobesia membranacea. A, B Weibliche Konzeptakeln nach Entkalkung; Porus und Karposporen. C, D Ungeschlechtiche Konzeptakeln nach Entkalkung; Porenplatte und Tetrasporangien. E Vegetative Kruste auf Eihülle von Agonus. Maßstrecken: A-D $=100 \mu \mathrm{m}$; $\mathrm{E}=50 \mu \mathrm{m}$ 
in einem entkalkten Präparat Abb. 117 C, D. Die einporigen Konzeptakeln enthalten Karposporen, vgl. Abb. 117 A, B.

Neben anderen Kleinalgen kann sich Melobesia membranacea auch auf Eiern von Agonus cataphractus ansiedeln, die als dichte Ballen zwischen den Haftikrallen von Laminaria abgelegt werden. Auf diesem durchsichtigen Substrat läßt sich der nur wenig verkalkte Thallus in lebendem Zustand selbst bei stärkerer Vergrößerung gut studieren (Abb. $117 \mathrm{E})$.

Im allgemeinen wird Furcellaria als Wirtspflanze von Melobesia membranacea angegeben. Das triff auch für Helgoland zu, und auf diesem Substrat ist die Kruste leicht zu erkennen. Während aber Furcellaria nur wenig verbreitet ist, steht der Epiphyt auf den Krallen von Laminaria byperborea reichlich zur Verfügung.

\section{Pbymatolithon lenormandii (Aresch. in J. Ag.) Adey}

Von den drei Phymatolithon-Arten hat Ph. lenormandii in der Gezeitenzone die größte vertikale Verbreitung. An ihrer oberen Grenze triff man kleine Krusten schon auf der ziemlich kahlen, fast nur von Ralfsia verrucosa besiedelten Fläche an. Im Bereich von Fucus serratus werden die Krusten ausgedehnter, besonders auf den geneigten Schichtflächen und an deren steiler Stirnseite. Die meist grau-violette Kruste ist an ihrer rauhen, körnig-schuppigen Oberfläche leicht zu erkennen; diese Struktur kommt durch die oft dicht gedrängten Konzeptakeln und das Mosaik blattartiger vegetativer Auswüchse aus der oberen Thallusschicht zustande (A). Die peripheren Teile frisch wachsender Krusten sind dagegen glatte, etwas ausgebuchtete, abgerundete Lappen mit einem weißen Rand.

Die Konzeptakeln erheben sich als flach-halbkugelige Hügel ïber die Oberfläche; meist findet man Sporophyten, das oft leicht eingedrückte Dach ihrer Konzeptakeln ist von 20 bis 45 Poren durchsetzt (B, C). Häufig verschmelzen zwei oder auch drei Konzeptakelgruben miteinander. Die Ränder überständiger Konzeptakeln bleiben als Krater sichtbar, bevor sie überwachsen werden.

Die Konzeptakeln der Gametophyten sind ebenfalls nahezu halbkugelig vorgewölbt und haben eine zentrale Offnung (D). Sie kommen nicht auf den gleichen Pflanzen vor wie die ungeschlechtlichen, wenn auch ihr Ineinanderwachsen diesen Anschein erwecken mag.

Abb. 118: Phymatolithon lenormandii. A Aufsicht auf eine Kruste mit Konzeptakeln und vegetativen Auswüchsen (21. 4. 1976). B, C Thallusausschnitte mit ungeschlechtlichen, D mit geschlechtlichen Konzeptakeln. $A=1 \mathrm{~cm} ; \mathrm{B}, \mathrm{D}=1 \mathrm{~mm}, \mathrm{C}=500 \mu \mathrm{m}$ 

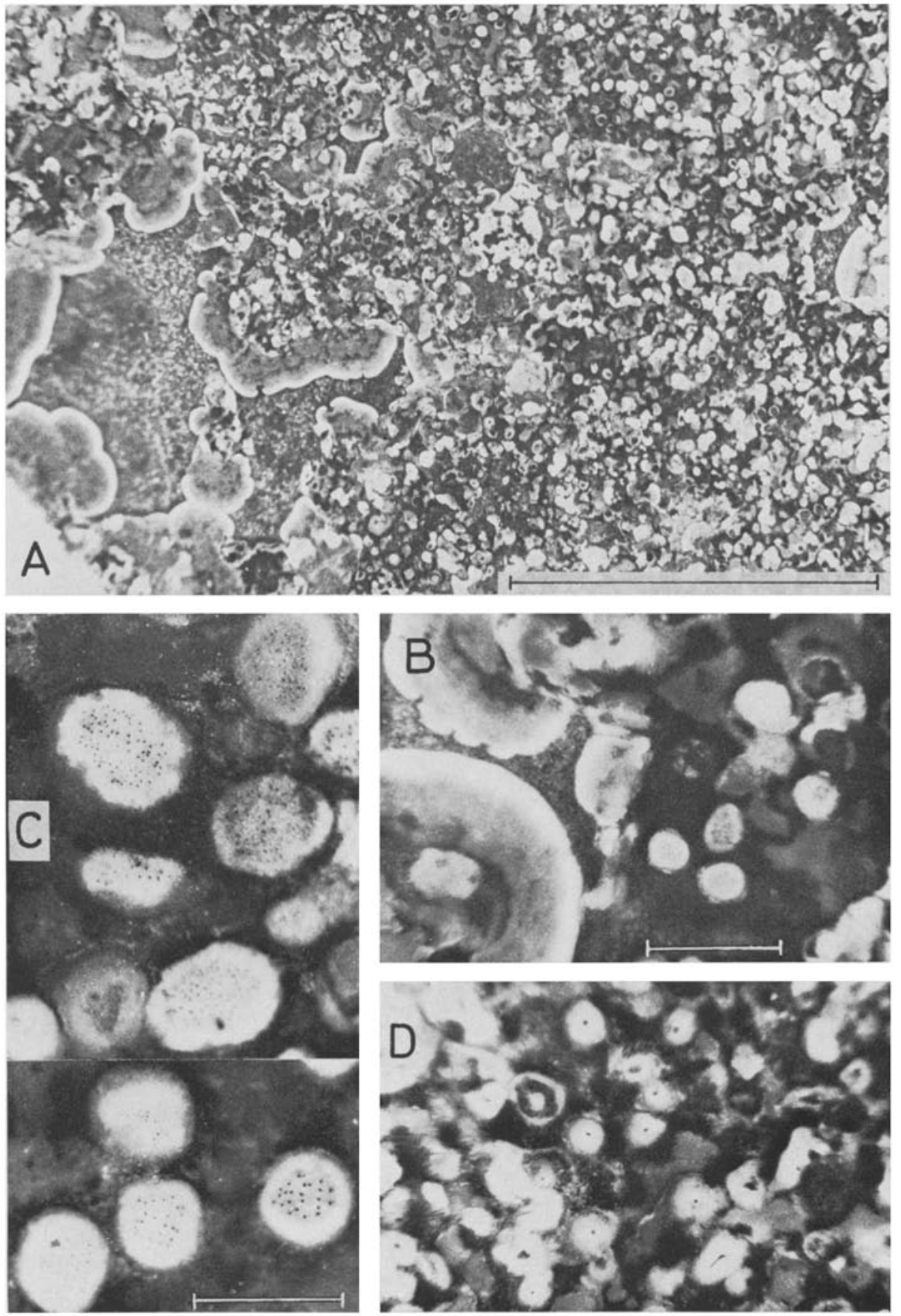

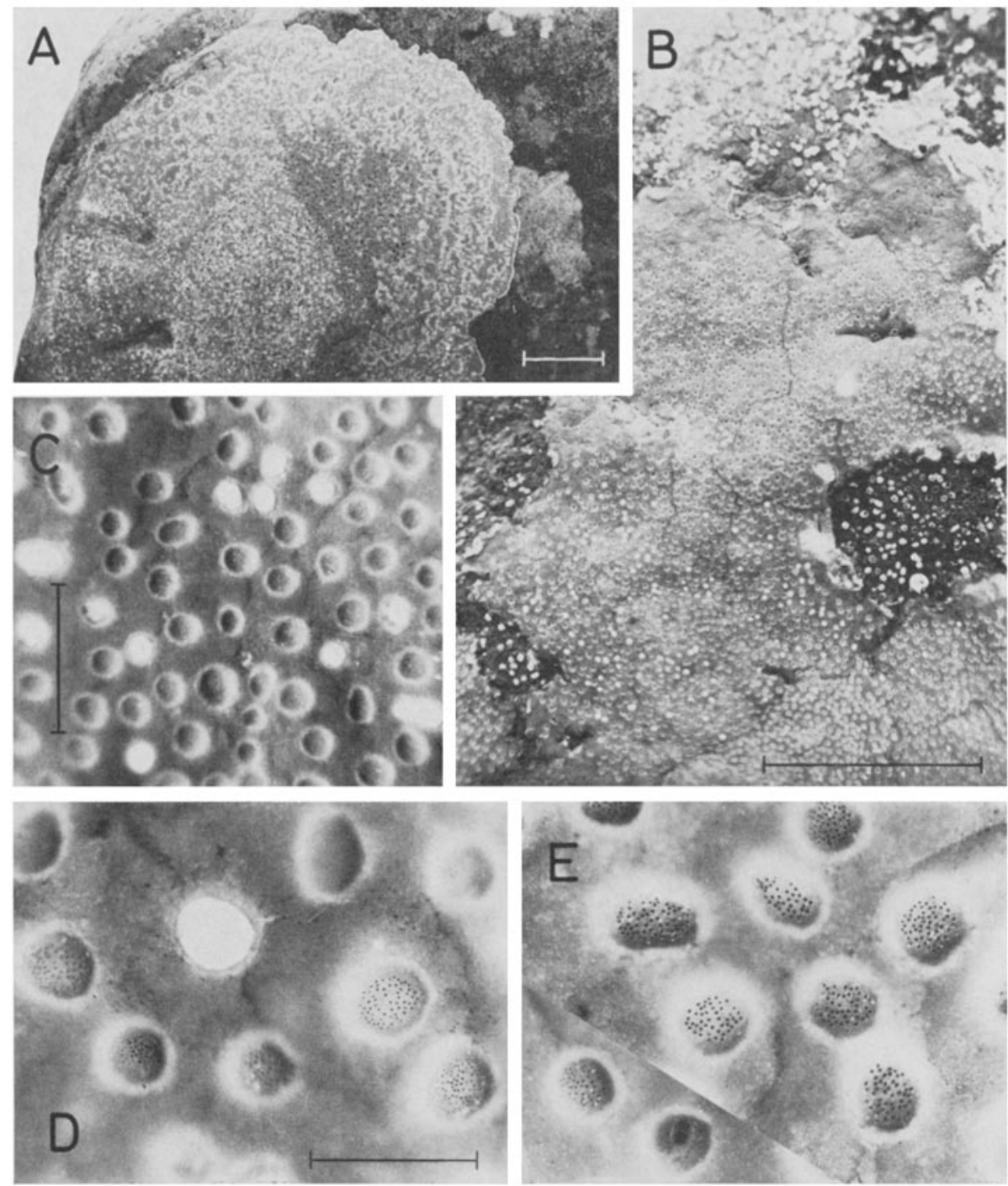

Abb. 119: Pbymatolithon laerigatum. A Kruste auf einem Stein rom Nordost-Felswatt (8. 3. 1976). B Zusammen mit Lithothamnium sonderi aus $6 \mathrm{~m}$ Tiefe (19. 2. 1976). C-E Ungeschlechtliche Konzeptakeln, einige noch mit Kalkdeckeln, bei $\mathrm{E}$ ein ausgetretenes Bisporangium. Maßsstrecken: $A, B$ jeweils $=1 \mathrm{~cm} ; C=1 \mathrm{~mm} ; D, E=500 \mathrm{~km}$ 


\section{Phymatolithon laevigatum (Fosl.) Fosl.}

Pbymatolithon laevigatum kommt in der unteren Gezeitenzone gern in flachen Mulden vor, gemeinsam mit $\mathrm{Ph}$. polymorphum und $\mathrm{Ph}$. lenormandii. Auf dem bei $\mathrm{B}$ abgebildeten Stein aus $6 \mathrm{~m}$ Tiefe wächst $P h$. laevigatum zusammen mit Lithotbamnitum sonderi (oben sowie links und rechts). Die oft ausgedehnten rötlich-violetten Krusten haben eine ebene Oberfläche, die aber, besonders in Randnähe, durch unregelmäßige, leicht erhabene Grate oder rundliche Hügelchen häufig ein ganz charakteristisches Relief erhält (A).

Die ungeschlechtlichen Konzeptakeln sind als Gruben in den Thallus eingesenkt und von einem nur flach über die Oberfläche erhöhten Ring umgeben (C-E). Dicht nebeneinanderliegend bedecken sie oft die ganze Fläche bis auf einen schmalen vegetativen Saum. Vor ihrer Reife sind sie mit einer weißen Deckschicht verschlossen, die als Ganzes herausbricht (C, D). Erst dann wird das leicht vertiett liegende Konzeptakeldach sichtbar, eine Porenplatte mit etwa 50 bis 60 Offnungen $(D, E)$. In den ungeschlechtlichen Konzeptakeln werden Bisporen gebildet.

\section{Phymatolithon polymorphum (L.) Fosl.}

Phymatolithon polymorphum ist die im unteren Gezeitenbereich auffälligste Krustenalge. Sie bildet in flachen Mulden und auf harten Schichtflächen unter Fucus serratus ausgedehnte frohwüchsige Scheiben. Die Farbe ist ein kräftiges Rosa bis Bräunlichrot, in der Randzone etwas mehr rötlich. Die Kante der dicken Kruste ist weiß. Wachsen zwei Thalli gegeneinander, so kräuseln sich ihre Ränder in einer weißen Falte hoch, die sich etwa $2 \mathrm{~mm}$ über die Fläche erhebt (A).

In den Wintermonaten findet man die Krusten dicht mit Konzeptakeln bedeckt. Sie sind in den Thallus eingesenkt; die einporigen geschlechtlichen erheben sich als flache Hügelchen über die Oberfläche (E, F). Die ungeschlechtlichen Konzeptakeln sind von einem ausgeprägt erhabenen Wall umgeben und vor ihrer Reife mit einem dicken Kalkdeckel verschlossen (B, C). Am Grunde eines ziemlich tiefen Kraters wird das Porendach sichtbar, unter dem sich die Konzeptakelhöhlung ausweitet. Dies veranschaulichen die an einer Bruchkante erzielten Bilder (D). Unten links ist ein Konzeptakel etwa median durchbrochen; das Bild oben rechts zeigt die angeschnittene Höhlung unter einem Porendach. 

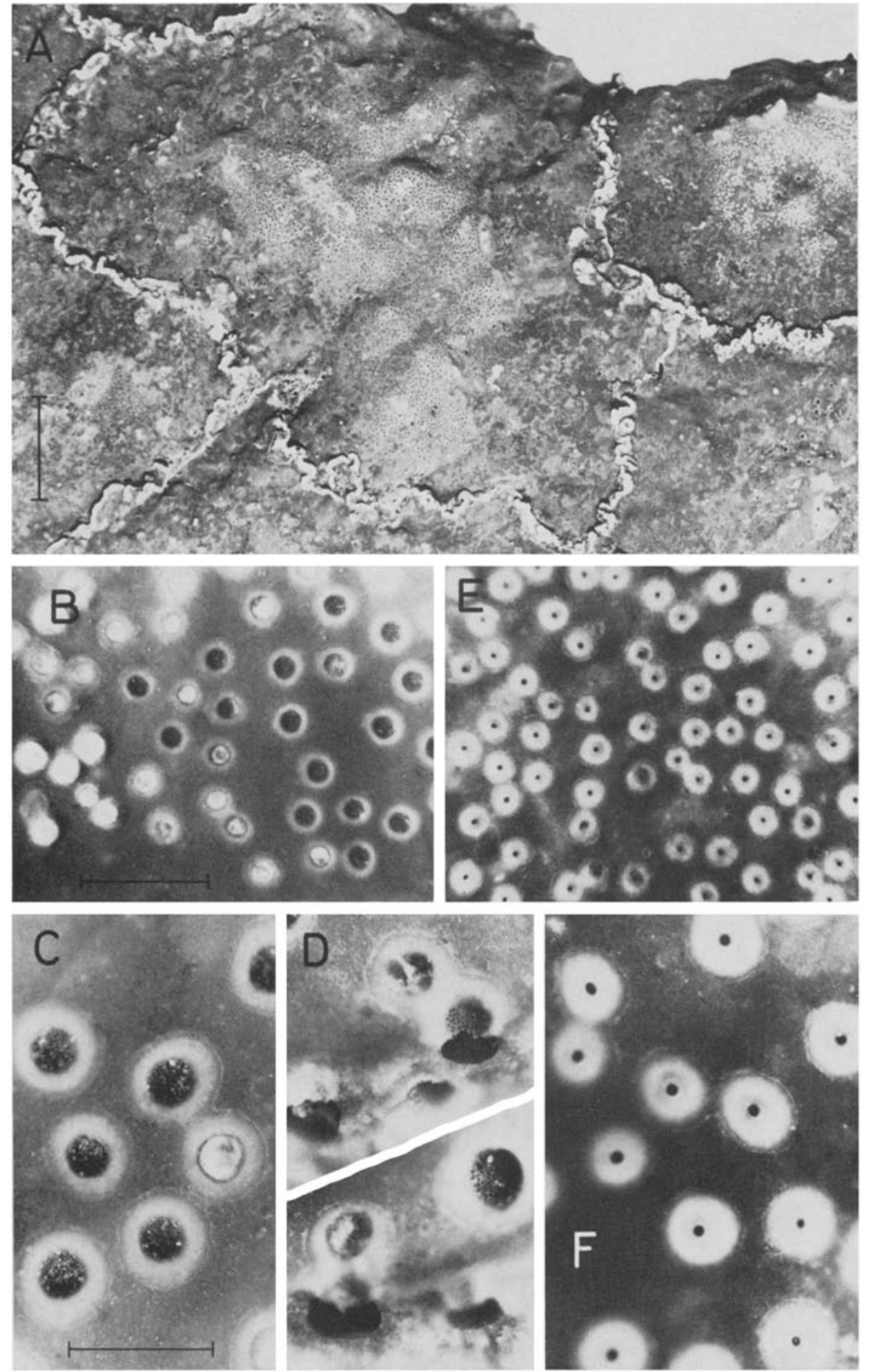


\section{Lithophyllum orbiculatum (Fosl.) Fosl.}

Die nur einmal auf Steinen in $2 \mathrm{~m}$ Tiefe gefundene Alge hat als einzige der bei Helgoland beobachteten epilithischen Corallinaceen ungeschlechtliche Konzeptakeln mit nur einer Offnung (C). Für diesen Nachweis genügt ein Flächenschnitt von leicht entkalktem Material (D, E).

Die Kruste fiel durch ihre grauviolette Farbe und etwas schuppig-höckerige Oberfläche auf (A). Bei stärkerer Vergrößerung ließen diese Schuppen einen nur schwach über die Oberfläche erhabenen Porus erkennen (B, C). Die ganz in den Thallus eingesenkten Konzeptakeln enthielten Tetrasporangien (E).

\section{Lithotbamnium sonderi Hauck}

Lithotbamnium sonderi überzieht als dünne rosarote Kruste meist kleinere Geröllsteine in Tiefen von 2 bis $11 \mathrm{~m}$. Die Oberfläche ist im allgemeinen glatt, kann aber zuweilen auch höckerig-warzig sein. Die Art ist leicht an ihren ganz charakteristischen Konzeptakeln zu erkennen. Die nur flach in den Thallus eingesenkten Gruben erheben sich mit ihrer weißen Wandung weit über die Oberfläche (A). Die halbkugelig bis kegelförmigen geschlechtlichen Konzeptakeln haben einen deutlichen Porus (B, C). Die ungeschlechtlichen, in denen Tetrasporangien gebildet werden, sind etwas flacher. Bei der Reife wird die einschichtige Decke abgestoßen und das siebartig durchlöcherte Konzeptakeldach sichtbar (D, E). Nach dem Zerbrechen der hinfälligen Konzeptakeln bleibt ein weißer Randring bestehen (F).

Abb. 120: Phymatolitbon polymorphum. A Gegeneinanderwachsende Krusten mit aufgekräuseltem Rand. Die feinen Poren sind Höhlungen bereits entleerter Konzeptakeln, die größeren Mündungen der Wohnröhren des Polychaeten Polydora ciliata $(6.3 .1976)$. B, C Ungeschlechtliche Konzeptakeln, zum Teil mit Kalkdedseln (19.11. 1976). D Konzeptakeln an der Bruchkante einer Kruste; Näheres im Text. E, F Geschlechtliche Konzeptakeln (19. 11. 1976). Maßstrecken: $\mathrm{A}=1 \mathrm{~cm} ; \mathrm{B}, \mathrm{E}=1 \mathrm{~mm} ; \mathrm{C}, \mathrm{D}, \mathrm{F}=500 \mathrm{~mm}$ 

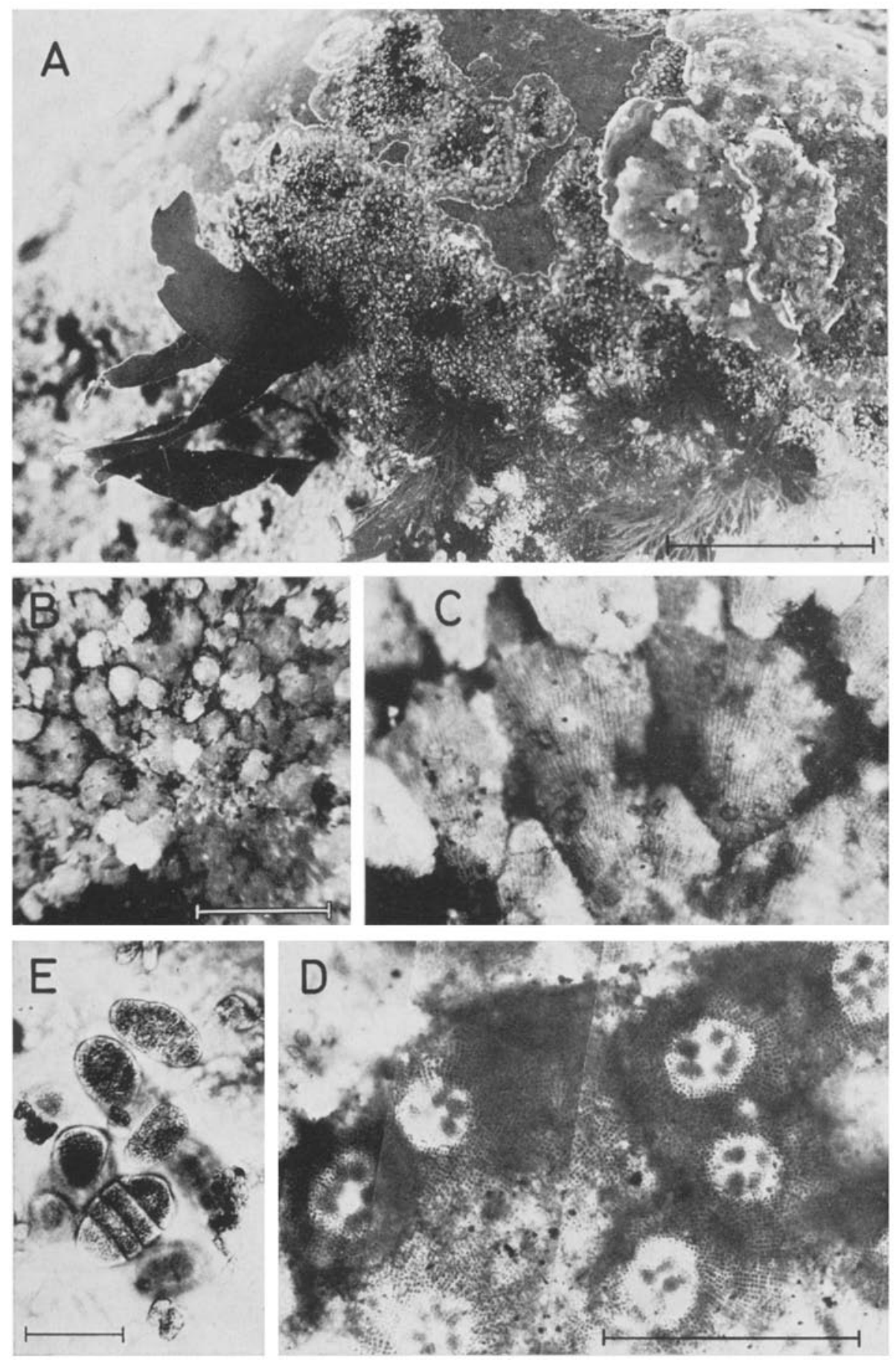

Abb. 121: Lithopbyllum orbiculatum. A Unregelmäßige, aus mehreren Pflanzen zusammengewachsene Kruste aus $2 \mathrm{~m}$ Tiefe (13. 9. 1976). B, C Aufsicht auf die fertile Kruste. D Flächenschnitt durch entkalktes Material mit ungeschlechtlichen Konzeptakeln. E Tetrasporangien. Maßstrecken: $\mathrm{A}=1 \mathrm{~cm} ; \mathrm{B}=1 \mathrm{~mm} ; \mathrm{C}, \mathrm{D}=500 \mu \mathrm{m} ; \mathrm{E}=50 \mu \mathrm{m}$ 

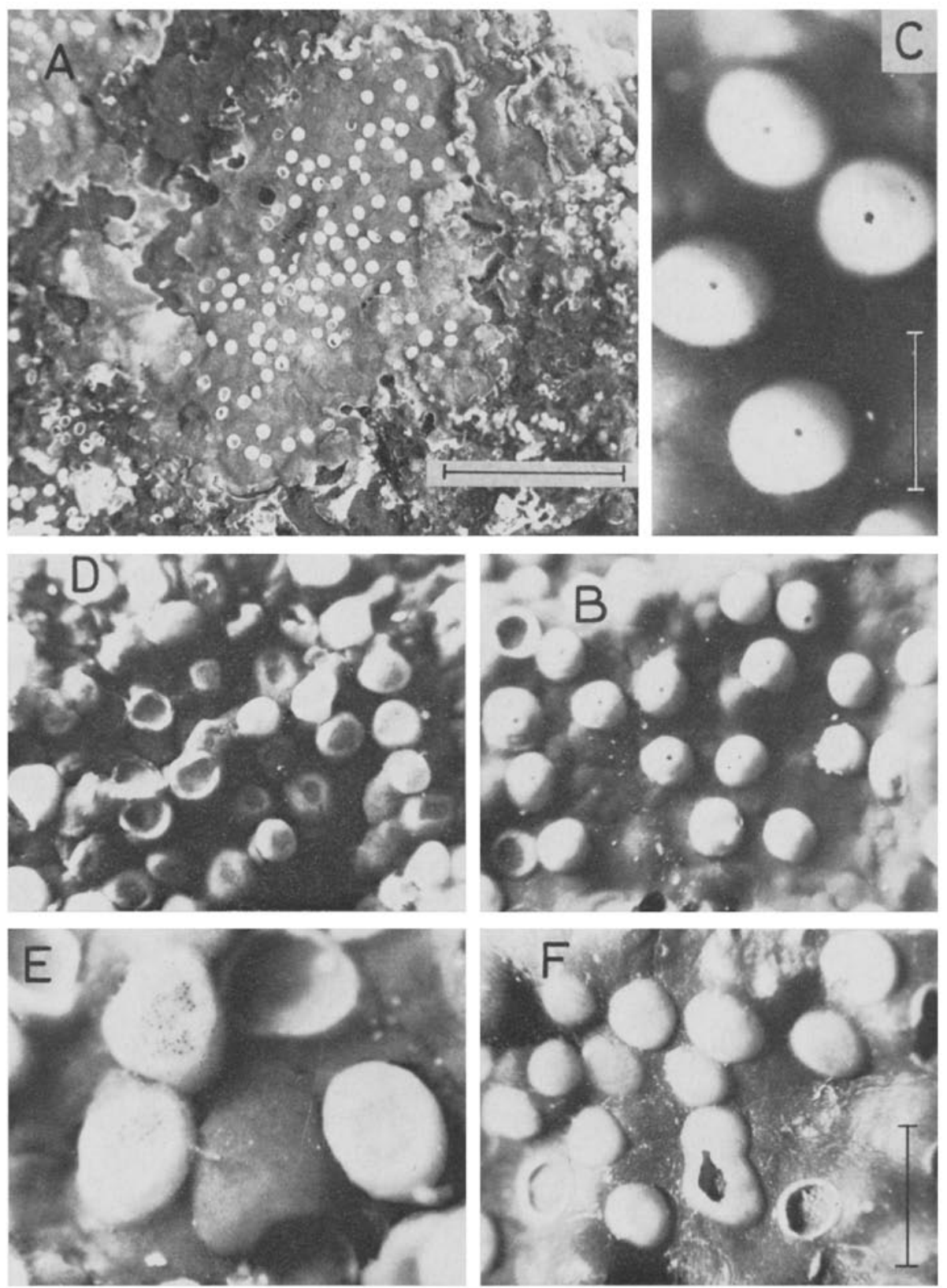

Abb. 122: Lithothamnium sonderi. A Kruste mit Konzeptakeln auf einem Stein aus $6 \mathrm{~m}$ Tiefe (19. 2. 1976). B, C Geschlechtliche Konzeptakeln. D-F Ungeschlechtliche Konzeptakeln, bei einigen ist nur noch der Rand erhalten ( $F$ aus $11 \mathrm{~m}$ Tiefe, 10. 3. 1976). Maßstrecken: $A=5 \mathrm{~mm}$; $\mathrm{B}, \mathrm{D}, \mathrm{F}=1 \mathrm{~mm} ; \mathrm{C}, \mathrm{E}=500 \mu \mathrm{m}$ 
Dumontia incrassata (O. F. Müll.) Lamour.

Während der ersten Jahreshälfte gehört Dumontia incrassata zu den häufigen Algen in der unteren Gezeitenzone. In manchen Jahren kann man junge Pflanzen, wie sie bei A dargestellt sind, schon im Januar finden. Mehrere aufrechte Sprosse erheben sich auf einer gemeinsamen Haftscheibe; die runde Hauptachse ist mehr oder weniger dicht mit kurzen dünnen Seitenzweigen besetzt. An solchen Sproßenden läßt sich der Aufbau der Alge klar erkennen: Sie wird von einem langzelligen zentralen Achsenfaden durchzogen, dessen Zweige fortschreitend kleinzelliger werden und zu einer Rinde zusammenschließen.

Bei den ausgewachsenen Pflanzen tritt die Hauptachse oft nicht mehr deutlich in Erscheinung, sie kann von den Seitenzweigen überwachsen sein. Der hohle Thallus der weichen, etwas gallertigen Alge flacht sich ab und gleicht einem verdrehten Band. Während ihrer vollen Entwicklung, im April bis Juni, bedecken die Pflanzen oft größere Felsflächen als einzige Besiedler und liegen wie gekämmt auf dem Boden. Ihre Farbe ist schmutzig braunrot, mit zunehmender Einstrahlung im Juni heller oder gar grünlich braun.

Ab Mitte Juni beginnt die von der Spitze zur Basis fortschreitende Degeneration der Thalli. Dabei werden auch die in der Rindenschicht eingelagerten kreuzgeteilten Tetrasporangien (C, D) und entsprechend auch die Gonimoblasten frei. Bis Ende Juli kann man noch 3 bis $4 \mathrm{~cm}$ hohe basale Reste der Pflanze finden, mitunter stark von Epiphyten, meist Ceramium rubrum, besetzt.

\section{Choreocolacacea}

\section{Harveyella mirabilis (Reinsch) Reinke}

In manchen Jahren tritt diese parasitische Rotalge von Januar bis April so häufig auf, daß sie dem Sammler nicht entgehen wird. Sie kommt auf beiden RhodomelaArten vor, doch wird man sie meist auf der im Felswatt verbreiteten $R h$. confervoides finden. Es sind weiße, etwa 1 bis $2 \mathrm{~mm}$ große, nahezu kugelige Knötchen, die ihre Wirtspflanze vereinzelt oder zahlreich besiedeln.

Die verzweigten Zellfäden des Parasiten durchdringen interzellular den Thallus ihrer Wirtspllanze, in deren Zellen sie Haustorien entsenden. Uber die Biologie von Harveyella haben Goff \& Cole (1973) und Goff (1976) ausführlich berichtet; es sind hier nur Teil 1 und 5 einer Serie von Arbeiten zitiert. 

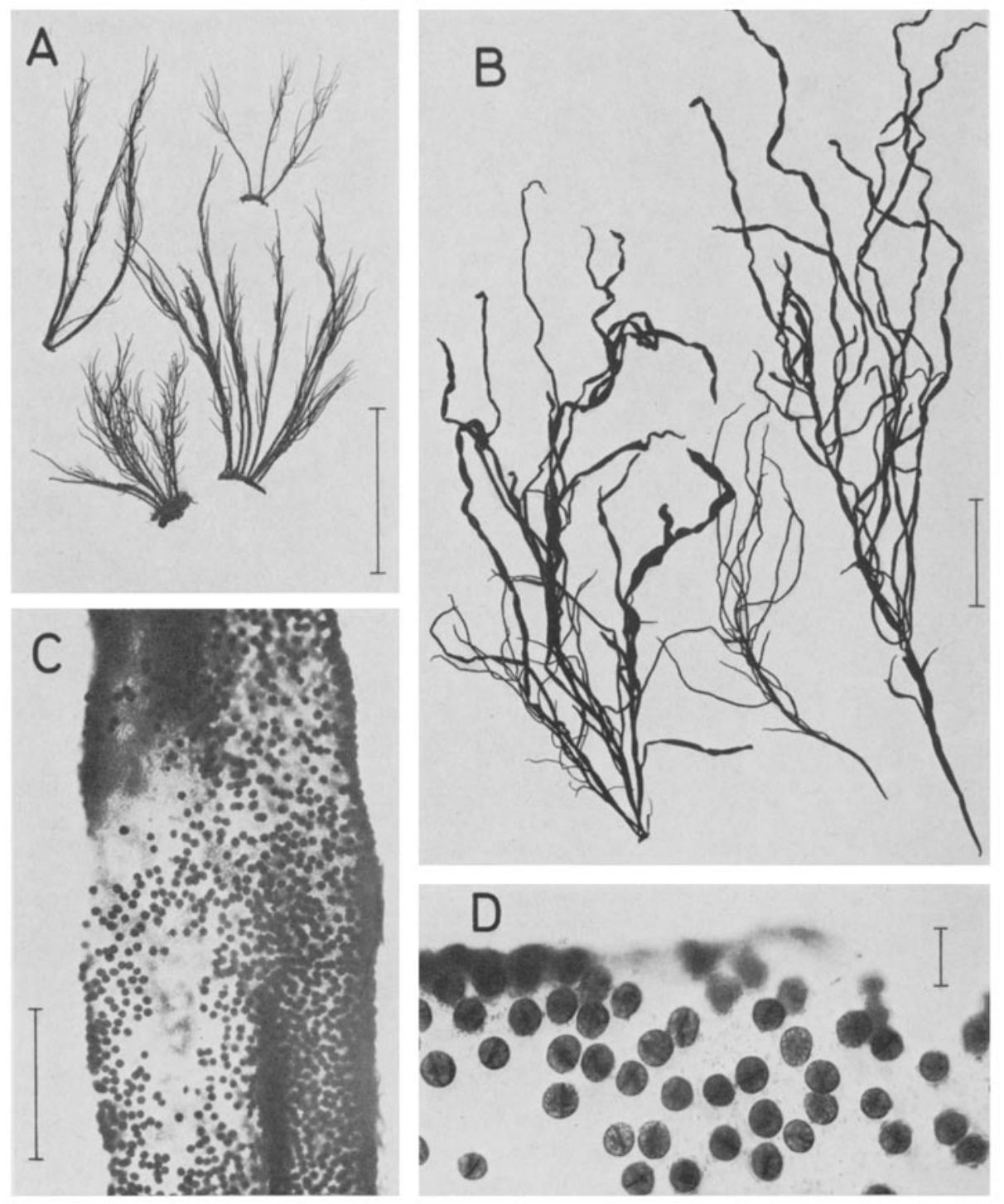

Abb. 123: Dumontia incrassata. A Junge Pflanzen (26. 2. 1970). B Ausgewachsene Pflanzen (25. 4. 1973). C, D Thallusstïcke mit Tetrasporangien (29. 5. 1971). Maßstrecken: A, B jeweils $=2 \mathrm{~cm} ; \mathrm{C}=1 \mathrm{~mm} ; \mathrm{D}=100 \mu \mathrm{m}$ 


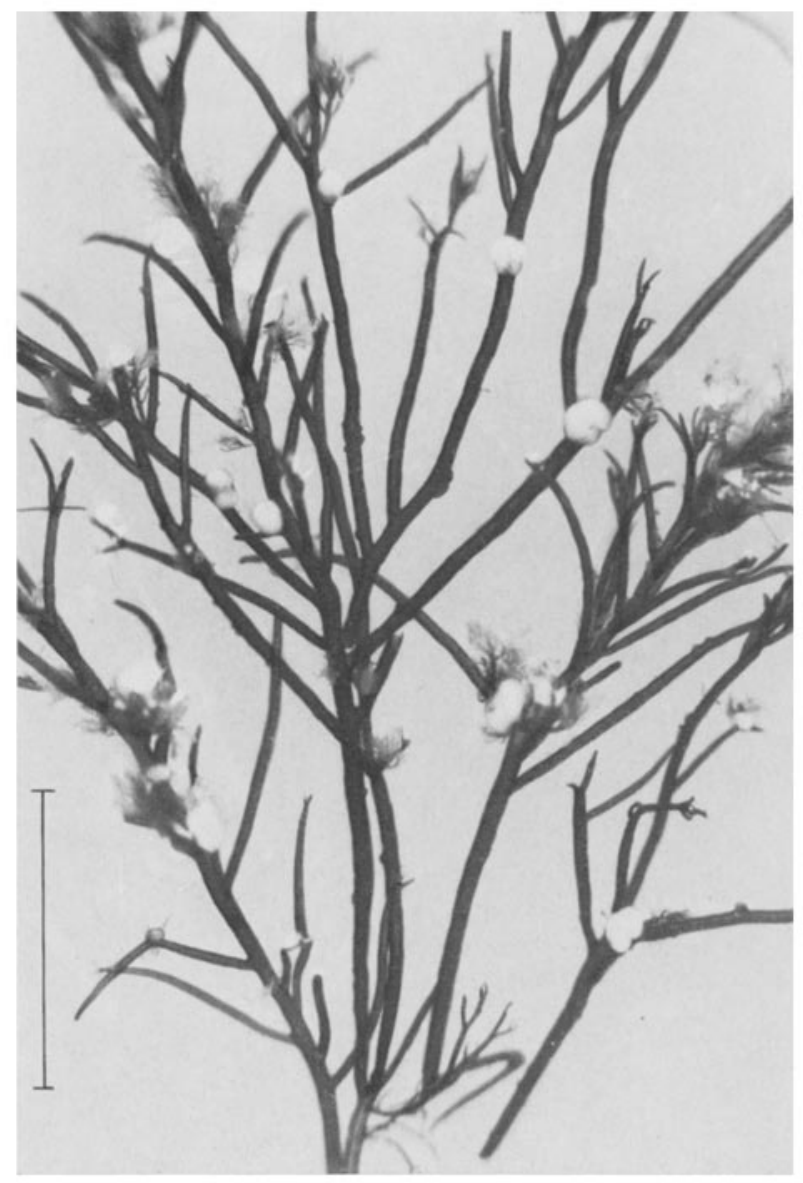

Abb. 124: Harveyella mirabilis auf Rhodomela confervoides (28. 2. 1974). Ma\}sstrecke $=1 \mathrm{~cm}$

\section{Peyssonneliaceae}

Peyssonnelia dubyi Crouan frat.

Die dunkelpurpurroten dünnen Krusten wachsen sublitoral in mehreren Meter Tiefe auf Steinen und auf den Haftkrallen von Laminaria byperborea. Junge Krusten sind rundlich, später können sie sich unregelmäßig ausbreiten. Der Thallusrand ist leicht ausgebuchtet (B). Ein Querschnitt zeigt fest aneinanderschließende Reihen groBer, etwa isodiametrischer Zellen (C). 
Die Oberfläche fertiler Pflanzen trägt graurote, etwas warzenförmige Nemathezien (A), zwischen deren Paraphysen die Fortpflanzungsorgane eingelagert sind. Die kurzgestielten Tetrasporangien sind kreuzgeteilt (D); die Nemathezien weiblicher Pflanzen enthalten bei der Reife gereiht liegende, große kugelige Karposporen (E).
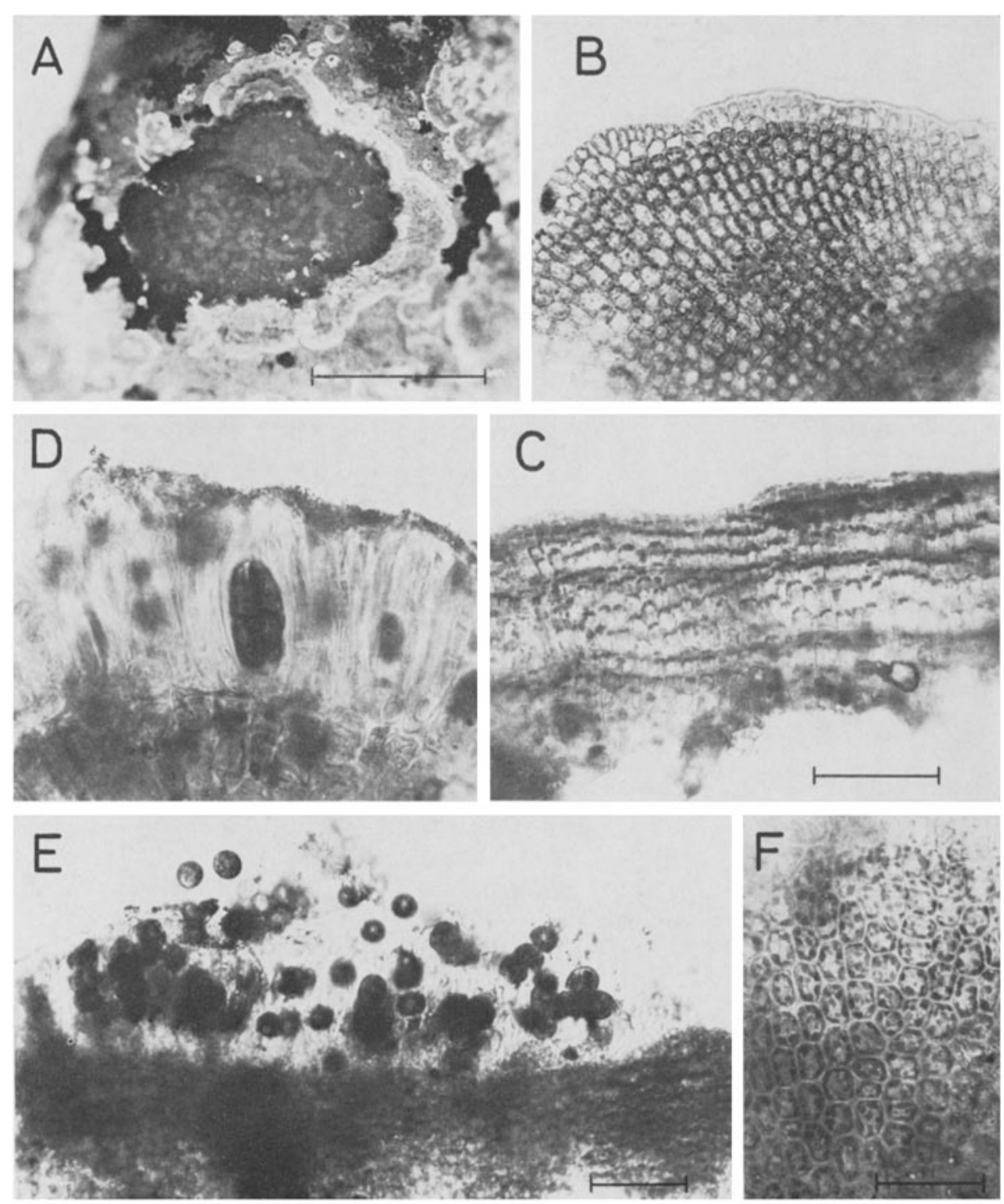

Abb. 125: Peyssonnelia dubyi. A Thallus mit Nemathezien auf einer Pbymatolitbon-Kruste (28. 6. 1976). B, C Thallusrand und Querschnitt. D Nemathezium mit Tetrasporangium (10. 2. 1976). E Nemathezium mit reifen Karposporen (25. 3. 1976). F Aufsicht auf den vegetativen Thallus. Maßstrecken: $\mathrm{A}=1 \mathrm{~cm} ; \mathrm{B}, \mathrm{C}=100 \mu \mathrm{m} ; \mathrm{D}, \mathrm{F}=50 \mu \mathrm{m} ; \mathrm{E}=100 \mu \mathrm{m}$ 
Rbodophysema elegans (Crouan frat. ex J.Ag.) Dixon Bei Kuckuck (1897a) als Rbododermis parasitica Batters

Rhodophysema elegans ist auf Steinen in der Gezeitenzone nicht gerade häufig, aber in Gesellschaft der speckigen, fast schwarzen Krusten von Petrocelis bennedyi vereinzelt $z u$ finden. Im Spätherbst erreichen hier die glatten rundlichen Scheiben, die fest auf dem Substrat haften, einen Durchmesser von 3-4 cm. Die Farbe der dünnen
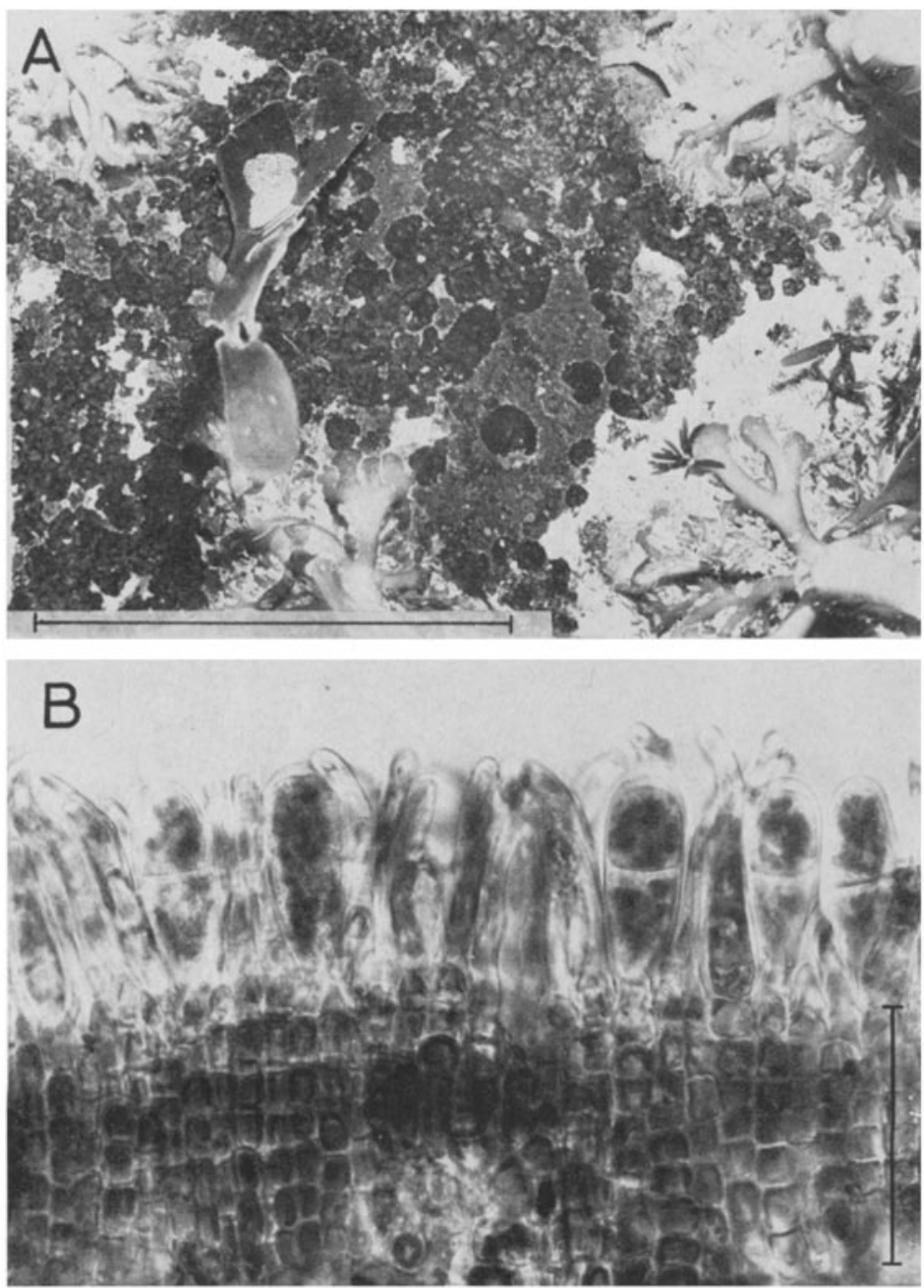

Abb. 126: Rhodopbysema elegans. A Stein mit jungen rundlichen Krusten auf einem älteren Lager, zusammen mit Laminaria digitata und Chondrus crispus (5. 3. 1976). B Querschnitt durch den fertilen Thallus. Maßstrecken: $\mathrm{A}=5 \mathrm{~cm} ; \mathrm{B}=50 \mu \mathrm{m}$ 
peripheren Partien ist leuchtend weinrot, in der Mitte sind die Krusten dunkelrot bis fast schwarz. Die äußere Ahnlichkeit könnte zu einer Verwechslung mit Hildenbrandia rubra führen, die aber an einem Oberflächenschnitt leicht zu erkennen ist (Abb. 127).

Das eigentliche Areal von Rhodopbysema ist jedoch das obere Sublitoral. Bei einem ungewöhnlich tiefen Niedrigwasser Anfang März 1976 fielen die Bestände von Laminaria digitata vor der Kurpromenade trocken. Viele der meist noch von Wellen überspülten Steine waren stark von den schwärzlichroten Krusten überzogen, die ineinanderfließend sich zu größeren Flächen vereinigten. Sie trugen zahlreiche junge rundliche Krusten von etwa 6 bis $10 \mathrm{~mm}$ Durchmesser (A). Sehr wahrscheinlich geht Rhodophysema in der Gezeitenzone in jedem strengen Winter durch Frost und Austrocknung zugrunde, ebenso wie die unbedeckt trockenfallenden Corallinaceen.

Das Querschnittsbild zeigt den aus vertikalen Reihen etwa isodiametrischer Zellen bestehenden Thallus. Die Oberfläche trägt in Nemathezien die von gekrümmten Paraphysen begleiteten Sporangien (B). In allen untersuchten Proben waren sie nur zweigeteilt; Kuckuck (1897a) bildet auch unregelmäßig kreuzgeteilte Tetrasporangien ab. Geschlechtliche Fortpflanzung ist nicht bekannt; Ganesan \& West (1975) untersuchten eine Population aus Kalifornien und exhielten aus den Tetrasporen eine in gleicher Weise fruktifizierende Generation. Das gleiche Ergebnis hatten auch Kulturversuche von South \& Whittick (1976) mit Material von Neufundland. Bisporangien und Monosporangien kamen reichlich neben Tetrasporangien vor; in den Kulturen entstanden meist Bisporangien und nur wenige Tetrasporen.

\section{Hildenbrandiaceae \\ Hildenbrandia rubra (Sommerf.) Menegh. syn. Hildenbrandia prototypus}

Die Krusten von Hildenbrandia sind in der Gezeitenzone weit verbreitet. Sie besiedeln hartes Gestein; Schichtflächen, auf denen auch Fucus serratus wächst und vorspringende Schichtköpfe sind oft von ausgedehnten Lagern der harten, braunroten Kruste überzogen. Besonders gern aber siedelt sich Hildenbrandia auf den in den Prielen zerstreut liegenden Feuersteinen an, auf denen sie sich nach Benetzung in vielen Farbabstufungen zeigt. Junge, noch ziemlich rundliche Thalli sind blutrot, mit zunehmender Dicke werden die Krusten weinrot und schließlich braunrot. Die Lager sind mehrjährig; durch Schnecken abgeweidete Krusten regenerieren leicht.

Der Thallus besteht aus vertikalen Reihen kleiner, fast kubischer Zellen, die dicht zusammenschließen (D). Das ganze Jahr über findet man die unter die Thallusoberfläche eingesenkten, etwa kugeligen Konzeptakeln mit apikaler Mündung (B, D). Es sind nur Tetrasporangien bekannt, die laufend an der Grubenwandung erneuert werden. Was man auf den Querschnittsbildern für Paraphysen halten könnte, sind leere Sporangienhülllen. Die Sporangien sind glasig-blaß, durch schräge Wände unregelmäßig aufgeteilt (D). In frischen Schnittpräparaten sieht man häufig Sporen eines oder mehrerer Tetrasporangien vor der Konzeptakelmündung liegen $(\mathrm{E})$. 

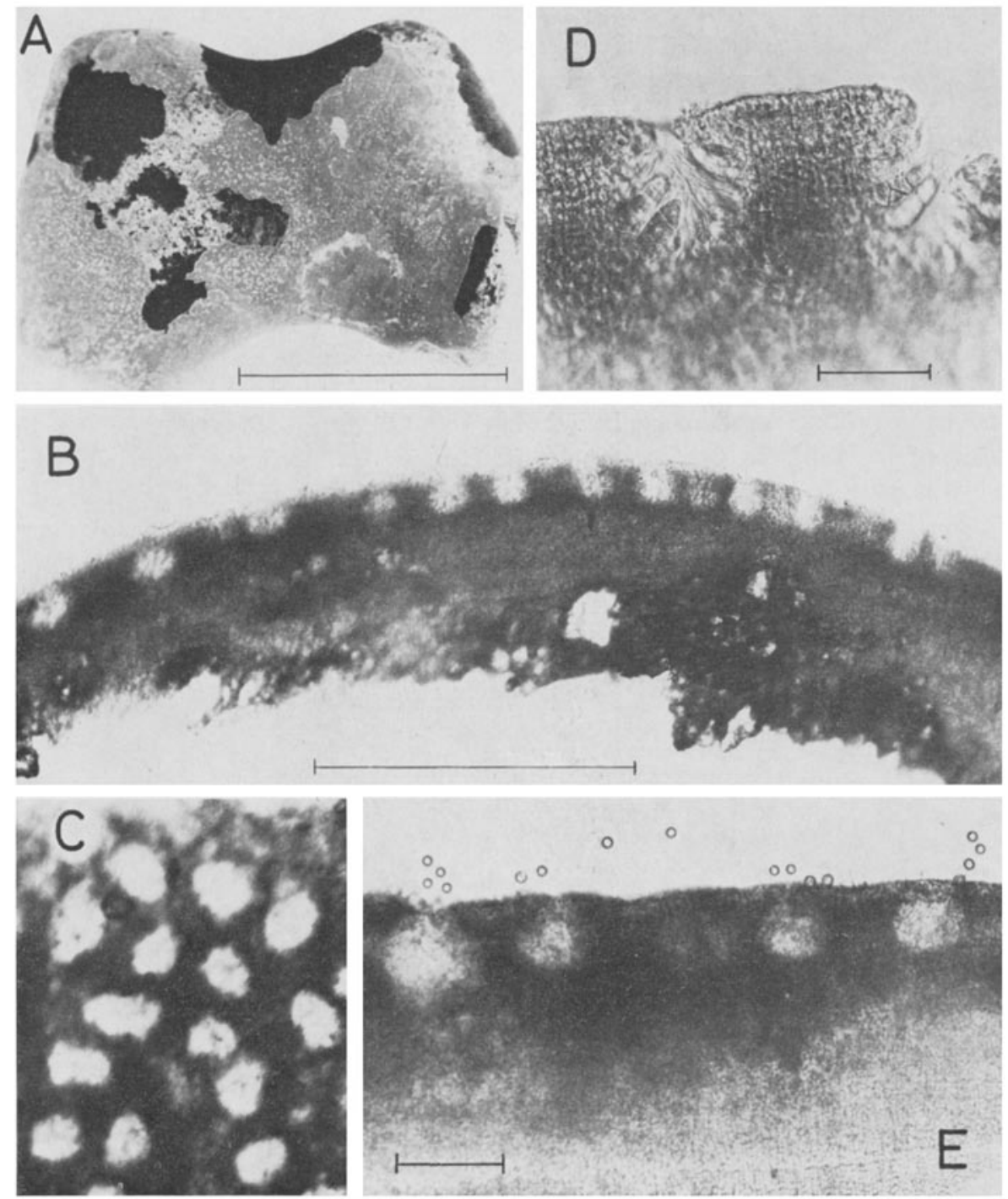

Abb. 127: Hildenbrandia rubra. A Auf einem Feuerstein zusammen mit Phymatolithon leavigatum (5. 3. 1976). B Querschnitt durch die Kruste mit Konzeptakeln. C Dünner Oberflächenschnitt, die Konzeptakel-Höhlungen sind hell. D Zwei Konzeptakeln mit Sporangien und leeren Sporangienhüllen. E Frisches Schnittpräparat mit ausgetretenen Tetrasporen. Maßstredken: $\mathrm{A}=$ $5 \mathrm{~cm} ; \mathrm{B}, \mathrm{C}=500 \mu \mathrm{m} ; \mathrm{D}=50 \mu \mathrm{m} ; \mathrm{E}=100 \mu \mathrm{m}$ 


\title{
RHODYMENIALES
}

\author{
Champiacea e
}

\section{Lomentaria clavellosa (Turn.) Gaill.}

Zwei Abbildungen zeigen die Variabilität der Erscheinungsform von Lomentaria clavellosa. Selbst größere Exemplare als das bei A dargestellte können das lockere und klare Muster einer nahezu gegenständigen Verzweigung haben. Die Alge kann aber bei etwas verbreiterten Achsen auch dicht büschelig verzweigt sein (B). Dieser Variation unterliegen die geschlechtliche und die ungeschlechtliche Generation in gleicher Weise wie sterile Pflanzen. Die schlaffen, etwas gallertigen Büschel von himbeerroter Farbe werden etwa $15 \mathrm{~cm}$ hoch. Die etwa $1 \mathrm{~mm}$ dicken Achsen sind meist rund und röhrig hohl, oft mit eingeschlossenen Luftblasen (D); sie können aber auch breiter und etwas abgeflacht sein. Die $Z$ weige sind an ihrer Basis deutlich verjüngt.

In Kratzmaterial von den Hafenmolen und auf Steinen aus 4 bis $7 \mathrm{~m}$ Tiefe ist Lomentaria clavellosa regelmäßig anzutreffen. Bei besonders niedrigem Wasser kann man sie auch an einigen schattigen Stellen zu Fuß erreichen. Geschlechtspflanzen und Tetrasporophyten kommen nebeneinander während des ganzen Jahres vor, sicherlich in mehreren Generationen. Die Tetrasporangien liegen in kleinen Sori in Gruben unter der Oberfläche jüngerer Zweige (D). Die Zystokarpien sitzen zerstreut mit breiter Basis den Ästchen auf, das Perikarp hat eine offene Mündung (E, F).

\section{Lomentaria orcadensis (Harv.) Coll. ex Taylor syn. Lomentaria rosea}

Lomentaria orcadensis ist eine Alge des Sublitorals, sie kommt erst in Tiefen unter $3 \mathrm{~m}$ vor. Sie wächst auf festem Substrat sowie epiphytisch auf den Stielen oder Haftkrallen von Laminaria hyperborea. Auch am unteren Teil von Bojen, die an Land gebracht werden, ist sie ziemlich regelmäßig anzutreffen. Am Strand wird man die 1 bis $2 \mathrm{~cm}$ hohen Pflänzchen nur gelegentlich an ausgeworfenen Laminarien finden.

Der rosafarbene, längliche, in der Mitte bis $0,5 \mathrm{~cm}$ breite blattartige Hauptsproß ist von ovalen bis länglichen Seitenblättchen gesäumt, ein Habitus, der die Alge eindeutig kennzeichnet. Als Fortpflanzungszellen sind nur Tetrasporangien bekannt, aus denen in unseren Kulturen wieder eine gleichartige Generation hervorging. Die Tetrasporangiensori liegen im allgemeinen in den Seitenblättchen in kleinen Vertiefungen unter der Thallusoberfläche, zuweilen aber auch unregelmäßig im Hauptsproß verteilt.

Lomentaria orcadensis wurde von Mai bis Dezember beobachtet, alle Aufsammlungen waren fertil. 

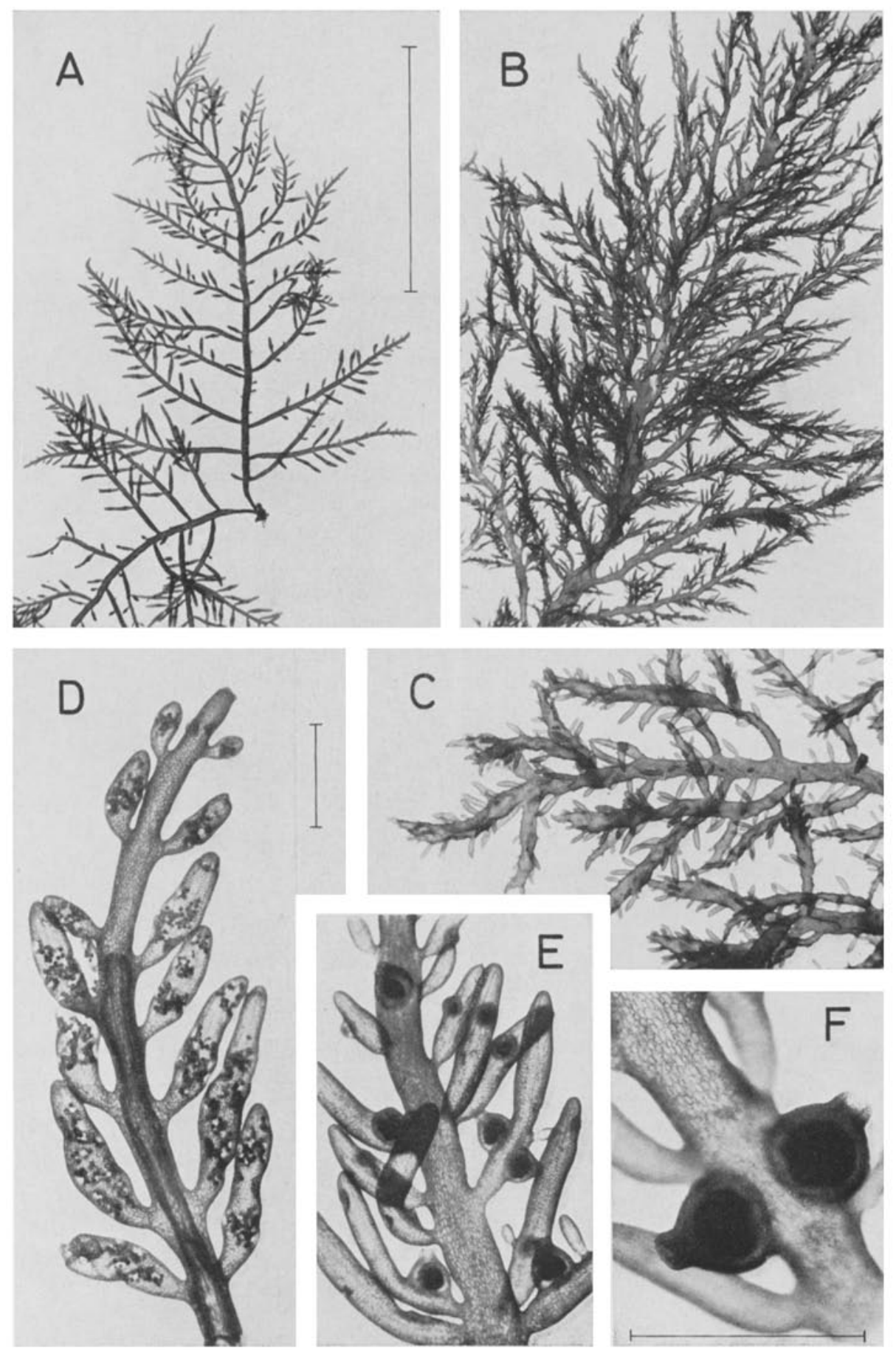

Abb. 128: Lomentaria clavellosa. A Wenig und ziemlich regelmäßig verzweigtes Exemplar, Tetrasporophyt $(28,9.1972)$. B, C Reichlich und unregelmäßig verzweigte Pflanzen (26. 6. 1971 und 4. 5. 1972). D Fiederästchen mit Tetrasporangiensori (1.8. 1973). E, F Zweigstücke mit Zystokarpien (1.8.1973). Maßsstrecken: $A, B=2,5 \mathrm{~cm} ; D, E=1 \mathrm{~mm} ; F=1 \mathrm{~mm}$ 


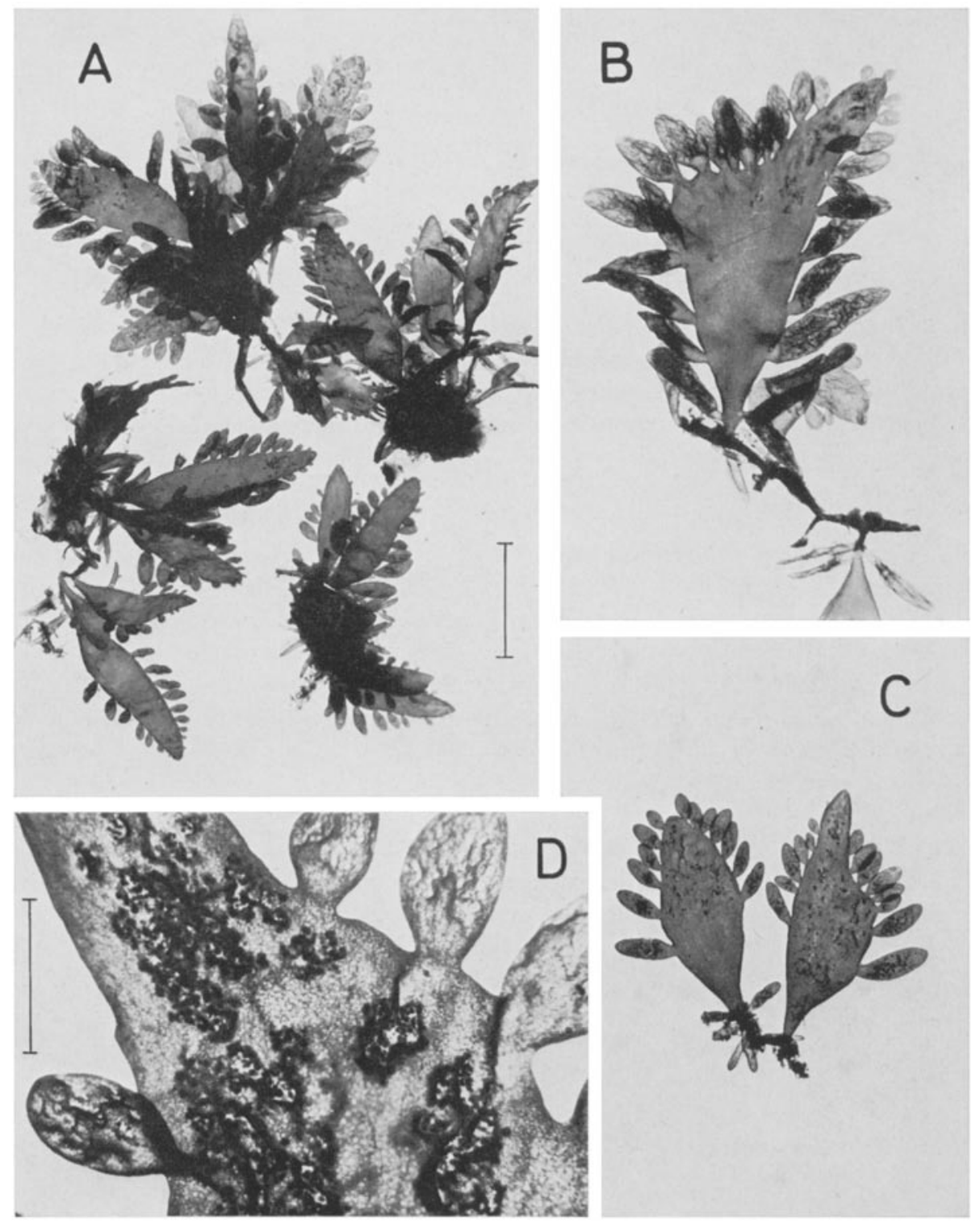

Abb. 129: Lomentaria orcadensis. A Pflanzen von einem Kabel im Nordosthafen aus 3-4 m Tiefe (9. 5. 1974). B Thallus mit fertilen Seitenblättchen. $C_{3} D$ Tetrasporangiensori in Hauptund Seitensprossen. Maßstrecken: $A=1 \mathrm{~cm} ; D=1 \mathrm{~mm}$ 


\section{CERAMIALES}

\section{Cer a miacea}

\section{Antithamnion plumula (Ellis) Thur. in Le Jolis}

Das schön rosafarbene Antithamnion plumula ist eine der zartesten und durch seine regelmäßige Verzweigung eine der zierlichsten Rotalgen unseres Gebietes. Die in einer Ebene verzweigten Thalli werden bis $\mathrm{zu} 10 \mathrm{~cm}$ hoch. Die unberindeten Hauptfäden tragen an allen Gliederzellen in weitem Winkel abstehend opponierte Zweige, mitunter auch ein weiteres Paar senkrecht dazu orientierter kurzer, dornartiger Astchen. Die Zweige verjüngen sich in eine spitze Endzelle; sie können auf ihrer Oberseite sekundäre Fiederchen oder unmittelbar fertile Ästchen tragen. Schon bei geringer Vergrößerung fallen die farblosen, stark lichtbrechenden Blasenzellen auf (bei B und D deutlich sichtbar), deren Funktion nicht bekannt ist.

Im allgemeinen sind die Tetrasporophyten die größeren und dichter verzweigten (A). Weibliche Gametophyten aus derselben Aufsammlung können sehr viel lockerer verzweigt sein (F); männliche Gametophyten bleiben meist kleiner, sie sind auch seltener. Die kreuzgeteilten Tetrasporangien sitzen an den Endzellen verzweigter Kurztriebe $(B, C)$. Ganz entsprechend bilden auch die Spermatangienstände kleine kugelige Büschelchen $(\mathrm{D}, \mathrm{E})$. Die paarig nahe den Sproßspitzen angelegten weiblichen Organe entwickeln sich zu unregelmäßigen, dichten, von lockeren Hüllfäden umgebenen Gonimoblasten $(\mathrm{F}-\mathrm{H})$.

Antithamnion plumula ist eine Alge des Sublitorals; in dem von Tauchern aus 6-7 m Tiefe besorgten oder von den Molenwänden gekratzten Material ist sie besonders im Juli und August regelmäßig in stattlichen Exemplaren anzutreffen. Junge Pflanzen wurden ab Mitte Mai beobachtet, mit Ausnahme von März und April ist Antithamnion das ganze Jahr über vorhanden.

Abb. 130: Antithamnion plumula. A Tetrasporophyt (30.8. 1969). B, C Zweigstücke mit Tetrasporangien und leeren Hüllen. D, E Zweigstïcke eines männlichen Gametophyten. F Weiblicher Gametophyt yon besonders lockerer Wudsform (30.8. 1969). G, H Zweigenden mit jungen und reifen Gonimoblasten. Maßstrecken: $A, F=2 \mathrm{~cm} ; B-D=200 \mu \mathrm{m} ; \mathrm{G}, \mathrm{H}=200 \mu \mathrm{m}$ 

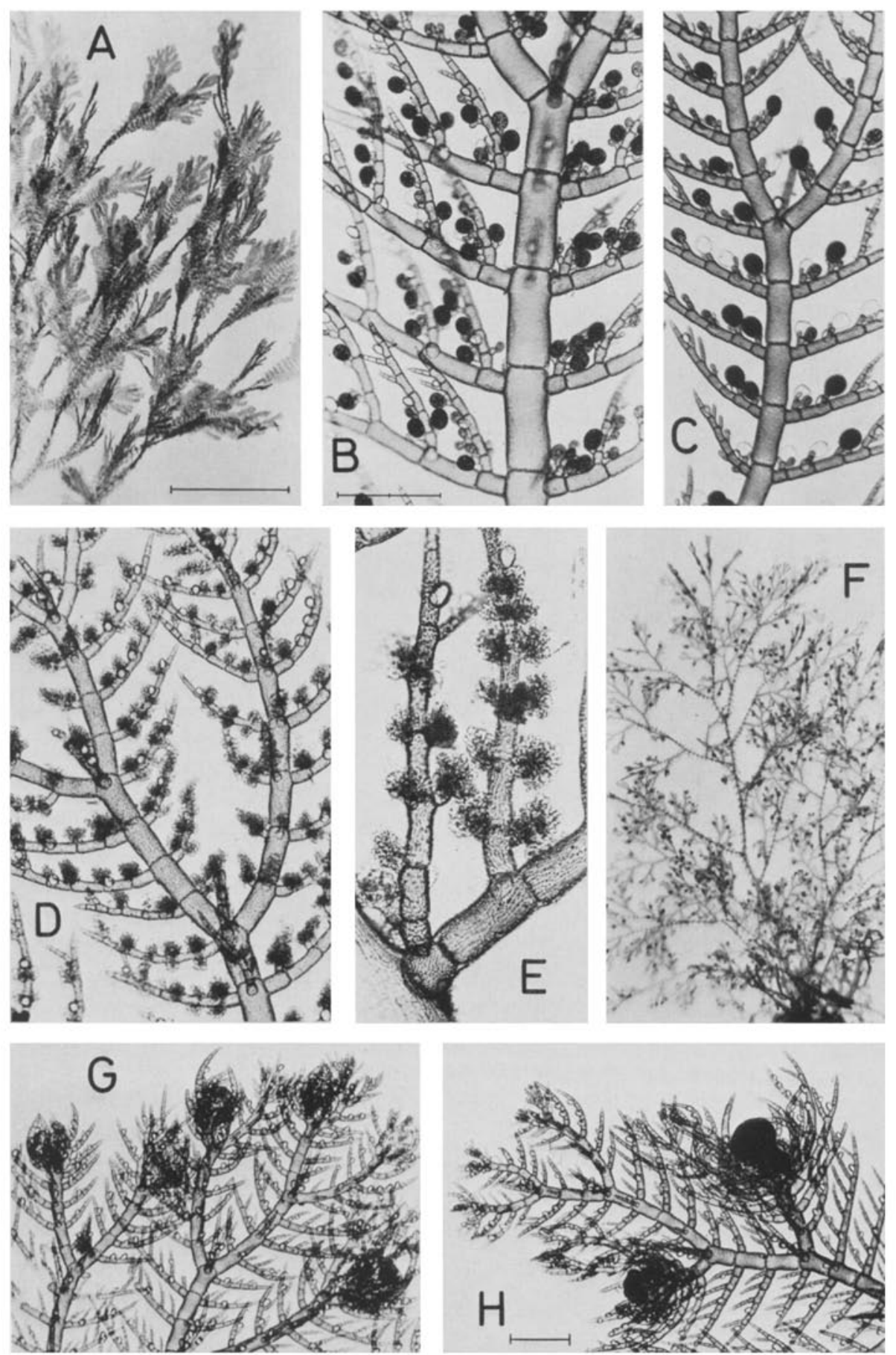


\section{Callithamnion bookeri (Dillw.) S. F. Gray}

Die nur 1-2 cm hohen, braunroten Büschel bilden an schattigen Standorten in der Gezeitenzone auf Betonflächen oder auf Balanus und Mytilus oft einen dichten Überzug; die Alge ist während des ganzen Jahres anzutreffen. Die einreihigen Stämmchen sind nur ganz unten durch Rhizinen schwach berindet. Die Verzweigung ist in den oberen Thallusteilen zweizeilig; jeder Zelle der in charakteristischer Weise abgewinkelten Hauptfäden entspringt abwechselnd nach links und rechts ein Seitenzweig. Auf der Oberseite der $Z_{w}$ eige werden in Achsennähe die sitzenden, tetraedrisch geteilten Tetrasporangien $(B, C)$ und Spermatangienstände $(G)$ gebildet, in ihrem oberen $A b-$ schnitt tragen sie sekundäre Ästchen.

Die Tetrasporophyten und diözischen Gametophyten unterscheiden sich in ihrer Größe nicht. Die Karpogonäste werden seitlich an Zellen im oberen Teil von Langtrieben angelegt (D). Aus ihnen entwickeln sich abgerundete Gonimoblasten ohne besondere Hüllfäden (E, F).

\section{Ceraminm Roth}

Bei Helgoland kommen nur zwei leicht unterscheidbare Arten vor.

\section{Ceramium rubrum (Huds.) C. Ag.}

Die monosiphone, dichotom verzweigte Zentralachse ist vollständig berindet, doch schimmern ihre Zellen in der Mitte deutlich durch und lassen die Stämmchen geringelt erscheinen. Die jüngsten đ̈stchen sind zangenartig einwärts gekrümmt. Adventivzweige entspringen den Rindenzellen in unregelmäßiger oder streckenweise auch einseitiger Anordnung; sie sind unverzweigt, einfach oder wiederholt dichotom geteilt (A).

Reife weibliche Gametophyten erkennt man leicht an den kugeligen Zystokarpien; sie sitzen an kurzen Seitenzweigen, zusammen mit wenigen kleinen Hüllästchen (B). Die männlichen Gametophyten tragen in ihren oberen Teilen eine geschlossene Schicht farbloser Spermatangien (D). Dadurch erscheinen sie wie von einem schimmeligen Belag überzogen und lassen sich schon am Standort im ruhigen flachen Wasser erkennen. Die Tetrasporangien liegen zu mehreren nebeneinander in den Rindengürteln (C).

Ceramium rubrum ist eine der verbreitetsten Algen im unteren Litoral und oberen Sublitoral. Sie wächst auf festem Substrat und ist ein häufiger Epiphyt auf vielen Algen, besonders auf $F$ ucus serratus. Größe, Farbe und Wuchsform sind sehr variabel. Pflanzen von lockerem Wuchs können über $20 \mathrm{~cm}$ lang werden, die gedrungeneren erreichen etwa $10 \mathrm{~cm}$ Höhe. Alle Farbtöne von dunkelrot bis grünlich-rot sind in Abhängigkeit von dem Lichtgenuß vertreten. Ceramium rubrum ist in den Sommermonaten besonders reichlich vorhanden, kommt aber während des ganzen Jahres vor. 

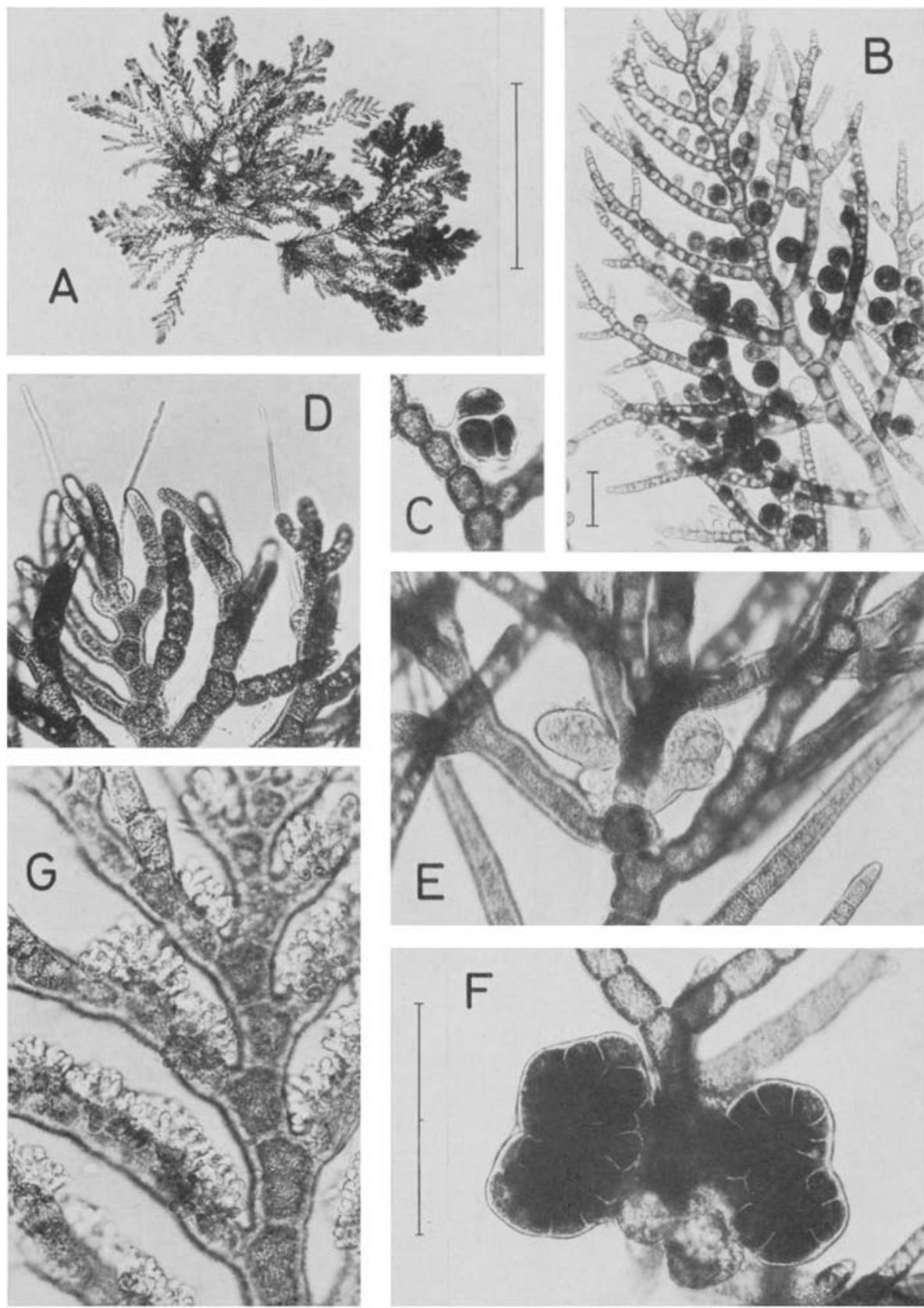

Abb. 131: Callithamnion hookeri. A Links Tetrasporophyt, rechts weiblicher Gametophyt (19. 7. 1971). B, C Zweigende mit Tetrasporangien und ein sich öffnendes Sporangium. D-F Weiblicher Gametophyt; Karpogone mit Trichogyne, junge und reife Gonimoblasten. G Zweigstück eines männlichen Gametophyten. Maßstrecken: $A=1 \mathrm{~cm} ; B=100 \mu \mathrm{m} ; \mathrm{C}-\mathrm{F}=200 \mu \mathrm{m}$ 

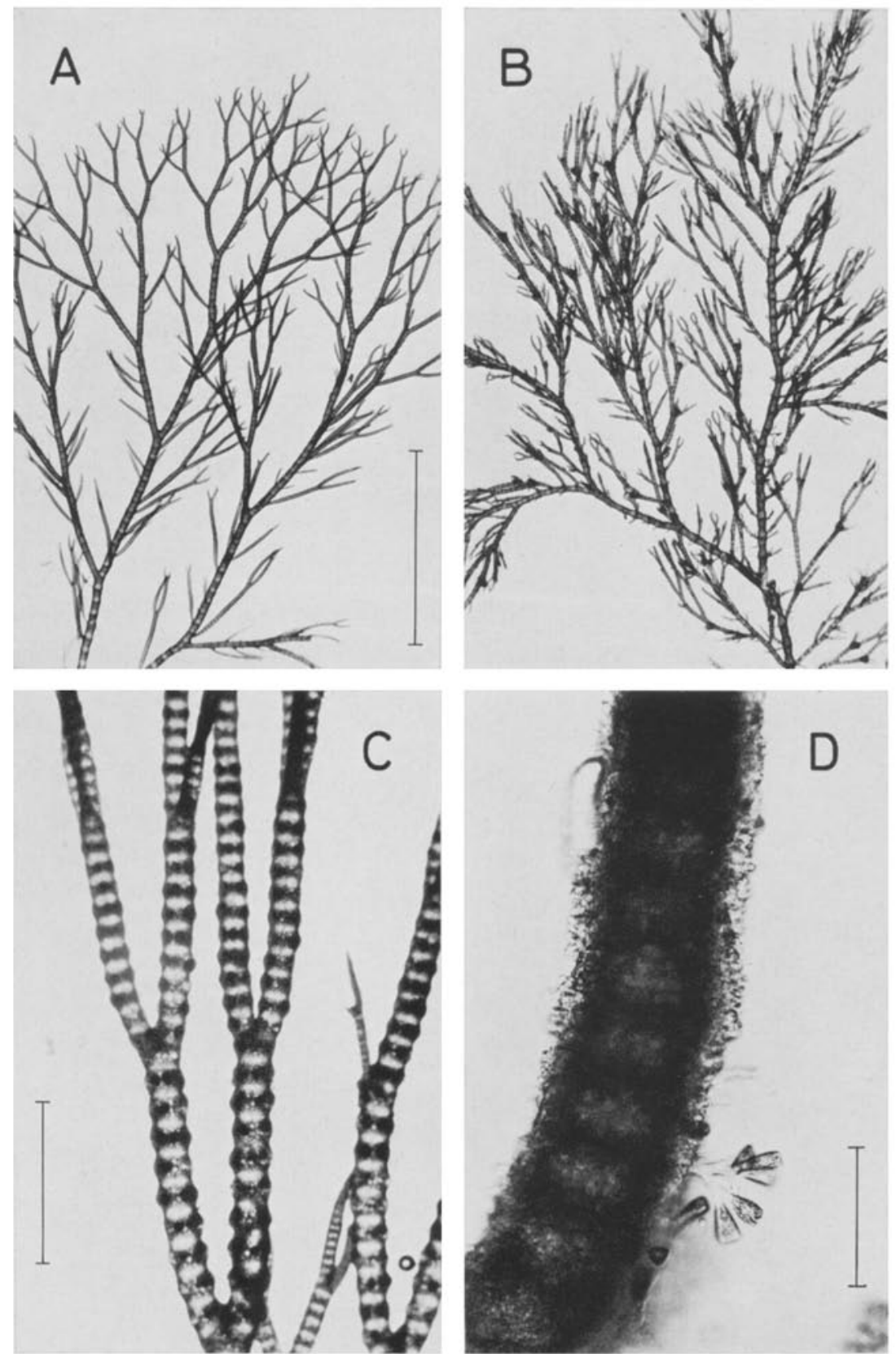

Abb. 132: Ceramium rubrum. A, B Männlicher und weiblicher Gametophyt (30. 8.1972 und 15. 6. 1971). C Ausschnitt aus dem oberen Teil eines Tetrasporophyten $(25,6.1970)$. D Fadenstück mit reifen Spermatangien (23. 5. 1972). Maßstrecken: $A, B=1 \mathrm{~cm} ; C=1 \mathrm{~mm} ; D=$ $100 \mu \mathrm{m}$ 

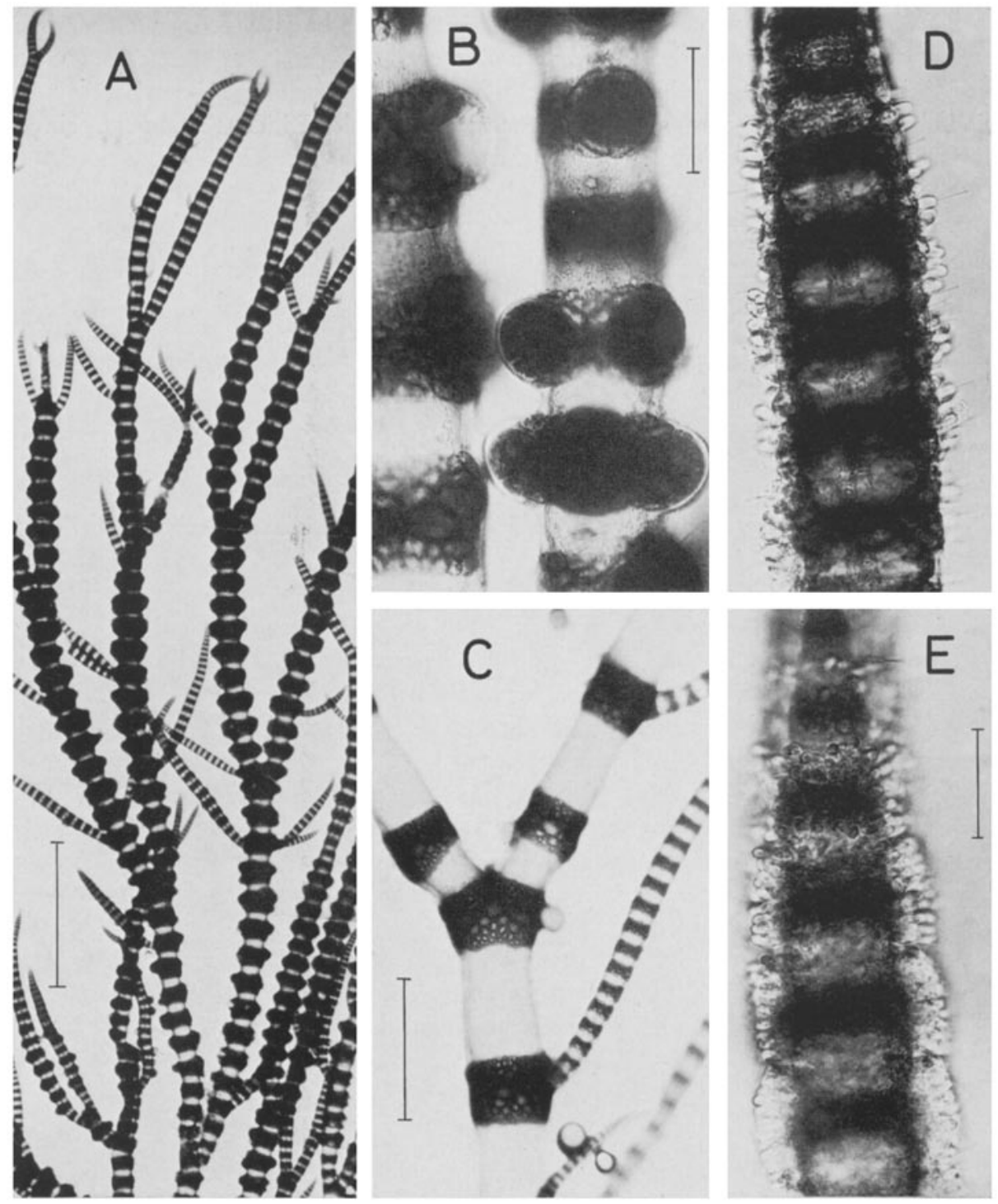

Abb. 133: Ceramium deslongchampsii. A Zweigende eines Tetrasporophyten (14. 10. 1972). B Fadenstïcke mit Tetrasporangien, unter dem Buchstaben eine leere Hülle. C Ausschnitt aus dem mittleren Teil einer vegetativen Pflanze. D, E $Z$ wreigstücke mit jüngeren und reifen Spermatangien. Maßstrecken: $\mathrm{A}=1 \mathrm{~mm} ; \mathrm{B}=100 \mu \mathrm{m} ; \mathrm{C}=500 \mu \mathrm{m} ; \mathrm{D}, \mathrm{E}=50 \mu \mathrm{m}$ 


\section{Ceramium deslongchampsii Chauv. in Duby}

Ceramium deslongchampsii ist unvollständig berindet, zwischen den Rindengürteln sind die zentralen Achsenzellen sichtbar (C). In den basalen Teilen etwa dreimal so lang wie breit, werden die Achsenzellen nach oben fortschreitend kürzer. Die Fäden sind dichotom verzweigt, jedoch in einem recht spitzen Winkel. Die spitzen Zweigenden sind meist gerade oder nur ganz wenig gekrümmt. Aus den Rindengürteln entspringen einfache oder wenig verzweigte kurze Adventiväste in unregelmäßiger Anordnung $(A, C)$.

Die oberen Abschnitte männlicher Gametophyten sind von den farblosen Spermatangien umhüllt (D, E). Die Tetrasporangien lassen die Gürtel kräftig und unregelmäßig anschwellen $(A, B)$.

Ceramium deslongchampsii findet man während des ganzen Jahres an schattigen Stellen im unteren Litoral. Die dunkelbraunroten bis schwärzlichen Büschel werden bis $9 \mathrm{~cm}$ lang.

\section{Plumaria elegans (Bonnem.) Schmitz}

Eine ausgeprägte, etwas abgeflachte Hauptachse trägt die wiederholt gefiederten Zweige. Alle Verzweigungen liegen in einer Ebene. Mit Ausnahme der Fiederchen letzter Ordnung ist der Thallus berindet. Die Pflanzen können bis zu $12 \mathrm{~cm}$ hoch werden, die Hauptachsen sind an der Basis bis knapp $1 \mathrm{~mm}$ breit.

Am ansehnlichsten ist die Alge in den Frühjahrsmonaten, wenn die frisch ausgetriebenen, kräftig rotgefärbten jungen Sprosse voll entwickelt sind (A, B). Im jährlichen Entwicklungsrhythmus findet ab Januar eine Lauberneuerung aus überständigen Thallusresten statt (D). Im Laufe des Sommers verlängern sich besonders die Enden der Hauptachsen (C), gleichzeitig wird die Alge schwärzlich-dunkelrot.

Als einzige Fortpflanzungsorgane wurden von Oktober bis Juni Parasporangien beobachtet, die an den Fiederchen sitzen und 6-8 Parasporen enthalten (E, F). An den englischen und französischen Küsten sind auch Tetrasporophyten und Gametophyten bekannt.

Plumaria elegans wächst in der unteren Gezeitenzone besonders an schattigen Hafenwänden oder auf dicht mit Fucus serratus bedeckten Flächen. Seltener kommt sie auch im Sublitoral vor, zum Beispiel epiphytisch auf den Stielen von Laminaria byperborea.

Abb. 134: Plumaria elegans. A Teil einer Pflanze mit voll entwickelten Sprossen (3. 5. 1971). $B$ Ende eines jungen Zweiges (30.1. 1970). C Habitus im Sommer (12. 8. 1972). D Vorjähriger Thallus mit jungen Sprossen (8.1. 1973). E, F Parasporangien (8. 1. 1973). Maßstrecken: A, C $=1 \mathrm{~cm} ; \mathrm{B}, \mathrm{D}=$ je $1 \mathrm{~mm} ; \mathrm{F}=100 \mu \mathrm{m}$ 

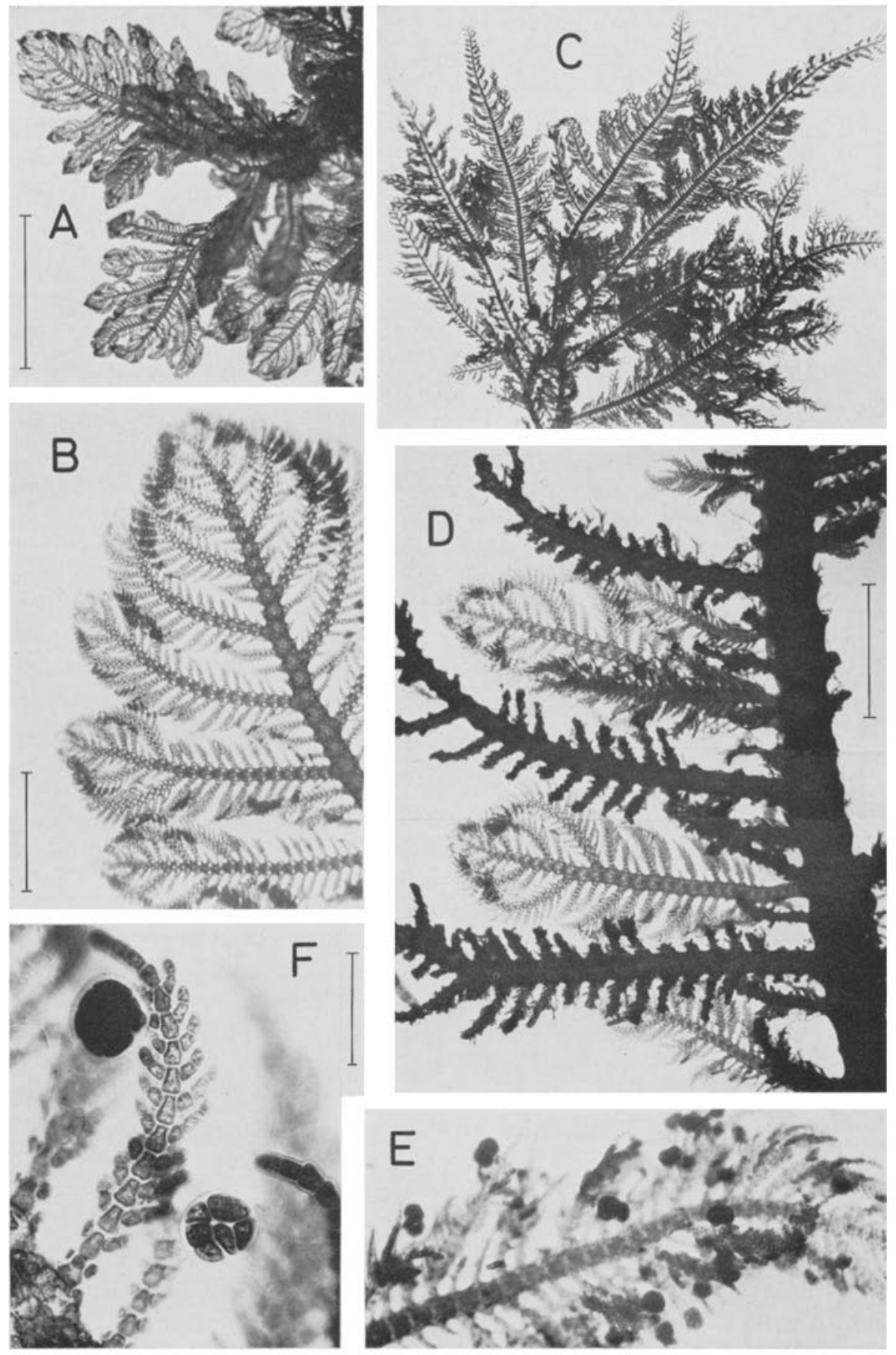


\section{Delesseria sanguinea (Huds.) Lamour.}

Der deutlich gestielte, blattartige Thallus wird von einer krättigen Mittelrippe durchzogen; die Fläche zwischen den paarigen Seitennerven ist einschichtig. Delesseria sanguinea ist eine mehrjährige Alge, deren Mittelrippen überwintern. Aus ihnen entsprossen am Ende des Winters zahlreiche schmale Blättchen (A), die in den Frühjahrsmonaten zu glatten, breit-lanzettlichen Thalli von rosenroter Farbe heranwachsen (B). Nach einem verstärkten Wachstum besonders in ihrem oberen Teil wird die Alge breitlappig mit stark gekräuseltem Rand (C); in dieser Tracht findet man sie von Juni bis August. Aus der Mittelrippe können dann auch einzelne Adventivblätter austreiben. $\mathrm{Ab}$ August beginnt die Degeneration; Blattfläche und Seitennerven gehen verloren (D).

Auf getrennten Pflanzen entstehen während des Winters die Fortpflanzungsorgane an den Mittelrippen. Schon ab Oktober findet man die kleinen farblosen männlichen Blättchen mit Spermatangien (E). Die Zystokarpien entwickeln sich an der Mittelrippe fertiler Blättchen und schwellen zu schmal gesäumten Knötchen an; sie haben eine deutliche Mündung und sind Ende Februar reif $(F, G)$. In ganz entsprechender Weise entstehen auch die Tetrasporangien in besonderen Blättchen $(\mathrm{H})$.

Delesseria sanguinea ist im Sublitoral sehr verbreitet und wird nach stürmischem Wetter oft in großen Mengen an den Strand geworfen.

\section{Phycodrys rubens (L.) Batt.}

Pbycodrys rubens ist wie Delesseria sanguinea eine Alge des Sublitorals, jedoch lange nicht so häufig wie diese und daher seltener am Strand ausgeworfen zu finden. Auch sie ist mehrjährig und beginnt im Winter ihr Laub zu erneuern. Der einschichtige, von einer Mittelrippe und gegenständigen Seitennerven durchzogene Thallus ist tief ausgebuchtet oder fiederlappig, der Blattrand ist gezähnt. In der bei A dargestellten Tracht findet man die Alge von Mitte April bis August; danach beginnt sie am Rand fransige Proliferationen oder auch kleine Blättchen auszutreiben (B). An solchen jungen Randblättchen wurden im Oktober Spermatangien beobachtet; ganz entsprechend entstehen auch die Zystokarpien (F) und Tetrasporangien (D). Zystokarpien können aber auch zerstreut auf den Rippen frisch ausgetriebener Blätter gebildet werden (G), wie auch der Rand solcher jungen Blättchen von Tetrasporangien gesäumt sein kann $(\mathrm{C}, \mathrm{E})$.

Abb. 135: Delesseria sanguinea. A-D Jahreszeitliche Veränderung des Habitus: A 11, 2. 1971; B 22. 4. 1970; C 1.7. 1971; D 19. 11. 1970. E Fertiles männliches Blättchen (3. 10. 1962). F, G Weibliche Pflanze mit Zystokarpien und jungen vegetativen Blättchen, bei $G$ mehrere Haufen entleerter Karposporen (29.1. 1971 und 25. 2. 1970). H Tetrasporophyt mit fertilen Blättchen

(23. 1. 1971). Maßstrecken: $A, B$ jeweils $=4 \mathrm{~cm} ; C=8 \mathrm{~cm} ; E=1 \mathrm{~mm} ; G=1 \mathrm{~cm}$ 


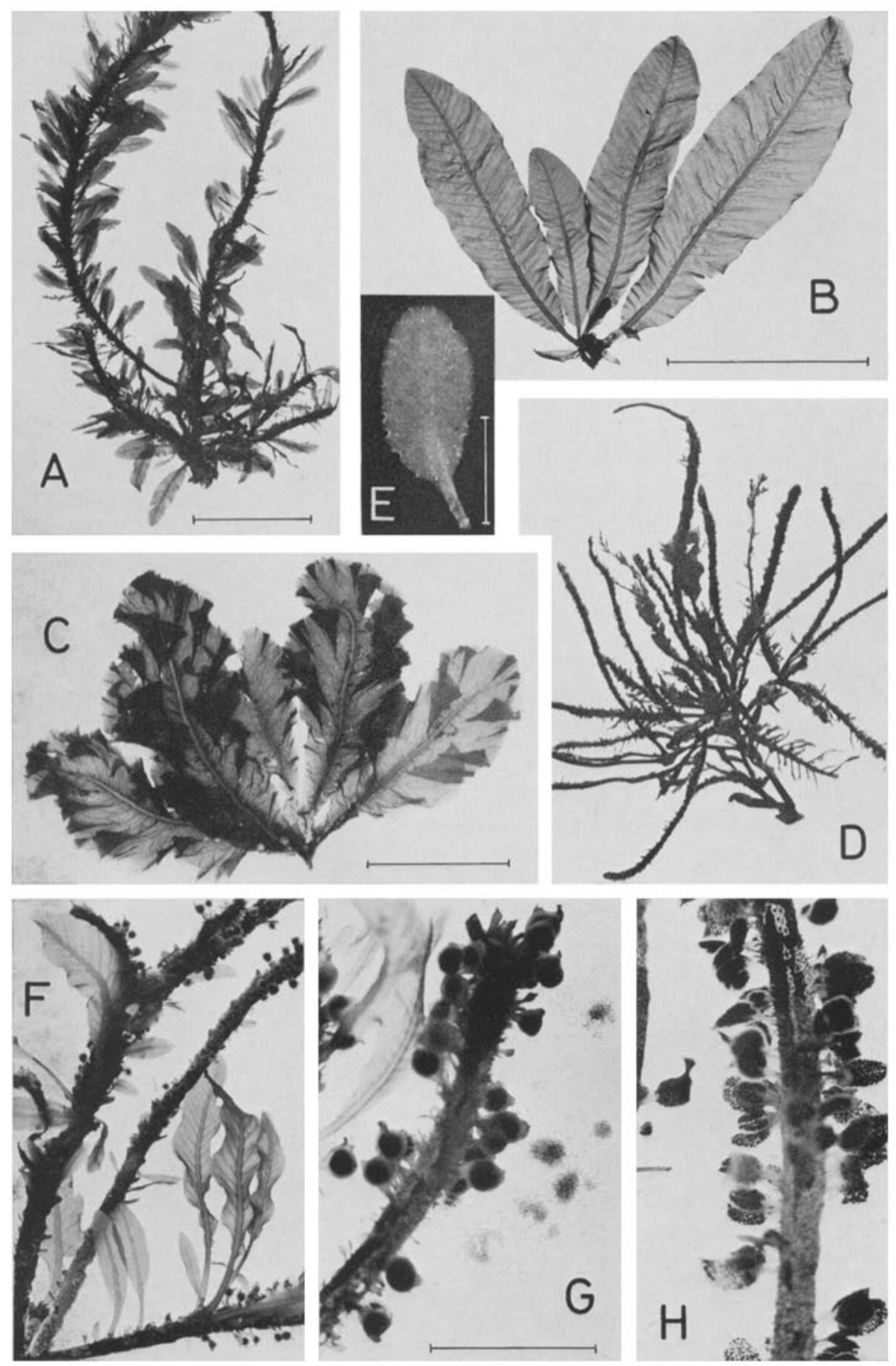



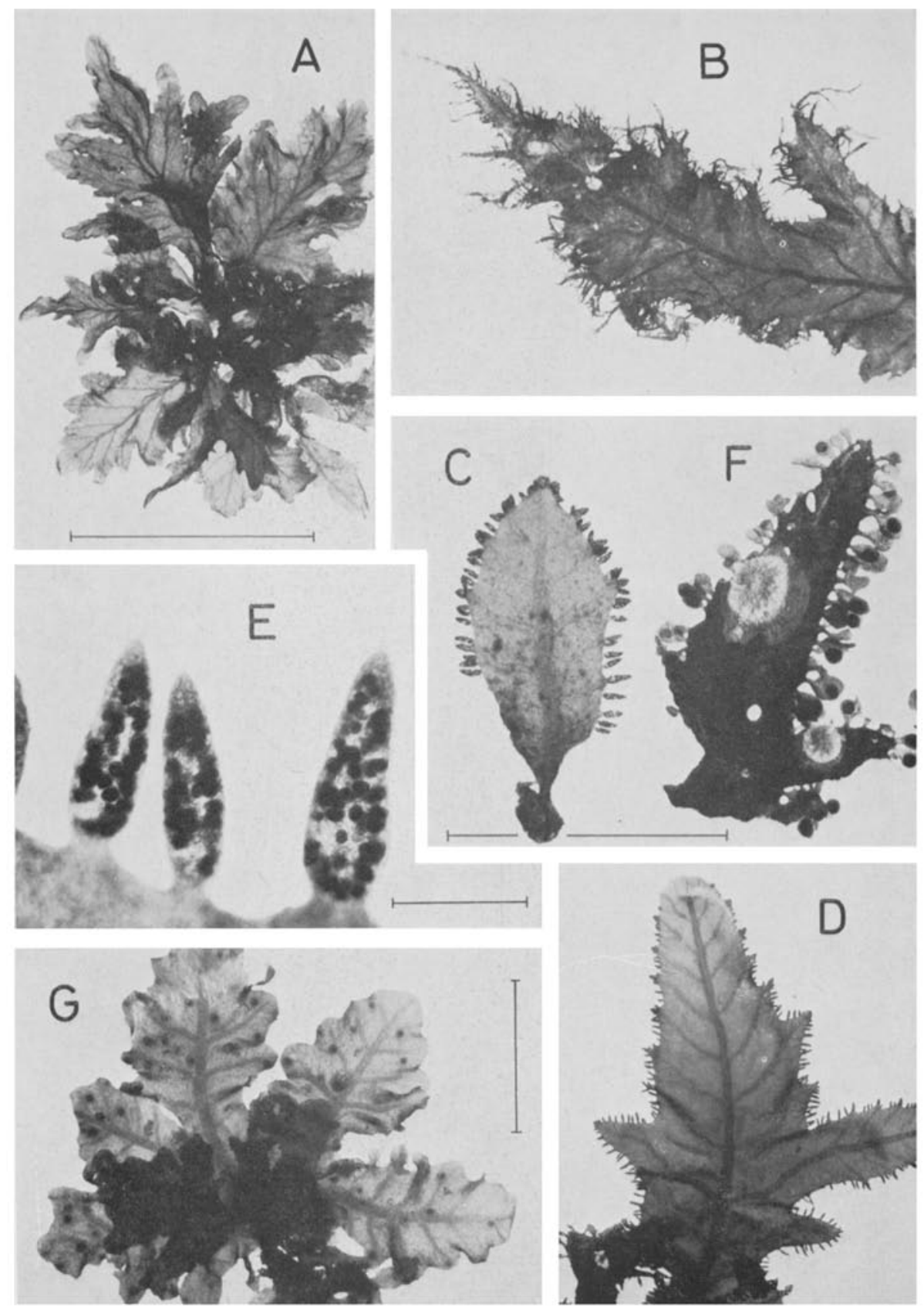

Abb. 136: Phycodrys rubens. A Vollentwickelte Pflanze (15.6. 1971). B Thallusende einer überständigen Pflanze (16. 12. 1972). C, E Tetrasporangien am Rande eines frisch ausgetriebenen Blättchens (31.1. 1973). D Tetrasporangien an einem alten Thallus (19.12. 1972). F Zystokarpien an besonderen, am Thallusrand proliferierenden Blättchen (31. 1. 1973, mit zwei aufsitzenden Bryozoen-Kolonien). G Zystokarpien an den Rippen frisch ausgewadhsener Blättchen (19. 12. 1972). Maßstrecken: $A=5 \mathrm{~cm} ; C, G=$ je $1 \mathrm{~cm} ; E=0,5 \mathrm{~mm}$ 

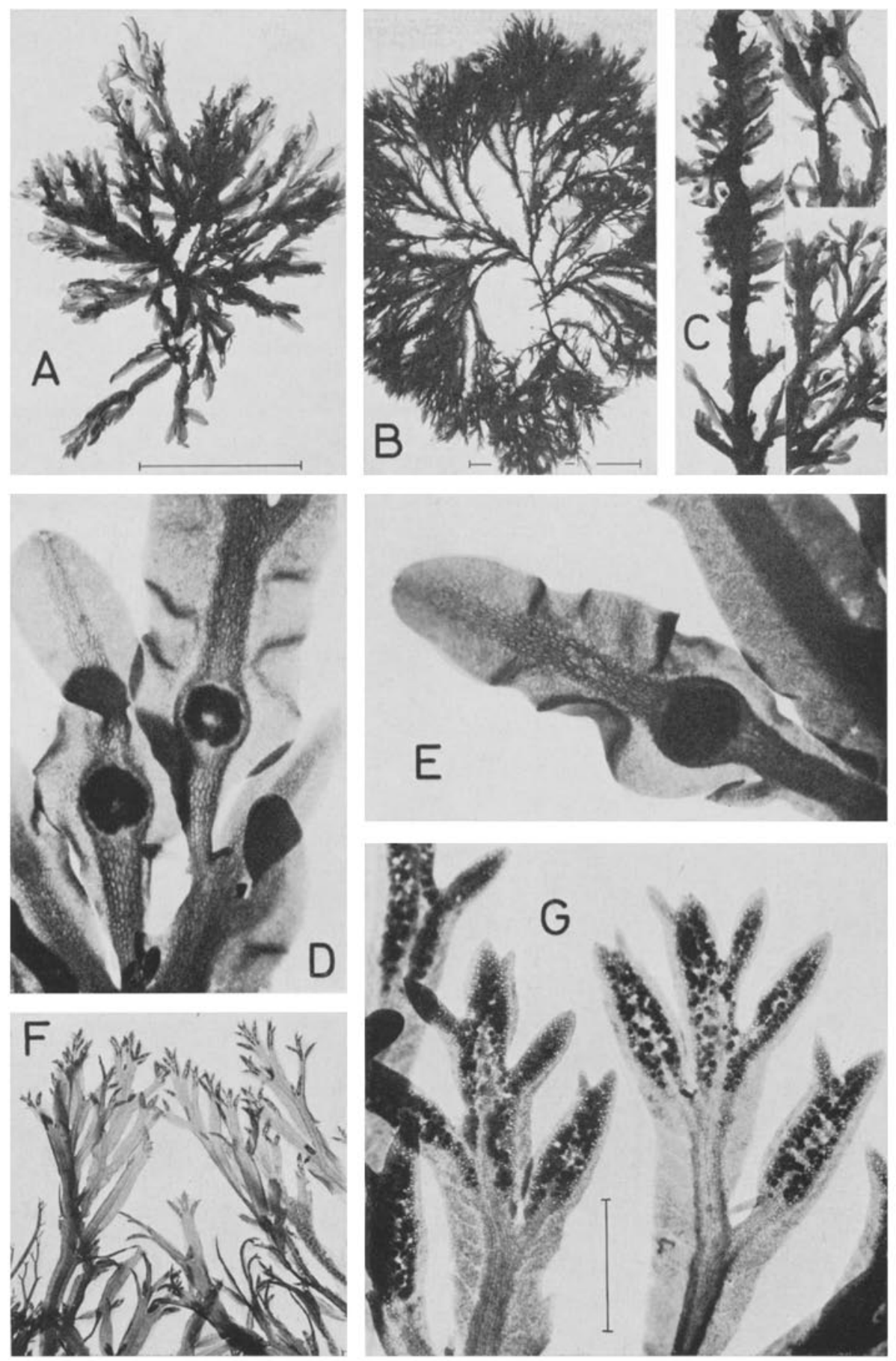

Abb. 137: Membranoptera alata. A Habitus einer jungen Pflanze (30.1. 1971). B Überständiges Exemplar (8. 8. 1970). C-E Zystokarpien an besonderen fertilen Blättchen bzw, an der Mittelrippe frischer Sprosse (17. 2. 1971). F, G Thallusenden mit Tetrasporangien (23. 1. 1971). Maßstrecken: $A=2,5 \mathrm{~cm} ; B=5 \mathrm{~cm} ; D, E, G=1 \mathrm{~mm}$ 


\section{Membranoptera alata (Huds.) Stackh.}

In ihrem jahreszeitlichen Vegetationsrhythmus gleicht diese Art den beiden vorhergehenden. Aus den dunkelbraunroten nackten Achsen des Vorjahres sprossen im Januar und Februar die schmalen hellroten jungen Thalli aus (A, C). Zu dieser Zeit fruktifiziert Membranoptera; die Zystokarpien werden entweder an besonderen kleinen Blättchen angelegt (C) oder sie entstehen an der Mittelrippe frisch ausgewachsener verzweigter Sprosse (D, E). Die Tetrasporangien liegen zu beiden Seiten der Mittelrippe junger, schmaler Triebspitzen $(F, G)$.

Die kräftige Mittelrippe wird von einer einschichtigen Blattfläche gesäumt. Seitennerven sind nur an älteren Pflanzen, etwa ab Juni, mit bloßem Auge zu erkennen. Der geflügelte Thallus ist im allgemeinen 3 bis $4 \mathrm{~mm}$ breit, kann aber $8 \mathrm{~mm}$ Breite erreichen. Die bis $15 \mathrm{~cm}$ hohen Büschel sind reichlich verzweigt; die Verzweigung ist unregelmäßig gabelig. Im August wird der Höhepunkt der Entwicklung überschritten, die Blattsäume beginnen zu degenerieren (B).

Ihre Hauptverbreitung hat Membranoptera alata im Sublitoral, wo sie auf Steinen und besonders auf alten Stielen von Laminaria byperborea wächst. Bei gutem Niedrigwasser kann man einzelne Pflanzen auch unter Fucus serratus finden. 


\section{Rhodomelaceae}

\section{Polysiphonia Greville}

Der allseitig verzweigte, runde Thallus besteht aus Segmenten gleichhoher Zellen; eine Zentralzelle ist von einer für die betreffende Art charakteristischen Anzahl von Perizentralzellen umgeben. An den wachsenden Spitzen befinden sich farblose, monosiphone Haartriebe, die aber meist frühzeitig abgeworfen werden.

Vier bei Helgoland häufig vorkommende Polysiphonia-Arten sind an ihren morphologischen Merkmalen leicht zu unterscheiden. Die zartfädige $P$. urceolata mit 4 Perizentralen hat keine besonders hervortretenden Hauptachsen; die Fäden sind völlig unberindet (Abb. 139). Ebenfalls 4 Perizentralen hat die bräunlichviolette P. violacea, deren Stämmchen buschig verzweigt und nur in den unteren Teilen berindet sind (Abb. 140). Bei P. elongata mit 4 Perizentralen sind die kräftigen kahlen Sprosse erst an ihren Enden etwas dichter verzweigt, im Frühjahr schopfig. Trotz ihrer hoch hinaufreichenden Berindung sind die Segmente deutlich zu erkennen (Abb. 141). Von diesen 3 Arten unterscheidet sich $P$. nigrescens durch 12-16 Perizentralen (Abb. 142).

Die bei Helgoland seltene Polysiphonia nigra wird in einem besonderen Abschnitt aufgeführt (p. 284).

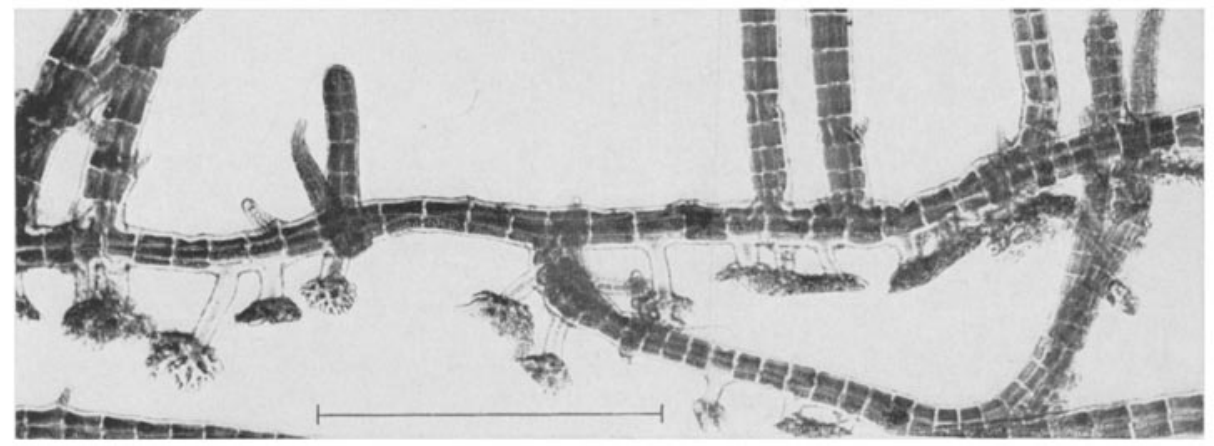

Abb. 138: Polysiphonia urceolata. Niederliegender Faden mit Hapteren und aufrechten Sprossen. Maßstrecke $=500 \mu \mathrm{m}$ 


\section{Polysiphonia urceolata (Lightf. ex Dillw.) Grev.}

Sie ist die einzige der 4 Helgoländer Arten ohne ausgeprägte Hauptachse: die wenigen Seitenzweige in den unteren Abschnitten sind von gleicher Stärke (G). Oft sind die zarten, hellroten bis dunkelroten Fäden zu seilartigen Strängen umeinandergewunden, die sich erst oben locker auflösen und etwas reichlicher verzweigen $(A, B)$. Die Wuchsform und rasenartige Ausbreitung der Alge wird verständlich durch die niederliegenden und mit Rhizoidzellen auf dem Substrat verankerten Fäden, auf denen sich die aufrechten Sprosse erheben (Abb. 138 und Abb. 139 C). Solche Ausläufer können sich über mehrere Zentimeter auf dem Substrat, z. B. einem Stiel von Laminaria byperborea, ausbreiten.

Die Segmente mit ihrer engen Zentralzelle und 4 Perizentralen sind auffallend langgliedrig; mitunter sind die Perizentralen schraubig gewunden $(G, H)$. In den oberen Teilen werden die Segmente kürzer; die dichter aufeinanderfolgenden Zweige tragen oft kurze Hakenäste (B).

Die Tetrasporangien liegen wie bei allen Arten der Gattung einzeln in den Segmenten der obersten Verzweigungen (D). Die Spermatangien stehen dicht gedrängt an den Zweigspitzen, sie haben einen kurzen Stiel und eine wenigzellige sterile Spitze (E). Thren Artnamen verdankt die Alge den urnenförmigen Zystokarpien mit lang vorgezogener Mündung (F). Fertile Pflanzen findet man hauptsächlich von April bis September.

Polysiphonia urceolata kommt das ganze Jahr über vor. Ihre Hauptverbreitung hat sie im Sublitoral; nach Stürmen wird sie oft in größerer Menge am Strand angespïlt. Auch an den Stielen ausgeworfener Laminaria byperborea trifft man sie häufig zusammen mit Membranoptera alata an. Bei tiefem Niedrigwasser kann man $P$. urceolata auch auf Fels unter $F$ ucus serratus oder an den Buhnenresten der Düne finden.

Abb. 139: Polysiphonia urceolata. Büschel auf ausgebreiteter kriechender Basis (25. 4. 1969). B Zweigstidk aus dem oberen Teil mit kurzen Segmenten und hakigen Astchen. $C$ Kriechender Faden mit Rhizoidästchen und aufrechten Sprossen. D Zweigende mit Tetrasporangien (16. 6. 1971). E Spermatangien (8.5. 1970). F Reife Zystokarpien (Juni). G, H Lange Segmente mit geraden und schraubig gedrehten Perizentralen (24.4.1972). Maßstrecken: $A=10 \mathrm{~cm} ; \mathrm{B}=$ $500 \mu \mathrm{m} ; \mathrm{C}, \mathrm{D}, \mathrm{F}-\mathrm{H}=500 \mu \mathrm{m}$ 

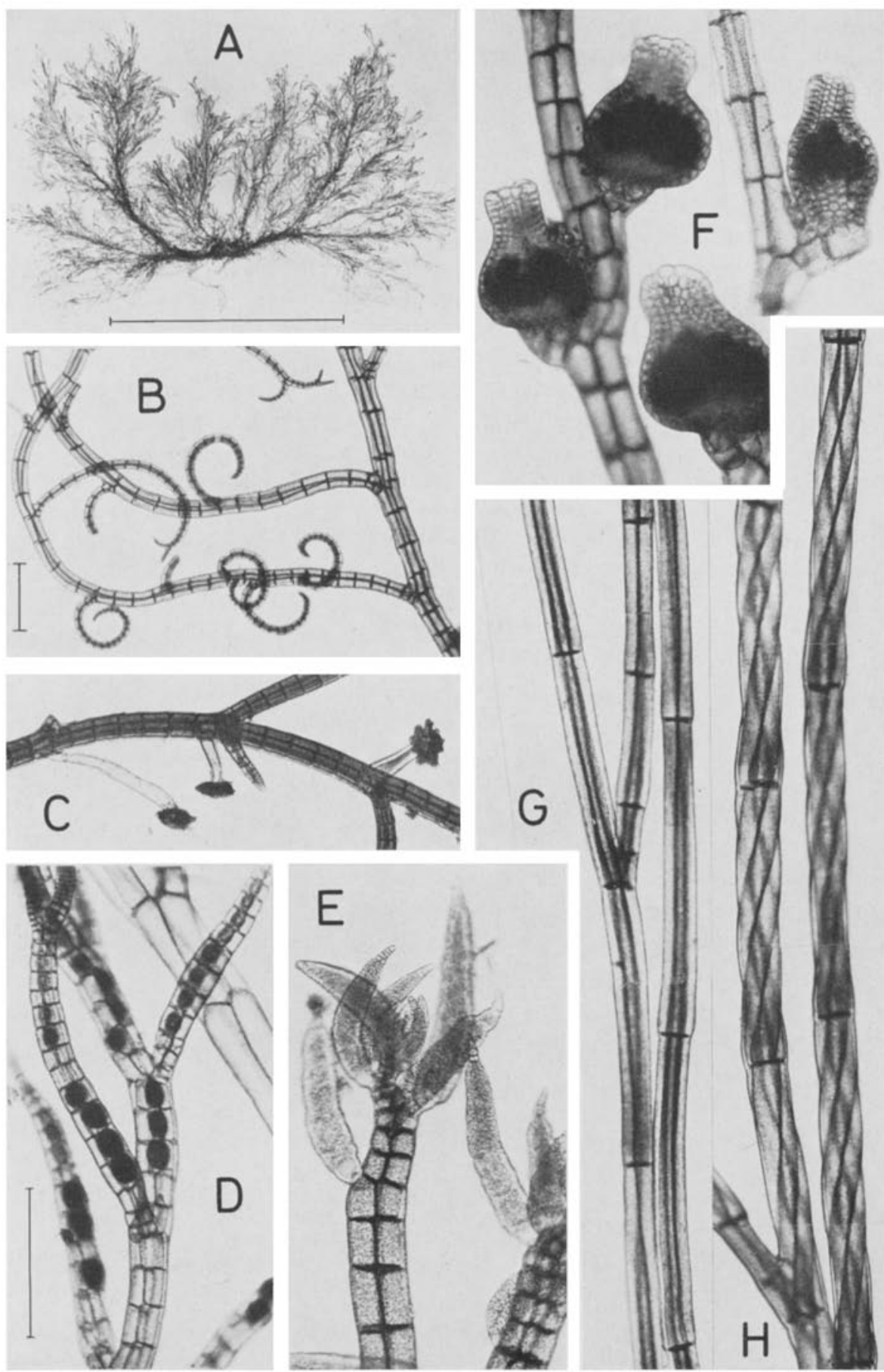


\section{Polysipbonia violacea (Roth) Spreng.}

Der Thallus verzweigt sich schon kurz oberhalb der Haftscheibe allseitig und reichlich; die $Z$ weige höherer Ordnung werden zunehmend dünner und kürzer. Die Büschel sind schlaff und fühlen sich etwas schleimig an; sie sind von matt-bräunlichvioletter Farbe. Dickere Achsen sind an ihrer Basis berindet.

Polysiphonia violacea wächst vornehmlich epiphytisch auf verschiedenen Algen an der Niedrigwassergrenze, z. B. auf Scytosiphon, Chondrus, Chorda flum und Fucus serratus, kommt aber auch auf totem Substrat vor. Am reichlichsten triff man sie in den Sommermonaten an, doch sind fertile Pflanzen auch von Oktober bis Februar in Kratzmaterial von den Hafenmolen zu finden. Sicherlich ist Polysiphonia violacea eine kurzlebige Art mit zeitlich sich überlagernden Generationen. Die Büschel werden bis $17 \mathrm{~cm}$ hoch; am häufigsten findet man Tetrasporophyten (A), am spärlichsten männliche Gametophyten, die im allgemeinen auch die kleineren sind (C). An fertilen weiblichen Pflanzen sind die kugeligen Zystokarpien mit bloßem Auge sichtbar (E).

Polysiphonia violacea ist ein beliebtes Objekt zum Studium der Fortpflanzungsorgane. Die Tetrasporangien liegen einzeln und spiralig gereiht in den Segmenten der Endzweige (B). Die Spermatangienstände stehen seitlich an Trichoblasten, Haartrieben, die aus jedem Segment an den wachsenden Spitzen entspringen, meist aber frühzeitig abgeworfen werden. Dabei bleiben kleine Narbenzellen zurück, die in Figur D links unterhalb der fertilen Astchen deutlich erkennbar sind. Die monosiphonen Haartriebe sind dichotom geteilt, ihre Zellen farblos. Die hier abgebildeten männlichen Organe sind unterschiedlich: walzlich mit stumpfer Kuppe (D, links) neben länger gestreckten mit steriler Spitzenzelle auf anderen Pflanzen (D, rechts).

Auch die Prokarpien werden an der Basis von Trichoblasten angelegt $(F)$, die aber bald verlorengehen. Der bei $G$ rechts neben dem sich entleerenden Zystokarp sichtbare Haartrieb entspringt dem nächsthöheren Segment.

Polysiphonia ist das klassische Objekt für den 1906 zytologisch nachgewiesenen Kernphasenwechsel bei den Rhodophyceen. Die Reduktionsteilung erfolgt im Tetrasporangium; die diploide Phase umfaßt das aus dem befruchteten Karpogon auf dem Gametophyten sich entwickelnde Karposporophytenstadium (Gonimoblast) sowie die aus den Karposporen hervorgehende selbständige und den Gametophyten gleichgestaltete Tetrasporophytengeneration.

Abb. 140: Polysiphonia violacea. A, C, E Tetrasporophyt, männlicher und weiblicher Gametophyt (23.9.1971). B Zweigende mit Tetrasporangien. D Zweigenden mit Spermatangien; links mit abgerundeter Kuppe, rechts mit steriler Endzelle. F Prokarp mit Trichogyne. G Junge Zystokarpien und ein reifes mit entleerten Karposporen. Maßstredken: $A, C, E=3 \mathrm{~cm} ; B=$ $120 \mu \mathrm{m} ; \mathrm{D}$ und $\mathrm{G}$ rechts $=500 \mu \mathrm{m}$ 

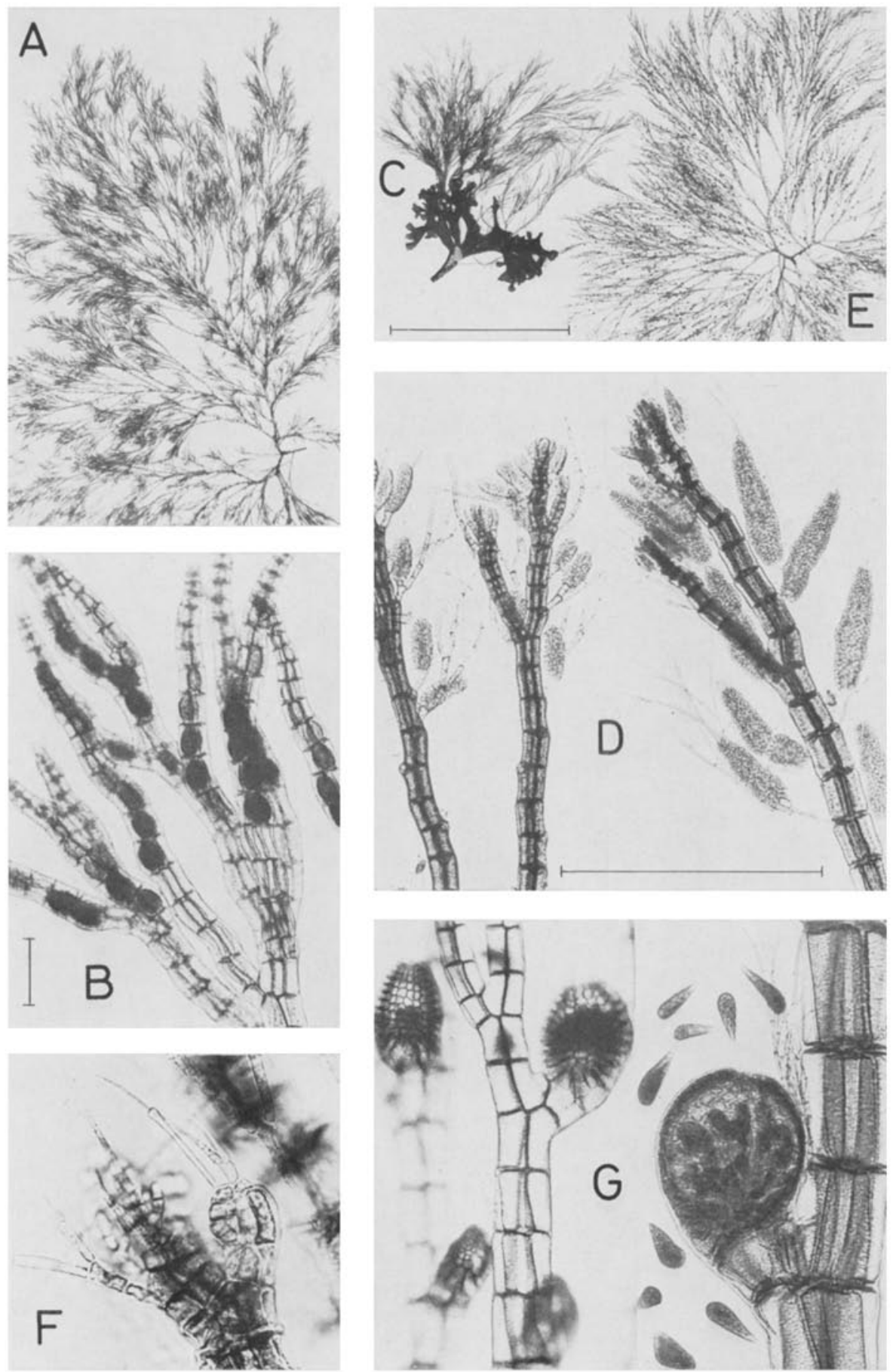


\section{Polysiphonia elongata (Huds.) Spreng.}

Neben ihren im unteren Abschnitt besonders dicken und fast kahlen Sprossen (A) hat Polysiphonia elongata in der stark verjüngten Basis der Zweige ein unverkennbares Merkmal (G). Trotz der Berindung lassen sich die Segmente in den häufig über $1 \mathrm{~mm}$ dicken Stämmchen gut wahrnehmen $(\mathrm{H})$. In der bei $\mathrm{A}$ abgebildeten Erscheinung trifft man die Alge etwa ab September an; sie verliert dann im Winter noch die meisten dünnen $Z$ weige, so daß nur wenige dicke Sprosse übrigbleiben. Aus ihren Enden sprossen mitunter schon im Januar und Februar junge, leuchtend rot gefärbte und sich verzweigende Astchen aus, und im April und Mai präsentiert sich Polysiphonia elongata im Schmuck ihrer schopfigen Zweigenden (B).

Fertile Pflanzen wurden von April bis September beobachtet. Nach der Fruktifikation werden erst die fertilen $Z$ weigenden, später auch die sie tragenden Aste abgeworfen.

Polysiphonia elongata wächst meist einzeln und ist mit einem ausgebreiteten Hapterenkranz auf dem Substrat befestigt. Im untersten Litoral findet man sie auf Steinen; sie siedelt sich aber auch gerne auf treibenden Gegenständen wie Pontons oder Bojen sowie deren Halteleinen an. Im Sublitoral kommt Polysiphonia elongata noch in 6 bis $7 \mathrm{~m}$ Tiefe vor. Die unterschiedlichen ökologischen Gegebenheiten an diesen verschiedenen Standorten wirken sich deutlich auf die Erscheinungsform und den jahreszeitlichen Entwicklungsrhythmus aus.

\section{Polysiphonia nigrescens (Huds.) Grev.}

Diese Art hat wie die bei Helgoland selten vorkommende Polysiphonia nigra (p. 284) mehr als 4 Perizentralen (C, D). Aber auch ihr Habitus trennt sie klar von allen anderen Arten. Die mehrjährige schwärzliche Pflanze ist steif und rauh und hat während der längsten Zeit des Jahres ein sparriges Aussehen. Im Februar bis April treiben aus den Thallusenden raschwachsende dunkelrote $Z$ weige aus. Sie verzweigen sich wiederholt wechselständig in einer Ebene (A, B).

Die Hauptachse der bis zu $30 \mathrm{~cm}$ hohen Pflanze ist allseitig reich verzweigt. Sie wird etwa $3 / 4 \mathrm{~mm}$ dick und trägt oft die Reste abgeworfener Äste. Die dickeren. Achsen sind berindet (E). Die Segmente können in den rasch wachsenden Sprossen über $1 \mathrm{~mm}$ hoch werden; ihre breite Zentralzelle ist von 12-16 geraden oder leicht gedrehten Perizentralen umgeben $(C, D)$.

Abb. 141: Polysiphonia elongata. A Erscheinungsform im Herbst und Winter (1. 9. 1969). B Ausschnitt aus dem dicht verzweigten Thallusende einer weiblichen Pflanze (26. 6. 1971). C Spermatangien. D Tetrasporangien. E, F Prokarp mit Trichogyne und reife Zystokarpien. G Verjungte $Z$ weigbasis. H Berindeter Sproßabschnitt. Maßstrecken: $A=5 \mathrm{~cm} ; \mathrm{C}-\mathrm{F}$ jeweils $=$ $100 \mu \mathrm{m} ; \mathrm{G}=300 \mu \mathrm{m} ; \mathrm{H}=1 \mathrm{~mm}$ 

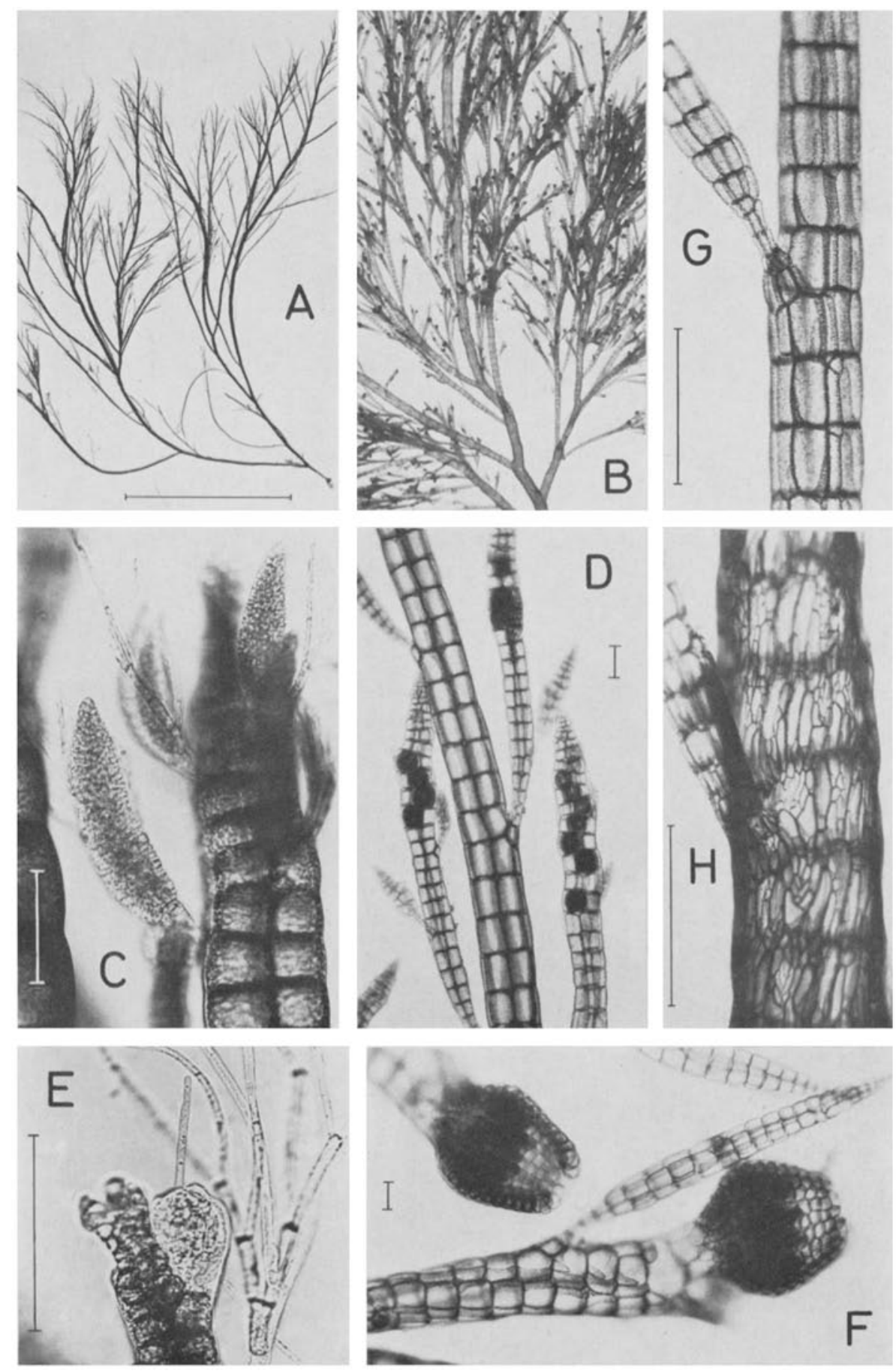

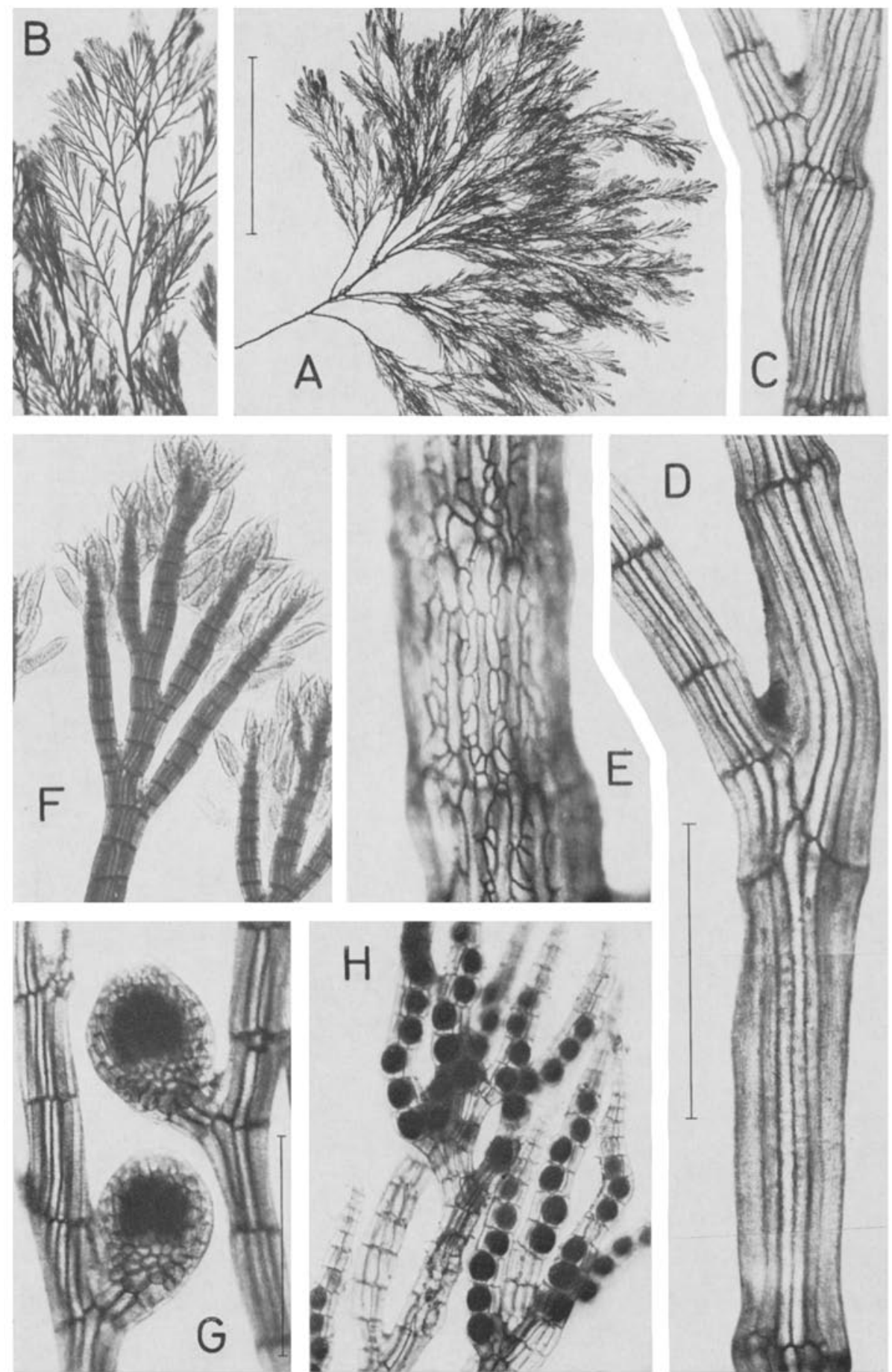

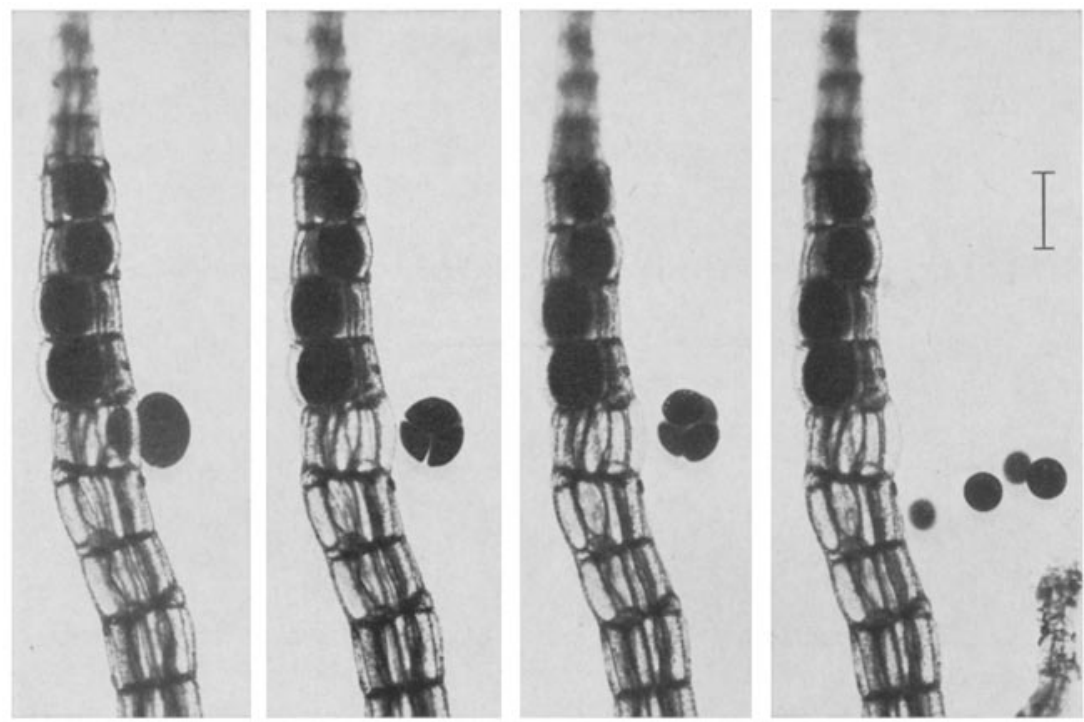

Abb. 143: Polysipbonia mgrescens. Entleerung eines Tetrasporangiums. Maßstredke $=100 \mu \mathrm{m}$

Mit dem Erscheinen und der Reifung der Fortpflanzungsorgane wird Polysipbonia nigrescens zunehmend sparriger. Zwar findet man auch im Spätsommer noch fertile Pflanzen im Frühjahrshabitus, offensichtlich sind dies junge oder in tieferem Wasser gewachsene Exemplare. Die überwinterten Gametophyten fruktifizieren etwa ab Ende Februar an den neuen Sprossen; Tetrasporangien findet man ab Mai. Männliche Pflanzen sind ohne weiteres an den gelblichen Zweigspitzen zu erkennen, an denen die länglichen Spermatangien dicht gedrängt stehen $(F)$; die breit ovalen Zystokarpien sind sitzend oder kurz gestielt (G). In den Segmenten fertiler Zweigenden der Sporophyten liegen die Tetrasporangien einzeln in schraubiger Anordnung $(\mathrm{H})$. Die Entleerung eines Sporangiums und Abrundung der tetraedrischen Sporen während etwa 2 Minuten ist in Abb. 143 dargestellt.

Polysiphonia nigrescens wächst meist in Büscheln von mehreren Pflanzen auf festem Substrat in der unteren Gezeitenzone und im Sublitoral.

Abb. 142: Polysiphonia nigrescens. A, B Habitus im Fruhjahr (17.2. 1971). C, D Unberindete Sproßglieder. E Berindetes Stämmchen. F Gedrängt an den Zweigspitzen stehende Spermatangien (19. 9. 1970). G Fast reife Zystokarpien (6.6. 1972). H Zweigenden mit Tetrasporangien (6. 6. 1972). Maßstrecken: $\mathrm{A}=4 \mathrm{~cm} ; \mathrm{C}-\mathrm{F}, \mathrm{H}=1 \mathrm{~mm} ; \mathrm{G}=500 \mu \mathrm{m}$ 


\section{Brongniartella byssoides (Good. et Woodw.) Schmitz}

Die kräftige polysiphone Hauptachse besteht aus einer Zentralzelle und 7 Perizentralen. Sie ist nicht berindet und trägt alternierende, in ziemlich weitem Winkel abstehende, nach oben kürzere Zweige (A), die mit spiralig angeordneten kurzen Kstchen besetzt sind (B). Deren Glieder tragen an kurzen Verzweigungen monosiphone, dichotom geteilte, gefärbte Haartriebe mit gekrümmten, spitz auslaufenden Zweigenden (B). Dadurch erscheint die bis $15 \mathrm{~cm}$ hohe, je nach ihrem Alter heller oder dunkelrot gefärbte Alge doch zierlich und zart. Die gefärbten, bleibenden Haartriebe trennen Brongniartella von der Gattung Polysiphonia, bei der sie frühzeitig abgeworfen werden.

Die Fortpflanzungsorgane werden an den letzten polysiphonen Astchen gebildet: walzliche gestielte Spermatangien (C) und sitzende Zystokarpien (D). Die Tetrasporangien liegen in schraubiger Anordnung einzeln in den aufeinanderfolgenden Segmenten eines Astchens (E).

Brongniartella byssoides ist eine Sommeralge des Sublitorals. Ende April findet man wenige Millimeter hohe, aus überwinterten Basalteilen entsprossene Pflänzchen; sie wachsen bis Juni rasch zu $10 \mathrm{~cm}$ großen Thalli heran. Im Juli und August sind sie fertil. Schon uberständig geworden, verschwindet Brongniartella im September.

Abb. 144: Brongniartella byssoides. A Habitus (22.7. 1975). B Ausschnitt aus einem Zweig (14.6. 1973). C, D Astchen mit Spermatangien bzw. einem Zystokarp (22.7.1975 and 30. 8. 1969). E Tetrasporangien (1.7. 1968). Maßstrecken: $A=5 \mathrm{~cm} ; \mathrm{B}=1 \mathrm{~mm} ; \mathrm{C}=100 \mu \mathrm{m} ; \mathrm{D}$, $\mathrm{E}=500 \mu \mathrm{m}$ 


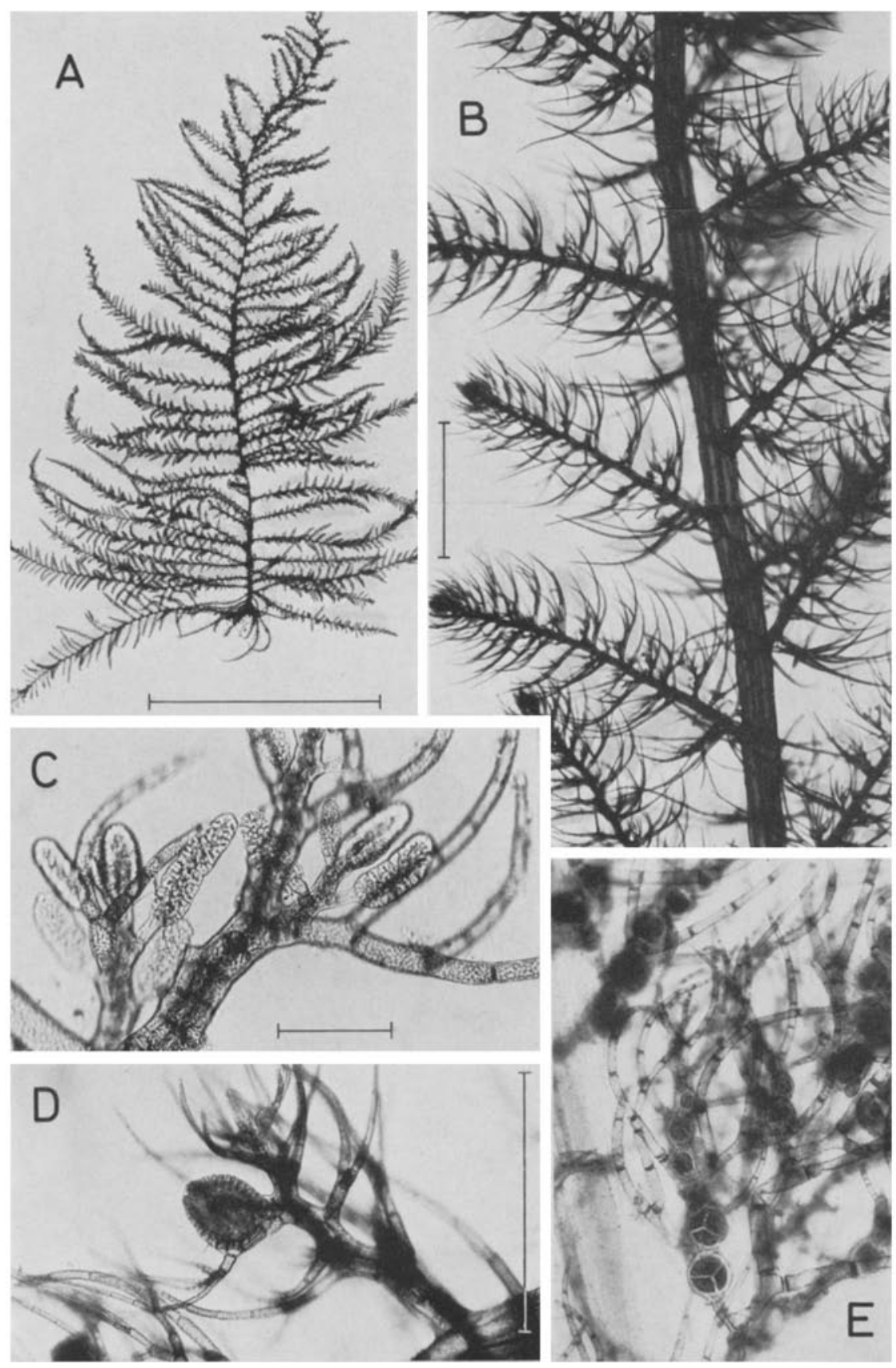




\section{Rbodomela confervoides (Huds.) Silva}

Es mag überraschen, daß die bei A und B dargestellten Formen zur selben Art gehören. Rhodomela confervoides ändert ihren Habitus wie manche anderen mehrjährigen Rotalgen im Jahresablauf. Im Januar erscheinen an den $Z$ weigenden der borstigen und dunkelroten Pflanze des Sommers und Herbstes hellrot gefärbte, dichter werdende pinselige Verzweigungen, die auch die Fortpflanzungsorgane tragen. $\mathrm{Ab}$ Mai, nachdem sich die neuen vegetativen $Z$ weige stark gestreckt haben und auch die fertilen Ästchen verlorengegangen sind, verändert sich das Aussehen immer mehr zu der kahlen Sommerform hin.

Rbodomela confervoides wächst reichlich auf Fels in flachen Tümpeln der unteren Gezeitenzone. Die Hauptachsen der bis $25 \mathrm{~cm}$ hohen Büschel sind allseitig mit wiederum verzweigten Asten besetzt. Der stielrunde Thallus besteht aus einer kräftigen Zentralachse mit 6 Perizentralen, die von einer mehrschichtigen Rinde umgeben sind. Figur $C$ läßt ihre kleinzellige Oberfläche gut erkennen.

Die fertilen männlichen Gametophyten tragen an ihren Zweigenden die dicht gebüschelten farblosen Spermatangien (D). Weibliche Gametophyten tragen bei ihrer Reife im. April und Mai die als kleine Knötchen sichtbaren Zystokarpien. Die gestielten kugeligen Behälter haben eine offene Mündung (F, G). Die Tetrasporangien liegen paarweise in den Segmenten der fertilen Astchen; sie sind tetraedrisch geteilt (C). 

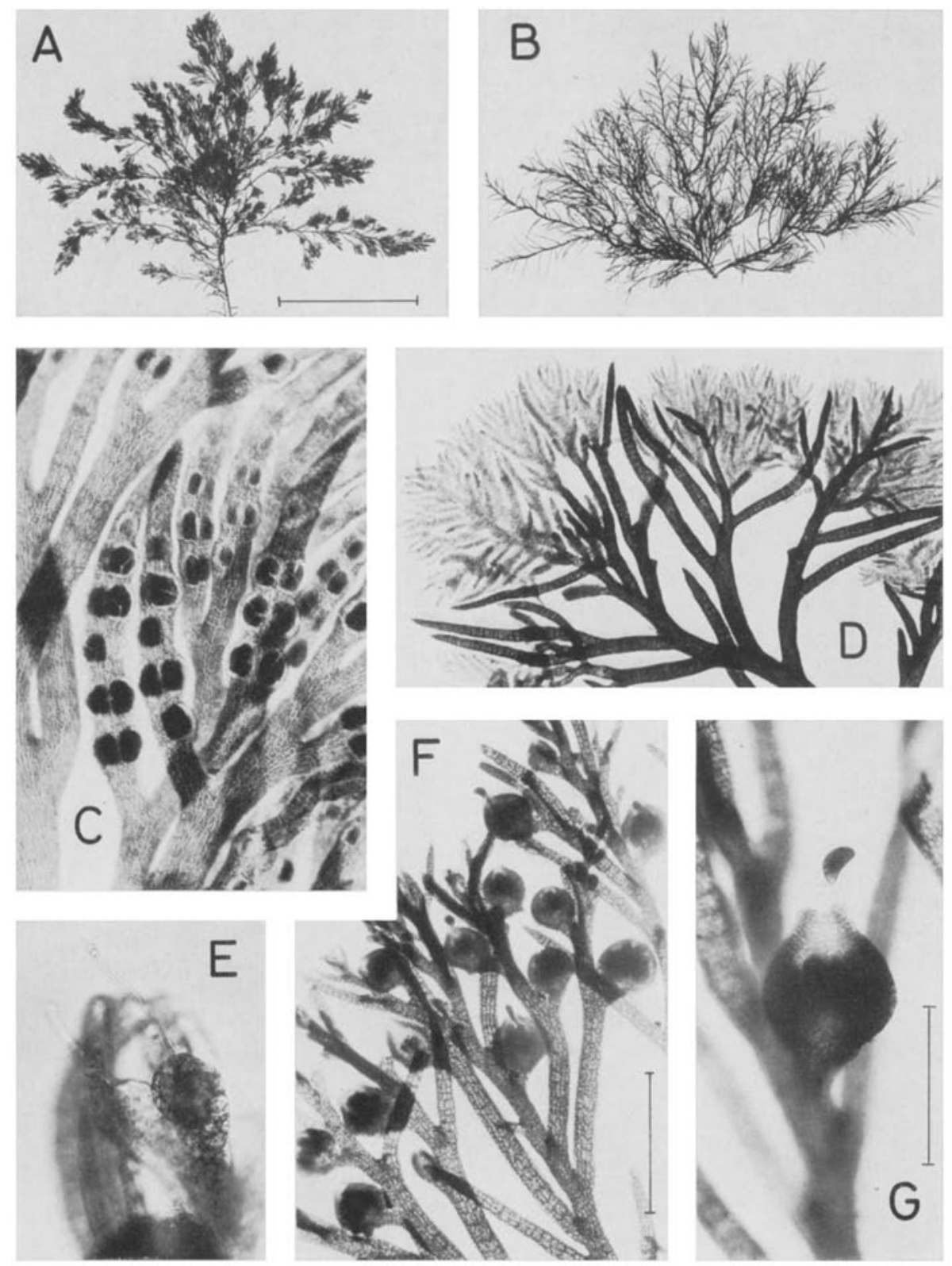

Abb. 145: Rhodomela confervoides. A Tetrasporophyt in der Frühjahrstracht (9. 4. 1969). B Habitus im Sommer und Herbst (23. 9. 1969). C Zweigstïcke mit Tetrasporangien. D Zweigenden mit Spermatangienständen (3. 4. 1969). E Prokarpien mit Trichogyne (9. 3. 1971). F, G Zweigstücke mit reifen Zystokarpien und einer freien Karpospore (5. 4. 1969). Maßstrecken: A, $\mathrm{B}=5 \mathrm{~cm} ; \mathrm{D}, \mathrm{F}=1 \mathrm{~mm} ; \mathrm{C}, \mathrm{G}=500 \mu \mathrm{m}$ 
Rhodomela virgata Kjellm.

Allein schon ihr Lebensraum trennt Rhodomela virgata von der vorhergehenden Art. Sie wächst nur im Sublitoral in mehreren Meter Tiefe, ist also nur in gedretschtem oder ertauchtem Material zu finden und wird gelegentlich auch am Strand ausgeworfen. Im vegetativen Zustand ist sie durch das sparrigere Aussehen der derberen und rotgefärbten Thalli nicht mit Rbodomela confervoides zu verwechseln.

Kennzeichnende Unterschiede prägen sich aber bei den fertilen Pflanzen aus. Die Fortpflanzungsorgane - geschlechtliche und ungeschlechtliche - entstehen nämlich nicht an den $Z$ weigspitzen wie bei $R h$. confervoides, sondern entsprossen den Achsen als besondere Kurztriebe, die nach der Fruktifikation abgeworfen werden.

Abb. 146: Rbodomela virgata. A Pflanze mit vegetativen Zweigen und fertilen Kurztrieben (11. 2. 1971) . B, C Ausschnitte aus einem Tetrasporophyten und einem weiblichen Gametophyten (25.1.1971). D Kurztrieb mit Spermatangien (29.1. 1971). E Tetrasporophyt mit fertilen Kurztrieben (25. 1. 1971). F Prokarpien mit Trichogyne. G, H Reife und sich entleerende Zystokarpien (25.1.1971). Maßstredken: $A=5 \mathrm{~cm} ; \mathrm{D}, \mathrm{G}=500 \mathrm{~mm} ; \mathrm{E}, \mathrm{H}=1 \mathrm{~mm}$ 

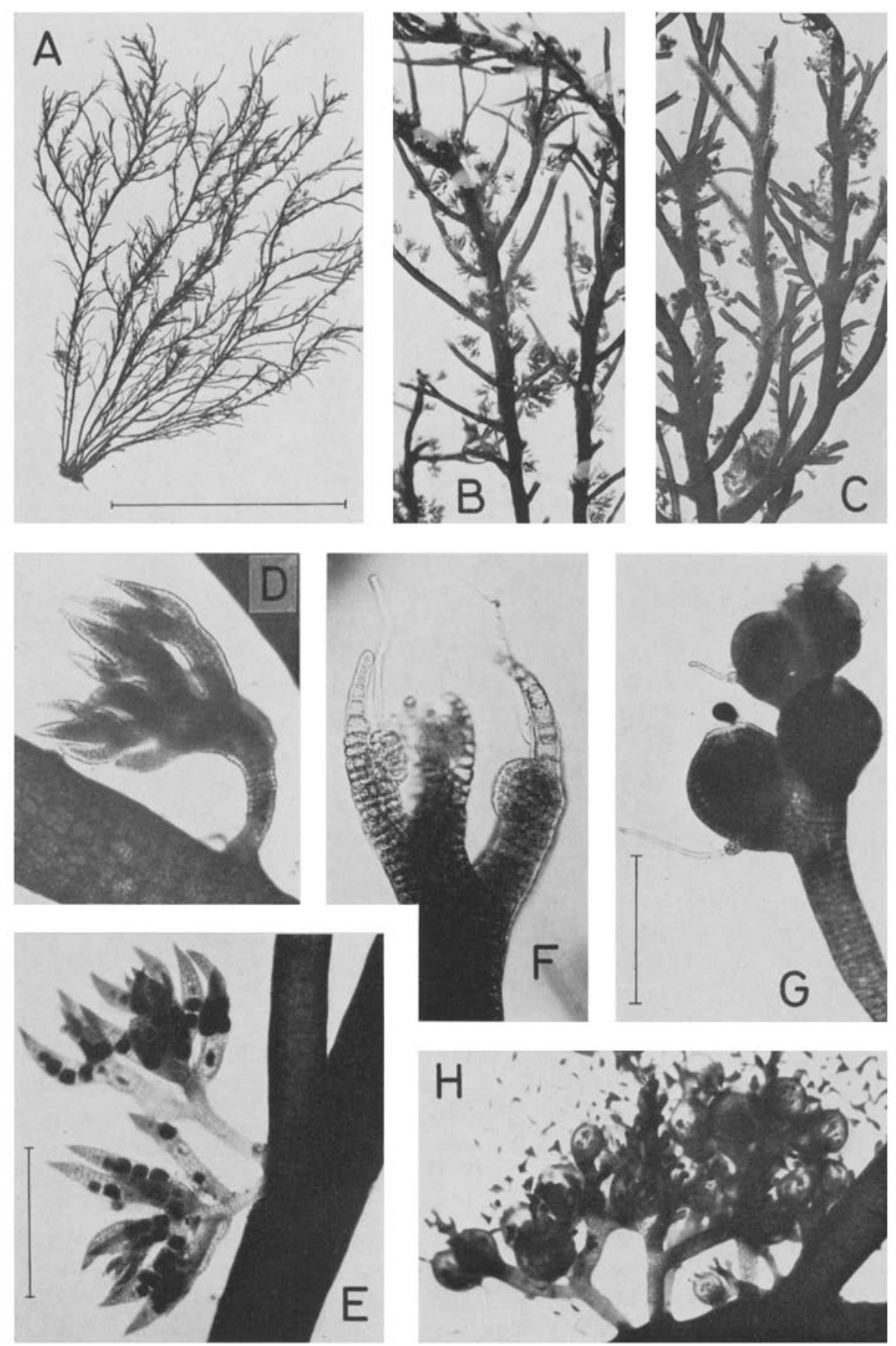


\section{Bangiophyceae}

Einfacher organisiert als die Florideophyceae, umfassen die beiden unten genannten Ordnungen dieser Klasse einzellige und koloniebildende, scheibenförmige sowie unverzweigte fädige und flächige ein- bis zweischichtige Algen. Das Wachstum erfolgt durch interkalare Teilung der Zellen, die nicht durch Tüpfel miteinander in Verbindung stehen wie die der Florideophyceae.

Alle Vermehrungszellen sind unbeweglich. Neben Monosporen, die in undifferenzierten Thalluszellen oder in besonderen Monosporangien gebildet werden, entstehen bei den Bangiaceae auch kleine und große Sporen durch Teilung von Mutterzellen. Uber die Entwicklung von Porphyra wird auf p. 264 berichtet.

Der systematischen Gliederung liegt die morphologische Organisation des Thallus zugrunde. Die Porphyridiales umfassen in mehreren Familien Einzeller sowie in Gallerthüllen fadenartig zusammengeschlossene Zellen (Goniotrichaceae, p. 256). Die Bangiales enthalten in der Familie Erythropeltidaceae (p. 258) scheibenartige Thalli oder mit einem basalen Rhizoid verankerte Fäden; die flächige Porphyropsis entwickelt sich aus einer Scheibe. Zu den Bangiaceae (p. 262) gehören die fadenförmige Bangia und die flächige Porpbyra.

\section{PORPHYRIDIALES}

Goniotrichaceae

Goniotrichum alsidii (Zanard.) Howe

Man triff diese epiphytische Kleinalge in den Sommermonaten auf Algen in abgeschlossenen Wasserbecken an, zum Beispiel in den Vertiefungen der Betonblöcke vor den Molen. Sie wächst dort häufig zusammen mit Erythrotrichia auf Ceramium rubrum, Chaetomorpha aerea oder anderen Bewohnern dieser Becken. In den bis etwa $5 \mathrm{~mm}$ hohen Büschelchen leben Einzelzellen in einem fadenförmigen Zellverband; sie liegen in einer weiten gallertigen Membran perlschnurartig gereiht (A, B). Die Fäden sind reichlich, aber unecht verzweigt. Eine beliebige Zelle ändert ihre Teilungsrichtung, durchwächst die Gallertmembran und wird zur Ausgangszelle einer Verzweigung. Gelegentlich drängen sich die Zellen in einzelnen Fadenabschnitten zusammen, jedoch geht diese scheinbare Mehrreihigkeit des Fadens nicht auf eine Längsteilung einzelner Zellen zurück (C). Die Zellen enthalten einen sternförmigen Chromatophor mit zentralem Pyrenoid (B). Er ist meist lilafarben, kann aber bei starkem Lichtgenuß der Alge recht blaß werden.

Alle Zellen sind befähigt, die vegetativen Teilungen einzustellen und als Monosporen aus dem Faden auszutreten. Die Schlauchhüllen sind dann auf längeren Strecken leer (D). Das Ausschlüpfen einer Spore ist bei $\mathrm{E}$ in vier Aufnahmen dargestellt. Die Monospore unterhalb des Buchstabens wird beim Durchtritt durch die Wandung läng. lich und kugelt sich nach dem Freiwerden wieder ab. 


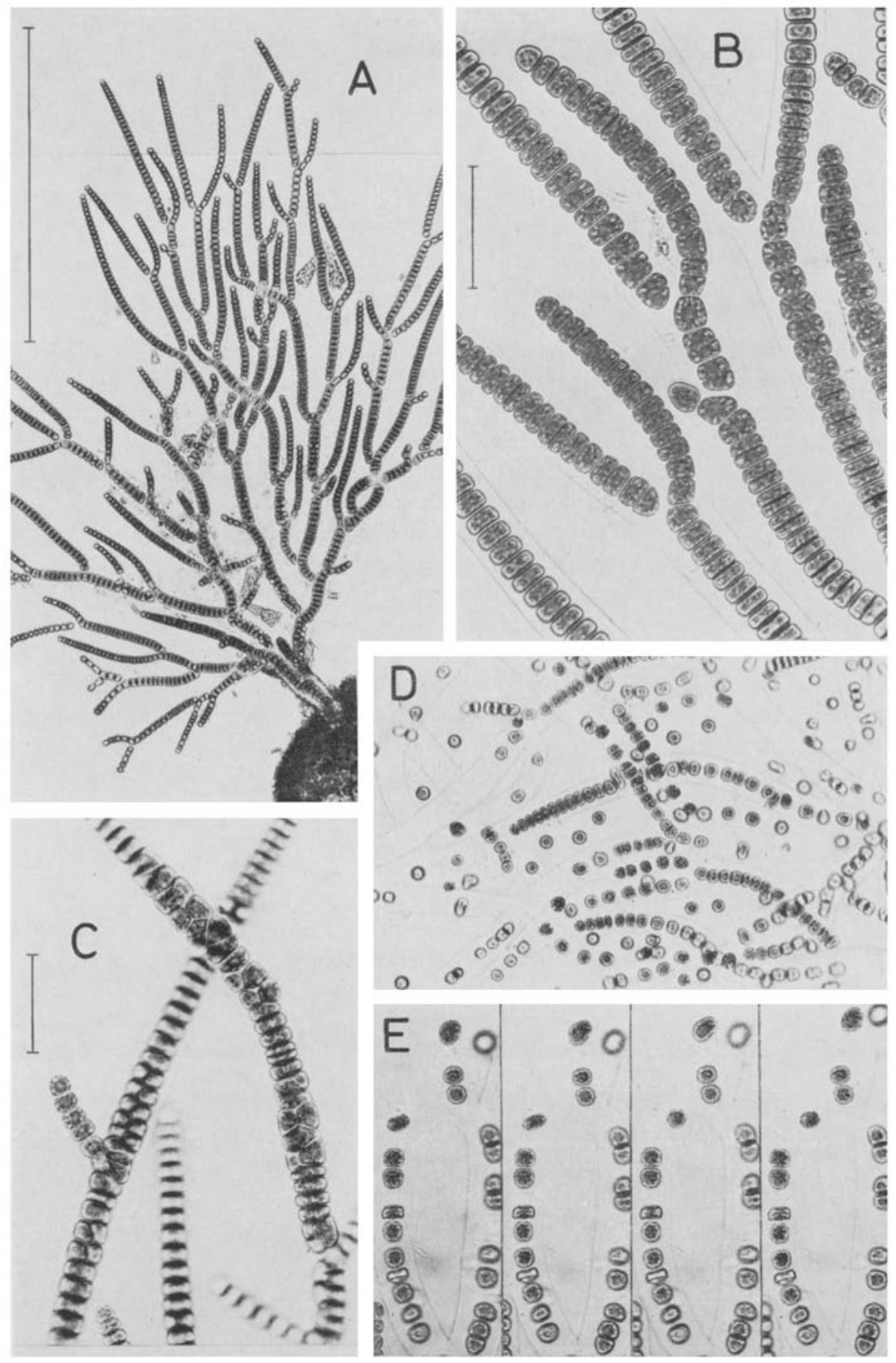

Abb. 147: Goniotrichum alsidil. A Aufbau eines Pflänzchens (18.9.1972). B, C Einreihige und scheinbar mehrreihige Fäden. D Schläuche mit Monosporen, zum Teil schon entleert. E Die Monospore unterhalb des Buchstabens durchdringt die Membran und kugelt sich wieder $a b$. Maßstrecken: $A=0,5 \mathrm{~mm} ; \mathrm{B}, \mathrm{C}, \mathrm{E}=50 \mu \mathrm{m}$ 


\section{BANGIALES}

\section{Erythropeltidaceae}

\section{Erytbrotricbia carnea (Dillw.) J. Ag.}

Mitunter hüllen die monosiphonen Fäden dieses Epiphyten ihre Wirtspflanze in einen rosafarbenen Flaum ein. Im allgemeinen tragen diese noch andere kleine Aufwuchsalgen, wie Goniotrichum oder Acrochaetium. Ceramium rubrum in abgeschlossenen Wasserlöchern, aber auch im unteren Litoral wachsend, wird gerne von Erythrotrichia carnea besiedelt. Am häufigsten kommt die Alge in den Sommermonaten vor, doch wurde sie auch einmal im Januar beobachtet.

Die unverzweigten, dünnwandigen Fäden können etwa 2,5 cm lang werden. Sie wachsen einzeln; die Basalzelle jedes Fadens bildet ein verzweigtes Rhizoid. Die Zellen enthalten einen sternförmigen Chromatophor mit zentralem Pyrenoid.

Anders als bei Goniotrichum entstehen die Monosporen hier in besonderen Sporangien. Durch eine schräge, etwas gekrümmte Wand wird aus dem oberen Teil einer Fadenzelle ein Sporangium abgetrennt. Die größere sterile Zelle hat zunächst einen lockeren Chromatophor, während der Inhalt des Sporangiums sich zur Monospore verdichtet und durch eine papillenartig vorgewölbte Offnung austritt (B, C). Die Mutterzelle kann wiederholt Monosporen bilden.

\section{Erythrotricbia reflexa (Crouan frat.) Thur. ex De Toni}

Die meist in ganz charakteristischer Weise sichelförmig gekrümmten, dunkelroten Epiphyten kommen nicht selten zusammen mit der vorigen Art und mit Goniotrichum auf Ceramium rubrum oder Chaetomorpha aerea in abgeschlossenen Wasserbecken vor. Daneben wurden sie häufig auf verschiedenen Algen in der unteren Gezeitenzone und im Sublitoral beobachtet. Zweigenden von Cladophora rupestris erschienen im August 1972 durch einen dichten Pelz von Erytbrotrichia reflexa rotgefärbt. Diese Epiphyten waren kaum länger als $1 \mathrm{~mm}$; die bei $\mathrm{D}$ abgebildeten sind ungewöhnlich großs.

Der in seinem basalen Teil einreihige Faden wird in seinem mittleren Abschnitt durch Längsteilung der Zellen mehrreihig; er erreicht hier seine größte Dicke und verjüngt sich wieder zur Spitze hin. Die Bilder $E$ und $F$ zeigen vegetative Abschnitte desselben Fadens mit besonders klaren Chromatophoren. Monosporen werden ähnlich wie bei $E$. carnea in besonderen Sporangien gebildet.

Wahrscheinlich kommt $E$. reflexa während des ganzen Jahres vor; sie wurde im Januar bis März sowie im Juni bis September beobachtet. 

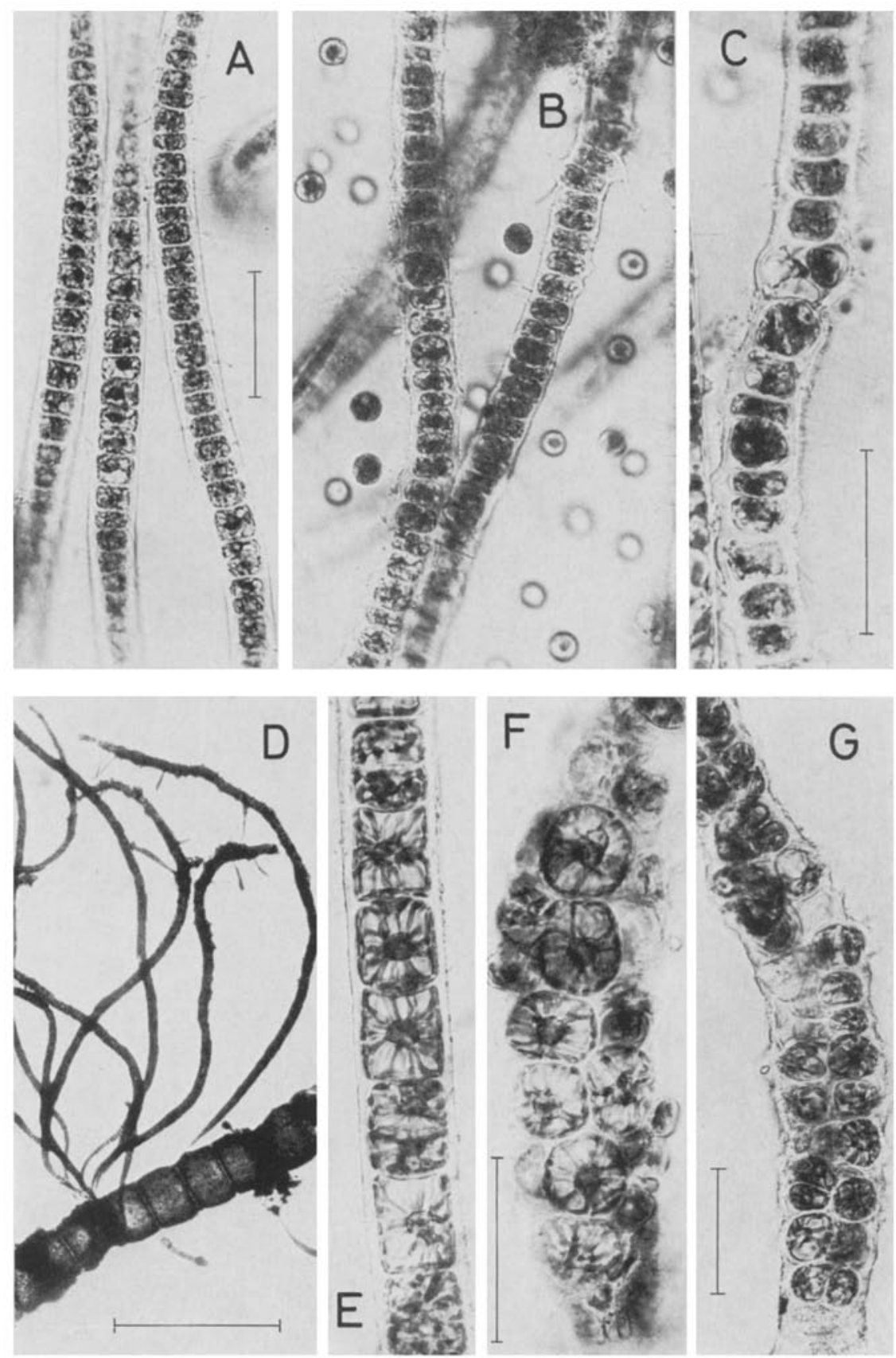

Abb. 148: A-C Erytbrotricbia carnea. A Vegetative Fäden. B, C Fäden mit Monosporangien und freien Sporen. D-G Erytbrotrichia reflexa. D Sichelförmig gekrümmte Epiphyten auf Chaetomorpha aerea (21. 6. 1975). E, F Vegetative Fadenabschnitte. G Fertiles Fadenstiuck (2. 8. 1969). Maßstrecken: $A, B, G=50 \mu \mathrm{m} ; C, E, F=50 \mu \mathrm{m} ; \mathrm{D}=1 \mathrm{~mm}$ 
Porpbyropsis coccinea (J. Ag. ex Aresch.) Rosenv.

Einer kleinen Porpbyra-Art ähneln die zarten, einschichtigen, bis etwa $3 \mathrm{~cm}$ großen, rundlich-ovalen Thalli von kräftig rosenroter Farbe (A, B). Die Abtrennung von dieser Gattung ist durch mehrere Unterschiede begründet. Anders als Porpbyra bildet Porpbyropsis Monosporen in besonderen Sporangien, dabei wird wie bei Erythrotrichia nach einer ungleichen Teilung die kleinere Zelle zum Sporangium, während die größere vegetativ bleibt.

Auch die Entwicklung zeigt eigene Merkmale. Eine auf dem Substrat kriechende, parenchymatische Scheibe wölbt sich zu einem kugeligen Bläschen auf. Es reißt schon frühzeitig auf, und der einschichtige Thallus entsteht in ähnlicher Weise wie bei Monostroma (C, D). Ein weiteres unterscheidendes Merkmal gegen Porphyra ist der wandständige, stark ausgebuchtete Chromatophor ohne Pyrenoid in den viel kleineren Zellen $(\mathrm{E}$, rechts).

Vollentwickelte Pflanzen sind von Juni bis August häufig als Epiphyten auf Desmarestia aculeata oder Rbodomela virgata in $6 \mathrm{~m}$ Tiefe anzutreffen. Zu dieser Zeit treiben Porpbyropsis-Fragmente nach stümischem Wetter stets im Plankton. Junge Stadien, die den bei C, D abgebildeten entsprechen, fanden wir wiederholt schon Anfang April auf Chaetomorpha melagonium dicht unter der Niedrigwasserlinie an schattigen Stellen. An diesen Standorten wächst Porphyropsis jedoch nicht zu voller Größe heran. 

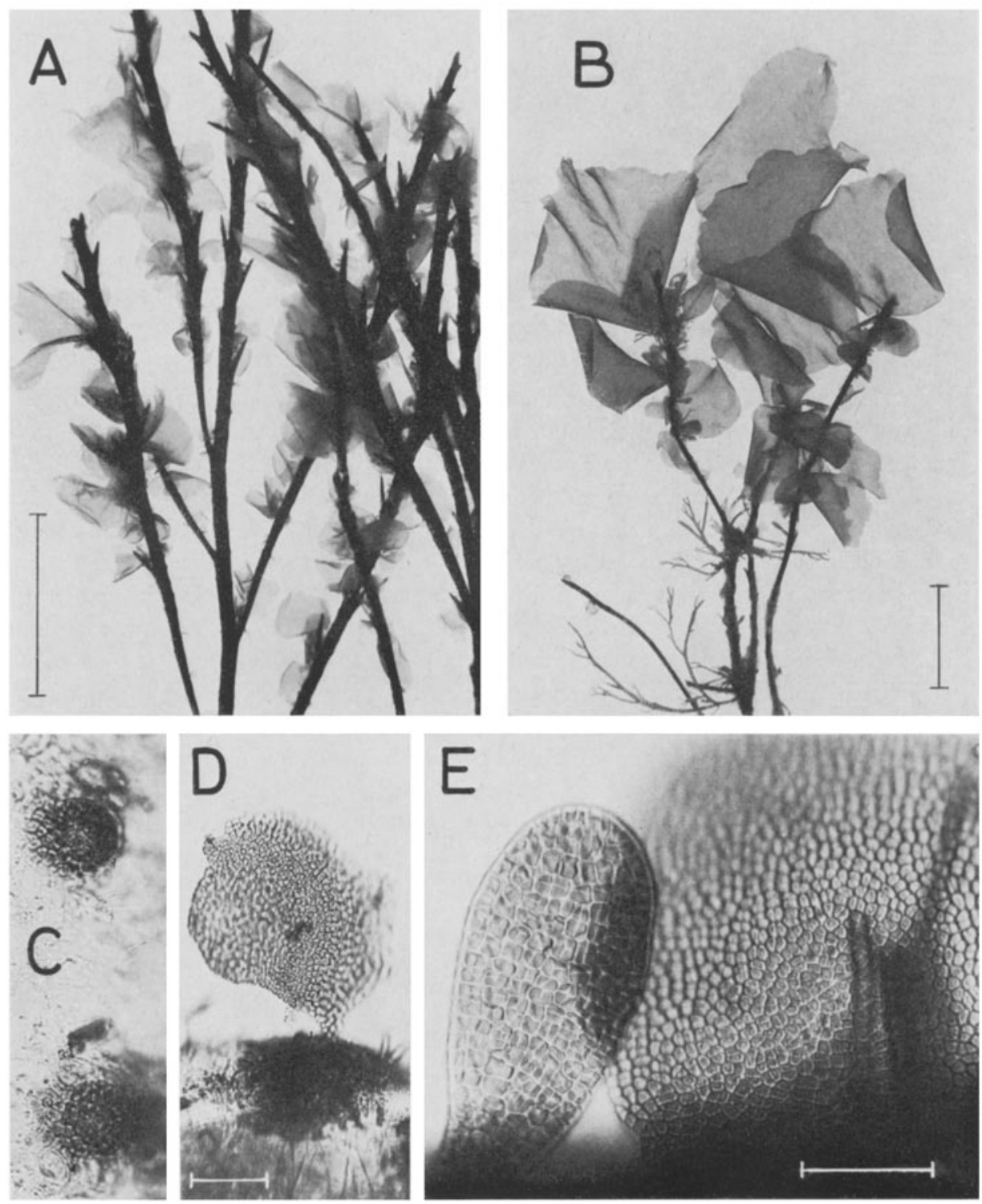

Abb. 149: Porphyropsis coccinea. A, B Epiphytisch auf Desmarestia aculeata (3. und 26. 6. 1971). C, D Jugendstadien auf dem Hydroidpolyp Laomedea (25. 5. 1972). E Links ein noch einschichtiger Laminaria-Sporophyt, rechts die kleinzellige Fläche von Porphyropsis (10. 4. 1975). Maßstrecken: $A$ und $B$ jeweils $=1 \mathrm{~cm} ; C, D=50 \mu \mathrm{m} ; \mathrm{E}=50 \mathrm{~mm}$ 


\section{Bangia atropurpurea (Roth) C. Ag. syn. Bangia fuscopurpurea}

Als rotbraunes Band glattgekämmter fädiger Algen hat Bangia atropurpurea ihren Platz in einer Zone über der Hochwasserlinie, die regelmäßig von den auflaufenden Wellen überspült wird. An der Uferschutzmauer im Südwesten der Insel kann Bangia zeitweilig ein geschlossenes Band oberhalb von Blidingia minima bilden (A, der helle Streifen in der Mitte des Bildes ist Blidingia). Auch die Flächen der den Molen als Wellenbrecher vorgelagerten Betonblöcke sind von Herbst bis Frühjahr oft vollständig von Bangia überzogen. Auf Bojen siedelt sie sich in der Zone des schwankenden Eintauchens an. Hier findet man sie auch in den Sommermonaten langfädig und gut entwickelt, während sie dann an anderen Standorten meist nicht genügend benetzt wird und ihre Reste einen kurzen krausen Belag bilden.

Die Fäden von Bangia atropurpurea sind unverzweigt und zumindest an der Basis einreihig. Meist werden aber die flachen Zellen durch radiale Längswände geteilt, so daß ein mehrreihiger Thallus entsteht. Da diese Teilungen in den übereinanderliegenden Scheiben nicht korreliert sind oder in einzelnen Zellen unterbleiben, haben die Fäden oft ein etwas unregelmäßig knotiges Aussehen (C, D). Die Zellen enthalten einen zentralen sternförmigen Chromatophor mit Pyrenoid (C).

Die Helgoländer Population von Bangia atropurpurea vermehrt sich durch Monosporen, die unmittelbar aus vegetativen Zellen entstehen (E, F). Die fertilen Thallusenden verquellen, und die freigewordenen Sporen keimen zu einer neuen Fadengeneration aus. Nur äußerst selten wurden Fäden beobachtet, deren Zellen in kleine Sporen aufgeteilt waren.

\section{Porphyra C. Agardh}

Der Thallus der bei Helgoland vorkommenden Arten besteht aus einer einschichtigen Zellfläche, in der alle Zellen sich mehr oder weniger regelmäßig in zwei Hauptrichtungen teilen (Abb. $153 \mathrm{C}$ ). Sie enthalten einen zentralen sternförmigen Chromatophor mit Pyrenoid. Nahe der Basis wachsen die Zellen rhizoidartig aus und schließen sich zu einem kurzen Stielchen mit einer Haftscheibe zusammen.

Als Fortpflanzungszellen werden im allgemeinen in getrennten Arealen derselben Pflanze kleine und große Sporen gebildet. Dabei wird eine Mutterzelle durch senkrecht aufeinanderstehende Wände in 64 kleine, nahezu farblose Sporen aufgeteilt $(\mathrm{Abb} .155 \mathrm{C}, \mathrm{D})$; die großen Sporen entstehen $\mathrm{zu}$ acht aus einer Mutterzelle. Die Anzahl der Sporen ist artspezifisch. Es lag nahe, diese Sporen mit einer geschlechtlichen Fortpflanzung in Beziehung zu bringen und die kleinen als Spermatien, die großen als "Karposporen" nach vorausgegangener Befruchtung anzusehen. Ein überzeugender Nachweis für diese Deutung konnte jedoch noch nicht erbraçht werden. 


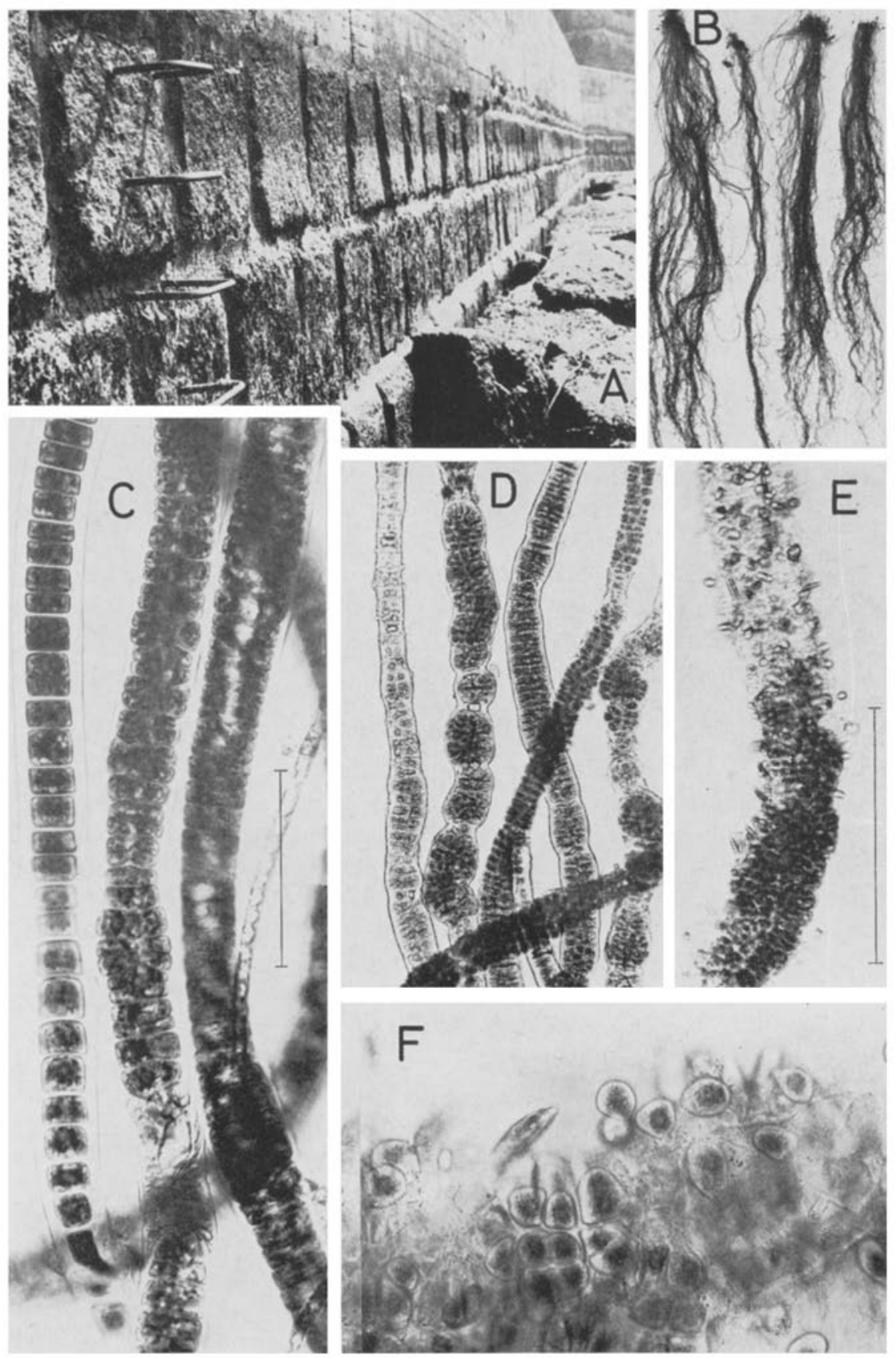

Abb. 150: Bangia atropurpurea. A Uferschutzmauer mit breitem Band von Bangia über der weiß reflektierenden Zone von Blidingia minima, darunter Porphyra umbilicalis (5.6.1972). B Etwa $8 \mathrm{~cm}$ lange Fäden von einer Boje (8.5.1970). C, D Ein- und mehrreihige Fäden, E, F Fertile Thallusenden. Maßștrecken: $C, F=100 \mu \mathrm{m} ; \mathrm{D}, \mathrm{E}=500 \mu \mathrm{m}$ 
Aus den großen Sporen entwickelt sich eine ganz andersartige Generation: das aus dünnen, einreihigen verzweigten Fäden bestehende Conchocelis-Stadium. In freier Kultur bildet sie lockere Watten, in Berührung mit Kalkschalen dringen die Fäden aber in dieses Substrat ein und verzweigen sich ziemlich regelmäßig (Abb. $151 \mathrm{E}, \mathrm{F}$ ). Als kalkbohrende Rotalge ist Conchocelis rosea schon seit 1892 bekannt, doch war ihre systematische Stellung unsicher, bis Drew (1949) den entwicklungsgeschichtlichen Zusammenhang aufklärte. Außerhalb des Substrats entstehen an besonderen, dickeren Zweigsystemen Sporen (Abb. 151 F), aus denen die Porphyra-Generation hervorgeht. In dieser Aufeinanderfolge heteromorpher Generationen sind jedoch die zytologischen Verhältnisse ungeklärt, da weder Kernverschmelzung noch Reduktionsteilung mit Sicherheit beobachtet werden konnten.

Die fünf bei Helgoland vorkommenden Porphyra-Arten sind morphologisch genügend gekennzeichnet, um an Hand der folgenden Beschreibungen und Abbildungen erkannt zu werden.

\section{Porphyra umbilicalis (L.) J. Ag.}

Diese Art ist in der Gezeitenzone bis zur Hochwasserlinie weit verbreitet. Die Standortaufnahme (A) an einer inneren Hafenmole zeigt sie zwischen Prasiola stipitata und Blidingia minima wachsend. Die herabhängenden Talli sind zu derb, um sich dem Substrat anzuschmiegen, sie trocknen bis zur nächsten Benetzung zu harten Zöpfen ein.

Der in Wasser untergetauchte Thallus ist eine wellig-faltige, gallertig sich anfuhlende Haut; die scheinbar zentrale Anheftung bei vielen Pflanzen (B) ergibt sich aus dem frühzeitig einsetzenden fächerförmigen Umwachsen des basalen Haftorgans. Da bei kann es auch zur Ausbildung einzelner Thalluslappen kommen. Langgestreckte oder unregelmäßig gelappte Exemplare mit einer Haftscheibe am Grunde einer herzförmigen Einbuchtung findet man besonders in der mittleren Gezeitenzone. Die Farbe von Porpbyra umbilicalis variiert je nach den jahreszeitlich und der Lage des Standorts bedingten Lichtverhältnissen von violettrot zu rotbraun bis grünlich-violett. Sporenbildende Randpartien heben sich durch ihre gelblich-weiße beziehungsweise dunkler rote Färbung von dem vegetativen Thallus $a b$; die Sporen werden durch Verquellen und Auflösung des Thallusrandes frei $(C, D)$.

Porphyra umbilicalis ist während des ganzen Jahres an Hafenmauern und Wellenbrechern an der Hochwasserlinie zu finden. Sie kommt auch in der Eintauchzone von Bojen vor, wo ihre Thalli aber zarthäutiger sind als bei den lange trockenfallenden Pflanzen an der Hodwasserlinie. Besonders in den Sommermonaten triff man Porphyra umbilicalis auch auf dem Felswatt in der Zone von $F$ zucus vesiculosws und $F$. serratus an.

Abb. 151: Porphyra umbilicalis. A Innere Mole des Südhafens; oben Prasiola stipitata, in der Mitte Porpbyra umbilicalis, darunter Blidingia minima (23.9. 1971). B Thallus mit zentraler Haftscheibe (11. 8. 1972). C, D Verquellende Randpartien mit kleinen beziehungsweise großen Sporen. E Conchocelis-Stadium in einer dünnen Kalkschale wachsend. F Conchocelis-Stadium in freier Kultur mit breiten, sporogenen $Z_{\text {weigen. Maßstrecken: } B}=5 \mathrm{~cm} ; C, D=500 \mu \mathrm{m}$; $\mathrm{E}, \mathrm{F}=300 \mu \mathrm{m}$ 

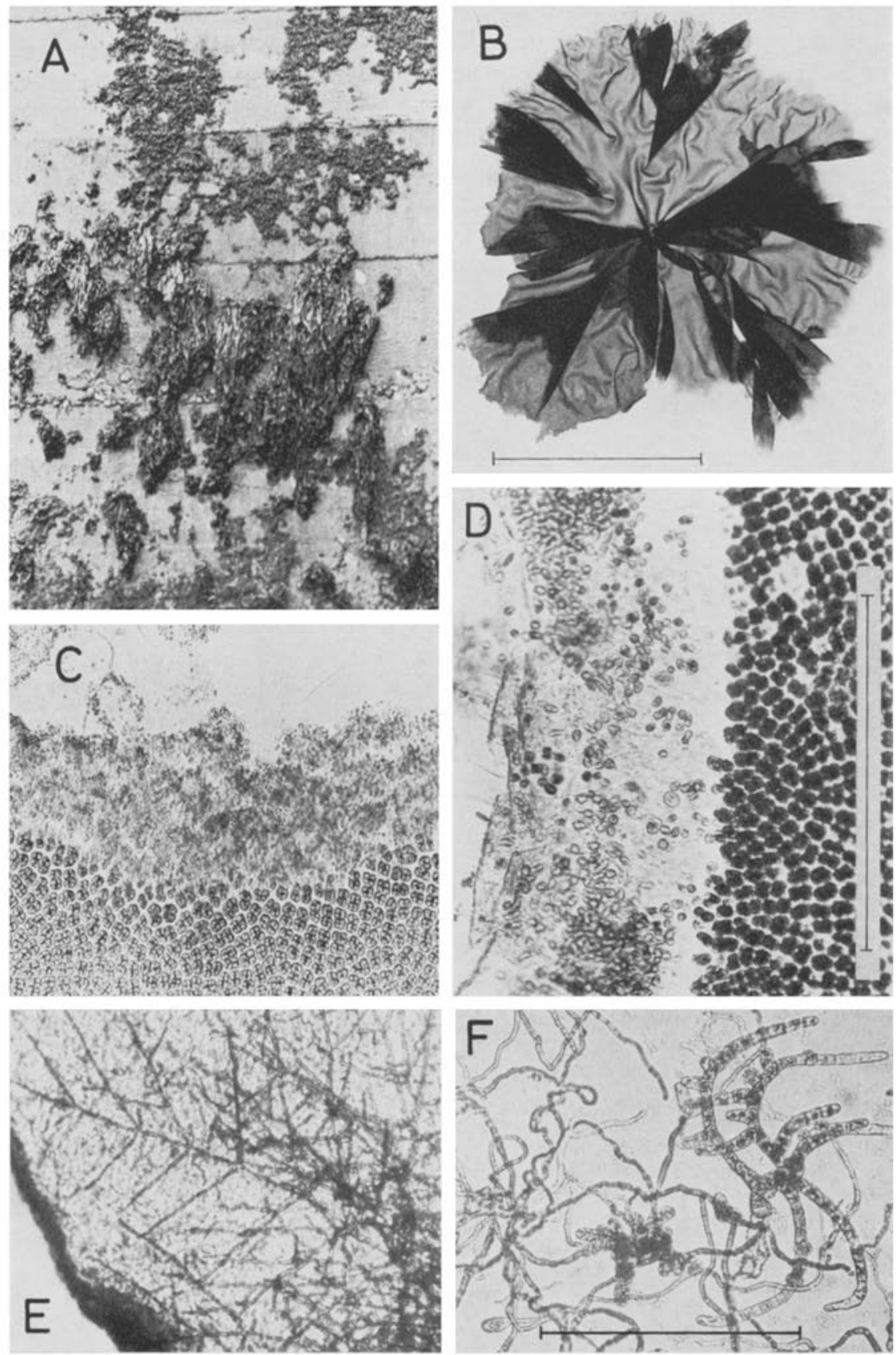
Porphyra purpurea (Roth) C. Ag.

In ihrer äußeren Erscheinung ist Porpbyra purpurea sehr variabel: schmal lanzettliche oder breit zungenförmige Pflanzen mit basaler Haftscheibe (A) kommen neben ovalen, exzentrisch verankerten Formen vor (B), und schließlich kann der Thallus auch in mehrere unregelmäßige Lappen aufgeteilt sein. Die dünne, braunrote Fläche hat einen gewellten Rand. Von Juni bis Anfang Oktober kommt Porpbyra purpurea häufig auf Steinen, seltener epiphytisch auf Fucus in der oberen und mittleren Gezeitenzone vor. Lose liegende Felsblöcke sind oft dicht besiedelt; zur Ebbezeit schmiegen sich die dünnen Thalli den Unebenheiten des Substrats an. Von Sonne und Wind getrocknet, überziehen sie die Blöcke als ladkartig glänzende Schicht (D).

Fertile Pflanzen sind ab Juli immer zu finden. Oft trennt eine scharfe Grenze den Thallus in einen blaßroten, nach außen gelblich werdenden Teil von der intensiv dunkelbraunrot gefärbten Hälfte ab (A). Da die kleinen Sporen früher entleert werden, ist der hellgefärbte Teil meist kleiner als der dunklere oder auch schon vollständig abgelöst (B).

\section{Porphyra leucosticta Thur. in Le Jol.}

Von April bis Ende Juli findet man Porphyra leucosticta vorwiegend epiphytisch auf Fucus serratus, seltener auf totem Substrat. Nur die jungen Pflanzen sind fast eben und lassen die basale Anheftung erkennen. Altere Pflanzen sind faltig-gewellt; das inzwischen von den basalen Partien umwachsene Haftorgan liegt exzentrisch in einem länglich-ovalen bis rundlichen, äußerst zarthäutigen Thallus. Ihren Artnamen verdankt Porpbyra lewcosticta den fast farblosen, scharf abgegrenzten Inseln in Randnähe (B). In ihnen werden kleine Sporen, in den sie umgebenden dunkler gefärbten Teilen große Sporen gebildet (D-F).

Porphyra lencosticta ist kräftig rosenrot bis braunrot, die Pflanzen können etwa $30 \mathrm{~cm}$ groß werden.

\section{Porphyra linearis Grev.}

Durch ihren Artnamen ist Porphyra linearis treffend gekennzeichnet; der lanzettliche Thallus wird im allgemeinen nicht breiter als $1 \mathrm{~cm}$. Die Flächen sind eben oder nur am Rand leicht gewellt (A). Uber dem kurz gestielten basalen Haftorgan erreicht der Thallus schnell seine volle Breite (C).

Von Mitte Oktober bis Ende März findet man die braunrote Alge auf festem Substrat an der Hochwasserlinie und in der Spritzzone, häufig zusammen mit Bangia atropurpurea. Selbst auf der Krone der Uferschutzmauer im Südwesten der Insel kann Porpbyra linearis an einzelnen, häufig durch Spritzwasser benetzten Stellen gedeihen. 

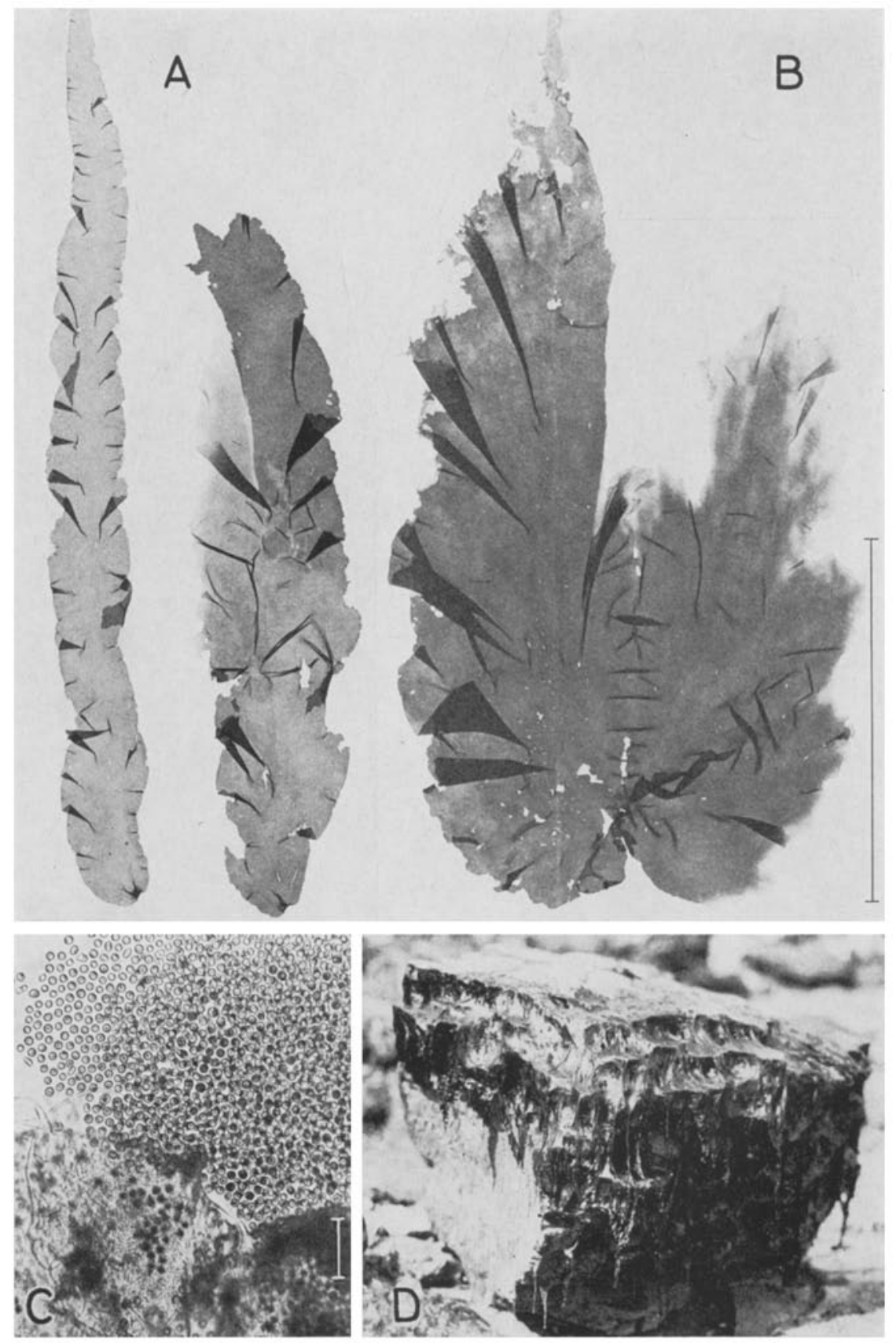

Abb. 152: Porphyra purpurea. A Langgestreckte Formen mit basaler Haftscheibe (Herbarblatt, 9. 8. 1963). B Ovaler Thallus mit exzentrischer Haftscheibe, ein Teil der kleine Sporen erzedgenden Flächen ist schon verloren (Herbarblatt, 26. 9. 1961). C Entleerte große Sporen. D Felsblock mit einem lackartig glänzenden Überzug von angetrockneter Porphyra purpurea (25. 7, 1970). Maßsțrecken: $A, B=10 \mathrm{~cm} ; C=100 \mu \mathrm{m}$ 

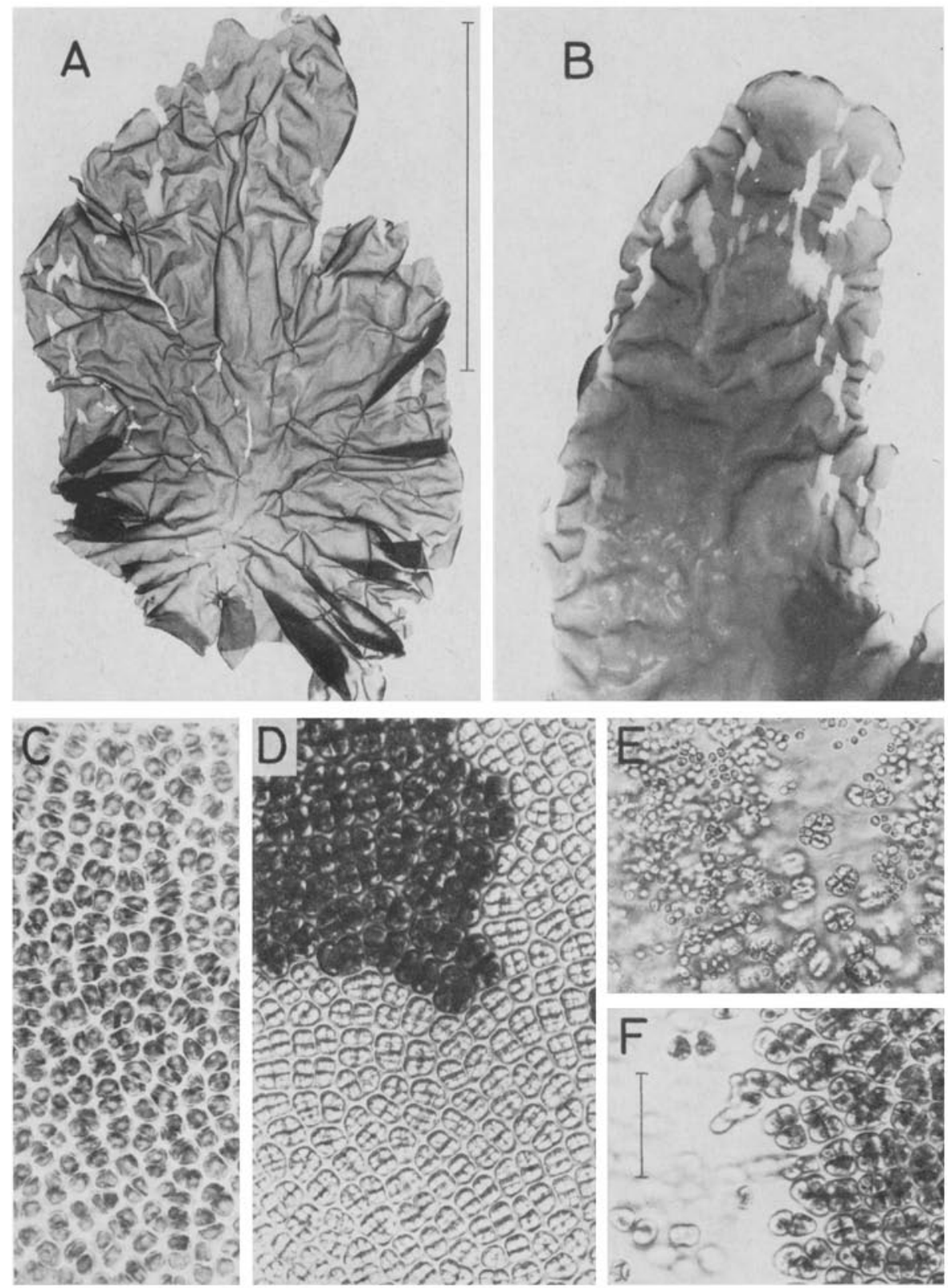

Abb. 153: Porphyra leucosticta. A Fertile Pflanze (16.6.1972). B Fertiles Thallusstiuck in etwa natürlicher Größe (7. 7. 1970). C Aufsicht auf den vegetativen Thallus. D Fertiles Thallusstüick mit groß-bzw. kleinsporigem Areal. E, F Verquellende Thallusstücke mit kleinen bzw. großen Sporen. Maßstrecken: $A=10 \mathrm{~cm} ; C-F=50 \mu \mathrm{m}$ 

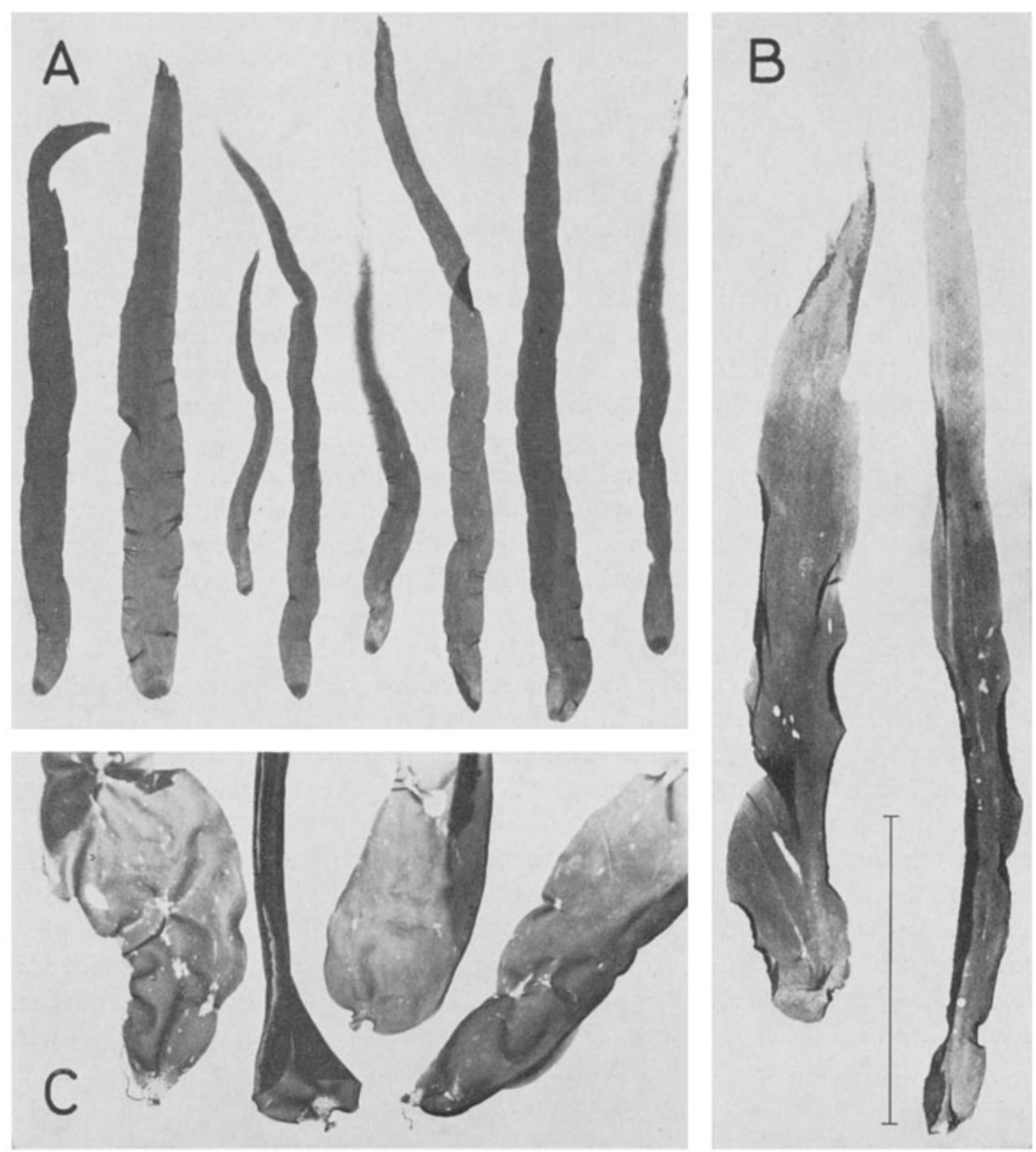

Abb. 154: Porphyra linearis. A, B Herbarmaterial vom 9. 11. 1968 und 9. 1. 1964. C Basis lebender, schon etwas überständiger Pflanzen, etwa $\times 2$. Maßsstrecke: $A, B=5 \mathrm{~cm}$ 


\section{Porphyra spec.}

Es handelt sich hier um die Art, die mit Vorbehalt als Porpbyra amethystea Kütz. bezeichnet wurde (Kornmann, 1961c). Ob sie mit dem im Leidener Herbarium verwahrten Typus übereinstimmt, läßt sich nicht mit Sicherheit feststellen. Conway (1964) untersuchte die Porphyra-Populationen an einigen als Fundort des Typus in Betracht kommenden irischen Küstenabschnitten (der eigentliche Fundort ist nicht bekannt) mit dem Ergebnis, daß Porphyra amethystea eine durch die ökologischen Verhältnisse des Standorts bedingte Form von Porpbyra umbilicalis ist.

Dieser Befund triff für die Helgoländer Pflanze sicherlich nicht zu. Als "andersartig" fiel sie bei ihrer ersten Beobachtung am 6. März 1959 an einem eng begrenzten Standort der Düne durch ihren dicken, schwärzlich-grünlich-violetten Thallus auf. In den folgenden fünf Jahren siedelte sie sich im Bereich der Düne an mehreren Stellen an, 1968 wurde sie erstmals an Betonblöcken am Strand vor der Kurpromenade der Hauptinsel beobachtet. 1972 trat die Alge zunächst im Nordost-Felswatt an Betonblöcken und 1975 auch an der Südwestseite in einzelnen Exemplaren auf. Jedesmal war es ihr andersartiger. Habitus, durch den sie in dem seit vielen Jahren gut bekannten und räumlich begrenzten Beobachtungsgebiet als Besonderheit auffiel.

Ein objektives Merkmal für die Spezifität dieser Form bietet die Ausbildung des freiwachsenden Conchocelis-Stadiums, worauf bereits früher hingewiesen wurde (Kornmann, 1961c). Fadendicke und Wuchsform dieser Generation sind bei Porphyra umbilicalis und der noch unbestimmten Art völlig verschieden. Auch die in Kalkschalen wachsenden Conchocelis-Stadien zeigen Unterschiede in der Fadendicke und dem Verzweigungswinkel (Abb. $151 \mathrm{E}$ und $155 \mathrm{~F}$ ).

Porphyra spec. ist das ganze Jahr über in der oberen Gezeitenzone im Bereich von Porphyra umbilicalis vorhanden. In ihrer äußeren Form ist sie recht vielgestaltig; sie kann breit zungenförmig (A) oder herzförmig sein mit basaler Haftscheibe. Wächst dann die Fläche vorzugsweise in tangentialer Richtung weiter, rückt die Haftscheibe in die Mitte eines genabelt erscheinenden Thallus (B). Schließlich gibt es auch unregelmäßige gelappte Pflanzen. Im Durchschnitt schon größer als Porpbyra umbilicalis, können die Pflanzen $40 \mathrm{~cm}$ Durchmesser oder eine Länge von $60 \mathrm{~cm}$ bei $25 \mathrm{~cm}$ Breite erreichen. Durch die besonders dicke und feste Membran sowie ihre eigentümlich schwärzlich graugrüne oder braunrote bis violette Farbe unterscheidet sie sich äußerlich klar von $P$. umbilicalis. Der oft nur schmale Saum, in dem die kleinen Sporen entstehen, ist auffallend hell-gelblich, während die Zonen, in denen große Sporen gebildet werden, ihre Farbe nur geringfügig ändern. Gelegentlich werden die sporenbildenden Areale durch eine deutliche Linie voneinander getrennt.

Abb. 155: Porpbyra spec. A Breit zungenförmiger Thallus (3. 2. 1971). B Lappig zerteilter Thallus mit zentraler Anheftung (25.6. 1970). C, D Thallusrand mit kleinen Sporen in der Aufsicht und im Querschnitt. E Verquellender Rand mit großen Sporen (wie vorige 20. 8. 1970). F Conchocelis-Stadium in Kalkschale wachsend. Maßstrecken: $A, B=10 \mathrm{~cm} ; C-E=$ $50 \mu \mathrm{m} ; \mathrm{F}=300 \mu \mathrm{m}$ 

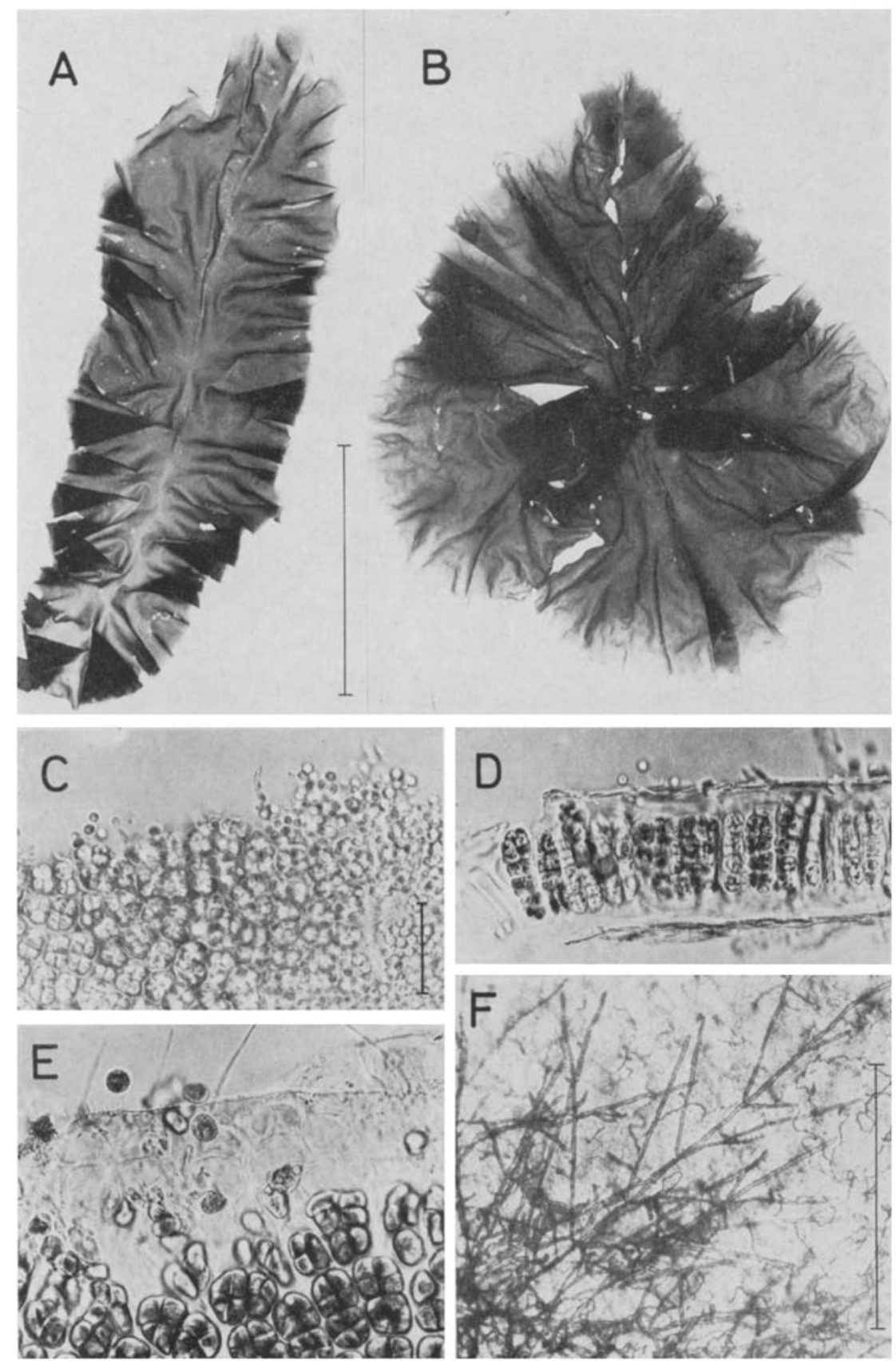


\title{
Einige selten beobachtete Arten
}

In der Systematischen Ubersicht (p. 3) sind die Gattungsnamen in Klammern aufgeführt.

\section{CHLOROPHYTA}

\author{
Kornmannia leptoderma (Kjellm.) Bliding \\ syn. Monostroma leptodermum
}

Über diese zu Anfang der 60er Jahre bei Helgoland recht häufige Frühjahrsalge wurde früher ausführlich berichtet (Kornmann \& Sahling, 1962b). Nach 1966 haben wir sie nur 1974 und 1975 jeweils einmal im Plankton treibend wieder beobachtet. Doch ist ihr Vorkommen auch schon 1934 belegt: O. C. Schmidt (1938) beschrieb sie als neue Art unter dem Namen Monostroma belgolandicum, weist aber auf "eine gewisse Strukturähnlichkeit" mit Monostroma leptodermum hin. Da ihre Entwicklungsgeschichte die Zugehörigkeit zu Monostroma ausschließt, schuf Bliding (1968) die Gattung Kornmannia, die er zusammen mit Blidingia als abweichende Gattungen den Monostromataceae angliedert. Mit der gleichen. Einschränkung haben wir sie zu den Ulvaceae gestellt.

Die äußerst zarthäutige, sehr hellgrün gefärbte Alge wuchs - mitunter in dichtem Bestand - auf Steinen im unteren Litoral an mehreren Stellen des Hafengebiets und auf der Düne. Wenn sie in flachem Wasser flutet, wird man leicht auf sie aufmerksam, trockenliegende Exemplare fallen überhaupt nicht auf. $1963 \mathrm{kam}$ diese Art am reichlichsten und zugleich auch mit den größten Exemplaren vor, einige erreichten $12 \mathrm{~cm}$ Länge. Der rundliche bis langgestreckte Thallus ist nur leicht gewellt, einfach oder in mehrere Lappen geteilt. Die Fläche setzt sich meist deutlich gegen den hohlen Stiel ab, in dem sich mitunter Detritus ansammelt (Abb. 156). Trotz ihrex Zartheit hat die sehr kleinzellige Membran eine erhebliche Festigkeit. Selbst die ausgeschwärmten Partien werden nicht abgestoßen; ein meist 1-3 Reihen breiter Saum von vegetativen Zellen bleibt erhalten.

Die Vermehrung erfolgt durch viergeißelige Schwärmer. Aus ihnen entsteht eine fest auf dem Substrat haftende Scheibe, auf der sich die röhrige Basis des oben flächig sich erweiternden Thallus erhebt. Die ontogenetische Entwidklung ist also der von Blidingia recht ähnlich. 


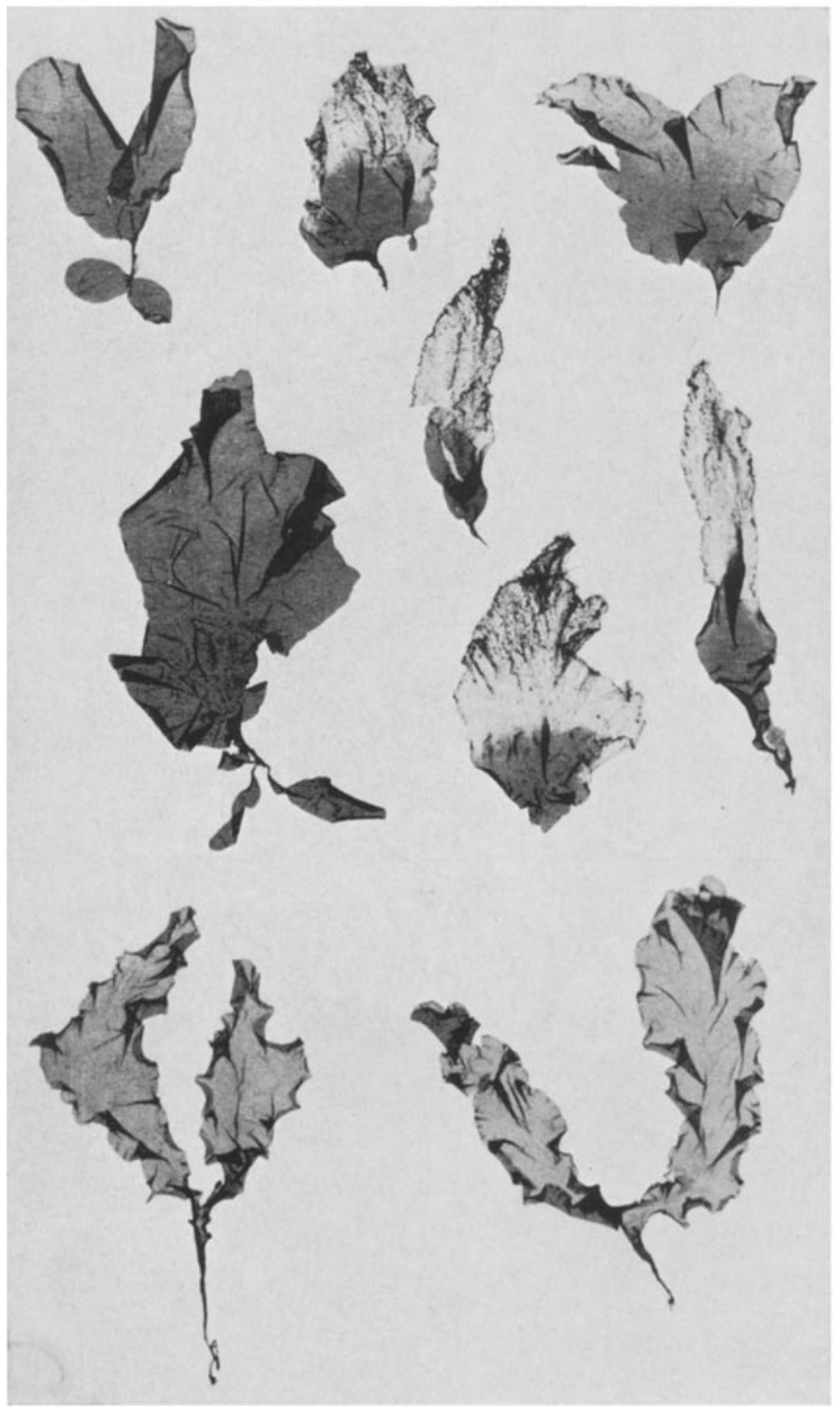

Abb. 156: Kornmannia leptoderma (2.5.1962, die beiden unteren 23. 5. 1963). Auf den ausgeschwärmten Flächen mit Zoosporenkeimlingen. Natürliche Größe 


\section{PHAEOPHYTA}

\section{Mikrosyphar polysipboniae Kuck.}

Kuckuck (1897a) entdeckte die in der Membran von Rotalgen kriechende Ectocarpacee in Polysiphonia urceolata, doch kommt sie auch in anderen Wirtsalgen vor. Wir sammelten die Art im Mai 1972 in Ceramium deslongchampsii (Abb. 157). Die monosiphonen, wenig verzweigten Fäden aus rundlichen Zellen können sich flächenartig zusammenschließen und geben dann den Wirtspflanzen einen bräunlichen Anflug. Die Zellen enthalten meist 1-2 Chromatophoren, ausgebuchtete, zuweilen etwas bandförmig verlängerte Platten.
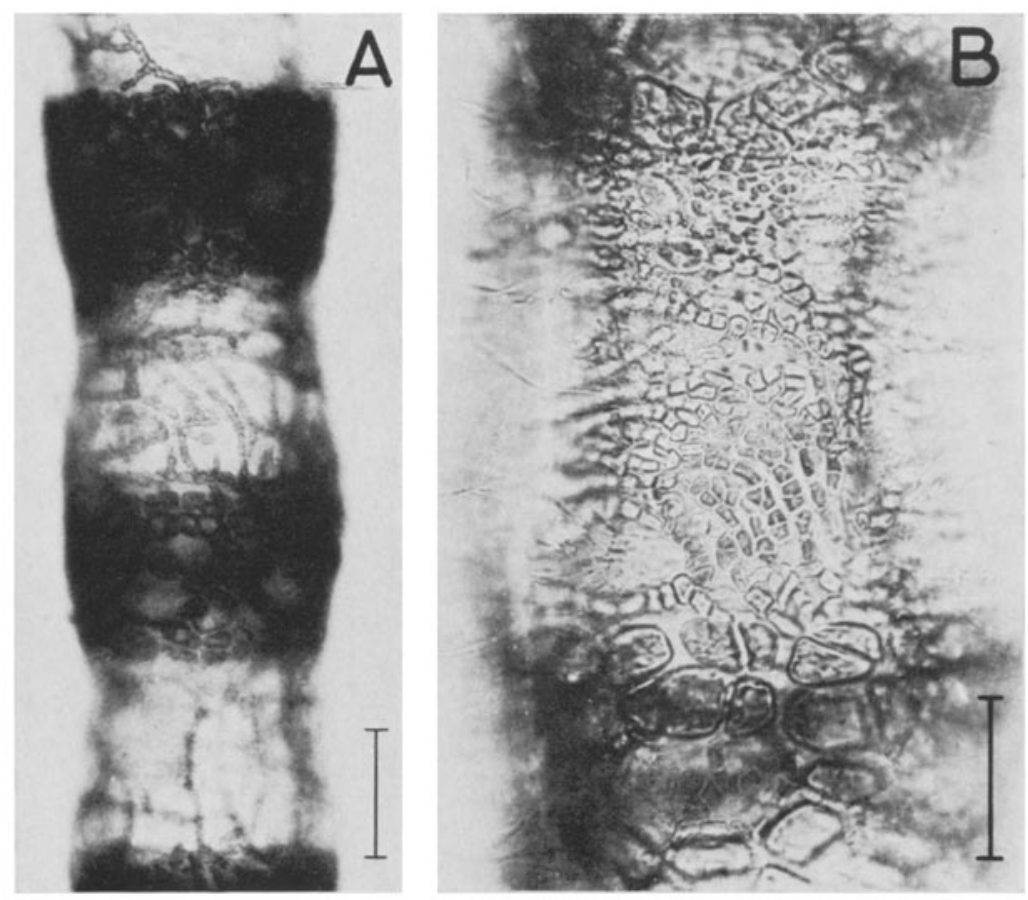

Abb. 157: Mikrosyphar polysiphoniae. In Ceramium deslongchampsii (24. 5. 1972). Maßstrecken: $\mathrm{A}=100 \mu \mathrm{m} ; \mathrm{B}=50 \mu \mathrm{m}$ 
Protectocarpus speciosus (Børgs.) Kudk.

Vielleicht sollte man diese Alge eher zu den oft übersehenen als zu den seltenen Arten zählen. Sie bildet unscheinbare Uberzüge auf anstehendem Fels, an Bojen oder wẳhst als Epiphyt auf verschiedenen Algen, auch auf Laminaria. Einer einschichtigen Basalscheibe entspringen die meist unverzweigten, bis $800 \mu \mathrm{m}$ langen aufrechten Fäden sowie sitzende bis länger gestielte lanzettliche plurilokuläre Sporangien (Abb. 158 B, C). Die aufrechten Fäden tragen einseitig gereiht plurilokuläre Sporangien, sitzend oder kurz gestielt. Oft werden auch die Tragzellen fertilisiert, und an den Fadenenden entsteht dann das für die Art so charakteristische zurückgebogene hahnenkammförmige terminale Sporangium (C). Von Kuckuck $†$ (1955) wurde dieses weitverbreitete Pflänzchen eingehend bearbeitet.

Stictyosiphon soriferus (Reinke) Rosenv.

Wir haben die Alge dreimal gefunden: am 1. September 1952 auf dem Boden eines Bootes, danach am 21. Juli und 26. August 1960 zusammen mit Callithamnion bzw. dicht auf Scytosipbon in einem Hafenbecken wachsend. Diese Pflanzen waren bis $5 \mathrm{~cm}$ hoch und reich verzweigt; einen Ausschnitt zeigt Abbildung 159 bei $\mathrm{A}$, die für die Art charakteristischen rundlichen, zentralen Zellen bei D. Alle Pflanzen trugen reichlich plurilokuläre Sporangien und Haare $(B, C)$.

Von dem 1952 gesammelten Material wurden - damals noch in List/Sylt - Kulturen angelegt. Nach 20 Tagen fruktifizierten die bis zu $3 \mathrm{~cm}$ hohen Pflanzen mit plurilokulären Sporangien an den Basalteilen, vereinzelt auch schon an den Zweigenden. Damit wird die von South \& Hooper (1976) an Material von Neufundland beobachtete direkte Entwicklung von Stictyosiphon soriferus erneut bestätigt. 

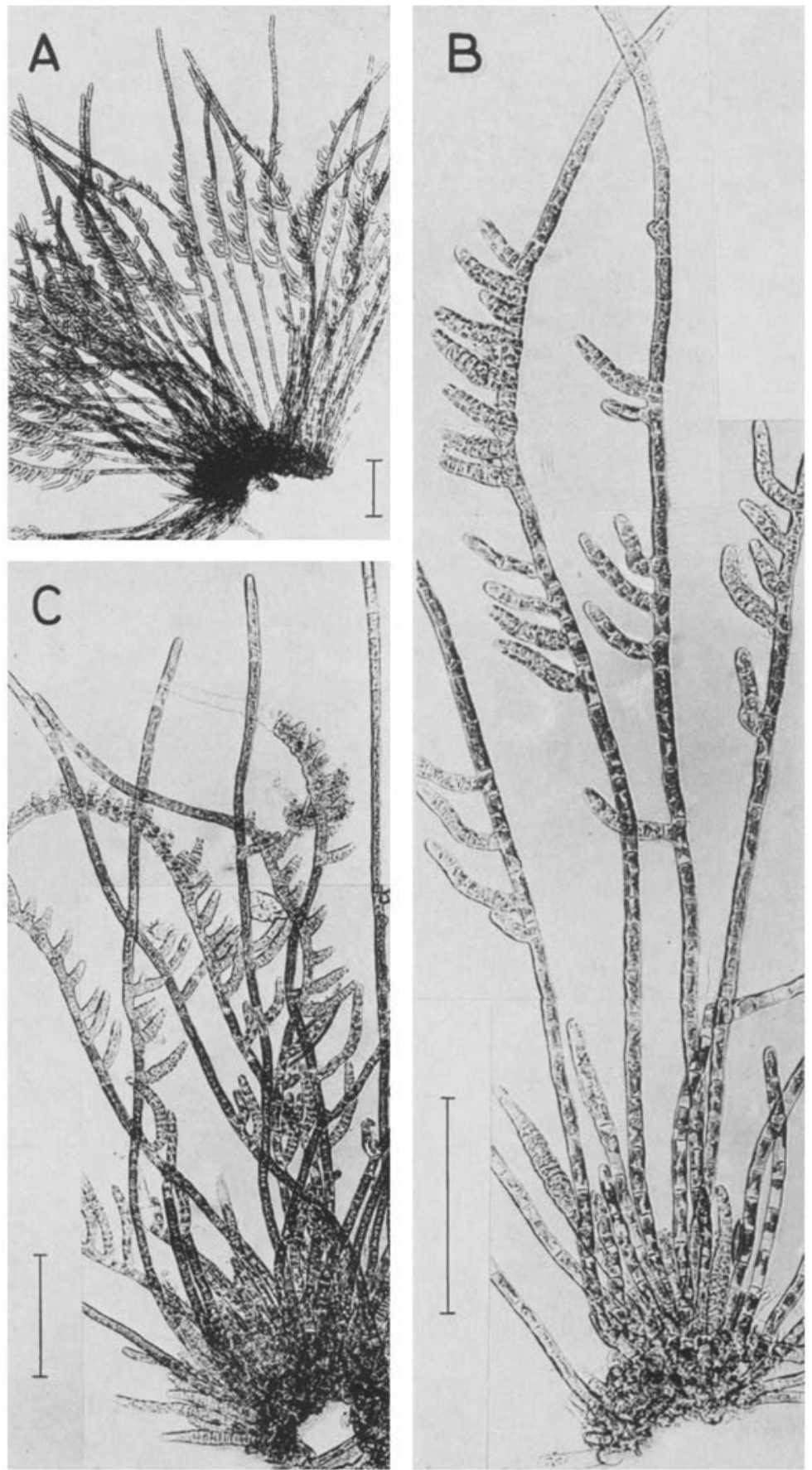

Abb. 158: Protectocarpus speciosus (10. 11, 1970). A-C Teile eines Büschels. Maßstrecken jeweils $=100 \mu \mathrm{m}$ 

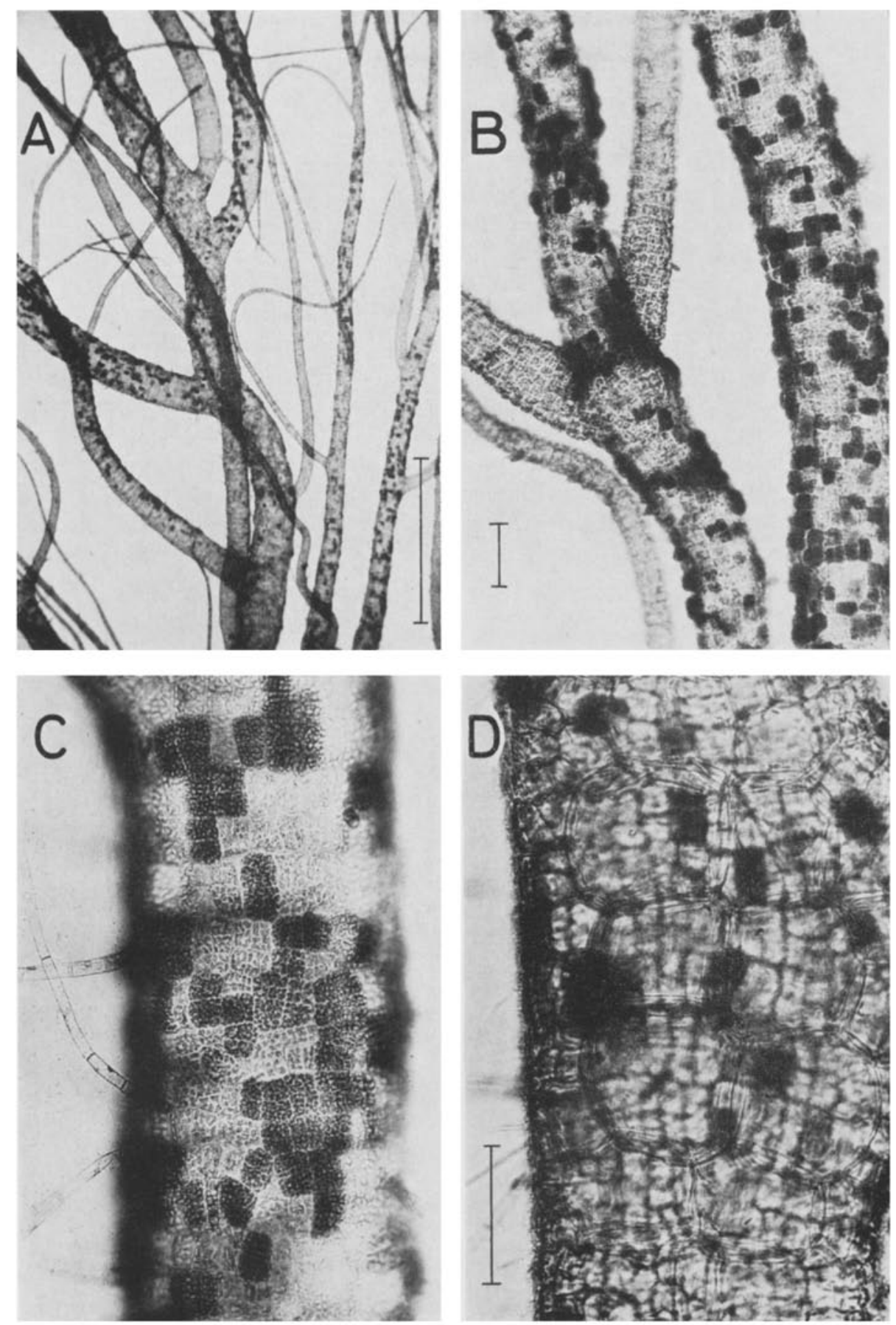

Abb. 159: Stictyosipbon soriferus (Präparat vom 26. 8, 1960). A Teil aus einer etwa $5 \mathrm{~cm}$ hohen Pflanze. B, C Thallusstücke mit plurilokulären Sporangien und Haaren. D Abgerundete Achsenzellen im optischen Schnitt. Maßstrecken: $A=1 \mathrm{~mm} ; \mathrm{B}=100 \mu \mathrm{m} ; \mathrm{C}, \mathrm{D}=100 \mu \mathrm{m}$ 


\section{Punctaria biemalis Kylin}

Wegen ihrer Seltenheit soll hier etwas ausführlicher auf eine Alge eingegangen werden, die offenbar mit einer von Kylin (1907) beschriebenen Art identisch ist und die er danach noch mehrere Male an der schwedischen Westküste fand (1947). Wir sammelten die buschig wachsenden zarten Pflänzchen mehrfach in den Wintermonaten an Bojen. Sie sind schmal bis breit lanzettlich (Abb. $160 \mathrm{~A}$ ) und stimmen in Größe und Form gut mit der Darstellung bei Kylin (1947) überein.

Die Aufsicht auf den fertilen Thallus bietet ein eigenartiges Bild. Die plurilokulären Sporangien liegen in unregelmäßig rechtwinklig begrenzten Gruppen mosaikartig $z$ wischen bereits entleerten und noch vegetativen Arealen (B-D). An seinem fertilen Ende erscheint der degenerierende Thallus mitunter grob netzförmig. Ebenso eigenartig sind die scharf gegeneinander abgegrenzten Zonen der periodisch basipetal fortschreitenden Fertilisierung (B). Uber einem noch vegetativen Basisabschnitt trkennt man drei Zonen mit Sporangiensori von verschiedener Reife, sie sind durch gerade Linien voneinander getrennt. Die Sporangien gehen unmittelbar aus einander gegenüberliegenden Zellen des zweischichtigen Thallus hervor; sie erheben sich nur ganz wenig uber die Oberfläche (E). Nur an dem schmal auslaufenden Thallusende ragen sie papillenartig vor $(F)$, dort triff man auch vereinzelte Haare.

\section{Dictyosiphon foeniculaceus (Huds.) Grev.}

Während der letzten 10 Jahre haben wir diese früher nicht gerade seltene Alge nicht mehr beobachtet. Sie wächst auf Steinen und epiphytisch auf Fucus oder Ulva, besonders gerne aber auf Chordaria flagelliformis. Zur Unterscheidung von dieser äußerlich etwas ähnlichen Wirtspflanze wurde sie schon bei Chordaria kurz gekennzeichnet (p. 124, nicht abgebildet).

Abb. 160: Punctaria biemalis. A Lebende Pflanzen in natürlicher Größe; der dunkle Rand an einigen Pflanzen ist ein Diatomeen-Aufwuchs (28.2.1975). B Aufsicht auf den zonenweise fertil gewordenen Thallus (26. 2. 1975). C, D Ausschnitte stärker vergrößert. E Querschnitte durch den lebend eingefrorenen Thallus. F Schmales Thallusende mit papillenartig vortretenden Sporangien (21. 10. 1976). Maßstrecken: $\mathrm{A}=1 \mathrm{~cm} ; \mathrm{B}=1 \mathrm{~mm} ; \mathrm{C}=500 \mu \mathrm{m} ; \mathrm{D}, \mathrm{E}=$ $50 \mu \mathrm{m} ; \mathrm{F}=100 \mu \mathrm{m}$ 


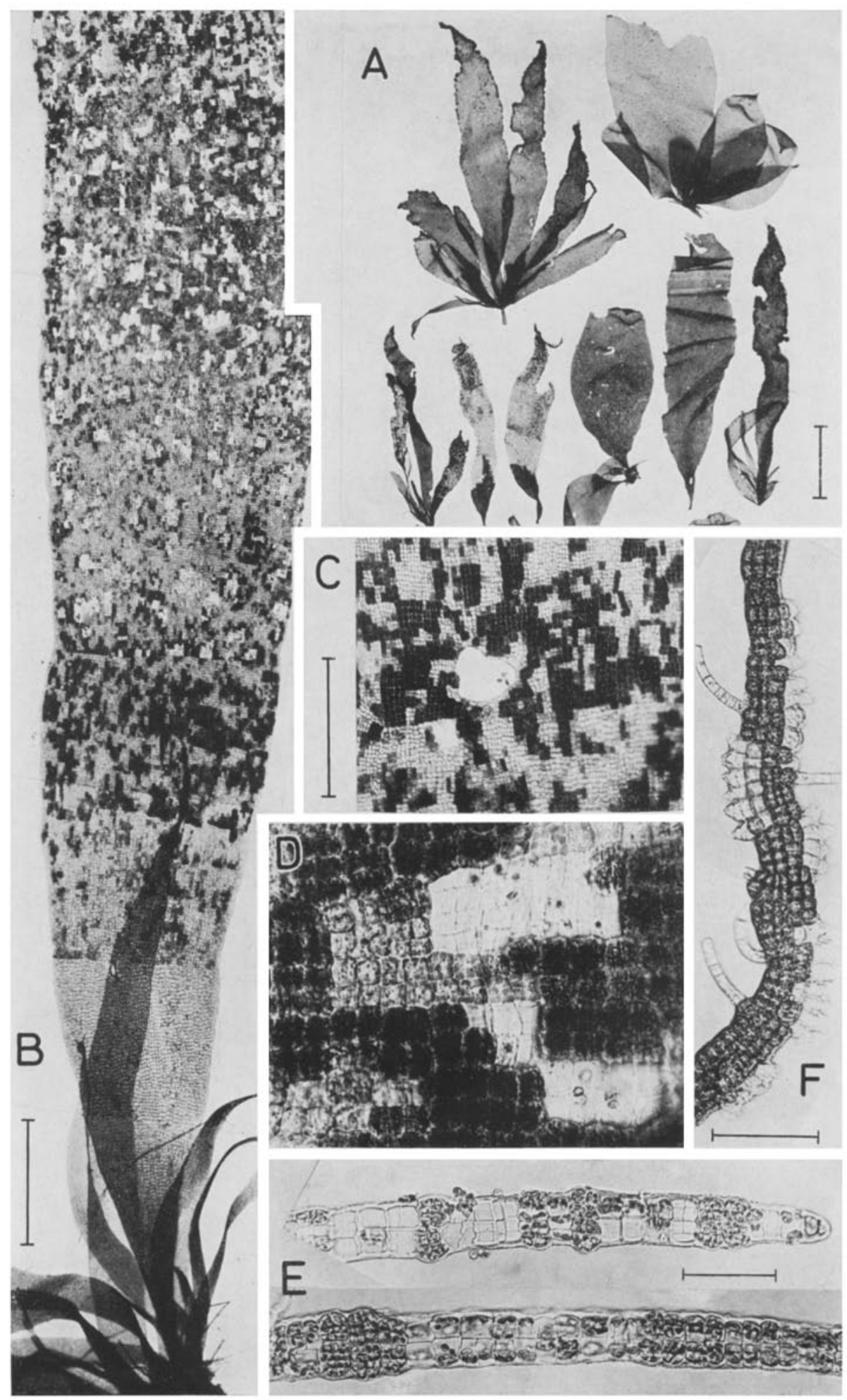


Striaria attenuata (Grev.) Grev.

Der einzige Fund am 1. Juli 1971 stammt aus einem tiefen künstlichen Gezeitenbecken im Hafengebiet. Die beiden Exemplare waren etwa 3 und $4 \mathrm{~cm}$ hoch und stark verzweigt (Abb. 161), sie trugen epiphytisch Giffordia sandriana.

Die Pflanzen fruktifizierten reichlich mit unilokulären Sporangien und dienten als Ausgangsmaterial für eine Wachstumsanalyse des Thallus und entwicklungsgeschichtliche Untersuchungen (Kornmann \& Sahling, 1973). Innerhalb von 7 Monaten folgten 5 Generationen gleichartiger, bis zu $10 \mathrm{~cm}$ hoher Pflanzen mit unilokulären Sporangien aufeinander.

Die Lebensgeschichte von Striaria-Populationen verschiedener europäischer Küstenabschnitte erwies sich als nicht einheitlich. Die in Frankreich reichlich vorkommende Alge kann sowohl Sporophyt in einem heteromorphen Zyklus als auch Gametophyt sein, in diesem - dem selteneren - Falle kopulieren Schwärmer der unilokulären Sporangien (Caram, 1965). In Schweden ist Striatia nicht regelmäßig anzutreffen. Aus den Schwärmern entwickelte sich direkt eine gleichartige Generation auf einem Kriechstadium, das auch plurilokuläre Sporangien trug (Caram \& Nygren, 1970). In den Helgoländer Kulturen wurden niemals plurilokuläre Sporangien beobachtet, nur ausnahmsweise kamen unilokuläre Sporangien auch auf dem monosiphonen niederliegenden Thallus vor.

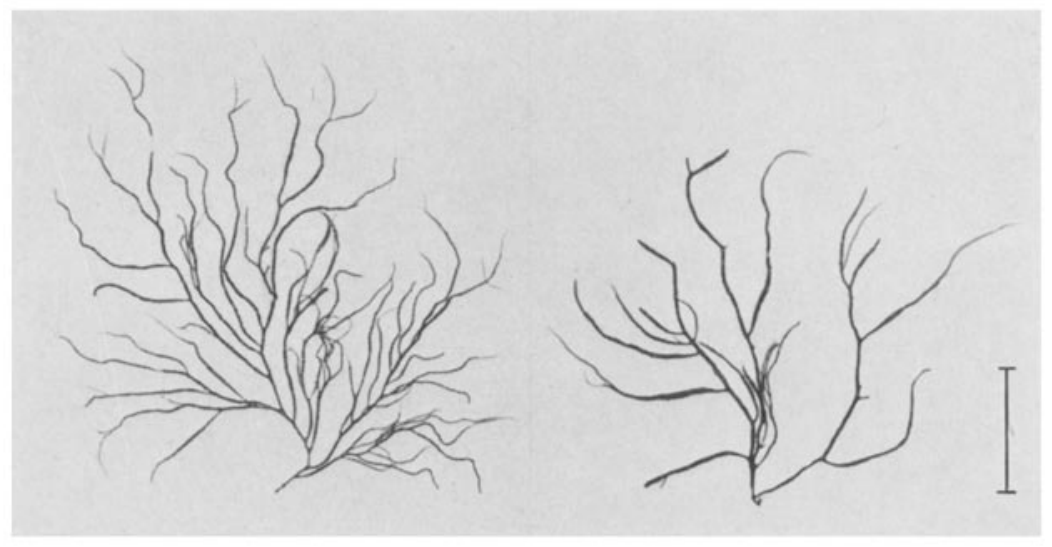

Abb. 161 : Striaria attenuata (1.7. 1971). Maßstredke $=1 \mathrm{~cm}$ 


\section{RHODOPHYTA}

\section{Nemalion helminthoides (Vell. in With.) Batt.}

Sie wurde nur einmal am 7. September 1959 an den der Westmole als Wellenbrecher vorgelagerten Blöcken gefunden, zusammen mit Dictyota dichotoma, die etwas tiefer wuchs. An ihrem Standort ist Nemalion stets einer starken Wasserbewegung ausgesetzt. Die beiden Belegexemplare sind etwa $5 \mathrm{~cm}$ hoch und unregelmäßig gabelig verzweigt (nicht abgebildet).

\section{Platoma bairdii (Farl.) Kuck.}

Diese Rotalge ist nur an wenigen Stellen der Küsten von Europa und Nordostamerika gefunden worden. Sie hat durch Kuckuck (1912) eine ausführliche Darstellung von klassischem Rang erfahren. Platoma bairdii trägt entweder Tetrasporangien oder Zystokarpien, männliche Pflanzen sind unbekannt. Dies erschwert die Deutung ihrer Lebensgeschichte ebenso wie die Besonderheit der "Prosporie", das Vorkommen von Tetrasporangien auf der Basalscheibe, von der sich der multiaxiale aufrechte Thallus erhebt.

Platoma bairdii ist uns in den letzten 17 Jahren nur viermal begegnet; zwei weibliche Fragmente trieben am Strand bzw. im Plankton, die beiden anderen Funde waren büschelige Pflanzen auf Steinen, die Taucher besorgt hatten. Die Thalli vom 21. Juli waren knapp $3 \mathrm{~cm}$ hoch und trugen Tetrasporangien. Das am 19. Juni 1973 gefundene etwa $5 \mathrm{~mm}$ hohe Büschel liegt der Abbildung 162 zugrunde. Sie zeigt die auf einer basalen Sohle sich erhebenden Fäden des zentralen Stranges, aus deren langgestreckten Zellen jeweils ein sich verzweigender Kurztrieb entspringt. Der Thallus wird hauptsächlich durch Gallerte zusammengehalten. Er ist zunächst rund und flacht sich bei älteren und größeren Pflanzen ab. Nach spärlicher und unregelmäßig gabeliger Verzweigung verjüngen sich die Thallusenden. 


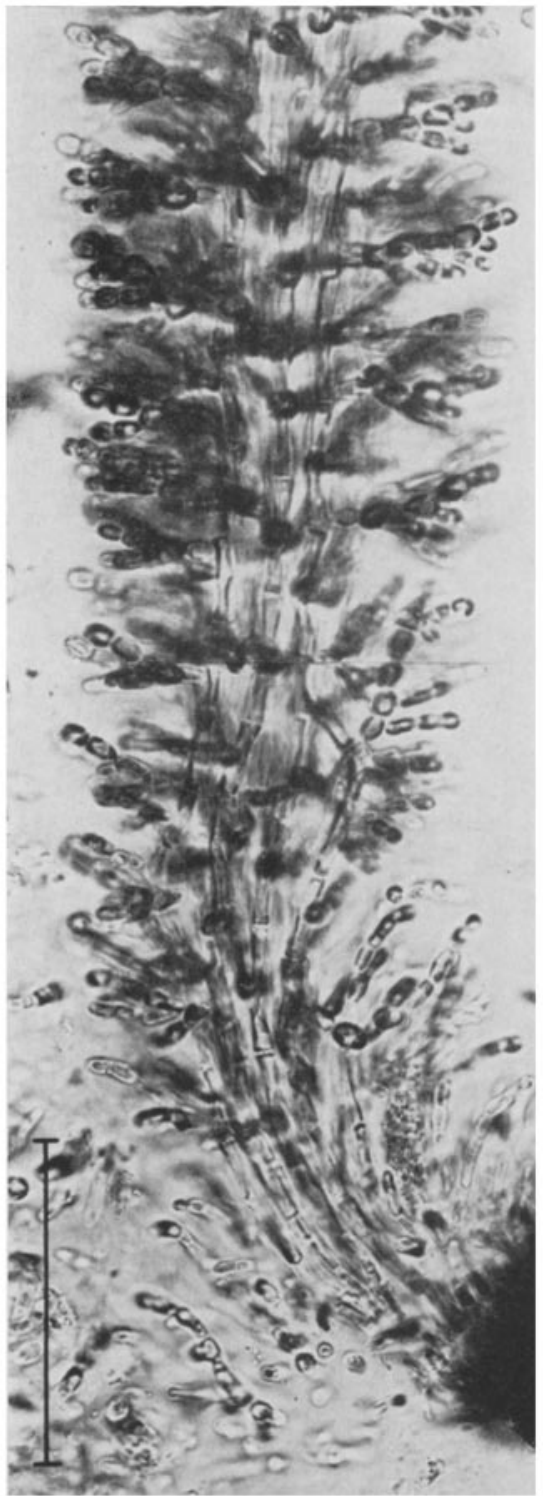

Abb. 162: Platoma bairdii (19.6. 1973). Der Basalscheibe entspringender junger Thallus. Maßstrecke $=100 \mu \mathrm{m}$ 
Dudresnaya verticillata (With.) Le Jol.

Ihr Vorkommen ist durch einen Fund vom 3. August 1972 belegt (Abb. 163 A). Das etwa $2 \mathrm{~cm}$ hohe Pflänzchen wuchs auf einem von Tauchern beschaften Stein. Der runde, stark gallertige Thallus ist allseitig reich verzweigt. Den Zellen des zentralen Achsenfadens entspringen wirtelige Kurztriebbüschel.
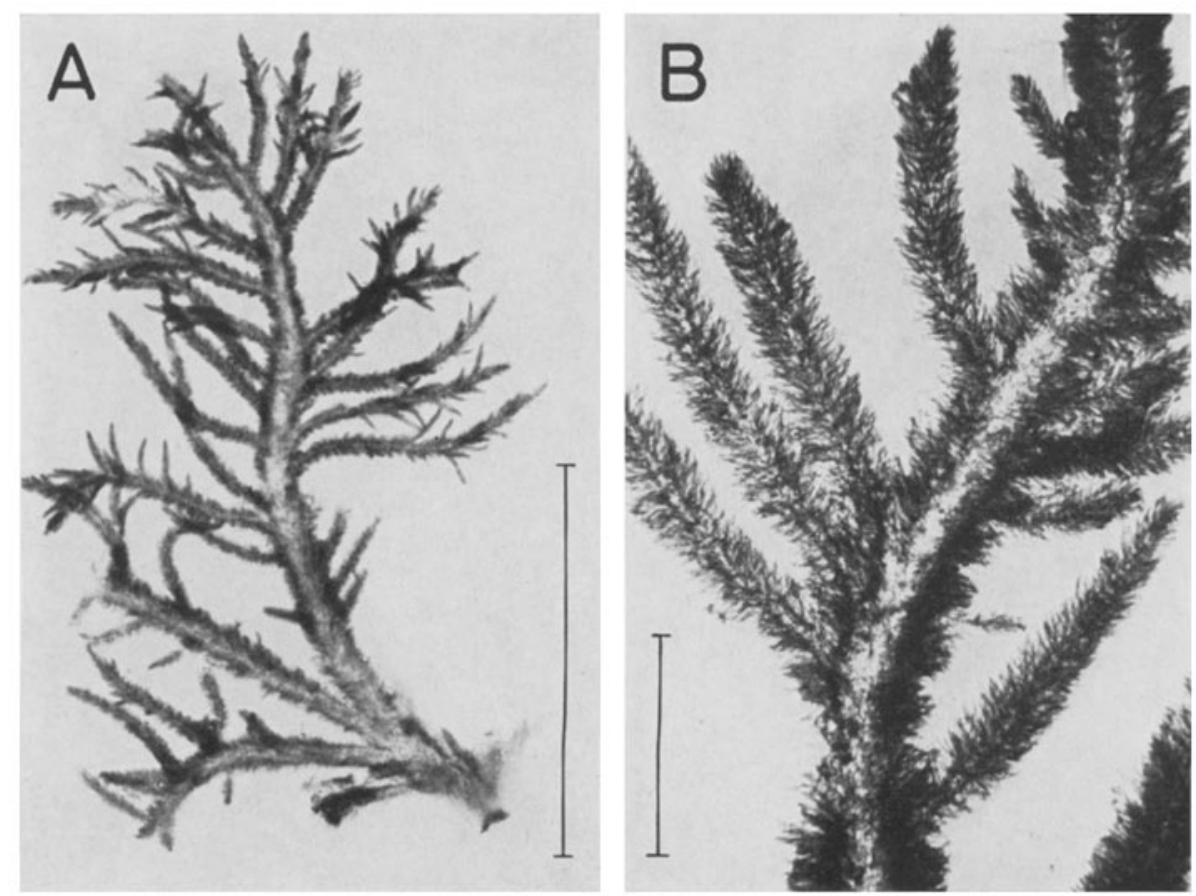

Abb. 163: Dudresnaya verticillata (3. 8. 1972). Maßstrecken: $A=1 \mathrm{~cm} ; B=1 \mathrm{~mm}$

Gloiosiphonia capillaris (Huds.) Carm. ex Berk.

Diese Alge wurde mehrere Male sowohl im Plankton treibend als auch an Steinen aus mehreren Meter Tiefe gefunden. Am 6. August 1964 konnte eine weibliche Pflanze bei tiefem Niedrigwasser im Hafengebiet auf einem Stein gesammelt werden, ganz in der Nähe wuchs Cladostepbus verticillatus. Mehrere bis $5 \mathrm{~cm}$ hohe und allseitig reich verzweigte Pflanzen waren $z u$ einem dichten Büschel vereinigt (Abb. $164 \mathrm{~A}$ ). Wesentlich lockerer aufgebaut war ein aus tieferem Wasser stammendes Exemplar (B). 


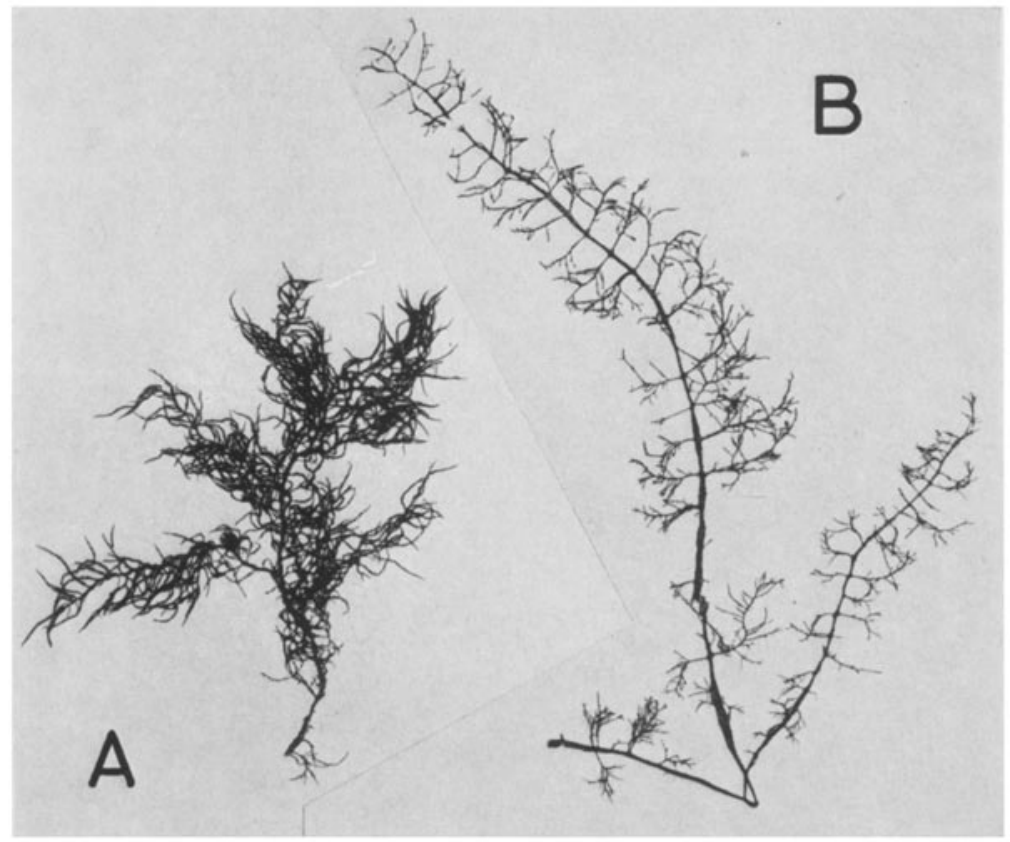

Abb. 164: Gloiosiphonia capillaris, Herbarexemplare, natürliche Größe. A Aus einem Büschel im oberen Sublitoral (6. 8. 1964), B Aus tieferem Wasser (21.7. 1967)

Polysiphonia nigra (Huds.) Batt.

Das einzige, im Sommer 1976 treibend gefundene Exemplar läßt vermuten, daß Polysiphonia nigra im Bereich der Düne - vielleicht an dem vor einigen Jahren dort errichteten Tetrapodenwall - vorkommt. Das Herbarium Kuckuck enthält viele auf den Dünenklippen sowie in einem Gebiet gesammelte Proben, aus dem sie auch noch mit Exsikkaten von 1936 belegt ist. Die damals bei Niedrigwasser trockenfallende Felsfläche liegt heute unter aufgespültem Sand.

Die $10 \mathrm{~cm}$ hohe dunkelrote Pflanze trägt die den Sporophyten kennzeichnenden kurzen Zweigbüschel (Abb. $165 \mathrm{~A}, \mathrm{C}$ ). Die weiblichen Pflanzen dagegen sind nahezu kahl und erscheinen sparriger; die kugeligen Zystokarpien sind nur kurz gestielt oder sitzend (B).

Polysiphonia nigra ist auch an der Basis nicht berindet, die 8-14 Perizentralzellen sind mitunter spiralig gedreht (C). 

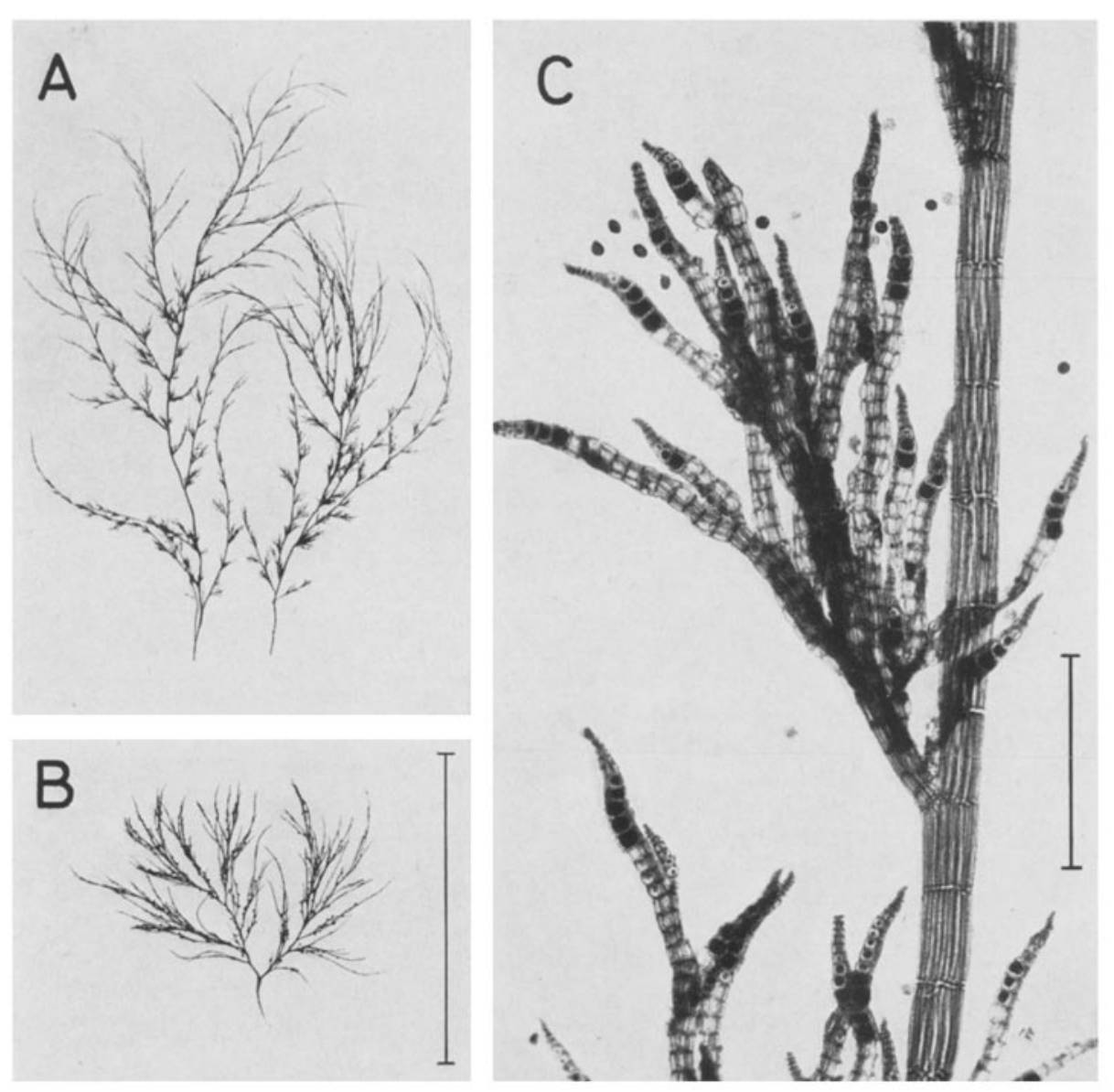

Abb. 165: Polysipbonia nigra. A Tetrasporophyt (5. 7. 1976). B Pflanze mit Zystokarpien (Kalbertan, 21. 9. 1936). C Zweigstück aus dem mit Ephelota (Suctoria) besetzten Tetrasporophyten. Maßstrecken: $A, B=5 \mathrm{~cm} ; C=2 \mathrm{~mm}$ 


\section{ZITIERTE LITERATUR}

Adey, W. H. \& Adey, P. J., 1973. Studies on the biosystematics and ecology of the epilithic crustose Corallinaceae of the British Isles. Br. phycol. J. 8, 343-407.

Bliding, C., 1957. Studies in Rhizoclonizm. I. Life history of two species. Bot. Notiser 110, $271-275$.

- 1963. A critical survey of European taxa in Ulvales. Part I. Capsosiphon, Percursaria, Blidingia, Enteromorpha. Op. bot. Soc. bot. Lund, 8 (3), 1-160.

- 1968. A critical survey of European taxa in Ulvales, II. Ulva, Ulvaria, Monostroma, Kornmannia. Bot. Notiser 121, 535-629.

Boillot, A., 1972. Le cycle de l'Halarachnion ligulatum (Woodward) Kuetzing (Rhodophycée, Gigartinale). Mém. Soc. bot. Fr. 1972, 275-292.

Caram, B., 1965. Recherches sur la reproduction et le cycle sexué de quelques Phéophycées. Vie Milieu (A) 16, 21-226.

- \& Nygren, S., 1970. A propos de la reproduction comparée en France et en Suède d'une Phéophycée-Phéosporée: le Striaria attenuata. Helgoländer wiss. Meeresunters. 20, 130-135.

Chemin, E., 1929. L'Asparagopsis bamifera (Hariot) Okamura et son mode de multiplication. Revue algol. 4, 29-42.

Conway, E., 1964. Autecological studies of the genus Porpbyra: II. Porpbyra umbilicalis (L.) J. Ag. Br. phycol. Bull. 2, 349-363.

Denizot, M., 1968. Les Algues Floridées encroûtantes (à l'exclusion des Corallinacées). Museum National d'Histoire Naturelle, Paris, 310 pp.

Dixon, P. S., 1973. Biology of the Rhodophyta. Oliver \& Boyd, Edinburgh, 285 pp.

Dodel, A., 1876. Ulothrix zonata, ihre geschlechtliche und ungeschlechtliche Fortpflanzung, ein Beitrag zur Kenntnis der unteren Grenze des pflanzlichen Sexuallebens. Jb. wiss. Bot. 10, 417-550.

Drew, K. M., 1949. Conchocelis-phase in the life-history of Porphyra umbilicalis (L.) Kütz. Nature, Lond. 164, 748 .

Farnham, W. F. \& Fletcher, R. L., 1976. The occurrence of a Porplyrodiscus simulans Batt. phase in the life history of Abnfeltia plicata (Huds.) Fries. Br. phycol. J. 11, 183-190.

Fletcher, R. L., 1974. Studies on the brown algal families Ralfsiaceae and Scytosiphonaceae. Br. phycol. J. 9, 218.

Ganesan, E. K. \& West, J. A., 1975. Culture studies on the marine red alga Rbodophysema elegans (Cryptonemiales, Peysonneliaceae). Phycologia 14, 161-166.

Goff, L. J., 1976. The biology of Harveyella mirabilis (Cryptonemiales; Rhodophyceae). V. Host responses to parasite infection. J. Phycol. 12, 313-328.

- \& Cole, K., 1973. The biology of Harveyella mirabilis (Cryptonemiales, Rhodophyceae). 1. Cytological investigations of Harveyella mirabilis and its host, Odontbalia floccosa. Phycologia 12, 237-245.

Hauck, F., 1885. Die Meeresalgen Deutschlands und Oesterreichs. Kummer, Leipzig, 575 pp. (Rabenhorst's Kryptogamen-Flora von Deutschland, Oesterreich und der Schweiz, Bd 2.)

Hoek, C. van den, 1963. Revision of the European species of Cladophora. Brill, Leiden, 248 pp.

Hoppe, H. A., 1962. Geschichtliche Entwicklung der Auswertung von Meeresalgen. Botanica mar. (Suppl.) 3, 12-15.

- \& Schmid, O. J., 1962. Die Meeresalgen als moderne Industrieprodukte. Botanica mar. (Suppl.) 3, 16-66.

Knaggs, F. W., 1968. Rbodochorton purpureum (Lightf.) Rosenvinge. The morphology of the gametophytes and of the young carposporophyte. Nova Hedwigia 16, 449-457.

- \& Conway, E., 1964. The life-history of Rbodocborton floridulum (Dillwyn) Näg. I. Spore germination and the form of the sporelings. Br. phycol. Bull. 2, 339-341.

Koch, W., 1950. Entwicklungsgeschichtliche und physiologische Untersuchungen an Laboratorumskulturen der Rotalge Trailliella intricata Batters (Bonnemaisoniaceae). Arch. Mikrobiol. 14, 635-660. 
Kornmann, P., 1938. Zur Entwidklungsgeschichte von Derbesia und Halicystis. Planta 28, $464-470$.

- 1953. Der Formenkreis von Acinetospora crinita (Carm.) nov. comb. Helgoländer wiss. Meeresunters. 4, 205-224.

- 1956a. Zur Morphologie und Entwicklung von Percursaria percursa. Helgoländer wiss. Meeresunters. 5, 259-272.

- 1956b. Uber die Entwicklung einer Ectocarpus confervoides-Form. Pubbl. Staz. zool. Napoli 28, 32-43.

- 1959. Die heterogene Gattung Gomontia I. Der sporangiale Anteil, Codiolum polyrbizum. Helgoländer wiss. Meeresunters. 6, 229-238.

- 1961a. Über Spongomorpha lanosa und ihre Sporophytenformen. Helgoländer wiss. Meeresunters. 7, 195-205.

- 1961b. Uber Codiolum und Urospora. Helgoländer wiss. Meeresunters. B, 42-57.

- 1961c. Zur Kenntnis der Porpbyra-Arten von Helgoland. Helgoländer wiss. Meeresunters. 8, 176-192.

- 1962a. Die Entwicklung von Monostroma grevillei. Helgoländer wiss. Meeresunters. 8, 195-202.

- 1962b. Plurilokuläre Sporangien bei Elachista fucicola. Helgoländer wiss. Meeresunters. 8, 293-297.

- 1964. Die Ulothrix-Arten von Helgoland. I. Helgoländer wiss. Meeresunters, 11, 27-38.

- 1965. Zur Analyse des Wachstums und des Aufbaus von Acrosipbonia. Helgoländer wiss. Meeresunters. 12, 219-238.

- 1966a. Wachstum und Zellteilung bei Urospora. Helgoländer wiss. Meeresunters. 13, 73-83.

- 1966b. Hormiscia neu definiert. Helgoländer wiss. Meeresunters. 13, 408-425.

- 1972. Ein Beitrag zur Taxonomie der Gattung Chaetomorpha (Cladophorales, Chlorophyta). Helgoländer wiss. Meeresunters. 23, 1-31.

- 1973. Codiolophyceae, a new class of Chlorophyta. Helgoländer wiss. Meeresunters. 25, $1-13$.

Kornmann, P. \& Sahling, P.-H., 1962a. Geschlechtspflanzen von Bonnemaisonia hamifera Hariot bei Helgoland. Helgoländer wiss. Meeresunters. 8, 298-301.

- 1962b. Zur Taxonomie und Entwicklung der Monostroma-Arten von Helgoland. Helgoländer wiss. Meeresunters. 8, 302-320.

- 1973. Striaria attenuata (Phaeophyta, Dictyosiphonales), neu bei Helgoland: Entwicklung und Aufbau. Helgoländer wiss. Meeresunters. 25, 14-25.

- 1974. Prasiolales (Chlorophyta) von Helgoland. Helgoländer wiss. Meeresunters. 26, 99-133.

- 1976. Wiedereinführung von Bryopsis lyngbyei (Bryopsidales, Chlorophyta) als selbständige Arr. Helgoländer wiss. Meeresunters. 28, 217-225.

Kuckuck, P., 1892. Ectocarpus siliculosus Dillw. sp. forma varians n. f., ein Beispiel für außerordentliche Schwankungen der pluriloculären Sporangienform. Ber. dt. bot. Ges. 10, 256 bis 259.

- 1894. Bemerkungen zur marinen Algenvegetation von Helgoland. Wiss. Meeresunters. (Helgoland) 1, 225-263.

- 1897a. Beiträge zur Kenntnis der Meeresalgen. 1. Über Rbododermis parasitica Batters. 2. Ober Rbodochorton membranaceum Magnus, eine chitinbewohnende Alge. - 3. Die Gattung Mikrosyphar Kuckuck. - 4. Über zwei höhlenbewohnende Phaeosporeen. Wiss. Meeresunters. (Helgoland) 2, 329-370.

- 1897b. Bemerkungen zur marinen Algenvegetation von Helgoland. II. Wiss. Meeresunters. (Helgoland) 2, 373-400.

- 1897c. Uber marine Vegetationsbilder. Ber. dt. bor. Ges. 15, 441-447.

- 1912. Beiträge zur Kenntnis der Meeresalgen. 12. Uber Platoma Bairdii (Farl.) Kck. Wiss. Meeresunters. (Helgoland) 5, 189-210.

- 1930. Fragmente einer Monographie der Phaeosporeen. Nach dem Tode des Verfassers hrsg. von Wilhelm Nienburg. Wiss. Meeresunters. (Helgoland) 17 (2), 1-93.

- 1955. Ectocarpaceen-Studien III. Protectocarpus nov. gen. Hrsg. von Peter Kornmann. Helgoländer wiss. Meeresunters. 5, 119-140. 
- 1961. Ectocarpaceen-Studien VII. Giffordita. Hrsg. von Peter Kornmann. Helgoländer wiss. Meeresunters. 8, 119-152.

- 1964. Ectocarpaceen-Studien. Hrsg. von Peter Kornmann. Biologische Anstalt Helgoland, Hamburg, 239 pp. (Unveränd. Nachdr. von Beitr. 1-8 aus Helgoländer wiss. Meeresunters. 4. 1953 - 8. 1963. Erw. durch T. 9.)

Kützing, F. T., 1845. Phycologia germanica, d. i. Deutschland Algen in bündigen Beschreibungen. Köhne, Nordhausen, 340 pp.

Kylin, H., 1907. Studien uber die Algenflora der schwedischen Westküste. Akad. Abhandl., Uppsala, 288 pp.

- 1933. Uber die Entwidklungsgeschichte der Phaeophyceen. Lunds Univ. Årsskr. (Avd. 2) 29 (7), 1-102.

- 1947. Die Phaeophyceen der schwedischen Westküste. Lunds Univ. Årsskr. (Avd. 2) 43 (4), 1-99.

Lüning, K., 1970a. Cultivation of Laminaria byperborea in situ and in continuous darkness under laboratory conditions. Helgoländer wiss. Meeresunters, 20, 79-88.

- 1970b. Tauchuntersuchungen zur Vertikalverteilung der sublitoralen Helgoländer Algenvegetation. Helgoländer wiss. Meeresunters. 21, 271-291.

Lund, S. \& Christensen, J., 1969. On the collection of Furcellaria in Denmark during the years 1961-1967. Proc. int. Seaweed Symp. 6, 699-701.

Maass, H., 1962. Uber die Verwendungsmöglichkeiten von Alginaten. Botanica mar. (Suppl.) $3,86-100$.

Müller, D. G., 1972. Life cycle of the brown alga Ectocarpus fasciculatus var. refractus (Kütz.) Ardis. (Phaeophyceae, Ectocarpales) in culture. Phycologia 11, 11-13.

Nakamura, Y., 1965. Development of zoospores in Ralfsia-like thallus, with special reference to the life cycle of the Scytosiphonales. Bot. Mag., Tokyo 78, 109-110.

Neumann, K., 1969. Protonema mit Riesenkern bei der siphonalen Grïnalge Bryopsis bypnoides und weitere cytologische Befunde. Helgoländer wiss. Meeresunters. 19, 45-57.

Newroth, P. R., 1971. Studies on life histories in the Phyllophoraceae. I. Phyllophora truncata (Rhodophyceae, Gigartinales). Phycologia 10, 345-354.

Newton, L, 1931. A handbook of the British seaweeds. British Museum, London, $478 \mathrm{pp}$.

Nienburg, W., 1925. Die Besiedelung des Felsstrandes und der Klippen von Helgoland. II. Die Algen. Wiss. Meeresunters. (Helgoland) 15 (19), 1-15.

Parke, M. \& Dixon, P. S., 1976. Check-list of British marine algae - third revision. J. mar. biol. Ass. U. K. 56, 527-594.

Pedersen, P. M., 1974. The life history of Sorocarpus micromoras (Phaeophyceae, Ectocarpaceae) in culture. Br. phycol. J. 9, 57-61.

- 1975. Culture studies on marine algae from West Greenland I. Chromosomal information relating to the life history of 1 stbmoplea sphaerophora (Phaeophyceae, Dictyosiphonales). Br. phycol. J. 10, 165-168.

Printz, H., 1926. Die Algenvegetation des Trondhjemsfjordes. Skr. norske Vidensk.Akad. (Mat.-nat, Kl.) 1926 (5) 1-274.

Prud'homme van Reine, W. F., 1972. Notes on Sphacelariales (Phaeophyceae) II. On the identity of Cladostephus setaceus Suhr and remarks on European Cladostephus. Blumea 20, 138-144.

Reinke, J., 1891. Die braunen und rothen Algen von Helgoland. Ber. dt. bot. Ges. 9, 271-273.

Rietema, H., 1971. Life-history studies in the genus Bryopsis (Chlorophyceae) IV. Life-histories in Bryopsis bypnoides Lamx. from different points along the European coasts. Acta bot. neerl. 20, 291-298.

Round, F. E., 1971. The taxonomy of the Chlorophyta. II. Br. phycol. J. 6, 235-264.

Rueness, J., 1974. Life history in culture and chromosome number of Istbmoplea sphaerophora (Phaeophyceae) from southern Scandinavia. Phycologia 13, 323-328.

Russell, G., 1961. The taxonomic status of Pylaiella rupincola. Br. phycol. Bull. 2, 101.

- \& Fletcher, R. L., 1975. A numerical taxonomic study of the British Phaeophyta. J. mar. biol. Ass. U. K. 55, 763-783. 
Schiller, J., 1928. Ulva curvata Kütz. und Porpbyra linearis Grev., zwei für Helgoland neue Meeresalgen. Hedwigia 68, 115-118.

Schmid, O. J., 1962. Die Inhaltsstoffe der Meeresalgen. Botanica mar. (Suppl.) 3, 67-74.

- \& Hoppe, H. A., 1962. Meeresalgen als Dünge-, Futter- und Nahrungsmittel. Botanica mar. (Suppl.) 3, 101-119.

Schmidt, O. C., 1928. Die Algenvegetation Helgolands. Vegetationsbilder 19 (5), Taf. 25-30.

- 1936. Neue oder bemerkenswerte Meeresalgen aus Helgoland I. Hedwigia 75, 150-158.

- 1938. Neue oder bemerkenswerte Meeresalgen aus Helgoland II. Hedwigia 77, 7-10.

Schotter, G., 1968. Recherches sur les Phyllophoracées. Notes posthumes publiées par Jean Feldmann et Marie-France Magne. Bull. Inst. océanogr. Monaco, 67, 1-99.

Schulzen, H., 1962. Die chemisch-physikalischen Eigenschaften der Alginate und Carraghenate. Botanica mar. (Suppl.) 3, 75-85.

Silva, M. W. R. N. de \& Burrows, E. M., 1973. An experimental assessment of the status of the species Enteromorpha intestinalis (L.) Link and Enteromorpha compressa (L.) Grev. J. mar. biol. Ass. U. K. 53, 895-904.

Söderström, J., 1963. Studies in Cladophora. Bot. Gothoburg. 1, 1-147.

South, G. R., 1975. Contributions to the flora of marine algae of eastern Canada III. Order Tilopteridales. Naturaliste can. 102, 693-702.

- \& Hooper, R., 1976. Stictyosipbon soriferus (Phaeophyta, Dictyosiphonales) from eastern North America. J. Phycol. 12, 24-29.

- \& Whittick, A., 1976. Aspects of the life history of Rbodopbysema elegans (Rhodophyta, Peyssonneliaceae). Br. phycol. J. 11, 349-354.

Sundene, O., 1966. Haplospora globosa Kjellm. and Scaphospora speciosa in culture. Nature, Lond., 209, 937-938.

Tatewaki, M., 1972. Life history and systematics in Monostroma. In: Contributions to the systematics of benthic marine algae of the North Pacific. Ed. by I. A. Abbott \& M. Kurogi. Jap. Soc. of Phycology, Kobe, 1-15.

West, J. A., 1969. The life histories of Rbodocborton purpureum and $R$, tenue in culture. $J$. Phycol. 5, 12-21.

- 1972. The life history of Petrocelis franciscana. Br. phycol. J. 7, 299-308.

Woelkerling, W. J., 1971. Morphology and taxonomy of the Audouinella complex (Rbodopbyta) in Southern Australia. Aust. J. Bot. (Suppl.) 1, 1-91.

- 1973. The morphology and systematics of the Audoninella complex (Acrochaetiaceae, Rhodophyta) in northeastern United States. Rhodora 75, 529-621.

Wright, E. P., 1877. On a new species of parasitic green algae belonging to the genus Chlorochytrium of Cohn. Trans. R. Ir. Acad. 26, 355-368.

Wynne, M. J. \& Loiseaux, S., 1976. Recent advances in life history studies of the Phaeophyta. Phycologia 15, 435-452.

Anschrift des erstgenannten Autors: Dr. Dr. h. c. P. Kornmann

Biologische Anstalt Helgoland (Meeresstation)

D-2192 Helgoland

Bundesrepublik Deutschland 